\title{
The healthy primary school of the future
}

Citation for published version (APA):

Oosterhoff, M. (2021). The healthy primary school of the future: evaluating the health-economic impact of primary school-based lifestyle interventions. [Doctoral Thesis, Maastricht University]. Gildeprint

Drukkerijen. https://doi.org/10.26481/dis.20210305mo

Document status and date:

Published: 01/01/2021

DOI:

10.26481/dis.20210305mo

Document Version:

Publisher's PDF, also known as Version of record

\section{Please check the document version of this publication:}

- A submitted manuscript is the version of the article upon submission and before peer-review. There can be important differences between the submitted version and the official published version of record.

People interested in the research are advised to contact the author for the final version of the publication, or visit the DOI to the publisher's website.

- The final author version and the galley proof are versions of the publication after peer review.

- The final published version features the final layout of the paper including the volume, issue and page numbers.

Link to publication

\footnotetext{
General rights rights.

- You may freely distribute the URL identifying the publication in the public portal. please follow below link for the End User Agreement:

www.umlib.nl/taverne-license

Take down policy

If you believe that this document breaches copyright please contact us at:

repository@maastrichtuniversity.nl

providing details and we will investigate your claim.
}

Copyright and moral rights for the publications made accessible in the public portal are retained by the authors and/or other copyright owners and it is a condition of accessing publications that users recognise and abide by the legal requirements associated with these

- Users may download and print one copy of any publication from the public portal for the purpose of private study or research.

- You may not further distribute the material or use it for any profit-making activity or commercial gain

If the publication is distributed under the terms of Article $25 \mathrm{fa}$ of the Dutch Copyright Act, indicated by the "Taverne" license above, 
The Healthy Primary School of the Future:

evaluating the health-economic impact of primary school-based lifestyle interventions 
The research presented in this thesis was conducted at CAPHRI Care and Public Health Research Institute, Department of Clinical Epidemiology and Medical Technology Assessment, of Maastricht University Medical Center +. CAPHRI participates in the Netherlands School of Public Health and Care Research CaRe. The study was funded by Limburg provincial authorities (Project Number 200130003), Friesland Campina (Project Number LLMVOO), and Maastricht University.

@ copyright Marije Oosterhoff, Maastricht 2020

Cover: Sanne Slegers en Tim van Waas

Layout: Tiny Wouters

Printing: Gildeprint (www.gildeprint.nl)

ISBN: 978-94-6419-118-9

All rights reserved. No part of this publication may be reproduced or transmitted, in any form or by any means, electronic, mechanical, photocopying, recording or otherwise, without prior permission of the author or the publishers of the published chapters. 


\title{
The Healthy Primary School of the Future: evaluating the health-economic impact of primary school-based lifestyle interventions
}

\author{
PROEFSCHRIFT \\ ter verkriiging van de graad van doctor aan de Universiteit Maastricht, \\ op gezag van de Rector Magnificus, Prof. dr. Rianne M. Letschert, \\ volgens het besluit van het College van Decanen, \\ in het openbaar te verdedigen op \\ vrijdag 5 maart 2021 om 14.00 uur \\ door \\ Martha Oosterhoff \\ Geboren 8 april 1991, Groningen
}




\section{Promotores}

Prof. dr. M.A. Joore

Prof. dr. O.C.P. van Schayck

Prof. dr. H. Bosma

\section{Beoordelingscommissie}

Prof. dr. S.P.J. Kremers (voorzitter)

Prof. dr. T.L. Feenstra (Rijksuniversiteit Groningen)

Prof. dr. J.A. Knottnerus

Prof. dr. M. Pavlova

Prof. dr. M.P.M.H. Rutten-van Mölken (Erasmus Universiteit Rotterdam) 


\section{Table of contents}

Chapter 1 General introduction 7

Chapter 2 Longitudinal analysis of health disparities in childhood 19

Published in Archives of Diseases in Childhood

Chapter 3 The effects of school-based lifestyle interventions on body mass

index and blood pressure: a multivariate multilevel meta-analysis of randomized controlled trials

Published in Obesity Reviews

Chapter 4 A systematic review on economic evaluations of school-based lifestyle interventions targeting weight-related behaviours among 4- 12 year olds: Issues and ways forward Published in Prevention Science

Chapter 5 A Cost Analysis of School-Based Lifestyle Interventions

Published in Prevention Science

Chapter 6 The short-term value of the 'Healthy Primary School of the Future' initiative: a social return on investment analysis

Published in Frontiers in Public Health

Chapter $7 \quad$ BMI trajectories after primary school-based lifestyle interventions: unravelling an uncertain future. A mixed methods study Accepted for publication in Preventive Medicine Reports

Chapter 8 Lifetime cost-effectiveness and equity impacts of the Healthy

Primary School of the Future initiative

Published in BMC Public Health

Chapter 9 General discussion

Addenda Summary

Samenvatting

Valorisation

List of publications

About the author

Dankwoord 



\section{Chapter 1}

General introduction 

More than half of the adults in the Netherlands are currently overweight or obese. 'It is expected that the prevalence rates of overweight and obesity will continue rising, by 2040 $62 \%$ of Dutch adults will be overweight. ${ }^{2}$ The need for prevention measures is widely recognized in order to turn off the tap. ${ }^{3}$ In childhood already, there is considerable room for improvement in healthy eating and physical activity. Among Dutch 4-9 year olds, only 41\% and $42 \%$ adhere to the recommendations of eating at least 150 grams vegetables and 150 grams of fruit per day, respectively. These rates even decrease to $25 \%$ and $20 \%$ among 912 year olds. ${ }^{4}$ In addition, the high consumption of energy-dense snack food and drinks is worrying. ${ }^{5}$ Children also spend too little time in physical activity as only half $(48 \%)$ of Dutch children are sufficiently physically active. ${ }^{6}$ Sustained periods of excess energy intake and too little energy expenditure result in the accumulation of excess fat mass and overweight. In the 1980's, one in 20 children in the Netherlands were classified as overweight or obese, which has increased to one in seven children in 2009. ${ }^{7}$ Next to the group with an early onset of overweight or obesity, a significant proportion develops overweight in late adolescence or early adulthood. ${ }^{8,9}$ Furthermore, Geserick et al. (2018) reported that the most rapid increase in BMI among overweight adolescents had occurred between 2 and 6 years of age. ${ }^{10}$ Overall, these findings stress the need for intervening early in childhood with the notion: the earlier the better. To deliver lifestyle interventions in childhood, investments need to be made on the short run, while the benefits stretch over a longer time period (from childhood into adulthood). To inform investment and adoption decisions it is important to have insight into the effectiveness and cost-effectiveness of interventions on the short, medium, and long-term.

\section{Consequences of unhealthy behaviours}

\section{Childhood}

Acquiring unhealthy behaviours has adverse consequences that can already manifest in childhood. These impacts are seen for the physical, mental, and social aspects of health. ${ }^{11}$ In addition to the development of overweight or obesity, children's health may be compromised by metabolic deficiencies, such as insulin resistance, diabetes type 2, high blood pressure, and elevated levels of blood cholesterol. Whereas these precursors of cardiovascular disease were previously only seen in adults, they are nowadays also observed in overweight and obese children. ${ }^{12,13}$ Studies have also reported links between lifestyle factors and children's emotional health, social wellbeing, and HRQOL, which may be compromised by problems such as peer difficulties, bullying, and a low self-esteem. ${ }^{14-16}$ Furthermore, there is increasing evidence that health behaviours are associated with 
children's ability to learn. ${ }^{17,18}$ High BMI values are more prevalent among children with a low socioeconomic background, and evidence suggests that the socioeconomic inequalities in metabolic health also emerge in early childhood. ${ }^{19-22}$

\section{Adolescence and adulthood}

The burden of unhealthy lifestyles in childhood also affects outcomes in adolescence and adulthood. Obese children and adolescents are about five to six times more likely to become obese in adulthood as compared to their peers who are not obese. ${ }^{23-25}$ The high prevalence of childhood overweight and the persistence of it add to the already worrisome occurrence of overweight in adults. ${ }^{24}$ Depending on the age of onset and duration of excess weight, overweight children are at an increased risk of developing chronic disease in adulthood, such as type 2 diabetes, chronic heart disease, several types of cancer, and joint problems. ${ }^{26}$ An earlier onset of chronic disease has also been associated with more complications: Hillier \& Pedula (2003) found that persons who were diagnosed with type 2 diabetes before the age of 44 , were 14 times more likely to develop myocardial infarction in comparison to those who developed type 2 diabetes at older ages. ${ }^{27}$ Chronic disease leads to reduced HRQOL, high healthcare costs, and lost productivity (absence from work due to disease). ${ }^{28}$

Hamilton et al. (2018) reported that the lifetime cost of an obese child amounted to $€ 149,206$ (boys) and $€ 148,196$ (girls), which was made up of $€ 16,229$ (11\%) in healthcare costs and $€ 132,977$ (89\%) in productivity losses due to workdays lost or income penalty as a result of an individual's weight status. ${ }^{29}$ Socioeconomic disadvantage in early life is associated with an increased cardiovascular disease prevalence and mortality in adulthood, which seems to be driven by a combination of biological, behavioural, psychological, and social factors. ${ }^{30,31}$ The burden of unhealthy behaviours thus manifests throughout childhood, adolescence, and adulthood, which accumulates the longer someone engages in unhealthy behaviours.

\section{School-based prevention of unhealthy behaviours}

The Dutch government has emphasized the need for actions that promote health and prevent disease. $^{3}$ More specifically, childhood programs are considered to have a high potential, because health behaviours are still acquired and shaped in childhood, and because the later burden associated with unhealthy behaviours can still be prevented. ${ }^{32}$ 
Many social and environmental factors within households, schools, community, industry, and government influence children's health behaviours and contribute to childhood overweight, such as the availability of healthy foods and the presence of a movementfriendly environment (physical circumstances), the attitudes towards health behaviours (sociocultural aspects), costs (economic aspects), and policies and rules (political circumstances). ${ }^{33,34}$ Multiple efforts are thus needed to prevent unhealthy behaviours. Health promotion in the school setting has been recommended as an important area for intervention because children spent a lot of time at school and children from various backgrounds can be reached. Schools also play a role in acquiring knowledge and competences, and therefore provide room to promote healthy choices. Traditionally, health promotion in the school setting focused on health education, consisting of lessons on healthy eating and physical activity. Internationally, the need for broader interventions like Health Promoting Schools (HPS) has now been recognized. HPS aim to address the wider environment by making changes to the school ethos and/or physical environment, the school curriculum, and involve the family and/or community. ${ }^{24}$ The effects of school-based lifestyle programs vary across studies. $^{35-37}$ Bleich et al. (2018) found that among 24 randomized controlled trials, $17(71 \%)$ studies showed BMI reductions in the overall group or in specific subgroups (depending on the outcome and intervention duration), while seven (29\%) studies did not find any effects on reduced $\mathrm{BMI}^{35}$ In general, interventions that target at diet and physical activity simultaneously, involve a family component, and have longer duration are found to be more effective. ${ }^{35,36,38-42}$

\section{The Healthy Primary School of the Future}

In the Netherlands, there are substantial differences in health behaviours when comparing regions with a high socioeconomic character to regions with a low socioeconomic status. The Parkstad region, a former mining area in the southern part of the Netherlands (province of Limburg) is characterized by poorer health as compared to the Dutch average. ${ }^{43}$ Adults in southern Limburg live in good perceived health for an additional 43 years, compared to the Dutch average of almost 47 years. ${ }^{44}$ In 2016, 52\% of adults in southern Limburg were overweight, as compared to $43 \%$ in the rest of the Netherlands. ${ }^{45}$ Prevalence rates of overweight among 4-12 year olds are also higher as compared to the Dutch average: $24 \%$ percent of 10 year olds in Heerlen were classified as having overweight (including obesity) (2013) as compared to $12.5 \%-16.2 \%$ in the rest of the Netherlands (2009)., ${ }^{7,46}$ The Movare educational board consists of 53 primary schools in the Parkstad region. Like other primary schools in the Netherlands, schools of Movare consist of eight grades, where children enter primary school at the age of four and finish around the age of 12 . The 
Movare educational board observed unhealthy behaviours among children, which induced them to take action. Together with the regional Public Health Services and Maastricht University, they started the Healthy Primary School of the Future initiative.

Most children in the Netherlands stay at school during the lunch break, which varies from 30 to 60 minutes, to eat their packed lunch that they brought from home and play outside. At some schools, children can go home during the lunch break. Physical activity is mainly restricted to one or two hours of physical education per week. The Healthy Primary School of the Future initiative focused on two main changes, namely 1) the provision of a daily healthy lunch at school, and 2) daily structured physical activity and cultural sessions after the lunch. It was hypothesized that these changes contributed to additional health promoting changes in the school. Two schools decided to implement the daily lunch and the physical activity and cultural sessions, and are referred to as Healthy Primary Schools of the Future (HPSF). Two other schools continued with the implementation of the daily structure physical activity and cultural sessions only. These schools are referred to as Physical Activity Schools (PAS). To implement the changes during school hours, HPSF extended the lunch break and the school day. The lunch break time was extended from approximately 30-45 minutes to 90-105 minutes. Children attended school to approximately 15:30-15:45 instead of 14.45-15:00, and some of the lunch breaks involve an educational component to meet the education hour requirements. The lunch and structured physical activity and cultural sessions are prepared and led by external pedagogical employees from childcare organizations, who are supported by volunteers. The daily lunch is provided by the catering company Sodexo, and further prepared/distributed at schools. Staff from the sports and leisure organization the Move Factory, developed the physical activity sessions and provided instructions. Schools also received support from a health promoter from the regional Public Health Service. Financial support was received from the Limburg provincial authorities for the period between 2015 and 2019.

The implementation and the effects of the Healthy Primary School of the Future were examined in a quasi-experimental study from 2015 until 2019..$^{47}$ Eight schools participated in this study, consisting of two schools who adopted the HPSF changes, two other schools who implemented PAS, and four schools that maintained the usual school curriculum (control schools). Schools were not randomly assigned to the interventions because voluntary support was required for the intervention implementation. All children and their parents were invited to participate in data collection. The study sample was characterized by a dynamic cohort, because some children finished school between 2015 and 2019, and some children entered the participating schools during the study period. A multi-disciplinary research group from Maastricht University investigated the implementation ${ }^{48,49}$, the impact 
on children's health and wellbeing ${ }^{50}$, socio-economic effects, costs, and legal implications. ${ }^{47}$

\section{Informing decisions on school-based prevention}

In the context of school health promotion, decisions need to be made on whether and how to deliver them, and how to finance them. For example, school principals and teachers need to choose which activities they want to implement, parents are consulted by schools and need to decide on their support, health promoters, childcare professionals and other organizations can collaborate, and policy-makers at local and national governments decide how much they want to invest in school-based prevention. Information on the costs and outcomes of school-based lifestyle interventions can help people in making and substantiating their decisions, in developing an implementation strategy, or in evaluating whether the intended results are achieved. ${ }^{51}$ Economic evaluation is a field within health technology assessment that is directed at comparing the costs and consequences of alternative health programs. ${ }^{52,53}$ Economic evaluations on curative interventions are frequently employed to inform decision-makers on whether interventions offers value for money, or in other words: whether a program is cost-effective. Health technology assessment and economic evaluations on health promoting programs are still relatively scarce. The complex nature of programs, which may involve multiple components and stakeholders, the non-randomized designs of empirical studies, and the various potential outcomes of health promoting programs have been mentioned as potential reasons for the scarcity in economic evaluations on health promotion. ${ }^{54,55}$

\section{Type of economic evaluations}

Various types of economic evaluations can be employed, expressing cost-effectiveness in different ways. Economic evaluations of health interventions often take the form of costeffectiveness (CEA) or cost-utility analysis (CUA). Both types express cost-effectiveness as the extra costs per additional unit of outcome that is generated by an intervention. In a CEA, outcomes are expressed in physical outcomes such as the reduction in body weight or BMI. In a CUA, cost-effectiveness is reflected by the extra costs per quality-adjusted life year (QALY) gained. The QALY measure combines the improvement in quality of life and length of life. Other types of economic evaluations are the cost-consequence analysis (CCA), costbenefit analysis (CBA) and social return on investment analysis (SROI). In a CBA and SROI, health and non-health outcomes are expressed in monetary terms if deemed possible. Cost- 
effectiveness is then calculated as the net benefit (CBA) or as a ratio of the value of returns and costs (SROI). In the United Kingdom, the National Institute for Health and Care Excellence recommended the use of the CUA for health promotion programs up to 2012 , but thereafter placed more emphasis on conducting CCA and CBA analyses. ${ }^{56}$ This change in recommendations was made to ensure that all relevant benefits, including non-health and community benefits, are incorporated in the economic evaluation. ${ }^{56}$

School-based health promotion may give rise to benefits within and outside the healthcare sector (e.g. educational outcomes, community engagement, and parental wellbeing). This also raises the question who should pay for health promotion programs when multiple groups benefit from it. In the Netherlands, it is recommended to adopt a societal perspective in economic evaluations, ${ }^{5}$ meaning that all relevant costs and consequences are included, independently of who incurs them. ${ }^{58}$ By taking a societal perspective, economic evaluations may inform decision-making across and between multiple groups or sectors.

\section{Trial-based and model-based}

Furthermore, a distinction is made between trial-based evaluations and decision analytic models (model-based evaluations). Trial-based economic evaluations consider a relatively short time horizon by using the costs and consequences collected during the period of an empirical study (trial). Trial-based studies on school health promotion generally have a horizon of 1-2 years, and include outcomes such as the change in health behaviours, reductions in weight or $\mathrm{BMI}$, and impact on $\mathrm{HRQOL}$. Modelling studies use mathematical relationships and combine multiple sources of information to link short-term outcomes to potential impacts and cost-effectiveness on the long-term.

\section{Aim and outline of the thesis}

The overall aim of this thesis is to evaluate the health-economic impact of primary schoolbased lifestyle interventions. The thesis focuses on three main research questions:

\section{1) To which extent can school health promotion contribute to children's health and wellbeing on the short-term?}

School health promotion has been put forward as a means to tackle health inequalities. ${ }^{59}$ Chapter 2 investigates how health behaviours and outcomes are distributed across children with different socioeconomic backgrounds and explores the potential of lifestyle promotion in decreasing disparities in childhood health outcomes. 
The effectiveness of school-based health promotion programs is often evaluated by assessing the impact on BMI (z-score), but the impact on other health parameters is less frequently examined. ${ }^{13}$ Chapter 3 reviews and synthesizes the effects of primary schoolbased lifestyle interventions on children's body mass index and/or blood pressure levels.

2) Which methods are used for evaluating the health-economic impact of school health promotion?

Guidelines for economic evaluations are traditionally designed for evaluating clinical or medical interventions and are therefore not fully applicable to health promotion programs. Chapter 4 reviews the methods of cost-effectiveness studies on primary school-based lifestyle interventions and advises on directions for advancement.

3) What is the short- and long-term health-economic impact of the Healthy Primary School of the Future initiative?

Primary school-based interventions make use of scarce available financial resources and time. It is therefore important that the expectations regarding its impact are realistic.

Chapter 5 identifies the cost components of school-based lifestyle interventions, and calculates the costs of delivering the HPSF and PAS interventions. Chapter 6 describes a social return on investment analysis to assess the social value of HPSF and PAS after a twoyear intervention period.

The benefits of primary school-based lifestyle interventions are expected to reach into adulthood, through the prevention of chronic disease. Modelling techniques are used to estimate the long-term outcomes of primary school-based lifestyle interventions.

Chapter 7 investigates the development of children's weight trajectories after primary school-based lifestyle interventions, and identifies the related uncertainty. Chapter 8 examines the potential health and economic impacts of the Healthy Primary School within childhood and adulthood.

The results of the dissertation will be summarized and discussed in Chapter 9. 


\section{References}

1. Statline. Leefstijl en (preventief) gezondheidsonderzoek; persoonskenmerken 2019 [Available from: https://opendata.cbs.nl/statline/\#/CBS/nl/dataset/83021 NED/table?ts=1522312658353].

2. VTV. Leefstijl. Hoe (on)gezond leven we in de toekomst? 2018.

3. Nationaal Preventieakoord. Naar een gezonder Nederland. Ministerie van Volksgezondheid, Welzijn en Sport; 2018.

4. Ervaren gezondheid, zorggebruik en leefstijl bij kinderen tot 12 jaar: Statline. Central Bureau for Statistics (CBS). n.d. [Available from: https://opendata.cbs.nl/\#/CBS/nl/dataset/83716NED/ table?ts=1539253432988].

5. Gevers DW, Kremers SP, de Vries NK, van Assema P. Intake of energy-dense snack foods and drinks among Dutch children aged 7-12 years: how many, how much, when, where and which? Public Health Nutr. 2016;19(1):83-92.

6. Edwards RT. Paradigms and research programmes: is it time to move from health care economics to health economics? Health Econ. 2001;10(7):635-49.

7. Schonbeck Y, Talma H, van Dommelen P, Bakker B, Buitendijk SE, Hirasing RA, et al. Increase in prevalence of overweight in Dutch children and adolescents: a comparison of nationwide growth studies in 1980, 1997 and 2009. PloS one. 2011;6(11):e27608.

8. Elsenburg LK, Smidt N, Hoek HW, Liefbroer AC. Body Mass Index Trajectories from Adolescence to Early Young Adulthood: Do Adverse Life Events Play a Role? Obesity. 2017;25(12):2142-8.

9. De Kroon ML, Renders CM, Van Wouwe JP, Van Buuren S, Hirasing RA. The Terneuzen birth cohort: BMI changes between 2 and 6 years correlate strongest with adult overweight. PloS one. 2010;5(2):e9155.

10. Geserick M, Vogel M, Gausche R, Lipek T, Spielau U, Keller E, et al. Acceleration of BMI in Early Childhood and Risk of Sustained Obesity. New Eng J Med. 2018;379(14):1303-12.

11. International Health C. Constitution of the World Health Organization. 1946. Bull World Health Organ. 2002;80(12):983-4.

12. Friedemann C, Heneghan C, Mahtani K, Thompson M, Perera R, Ward AM. Cardiovascular disease risk in healthy children and its association with body mass index: systematic review and meta-analysis. BMJ. 2012;345:e4759.

13. Karnebeek K, Thapar S, Willeboordse M, van Schayck OCP, Vreugdenhil ACE. Comorbidities in Primary vs Secondary School Children With Obesity and Responsiveness to Lifestyle Intervention. J Clin Edocrinol Metab. 2019;104(9):3803-11.

14. Friedlander SL, Larkin EK, Rosen CL, Palermo TM, Redline S. Decreased quality of life associated with obesity in school-aged children. Arch Pediatr Adolesc Med. 2003; 157(12):1206-11.

15. Pitrou I, Shojaei T, Wazana A, Gilbert F, Kovess-Masféty V. Child Overweight, Associated Psychopathology, and Social Functioning: A French School-based Survey in 6- to 11-year-old Children. Obesity. 2010;18(4):809-17.

16. Williams J, Wake M, Hesketh K, Maher E, Waters E. Health-related quality of life of overweight and obese children. Jama. 2005;293(1):70-6.

17. Jirout J, LoCasale-Crouch J, Turnbull K, Gu Y, Cubides M, Garzione S, et al. How Lifestyle Factors Affect Cognitive and Executive Function and the Ability to Learn in Children. Nutrients. 2019;1 1(8).

18. Singh AS, Saliasi E, van den Berg V, Uijtdewilligen L, de Groot RHM, Jolles J, et al. Effects of physical activity interventions on cognitive and academic performance in children and adolescents: a novel combination of a systematic review and recommendations from an expert panel. Br J Sports Med. 2019;53(10):640-7.

19. Bann D, Johnson W, Li L, Kuh D, Hardy R. Socioeconomic inequalities in childhood and adolescent bodymass index, weight, and height from 1953 to 2015: an analysis of four longitudinal, observational, British birth cohort studies. Lancet Public Health. 2018;3(4):e194-e203.

20. van den Berg G, van Eijsden M, Vrijkotte TGM, Gemke RJBJ. Socioeconomic inequalities in lipid and glucose metabolism in early childhood in a population-based cohort: the ABCD-Study. BMC Public Health. $2012 ; 12(1): 591$. 
21. Puolakka E, Pahkala K, Laitinen TT, Magnussen CG, Hutri-Kähönen N, Tossavainen P, et al. Childhood Socioeconomic Status in Predicting Metabolic Syndrome and Glucose Abnormalities in Adulthood: The Cardiovascular Risk in Young Finns Study. Diabetes care. 2016;39(12):231 1-7.

22. Hostinar CE, Ross KM, Chen E, Miller GE. Early-Life Socioeconomic Disadvantage and Metabolic Health Disparities. Psychosom Med. 2017;79(5):514-23.

23. Simmonds $M$, Llewellyn A, Owen CG, Woolacott N. Predicting adult obesity from childhood obesity: a systematic review and meta-analysis. Obes Rev. 2016;17(2):95-107.

24. Herman KM, Craig CL, Gauvin L, Katzmarzyk PT. Tracking of obesity and physical activity from childhood to adulthood: the Physical Activity Longitudinal Study. Int J Pediatr Obes. 2009;4(4):281-8.

25. Evensen E, Wilsgaard T, Furberg AS, Skeie G. Tracking of overweight and obesity from early childhood to adolescence in a population-based cohort - the Tromso Study, Fit Futures. BMC Pediatr. 2016; 16:64.

26. Scarborough P, Bhatnagar P, Wickramasinghe KK, Allender S, Foster C, Rayner M. The economic burden of ill health due to diet, physical inactivity, smoking, alcohol and obesity in the UK: an update to 2006-07 NHS costs. J Publ Health. 201 1;33(4):527-35.

27. Hillier TA, Pedula KL. Complications in young adults with early-onset type 2 diabetes: losing the relative protection of youth. Diabetes care. 2003;26(11):2999-3005.

28. Heyworth ITM, Hazell ML, Linehan MF, Frank TL. How do common chronic conditions affect health-related quality of life? BrJ Gen Pract. 2009;59(568):e353-e8.

29. Hamilton D, Dee A, Perry IJ. The lifetime costs of overweight and obesity in childhood and adolescence: a systematic review. Obes Rev. 2018;19(4):452-63.

30. Liu RS, Burgner DP, Sabin MA, Magnussen CG, Cheung M, Hutri-Kähönen N, et al. Childhood Infections, Socioeconomic Status, and Adult Cardiometabolic Risk. Pediatrics. 2016;137(6):e20160236.

31. Pulkki-Raback L, Elovainio M, Hakulinen C, Lipsanen J, Hintsanen M, Jokela $M$, et al. Cumulative effect of psychosocial factors in youth on ideal cardiovascular health in adulthood: the Cardiovascular Risk in Young Finns Study. Circulation. 2015; 131 (3):245-53.

32. Mollborn S, James-Hawkins L, Lawrence E, Fomby P. Health lifestyles in early childhood. J Health soc Behav. 2014;55(4):386-402.

33. Ohri-Vachaspati P, DeLia D, DeWeese RS, Crespo NC, Todd M, Yedidia MJ. The relative contribution of layers of the Social Ecological Model to childhood obesity. Public Health Nutr. 2015; 18(1 1):2055-66.

34. Swinburn B, Egger G, Raza F. Dissecting obesogenic environments: the development and application of a framework for identifying and prioritizing environmental interventions for obesity. Prev Med. 1999;29/6 Pt 1):563-70.

35. Bleich SN, Vercammen KA, Zatz LY, Frelier JM, Ebbeling CB, Peeters A. Interventions to prevent global childhood overweight and obesity: a systematic review. Lancet Diabetes Endicrinol. 201 8;6(4):332-46.

36. Verjans-Janssen SRB, van de Kolk I, Van Kann DHH, Kremers SPJ, Gerards S. Effectiveness of school-based physical activity and nutrition interventions with direct parental involvement on children's $\mathrm{BMI}$ and energy balance-related behaviors - A systematic review. PloS one. 2018;13(9):e0204560.

37. Kobes A, Kretschmer T, Timmerman G, Schreuder $P$. Interventions aimed at preventing and reducing overweight/obesity among children and adolescents: a meta-synthesis. Obes Rev. 2018;19(8):1065-79.

38. Katz DL, O'Connell M, Niike VY, Yeh MC, Nawaz H. Strategies for the prevention and control of obesity in the school setting: systematic review and meta-analysis. Int J Obes. (2005). 2008;32(12):1780-9.

39. Khambalia AZ, Dickinson S, Hardy LL, Gill T, Baur LA. A synthesis of existing systematic reviews and metaanalyses of school-based behavioural interventions for controlling and preventing obesity. Obes Rev. 2012;13(3):214-33.

40. Gonzalez-Suarez C, Worley A, Grimmer-Somers K, Dones V. School-based interventions on childhood obesity: a meta-analysis. Am J Prev Med. 2009;37(5):418-27.

41. Gori D, Guaraldi F, Cinocca S, Moser G, Rucci P, Fantini MP. Effectiveness of educational and lifestyle interventions to prevent paediatric obesity: systematic review and meta-analyses of randomized and nonrandomized controlled trials. Obes Sci Pract. 2017;3(3):235-48.

42. Lavelle HV, Mackay DF, Pell JP. Systematic review and meta-analysis of school-based interventions to reduce body mass index. J Pub Health. 2012;34(3):360-9.

43. Bosma H, Jansen M, Groffen D, Mujakovic S, Feron F. Een nadere analyse van de gezondheidsachterstand in stadsregio Parkstad. TSG. 2013;91(6):318-23. 
44. Volksgezondheid en zorg. Levensverwachting in goede ervaren gezondheid per GGD-regio n.d. [Available from: https://www.volksgezondheidenzorg.info/onderwerp/gezonde-levensverwachting/ regionaalinternationaal/regionaal\#methoden].

45. Volksgezondheid en zorg. Overgewicht per GGD-regio. n.d.

46. Braun M. Jongeren op Gezond Gewicht Heerlen.: JOGG gemeente Heerlen.

47. Willeboordse M, Jansen MW, van den Heijkant SN, Simons A, Winkens B, de Groot RH, et al. The Healthy Primary School of the Future: study protocol of a quasi-experimental study. BMC Public Health. 2016;16:639.

48. Bartelink N, van Assema P, Jansen M, Savelberg H, Kremers S. The Moderating Role of the School Context on the Effects of the Healthy Primary School of the Future. Int J Environ Res Public Health. 2019; 16(13):2432.

49. Bartelink NHM, van Assema P, Jansen MWJ, Savelberg HHCM, Moore GF, Hawkins J, et al. Process evaluation of the healthy primary School of the Future: the key learning points. BMC Public Health. 2019;19(1):698.

50. Bartelink NHM, van Assema P, Kremers SPJ, Savelberg HHCM, Oosterhoff M, Willeboordse M, et al. Oneand Two-Year Effects of the Healthy Primary School of the Future on Children's Dietary and Physical Activity Behaviours: A Quasi-Experimental Study. Nutrients. 2019;11(3):689.

51. Promoting Health, Preventing Disease. The economic case.

52. 2015 Global Survey on Health Technology Assessment by National Authorities. World Health Organization; 2015.

53. Polus S, Mathes T, Klingler C, Messer M, Gerhardus A, Stegbaver C, et al. Health Technology Assessment of Public Health Interventions Published 2012 to 2016: An Analysis of Characteristics and Comparison of Methods. International journal of technology assessment in health care. 2019;35(4):280-90.

54. Holland W. Health technology assessment and public health: a commentary. Int J Technol Assess Health Care. 2004;20(1):77-80.

55. Burford B, Lewin S, Welch V, Rehfuess E, Waters E. Assessing the applicability of findings in systematic reviews of complex interventions can enhance the utility of reviews for decision making. J Clin Epid. 2013;66(11):1251-61.

56. Judging whether public health interventions offer value for money. National Institute for Health and Care Excellence (NICE); 2013.

57. Zorginstituut Nederland. Kostenhandleiding: Methodologie van kostenonderzoek en referentieprijzen voor economische evaluaties in de gezondheidszorg.: Zorginstituut Nederland; 2015.

58. Jönsson B. Ten arguments for a societal perspective in the economic evaluation of medical innovations. Eur J Health Econ. 2009; 10(4):357-9.

59. Mackenbach JP, Stronks K. A strategy for tackling health inequalities in the Netherlands. BMJ. 2002;325(7371):1029-32. 


\title{
Chapter 2
}

Longitudinal analysis of health disparities in childhood

\author{
Marije Oosterhoff \\ Manuela A. Joore \\ Nina H.M. Bartelink \\ Bjorn Winkens \\ Onno C.P. van Schayck \\ Hans Bosma
}

Archives of Diseases in Childhood, 2019; 104:781-788 


\section{Abstract}

\section{Objective}

Combatting disparities in health outcomes among children is a major public health concern. This study focuses on two questions: 1) to what extent does socioeconomic status (SES) contribute to disparities in health outcomes; and 2) to what extent can social inequalities in health outcomes be explained by differences in children's health behaviours?

\section{Design}

This study included two- year follow-up data of 1259 children (4-12 years of age) who participated in the 'Healthy Primary School of the Future' project. SES was measured by maternal and paternal education and household income (adjusted for family size). Health outcomes were BMI z-score (body mass index), health resource use, school absenteeism, health-related quality of life (HRQOL), and psychosocial health, measured over two years of follow-up (2015-2017). Health behaviours included physical activity, consumption of fruit, vegetables, and sweetened beverages. Associations between SES and baseline health behaviours were examined, and mixed models for repeated measures were used to assess associations between SES and health outcomes over two years of follow-up.

\section{Results}

A high socioeconomic background was significantly associated with better health outcomes (all outcomes). For example, children with a low SES had higher BMI z-scores (beta coefficient: $0.42,95 \% \mathrm{Cl}: 0.22 ; 0.62$ ), and higher consumption healthcare costs (ratio of mean costs: $2.21,95 \% \mathrm{Cl}: 1.57 ; 3.10)$. Effects of SES changed very little after controlling for health behaviours.

\section{Discussion}

Our findings strongly suggest that socioeconomic background has a pervasive impact on disparities in child health, but give little support to the idea that social inequalities in child health can be tackled by means of lifestyle interventions. 


\section{Introduction}

Health disparities are defined as gaps in health outcomes between different groups in society. When disparities are related to social factors such as ethnicity, family income, and parental education, they are considered to be unfair and are labelled as social inequalities.' Despite various policies and initiatives, the social gradient in child health remains stable or is even increasing. ${ }^{2,3}$ Continued efforts are of utmost importance to improve the health of all children. ${ }^{3-6}$

Adverse health outcomes such as poor health-related quality of life (HRQOL) and absenteeism from school due to sickness, are disproportionally concentrated in children who engage in unhealthy lifestyle behaviours and in children that grow up in families with a lower socioeconomic position. ${ }^{7-10}$ Various interventions that aim to tackle child health inequalities are focused on promoting a healthy lifestyle (Figure 1). ${ }^{11,12}$ This strategy is supported by previous findings which show that health-compromising behaviours, such as engaging in unhealthy lifestyles, are more often prevalent in children with a lower socioeconomic background. ${ }^{13-15}$ So far, it remains unclear whether lifestyle interventions have the potential to reduce child health inequalities because of the contradicting findings that have been reported. ${ }^{16}$ This lack of insight is driven by the poor understanding about the impact of health behaviours in relation to the emergence and persistence of child health inequalities. ${ }^{16,17}$ Veldhuis et al. (2013) found that some child health behaviours (watching TV and breakfast consumption) partially contributed to the inverse relation between SES and overweight/obesity. $^{18}$ In general, however, little is known about the role of health behaviours as a potential mediator in the relation between socioeconomic position and health-related outcomes in school-aged children. This study therefore focuses on two questions: 1) to what extent does socioeconomic background contribute to disparities in health outcomes over time in children aged 4-12 years; and 2) to what extent can these social inequalities in health outcomes be explained by differences in children's health behaviours?

\section{Methods}

\section{Participants}

We analysed data of primary school-aged children (according to the Dutch school system children are between 4-12 years of age) being enrolled in the Healthy Primary School of the Future project. This quasi-experimental study studies the effects of two healthy school 
types, named 'the Healthy School of the Future' (HPSF) and 'the Physical Activity School' (PAS) that are aimed at improving dietary behaviours and physical activity. The effects of HPSF and PAS were compared to control schools who maintained the usual school curriculum. Children were included in the annual measurements if an informed consent form was signed by their parents. The need for ethical approval was waived by the Medical Ethics Committee Zuyderland, Heerlen (MEC 14-N-142). Details on the interventions, study cohort, and data collection procedures have previously been reported. ${ }^{19}$ Data for the current study was collected in 2015 (baseline), 2016 (one-year follow-up) and 2017 (twoyear follow-up). We selected a subsample of children who participated in the measurements from baseline onwards. Children who were in the last grade at baseline were excluded because follow-up scores could not be obtained.

\section{Health outcomes}

Health outcomes included: 1) physical health; 2) health resource use; 3) health-related school absenteeism; 4) HRQOL; and 5) psychosocial health. Children's body height and weight were measured with a stadiometer and a weighting scale. BMI z-scores were calculated from Dutch reference values. ${ }^{20}$ Health resource use was measured by means of a parental questionnaire with a 12-month recall and valued with Dutch unit costs (Appendix 1). ${ }^{21,22}$ School absenteeism was expressed as the annual number of missed school days due to illness or healthcare visits and was retrieved from school records. HRQOL was measured with the visual analogue scale (VAS) and the Pediatric Quality of Life Inventory (PedsQL) instrument. ${ }^{23-26}$ In accordance to the user guidelines, parent-ratings were used to reflect HRQOL scores for 4-8 year olds, and self-reports were used for 8-12 year olds. The VAS records individual health status which is scored between 0 (worst HRQOL) and 100 (best imaginable HRQOL). The PedsQL instrument measures physical health, emotional, social, and school functioning. ${ }^{27,28}$ Reverse scoring was used such that higher summary score indicate a better HRQOL. The parent-reported strengths and difficulties questionnaire (SDQ) was used to examine the presence of psychological and psychosocial functioning problems. ${ }^{29}$ A total difficulties score was calculated by summing the scores for emotional, hyperactivity/inattention, conduct, and peer relationship difficulties, with a higher score indicating more problems. ${ }^{30}$ SDQ scores were available for one year of follow-up because the instrument was not included in the parental questionnaire at Year 2.

\section{Main determinants}

SES and health behaviours were measured at baseline to assess the prospective relationships with health outcomes. SES was calculated as the mean of standardized scores on maternal education level, paternal educational level, and household income (adjusted 
for household size) ${ }^{31}$ and categorized SES into low, middle, and high SES based on tertiles. We considered the following health behaviours: physical activity, vegetable intake, fruit intake, and consumption of sweetened beverages. Physical activity levels were measured with an ActiGraph accelerometer (Actigraph GT3X+, $30 \mathrm{~Hz}$, processing by Actilife 6.10.4) for 7 consecutive days. Physical activity was calculated for children who wore the accelerometer for at least an average time of 8 hours on 3 weekdays and 1 weekend day ( $n=864,76.7 \%$ of the 1127 pupils that wore the accelerometer). The average daily minutes of moderate and vigorous physical activity (MVPA) were calculated. Information on dietary behaviours was obtained from a parent-reported food frequency questionnaire. ${ }^{32-34}$ For statistical analyses, units of average daily consumption were converted to hours of MVPA (physical activity), pieces of fruit, 100 grams of vegetables, and 250 millilitres of sweetened beverages (one serving).

\section{Statistical analysis}

The associations between SES at baseline and health outcomes over time (baseline, Year 1, and Year 2) were assessed using mixed models (Figure 1: solid arrow A). Mixed model analyses were applied to account for the dependency due to repeated measurements and clustering of children within schools. We determined the random components with a 2-level (level 1: repeated measurements; level 2: child) and a 3-level (level 1: repeated measurements; level 2: child; level 3: school) random intercept and random slope (time) model. Because the explained variance at level 3 was not larger than $0.2 \%$ and similar results were found, only the results from the 2-level models were reported.

Linear mixed models were used for numerical outcomes, but to account for the zero-values and the positive skewness of the cost data we used a two-part generalized linear model (GLMM) for cost data: 1) a GLMM with a binomial distribution and a logit link function, and 2) a GLMM with a Gamma distribution and a log link function. A GLMM with a Poisson distribution (log link function) was used for school absenteeism which reflected count data. The interaction between SES and time was studied to assess whether SES had a different impact on health for the different time points. If no significant interaction effects were found, we reported the overall effect estimates. In case of interaction effects, we reported the effect estimates of SES for the three different time points. Analyses were adjusted for sex (boys, girls), grade (numerical; 1-7), school type (HPSF, PAS, control), time (categorical; year 0, 1,2 ), and school type * time to adjust for the effect of the different school types. Differences in baseline health behaviours across SES groups (Figure 1: dashed arrow B) were tested using Kruskal-Wallis and chi-square tests. Associations between baseline health behaviours and health outcomes over time (Figure 1: dashed arrow C) were examined using mixed model analyses (adjusted for sex, grade, school type, time, school type ${ }^{*}$ time, 
behaviours *ime). Last, we studied the associations between SES and health outcomes over time with additionally adjusting for baseline health behaviours (Figure 1: dashed arrow $A^{\prime}$ ).

Missing data were present because some participants did not give informed consent for all three time points, the parental questionnaire was not completed, respondents skipped or refused to answer questions, or data could not be obtained due to absence of the child. Missing data were handled with multiple imputation which generated 5 imputed datasets with 20 iterations. To impute missing values on SES indicators and health behaviours, demographic variables (age, sex, school type, ethnicity, family composition, disease status) and all health outcomes at the different time points (anthropometrics [BMI-z scores, waist circumference, ratio of hip and waist circumference], healthcare resource use, school absenteeism, HRQOL, psychosocial health) were used. Missing data on outcome variables were imputed using SES, health behaviours, demographic variables, and the specific healthrelated outcome at each time point (baseline, year 1, and year 2).

As a sensitivity analysis we replicated the analyses with only selecting the children from control schools to account for any residual confounding pertaining to the effect of school types (HPSF and PAS). All analyses were carried out with IBM SPSS Statistics for Windows (version 24.0. Armonk, NY: IBM Corp.) and the glmer package for R version 3.2.3.

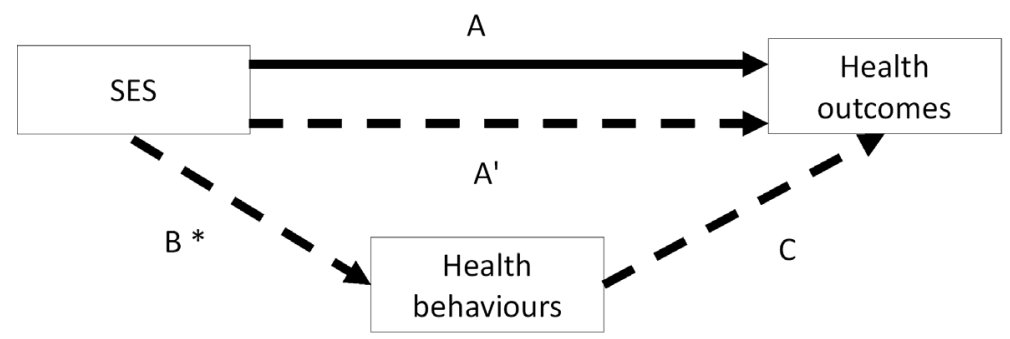

Figure 1 Graphical representation of the research questions.

Notes: $\mathrm{SES}=$ socioeconomic status. Solid arrow: research question 1 examined the prospective associations between SES and multifaceted health outcomes. Dashed arrows: research question 2 focused on the associations between SES and health behaviours (B), health disparities due to differences in health behaviours (C), and examined whether the gap in health outcomes between children with a high versus a low SES was influenced by health behaviours ( $\left.A^{\prime}\right)$. * Associations between SES and health behaviours were assessed, rather than the causal direction. However, as children's socioeconomic background is based on parental education levels and household income, it is assumed that children's socioeconomic background may influence their health behaviours during childhood instead of the other way around. 


\section{Results}

\section{Population characteristics}

Baseline data were collected for 1403 children ( $N=2326$ were invited, 60.3\%), of which 1259 children (HPSF: $N=361$, PAS: $N=409$, control: $N=489$ ) were included in this study (excluded: eight grade) (Figure 2). In this sample, 944 (75\%) children participated in all three measurements. In the current observational study we did not exclude children who changed schools $(\mathrm{N}=4)$. Participants with missing data on exposures and/or covariates were older, were more likely to come from control schools, live in an one-parent or reconstituted family, have a low SES, a higher BMI z-score, more psychosocial problems, and a lower HRQOL (PedsQL) (results not shown). Tables 1 and 2 show the sample characteristics (see Appendix 2 for data after imputation).

\begin{tabular}{|c|c|c|}
\hline & $\begin{array}{r}\text { Base } \\
\text { ting children: } n\end{array}$ & dren) \\
\hline \multicolumn{3}{|c|}{ Selected for the current study, participating children in grade 1-7 $(n=1259)$ * } \\
\hline HPSF $(n=361)$ & PAS $(n=409)$ & Control $(n=489)$ \\
\hline \multicolumn{3}{|c|}{ One year follow up (Year 1) } \\
\hline \multicolumn{3}{|c|}{ Participating $(n=1198)$, Drop-out after baseline ** $(n=61)$} \\
\hline $\begin{array}{l}\text { HPSF ( } \mathbf{n}=337 \text { ) } \\
\text { Drop-out: } n=24\end{array}$ & $\begin{array}{l}\text { PAS }(\mathbf{n}=395) \\
\text { Drop-out: } n=14\end{array}$ & $\begin{array}{l}\text { Control }(\mathbf{n}=466) \\
\text { Drop-out: } n=23\end{array}$ \\
\hline \multicolumn{3}{|c|}{ Two year follow up (Year 2) } \\
\hline \multicolumn{3}{|c|}{ Participating $(n=944)$, Drop-out after Year $1^{* * *}(n=254)$} \\
\hline $\begin{array}{l}\text { HPSF }(\mathbf{n}=\mathbf{2 7 6}) \\
\text { Drop-out: } n=61\end{array}$ & $\begin{array}{l}\text { PAS }(\mathbf{n = 3 1 1 )} \\
\text { Drop-out: } n=84\end{array}$ & $\begin{array}{l}\text { Control }(\mathbf{n}=\mathbf{3 5 7}) \\
\text { Drop-out: } n=109\end{array}$ \\
\hline
\end{tabular}

Figure 2 Flow diagram.

Notes: Year 1= after 12 months; Year 2 = after 24 months. * We selected a subsample of children $(n=1259)$ who participated at least in the baseline measurements (75\% participated at baseline, Year 1, and Year 2, N=944); ** Reasons drop out Year 1: e.g. moved out or actively stopped participation; *** Reasons drop out Year 2: finished school, moved out, or actively stopped participation. HPSF = Healthy Primary School of the Future, PAS = Physical Activity School. 
Table 1 Baseline exposures and demographics of the analysed sample (pre-imputation).

\begin{tabular}{|c|c|c|}
\hline Analysed sample (N=1259) & Mean (SD) / N (\%) & $\%$ missing \\
\hline Age & $7.9(2.1)$ & $0.0 \%$ \\
\hline Sex & & $0.0 \%$ \\
\hline Boys & $623(49.5 \%)$ & \\
\hline Girls & $636(50.5 \%)$ & \\
\hline School type & & $0.0 \%$ \\
\hline Intervention (HPSF) & $361(28.7 \%)$ & \\
\hline Intervention (PAS) & $409(32.5 \%)$ & \\
\hline Control, N (\%) & $489(38.8 \%)$ & \\
\hline Education level mother at baseline ${ }^{\prime}$ & & $44.6 \%$ \\
\hline Low & $108(15.5 \%)$ & \\
\hline Intermediate & $333(47.8 \%)$ & \\
\hline High & $256(36.7 \%)$ & \\
\hline Education level father at baseline ${ }^{1}$ & & $47.3 \%$ \\
\hline Low & $126(19.0 \%)$ & \\
\hline Intermediate & $300(45.2 \%)$ & \\
\hline High & $238(35.8 \%)$ & \\
\hline Net household income $(€)$ & & $59.0 \%$ \\
\hline Up to 1500 & $61(11.8 \%)$ & \\
\hline 1500 to $<2500$ & $78(15.1 \%)$ & \\
\hline 2500 to $<3500$ & $187(36.2 \%)$ & \\
\hline 3500 and above & $190(36.8 \%)$ & \\
\hline Socioeconomic status $^{2}$ & $0.08(0.73)$ & $61.7 \%$ \\
\hline MVPA (minutes/day), median (IQR) & $54.25(42.17-67.31)$ & $31.0 \%$ \\
\hline$\leq 0.5$ hour/day & $51(5.9 \%)$ & \\
\hline 0.5 to 1 hour per day & $492(56.6 \%)$ & \\
\hline$\geq 1$ hour per day & $326(37.5 \%)$ & \\
\hline Fruit intake (pieces/day), median (IQR) & $0.43(0.36-0.71)$ & $43.1 \%$ \\
\hline$<0.5$ piece a day & $385(53.8 \%)$ & \\
\hline 0.5 to 1 piece a day & $208(29.0 \%)$ & \\
\hline$\geq 1$ piece a day & $123(17.2 \%)$ & \\
\hline Vegetable intake (gr/day), median (IQR) & $88.57(57.14-128.00)$ & $43.1 \%$ \\
\hline$<100 \mathrm{gr} /$ day & $405(56.6 \%)$ & \\
\hline 100 to $200 \mathrm{gr} /$ day & $270(37.7 \%)$ & \\
\hline$\geq 200 \mathrm{gr} /$ day & $41(5.7 \%)$ & \\
\hline Consumption sweetened beverages (ml/day), median (IQR) & $142.90(57.14-400.00)$ & $43.4 \%$ \\
\hline$<250 \mathrm{ml} /$ day & $481(67.6 \%)$ & \\
\hline $250-500 \mathrm{ml}$ day & $126(17.7 \%)$ & \\
\hline$>500 \mathrm{ml} /$ day & $105(14.7 \%)$ & \\
\hline Ethnicity & & $34.7 \%$ \\
\hline Native background & $688(83.7 \%)$ & \\
\hline Western background & $91(11.1 \%)$ & \\
\hline Non-Western background & $43(5.2 \%)$ & \\
\hline Family composition & & $44.9 \%$ \\
\hline Nuclear family or co-parenting & $603(86.9 \%)$ & \\
\hline One-parent family & $43(6.2 \%)$ & \\
\hline Reconstituted family & $37(5.3 \%)$ & \\
\hline Other & $11(1.6 \%)$ & \\
\hline
\end{tabular}

Notes: $I Q R=$ interquartile range $(25$ th -75 th percentile); HPSF = Healthy Primary School of the Future; MVPA = moderate to vigorous physical activity; PAS = Physical Activity School; SD = standard deviation. ' $L$ Low = primary, vocational and lower general secondary education; average $=$ higher general and pre-university secondary education, lower professional education; high $=$ higher professional and academic education. ${ }^{2}$ Average of the standardized scores of maternal education level, paternal education level, and income adjusted for household size. 
Table 2 Health-related outcomes of the analysed sample at baseline and follow-up (pre-imputation).

\begin{tabular}{|c|c|c|c|}
\hline Analysed sample (N=1259) & $\begin{array}{c}\text { Baseline } \\
(2015 / 2016)\end{array}$ & $\begin{array}{c}\text { Year } 1 \\
(2016 / 2017)\end{array}$ & $\begin{array}{c}\text { Year } 2 \\
(2017 / 2018)\end{array}$ \\
\hline BMI z-score, mean (SD) & $0.14(1.0)$ & $0.07(1.0)$ & $0.10(1.1)$ \\
\hline Normal weight & $889(80.0 \%)$ & $938(81.1 \%)$ & $707(78.6 \%)$ \\
\hline Overweight & $176(15.9 \%)$ & $170(14.7 \%)$ & $150(16.7 \%)$ \\
\hline Obesity & $45(4.1 \%)$ & $49(4.2 \%)$ & $43(4.8 \%)$ \\
\hline \multicolumn{4}{|l|}{ GP visits } \\
\hline Total mean costs (SD) & $24.07(45.9)$ & $20.24(40.2)$ & $16.06(32.1)$ \\
\hline$N(\%)$ & $226(32.4 \%)$ & $161(29.0 \%)$ & $110(29.3 \%)$ \\
\hline \multicolumn{4}{|l|}{ Speech therapist visits } \\
\hline Total mean costs (SD) & $54.47(231.5)$ & $39.06(200.2)$ & $31.49(155.7)$ \\
\hline$N(\%)$ & $55(7.9 \%)$ & $36(6.5 \%)$ & $29(6.8 \%)$ \\
\hline \multicolumn{4}{|l|}{ Specialist visits } \\
\hline Total mean costs (SD) & 75.25 (219.9) & $73.31(241.5)$ & $54.58(138.0)$ \\
\hline$N(\%)$ & $204(29.2 \%)$ & $146(26.3 \%)$ & $102(23.9 \%)$ \\
\hline \multicolumn{4}{|l|}{ Physiotherapist / Occupational therapist visit } \\
\hline Total mean costs (SD) & $8.84(93.1)$ & $4.05(47.5)$ & $3.71(36.1)$ \\
\hline$N(\%)$ & $13(1.9 \%)$ & $6(1.1 \%)$ & $6(1.4 \%)$ \\
\hline \multicolumn{4}{|l|}{ Psychologist / social worker } \\
\hline Total mean costs (SD) & $24.51(176.4)$ & $19.10(109.2)$ & $17.41(145.5)$ \\
\hline$N(\%)$ & $34(4.9 \%)$ & $24(4.3 \%)$ & $14(3.3 \%)$ \\
\hline \multicolumn{4}{|l|}{ Youth care $^{1}$} \\
\hline Total mean costs (SD) & $25.77(274.6)$ & $17.49(147.3)$ & $22.21(227.6)$ \\
\hline$N(\%)$ & $23(3.3 \%)$ & $17(3.1 \%)$ & $13(3.1 \%)$ \\
\hline \multicolumn{4}{|l|}{ Medication use } \\
\hline Total mean costs (SD) & $20.02(115.9)$ & $23.61(129.7)$ & $22.99(133.7)$ \\
\hline$N(\%)$ & $66(9.6 \%)$ & $67(11.5 \%)$ & $54(11.5 \%)$ \\
\hline \multicolumn{4}{|l|}{ Hospital admissions } \\
\hline Total mean costs (SD) & $97.98(920.9)$ & $67.62(588.7)$ & $45.31(383.8)$ \\
\hline$N(\%)$ & $26(3.7 \%)$ & $23(4.1 \%)$ & $11(2.6 \%)$ \\
\hline Total healthcare costs, median (IQR) & $33.53(0-215)$ & $33.53(0-207)$ & $33.53(0-185)$ \\
\hline$N(\%)$ & $400(58.6 \%)$ & $315(56.8 \%)$ & $219(51.5 \%)$ \\
\hline If any costs are incurred, median (IQR) & $184.90(92-526)$ & $184.90(75-488)$ & $184.90(67-384)$ \\
\hline \multicolumn{4}{|l|}{ Health-related school absenteeism } \\
\hline Absenteeism days, median (IQR) & $5.00(2.0-9.0)$ & $4.50(2.0-8.5)$ & $4.00(2.0-7.0)$ \\
\hline$N(\%)$ & $901(95.6 \%)$ & $851(98.2 \%)$ & $716(97.5 \%)$ \\
\hline \multicolumn{4}{|l|}{ HRQOL } \\
\hline VAS (EQ-5D-Y), mean (SD) ${ }^{2}$ & $88.58(14.6)$ & $86.54(16.7)$ & $86.61(16.2)$ \\
\hline PedsQL, mean $(S D)^{3}$ & $79.35(13.4)$ & $80.69(13.0)$ & $82.61(13.2)$ \\
\hline \multicolumn{4}{|l|}{ Psychosocial health } \\
\hline $\mathrm{SDQ}$, mean $(\mathrm{SD})^{4}$ & $6.84(5.0)$ & $6.69(5.0)$ & NA \\
\hline
\end{tabular}

Notes: $B M I=$ body mass index; $E Q-5 D-Y=$ EuroQol 5 Dimensions Questionnaire; $H R Q O L$ = health-related quality of life; $I Q R=$ interquartile range (25th - 75th percentile); $N=$ number of observations; Peds $Q L=$ Pediatric Quality of Life Inventory; $S D=$ standard deviation; $S D Q=$ Strengths and Difficulties Questionnaire; VAS = Visual Analogue Scale. 'Dutch: jeugdzorg en jeugdhulpverlening; ${ }^{2}$ The VAS score ranged from 0 to 100 , where 100 is best imaginable health; ${ }^{3}$ Higher PedsQL scores represent better quality of life; ${ }^{4}$ Higher SDQ scores indicate more problems. 
1) To what extent does socioeconomic background contribute to disparities in health outcomes over time in children aged $4-12$ years?

The effect estimates of SES on health outcomes (Figure 1: solid arrow A) are reported in Table 3, model 1. A high socioeconomic background was associated with better health outcomes. Children with a low socioeconomic background had higher BMI z-scores (beta coefficient: $0.42,95 \% \mathrm{Cl}: 0.22 ; 0.62)$, and a higher consumption of healthcare resources (ratio of mean costs: $2.21,95 \% \mathrm{Cl}: 1.57 ; 3.10$ ) compared to children with a high SES. Cost increases were also found for hospital admissions, medication use, and specialists visits (data not shown). A low SES background was associated with higher school absenteeism at baseline and after two-years of follow-up (rate ratio Y2: 1.42, 95\% Cl: 1.14;1.75). Children with a low SES had lower HRQOL (PedsQL) after one and two years of follow-up (beta coefficient $Y 2$ : $-2.94,95 \% \mathrm{Cl}$ : $-5.30 ;-0.58$ ) compared to children with a high SES. A low SES was (not statistically significant) related to more psychosocial problems (beta coefficient $\mathrm{Y} 1: 0.44,95 \% \mathrm{Cl}:-0.38 ; 1.27)$. More specifically, social inequalities in psychosocial health at one-year follow-up were found for behavioural problems, peer problems, and hyperactivity (data not shown). The conclusions were similar when using a significance level $\alpha$ of 0.01 instead of 0.05 in order to take account of the potential biases due to multiple testing (Table 3). Results were similar for the continuous measure of SES, except that the effect estimates of SES on HRQOL (EQ5D) and psychosocial health were only statistically significant with the continuous measure of SES.

2) To what extent can social inequalities in health outcomes be explained by children's health behaviours?

No significant differences were found in health behaviours across children's socioeconomic background (Table 4) (Figure 1: dashed arrow B). Health behaviours were statistically significant associated with a few, but not all health outcomes (Figure 1: dashed arrow C, Appendix 3). Higher physical activity levels were associated with a lower BMI z-score (beta coefficient MVPA: $-0.55,95 \% \mathrm{Cl}:-0.80 ;-0.29)$. Children who were more physical active had up to $24 \%$ fewer annual absence days compared to children who were less physical active (rate ratio: $0.76,95 \% \mathrm{Cl}: 0.60 ; 0.95$ ). A high vegetable intake was associated with higher PedsQL scores (beta coefficient vegetable intake/day: $1.57,95 \% \mathrm{Cl}: 0.46 ; 2.67$ ) and a trend towards lower healthcare absenteeism was observed (rate ratioY $1: 0.90,95 \%$ $\mathrm{Cl}: 0.81 ; 1.00)$. After controlling for health behaviours, the effects of SES on health outcomes changed very little (Figure 1: dashed arrow A', Table 3, model 2). Only for psychosocial health (SDQ), the association with SES became statically significant. When analysing control schools only, the results pointed to the same direction, but the effect estimates of SES on VAS and psychosocial health did not remain statistically significant (Appendix 4). 


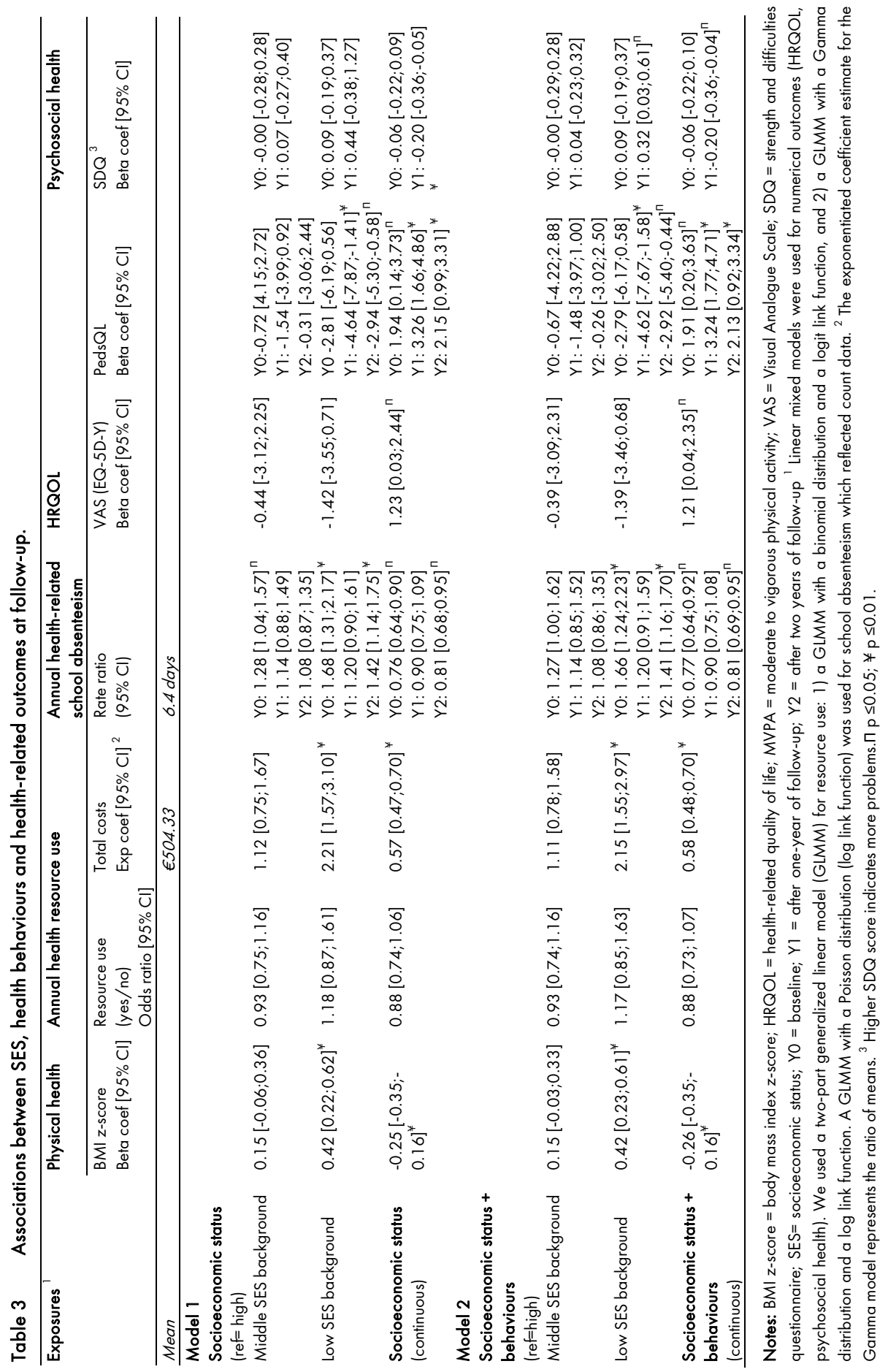


Table 4 Health behaviours per SES group.

\begin{tabular}{|c|c|c|c|c|}
\hline Analysed sample (N=1259) & $\begin{array}{l}\text { Low SES } \\
(N=416)\end{array}$ & $\begin{array}{c}\text { Middle SES } \\
(\mathrm{N}=423)\end{array}$ & High SES $(\mathrm{N}=420)$ & $p$ \\
\hline MVPA (minutes/day), median (IQR) & $\begin{array}{c}54.50 \\
(40.50-68.04)\end{array}$ & $\begin{array}{c}54.33 \\
(42.00-68.69)\end{array}$ & $\begin{array}{c}54.89 \\
(42.54-68.05)\end{array}$ & 0.96 \\
\hline$\leq 0.5$ hour/day, $\mathrm{N}(\%)$ & $21(5.0 \%)$ & $27(6.4 \%)$ & $18(4.2 \%)$ & 0.73 \\
\hline 0.5 to 1 hour per day, $\mathrm{N}(\%)$ & $237(57.0 \%)$ & $235(55.6 \%)$ & $243(57.9 \%)$ & \\
\hline$\geq 1$ hour per day, $N(\%)$ & $158(38.0 \%)$ & $161(38.0 \%)$ & $159(37.9 \%)$ & \\
\hline Fruit intake (pieces/day), median (IQR) & $\begin{array}{c}0.43 \\
(0.29-0.71)\end{array}$ & $\begin{array}{c}0.43 \\
(0.29-0.50)\end{array}$ & $\begin{array}{c}0.43 \\
(0.36-0.71)\end{array}$ & 0.19 \\
\hline$<0.5$ piece a day, $\mathrm{N}(\%)$ & $246(59.1 \%)$ & $236(55.8 \%)$ & $219(52.1 \%)$ & 0.37 \\
\hline 0.5 to 1 piece a day, $\mathrm{N}(\%)$ & $110(26.5 \%)$ & $121(28.6 \%)$ & $133(31.7 \%)$ & \\
\hline$\geq 1$ piece a day, $\mathrm{N}(\%)$ & $60(14.4 \%)$ & $66(15.6 \%)$ & $68(16.2 \%)$ & \\
\hline Vegetable intake (gr/day), median (IQR) & $\begin{array}{c}88.57 \\
(58.87-124.30)\end{array}$ & $\begin{array}{c}87.86 \\
(55.00-131.40)\end{array}$ & $\begin{array}{c}87.50 \\
(53.39-128.60)\end{array}$ & 0.82 \\
\hline$<100 \mathrm{gr} /$ day, N (\%) & $236(56.7 \%)$ & $246(58.1 \%)$ & $237(56.4 \%)$ & 0.81 \\
\hline 100 to $200 \mathrm{gr} /$ day, $\mathrm{N}(\%)$ & $157(37.8 \%)$ & $153(36.2 \%)$ & $165(39.3 \%)$ & \\
\hline$\geq 200 \mathrm{gr} /$ day, $\mathrm{N}(\%)$ & $23(5.5 \%)$ & $24(5.7 \%)$ & $18(4.3 \%)$ & \\
\hline Consumption sweetened beverages & 171.40 & 171.40 & 142.90 & 0.44 \\
\hline (ml/day), median (IQR) & $(57.14-400.00)$ & $(57.14-400.00)$ & $(57.14-342.90)$ & \\
\hline$<250 \mathrm{ml} /$ day, $\mathrm{N}(\%)$ & $268(64.5 \%)$ & $274(64.8 \%)$ & $285(67.9 \%)$ & 0.48 \\
\hline $250-500 \mathrm{ml}$ day, $\mathrm{N}(\%)$ & $73(17.5 \%)$ & $82(19.4 \%)$ & $78(18.6 \%)$ & \\
\hline$>500 \mathrm{ml} /$ day, $\mathrm{N}(\%)$ & $75(18.0 \%)$ & $67(15.8 \%)$ & $57(13.6 \%)$ & \\
\hline
\end{tabular}

Notes: $I Q R=$ interquartile range $(25$ th -75 th percentile); $N=$ number of observations; $M V P A=$ moderate to vigorous physical activity; $\mathrm{SES}=$ socioeconomic status.

\section{Discussion}

This study shows that a low socioeconomic background negatively affects a wide range of health outcomes in early childhood (4-12 year of age) including BMI, health-related school absenteeism, health resource use, HRQOL, and psychosocial health (Figure 3). Health behaviours were not associated with all health outcomes: low PA levels were associated with higher BMI z-scores and more health-related school absenteeism, and a low vegetable intake was associated with lower HRQOL. Social inequalities in health outcomes could not be explained by differences in children's health behaviours.

Our findings indicate that children with a low SES background suffer from poorer health compared to their peers with a higher SES background. This is in accordance to the findings of Veldhuis et al. (2013) who reported an inverse relation between SES and overweight/obesity among 5 -year olds. ${ }^{18}$ In contrast to our findings, the authors found that lifestyle-characteristics of the child partially explained the increased risk for overweight/obesity for the lowest SES subgroup. However, the inverse association between SES and overweight/obesity remained substantial even after correcting for health behaviours. Perhaps noteworthy, Veldhuis et al. (2013) measured children's health 
behaviours by self-reported breakfast consumption and TV watching, while we focused on fruit and vegetable consumption and objectively measured physical activity. ${ }^{18}$

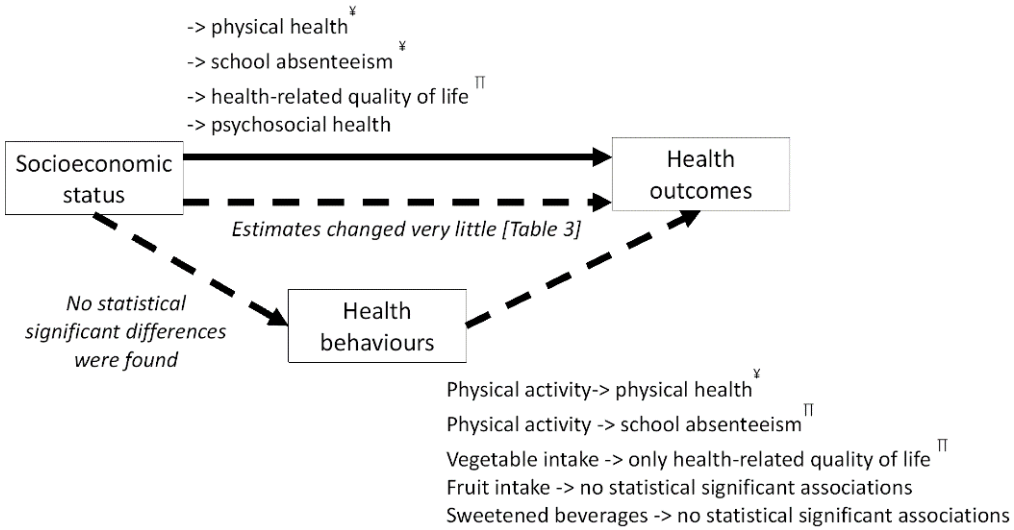

Figure 3 Graphical representation of the results.

Notes: Low socioeconomic status -> body mass index. Beta coefficient: $0.42,95 \% \mathrm{Cl}:[0.22 ; 0.62]$. Low SES-> annual health-related school absenteeism days. Rate ratio: $2.21,95 \% \mathrm{Cl}:[1.15 ; 3.10]$; Low SES -> health-related quality of life. Beta coefficient (PedsQL, year 2): -2.94, 95\% Cl: [-5.30;0.58]; Low SES -> psychosocial health. Beta coefficient (SDQ, year 1: $0.44,95 \%$ Cl: $[-0.38 ; 1.27]$; Physical activity (per hour of MVPA) -> body mass index. Beta coefficient: -0.55 [-0.80;-0.29]; Physical activity (per hour of MVPA) -> annual health-related school absenteeism days. Rate ratio: 0.76 [0.60;0.95]; Vegetable intake (100 grams) $->$ health-related quality of life. Beta coefficient (PedsQL): 1.57, 95\% Cl: [0.46;2.67]; PedsQL = Pediatric Quality of Life Inventory; SDQ = Strengths and Difficulties Questionnaire; SES = Socioeconomic status; MVPA = moderate to vigorous physical activity. ${ }^{\Pi} p \leq 0.05 ;{ }^{*} p \leq 0.01$.

The current study showed that socioeconomic background is adversely related impact to multifaceted health outcomes among children, including health resource use. Because the Dutch health insurance covers specialists visits, hospital care (including hospital admissions), and most prescribed medications, we believe that the differences in health and health resource use will not severely affect families' health expenditures. Social inequalities in health outcomes were not explained by health behaviours, mainly because health behaviours did not differ across SES groups.

The current findings give little support to the idea that social inequalities in child health can be tackled by means of lifestyle interventions. It is important to note that these findings do not imply that lifestyle interventions are fruitless or should not be implemented. Health behaviours are modifiable risk factors that are important target points for improving children's health. Previously, some authors have argued that we should aim for a better balance between lifestyle interventions and strategies that focus on cultural, political, material and social resources (by e.g., supporting access to quality services, providing financial support, 
generating strong supportive communities) in order to combat child health inequalities. ${ }^{3,5,6,11}$ The findings of the current study corroborate the suggestion to enrich policies with so-called community or upstream interventions because SES is strongly related to child health inequalities, independently of health behaviours.

Our study also suffered from some limitations. Second, in the current sample, health behaviours did not differ significantly across SES groups. Several studies found that children with a low SES had less healthy behaviours compared to peers with a higher socioeconomic position. ${ }^{15,35,36}$ It is however difficult to compare findings because multiple indicators can be used to measure SES (e.g., education of the mother, deprivation, area-based measures, composite measures) and lifestyle behaviours. In a post-hoc analysis, some associations were found between SES and health behaviours when using maternal education as SESindicator, but this did not change the main conclusions (Appendix 4). In a recent study conducted by our study group, it was found that parents of responders were more often unemployed and had lower education levels compared to Dutch averages (not for maternal education). ${ }^{37}$ These findings accord with those of other studies, which show that the southern area in the Netherlands is a relatively poor region with a lower socioeconomic position as compared to other parts of the Netherlands. ${ }^{38}$ The generalizability of the study sample is therefore considered high when compared to the regional population but low when compared to the national sample. ${ }^{37}$ The analyzed sample in the current study did not include the last grade, but this did not affect the representativeness of the study sample. Although the generalizability to the Dutch population is limited, conducting the study in a low SES area (partially) accounted for the fact that people with a low socioeconomic background are usually underrepresented in scientific studies. ${ }^{39}$ This helped us to study the relationships between socioeconomic status, health behaviours, and health outcomes. Last, we recognize that a composite measure of dietary behaviour (e.g., healthy eating index) may be recommended to examine the effects of diet. However, we were able to include multiple aspects that include both healthy behaviours (fruit and vegetable) and unhealthy behaviours (consumption of sweetened beverages).

To our knowledge, this is the first study formally investigating the mediating role of health behaviours in relation to the link between socioeconomic position and various child health outcomes. Our findings showed that health inequalities were already present at baseline and did not widen during the two-year follow-up. Further research with a longer follow-up period is needed to more fully examine the emergence and persistence of health inequalities from early childhood into adolescence. 


\section{Conclusion}

The findings of the current study strongly suggest that socioeconomic background has a pervasive impact on disparities in child health, but give little support to the idea that social inequalities in child health can be tackled by means of lifestyle interventions. 


\section{References}

1. Halle T, Forry N, Hair E, Perper K, Wandner L, Wessel J, et al. Disparities in Early Learning and Development: Lessons From the Early Childhood Longitudinal Study - Birth Cohort (ECLS-B). Washington DC, 2009: 1-7.

2. Hargreaves DS, Diafari Marbini A, Viner RM. Inequality trends in health and future health risk among English children and young people, 1999-2009. Arch Dis Child. 2013;98(11):850-5.

3. Law C, Parkin C, Lewis H. Policies to tackle inequalities in child health: why haven't they worked (better)? Arch Dis Child. 2012;97(4):301-3.

4. Prus SG. Age, SES, and health: a population level analysis of health inequalities over the lifecourse. Social Health Illn. 2007;29(2):275-96.

5. Moore TG, McDonald M, Carlon L, O'Rourke K. Early childhood development and the social determinants of health inequities. Health promotion international. 2015;30 Suppl 2:ii 102-15.

6. Spencer N. Reducing child health inequalities: what's the problem? Arch Dis Child. 2013;98(1 1):836-7.

7. Chen G, Ratcliffe J, Olds T, Magarey A, Jones M, Leslie E. BMI, Health Behaviors, and Quality of Life in Children and Adolescents: A School-Based Study. Pediatr. 2014.

8. Hansen AR, Pritchard T, Melnic I, Zhang J. Physical activity, screen-time, and school absenteeism: Selfreports from NHANES 2005-2008. Cuur Res Med Opin. 2015:1-30.

9. Kirk SF, Kuhle S, Ohinmaa A, Veugelers PJ. Health behaviours and health-care utilization in Canadian schoolchildren. Public Health Nutr. 2013;16(2):358-64.

10. Howe LD, Lawlor DA, Propper C. Trajectories of socioeconomic inequalities in health, behaviours and academic achievement across childhood and adolescence. J Epidemiol Community Health. 2013; 67(4):358-64.

11. Pons-Vigués M, Diez È, Morrison J, Salas-Nicás S, Hoffmann R, Burstrom B, et al. Social and health policies or interventions to tackle health inequalities in European cities: a scoping review. BMC Public Health. $2014 ; 14(1): 198$.

12. Irwin A, Valentine N, Brown C, Loewenson R, Solar O, Brown H, et al. The commission on social determinants of health: tackling the social roots of health inequities. PLoS Med. 2006;3(6):e106-e.

13. Hilpert M, Brockmeier K, Dordel S, Koch B, Weiss V, Ferrari N, et al. Sociocultural Influence on Obesity and Lifestyle in Children: A Study of Daily Activities, Leisure Time Behavior, Motor Skills, and Weight Status. Obesity facts. 2017;10(3):168-78.

14. Ranjit N, Wilkinson AV, Lytle LM, Evans AE, Saxton D, Hoelscher DM. Socioeconomic inequalities in children's diet: the role of the home food environment. Int J Behav Nutr Phys Act. 2015; 12(Suppl 1):S4-S.

15. Vermeiren AP, Willeboordse M, Oosterhoff $M$, Bartelink N, Muris $P$, Bosma H. Socioeconomic multi-domain health inequalities in Dutch primary school children. Eur J Public Health. 2018;28(4):610-6.

16. Magnee T, Burdorf A, Brug J, Kremers SP, Oenema A, van Assema P, et al. Equity-specific effects of 26 Dutch obesity-related lifestyle interventions. Am J Prev Med. 2013;44(6):e57-66.

17. Hillier-Brown FC, Bambra CL, Cairns JM, Kasim A, Moore HJ, Summerbell CD. A systematic review of the effectiveness of individual, community and societal level interventions at reducing socioeconomic inequalities in obesity amongst children. BMC Public Health. 2014;14:834.

18. Veldhuis L, Vogel I, van Rossem L, Renders CM, Hirasing RA, Mackenbach JP, et al. Influence of maternal and child lifestyle-related characteristics on the socioeconomic inequality in overweight and obesity among 5-year-old children; the "Be Active, Eat Right" Study. Int J Environ Res Public Health. 2013; 10(6):2336-47.

19. Willeboordse M, Jansen MW, van den Heijkant SN, Simons A, Winkens B, de Groot RHM, et al. The Healthy Primary School of the Future: study protocol of a quasi-experimental study. BMC Public Health. $2016 ; 16(1): 639$.

20. Schonbeck Y, Talma H, van Dommelen P, Bakker B, Buitendijk SE, Hirasing RA, et al. Increase in prevalence of overweight in Dutch children and adolescents: a comparison of nationwide growth studies in 1980, 1997 and 2009. PloS one. $2011 ; 6(11): e 27608$. 
21. Zorginstituut Nederland. Kostenhandleiding: Methodologie van kostenonderzoek en referentieprijzen voor economische evaluaties in de gezondheidszorg. 2015. [Available from: https://www.zorginstituutnederland.nl/over-ons/werkwijzen-en-procedures/adviseren-over-en-verduidelijken-van-het-basispakketaan-zorg/beoordeling-van-geneesmiddelen/richtlijnen-voor-economische-evaluatie]. Accessed 1 March 2016.

22. KPMG Plexus. Inzicht in tarieven Wmo en jeugdzorg Fase 2. Eindrapportage. 2014. [Available from: https://vng.nl/onderwerpenindex/jeugd/jeugdhulp/publicaties/inzicht-in-tarieven-wmo-en-jeugdzorg]. Accessed 1 March 2015.

23. Varni J, Burwinkle T, Seid M. The PedsQLTM 4.0 as a School Population Health Measure: Feasibility, Reliability, and Validity. Qual Life Res. 2006; 15(2):203-15.

24. Williams J, Wake M, Hesketh K, Maher E, Waters E. Health-related quality of life of overweight and obese children. Jama. 2005;293(1):70-6.

25. Boyle SE, Jones GL, Walters SJ. Physical activity, quality of life, weight status and diet in adolescents. Qual Life Res. 2010;19(7):943-54

26. Wu XY, Ohinmaa A, Veugelers PJ. Diet quality, physical activity, body weight and health-related quality of life among grade 5 students in Canada. Public Health Nutr. 2012;15(1):75-81.

27. Varni JW, Limbers CA, Burwinkle TM. How young can children reliably and validly self-report their healthrelated quality of life?: an analysis of 8,591 children across age subgroups with the PedsQL 4.0 Generic Core Scales. Health Qual Life Outcomes. 2007; 5:1.

28. Engelen V, Haentjens MM, Detmar SB, Koopman HM, Grootenhuis MA. Health related quality of life of Dutch children: psychometric properties of the PedsQL in the Netherlands. BMC Pediatrics. 2009;9:68.

29. Achenbach TM, Becker A, Dopfner M, Heiervang E, Roessner V, Steinhausen HC, et al. Multicultural assessment of child and adolescent psychopathology with ASEBA and SDQ instruments: research findings, applications, and future directions. J Child Psychol Psychiatry. 2008;49(3):251-75.

30. Crone MR, Vogels AG, Hoekstra F, Treffers PD, Reijneveld SA. A comparison of four scoring methods based on the parent-rated Strengths and Difficulties Questionnaire as used in the Dutch preventive child health care system. BMC Public Health. 2008;8:106.

31. Shavers VL. Measurement of socioeconomic status in health disparities research. Natl Med Assoc. 2007;99(9): 1013-23.

32. van Assema P, Brug J, Ronda G, Steenhuis I. The relative validity of a short Dutch questionnaire as a means to categorize adults and adolescents to total and saturated fat intake. J Hum Nutr Diet. 200 1; 14(5):377-90.

33. Van Assema P, Brug J, Ronda G, Steenhuis I, Oenema A. A short dutch questionnaire to measure fruit and vegetable intake: relative validity among adults and adolescents. Nutr Health. 2002; 16(2):85-106.

34. van Rossum CTM, Fransen HP, Verkaik-Kloosterman J, Buurma-Rethans EJM, Ocké MC. Dutch National Food Consumption Survey 2007-2010. Diet of children and adults aged 7 to 69 years. National Institute for Public Health and the Environment (RIVM). 2011 . [Available from: https://www.rivm.nl/ Documenten_en_publicaties/Wetenschappelijk/Rapporten/2011/oktober/Dutch_National_Food_Consu mption_Survey_2007_2010_Diet_of_children_and_adults_aged_7_to_69_years]. Accessed 1 August 2017.

35. Magnusson MB, Sjöberg A, Kjellgren KI, Lissner L. Childhood obesity and prevention in different socioeconomic contexts. Prev Med. 201 1;53(6):402-7.

36. Moraeus L, Lissner L, Yngve A, Poortvliet E, Al-Ansari U, Sjoberg A. Multi-level influences on childhood obesity in Sweden: societal factors, parental determinants and child's lifestyle.Int J Obes. (2005). 2012;36(7):969-76.

37. Boudewijns EA, Pepels JJS, van Kann D, Konings K, Van Schayck CP, Willeboordse M. Healthy, happy, and rich? A cros-sectional assessment of non-response and external validity in a school-based quasiexperimental study. [submitted].

38. Jansen MW, Kuppens E. Op zoek naar de Limburg factor [Seeking the Limburg-factor]. Geleen: GGD Zuid Limburg; 2015.

39. Vermaire J, Van Loveren C, Poorterman J, Hoogstraten J. Non-participation in a randomized controlled trial: the effect on clinical and non-clinical variables. Caries research. 201 1;45(3):269-74. 


\section{Appendix 1}

\section{Measurement of disease status and calculation of healthcare costs}

This appendix includes additional information on the measurement of disease status and the calculation of healthcare costs, containing costs of healthcare visits, hospital admissions and drug use.

\section{Disease status}

Disease status was measured by parental report as the current presence of any chronic condition, including asthma or chronic bronchitis; allergies, eczema and other skin conditions; frequent abdominal pain, obstipation and bowel disorders; diabetes; frequent complaints of back, knee, ankle, hip, shoulder, wrist and hand; neurological diseases like epilepsy; frequent severe headaches and migraine; being overly stressed, depressed or anxious; eating disorders; attention deficit (hyperactivity) disorder; autism, Asperger syndrome; not otherwise specified pervasive developmental disorder; cancer; and congenital heart disease.

\section{Hospital admissions}

The amount of hospital admissions over the last 12 months were measured by a parental questionnaire. Costs of hospital admissions were calculated using reference prices (Table A1).

Table A1 Unit costs for hospital admissions.

\begin{tabular}{lcc}
\hline Cost item parental questionnaire & Unit costs (day) 2017 & Reference \\
\hline Hospital admissions & $€ 483.71$ & {$[21]$} \\
\hline
\end{tabular}

\section{Physician and therapist visits}

The amount of physician and therapist visits over the last 12 months were measured by a parental questionnaire. Resource use was combined with unit costs to calculate total costs of healthcare visits (Table A2). 
Table A2 Unit costs for healthcare and youth care visits.

\begin{tabular}{lcc}
\hline Cost item parental questionnaire & Unit costs (visit) 2017 & Reference \\
\hline General practitioner & $€ 33.53$ & {$[21]$} \\
Paediatrician & $€ 92.47$ & {$[21]$} \\
Ophthalmologist / orthoptist & & \\
Ear, nose, and throat (ENT) specialist & & \\
Other specialist & & \\
Speech therapist & $€ 33.53$ & {$[21]$} \\
Psychologist / social worker (mental health care) & $€ 65.04$ & {$[21]$} \\
Occupational therapist & $€ 33.53$ & {$[21]$} \\
Physiotherapist & $€ 33.53$ & {$[21]$} \\
Youth care services * & $€ 62.24$ & {$[22]$} \\
\hline
\end{tabular}

* In the Netherlands: jeugdzorg en jeugdhulpverlening.

Drug use

The type and amount of drugs used by children were obtained from the parental questionnaire. Parents were asked to recall the medications their child had used during the last 12 months. This included the 1) name of the drug, 2) dose of the drug, 3) frequency of utilization, and 4) duration of utilization (months). The related costs were estimated by a four-step approach. For the calculation of costs, we followed the recommendations for calculating drug costs by using reference prices.

\section{Step 1: Drug use}

\subsection{Select type of drug}

First, the type of drug that was reported by parental report was linked to drugs in the Dutch database for drug costs (www.medicijnkosten.nl). For each type of drug mentioned, we selected the drug dose that was most often reported. When the drug dose was not reported, Dutch standards (NHG standard) were used to select the drug type.

1.2 Number of units

Second, the average number of units taken per day was calculated. This was done by dividing the total dose taken per day (reported dose times the reported frequency) divided by the selected drug dose.

Step 2: Annual costs of drugs

Annual drug costs were calculated using two approaches. With approach $A$, drug costs were calculated by means of reported utilization. With approach $B$, drug costs were calculated using average drug use. 


\subsection{Approach A}

The number of units taken per year was calculated from the number of units taken per day and the number of months the drug was taken. The number of units per year was multiplied by the average unit costs for each drug.

\subsection{Approach B}

The average drug use per 15 days was obtained. Subsequently, the average drug use per year was calculated. The average drug use per year was multiplied by the average unit costs for each drug.

\subsection{Comparing approaches}

The number of units (approach A) and the average drug use (approach B) were compared. When the average drug use was not reported or the average drug use was significantly higher than the reported frequency, the drug costs of approach $A$ were selected. The drug costs of approach $B$ were selected when the number of units consumed could not be calculated or the costs of both approaches were comparable.

Step 3: Total costs of drugs

Annual dispensing fees were added to the drug costs. When the drug was used for less than one month, the costs were not valued as the length of duration (in days) was unknown.

Step 4: Total costs of drugs per child

The costs of all drugs consumed per child were added. 


\section{Appendix 2}

\section{Baseline characteristics and outcome variables (post-imputation)}

Table A3 Baseline characteristics (post-imputation)

\begin{tabular}{|c|c|}
\hline Analysed sample (N=1259) & Total \\
\hline Age, mean (SD) & $7.9(2.1)$ \\
\hline \multicolumn{2}{|l|}{ Sex } \\
\hline Boys, N (\%) & $623(49.5 \%)$ \\
\hline Girls, N (\%) & $636(50.5 \%)$ \\
\hline \multicolumn{2}{|l|}{ School type } \\
\hline Intervention (HPSF), N (\%) & $361(28.7 \%)$ \\
\hline Intervention (PAS), N (\%) & $409(32.5 \%)$ \\
\hline Control, N (\%) & $489(38.8 \%)$ \\
\hline \multicolumn{2}{|l|}{ Education level mother at baseline ${ }^{1}$} \\
\hline Low, N (\%) & $229(18.2 \%)$ \\
\hline Intermediate, N (\%) & $573(45.5 \%)$ \\
\hline High, $N(\%)$ & $457(36.3 \%)$ \\
\hline \multicolumn{2}{|l|}{ Education level father at baseline ${ }^{1}$} \\
\hline Low, N (\%) & $278(22.1 \%)$ \\
\hline Intermediate, $\mathrm{N}(\%)$ & $550(43.7 \%)$ \\
\hline High, $N(\%)$ & $431(34.2 \%)$ \\
\hline \multicolumn{2}{|l|}{ Net household income $(€)$} \\
\hline Up to $1500, N(\%)$ & $152(12.1 \%)$ \\
\hline 1500 to $<2500, \mathrm{~N}(\%)$ & $224(17.8 \%)$ \\
\hline 2500 to $<3500, \mathrm{~N}(\%)$ & $424(33.7 \%)$ \\
\hline 3500 and above, $N(\%)$ & $459(36.4 \%)$ \\
\hline Socioeconomic status 2 , mean (SD) & $0.00(0.72)$ \\
\hline MVPA (minutes/day), median (IQR) & $54.53(42.08-68.05)$ \\
\hline$\leq 0.5$ hour/day, $\mathrm{N}(\%)$ & $66(5.2 \%)$ \\
\hline 0.5 to 1 hour per day, $\mathrm{N}(\%)$ & $715(56.8 \%)$ \\
\hline$\geq 1$ hour per day, $\mathrm{N}(\%)$ & $478(38.0 \%)$ \\
\hline Fruit intake (pieces/day), median (IQR) & $0.43(0.36-0.71)$ \\
\hline$<0.5$ piece a day, $\mathrm{N}(\%)$ & $701(55.7 \%)$ \\
\hline 0.5 to 1 piece a day, $\mathrm{N}(\%)$ & $364(28.9 \%)$ \\
\hline$\geq 1$ piece a day, $N(\%)$ & $194(15.4 \%)$ \\
\hline Vegetable intake (gr/day), median (IQR) & $87.86(55.71-126.40)$ \\
\hline$<100 \mathrm{gr} /$ day, $\mathrm{N}(\%)$ & $719(57.1 \%)$ \\
\hline 100 to $200 \mathrm{gr} /$ day, $\mathrm{N}(\%)$ & $475(37.7 \%)$ \\
\hline$\geq 200 \mathrm{gr} /$ day, $\mathrm{N}(\%)$ & $65(5.2 \%)$ \\
\hline Consumption of sweetened beverages (ml/day), median (IQR) & $171.40(57.14-400.00)$ \\
\hline$<250 \mathrm{ml} /$ day, $\mathrm{N}(\%)$ & $827(65.7 \%)$ \\
\hline $250-500 \mathrm{ml}$ day, $\mathrm{N}(\%)$ & $233(18.5 \%)$ \\
\hline$>500 \mathrm{ml} /$ day, $\mathrm{N}(\%)$ & $199(15.8 \%)$ \\
\hline \multicolumn{2}{|l|}{ Ethnicity } \\
\hline Native background, N (\%) & $1032(82.0 \%)$ \\
\hline Western background, $\mathrm{N}(\%)$ & $152(12.1 \%)$ \\
\hline Non-Western background, N (\%) & $75(6.0 \%)$ \\
\hline \multicolumn{2}{|l|}{ Family composition } \\
\hline Nuclear family or co-parenting, $\mathrm{N}(\%)$ & 1069 (84.9\%) \\
\hline One-parent family, N (\%) & $90(7.1 \%)$ \\
\hline Reconstituted family, N (\%) & $73(5.8 \%)$ \\
\hline Other, $N(\%)$ & $27(2.1 \%)$ \\
\hline
\end{tabular}

Notes: HPSF = Healthy Primary School of the Future; IQR = interquartile range (25th -75 th percentile); MVPA = moderate to vigorous physical activity; PAS = Physical Activity School; SD = standard deviation. ' Low = primary, vocational and lower general secondary education; average = higher general and pre-university secondary education, lower professional education; high $=$ higher professional and academic education. ${ }^{2}$ Average of the standardized scores of maternal education level, paternal education level, and income adjusted for household size. 
Table A4 Health-related outcomes of the analysed sample at baseline and follow-up (post-imputation).

\begin{tabular}{|c|c|c|c|c|}
\hline Analysed sample (N=1259) & $\begin{array}{l}\text { Unit costs } \\
(2017)\end{array}$ & $\begin{array}{l}\text { Baseline } \\
(2015 / 2016)\end{array}$ & $\begin{array}{l}\text { Year } 1 \\
(2016 / 2017)\end{array}$ & $\begin{array}{l}\text { Year } 2 \\
(2017 / 2018)\end{array}$ \\
\hline BMI z-score, mean (SD) & & $0.14(1.0)$ & $0.08(1.0)$ & $0.16(1.1)$ \\
\hline GP visits & $€ 35.53$ & & & \\
\hline Total mean costs & & 27.22 & 20.67 & 15.93 \\
\hline$N(\%)$ & & $417(33.1 \%)$ & $363(28.8 \%)$ & $318(25.3 \%)$ \\
\hline Speech therapist visits & $€ 30.49$ & & & \\
\hline Total mean costs & & 54.10 & 48.73 & 42.48 \\
\hline$N(\%)$ & & $95(7.5 \%)$ & $105(8.3 \%)$ & $102(8.1 \%)$ \\
\hline Specialist visits & $€ 92.47$ & & & \\
\hline Total mean costs & & 73.67 & 80.13 & 61.55 \\
\hline$N(\%)$ & & $366(29.1 \%)$ & $334(26.5 \%)$ & $330(26.2 \%)$ \\
\hline $\begin{array}{l}\text { Physiotherapist / Occupational } \\
\text { therapist visit }\end{array}$ & $€ 35.53$ & & & \\
\hline Total mean costs & & 11.51 & 6.79 & 7.35 \\
\hline$N(\%)$ & & $26(2.1 \%)$ & $20(1.6 \%)$ & $25(2.0 \%)$ \\
\hline Psychologist / social worker & $€ 65.04$ & & & \\
\hline Total mean costs & & 58.48 & 24.69 & 25.68 \\
\hline$N(\%)$ & & $64(5.1 \%)$ & $64(5.1 \%)$ & $49(3.9 \%)$ \\
\hline Youth care $^{1}$ & $€ 62.24$ & & & \\
\hline Total mean costs & & 17.15 & 16.07 & 51.86 \\
\hline$N(\%)$ & & $40(3.2 \%)$ & $44(3.5 \%)$ & $52(4.1 \%)$ \\
\hline Medication use & See & & & \\
\hline Total mean costs & methods & 20.20 & 22.59 & 26.41 \\
\hline$N(\%)$ & & $114(9.1 \%)$ & $156(12.4 \%)$ & $149(11.8 \%)$ \\
\hline Hospital admissions & $€ 483.71$ & & & \\
\hline Total mean costs & & 81.83 & 51.48 & 49.95 \\
\hline$N(\%)$ & & $37(2.9 \%)$ & $44(3.5 \%)$ & $35(2.8 \%)$ \\
\hline Total healthcare costs, median (IQR) & & $67.06(0-252)$ & $67.06(0-227)$ & $67.06(0-201)$ \\
\hline$N(\%)$ & & $783(62.2 \%)$ & $776(61.6 \%)$ & $736(58.5 \%)$ \\
\hline If any costs are incurred, median (IQR) & & $184.90(92-491)$ & $184.90(185-484)$ & $184.90(92-459)$ \\
\hline \multicolumn{5}{|l|}{ Health-related school absenteeism } \\
\hline Absenteeism days, median (IQR) & & $5.00(2.0-8.3)$ & $4.50(2.0-8.3)$ & $3.50(2.0-7.0)$ \\
\hline$N(\%)$ & & $1194(94.8 \%)$ & $1237(98.3 \%)$ & $1221(97.0 \%)$ \\
\hline \multicolumn{5}{|l|}{ HRQOL } \\
\hline VAS (EQ5D), mean (SD) ${ }^{2}$ & & $88.20(15.2)$ & $86.60(16.9)$ & $85.82(17.0)$ \\
\hline PedsQL, mean $(S D)^{3}$ & & 79.09 (13.3) & $80.71(13.2)$ & $80.33(13.2)$ \\
\hline \multicolumn{5}{|l|}{ Psychosocial health } \\
\hline$S D Q$, mean $(S D)^{4}$ & & $6.98(4.2)$ & $8.03(4.4)$ & NA \\
\hline
\end{tabular}

Notes: $\mathrm{BMI}=$ body mass index; $\mathrm{EQ5D}=$ EuroQol 5 Dimensions Questionnaire; $\mathrm{HRQOL}=$ health-related quality of life; $N$ = number of observations; PedsQL = Pediatric Quality of Life Inventory; $S D=$ standard deviation; $S D Q=$ Strengths and Difficulties Questionnaire; VAS = Visual Analogue Scale. ' Dutch: jeugdzorg en jeugdhulpverlening; ${ }^{2}$ The VAS score ranged from 0 to 100 , where 100 is best imaginable health; ${ }^{3}$ Higher PedsQL scores represent better quality of life; ${ }^{4}$ Higher SDQ scores indicate more problems. 


\section{APPENDIX 3}

Associations between health behaviours and health outcomes

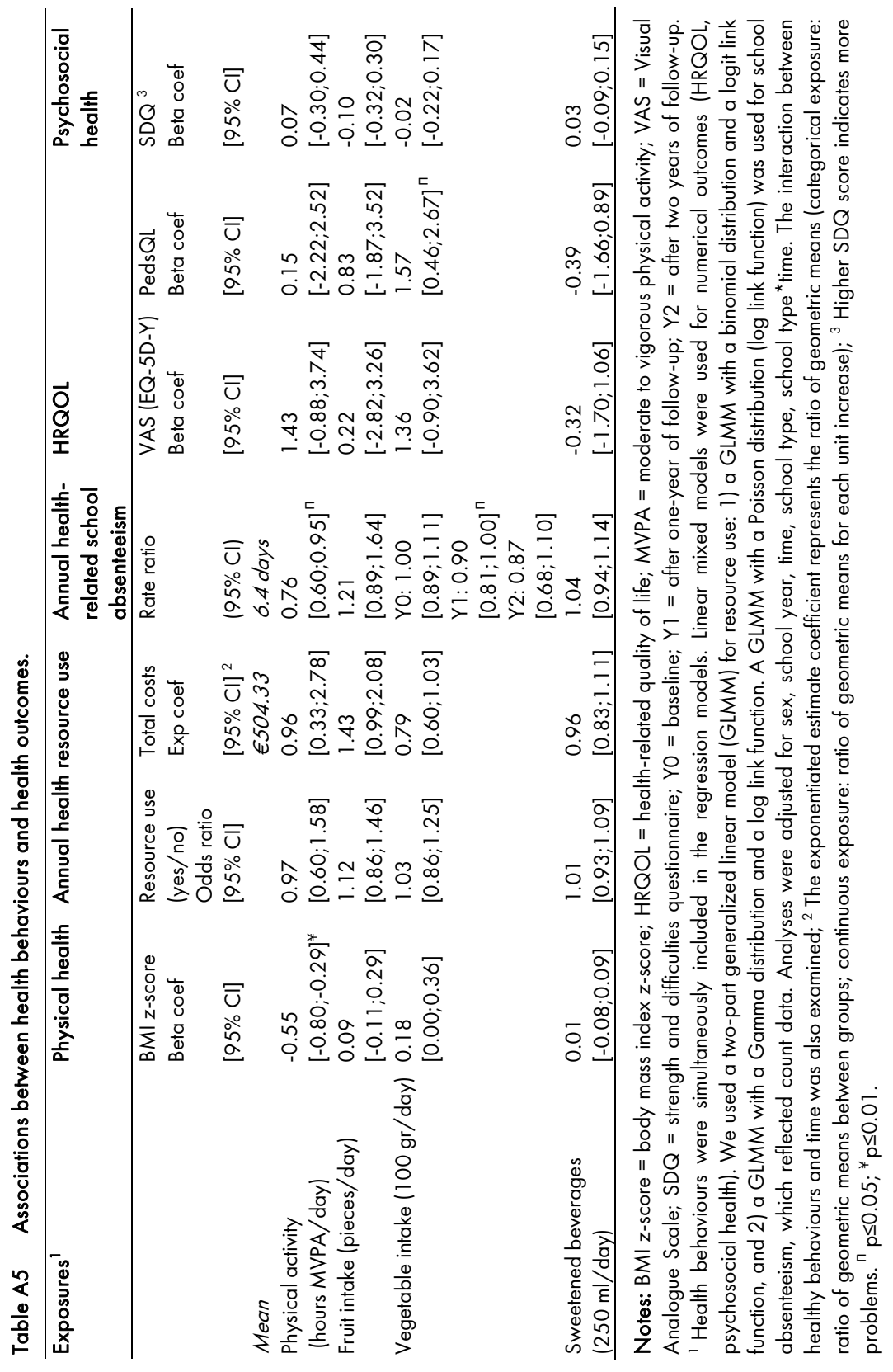




\section{APPENDIX 4}

Post hoc analysis

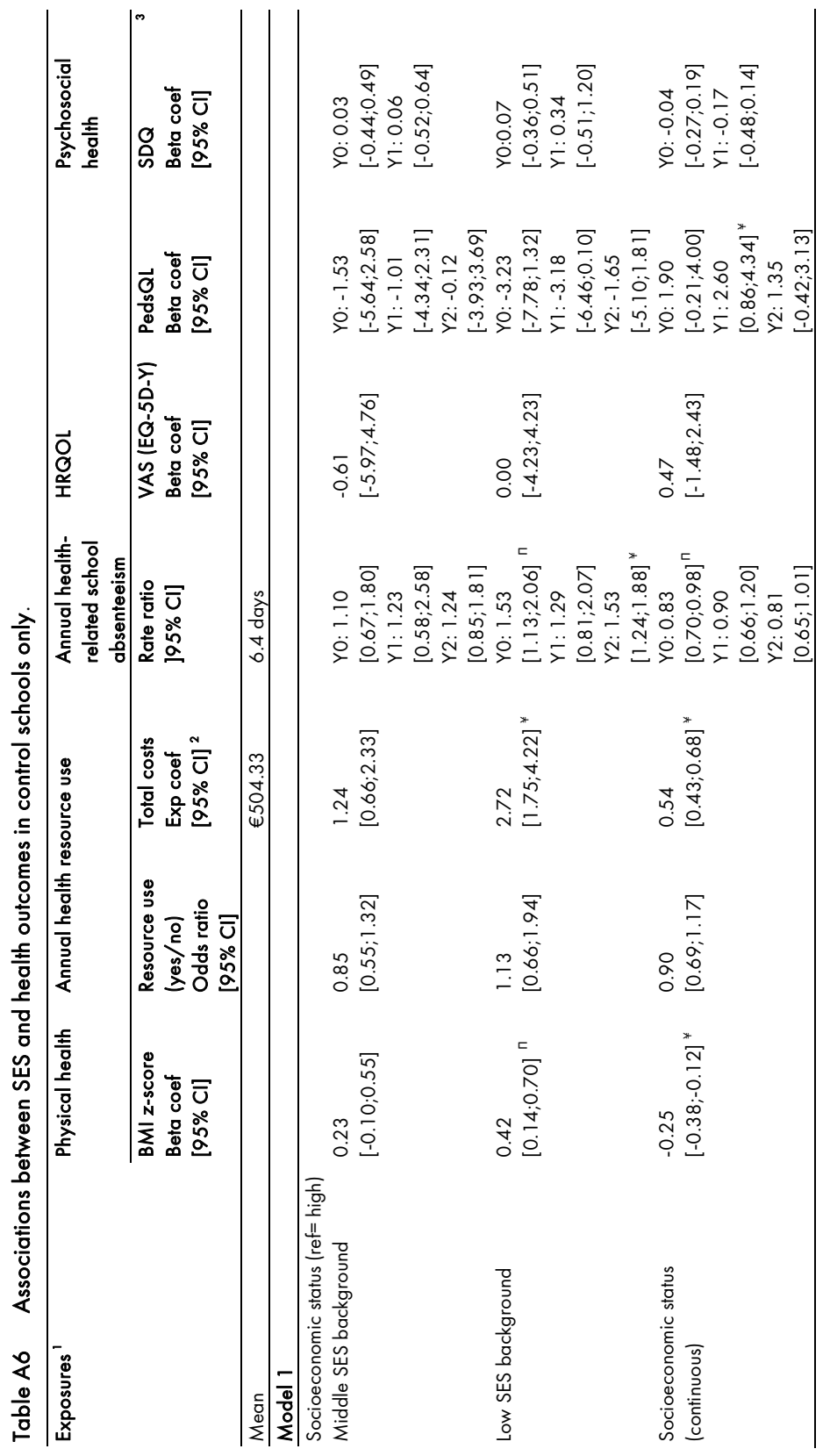




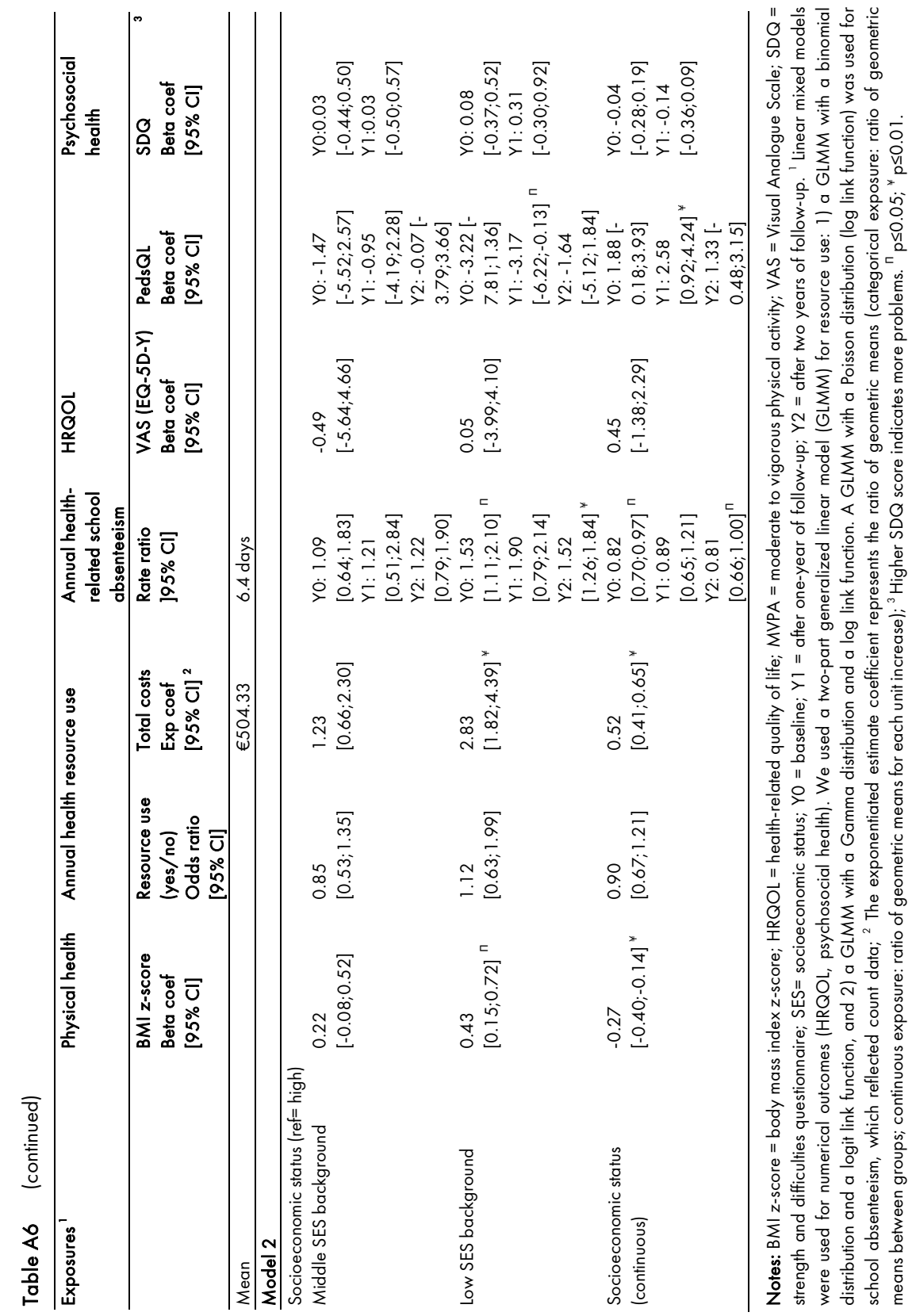




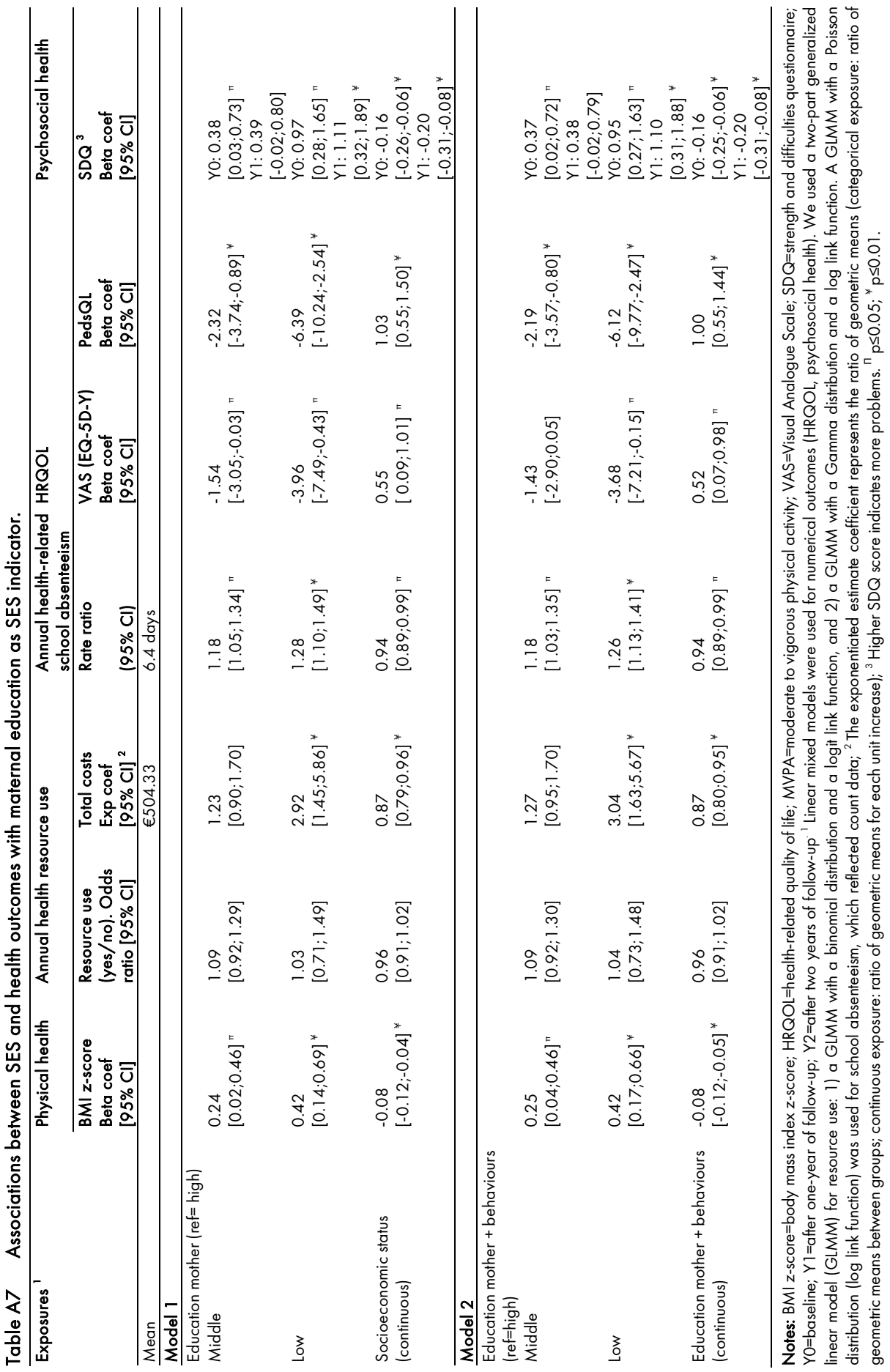




\section{Chapter 3}

The effects of school-based lifestyle interventions on body mass index and blood pressure: a multivariate multilevel meta-analysis of randomized controlled trials 


\section{Abstract}

Primary prevention of childhood obesity and related hypertension is warrant given that both risk factors are intertwined and track into adulthood. This systematic review and metaanalysis assesses the impact of school-based lifestyle interventions on children's body mass index (BMI) and blood pressure (BP). We searched databases and prior reviews. Eligibility criteria were: randomized controlled trial design, evaluation of a school-based intervention, targeting children aged 4-12 years, reporting on BMI and/or related cardiovascular risk factors, reporting data on at least one follow-up moment. The effects on BMI, systolic (SBP) and diastolic blood pressure (DBP) were evaluated by means of univariate and multivariate three-level random effects models. 85 RCTs (91 papers) were included in the metaanalyses. In univariate models the pooled effects were -0.072 (95\% $\mathrm{Cl}:-0.106 ;-0.038)$ for BMI, -0.183 (95\% Cl:-0.288;-0.078) for SBP, and -0.071 (95\% Cl:-0.185; 0.044) for DBP. In multivariate analyses, the pooled effects of interventions were -0.054 (95\%Cl:-0.131;0.022) for BMI, -0.182 (95\%Cl:-0.266;-0.098) for SBP, and -0.144 (95\%Cl:-0.230;-0.057) for DBP. Parental involvement accentuated the beneficial effects of interventions. School-based lifestyle prevention interventions result in beneficial changes in children's BMI and BP, and the effects on the latter may be stronger than and accrue independently from those in the former. 


\section{Introduction}

The increases in the prevalence of overweight and obesity observed over the last decades in children and adolescents are recognized as a major Public Health challenge worldwide. 'In children and adolescents, higher levels of adiposity or obesity (most often ascertained by means of the body mass index - BMI) are strongly associated with higher levels of blood pressure (BP). ${ }^{2-4}$ Indeed, recent increases in the prevalence of elevated BP/hypertension in children and adolescents have been, to a great extent, attributed to the increasing prevalence of overweight. ${ }^{5-7} \mathrm{BMI}$ and $\mathrm{BP}$ are not only intertwined but both track strongly, from childhood into adulthood. ${ }^{8,9}$ Higher levels of BMI and/or BP in childhood/ adolescence, and sustained throughout the life-course, have a deleterious impact on cardiovascular health, as depicted by related arterial wall thickening and stiffening, and left ventricular hypertrophy already in childhood ${ }^{10,11}$ and in later in life. ${ }^{12-18}$ These (pre-clinical) adverse adaptations underlie the development of cardiovascular disease and may explain the increased cardiovascular mortality and shortened lifespan that has been attributed to childhood obesity and hypertension. ${ }^{19-23}$ All together these evidence support primary preventive measures among the young. Indeed, although obesity and/or hypertensionrelated cardiovascular events are rare at young age, the ultimate goal of preventive measures targeting BMI early in life is also to induce favourable changes on related risk factors, and to prevent its sequelae later in life (Figure 1). The extent to which this has been accomplished is not clear, however.

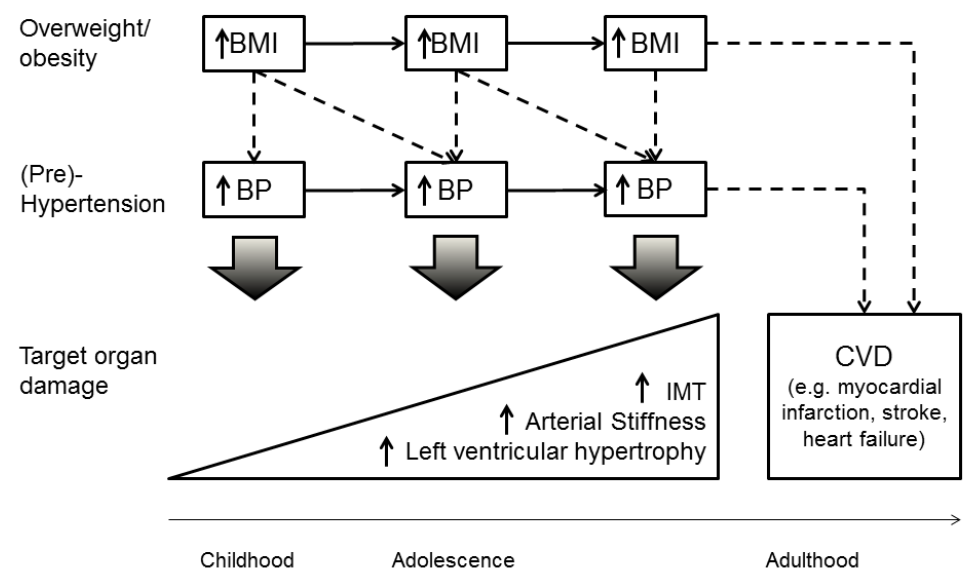

Figure 1 Body mass index (BMI) and blood pressure (BP) as closely intertwined risk factors for cardiovascular disease (CVD): tracking and impact on (pre-clinical) markers of target organ damage throughout the life-course, starting already at young age.

Notes: $\mathrm{BMI}=$ Body Mass Index; $\mathrm{BP}=$ blood pressure; $\mathrm{CVD}=$ cardiovascular disease $; \mathrm{IMT}=$ intimamedia thickness. 
Childhood constitutes a critical period for the establishment of health-related behaviours such as dietary and physical activity habits that may affect BMI and/or BP and persist into adulthood. ${ }^{24,25}$ As such, childhood provides a window of opportunity either to promote healthy lifelong trajectories or to interrupt unhealthy ones. ${ }^{26}$ Given that children spend a considerable part of their weekly day-time at school, and the fundamental educative role of schools, this setting has been recommended as preferential for the implementation of (large scale) interventions aiming at the primary prevention of obesity and general health promotion among children. ${ }^{27-31}$ Indeed, the school setting offers the advantages of facilitating compliance to intervention and reach of preventive measures to children from diverse socio-economic and ethnic backgrounds. ${ }^{27-29,31}$

In this line, recent systematic reviews and meta-analyses on general childhood obesity and/or hypertension prevention programmes have drawn their conclusions from a set of studies most of which were conducted in the school setting. ${ }^{32,33}$ The findings from these and other meta-analyses on the effect of school-based (lifestyle) interventions on children's BMI or BP have not been consistent, however. Different findings may have been explained, at least in part, by their different focus (e.g. some revised the effects of physical activity ${ }^{34-36}$ or educational $^{37}$ interventions specifically, whereas others included all of these ${ }^{28,38,39}$ ), and/or selection criteria (e.g. some included randomized controlled trials (RCTs) exclusively, ${ }^{35-37}$ whereas other included also any controlled intervention without the randomization criteria. ${ }^{28,32-34,38,39}$ An additional review refrained from summarizing the evidence quantitatively using heterogeneity of the populations and interventions as justification. ${ }^{36}$ Currently, examining the extent to which such heterogeneity can be explained by such moderators is a question of interest that can be addressed with modern meta-analytical tools. ${ }^{40}$ In addition, from a methodological point of view, these prior meta-analyses have not handled dependent effects within studies optimally.

Most meta-analytical procedures employed thus far (i.e. fixed effects and random effects models) assume independence among the effect sizes to be pooled, when, in fact, this hardly occurs. Very often RCTs on school-based interventions report on intervention-induced differences in the outcomes of interest: 1) across multiple comparison groups (e.g. boys and girls, separately); 2) between different intervention groups (e.g. physical activity, dietary, or educational intervention arms vs. the same control group); 3 ) across multiple time points (e.g. after 6 months and after one year); and/or 4) multiple outcomes (RCTs evaluating effects on systolic (SBP) and diastolic blood pressure (DBP), constitute a clear example of this situation). The effect sizes than can be retrieved from all these scenarios are not independent and, therefore, to meet the independence assumption, most often meta-analysts adopt strategies such as: ignoring dependence (most often seen when multiple comparison groups, such as subgroups of boys and girls within a study are considered independent, which is disputable); elimination (e.g. choosing only one treatment or time point effect size per study); 
averaging effect sizes within studies, and/or analysing multiple outcomes within studies separately. These strategies remain sub-optimal at the light of meta-analytical tools that are currently available and that allow proper modelling of dependencies within studies without the unnecessary loss of information/data-reduction aforementioned and thus yield a more robust pooled of effect sizes - i.e. multi-level meta-analysis techniques [details will be provided in the methods section]. ${ }^{41-43}$

In view of these considerations, we have revised, systematically, the current evidence on the impact of school-based lifestyle RCTs on children's BMI and BP with the use of multilevel meta-analysis techniques. By applying these models to the context of multiple outcomes we have also addressed whether, and the extent to which, any effects of such interventions differed between BMI and BP (and its systolic and diastolic components), a question that was left unanswered by the meta-analytical approaches used in prior meta-analyses.

\section{Methods}

\section{Search strategy and study selection criteria}

We searched MEDLINE, EMBASE, Web of Science and the Cochrane Library for relevant studies from their inception through 15th December 2013. Details of the search strategies implemented are shown in Appendix 1.

Two authors (M. O. and I. F.) independently assessed the abstracts of papers potentially eligible for inclusion. Studies were eligible if they met all of the following criteria:

- design was a randomized controlled trial (RCT) where the control group did not receive any intervention beyond the usual curricular activities;

- outcomes were BMI and/or related cardiovascular risk factors;

- data were reported at least at one follow-up moment since the start of the intervention;

- intervention was implemented in the school setting; and

- $\quad$ intervention targeted children in the age range of 4-12 years (rounded);

If there was doubt about study eligibility the full text of the paper was reviewed and any remaining discrepancies were resolved by consensus involving the third author (M.J.).

A lifestyle intervention was defined as any including changes towards healthier eating (e.g. by changes in foods provided by school canteens/cafeterias), physical (in)activity levels (e.g. increasing physical education load, adding additional physical activity (PA) programs after regular school time and/or reduction in time spent in sedentary behaviours), and/or education for healthier dietary and activity behaviours (e.g. through pamphlets, didactic 
materials and/or lectures). These interventions could vary in content and mode of delivery and were generally classified into single (i.e. diet, PA or education only) or multicomponent (i.e. any combination of the three).

Given that, among children the lifestyle strategies to prevent excessive weight gain and to treat obesity overlap considerably, we did not exclude RCTs that targeted overweight/obese (or (pre)hypertensive) children specifically. We did not implement restrictions on the duration of the interventions but papers reporting on outcomes years after the intervention ended were not included.

\section{Data extraction and quality management}

Data from each study included was extracted by one author (M.O.), cross-checked by another (I. F.) and imputed into a code sheet comprising population, intervention and methodological quality characteristics of interest, which were defined, a priori, on the basis of appreciation from previous reviews on the topic. Specifically, study population characteristics retrieved consisted of the number of children, sex distribution, mean age in intervention and control groups, and country of origin. Intervention characteristics consisted of the year of implementation start, duration (including multiple time points in samples where these were reported), intervention type (i.e. diet, PA, education or multicomponent and whether it included or not parental involvement), and timing of delivery (i.e. during and/or after regular class time). For the relevant RCTs the type of device used to measure BP was also considered.

Where more than one paper was found relating to the same RCT, either we extracted the data from the one providing the most detailed or complete information (e.g., in the case of final vs. preliminary reports on the same RCT), or we extracted the data from several papers if these reported complementary information on the same RCT (e.g., effects at different follow-up times since the start of intervention). Note that such (repeated) effects were those while children were still undergoing the intervention up to very soon after its end. When RCTs reported data for separate subgroups (e.g. boys and girls), these were extracted separately instead of pooling them into an overall score for the whole study sample. Likewise, when $\mathrm{RCT}$ s had more than one intervention group (vs. the same control group) we extracted the data from each such group separately.

We also evaluated study quality with the use of the Cochrane Collaboration's tool for assessing risk of bias in systematic reviews of interventions, ${ }^{44}$ covering the following categories: selection bias (sequence generation and allocation sequence concealment), detection bias (blinding of outcome assessment) and attrition bias (incomplete outcome data) (Appendix 2). Given the nature of the interventions, blinding of participants and personnel to treatment allocation was not feasible and therefore performance bias not 
considered. Also, we did not score the level of reporting bias (selective outcome reporting) because we did not have a means to verify, for all studies equally, the extent to which this potential bias could have occurred (as formal trial registration with protocol description prior to publication of intervention results could not be retrieved for most of the RCTs). We refrained from assigning a summary score to each study on the basis of these categories as recommend by the authors of this tool. ${ }^{44}$ Instead, the contribution of methodological aspects of study quality, and of the population and intervention characteristics to the heterogeneity of the pooled effect sizes was explored by means of meta-regression analyses (vide-infra).

\section{Data synthesis and meta-analyses}

\section{Main outcomes and computation of effect sizes}

The outcomes of interest were the differences in standardized mean changes (SMC) in BMI or $\mathrm{BP}$ between treatment and control groups. We chose $\mathrm{BMI}$ or, when $\mathrm{BMI}$ was not reported, BMI z-scores (i.e. BMI standardized for age and sex) because, in contrast to other measures of adiposity such as skinfolds, body circumferences or total body fat percentage derived from dual x-ray absorptiometry, either BMI or BMI z-scores (BMIz) were consistently reported across all studies selected. In addition, $\mathrm{BMI}$ and $\mathrm{BMIz}$ are highly correlated and, at the population level, are appropriate measures of adiposity in growing children. ${ }^{45}$ Furthermore, we did not undertake a meta-analysis on the effects of the interventions on the prevalence or incidence of overweight or obesity because: 1) the different definitions used across studies to classify children into these categories; and 2) these were not reported in the majority of the studies, where any shift in BMI was the primary outcome of interest. For the same reasons we chose SBP and/or DBP as the main BP outcomes of interest and not prevalence or incidence of (pre)hypertension.

We calculated, for each RCT, and when needed, for each subgroup within an RCT (vide supra), a SMC for pre-test post-test control group designs ${ }^{46}$ with the use of the escalc function implemented in the metaphor package in R. Specifically, SMC with raw score standardization (d) were first calculated for the treatment(s) group(s) and for the control group, separately, as:

$$
\begin{aligned}
& \mathrm{d}_{T}=c\left(n_{T}-1\right)\left(\frac{M_{p o s t, T}-M_{p r e, T}}{S D_{p r e, T}}\right) \\
& \mathrm{d}_{C}=c\left(n_{C}-1\right)\left(\frac{M_{p o s t, C}-M_{p r e, C}}{S D_{p r e, C}}\right)
\end{aligned}
$$


...where $M_{\text {post, }}$ and $M_{\text {pre, }}$ are the treatment group post-test and pre-test means, $S D_{\text {pre, }}$ is the standard deviations (SD) of the treatment group pre-test scores; likewise, $M_{\text {post, }}$ and $M_{\text {pre, } C}$ are the control group post-test and pre-test means, $S D_{\text {pre, } C}$ is the standard deviation of the control group pre-test scores and $c$ is a bias-correction factor applied to each $d$ as approximated by:

$$
c=1-\frac{3}{4(n-1)-1}
$$

...where $\mathrm{n}$ is the sample size in the treatment or control groups. The sampling variances of $d$ in each group were calculated as described by Becker ${ }^{47}$

$$
v(d)=\frac{2(1-r)}{n}+\frac{d^{2}}{2 n}
$$

... and thus are a function of the group mean change, size $(n)$ as well as of the pretest - post-test correlation ( $r$ ) in the outcome of interest; however, because such values of $r$ are often not reported, we used, as best available estimates, the tracking coefficient values estimated in meta-analyses of $\mathrm{BMI}^{8}$ and $\mathrm{BP}^{9}$, taking into account the children's age and the length of time elapsed between baseline and follow-up measure (Appendix 3).

The difference between the two SMC values [i.e. $d_{T}-d_{C}$ ] are then calculated as the effect size to be pooled in meta-analysis (denoted by $y_{i}$, indicating how much larger (or smaller) the change in $\mathrm{BMI}$ or $\mathrm{BP}$ in the treatment group was when compared with the change in the control group, expressed in SD units. Finally, the sampling variances of $y_{i}$ (denoted by $v_{i}$ ) were computed by adding the sampling variances of the two groups [i.e. $v_{T}+v_{C}$ ].

From most of the RCTs we could retrieve, for both the intervention(s) and the control groups, the pre-test and post-test means and SDs (though only the pre-test SDs were needed) to compute the effect sizes as described above. In the remaining, a mix of information was available. For instance, if only the change values were reported, post-test values were set to these values and the pre-test values were set to zero. When only the groups' pre-test means and SDs, and the net change values (i.e. the differences in changes between groups) were given, the post-test value in the intervention group was calculated as the pre-test + the net change values, while the post-test score in the control group was set to its pre-test value. When pre-test SDs, or standard errors or $95 \%$ confidence intervals $(\mathrm{Cl})$ to calculate it, were not provided, we imputed a SD value derived from a model regressing all other studies' SDs on sample size (in 4 RCTs only). Finally, when only the p-values derived from t-tests comparing changes in BMI (in 2 RCTs only) or BP (in 3 RCTs only) between the intervention and control groups were given, the standardized mean change difference (g) was calculated as: 
$g=t \sqrt{\left(\frac{1}{n 1}\right)+\frac{1}{n 2}}$

...and the sampling variance as

$$
v=\frac{1}{n}+\frac{g^{2}}{2 n}
$$

\section{Meta-analyses}

Due to the hierarchical or multilevel structure of the data, with multiple effect size estimates nested within the RCTs, we used a multilevel meta-analytic method of data analyses - i.e. a three-level model, ${ }^{41-43}$ recently implemented in the packages 'metafor' ${ }^{48}$ and 'metaSEM'49 in $\mathrm{R}$ (http://www.R-project.org/). Traditional random-effects models are equivalent to a two-level multilevel model where level 2 variance represents between-RCT differences in effect size estimates assuming that all RCTs are contributing independent effects sizes. In contrast, a three-level meta-analysis accounts for the clustering of dependent effect sizes within RCTs (at level 2) and between-RCTs effects are then estimated at level 3. With the use of multilevel analyses we can thus model dependence when the exact correlations between the dependent effect sizes are not known, because often these are not reported for the multiple effect sizes within a RCT. ${ }^{41-43}$ In addition, multilevel meta-analyses enables the use of all data retrievable from the individual RCTs instead of selecting or aggregating part of it, thereby boosting the power and the precision of the pooled estimates derived. ${ }^{41-43}$ We first conducted univariate random-effects three-level meta-analysis of the effects of schoolbased interventions on each of the outcomes of interest, separately: i.e. the standardized mean changes in BMI, SBP or DBP. Meta-analyses using the 'traditional' two-level random effects model were also conducted and their results presented for purposes of model comparisons. Heterogeneity in these models was tested by means of the $Q$ statistic and quantified at level 2 and/or level 3 by estimating the $\mathrm{T}^{2}$ and $\mathrm{I}^{2}$ values, as described in detail elsewhere. $^{49}$

For the BP outcomes, we then extended the univariate model to a multivariate one, i.e. by considering both outcomes simultaneously and thus also accounting for their dependency within studies. Indeed, most of the RCTs that reported on the effects of school-based interventions on BP did so for both SBP and DBP, which were measured in same samples and under the same conditions, and are thus correlated. Specifically, this was done by combining all effect sizes on SBP and DBP into a BP dataset and conducting, first, a threelevel multilevel model (without predictors) to estimate the mean overall effect on $B P$, which does not distinguishes between SBP and DBP; afterwards, an outcome indicator (dummy variable) was included as predictor in a mixed-effects model to estimate the mean effect for each outcome, allowing also for an appreciation of any differential mean effects or, in other 
words, the extent to which mean effects on SBP differed from those on DBP. ${ }^{43}$ These analyses were confined to the set of RCTs that reported on any BP outcomes. Likewise, we performed multivariate multilevel analyses with BMI, SBP and DBP as outcomes to enable us to ascertain whether and the extent to which the effects on BMI differed from those on $B P$ (analyses confined to the set of RCTs that reported on both on BMI and BP outcomes).

We have also conducted meta-regression analyses with the use of mixed-effects three-level models to examine population, intervention and methodological quality characteristics as potential moderators of the pooled effect sizes. The extent of heterogeneity explained by the moderators considered was quantified in \% of variance (expressed by $R^{2}$ ) at the levels 2 and/or 3. ${ }^{49}$ These analyses were first conducted with univariable models (i.e. each moderator analysed at a time) and then with multivariable models (all moderators included simultaneously). At this stage, and for the sake of clarity, it is important to stress that the terms univariate and univariable, as the terms multivariate and multivariable, used to describe the models used in our study, should not be used interchangeably (as often done in the published literature). Univariate (one) and multivariate (more than one) refer to the number or outcomes considered in a (regression) model whereas univariable (one) and multivariable (more than one) refer to the number of predictors included in a regression model.

The presence of publication biases was analysed visually by inspection of asymmetries in funnel plots and tested by including the inverse of the sample size as a potential covariate in the (univariate multi-level) models. ${ }^{50}$ A significant relationship between the inverse of the sample size and the observed effects size would be suggestive of publication bias.

\section{Results}

\section{Study selection}

The electronic search identified 957 papers. After removal of duplicates ( $n=459)$, we first excluded 196 papers on the basis of their titles, as they clearly did not match the scope of interest. After screening the abstracts of the 302 remaining papers, 215 were excluded because of not meeting the inclusion criteria. This left us with 87 papers reporting on 68 unique RCTs. At this stage, 28 additional papers reporting on 26 unique RCTs were identified by cross checking with our own records and reference lists from prior systematic reviews and/or meta-analyses. In total, we thus revised the full content of 115 papers but some of these ( $n=24$, reporting on 9 unique RCTs, listed in Supporting Information 4) were excluded because their data: were considered redundant, i.e. repeated or more detailed data on the same RCT could be retrieved from other paper(s) included ( $\mathrm{n}=10)$; concerned the long(er)-term effects after cessation of the intervention $(n=4)$; or referred to outcomes 
other than $\mathrm{BMI}$ or $\mathrm{BMIz}$ and/or $\mathrm{BP}(\mathrm{n}=10)$. Therefore, the present meta-analysis includes data retrieved from 91 papers, published between 1985 and 2013, reporting on 85 unique RCTs (Figure 2). ${ }^{51-141}$

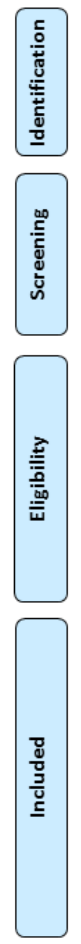

Figure 2
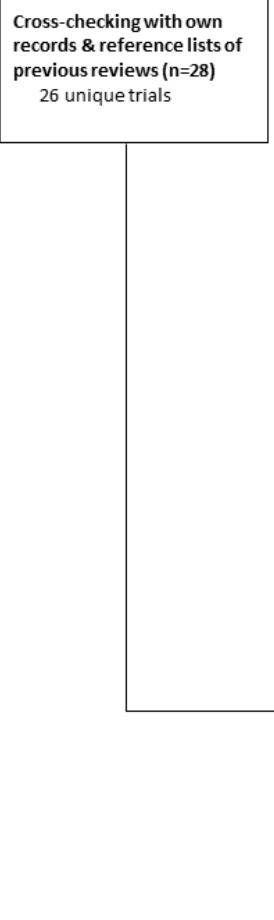
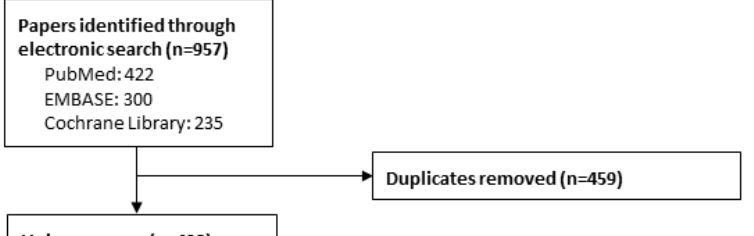

Unique papers ( $n=498)$

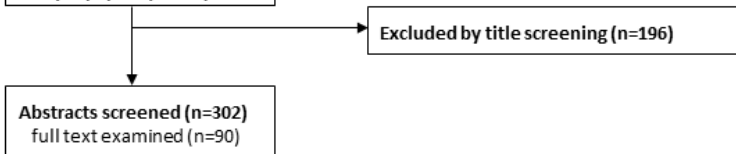

full text examined $(n=90)$

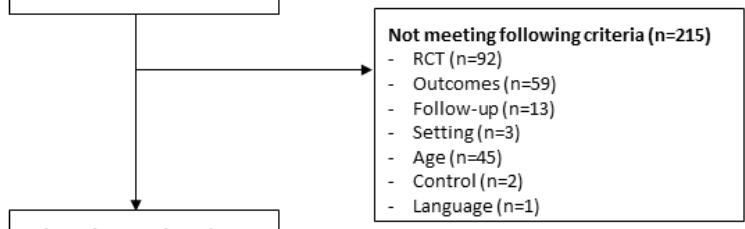

Selected papers ( $n=87)$

68 unique trials

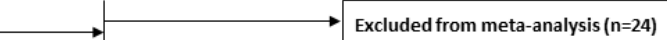

Meta-analysed BMI \& BP

85 unique trials ( 91 papers)

BMI: 83 trials ( 88 papers)

SBP: 23 trials (25 papers)

DBP: 22 trials (24 papers)
9 unique trials

More recent or detailed paper

included $(n=10)$

Outcomes not suitable $(n=10)$

Follow-up studies after

intervention cessation $(n=4)$

2 PRISMA Flow diagram for the selection of studies included in the systematic review and metaanalyses of the effects of school-based interventions on body mass index (BMI) and blood pressure.

Notes: $\mathrm{BMI}=$ Body Mass Index; $\mathrm{DBP}=$ diastolic blood pressure; $\mathrm{RCT}$ = randomized controlled trial; $\mathrm{SBP}=$ systolic blood pressure.

\section{General characteristics of the RCTs included}

The 85 unique RCTs identified were conducted in 29 different countries, mostly in Europe

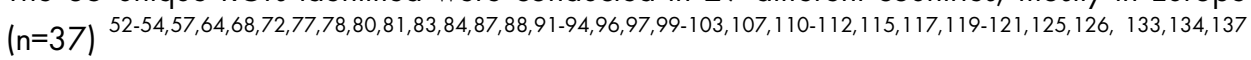

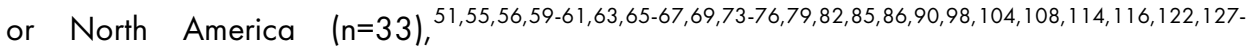
$131,136,138-141$ whereas the remaining were conducted in Oceania $(n=7),{ }^{58,62,70,120,123,132,135}$ Asia $(n=5),{ }^{89,95,105,106,109}$ South America $(n=2)^{113,124}$ and North Africa $(n=1)^{71}$ In total, the 85 RCTs included 72,934 pupils $(37,084$ boys, 35,850 girls $)$ and the median number of 
pupils included per RCT was 464 [range 50 to 8,301]. The vast majority of the RCTs included pupils irrespective of their weight status at baseline, but $3 \mathrm{RCT}$ s targeted only overweight/obese children. ${ }^{61,77,134}$ One RCT targeted boys ${ }^{52}$ and 2 RCTs targeted girls ${ }^{56,131}$ only. One RCT targeted both boys and girls but the effects sizes could only be estimated for boys. ${ }^{58}$ Most RCTs were conducted during school-time (i.e. within the normal curricular time) $(n=66)$ whereas others were conducted after-school hours (i.e. as additional curricular activities) $(n=9)$ or during and after school-hours $(n=10)$. RCTs included in the present review were implemented over the past three decades, the oldest starting in 1980 and the most recent starting in 2011 , and had a median duration of 12 months [range 1.596]. Most of the RCTs ( $n=80$ ) compared only one intervention arm with a control group; specifically, 32 of these RCTs evaluated the effects of one intervention comprising only one component, i.e. education $(n=15), 59,70,72,76,83,85,87,90,91,97,116,117,124,134,136$ physical activity $(n=16)^{51,55,67,68,81,84,93,94,103,106,114,115,119,121,122,128,133}$ or diet $(n=1)$, ${ }^{62}$ whereas 48 RCTs evaluated the effects of one intervention combining two or more of these components such as PA and education $(n=21), 57,61,65,71,78,86,88,89,92,95,96,99-101,109-112,125-127,129,137$ diet and education $(n=7), 52,64,66,75,107,113,140,141$ diet and PA $(n=3),{ }^{56,102,130}$ or a combination of diet, PA and education $(n=17) .53,54,58,60,63,69,73,74,77,79,80,98,108,120,131,132,138,139$ Five RCTs compared more than one intervention arm (consisting of single and/or multi-components) with the same control group. $82,104,105,123,135$ Fifty-three RCTs also included a parental involvement component (e.g. by newsletters, information sessions, via homework tasks for children) in addition to the single or multi lifestyle components delivered directly to the children. ${ }^{52-55,57-}$ $60,63,64,66,69-77,80,83,85-91,93,96-98,100,101,105,108-113,115,116,120,123,125-127,129,130,134,135,139$

From the 85 unique RCTs, most reported on $\mathrm{BMI}$ or $\mathrm{BMIz}$ (hereafter referred to as $\mathrm{BMI}$ ) outcomes only $(\mathrm{n}=61)$, $51,53,55-57,60,61,63-76,78,80,83,85-92,94-102,105-107,109-113,115-117,119,120,122$ $125,127,130,131,133,134,139$ and the remainder reported on BMI and both SBP and DBP outcomes ( $\mathrm{n}=19$ ), $52,54,59,62,79,81,82,84,93,103,104,108,114,121,126,132,135-138,140,141$ or on $\mathrm{BMI}$ and $\operatorname{SBP}(n=2)^{77,129}$ or on BMI and DBP $(n=1) .{ }^{58}$ Only 2 RCTs reported exclusively on both BP outcomes. $^{118,128}$

\section{Meta-analysis - effects on BMI}

\section{Single and multiple effect sizes retrieved per RCT}

From 50 RCTs we could only retrieve one effect size $(k)$ reported for a single intervention arm at a single time-point (that at or around the end-of the intervention period, the exact duration of each could differ between studies) $53-58,60-62,64-68,70-81,83,86,87,91-93,95,98,99$, 102,107,108, 114,116,117,120,124,125,127,129-131,134,136,137 (Figure 3, scenario A, 50 RCTs - data $(k=50)$ retrieved from 51 papers). 
From some RCTs we retrieved the effects sizes at a single time point for each of the two ${ }^{63,84}$ (2 RCTs, $k=4$ ) or three ${ }^{104,105,123}$ (3 RCTs, $k=9$ ) intervention arms reported, or for a single intervention arm concerning two (most often boys and girls) 51,82,88,89,96, 106, 109, $110,113,115,119,133$ (12 RCTs, $k=24$ ) or four (1 RCT, $k=4)^{94}$ subgroups separately. From one additional RCT we retrieved the effect sizes reported at a single time point for each of the five intervention arms reported, each of which tested in two subgroups separately ${ }^{135}$ (1 RCT, $k=10)$ (Figure 3, scenario $B, 19$ RCTs $(k=51)$ retrieved from 19 papers). Some RCTs reported effect sizes of a single intervention arm at multiple time-points (within RCTs) while participants were still on intervention; specifically, we retrieved these effect sizes which were reported at two different time-points in 7 RCTs $(k=14)^{52,69,90,97,100,101,111,112,132}$, at three different time-points in 2 RCTs $(k=6)^{85,140,141}$ and at 4 time-points in 1 RCT $(k=4)^{59}$ (Figure 3, scenario $C, 10 R C T s(k=24)$ retrieved from 13 papers). Finally, several $R C T s$ also reported effect sizes at multiple time-points while on intervention and for several subgroups and/or intervention arms separately; specifically, from $3 \mathrm{RCTs}$ we retrieved the effects sizes for a single intervention arm reported in two subgroups separately either at two $(k=4),{ }^{103,121}$ three $(k=6)^{122}$ or four $\left(k=8^{126}\right.$ different time-points; from 1 additional $\mathrm{RCT}^{139}$ we retrieved the effects sizes of two intervention arms, each reported in two subgroups separately and at two different time-points while on intervention $(k=8)$ (Figure 3, scenario D, 4 RCTs $(k=26)$ retrieved from 5 papers).

We have therefore pooled a total of 151 effects sizes $(k)$ on $\mathrm{BMI}$ accounting for their interdependence within the 83 unique RCTs (88 papers) from which they were retrieved. ${ }^{51-}$ $117,119-127,129-137,139-141$

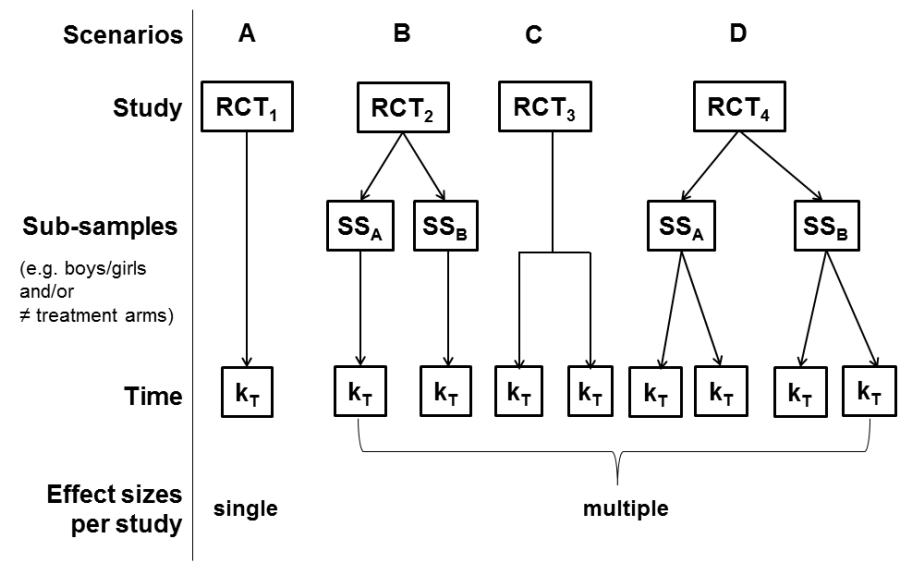

Figure 3 Illustration of four different scenarios yielding single and multiple effect sizes per randomized controlled trial (RCT) as observed in the present meta-analysis.

Notes: $k_{T}=$ number of effect sizes at different time points; $R C T$ = randomized controlled trial; $S S=$ sub-samples. 


\section{Pooled effect sizes - univariate analysis}

The estimated average effect under a two-level (random effects) model was -0.063 (-0.089 to -0.038$), p<0.001$. The $Q(d f=150)$ statistic was $897.7, p<0.001$ and the estimated amount of heterogeneity (per definition only at level 2 ) were $\tau^{2}=0.019$ and $I^{2}=86.7 \%$.

Under a three-level model the estimated average effect was $-0.072(95 \% \mathrm{Cl}:-0.106$ to -0.038 ), $p<0.001$ (Figure 4). The estimated level of heterogeneity at level $2 \tau^{2}{ }_{(2)}$ was nearly 0 and at level $3 \tau^{2}{ }_{(3)}$ was 0.020 , and the respective $\mathrm{I}^{2}$ were $\mathrm{I}_{(2)}{ }_{(2)}=0 \%$ and $\mathrm{I}_{(3)}^{2}=87.3 \%$ (Table 1). These values indicate that $87.3 \%$ of the total variation was explained by differences across the RCTs but not by differences within the RCTs, and the remaining $12.7 \%$ of the total variation was due to known sampling error.

From these data one could argue about the need of a three-level model since the variance at level 2 in the two-level model seem to have all been transferred to one level higher (to level 3 in the three-level model). However, when we compared the two models by means of a likelihood ratio test (tested on the boundary) the test-statistic was significant $\left[\chi^{2}(\mathrm{df}=1)\right.$ $=71.040, p<0.001]$. In other words, the three-level model provided a better fit to the data than the two-level model, which may have been miss-specified. This is supported by the fact that the width of the $95 \% \mathrm{Cl}$ around the estimated average effect (and thus of the SEs -0.013 vs. 0.017$)$ was smaller in the two-level model, which ignored the clustering of effects sizes within RCTs.

Finally, we did not find evidence of significant funnel plot asymmetry $(p=0.749)$ indicating that the pooled effect sizes seemed not to have been threatened by publication bias (Figure $5 a)$.

Table 1 Two-level and three-level random-effects meta-analyses of the impact of school based interventions on children's BMI.

\begin{tabular}{|c|c|c|}
\hline \multirow[t]{3}{*}{ Model Parameters } & \multicolumn{2}{|c|}{ BMI } \\
\hline & \multicolumn{2}{|c|}{$(\mathrm{k}=151 \mid 83 \mathrm{RCT} s)$} \\
\hline & Two-level & Three-level \\
\hline$\beta_{0}$ & -0.063 & -0.072 \\
\hline$(95 \% \mathrm{Cl})$ & $(-0.089 ;-0.038)^{\$}$ & $(-0.106 ;-0.038)^{\$}$ \\
\hline$\tau^{2}$ & 0.019 & 0.000 \\
\hline$\tau^{2}{ }_{(\text {level3) }}$ & $0^{a}$ & 0.020 \\
\hline$P_{(\text {level2) }}^{2}$ & $86.7 \%$ & $0 \%$ \\
\hline$P_{(\text {level3) }}^{2}$ & $0^{a}$ & $87.3 \%$ \\
\hline$Q$ & \multicolumn{2}{|c|}{$(d f, 150)=897.7^{\$}$} \\
\hline
\end{tabular}

Notes: $\mathrm{BMI}=$ Body Mass Index; $\mathrm{Cl}=$ confidence interval; $\mathrm{df}=$ degrees of freedom; $\mathrm{k}=$ number of effect sizes. ${ }^{\$} \mathrm{p}$ value $<0.001 ;{ }^{a}$ Per definition fixed at 0 in the two-level meta-analysis 


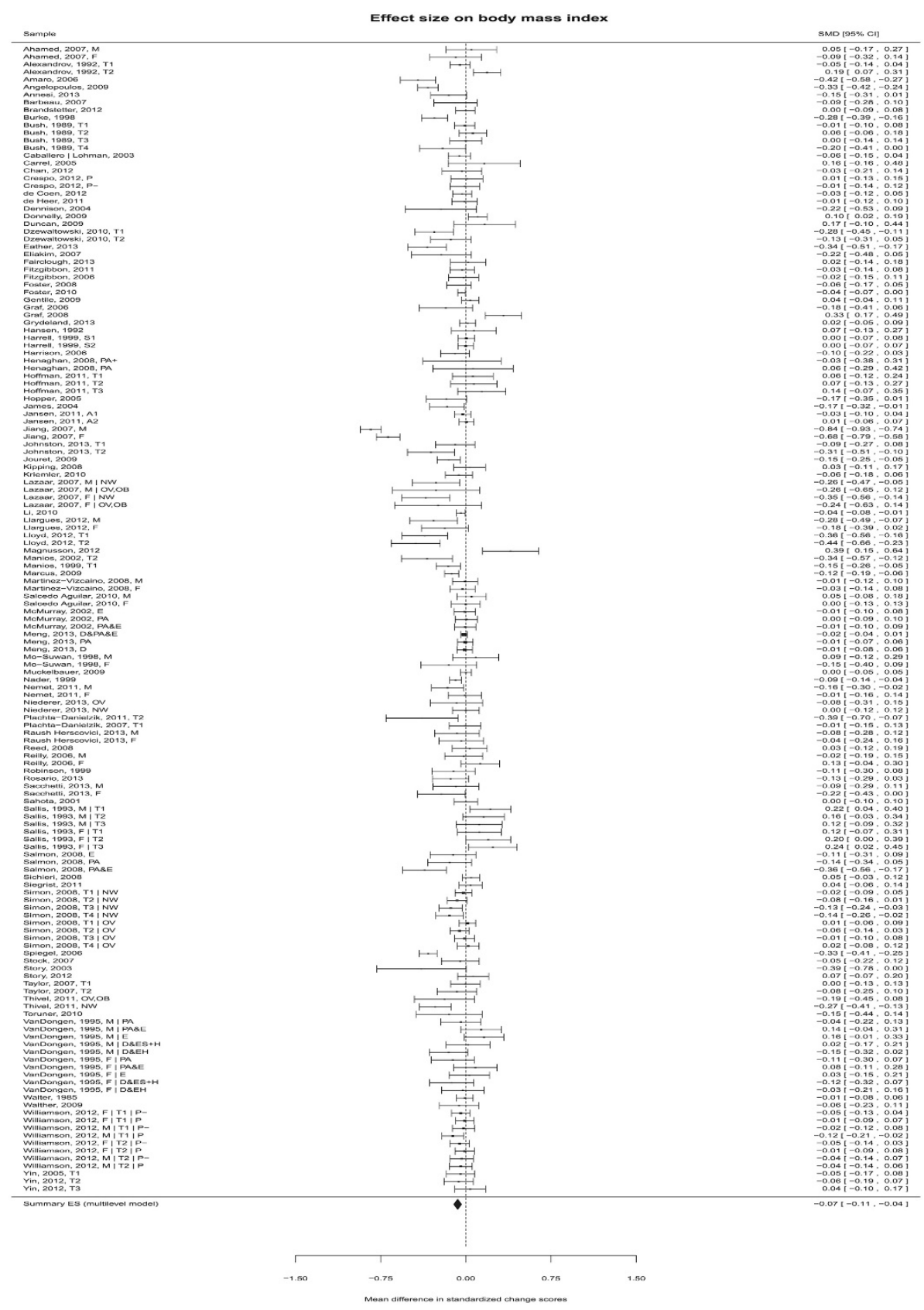

Figure 4 Forest plot of school-based intervention effects on changes in body mass index.

Notes: $D=$ dietary intervention arm; $E=$ education intervention arm; $F=$ girls subsample; $M=$ male subsample; $P A=$ physical activity intervention arm; $S=$ (other) subgroup; $S M D=$ standardized mean change. (BMI) $\backslash r \backslash n T$, indicates time when effects at multiple time points were reported. 


\section{Meta-regression analyses}

In an attempt to understand which factors explained the large heterogeneity of the effects of school-based interventions on pupils' changes in BMI, we analysed a set of population, intervention and study quality characteristics as moderators in univariable models (i.e. each moderator at a time) and a multivariable (i.e. all moderator simultaneously) meta-regression model (Table 2). Because results derived from univariable models do not account for the confounding effects of the other moderators, we confine our appreciations on the magnitude of such moderators' associations as obtained in the multivariable model. In brief, among all the moderators investigated, we found that only parental involvement and interventions that included activities conducted exclusively after school time seemed to significantly affect the beneficial effects of the lifestyle school-based interventions on children's BMI, in this case, accentuating it. Together, the population and the intervention characteristics considered explained $29.3 \%$ of the heterogeneity (all at level 3 ) of the effects between studies. Aspects of methodological quality did not explain any significant portion of the heterogeneity besides that already explained by the remaining moderators neither changed the magnitude of their coefficients and, therefore, to secure a parsimonious model, were left out of the multivariable model.

\section{Additional analyses}

We have also examined whether the mean effect sizes of school-based intervention as reported above [-0.072 (95\% Cl: -0.106 to -0.038 ] differed between studies that reported effects on adiposity expressed by changes in BMI vs. BMI z scores, but found no such differences; specifically, mean effects were $-0.077(-0.113$ to -0.040$), p<0.001$, for changes in $\mathrm{BMI}(\mathrm{k}=123)$, and $-0.051 \quad(-0.123$ to 0.021$), \mathrm{p}=0.169$, for changes in $\mathrm{BMIz}$ data $(k=28)$, but these did not differ significantly from one another: 0.026 (-0.052 to $0.104), p=0.512$.

\section{Meta-analysis - effects on BP (SBP \& DBP)}

Single and multiple effect sizes retrieved per RCT. We retrieved only one effect size reported for a single intervention arm at a single time-point in $10 \mathrm{RCTs}^{54,62,77,93,108,114,128,129,136,137}$ (Figure 3, scenario A, $10 \mathrm{RCTs}(\mathrm{k}=10)$ retrieved from 10 papers). From some RCTs we retrieved the effects sizes at a single time point for each of the two $(1 \mathrm{RCT}, \mathrm{k}=2)^{82,84}$ or three ( $1 \mathrm{RCT}, \mathrm{k}=3)^{104}$ intervention arms reported, or for a single intervention arm concerning two subgroups $^{82,118,138}$ ( $3 \mathrm{RCTs}, \mathrm{k}=6$ ); from one additional RCT we retrieved the effect sizes reported at a single time point for each of the five intervention arms reported, each of which tested in two subgroups separately ${ }^{135}(1 \mathrm{RCT}, \mathrm{k}=10)$ (Figure 3.3 , scenario $B, 6$ RCTs $(k=21)$ 
retrieved from 6 papers). Some RCTs reported effect sizes of a single intervention arm at multiple time-points (within RCTs) while participants were still on intervention; specifically, we retrieved these effect sizes which were reported at two different time-points in 3 RCTs $(\mathrm{k}=6)^{52,126,132}$ at three different time-points in $1 \mathrm{RCT}(\mathrm{k}=3)^{140,141}$ and at 4 time-points in 1 RCT $(k=4)^{59}$ (Figure 3, scenario C, 5 RCTs $(k=13)$ retrieved from 6 papers). Finally, we retrieved the effects sizes for a single intervention arm reported in two $(1 \mathrm{RCT}, k=4)^{103,121}$ or four $^{81}$ ( $1 \mathrm{RCT}, \mathrm{k}=8$ ) subgroups each at two different time-points while on intervention (Figure 3 , scenario $D, 2 R C T s(k=12)$ retrieved from 3 papers). We have therefore pooled a total of 56 effects sizes $(k)$ on SBP accounting for their interdependence within the 23 unique RCTs

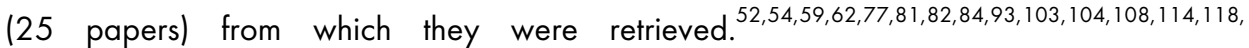
$121,126,128,129,132,135-138,140,141$ These numbers are slightly different for DBP (i.e. 55 k from 22 unique RCTs, 24 papers) because 2 RCTs mentioned above reported on SBP outcome only, ${ }^{77}$ and because one additional RCT reported on DBP only. ${ }^{58}$

\section{Pooled effect sizes - univariate analyses}

The estimated average effects under a two-level (random effects) model were -0.125 $(-0.206$ to -0.044$), p=0.002$ for SBP and $-0.079(-0.157$ to -0.001$), p=0.048$ for DBP. The $Q$ statistics were $Q(d f=55)=379.5$ and $Q(d f=54)=332.2$ (both $p<0.001$ ), respectively. The estimated amount of heterogeneity (per definition only at level 2) were $\tau^{2}=0.070$ $\left(I^{2}=88.6 \%\right)$ and $\tau^{2}=0.058\left(I^{2}=85.0 \%\right)$, for SBP and DBP respectively (Table 3$)$.

The $\tau^{2}$ (and $\mathrm{I}^{2}$ ) in the in the two-level random effects models were thus 'portioned' into $\tau^{2}{ }_{(2)}$ and $\tau^{2}{ }_{(3)}\left(I^{2}{ }_{(2)}\right.$ and $\left.I^{2}{ }_{(3)}\right)$ in the three level model. Ignoring the $3 \mathrm{rd}$ level in this hierarchical data structure of effect sizes would have led to an incorrect allocation of all study heterogeneity to level 2 only. Indeed, when we compared the two models by means of a likelihood ratio test (tested on the boundary) the test-statistics were significant for both SBP $\left[\chi^{2}(d f=1)=27.553, p<0.001\right]$ and $\operatorname{DBP}\left[\chi^{2}(d f=1)=12.518, p<0.001\right]$. In other words, the three-level model provided a better fit to the data than the two-level model, which may have been miss-specified. This is also supported by the fact that the width of the $95 \% \mathrm{Cl}$ around the estimated averaged effect (and thus of the SEs: 0.041 vs. 0.054 for SBP and 0.040 vs. 0.058 for DBP, in the two vs. three-level models, respectively) was smaller in the two-level model, which ignored the clustering of effects sizes within RCTs. Finally, we did not find evidence of significant funnel plot asymmetry ( $p$-value $=0.779$ for SBP and $p$-value $=0.546$ for DBP) indicating that the pooled effect sizes seemed not to have been threatened by publication bias (Figure $5 \mathrm{~b}$ and $5 \mathrm{c}$, respectively). 


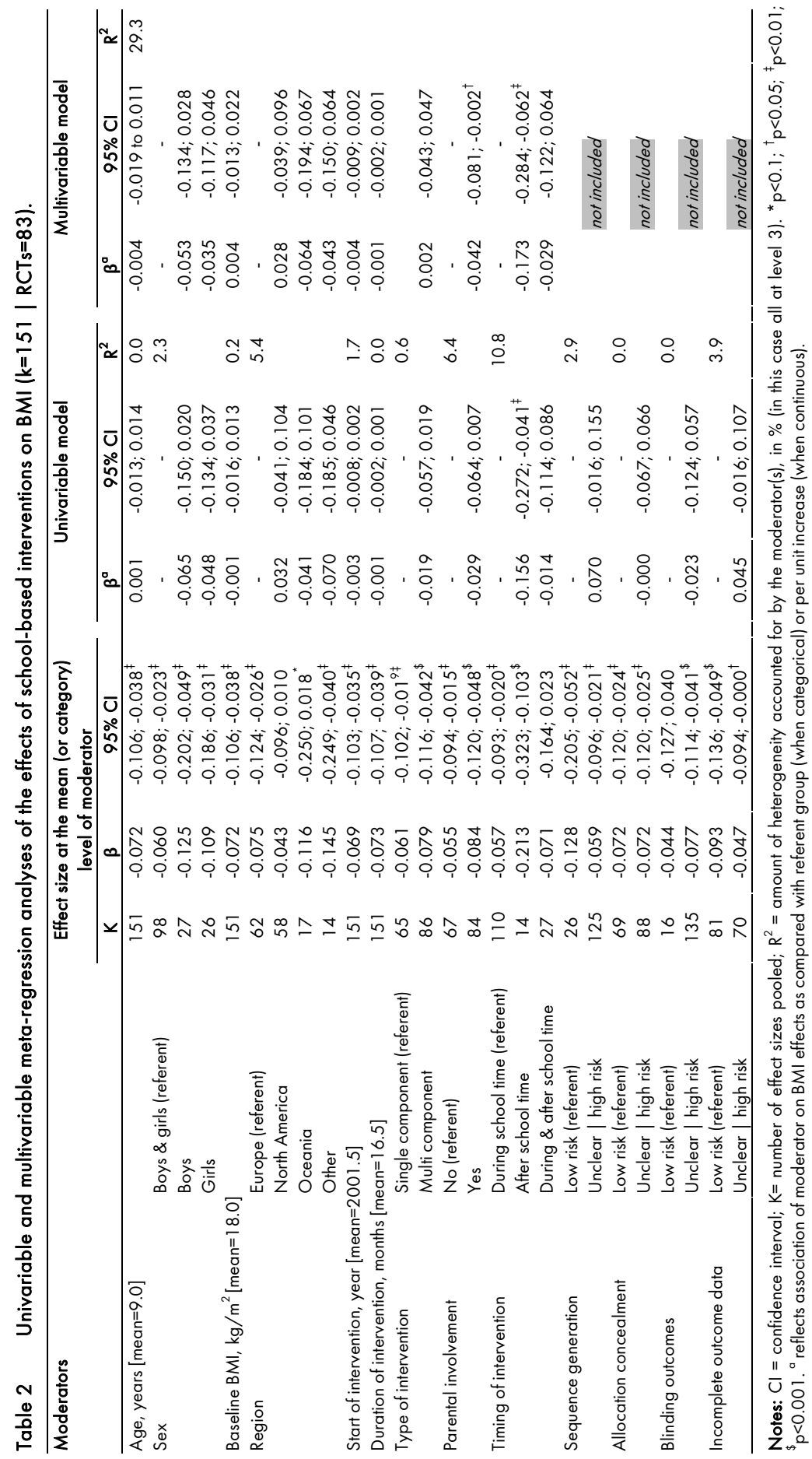



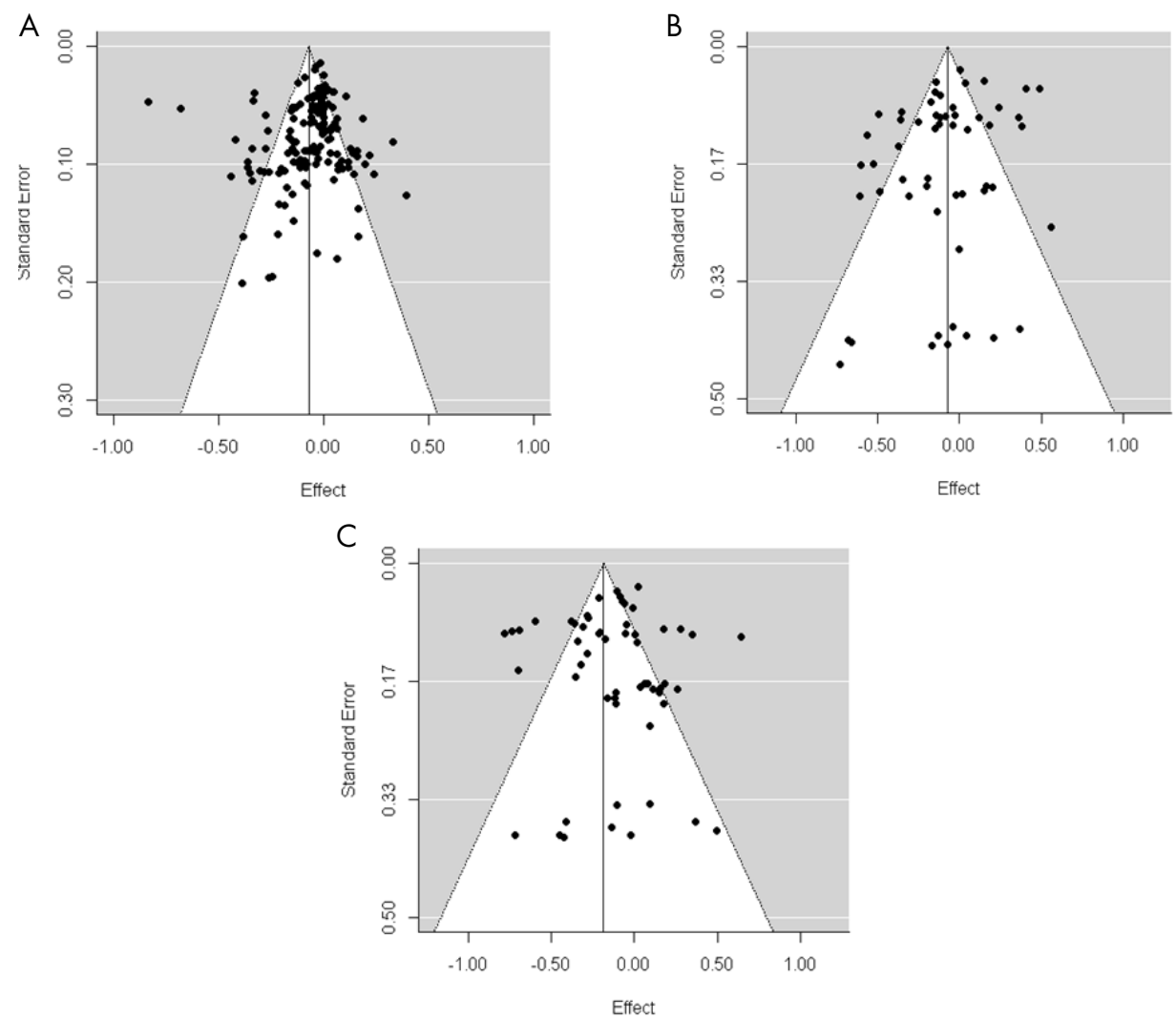

Figure 5 Funnel plots for (a) body mass index; (b) systolic blood pressure; and (c) diastolic blood pressure effect sizes.

\section{Pooled effect sizes - multivariate analyses}

The averaged effects on SBP and DBP described above were those pooled from models that ignored the interdependence of the two BP components. To circumvent the bias that may still have been present due to this dependency, we have therefore 'extended' the univariate three-level models presented above (i.e. for either SBP or DBP) to a multivariate BP model. Specifically, in this model all BP effects sizes were combined $(k=111)$ and a three-level multilevel model without predictors was first used to estimate the mean overall effect on BP, thus not distinguishing between SBP and DBP. The averaged effect on BP obtained from such model was $-0.128(95 \% \mathrm{Cl}$ : -0.224 to -0.032$), p=0.009 ; \mathrm{Q}(\mathrm{df}=110)$ statistic $=751.4$, $\mathrm{p}<0.001$; and $\tau^{2}{ }_{(2)}=0.025$ and $\tau^{2}{ }_{(3)}=0.042$ and $\mathrm{I}_{(2)}{ }_{(2)}=33.1 \%$ and $\mathrm{I}_{(3)}^{2}=54.6 \%$ (Table 3). Subsequently, an outcome indicator (dummy variable) was included in a mixed-effects model to estimate the mean effect for each outcome, allowing also for an appreciation of 
any differential mean effects-that is, the extent to which mean effects on SBP differ from those on DBP. These analyses yielded and averaged effect for SBP of $-0.151 \quad-0.253$ to $-0.049), p=0.004$, and for DBP of $-0.103(-0.206$ to 0.001$), p=0.053$, and although the averaged effects seemed stronger for the systolic than the diastolic BP component (Table 3), the difference was not statistically significant $[-0.048(-0.128$ to 0.031$), p=0.233]$. The multivariate analyses yielded averaged effects that were somewhat weaker for SBP $(-0.151$ vs. -0.183$)$ and somewhat stronger for $\operatorname{DBP}(-0.103$ vs. -0.071$)$ than the univariate analyses, but likely more robust as they took into account the covariance among them.

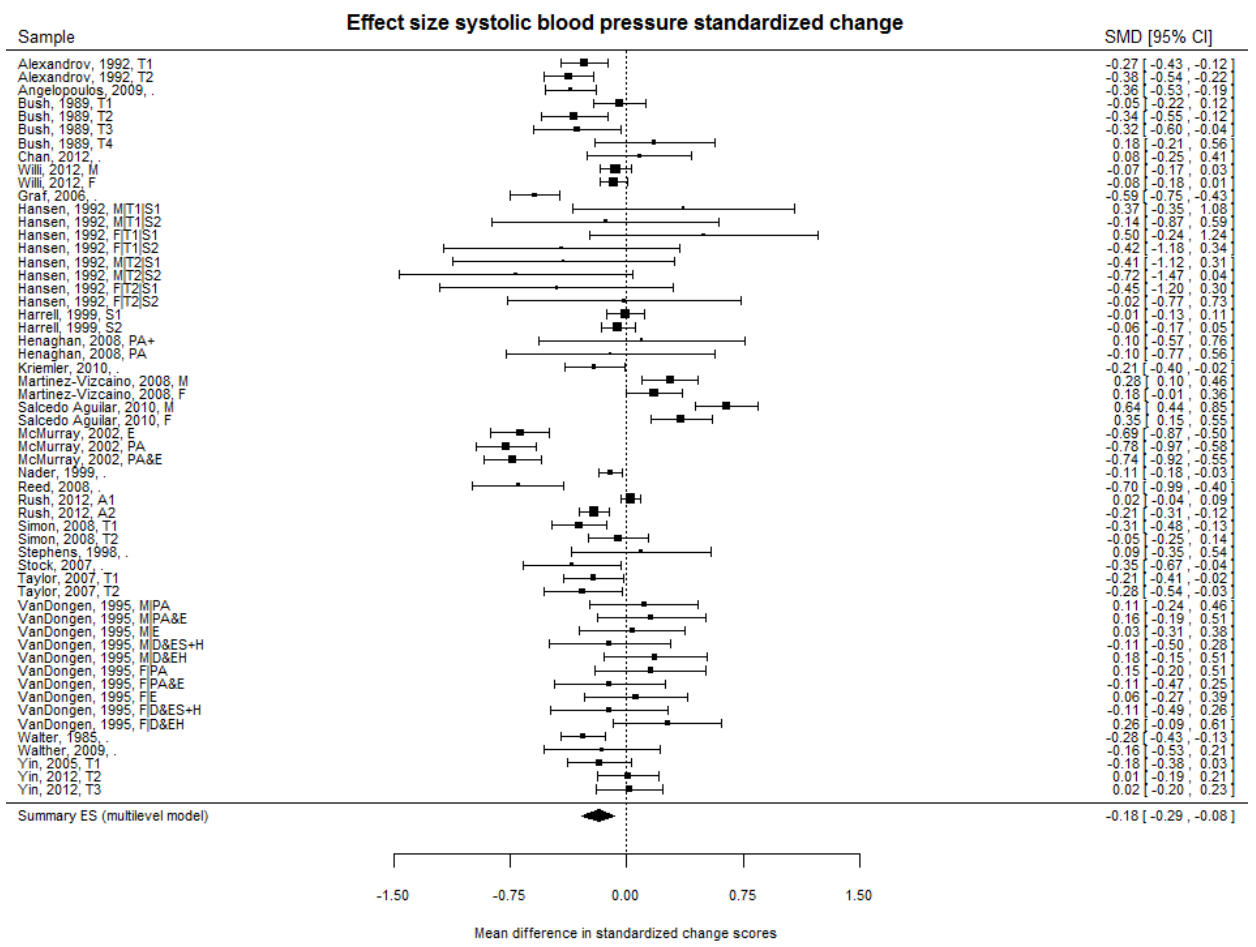

Figure 6 Forest plot of school-based intervention effects on changes in systolic blood pressure (SBP) univariate multilevel model.

Notes: $D=$ dietary intervention arm; $E=$ education intervention arm; $F=$ girls subsample; $M=$ male subsample; $\mathrm{PA}=$ physical activity intervention arm; $\mathrm{S}=$ (other) subgroup; $\mathrm{T}$ indicates time when effects at multiple time points were reported; $S M D=$ standardized mean change. 


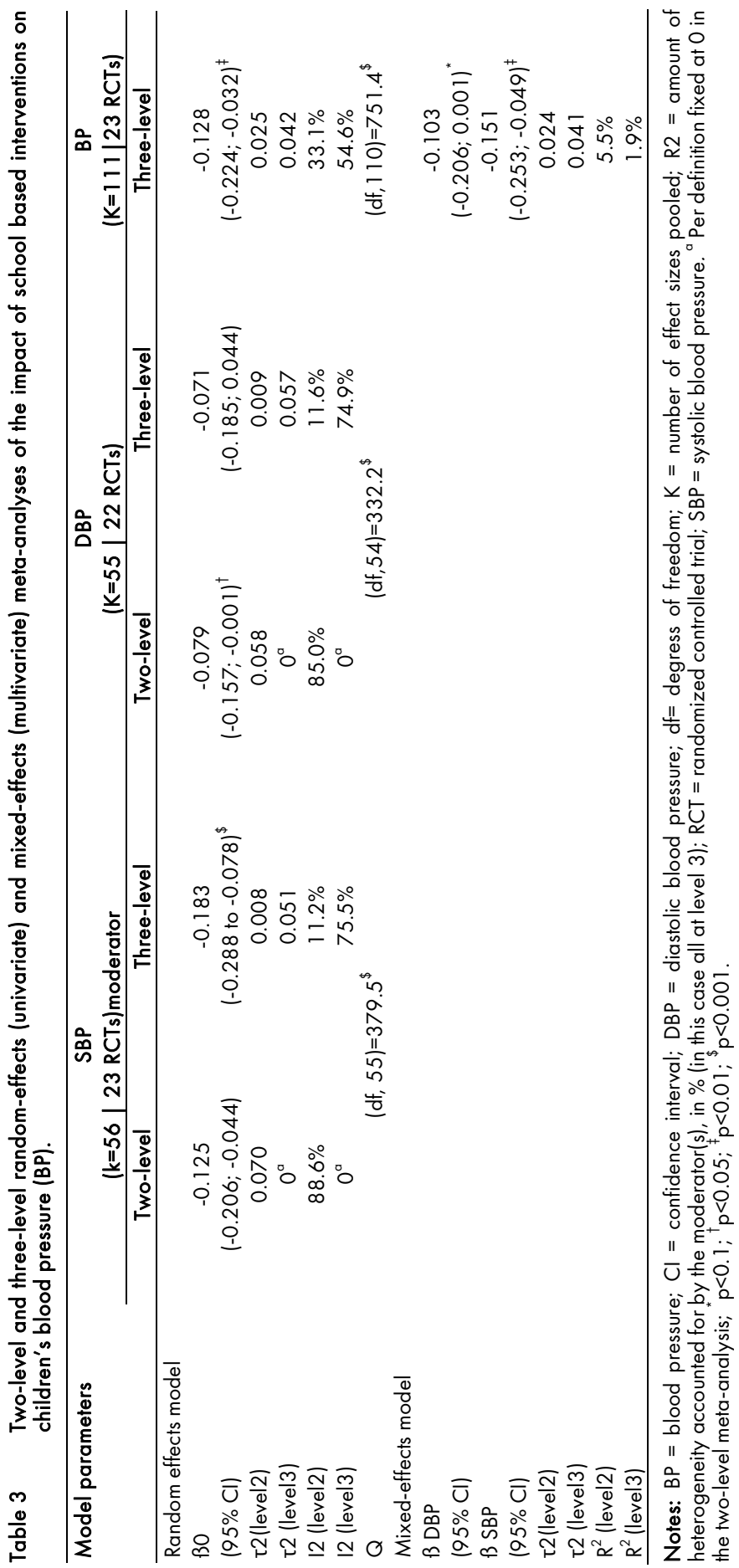




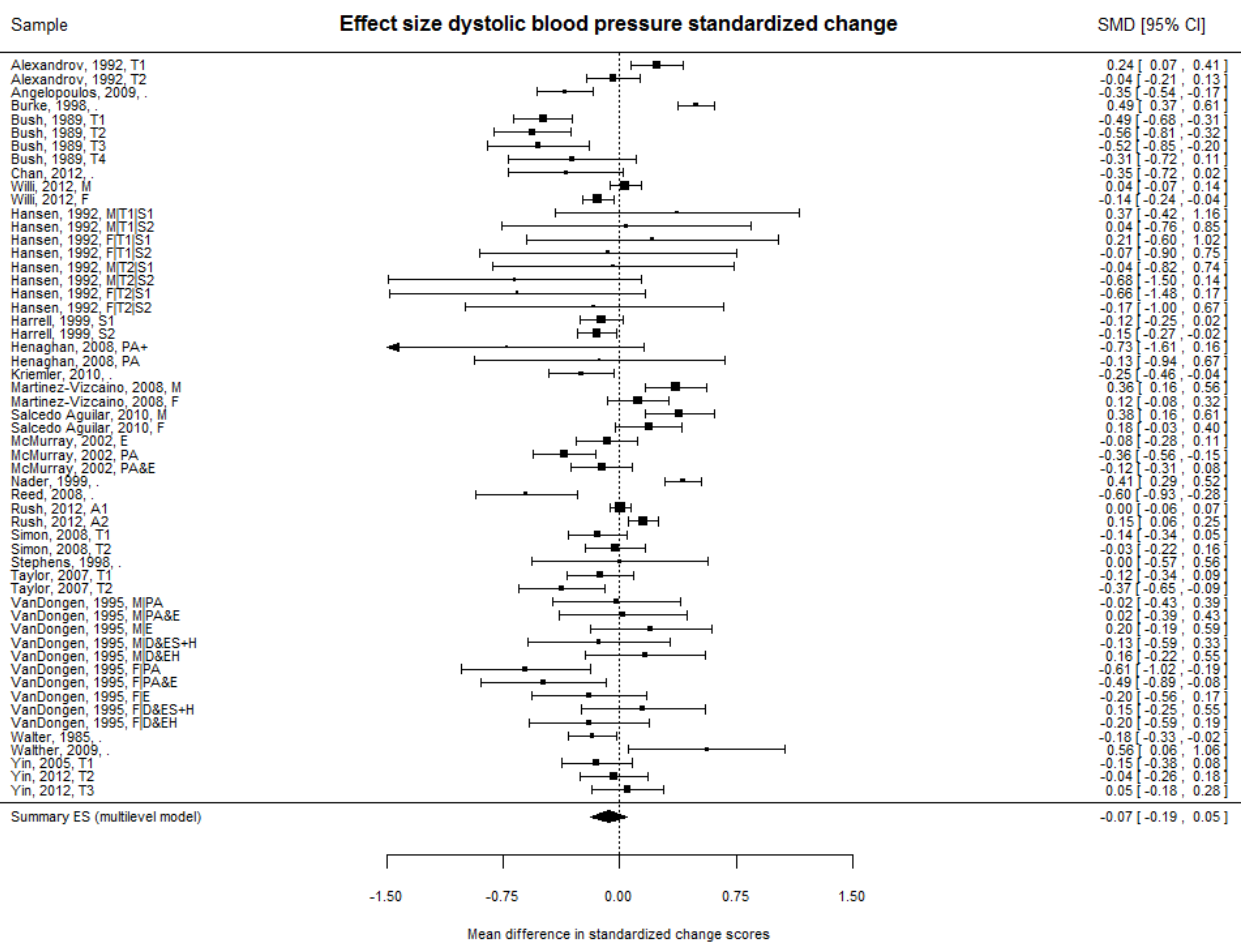

Figure 7 Forest plot of school-based intervention effects on changes in diastolic blood pressure (DBP) univariate multilevel model.

Notes: $D=$ dietary intervention arm; $E=$ education intervention arm; $F=$ girls subsample; $M=$ male subsample; $P A=$ physical activity intervention arm; $S=$ (other) subgroup; $T$ indicates time when effects at multiple time points were reported; $S M D=$ standardized mean change.

\section{Meta-regression}

In an attempt to understand which factors explained the large heterogeneity of the effects of school-based interventions on pupils' changes in BP, we also analysed a set of population, intervention and study quality characteristics as moderators in univariable models (i.e. each moderator at a time) and in a multivariable (i.e. all moderator simultaneously) metaregression models. Note that these analyses were built upon the multivariate BP model described above by adding interaction terms (or contrasts) to estimate potential differential moderating effects of predictors on SBP and DBP (Table 4). Again, here we confine our appreciation to the magnitude of such moderators' associations as obtained in the multivariable meta-regression model. 


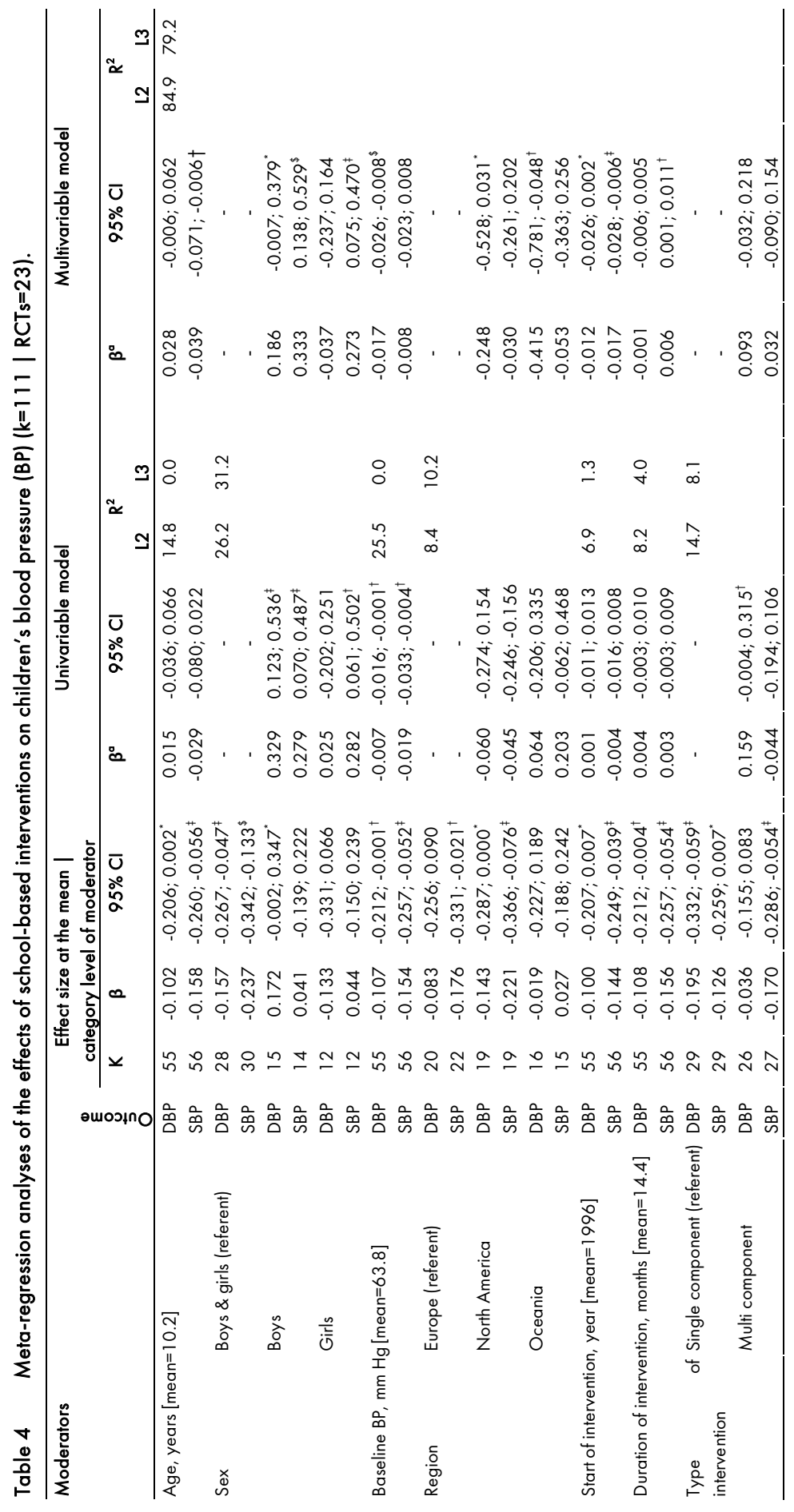




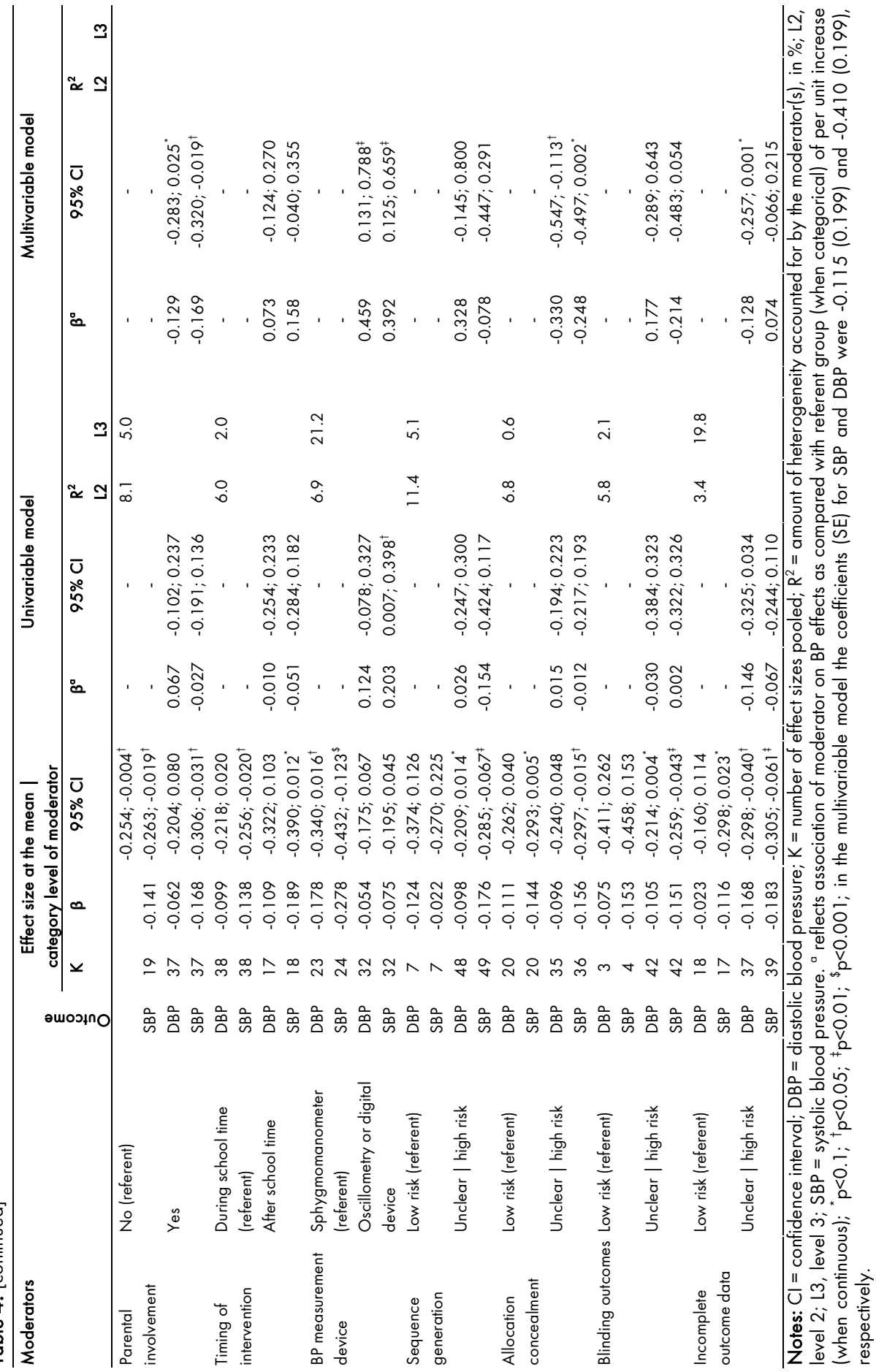


In brief, among all the moderators investigated, we found that children's age seemed to accentuate the beneficial effects of the lifestyle school-based interventions on SBP but not on DBP. Overall, the effects on both SBP and DBP extracted from sub-samples of boys or girls only were less pronounced than those extracted from samples comprising both boys and girls. Effects tended to be stronger among children's with higher levels of BP at baseline, particularly of DBP. Effects on DBP obtained in RCTs conducted in North America and Oceania tended also to be stronger than those conducted in Europe, and for both SBP and DBP effects were stronger in the more recent than the older RCTs. The effects on SBP but not on DBP tended to attenuate with longer intervention duration, and inclusion of a parental involvement component accentuated the beneficial effects of the interventions on both SBP and DBP. Effects on both SBP and DBP were significantly weaker among RCTs that used oscillometric or digital devices as compared with the standard manual Sphygmomanometer to measure BP. Finally, among the variables of methodological quality, RCTs that were scored with unclear or at high risk of bias regarding allocation concealment tended to inflate the beneficial effects of the interventions of children's SBP and DBP, as did those that were scored with unclear or high risk of bias for incomplete outcome data (SBP only).

Together the two outcomes and all population, intervention and methodological quality characteristics considered, accounted for $84.9 \%$ of the heterogeneity at level $3\left(\tau^{2}\right.$ decreased from 0.025 to 0.003 ) of the effects on SBP and $79.2 \%$ of the heterogeneity at level 3 ( $\tau^{2}$ decreased from 0.042 to 0.009 ) of the effects between on BP (Table 4).

\section{Meta-analysis - effects on BMI and BP}

We have also analysed, by means of univariate and multivariate three-level models, the set of 22 RCTs that reported on both BMI and BP outcomes (including those studies that reported on only $\mathrm{BMI}$ and SBP or only $\mathrm{BMI}$ and $\mathrm{DBP}$ ) (Table 5). Because all three outcomes were expressed in standardized mean changes units, they could be pooled into one dataset. For BMI (52 k) univariate three-level models yielded pooled effect sizes that were somewhat weaker, albeit not statistically significantly so, than the univariate effect sizes pooled from the whole set of $83 \mathrm{RCTs}(\mathrm{k}=151)$ reporting on BMI, i.e. -0.042 vs. -0.072 (Table 5 vs. Table 1).

The univariate mean effect sizes for $\operatorname{SBP}(k=53)$ and DBP $(k=52)$ did not materially differ from the whole set of RCTs reporting on BP given that the set of studies were essentially the same, i.e. -0.199 vs. -0.183 (SBP) and -0.082 vs. -0.071 (DBP) (Table 5 vs. Table 3).

Noteworthy, in a multivariate model including all three outcomes, i.e. SBP, DBP and BMI, and thus accounting for the covariance among them, the effect sizes for BMI (-0.054 vs. $-0.042)$ and SBP $(-0.182$ vs. -0.199$)$ remained practically unchanged whereas the effects sizes for DBP (-0.144 vs. -0.082 ) increased appreciably, as compared with the univariate 
models (Table 5). This suggests that the impact of the school-based interventions on BMI are independent of the concomitant effects on BP, but the effects on the later, particularly those on DBP, may be mediated by the former. In addition, comparisons of the strength of the effects sizes between the three outcomes indicate that the effects of the school-based interventions did not significantly differ between the 2 BP components, but the effect on both these were statistically stronger than those on $B M I:-0.128(-0.190$ to -0.065$), p<0.001$ for SBP vs. BMI and -0.089 (-0.157 to -0.022$), p=0.010$ for DBP vs. BMI.

Table 5 Univariate and multivariate three-level meta-analyses of the impact of school based interventions on children's body mass index (BMI) and blood pressure (BP).

\begin{tabular}{lccccc}
\hline & & \multicolumn{2}{c}{ Univariate } & \multicolumn{2}{c}{ Multivariate } \\
\cline { 3 - 6 } Outcome & $k$ & $\beta$ & $95 \% \mathrm{Cl}$ & $\beta$ & $95 \% \mathrm{Cl}$ \\
\hline BMI & 52 & -0.042 & $-0.076 ;-0.008^{\dagger}$ & -0.054 & $-0.131 ; 0.022^{*}$ \\
SBP & 53 & -0.199 & $-0.310 ;-0.088^{\$}$ & -0.182 & $-0.266 ;-0.098^{\$}$ \\
DBP & 52 & -0.082 & $-0.205 ; 0.042$ & -0.144 & $-0.230 ;-0.057^{\$}$ \\
\hline
\end{tabular}

Notes: $\mathrm{BMI}=$ body mass index; $\mathrm{Cl}=$ confidence interval; $\mathrm{DBP}=$ diastolic blood pressure; $\mathrm{k}=$ number of effects sizes pooled; $\mathrm{SBP}=$ systolic blood pressure. ${ }^{*} p<0.1 ;{ }^{\dagger} p<0.05 ;{ }^{\ddagger} p<0.01 ;{ }^{\$} p<0.001$.

\section{Discussion}

In this systematic review and meta-analysis we investigated, with the use of advanced metaanalytical tools, the effectiveness of school-based lifestyle preventive programmes on changes in BMI and BP. Overall, we found that such programmes induced favourable changes in both outcomes. However, it should be noted that such favourable changes do not necessarily mean reductions in these risk factors as often inferred by previous metaanalyses, because, in growing children, often the beneficial effects reflect less steep increases in $\mathrm{BMI}$ or $\mathrm{BP}$ children submitted to the intervention than the control groups.

Considering the magnitude of the SDs around the BMI mean values (on average $3.1 \mathrm{~kg} / \mathrm{m}^{2}$ ) of the studies reviewed herein, the mean effect sizes drawn from our univariate multilevel analyses comprising the biggest bulk of studies on BMI specifically (i.e., -0.072) translate to approximately $0.22 \mathrm{~kg} / \mathrm{m}^{2}$ favourable change in BMI. This effect is somewhat stronger than that reported in the most recent meta-analyses of school-based interventions, including multiple types of lifestyle interventions, on $\mathrm{BMI} .{ }^{38}$ Likewise, considering the magnitude of the SDs (on average $10.7 \mathrm{mmHg}$ for SBP and $8.5 \mathrm{mmHg}$ for DBP), the mean effect sizes drawn from our multivariate multilevel meta-analyses (respectively, -0.182 and -0.144 ) translate to approximately 1.9 and $1.2 \mathrm{mmHg}$ favourable changes in SBP and DBP, respectively. The effect size for SBP is thus a little bit higher whereas the effect size for DBP is somewhat lower than those reported in a recent relevant meta-analyses ( 1.6 and $1.4 \mathrm{mmHg}$, respectively). ${ }^{33}$ However, in contrast to ours, these prior meta-analyses did not model dependencies arising 
from multiple groups, treatment arms and/or multiple time points comparisons within studies, neither accounted for the dependencies of multiple outcomes within studies as naturally occurring in the case of variables such as SBP and DBP, which may thus explain the discrepancies. In addition, the fact that these prior meta-analyses included not only RCTs but also quasi-experimental studies and natural experiments, studies that were not confined to the school setting, and covered a wider range of children's age (i.e. 2 to 18 years) may also have accounted for some of the differences. It remains unclear the extent to which reductions in BMI and BP of these magnitude translate to clinical relevant outcomes later in life. Nevertheless, given the tracking of BMI and BP from childhood to adulthood and the fact that, among adults each unit increase in BMI, SBP and/or DBP are associated with increased CVD and mortality, lends some support for the relevancy of implementation of school-based interventions for the primary prevention of obesity and hypertension.

By conducting, for the first time, a multivariate meta-analyses of the effects of school-based lifestyle interventions on children's BMI and BP we were also able to contrast the effects on one or the other outcome. We found that the overall beneficial effects seemed stronger for SBP and DBP than for BMI, a comparison that was enabled by expressing all these outcomes in standardized measures. These findings thus suggest that school-based interventions may result, at least in part, in a decline or less steep increases in BP beyond or regardless of the concomitant changes in BMI. This is in agreement with the conclusions drawn from the recent meta-analysis of Cai et al. who found that $39 \%$ of the reviewed interventions did not decrease adiposity but did reduce BP levels. ${ }^{33}$ We have now extended these findings by testing the effect sizes obtained for one or the other type of outcome, instead of basing our conclusions on cross-tabulated counts of studies with vs. without significant effects, as done in that previous review. These findings were, however, restricted to the subset of RCTs included in the present meta-analyses that included both BMI and BP outcomes (22 RCTs out of all 85 RCTs reviewed). On itself, this unbalanced number illustrates the use of BMI as the main outcome of interest in most of the studies reviewed, but reinforces the need to extend main outcomes of interest to other related risk factors as well to enable a more comprehensive evaluation of the effectiveness of school-based lifestyle interventions on cardiovascular/general health. Still, the independent effects on BP do not remove the possibility that at least a portion may have been mediated by favourable changes in BMI. Indeed, school-based interventions induced favourable changes in BMI (path a) that, in turn, are thought to correlate with favourable changes in BP (path b). However, the vast majority of the RCTs revised did not inform on path b correlations, precluding us from quantifying the magnitude of any such mediation. Hereby we thus point the need for such analyses at the individual study level to enable meta-analysts to address, and test with empirical data, aetiological-like questions (i.e. how or through which mechanisms did the effects accrued ?) instead of simply being able to address descriptive- 
like questions (i.e. for whom and it what circumstances?) as enabled my means of moderator analyses. $^{142}$

The high heterogeneity of effect sizes pooled in our meta-analyses is in agreement with previous systematic reviews. We therefore investigated a set of population, intervention and study quality characteristics (moderators) in an attempt to understand the sources of such (anticipated) high heterogeneity. For BMI we found that interventions including a parental involvement component (vs. no such component) and those that were implemented as extracurricular activities (vs. embedded in the standard curricular activities) modified the effect sizes towards more favourable effects, but these two and the remaining moderators considered only explained about one third of the heterogeneity observed. It is thus possible that the set of moderators considered were not sufficient/the best to capture the sources of heterogeneity. Therefore, although we have analysed more moderators than in prior metaanalyses, and that also in these the extent of heterogeneity remained for a great deal unexplained, it remains that other moderators may need to be better identified and further investigated. For BP, almost all moderators considered modified the effects in an appreciable matter and, all together, explained the within- and between studies heterogeneity by about $80-85 \%$.

Worth to stress is the observation that, also with regard to BP outcomes, the inclusion of a parental involvement component in the interventions examined accentuated the beneficial effects. As noted by others, these findings suggest that targeting the home together with the school environment may lead to more effective interventions on both $\mathrm{BMI}$ and $\mathrm{BP}{ }^{28}$ For $\mathrm{BP}$ but not for BMI, the larger beneficial effects on outcomes were seen for children with the highest baseline levels of the specific outcomes. This suggests that the interventions reviewed may be more effective among children who are already (pre)hypertensive, which was also reported by Sbruzzi et al. ${ }^{37}$ but not necessarily so among children who are already overweight/obese. In other words, benefits may be booked to all children submitted to such interventions regardless of their baseline weight status. Prior meta-analyses argued that multicomponent interventions were more effective than interventions that targeted physical activity or diet only, ${ }^{28,33,38}$ but our findings do not seem to support this contention. Although this supports the value of any PA or dietary intervention as tools that can be used on their own right to prevent obesity and hypertension among the young, promoting multiple behaviours may induce a more comprehensive and coherent change in children's lifestyle and health status.

In conclusion, the present meta-analysis shows that school-based lifestyle interventions lead to favourable changes in BMI and BP and that such changes in BP may be induced beyond 
changes in BMI. It also stresses the importance of evaluating effects on outcomes metabolic (e.g. glucose metabolism, lipid levels) risk factors, to enable a more comprehensive appreciation of the effects of school-based lifestyle intervention programs on children's health. 


\section{References}

1. Wang Y, Lobstein T. Worldwide trends in childhood overweight and obesity. Int J Pediatr Obes 2006; 1: $11-25$.

2. Luma GB, Spiotta RT. Hypertension in children and adolescents. Am Fam Physician 2006;73:1558-68.

3. Sorof J, Daniels S. Obesity hypertension in children: a problem of epidemic proportions. Hypertension 2002; 40: 441-7.

4. Friedemann C, Heneghan C, Mahtani K, Thompson M, Perera R, Ward AM. Cardiovascular disease risk in healthy children and its association with body mass index: systematic review and meta-analysis. BMJ 2012; 345:e4759.

5. Muntner P, He J, Cutler JA, Wildman RP, Whelton PK. Trends in blood pressure among children and adolescents. JAMA 2004;291:2107-13.

6. Din-Dzietham R, Liu Y, Bielo MV, Shamsa F. High blood pressure trends in children and adolescents in national surveys, 1963 to 2002 . Circulation 2007;1 16:1488-96.

7. Rosner B, Cook NR, Daniels S, Falkner B. Childhood blood pressure trends and risk factors for high blood pressure: the NHANES experience 1988-2008. Hypertension 2013;62:247-54.

8. Bayer $\mathrm{O}$, Kruger $\mathrm{H}$, von Kries $\mathrm{R}$, Toschke AM. Factors associated with tracking of BMI: a meta-regression analysis on BMI tracking. Obesity (Silver Spring) 201 1;19:1069-76.

9. Chen $X$, Wang $Y$. Tracking of blood pressure from childhood to adulthood: a systematic review and metaregression analysis. Circulation 2008;1 17:3171-80.

10. Falkner B, Gidding S. Childhood obesity and blood pressure: back to the future? Hypertension $2011 ; 58$ : 754-55.

11. Lurbe E, Cifkova R, Cruickshank JK, et al. Management of high blood pressure in children and adolescents: recommendations of the European Society of Hypertension. J Hypertens 2009; 27:1719-42.

12. Ferreira I, van de Laar RJ, Prins MH, Twisk JW, Stehouwer CD. Carotid stiffness in young adults: a life-course analysis of its early determinants: the Amsterdam Growth and Health Longitudinal Study. Hypertension 2012; 59:54-61.

13. Li S, Chen W, Srinivasan SR, Berenson GS. Childhood blood pressure as a predictor of arterial stiffness in young adults: the bogalusa heart study. Hypertension 2004;43:541-6.

14. Li X, Li S, Ulusoy E, Chen W, Srinivasan SR, Berenson GS. Childhood adiposity as a predictor of cardiac mass in adulthood: the Bogalusa Heart Study. Circulation 2004; 1 10:3488-92.

15. Raitakari OT, Juonala M, Viikari JS. Obesity in childhood and vascular changes in adulthood: insights into the Cardiovascular Risk in Young Finns Study. Int J Obes (Lond) 2005;29 Suppl 2:S101-4.

16. Ferreira I, Twisk JW, van Mechelen W, Kemper HC, Seidell JC, Stehouwer CD. Current and adolescent body fatness and fat distribution: relationships with carotid intima-media thickness and large artery stiffness at the age of 36 years. J Hypertens 2004;22:145-55.

17. Li S, Chen W, Srinivasan SR, Bond MG, Tang R, Urbina EM, et al. Childhood cardiovascular risk factors and carotid vascular changes in adulthood: the Bogalusa Heart Study. JAMA 2003;290:2271-6.

18. Raitakari OT, Juonala $M$, Kahonen $M$, et al. Cardiovascular risk factors in childhood and carotid artery intima-media thickness in adulthood: the Cardiovascular Risk in Young Finns Study. JAMA 2003;290: 2277-83.

19. DiPietro L, Mossberg HO, Stunkard AJ. A 40-year history of overweight children in Stockholm: life-time overweight, morbidity, and mortality. Int J Obes Relat Metab Disord 1994; 18:585-90.

20. Gunnell DJ, Frankel SJ, Nanchahal K, Peters TJ, Davey Smith G. Childhood obesity and adult cardiovascular mortality: a 57-y follow-up study based on the Boyd Orr cohort. Am J Clin Nutr 1998;67:1 111 1-8.

21. Must A, Jacques PF, Dallal GE, Bajema CJ, Dietz WH. Long-term morbidity and mortality of overweight adolescents. A follow-up of the Harvard Growth Study of 1922 to 1935. N Engl J Med 1992;327:1350-5.

22. Must A, Phillips SM, Naumova EN. Occurrence and timing of childhood overweight and mortality: findings from the Third Harvard Growth Study. J Pediatr 2012; 160:743-50.

23. Franks PW, Hanson RL, Knowler WC, Sievers ML, Bennett PH, Looker HC. Childhood obesity, other cardiovascular risk factors, and premature death. N Engl J Med 2010;362:485-93. 
24. Lawlor DA, Chaturvedi N. Treatment and prevention of obesity--are there critical periods for intervention? Int J Epidemiol 2006;35:3-9.

25. Kelder SH, Perry CL, Klepp KI, Lytle LL. Longitudinal tracking of adolescent smoking, physical activity, and food choice behaviors. Am J Public Health 1994;84:1121-6.

26. Kuh D, Ben-Sholo Y. A life course approach to chronic disease epidemiology. Oxford, UK: Oxford University Press 2004.

27. Hayman LL, Williams CL, Daniels SR, Steinberger J, et al. Cardiovascular health promotion in the schools: a statement for health and education professionals and child health advocates from the Committee on Atherosclerosis, Hypertension, and Obesity in Youth (AHOY) of the Council on Cardiovascular Disease in the Young, American Heart Association. Circulation 2004; 1 10:2266-75.

28. Katz DL. School-based interventions for health promotion and weight control: not just waiting on the world to change. Annu Rev Public Health 2009;30:253-72.

29. Budd GM, Volpe SL. School-based obesity prevention: Research, challenges, and recommendations. J Sch Health 2006;76:485-95.

30. Briggs M, Fleischhacker S, Mueller CG, American Dietetic Association, School Nutrition Association, Society for Nutrition Education. Position of the American Dietetic Association, School Nutrition Association, and Society for Nutrition Education: comprehensive school nutrition services. J Nutr Educ Behav 2010;42: 360-71.

31. Pate RR, Davis MG, Robinson TN, et al. Promoting physical activity in children and youth: a leadership role for schools: a scientific statement from the American Heart Association Council on Nutrition, Physical Activity, and Metabolism (Physical Activity Committee) in collaboration with the Councils on Cardiovascular Disease in the Young and Cardiovascular Nursing. Circulation 2006; 11 14:1214-24.

32. Waters $E$, de Silva-Sanigorski A, Hall BJ, et al. Interventions for preventing obesity in children. Cochrane Database Syst Rev 2011 :CD001871.

33. Cai L, Wu Y, Wilson RF, Segal JB, Kim MT, Wang Y. Effect of childhood obesity prevention programs on blood pressure: a systematic review and meta-analysis. Circulation 2014;129:1832-9.

34. Harris KC, Kuramoto LK, Schulzer M, Retallack JE. Effect of school-based physical activity interventions on body mass index in children: a meta-analysis. CMAJ 2009; 180:719-26.

35. Guerra PH, Nobre MR, Silveira JA, Taddei JA. The effect of school-based physical activity interventions on body mass index: a meta-analysis of randomized trials. Clinics (Sao Paulo) 2013;68:1263-73.

36. Dobbins M, Husson H, DeCorby K, LaRocca RL. School-based physical activity programs for promoting physical activity and fitness in children and adolescents aged 6 to 18. Cochrane Database Syst Rev 2013; 2:CD007651.

37. Sbruzzi G, Eibel B, Barbiero SM, et al. Educational interventions in childhood obesity: a systematic review with meta-analysis of randomized clinical trials. Prev Med 2013;56:254-64.

38. Lavelle HV, Mackay DF, Pell JP. Systematic review and meta-analysis of school-based interventions to reduce body mass index. J Public Health (Oxf) 2012;34:360-9.

39. Gonzalez-Suarez C, Worley A, Grimmer-Somers K, Dones V. School-based interventions on childhood obesity: a meta-analysis. Am J Prev Med 2009;37:418-27.

40. Viechtbauer W. Accounting for heterogeneity via random-effects models and moderator analyses in metaanalysis. J Psychol 2007;215:104-21.

41. Konstantopoulos S. Fixed effects and variance components estimation in three-level meta-analysis. Res Synth Method $2011 ; 2: 61-76$.

42. Scammaca N, Roberts $G$. Meta-Analysis with complex research designs: dealing with dependence from multiple measures and multiple group comparisons. Rev Educ Res 2014;84:328-64.

43. Van den Noortgate W, Lopez-Lopez JA, Marin-Martinez F, Sanchez-Meca J. Three-level meta-analysis of dependent effect sizes. Behav Res Methods 2013;45:576-94.

44. Higging JP, Altman DG, Sterne JA, on behalf of the Cochrane Statistical Methods Group and the Cochrane Bias Methods Group. Assessing risk of bias in included studies. In: Higgins JP, Green S (eds.). Cochrane Handbook for Systematic Reviews of Interventions Version 5.1.0. Cochrane Collaboration 2011; Available at: http://www.handbook.cochrane.org (last accessed 30 Jan 2014).

45. Cole TJ, Faith MS, Pietrobelli A, Heo M. What is the best measure of adiposity change in growing children: BMI, BMI \%, BMI z-score or BMI centile? Eur J Clin Nutr 2005;59:419-25. 
46. Morris SB. Estimating effect sizes from pretest-posttest-control group designs. Organ Res Meth 2008; 11 : 364-86.

47. Becker BJ. Synthesizing standardized mean-change measures. Brit J Math Stat Psy 1988;41:257-78.

48. Viechtbauer W. Conducting meta-analysis in R with the metafor package. J Stat Softw 2010;36:1-48.

49. Cheung MW. Modeling dependent effect sizes with three-level meta-analyses: a structural equation modeling approach. Psychol Methods 2014;19:211-29.

50. Peters JL, Sutton AJ, Jones DR, Abrams KR, Rushton L. Comparison of two methods to detect publication bias in meta-analysis. JAMA 2006;295:676-80.

51. Ahamed Y, Macdonald H, Reed K, Naylor PJ, Liu-Ambrose T, McKay H. School-based physical activity does not compromise children's academic performance. Med Sci Sports Exerc 2007;39:371-6.

52. Alexandrov AA, Maslennikova GY, Kulikov SM, Propirnii GA, Perova NV. Primary prevention of cardiovascular disease: 3-year intervention results in boys of 12 years of age. Prev Med 1992;21:53-62.

53. Amaro S, Viggiano A, Di Costanzo A, et al. Kaledo, a new educational board-game, gives nutritional rudiments and encourages healthy eating in children: a pilot cluster randomized trial. Eur J Pediatr 2006; 165:630-5.

54. Angelopoulos PD, Milionis HJ, Grammatikaki E, Moschonis G, Manios Y. Changes in BMI and blood pressure after a school based intervention: the CHILDREN study. Eur J Public Health 2009; 19:319-25.

55. Annesi JJ, Smith AE, Tennant GA. Reducing high BMI in African American preschoolers: effects of a behaviorbased physical activity intervention on caloric expenditure. South Med J 2013;106:456-9.

56. Barbeau $\mathrm{P}$, Johnson $\mathrm{MH}$, Howe $\mathrm{CA}$, et al. Ten months of exercise improves general and visceral adiposity, bone, and fitness in black girls. Obesity (Silver Spring) 2007; 15:2077-85.

57. Brandstetter S, Klenk J, Berg S, et al. Overweight prevention implemented by primary school teachers: a randomised controlled trial. Obes Facts 2012;5:1-11.

58. Burke V, Milligan RA, Thompson C, et al. A controlled trial of health promotion programs in 11 -year-olds using physical activity "enrichment" for higher risk children. J Pediatr 1998; 132:840-8.

59. Bush PJ, Zuckerman AE, Taggart VS, Theiss PK, Peleg EO, Smith SA. Cardiovascular risk factor prevention in black school children: the "Know Your Body" evaluation project. Health Educ Q 1989;16:215-27.

60. Caballero B, Clay T, Davis SM, et al. Pathways: a school-based, randomized controlled trial for the prevention of obesity in American Indian schoolchildren. Am J Clin Nutr 2003;78:1030-8.

61. Carrel AL, Clark RR, Peterson SE, Nemeth BA, Sullivan J, Allen DB. Improvement of fitness, body composition, and insulin sensitivity in overweight children in a school-based exercise program: a randomized, controlled study. Arch Pediatr Adolesc Med 2005; 159:963-8.

62. Chan EK, Quach J, Mensah FK, Sung V, Cheung M, Wake M. Dark chocolate for children's blood pressure: randomised trial. Arch Dis Child 2012;97:637-40.

63. Crespo NC, Elder JP, Ayala GX, et al. Results of a multi-level intervention to prevent and control childhood obesity among Latino children: the Aventuras Para Ninos Study. Ann Behav Med 2012;43:84-100.

64. De Coen V, De Bourdeaudhuij I, Vereecken C, et al. Effects of a 2-year healthy eating and physical activity intervention for 3-6-year-olds in communities of high and low socio-economic status: the POP (Prevention of Overweight among Pre-school and school children) project. Public Health Nutr 2012;15:1737-45.

65. de Heer HD, Koehly L, Pederson R, Morera O. Effectiveness and spillover of an after-school health promotion program for Hispanic elementary school children. Am J Public Health 2011;101:1907-13.

66. Dennison BA, Russo TJ, Burdick PA, Jenkins PL. An intervention to reduce television viewing by preschool children. Arch Pediatr Adolesc Med 2004; 158:170-6.

67. Donnelly JE, Greene JL, Gibson CA, et al. Physical Activity Across the Curriculum (PAAC): a randomized controlled trial to promote physical activity and diminish overweight and obesity in elementary school children. Prev Med 2009;49:336-41.

68. Duncan MJ, Al-Nakeeb Y, Nevill AM. Effects of a 6-week circuit training intervention on body esteem and body mass index in British primary school children. Body Image 2009;6:216-20.

69. Dzewaltowski DA, Rosenkranz RR, Geller KS, et al. HOP'N after-school project: an obesity prevention randomized controlled trial. Int J Behav Nutr Phys Act 2010;7:90.

70. Eather N, Morgan PJ, Lubans DR. Improving the fitness and physical activity levels of primary school children: results of the Fit-4-Fun group randomized controlled trial. Prev Med 2013;56:12-9. 
71. Eliakim A, Nemet D, Balakirski Y, Epstein Y. The effects of nutritional-physical activity school-based intervention on fatness and fitness in preschool children. J Pediatr Endocrinol Metab 2007;20:71 1-8.

72. Fairclough SJ, Hackett AF, Davies IG, et al. Promoting healthy weight in primary school children through physical activity and nutrition education: a pragmatic evaluation of the CHANGE! randomised intervention study. BMC Public Health 2013;13:626.

73. Fitzgibbon ML, Stolley MR, Schiffer L, Van Horn L, KauferChristoffel K, Dyer A. Hip-Hop to Health Jr. for Latino preschool children. Obesity (Silver Spring) 2006;14:1616-25.

74. Fitzgibbon ML, Stolley MR, Schiffer LA, et al. Hip-Hop to Health Jr. Obesity Prevention Effectiveness Trial: postintervention results. Obesity (Silver Spring) 201 1; 19:994-1003.

75. Foster GD, Sherman S, Borradaile KE, et al. A policy-based school intervention to prevent overweight and obesity. Pediatrics 2008; 121:e794-802.

76. Gentile DA, Welk G, Eisenmann JC, et al. Evaluation of a multiple ecological level child obesity prevention program: Switch what you Do, View, and Chew. BMC Med: 2009;49.

77. Graf C, Koch B, Bjarnason-Wehrens B, et al. Who benefits from intervention in, as opposed to screening of, overweight and obese children? Cardiol Young 2006; 16:474-80.

78. Graf C, Koch B, Falkowski G, et al. School-based prevention: effects on obesity and physical performance after 4 years. J Sports Sci 2008;26:987-94.

79. Foster GD, Linder B, Baranowski T, et al. A school-based intervention for diabetes risk reduction. N Engl J Med 2010;363:443-53.

80. Grydeland M, Bjelland M, Anderssen SA, et al. Effects of a 20-month cluster randomised controlled schoolbased intervention trial on BMI of school-aged boys and girls: the HEIA study. Br J Sports Med 2014;48: 768-73.

81. Hansen HS, Froberg K, Hyldebrandt N, Nielsen JR. A controlled study of eight months of physical training and reduction of blood pressure in children: the Odense schoolchild study. BMJ 1991;303:682-5.

82. Harrell JS, McMurray RG, Gansky SA, Bangdiwala SI, Bradley CB. A public health vs a risk-based intervention to improve cardiovascular health in elementary school children: the Cardiovascular Health in Children Study. Am J Public Health 1999;89:1529-35.

83. Harrison M, Burns CF, McGuinness M, Heslin J, Murphy NM. Influence of a health education intervention on physical activity and screen time in primary school children: 'Switch Off--Get Active'. J Sci Med Sport 2006; 9:388-94.

84. Henaghan J, McWhannell N, Foweather L, et al. The effect of structured exercise classes and a lifestyle intervention on cardiovascular risk factors in primary schoolchildren: an exploratory trial (The A-CLASS Project). Pediatr Exerc Sci 2008;20:169-80.

85. Hoffman JA, Thompson DR, Franko DL, Power TJ, Leff SS, Stallings VA. Decaying behavioral effects in a randomized, multi-year fruit and vegetable intake intervention. Prev Med 201 1;52:370-5.

86. Hopper CA, Munoz KD, Gruber MB, Nguyen KP. The effects of a family fitness program on the physical activity and nutrition behaviors of third-grade children. Res Q Exerc Sport 2005;76:130-9.

87. James J, Thomas P, Cavan D, Kerr D. Preventing childhood obesity by reducing consumption of carbonated drinks: cluster randomised controlled trial. BMJ 2004;328:1237.

88. Jansen W, Borsboom G, Meima A, et al. Effectiveness of a primary school-based intervention to reduce overweight. Int J Pediatr Obes $2011 ; 6:$ e70-7.

89. Jiang J, Xia X, Greiner T, Wu G, Lian G, Rosenqvist U. The effects of a 3-year obesity intervention in schoolchildren in Beijing. Child Care Health Dev 2007;33:64 1-6.

90. Johnston CA, Moreno JP, El-Mubasher A, Gallagher M, Tyler C, Woehler D. Impact of a school-based pediatric obesity prevention program facilitated by health professionals. J Sch Health 2013;83:171-81.

91. Jouret B, Ahluwalia N, Dupuy M, et al. Prevention of overweight in preschool children: results of kindergarten-based interventions. Int J Obes (Lond) 2009;33:1075-83.

92. Kipping RR, Payne C, Lawlor DA. Randomised controlled trial adapting US school obesity prevention to England. Arch Dis Child 2008;93:469-73.

93. Kriemler S, Zahner L, Schindler C, et al. Effect of school based physical activity programme (KISS) on fitness and adiposity in primary schoolchildren: cluster randomised controlled trial. BMJ 2010;340:c785. 
94. Lazaar N, Aucouturier J, Ratel S, Rance M, Meyer M, Duche P. Effect of physical activity intervention on body composition in young children: influence of body mass index status and gender. Acta Paediatr 2007; 96:1315-20.

95. Li YP, Hu XQ, Schouten EG, et al. Report on childhood obesity in China (8): effects and sustainability of physical activity intervention on body composition of Chinese youth. Biomed Environ Sci 2010;23:180-7.

96. Llargues E, Recasens A, Franco R, et al. Medium-term evaluation of an educational intervention on dietary and physical exercise habits in schoolchildren: the Avall 2 study. Endocrinol Nutr 2012;59:288-95.

97. Lloyd JJ, Wyatt KM, Creanor S. Behavioural and weight status outcomes from an exploratory trial of the Healthy Lifestyles Programme (HeLP): a novel school-based obesity prevention programme. BMJ Open 2012;2.

98. Lohman T, Thompson J, Going S, et al. Indices of changes in adiposity in American Indian children. Prev Med 2003;37:59 1-6.

99. Magnusson KT, Hrafnkelsson H, Sigurgeirsson I, Johannsson E, Sveinsson T. Limited effects of a 2-year school-based physical activity intervention on body composition and cardiorespiratory fitness in 7-year-old children. Health Educ Res 2012;27:484-94.

100. Manios Y, Moschandreas J, Hatzis C, Kafatos A. Evaluation of a health and nutrition education program in primary school children of Crete over a three-year period. Prev Med 1999;28:149-59.

101. Manios Y, Moschandreas J, Hatzis C, Kafatos A. Health and nutrition education in primary schools of Crete: changes in chronic disease risk factors following a 6-year intervention programme. Br J Nutr 2002;88: 315-24.

102. Marcus C, Nyberg G, Nordenfelt A, Karpmyr M, Kowalski J, Ekelund U. A 4-year, cluster-randomized, controlled childhood obesity prevention study: STOPP. Int J Obes (Lond) 2009;33:408-17.

103. Martinez Vizcaino V, Salcedo Aguilar F, Franquelo Gutierrez R, et al. Assessment of an after-school physical activity program to prevent obesity among 9- to 10-year-old children: a cluster randomized trial. Int J Obes (Lond) 2008;32:12-22.

104. McMurray RG, Harrell JS, Bangdiwala SI, Bradley CB, Deng S, Levine A. A school-based intervention can reduce body fat and blood pressure in young adolescents. J Adolesc Health 2002;31:125-32.

105. Meng $\mathrm{L}, \mathrm{X} \cup \mathrm{H}$, Liu $\mathrm{A}$, et al. The costs and cost-effectiveness of a school-based comprehensive intervention study on childhood obesity in China. PLoS One 2013;8:e77971.

106. Mo-suwan L, Pongprapai S, Junjana C, Puetpaiboon A. Effects of a controlled trial of a school-based exercise program on the obesity indexes of preschool children. Am J Clin Nutr 1998;68:1006-11.

107. Muckelbaver R, Libuda L, Clausen K, Reinehr T, Kersting M. A simple dietary intervention in the school setting decreased incidence of overweight in children. Obes Facts 2009;2:282-5.

108. Nader PR, Stone EJ, Lytle LA, et al. Three-year maintenance of improved diet and physical activity: the CATCH cohort. Child and Adolescent Trial for Cardiovascular Health. Arch Pediatr Adolesc Med 1999; 153:695-704.

109. Nemet D, Geva D, Eliakim A. Health promotion intervention in low socioeconomic kindergarten children.J Pediatr $2011 ; 158: 796-801$ e791.

110. Niederer I, Burgi F, Ebenegger $V$, et al. Effects of a lifestyle intervention on adiposity and fitness in overweight or low fit preschoolers (Ballabeina). Obesity (Silver Spring) 2013;21:E287-93.

111. Plachta-Danielzik S, Landsberg B, Lange D, Seiberl J, Muller MJ. Eight-year follow-up of school-based intervention on childhood overweight--the Kiel Obesity Prevention Study. Obes Facts 201 1;4:35-43.

112. Plachta-Danielzik S, Pust S, Asbeck I, et al. Four-year follow-up of school-based intervention on overweight children: the KOPS study. Obesity (Silver Spring) 2007; 15:3159-69.

113. Rausch Herscovici C, Kovalskys I, De Gregorio MJ. Gender differences and a school-based obesity prevention program in Argentina: a randomized trial. Rev Panam Salud Publica 2013;34:75-82.

114. Reed KE, Warburton DE, Macdonald HM, Naylor PJ, McKay HA. Action Schools! BC: a school-based physical activity intervention designed to decrease cardiovascular disease risk factors in children. Prev Med 2008;46:525-31.

115. Reilly JJ, Kelly L, Montgomery C, et al. Physical activity to prevent obesity in young children: cluster randomised controlled trial. BMJ 2006;333:1041.

116. Robinson TN. Reducing children's television viewing to prevent obesity: a randomized controlled trial. JAMA 1999;282:1561-7. 
117. Rosario R, Araujo A, Oliveira B, et al. Impact of an intervention through teachers to prevent consumption of low nutrition, energy-dense foods and beverages: a randomized trial. Prev Med 2013;57:20-5.

1 18. Rush E, Reed P, McLennan S, Coppinger T, Simmons D, Graham D. A school-based obesity control programme: Project Energize. Two-year outcomes. Br J Nutr 2012;107:581-7.

119. Sacchetti R, Ceciliani A, Garulli A, Dallolio L, Beltrami P, Leoni E. Effects of a 2-year school-based intervention of enhanced physical education in the primary school. J Sch Health 2013;83:639-46.

120. Sahota P, Rudolf MC, Dixey R, Hill AJ, Barth JH, Cade J. Randomised controlled trial of primary school based intervention to reduce risk factors for obesity. BMJ 2001;323:1029-32.

121. Salcedo Aguilar F, Martinez-Vizcaino V, Sanchez Lopez M, et al. Impact of an after-school physical activity program on obesity in children. J Pediatr 2010;157:36-42 e33.

122. Sallis JF, McKenzie TL, Alcaraz JE, Kolody B, Hovell MF, Nader PR. Project SPARK. Effects of physical education on adiposity in children. Ann N Y Acad Sci 1993;699:127-36.

123. Salmon J, Ball K, Hume C, Booth M, Crawford D. Outcomes of a group-randomized trial to prevent excess weight gain, reduce screen behaviours and promote physical activity in 10-year-old children: switch-play. Int J Obes (Lond) 2008;32:601-12.

124. Sichieri R, Paula Trotte A, de Souza RA, Veiga GV. School randomised trial on prevention of excessive weight gain by discouraging students from drinking sodas. Public Health Nutr 2009; 12:197-202.

125. Siegrist M, Lammel C, Haller B, Christle J, Halle M. Effects of a physical education program on physical activity, fitness, and health in children: the JuvenTUM project. Scand J Med Sci Sports 2013;23:323-30.

126. Simon C, Schweitzer B, Oujaa M, et al. Successful overweight prevention in adolescents by increasing physical activity: a 4-year randomized controlled intervention. Int J Obes (Lond) 2008;32:1489-98.

127. Spiegel SA, Foulk D. Reducing overweight through a multidisciplinary school-based intervention. Obesity (Silver Spring) 2006; 14:88-96.

128. Stephens MB, Wentz SW. Supplemental fitness activities and fitness in urban elementary school classrooms. Fam Med 1998;30:220-3.

129. Stock S, Miranda C, Evans S, et al. Healthy Buddies: a novel, peer-led health promotion program for the prevention of obesity and eating disorders in children in elementary school. Pediatrics 2007; 120:e 1059-68.

130. Story M, Hannan PJ, Fulkerson JA, et al. Bright Start: Description and main outcomes from a grouprandomized obesity prevention trial in American Indian children. Obesity (Silver Spring) 2012;20:2241-9.

131. Story M, Sherwood NE, Himes JH, et al. An after-school obesity prevention program for African-American girls: the Minnesota GEMS pilot study. Ethn Dis 2003; 13:S54-64.

132. Taylor RW, McAuley KA, Barbezat W, Strong A, Williams SM, Mann JI. APPLE Project: 2-y findings of a community-based obesity prevention program in primary school age children. Am J Clin Nutr 2007;86: 735-42.

133. Thivel $D$, Isacco $L$, Lazaar $N$, et al. Effect of a 6-month school-based physical activity program on body composition and physical fitness in lean and obese schoolchildren. Eur J Pediatr 201 1;170:1435-43.

134. Toruner EK, Savaser S. A controlled evaluation of a school-based obesity prevention in Turkish school children. J Sch Nurs 2010;26:473-82.

135. Vandongen $R$, Jenner DA, Thompson $C$, et al. A controlled evaluation of a fitness and nutrition intervention program on cardiovascular health in 10- to 12-year-old children. Prev Med 1995;24:9-22.

136. Walter HJ, Hofman A, Connelly PA, Barrett LT, Kost KL. Primary prevention of chronic disease in childhood: changes in risk factors after one year of intervention. Am J Epidemiol 1985; 122:772-81.

137. Walther C, Gaede L, Adams V, et al. Effect of increased exercise in school children on physical fitness and endothelial progenitor cells: a prospective randomized trial. Circulation 2009; 120:2251-9.

138. Willi SM, Hirst K, Jago R, et al. Cardiovascular risk factors in multi-ethnic middle school students: the HEALTHY primary prevention trial. Pediatr Obes 2012;7:230-9.

139. Williamson DA, Champagne CM, Harsha DW, et al. Effect of an environmental school-based obesity prevention program on changes in body fat and body weight: a randomized trial. Obesity (Silver Spring) 2012;20:1653-61.

140. Yin Z, Gutin B, Johnson MH, et al. An environmental approach to obesity prevention in children: Medical College of Georgia FitKid Project year 1 results. Obes Res 2005; 13:2153-61.

141. Yin Z, Moore JB, Johnson MH, Vernon MM, Gutin B. The impact of a 3-year after-school obesity prevention program in elementary school children. Child Obes 2012;8:60-70. 
Chapter 3

142. Shadish WR. Meta-analysis and the exploration of causal mediating processes: a primer of examples, methods and issues. Psychol Methods 1996; 1:47-65. 


\section{Appendix 1}

\section{Search strategies}

\begin{tabular}{|c|c|}
\hline $\begin{array}{l}\text { A. PubMed } \\
\text { (preliminary search) Strategy }\end{array}$ & (\#1 OR \#2) AND \#3 AND \#4 AND \#5 \\
\hline \#1 & $\begin{array}{l}\text { obesity / prevention and control OR overweight/prevention and control OR } \\
\text { body mass index[tiab] OR waist circumference[tiab] OR overweight [tiab] OR } \\
\text { body composition[tiab] OR obesity[tiab] OR adiposity[tiab] }\end{array}$ \\
\hline \#2 & $\begin{array}{l}\text { diabetes OR glucose OR insulin OR blood pressure OR hypertension OR } \\
\text { cardiovascular OR metabolic syndrome OR risk factor clustering OR clustered } \\
\text { risk factors }\end{array}$ \\
\hline \#3 & school-based* OR school health services* \\
\hline $\begin{array}{l}\# 4 \\
\# 5 \\
\end{array}$ & $\begin{array}{l}\text { random * [tiab] OR randomized controlled trial } \\
\text { child* OR teenag* OR youth }\end{array}$ \\
\hline
\end{tabular}

B. EMBASE (adapted search strategy)

1. body mass index.mp,ti,ab.

2. waist circumference.mp, ti, ab.

3. overweight.mp,ti, ab.

4. obesity.mp, ti, ab.

5. body composition.mp,ti, ab.

6. adiposity.mp,ti, ab.

7. 1 or 2 or 3 or 4 or 5 or 6

8. diabetes.mp.

9. glucose.mp.

10. insulin.mp.

11. blood pressure.mp.

12. hypertension.mp.

13. cardiovascular.mp.

14. metabolic syndrome.mp.

15. risk factor clustering. $\mathrm{mp}$.

16. clustered risk factors. $\mathrm{mp}$.

17.8 or 9 or 10 or 11 or 12 or 13 or 14 or 15 or 16

18. 7 or 17

19. school-based\$.mp.

20. school health services $\$ . m p$.

21. 19 or 20

22. 18 and 21

23. random $\$ . t i, a b$.

24. randomized controlled trial.mp.

25. 23 or 24

26. 22 and 25

27. child\$.mp.

28. teenag \$.mp.

29. youth.mp.

30.27 or 28 or 29

31.26 and 30

32. 31 and "Journal: Article" [Publication Type] 
C. Cochrane Library (adapted search strategy)

1. body mass index:ti, ab, kw

2. waist circumference:ti, $a b, k w$

3. overweight:ti, ab, kw

4. obesity:ti, ab, kw

5. body composition:ti, ab, $\mathrm{kw}$

6. adiposity:ti, ab, kw

7. 1 or 2 or 3 or 4 or 5 or 6

8. diabetes

9. glucose

10. insulin

17. blood pressure

12. hypertension

13. cardiovascular

14. metabolic syndrome

15. risk factor clustering

16. clustered risk factors

17.8 or 9 or 10 or 11 or 12 or 13 or 14 or 15 or 16

18.7 or 17

19. school-based $\$$

20. School health services $\$$

21. 19 or 20

22. 18 and 21

23. random $\$: t i, a b, k w$

24. randomized controlled trial:pt

25. 23 or 24

26. 22 and 25

27. child\$

28. teenag $\$$

29. youth

30. 27 or 28 or 29

31.26 and 30

Limit to trial 


\section{Appendix 2}

Overview of the risk of bias assessments made to the individual studies included in the present meta-analysis

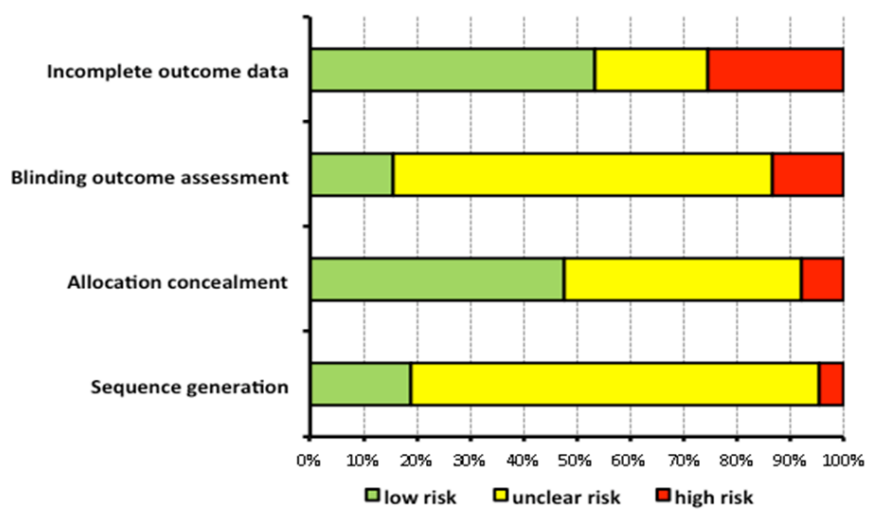

\begin{tabular}{|c|c|c|c|c|c|c|}
\hline Author & Year & $\begin{array}{l}\text { Sequence } \\
\text { generation }\end{array}$ & $\begin{array}{l}\text { Allocation } \\
\text { concealment }\end{array}$ & $\begin{array}{l}\text { Blinding } \\
\text { assessment }\end{array}$ & outcome & $\begin{array}{l}\text { Incomplete } \\
\text { outcome data }\end{array}$ \\
\hline Ahamed & 2007 & ? & $?$ & $?$ & & - \\
\hline Alexandrov & 1992 & $?$ & $?$ & $?$ & & + \\
\hline Amaro & 2006 & ? & + & ? & & + \\
\hline Angelopoulos & 2009 & + & + & ? & & - \\
\hline Annesi & 2013 & $?$ & $?$ & $?$ & & - \\
\hline Barbeau & 2007 & $?$ & - & ? & & + \\
\hline Brandstetter & 2012 & $?$ & + & ? & & + \\
\hline Burke & 1998 & ? & + & ? & & + \\
\hline Bush & 1989 & $?$ & + & $?$ & & - \\
\hline Caballero | Lohman & 2003 & $?$ & + & + & & + \\
\hline Carrel & 2005 & ? & + & ? & & + \\
\hline Chan & 2012 & + & + & + & & + \\
\hline Crespo & 2012 & $?$ & + & ? & & - \\
\hline de Coen & 2012 & $?$ & $?$ & $?$ & & + \\
\hline de Heer & 2011 & $?$ & $?$ & $?$ & & + \\
\hline Dennison & 2004 & + & + & $?$ & & $?$ \\
\hline Donnelly & 2009 & $?$ & $?$ & + & & - \\
\hline Duncan & 2009 & $?$ & $?$ & $?$ & & - \\
\hline Dzewaltowski & 2010 & + & + & - & & + \\
\hline Eather & 2013 & + & + & - & & + \\
\hline Eliakim & 2007 & $?$ & $?$ & $?$ & & + \\
\hline Fairclough & 2013 & + & - & $?$ & & $?$ \\
\hline Fitzgibbon & 2011 & $?$ & $?$ & - & & + \\
\hline Fitzgibbon & 2006 & $?$ & + & $?$ & & + \\
\hline Foster & 2008 & ? & $?$ & ? & & + \\
\hline Foster & 2010 & $?$ & $?$ & + & & + \\
\hline Gentile & 2009 & $?$ & + & $?$ & & - \\
\hline Graf & 2006 & $?$ & + & $?$ & & $?$ \\
\hline Graf & 2008 & $?$ & $?$ & $?$ & & - \\
\hline Grydeland & 2013 & $?$ & + & $?$ & & - \\
\hline Hansen & 1992 & $?$ & $?$ & $?$ & & $?$ \\
\hline Harrell & 1999 & $?$ & + & $?$ & & - \\
\hline Harrison & 2006 & $?$ & + & ? & & - \\
\hline
\end{tabular}




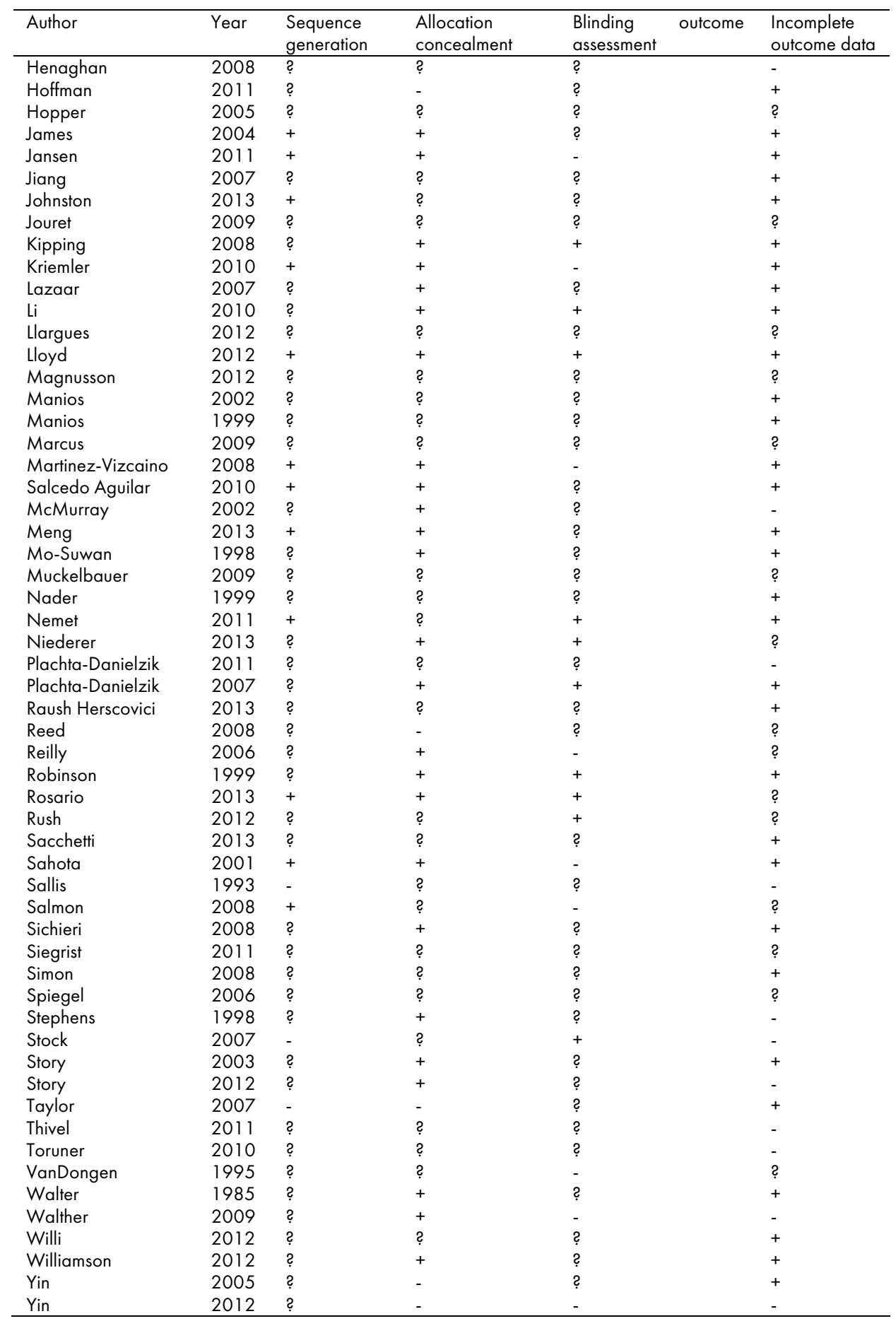




\section{Appendix 3}

Tracking (correlation) coefficients used for the calculation of the sampling variances of the standardized mean changes (equation 4 in main paper) in body mass index (BMI), and systolic (SBP) and diastolic blood pressure (DBP), taking into account the children's age and the length of time elapsed between baseline and follow-up measures.

\begin{tabular}{|l|r|r|c|c|}
\hline \multirow{3}{*}{ Age (years. } & Time (years) & $\mathrm{BMI}^{1}$ & $\mathrm{SBP}^{2}$ & $\mathrm{DBP}^{2}$ \\
\hline \multirow{3}{*}{$<10$} & 1 & 0.78 & & \\
& 2 & 0.76 & 0.31 \\
& 3 & 0.76 & 0.43 & \\
\hline \multirow{3}{*}{$\geq 10$} & 1 & 0.74 & & \multirow{2}{*}{0.31} \\
& 2 & 0.84 & & 0.43 \\
\hline
\end{tabular}

Notes: $\mathrm{BMI}=$ body mass index; $\mathrm{DBP}=$ diastolic blood pressure; $\mathrm{SBP}=$ systolic blood pressure. ${ }^{1}$ as retrieved from Bayer et al. ${ }^{8} ;{ }^{2}$ as retrieved from Chen \& Wang ${ }^{9}$; these coefficients were adjusted for age at baseline. 


\section{Appendix 4}

List of papers ( $n=24$, reporting on 9 unique RCTs that were considered in the meta-analysis) excluded due to redundancy in the data provided, referring to post-intervention cessation follow-up or outcomes other than body mass index and/or blood pressure. ${ }^{1-24}$

1 Carrel AL, Clark RR, Peterson S, Eickhoff J, Allen DB. School-based fitness changes are lost during the summer vacation. Arch Pediatr Adolesc Med 2007; 161:561-4.

2 Coleman KJ, Shordon M, Caparosa SL, Pomichowski ME, Dzewaltowski DA. The healthy options for nutrition environments in schools (Healthy ONES) group randomized trial: using implementation models to change nutrition policy and environments in low income schools. Int J Behav Nutr Phys Act 2012;9:80.

3 Cunha DB, de Souza Bda S, Pereira RA, Sichieri R. Effectiveness of a randomized school-based intervention involving families and teachers to prevent excessive weight gain among adolescents in Brazil. PLoS One 2013;8:e57498.

4 Fullerton G, Tyler C, Johnston CA, Vincent JP, Harris GE, Foreyt JP. Quality of life in Mexican-American children following a weight management program. Obesity (Silver Spring) 2007; 15 2553-6.

5 Gortmaker SL, Peterson K, Wiecha J, Sobol AM, Dixit S, Fox MK, et al. Reducing obesity via a school-based interdisciplinary intervention among youth: Planet Health. Arch Pediatr Adolesc Med 1999;153:409-18.

6 Greening L, Harrell KT, Low AK, Fielder CE. Efficacy of a school-based childhood obesity intervention program in a rural southern community: TEAM Mississippi Project. Obesity (Silver Spring) 201 1; 19:1213-9.

7 Harrell JS, Gansky SA, McMurray RG, Bangdiwala SI, Frauman AC, Bradley CB. School-based interventions improve heart health in children with multiple cardiovascular disease risk factors. Pediatrics 1998; 102:371-80.

8 Harrell JS, McMurray RG, Bangdiwala SI, Frauman AC, Gansky SA, Bradley CB. Effects of a school-based intervention to reduce cardiovascular disease risk factors in elementary-school children: the Cardiovascular Health in Children (CHIC) study. J Pediatr 1996; 128:797-805.

9 Jago R, McMurray RG, Drews KL, Moe EL, Murray T, Pham TH, et al. HEALTHY intervention: fitness, physical activity, and metabolic syndrome results. Med Sci Sports Exerc 201 1;43:1513-22.

10 James J, Thomas P, Kerr D. Preventing childhood obesity: two year follow-up results from the Christchurch obesity prevention programme in schools (CHOPPS). BMJ 2007;335:762.

11 Llargues E, Franco R, Recasens A, Nadal A, Vila M, Perez MJ, et al. Assessment of a school-based intervention in eating habits and physical activity in school children: the AVall study. J Epidemiol Community Health $2011 ; 65: 896-901$.

12 Luepker RV, Perry CL, McKinlay SM, Nader PR, Parcel GS, Stone EJ, et al. Outcomes of a field trial to improve children's dietary patterns and physical activity. The Child and Adolescent Trial for Cardiovascular Health. CATCH collaborative group. JAMA 1996;275:768-76.

13 Muckelbauer R, Libuda L, Clausen K, Toschke AM, Reinehr T, Kersting M. Promotion and provision of drinking water in schools for overweight prevention: randomized, controlled cluster trial. Pediatrics 2009; 123:e661-7.

14 Muckelbaver R, Libuda L, Clausen K, Toschke AM, Reinehr T, Kersting M. Immigrational background affects the effectiveness of a school-based overweight prevention program promoting water consumption. Obesity (Silver Spring) 2010; 18:528-34.

15 Nemet D, Geva D, Pantanowitz M, Igbaria N, Meckel Y, Eliakim A. Long term effects of a health promotion intervention in low socioeconomic Arab- Israeli kindergartens. BMC Pediatr 2013;13:45.

16 Perry CL, Sellers DE, Johnson C, Pedersen S, Bachman KJ, Parcel GS, et al. The Child and Adolescent Trial for Cardiovascular Health (CATCH): intervention, implementation, and feasibility for elementary schools in the United States. Health Educ Behav 1997;24:716-35. 
17 Rosario R, Oliveira B, Araujo A, Lopes O, Padrao P, Moreira A, et al. The impact of an intervention taught by trained teachers on childhood overweight. Int J Environ Res Public Health 2012;9:1355-67.

18 Telford RD, Cunningham RB, Telford RM, Daly RM, Olive LS, Abhayaratna WP. Physical education can improve insulin resistance: the LOOK randomized cluster trial. Med Sci Sports Exerc 2013;45:1956-64.

19 Trevino RP, Yin Z, Hernandez A, Hale DE, Garcia OA, Mobley C. Impact of the Bienestar school-based diabetes mellitus prevention program on fasting capillary glucose levels: a randomized controlled trial. Arch Pediatr Adolesc Med 2004; 158:91 1-7.

20 Warren JM, Henry CJ, Lightowler HJ, Bradshaw SM, Perwaiz S. Evaluation of a pilot school programme aimed at the prevention of obesity in children. Health Promot Int 2003; 18:287-96.

21 Webber LS, Osganian SK, Feldman HA, Wu M, McKenzie TL, Nichaman M, et al. Cardiovascular risk factors among children after a 2 1/2-year intervention-The CATCH Study. Prev Med 1996;25:432-41.

22 Wright K, Giger JN, Norris K, Suro Z. Impact of a nurse-directed, coordinated school health program to enhance physical activity behaviors and reduce body mass index among minority children: a parallel-group, randomized control trial. Int J Nurs Stud 2013;50:727-37.

23 Wright K, Norris K, Newman Giger J, Suro Z. Improving healthy dietary behaviors, nutrition knowledge, and self-efficacy among underserved school children with parent and community involvement. Child Obes 2012; 8:347-56.

24 Wyatt KM, Lloyd JJ, Creanor S, Logan S. The development, feasibility and acceptability of a school-based obesity prevention programme: results from three phases of piloting. BMJ Open 2011;1:e000026. 



\section{Chapter 4}

A systematic review on economic evaluations of schoolbased lifestyle interventions targeting weight-related behaviours among 4-12 year olds: Issues and ways forward

Marije Oosterhoff Hans Bosma Onno C.P. van Schayck

Silvia M.A.A. Evers

Carmen D. Dirksen Manuela A. Joore 


\section{Abstract}

Current guidelines for economic evaluations do not provide specific recommendations for the evaluation of school-based lifestyle interventions. This study examined and discussed the key aspects in the design of economic evaluations on school-based interventions targeting weight-related behaviours among 4-12 year olds. The PubMed and CRD databases (NHS EED) were searched. Grey literature was identified from reference lists and websites of relevant organizations. Full economic evaluations on school-based interventions targeting physical activity, sedentariness, or diet were selected. Key aspects included the objective, audience, intervention, comparator, population, type of analysis, perspective, costs, outcomes, and time horizon. Information was also extracted on measuring and valuing costs and outcomes, linking and extrapolating outcomes, and the maintenance of intervention effects. The 23 included studies reported on cost-effectiveness (CEAs) ( $N=12)$, cost-utility (CUAs) ( $N=9$ ), social cost benefit (SCBA) $(\mathrm{N}=2)$, and social return on investment (SROI) $(\mathrm{N}=1)$ analysis. The usual practice comparator was generally not clearly defined. The SROI analysis was the single study that included outcomes in other persons than the child. Healthcare costs $(N=14)$, productivity costs $(N=4)$, and costs to the household $(N=3)$, or education $(\mathrm{N}=2)$ sector were examined. The outcome in trial-based CEAs consisted of a variety of weight-related measures. Seven distinctive models were used to extrapolate health and/or productivity costs. To enhance the usefulness of economic evaluations on schoolbased lifestyle interventions in allocating public health budgets, transparent reporting on key aspects, broadening the scope of economic evaluations, and standardizing the measurement, valuation, and extrapolation of costs and outcomes should be improved. 


\section{Background}

Physical activity, dietary, and sedentary behaviours are important determinants of overweight and obesity, and play a critical role in children's physical, ${ }^{1,2}$ mental, ${ }^{3,4}$ and cognitive health. ${ }^{5}$ Numerous school-based interventions are being developed to prevent unhealthy weight-related behaviours and the negative consequences in childhood and in later life. ${ }^{6-11}$ However, limited financial resources are available for funding, so policymakers need to be able to select those interventions that offer value for money. Moreover, governments and local decision-makers are confronted with the question how much money should be allocated to prevention in youth which will come at the expense of other interventions. Economic evaluations are crucial for informing and supporting these decisionmaking processes.

Various guidelines have been developed to provide direction on the design of economic evaluations. For example, health economic guidelines provide recommendations on the various elements of an economic evaluation and the reporting of these aspects. ${ }^{12,13}$ Health economic guidelines are however focused on medical interventions in adult populations and are therefore not fully applicable for the economic evaluation of childhood lifestyle interventions. Another type of guidance are the guidelines on social cost-benefit analysis (SCBA). ${ }^{14-16}$ This type of analysis has originally been used by the public sector for studying environmental and infrastructural projects. So far, it remains unclear whether these guidelines are suitable for the evaluation of school-based lifestyle interventions. To design an economic evaluation, key aspects need to be defined, including the objective, audience, target population, and the intervention and comparator(s) that are being addressed. Other elements are the perspective, type of analysis, costs, outcomes, and time horizon of the economic evaluation. ${ }^{17,18}$ School-based lifestyle interventions are increasingly focused on the so-called whole-school approach, which is aimed at combining intervention components (e.g. education, policies, physical environment) and engaging with multiple stakeholders. ${ }^{10}$ It is likely that these interventions affect a wide range of costs and outcomes, including those that fall beyond health. Moreover, these costs and outcomes are accrued by different stakeholders or sectors. ${ }^{19-24}$ It can therefore be challenging to define the scope and the key aspects of an economic evaluation. Previous studies have found that the designs of economic evaluations on childhood interventions differ, particularly with regard to the perspective and the included cost categories. ${ }^{25}$ The design of an economic evaluation is also determined by the measurement and valuation of costs and outcomes, the methods for linking intermediate outcomes, and the extrapolation of outcomes and intervention effects beyond the range of data. This can be difficult due to a lack of evidence on the decay of intervention effects ${ }^{19}$ and the issues related to measuring childhood outcomes such as health-related quality of life 
(HR-QoL). ${ }^{20,24}$ The objective of this study is to examine the key aspects in the design of economic evaluations on school-based interventions targeting weight-related behaviours among 4-12 year olds, to discuss the main issues, and propose ways forward.

\section{Methods}

\section{Search strategy}

A systematic literature review was employed to review peer-reviewed and grey literature reporting on economic evaluations of school-based lifestyle interventions. The reporting of this systematic review is based on the PRISMA guidelines. ${ }^{26} \mathrm{~A}$ review protocol does not exist. Following the recommendations by Alton et al. (2006) for retrieving economic evaluations, electronic searches were completed in MEDLINE (via PubMed) and National Health Service Economic Evaluations Database (NHS EED). ${ }^{27}$ The databases were searched from inception up to March 2017 (MEDLINE). The NHS EED was updated until $31^{\text {st }}$ March 2015. Electronic searches were based on recommendations for preparing systematic literature reviews and developing search strategies. ${ }^{28,29}$ Search terms were related to school-aged children (population), health promotion and policy (intervention), and health economic evaluations (outcomes). Citation checking was carried out on the included studies, and hand searches were performed on the reference lists of included studies and previous reviews. ${ }^{19,20,25,30}$ Grey literature was searched by screening the reference lists, Google Scholar, and websites of the relevant organizations. Details of the search strings are provided in Table A 1 (Appendix 1).

\section{Study selection}

Two reviewers independently screened titles and abstracts ( $M O$ and MJ). If information about eligibility criteria could not fully be obtained from the abstract the full-text was screened. Disagreements about study inclusion were resolved by discussion between the reviewers. Studies were eligible based on the following criteria:

1. The study included the assessment of a school-based intervention. We defined a schoolbased intervention as an intervention that is, solely or in addition to other settings, situated in the school setting. Studies were also included when the intervention was situated in the after-school setting (e.g. community, after-school care, home clubs) and children were recruited from schools.

2. Participants were children between 4-12 years of age as this age range corresponds to the Dutch primary school setting. Studies were also eligible if the interventions targeted 4-12 year olds, and younger or older children simultaneously. 
3. The study was classified as a full economic evaluation, comparing two or more interventions in terms of both costs and effects. This included cost-effectiveness analyses (CEA), cost-utility analyses (CUA), cost-benefit analyses (CBA), and cost-minimization analyses (CMA), as well as societal cost-benefit analyses (SCBA) and societal return on investment analyses (SROI).

4. Interventions had to target lifestyle behaviours of children. In this review we focused on physical activity (PA), dietary and sedentary behaviours. Together, these lifestyle behaviours play an important role in the development of overweight and obesity among children.

\section{Data extraction}

Data extraction was conducted by one reviewer (MO) and independently checked by a second (MJ). A standardized template was developed to guide data extraction. General study characteristics (authors, year of publication, country of study) were extracted. Key aspects were examined by extracting information on the objective, audience, intervention, comparator(s), target population, type of analysis, perspective, costs, outcomes, and time horizon. ${ }^{18}$ Interventions were described by the intervention components, objectives, setting, and intervention duration. Studies were classified as a CEA, CUA, CBA, CMA, SCBA, SROI, or any combination. In line with Drummond et al. (2015), cost consequences were categorized as healthcare costs, cost in other sectors, patient and family costs, and productivity costs. ${ }^{17}$ Costs in other sectors included costs to the education sector, household and leisure sector (informal care, social care, leisure time and voluntary work), and criminal justice system. ${ }^{31}$ Outcomes were categorized into 1) outcomes on PA, diet, and sedentariness; 2) weight-related outcomes (anthropometrics); 3) other health-related outcomes; 4) outcomes beyond health; and 5) spillovers to other persons than the child. Furthermore, data was extracted on measuring and valuing costs and outcomes, linking outcomes, extrapolating outcomes over time, and the maintenance of intervention effects.

Because it is unclear whether the current guidelines for economic evaluations are fully applicable for school-based lifestyle interventions (see Introduction), we did not identify a 'quality standard'. For the identification of issues, we compared the key design aspects of the included studies to the recommendations that were given on these key aspects in both the Dutch health economic guideline, ${ }^{32}$ and in the guidelines for social cost-benefit analysis. ${ }^{14-16}$ 


\section{Key aspects}

The included studies assessed the cost-effectiveness of school-based lifestyle interventions aimed at obesity prevention $(\mathrm{N}=13 ; 57 \%)$, promoting PA or active transport $(\mathrm{N}=8 ; 35 \%)$, increasing fruit and vegetable intake $(\mathrm{N}=1 ; 4 \%)$, or embedding a good food culture in schools $(\mathrm{N}=1 ; 4 \%)$ (Table $\mathrm{A} 2$ and $\mathrm{A} .3$ ). The audience of the studies consisted of policy or decision makers $(\mathrm{N}=10 ; 43 \%)$, developers of new programs $(\mathrm{N}=1,4 \%)$, and the other half of the studies did not specify the audience that was to be informed (Table A2).

Single $(N=18 ; 78 \%)$ or multiple $(N=5 ; 22 \%)$ school-based lifestyle interventions were compared to usual practice or no intervention, but the standard practices in the comparators were generally not clearly defined (Table A3). The population in the studies had an average age of nine years. In one study, the population consisted of multiple stakeholders (Table A4). Nine studies were trial-based and the remaining fourteen were model-based studies. Eight of the nine trial-based studies were CEAs and one was a SROI analysis. One trial-based study combined a CEA with a CBA. The fourteen model-based studies reported on CUAs $(N=9 ; 64 \%)$, CEAs $(N=3 ; 21 \%)$, and SCBAs $(N=2 ; 14 \%)$. Five of the nine model-based CUAs were combined with a CEA or a CBA. Trial-based studies labelled the perspective as a societal perspective $(N=6,67 \%)$, programs perspective $(N=1,11 \%)$, or did not specify the perspective ( $\mathrm{N}=2 ; 22 \%)$. Model-based studies reported to use a societal perspective $(\mathrm{N}=9 ; 64 \%)$, a 'modified societal perspective' $(\mathrm{N}=2 ; 14 \%)$, or a healthcare perspective $(\mathrm{N}=3 ; 21 \%)$ (Table A4). The trial-based studies had a time horizon of one ( $\mathrm{N}=7 ; 78 \%)$, three $(\mathrm{N}=1 ; 11 \%)$, or four years $(\mathrm{N}=1 ; 11 \%)$, and the model-based studies used a 10 -year $(\mathrm{N}=3 ; 21 \%)$, till age $65(\mathrm{~N}=1 ; 7 \%)$, or a lifetime horizon $(\mathrm{N}=10 ; 71 \%)$. In all studies, the intervention costs included the recurring costs of intervention delivery and in a minority of studies the costs of intervention development $(N=5 ; 22 \%)$, or evaluation $(N=7 ; 30 \%)$ were added. Next to the intervention costs, one trial-based CEA included the costs of after-school care in the household sector. The SROI analysis also examined the productivity costs due to local employment, education costs, and costs in the household and leisure sector (Table A5). Model-based studies included the healthcare costs of obesity or related diseases in childhood $(\mathrm{N}=3 ; 21 \%)$, in adulthood $(\mathrm{N}=10 ; 71 \%)$, or in both childhood and adulthood $(\mathrm{N}=1 ; 7 \%)$. Four model-based studies additionally included the costs of after-school care to the household and leisure sector, education costs, or future productivity costs related to test scores or obesity. The outcomes in the trial-based CEAs were a variety of weight-related measures, while the model-based CEAs all used body mass index (BMI) as outcome (Table A6). The CUAs reported on the quality-adjusted life years ( $Q A L Y S)(N=4)$ or disabilityadjusted life years (DALYs) (N=5) in adulthood. In the SROI and SCBAs, outcomes (e.g. health, education, productivity-related outcomes, outcomes to the household and leisure 
sector, environmental impacts and externalities) were monetized and therefore included as costs.

If included, the healthcare costs and after-school care costs in childhood, and the future healthcare costs and productivity costs in adulthood were based on national survey data or retrieved from the literature. In the SROI study, the impact on productivity costs, education costs, and household costs were measured with stakeholder interviews and monetized using various financial proxies (Table A5). The two SCBA studies used models to estimate productivity and education costs from test scores or obesity-related employment rates. In trial-based studies PA, dietary, and weight-related outcomes were measured with objective measurements $(N=6,67 \%)$, derived from literature reviews $(N=2,22 \%)$, or based on stakeholder interviews $(\mathrm{N}=1,11 \%)$. The model-based studies used data from objective measurements of the corresponding trial $(N=5,36 \%)$, literature reviews $(N=7,50 \%)$, and surveys $(N=2,14 \%)$ to measure PA, diet, and weight-related outcomes. Nine CUAs obtained the preference-based HR-QoL inputs for adults from various published sources and instruments (national disability weights, Health Utility Index, EuroQol-5D, Nation Health Interview Survey data). One study measured and valued childhood HR-QoL with the parentversion of the Health Utility Index and valuations from the general public, but the results were not used to calculate cost-utility. Five of the fourteen model-based studies linked PA related outcomes to changes in BMI. Four studies first linked PA and/or energy intake to the excess energy expenditure, and then to the changes in BMI by using energy expenditure models. ${ }^{57,58}$ In one study, the minutes in moderate to vigorous physical activity were directly linked to the changes in BMI with a regression model (Table A6). Seven distinctive methods were used in the model-based studies to extrapolate risk factors, being BMI, weight status, or fruit and vegetable intake, over the range of the data (Table A7 and Box A1). These risk factors were consequently linked to the incidence of chronic diseases, morbidity (QALYs or DALYs), mortality, and healthcare costs. Two models also estimated the future productivity costs. The two models that extrapolated BMI over the remaining lifetime were comparable in terms of the chronic diseases in the model and the age (20 to 25 years of age) at which relative risks started to increase (Box S1). The SROI analysis and five out of the fourteen model-based studies (36\%) assumed a decay of intervention effects, varying from $1 \%$ decay starting at year five in the base-case analysis to a $75 \%$ decay in sensitivity analysis. All other studies assumed the intervention effect to be fully maintained for the time horizon of the study. An overview of the current practices is presented in Table 1.

\section{Main issues}

The limitations in the transparency of reporting was most striking for the audience, comparators, and the perspective of the study. Several studies did not report on the audience that was to be informed, and did not define the standard practices in the usual 
comparator arm. Besides the societal and healthcare perspective, the perspective was sometimes labelled as a programs perspective or modified societal perspective. It remained unclear what was meant by these perspectives.

The results also showed that the scope of studies varied considerably. The SCBAs and SROI included costs and outcomes beyond health (e.g. educational outcomes, wellbeing, labour market earnings) and costs and outcomes in other persons than the child (e.g. caregivers, school teaching staff, local suppliers), whereas these were often ignored in CUAs and CEAs (even if they mentioned the use of a societal perspective).

Healthcare costs were restricted to childhood or adulthood, and CUAs were only focused on QALYs/DALYs in adulthood. The time horizon of model-based studies ranged from 10 years to lifetime. The model-based studies that did not use a lifetime horizon might not have captured all relevant differences in costs and outcomes over time.

Last, different methods were used to measure, value and extrapolate cost and outcomes. The outcome in trial-based CEAs consisted of a variety of weight-related measures, which provided incomparable results. The SROI applied various financial proxies to monetize nonhealth outcomes, whereas the SCBAs made use of models for estimating the productivity and education costs associated with test scores. Several different models were used for extrapolating the impact on future health-related costs and outcomes, but few included the potential decay of intervention effects.

Table 1 Current practices on key aspects.

\begin{tabular}{|c|c|c|c|}
\hline \multicolumn{2}{|c|}{ Key aspects } & Current practices & $\mathrm{N}=23$ \\
\hline \multicolumn{2}{|l|}{ Objective } & $\begin{array}{l}\text { Asses the cost-effectiveness of school-based interventions targeted at } \\
\text { obesity prevention, PA, or nutrition. }\end{array}$ & 23 \\
\hline \multirow{3}{*}{\multicolumn{2}{|c|}{ Audience }} & Not specified & 12 \\
\hline & & Policy makers or decision makers & 10 \\
\hline & & Developers of new programs & 1 \\
\hline \multirow{3}{*}{\multicolumn{2}{|c|}{ Intervention }} & Obesity prevention & 13 \\
\hline & & PA or active transport & 8 \\
\hline & & Nutrition & 2 \\
\hline \multirow{2}{*}{\multicolumn{2}{|c|}{ Comparators }} & Single interventions versus usual practice / no intervention & 18 \\
\hline & & Multiple interventions versus usual practice / no intervention & 5 \\
\hline \multirow{2}{*}{\multicolumn{2}{|c|}{ Target population }} & Child & 22 \\
\hline & & Multiple stakeholders & 1 \\
\hline \multirow{5}{*}{$\begin{array}{l}\text { Type of } \\
\text { analysis }\end{array}$} & Trial-based & CEA & 8 \\
\hline & & SROI & 1 \\
\hline & Model- & CUA & 9 \\
\hline & based & CEA & 3 \\
\hline & & SCBA & 2 \\
\hline
\end{tabular}


Table 1. [continued]

\begin{tabular}{|c|c|c|c|}
\hline \multicolumn{2}{|l|}{ Key aspects } & Current practices & $\mathrm{N}=23$ \\
\hline \multirow[t]{6}{*}{ Perspective } & Trial-based & Societal perspective & 6 \\
\hline & & Not specified & 2 \\
\hline & & Programs perspective & 1 \\
\hline & Model- & Societal perspective & 9 \\
\hline & based & Healthcare perspective & 3 \\
\hline & & "Modified societal perspective" & 2 \\
\hline \multirow[t]{15}{*}{ Costs $^{A}$} & Trial-based । & Intervention costs & 9 \\
\hline & & Healthcare costs & 0 \\
\hline & & Patient \& family costs & 0 \\
\hline & & Productivity costs & 1 \\
\hline & & Intersectoral costs & \\
\hline & & Costs to the household & 2 \\
\hline & & Education costs & 1 \\
\hline & & Other & 1 \\
\hline & Model- & Intervention costs & 14 \\
\hline & based & Healthcare costs & 14 \\
\hline & & Patient \& family costs & 0 \\
\hline & & Productivity costs & 3 \\
\hline & & Intersectoral costs & \\
\hline & & Costs to the household & 1 \\
\hline & & Education costs & 1 \\
\hline \multirow[t]{7}{*}{ Outcomes $^{a}$} & Trial-based & Weight-related measures (CEAs) & 8 \\
\hline & & Outcomes beyond health (school behaviour, wellbeing) (SROI) & 1 \\
\hline & & $\begin{array}{l}\text { Spillovers to others than the child (school staff, local community, carers) } \\
\text { (SROI) }\end{array}$ & 1 \\
\hline & Model- & Adulthood DALYs (CUAs) & 5 \\
\hline & based & Adulthood QALYs (CUAs) & 4 \\
\hline & & BMI (CEAs) & 3 \\
\hline & & Monetization of outcomes (obesity, test-scores) (SCBAs) & 2 \\
\hline \multirow[t]{6}{*}{ Time horizon } & Trial-based & One year & 7 \\
\hline & & Three years & 1 \\
\hline & & Four years & 1 \\
\hline & Model- & Lifetime & 10 \\
\hline & based & Ten year time horizon & 3 \\
\hline & & Till age 65 & 1 \\
\hline \multirow{3}{*}{\multicolumn{2}{|c|}{ Measuring and valuing costs ${ }^{b}$}} & National survey data or literature & 20 \\
\hline & & $\begin{array}{l}\text { Monetizing outcomes with extrapolation models (e.g. labour market } \\
\text { earnings associated with test scores) }\end{array}$ & 2 \\
\hline & & Monetizing outcomes with financial proxies & 1 \\
\hline \multirow{6}{*}{$\begin{array}{l}\text { Measuring and } \\
\text { valuing } \\
\text { outcomes }^{c}\end{array}$} & Trial-based & Objective measurements & 6 \\
\hline & & Literature review & 2 \\
\hline & & Stakeholder interviews & 1 \\
\hline & Model- & Literature review & 7 \\
\hline & based & Objective measurements from the corresponding trial & 5 \\
\hline & & Surveys & 2 \\
\hline
\end{tabular}


Table 1. [continued]

\begin{tabular}{|c|c|c|}
\hline Key aspects & Current practices & $\mathrm{N}=23$ \\
\hline \multirow[t]{3}{*}{ Linking outcomes } & No linking & 18 \\
\hline & Linking PA to BMI with energy expenditure models & 4 \\
\hline & Linking MVPA minutes to $\mathrm{BMI}$ using regression models & 1 \\
\hline \multirow[t]{6}{*}{ Extrapolating outcomes } & No extrapolation & 9 \\
\hline & Assessing Cost-effectiveness (ACE) model & 4 \\
\hline & $\begin{array}{l}\text { Childhood Obesity Intervention Cost-Effectiveness Study (CHOICES) } \\
\text { model }\end{array}$ & 3 \\
\hline & Chronic Disease Model (CDM), New Zealand approach & 2 \\
\hline & Washington State Institute for Public Policy (WSIPP) benefit-cost model & 2 \\
\hline & Other & 3 \\
\hline \multirow{2}{*}{$\begin{array}{l}\text { Maintenance of Trial-based } \\
\text { intervention }\end{array}$} & Modeling the decay of intervention effects & 1 \\
\hline & No decay of intervention effects & 8 \\
\hline \multirow[t]{2}{*}{ effects } & Modeling the decay of intervention effects & 5 \\
\hline & No decay of intervention effects & 9 \\
\hline
\end{tabular}

Notes: $\mathrm{BMI}=$ body mass index; $\mathrm{CEA}=$ cost-effectiveness analysis; $\mathrm{CUA}=$ cost-utility analysis; $\mathrm{DALY}=$ disabilityadjusted life year; MVPA = moderate to vigorous physical activity; $P A=$ physical activity; $Q A L Y=$ quality-adjusted life year; SCBA = social cost-benefit analysis; SROI = social return on investment. ${ }^{a}$ Types of costs and outcomes that were included in the economic evaluations; ${ }^{b}$ Healthcare, patient \& family, productivity, and intersectoral costs; ${ }^{c}$ PA, diet, and weight-related outcomes.

\section{Discussion}

The aim of this review was to examine the key aspects in the design of economic evaluations on school-based interventions targeting weight-related behaviours among 4-12 year olds, and to discuss the main issues. With regard to the design aspects, the main issues pertained to the transparent reporting on key aspects (e.g. audience, standard practices in the usual comparator arms, labelling of the study perspective), the variation in the scope of the studies (e.g. costs and outcomes beyond health, outcomes in other persons than the child, costs and outcomes in childhood or adulthood), and the heterogeneity in the measurement, valuation, and extrapolation of costs and outcomes (e.g. little standardization in monetizing outcomes and handling the decay of intervention effects).

\section{Ways forwards}

With regard to reporting, more information should be provided on the audience (e.g. stakeholder views and relevance for stakeholders) and the comparators of the study to examine the appropriateness of the selected approaches and the generalizability of the results. Labels that are not commonly used in health economic evaluations, such as a programs perspective or 'modified societal perspective' should be avoided. 
Specific guidance concerning the scope of economic evaluations is warrant in order to broaden the focus of studies ${ }^{20,21,25,59}$ and best inform public health decision making. The adoption of a societal perspective is advised, which is also recommended by several health economic guidelines, because it supports the inclusion of all differences in costs and outcomes. $^{60}$ Reasons for in- or excluding costs and outcomes should be mentioned as ignoring them may result in an inefficient allocation of resources. ${ }^{20} \mathrm{~A}$ smaller perspective is appropriate if it corresponds to the requirements of the decision maker but we suggest that this is then justified. For trial-based studies we suggest to perform a cost-consequence analysis (CCA) or social return on investment analysis (SROI). In a CCA all relevant costs and outcomes are presented in a disaggregated way, and it is stated which costs and outcomes could not be quantified. ${ }^{61}$ In this way, trial-based studies serve as a data collection vehicle for secondary research (e.g. reviews, meta-analyses, decision models) and it allows model-based studies to make comprehensive assessments on the intervention (long-term) cost-effectiveness. A SCBA is recommended for model-based studies because outcomes beyond health can be integrated in the evaluation, and results can be compared across studies, populations, and settings. ${ }^{62}$ A core outcome set would be helpful to identify potential costs and outcomes, and the double counting (e.g. include impacts in terms of both costs and effects). For model-based evaluations a lifetime horizon seems to be most appropriate because many health gains do not occur in childhood but appear later in life. ${ }^{63}$ Full cost-effectiveness is thus only captured by examining the entire lifetime. Because gains accumulate over time, the costs and outcomes in both childhood and adulthood should be included.

To enhance the comparability of cost-effectiveness results the methods for measuring, valuing, and extrapolating costs and outcomes should become more standardized. A core outcome set that provides guidance on how to measure and value outcomes would be helpful. In addition to the changes in behavioural outcomes, we advise to use at least BMI and/or BMI Z-score as weight-related outcomes in trial-based studies. BMI and BMI Zscore are considered as more final outcome measures of interventions that are directed at weight-related behaviours. BMI and BMI z-score are also most suitable for use in health economic models to extrapolate trial findings and assess the intervention's long-term costeffectiveness. Researchers should be aware that the distribution of outcomes may be highly relevant to decision-makers in order to examine whether health disparities (e.g. by socioeconomic status or ethnicity) can be reduced. The measurement of childhood costs and outcomes such as preference-based HR-QoL is an important issue for future research. ${ }^{24}$ The Washington State Institute for Public Policy (WSIPP) cost-benefit model is the most extensive model for extrapolating outcomes, because it allows for estimating the future benefits of both health outcomes and outcomes beyond health (e.g. extrapolating test scores to productivity). 
The model should be adapted with national inputs if it is used for a different setting. ${ }^{64}$ Until evidence on the maintenance of intervention effects becomes available, we recommend to perform a sensitivity analysis for various decay rates. This is important as the assumptions on the maintenance of intervention effects have a major impact on the cost-effectiveness results. $^{33}$

It should also be noted that the main issues that were found in this study and the recommendations that were proposed also apply to interventions other than school-based lifestyle interventions. This is due to the fact that the challenges in evaluating school-based lifestyle interventions have to do with the difficulties in evaluating childhood interventions (e.g. measuring outcomes in children, extrapolating outcomes beyond the duration of the trial) and the evaluation of preventive lifestyle interventions which are often located in the public domain (e.g. identifying costs and outcomes that go beyond health and occur in persons other than the child).

\section{Limitations}

Although Alton et al. (2006) concluded that a search in the PubMed and NHS EED databases is appropriate to capture economic evaluations, some studies may have been missed. ${ }^{27}$ However, our search strategy was intentionally broad, we searched for schoolbased interventions by using the terms 'intervention' and 'health promotion' instead of more specific key words. Therefore, we are confident that the studies included are a good representation of economic evaluations in this field.

\section{Conclusion}

To enhance the usefulness of economic evaluations on school-based lifestyle interventions in allocating public health budgets, the reporting on key aspects should be improved, the scope of evaluations on childhood lifestyle interventions should be extended, and the standardization of methodologies should become a key area for further research. A core outcome set on the measurement and valuation of costs and outcomes, broad data collection vehicles such as CCA and SROI analysis, and lifetime model-based studies exploring the impact of the decay of intervention effects are therefore strongly recommended. To further standardise the design of economic evaluations in school-based lifestyle interventions our recommendations should be corroborated by multiple stakeholders. 


\section{References}

1. Eisenmann JC. Aerobic fitness, fatness and the metabolic syndrome in children and adolescents. Acta Pediatr. 2007;96(12):1723-9.

2. Wilkie HJ, Standage M, Gillison FB, Cumming SP, Katzmarzyk PT. Multiple lifestyle behaviours and overweight and obesity among children aged 9-11 years: results from the UK site of the International Study of Childhood Obesity, Lifestyle and the Environment. BMJ Open. 2016;6.

3. Biddle SJ, Asare M. Physical activity and mental health in children and adolescents: a review of reviews. $\mathrm{Br} \mathrm{J}$ Sports Med. 2011 ; 45(11):886-95.

4. Chen G, Ratcliffe J, Olds T, Magarey A, Jones M, Leslie E. BMI, health behaviors, and quality of life in children and adolescents: a school-based study. Pediatrics. 2014;33(4): 868-74.

5. Fedewa AL, Ahn S. The effects of physical activity and physical fitness on children's achievement and cognitive outcomes: a meta-analysis. Res $Q$ Exerc Sport. 2011;82(3):521-35.

6. Craigie AM, Lake AA, Kelly SA, Adamson AJ, Mathers JC. Tracking of obesity-related behaviours from childhood to adulthood: A systematic review. Maturitas. $2011 ; 70(3): 266-84$.

7. Deshmukh-Taskar P, Nicklas TA, Morales M, Yang SJ, Zakeri I, Berenson GS. Tracking of overweight status from childhood to young adulthood: the Bogalusa Heart Study. Eur J Clin Nutr. 2006;60(1) (2006):48-57.

8. Lim SS, Vos T, Flaxman AD, Danaei DG, Shibuya K, Adair-Rohani H, et al. A comparative risk assessment of burden of disease and injury attributable to 67 risk factors and risk factor clusters in 21 regions, 1990-2010: a systematic analysis for the Global Burden of Disease Study 2010. Lancet. 2012; 380(9859): 2224-60.

9. De Bourdeaudhuii I, Van Cauwenberghe E, Spittaels H, Oppert JM, Rostami C, Brug J, et al. School-based interventions promoting both physical activity and healthy eating in Europe: a systematic review within the HOPE project. Obes rev. $2011 ; 12(3): 205-16$

10. Langford R, Bonell CP, Jones HE, Campbell R. The WHO Health Promoting School framework for improving the health and well-being of students and their academic achievement. Cochrane Db Syst Rev. 2014;4:15.

11. Sobol-Goldberg S, Rabinowitz J, Gross R. School-based obesity prevention programs: A meta-analysis of randomized controlled trials. Obesity. 2013; $21(12): 2422-8$.

12. International Society for Pharmacoeconomics and Outcomes Research. Pharmacoeconomic guidelines around the world. [Available from: http://www.ispor.org/PEguidelines/index.asp]. Accessed September 21,2016

13. Husereau D, Drummond M, Petrou S, Carswell C, Moher D, Greenberg D, et al. Consolidated health economic evaluation reporting standards (CHEERS)-explanation and elaboration: a report of the ISPOR health economic evaluation publication guidelines good reporting practices task force. Value Health. 2013; 16(2):231-50.

14. Posner E, Adler M. New Foundations of Cost-Benefit Analysis. Harvard University Press (2006).

15. HM Treasury. The Green Book: Appraisal and evaluation in central government. 2003. London, UK: The Stationery Office.

16. Koopmans C, Heyma A, Hof B, Imandt M, Kok L, Pomp M. Manual for cost-benefit analysis in the social domain [Werkwijzer voor kosten-batenanalyse in het sociale domein]. 2016. Amsterdam: SEO Economisch Onderzoek, ISBN 978-90-6733-805-9.

17. Drummond M, Sculpher M, Torrance GW, O'Brien BJ, Stoddart GL. Methods for the economic evaluation of health care programme. 2015. Fourth edition ed. New York: Oxford University Press.

18. Fox-Rushby J, Cairns J. Economic Evaluation. 2005. London: Open University Press, pp. 19-31.

19. Flego A, Keating C, Moodie M. Cost-effectiveness of whole-of-community obesity prevention programs: An overview of the evidence. Expert Rev Pharmacoecon Outcomes Res. 2014;14(5):719-27.

20. Frew E. Economic Evaluation of Childhood Obesity Interventions: Reflections and Suggestions. PharmacoEconomics. 2016;34(8):733-40.

21. Weatherly H, Drummond M, Claxton K, Cookson R, Ferguson B, Godfrey C, et al. Methods for assessing the cost-effectiveness of public health interventions: key challenges and recommendations. Health Policy. 2009;93(2-3):85-92.

22. Wolfenstetter SB. Conceptual Framework for Standard Economic Evaluation of Physical Activity Programs in Primary Prevention. Prev Sci. 201 1; 12(4):435-51. 
23. de Salazar L, Jackson S, Shiell A, Rice M. Guide to economic evaluation in health promotion. 2007. Washington: Pan American Health Organization, ISBN 9789275128329.

24. Dirksen CD, Evers SMAA. Broad consultation as part of the standardization of economic evaluation research in the youth sector. 2016. Maastricht University Medical Center. Trimbos Institute, Netherlands Institute of Mental Health and Addiction, Centre for Economic Evaluations. ISBN 978-94-6228-772-3

25. Döring N, Mayer S, Rasmussen F, Sonntag D. Economic Evaluation of Obesity Prevention in Early Childhood: Methods, Limitations and Recommendations. Int J Environ Res Public Health. 2016;13(9).

26. Moher D, Shamseer L, Clarke M, Ghersi D, Liberati A, Petticrew M, et al. Preferred reporting items for systematic review and meta-analysis protocols (PRISMA-P) 2015 statement. Syst Rev. 2015;4(1).

27. Alton V, Eckerlund I, Norlund A. Health economic evaluations: how to find them. Int J Technol Assess Health Care. 2006;22(4):512-7.

28. van Mastrigt GA, Hiligsmann M, Arts JJ, et al. How to prepare a systematic review of economic evaluations for informing evidence-based healthcare decisions: a five-step approach (part 1/3). Expert Rev Pharmacoecon Outcomes Res. 2016;16(6):689-704.

29. Schardt C, Adams MB, Owens T, Keitz S, Fontelo P. Utilization of the PICO framework to improve searching PubMed for clinical questions. BMC Med Inform Decis Mak. 2007; 15:7-16.

30. Schwander B, Hiligsmann M, Nuijten M, Evers S. Systematic review and overview of health economic evaluation models in obesity prevention and therapy. Expert Rev Pharmacoecon Outcomes Res. 2016;16(5): 561-70

31. Drost RM, Paulus AT, Ruwaard D, Evers SM. Inter-sectoral costs and benefits of mental health prevention: towards a new classification scheme. J Ment Health Policy Econ. 2013;16(4):179-86.

32. Zorginstituut Nederland. Richtlijn voor het vitvoeren van economische evaluaties in de gezondheidszorg [Guideline for conducting health economic evaluations]. 2015. [Accessed 23th April 2018].

33. Haby MM, Vos T, Carter R, Moodie M, Markwick A, Magnus A, et al. A new approach to assessing the health benefit from obesity interventions in children and adolescents: the assessing cost-effectiveness in obesity project. Int J Obes. 2006;30(10):1463-75.

34. Moodie M, Haby M, Galvin L, Swinburn B, Carter R. Cost-effectiveness of active transport for primary school children - Walking School Bus program. Int J Behav Nutr Phys Act. 2009; 14 (6):63.

35. Moodie M, Haby MM, Swinburn B, Carter R. Assessing cost-effectiveness in obesity: active transport program for primary school children--TravelSMART Schools Curriculum program. J Phys Act Health. $2011 ; 8(4): 503-15$.

36. Moodie ML, Carter RC, Swinburn BA, Haby MM. The cost-effectiveness of Australia's Active After-School Communities program. Obesity. 2010;18(8): 1585-92.

37. Moodie ML, Herbert JK. de Silva-Sanigorski AM, Mavoa HM, Keating CL, Carter RC, et al. The costeffectiveness of a successful community-based obesity prevention program: the be active eat well program. Obesity. 2013;21(10):2072-80.

38. Wu S, Cohen D, Shi Y, Pearson M, Sturm R. Economic analysis of physical activity interventions. Am J Prev Med. $2011 ; 40(2): 149-158$.

39. Mernagh P, Paech D, Weston A. Cost effectiveness report of public health interventions to prevent obesity. Report prepared for the Health Council of New Zealand. 2010. Sydney: Health Technology Analysts Pty Ltd.

40. Jones M, Pitt H, Oxford L, Orme J, Gray S, Salmon D, et al. Food for Life: a social return on investment analysis of the locally commissioned programme. 2016. UWE Bristol.

41. Washington State Institute for Public Policy (WSIPP). School-based programs to increase physical activity. 2017a. Available from: http://www.wsipp.wa.gov/BenefitCost [Accessed 15th May 2017].

42. Washington State Institute for Public Policy (WSIPP). School-based obesity prevention education. $2017 \mathrm{~b}$. Available from: http://www.wsipp.wa.gov/BenefitCost [Accessed 15th May 2017].

43. Babey SH, Wu S, Cohen D. How can schools help youth increase physical activity? An economic analysis comparing school-based programs. Prev Med. 2014;69:S55-S60.

44. Barrett JL, Gortmaker SL, Long MW, et al. Cost Effectiveness of an Elementary School Active Physical Education Policy. Am J Prev Med. 2015;49(1):148-59.

45. Brown HS, Perez A, Li YP, Hoelscher DM, Kelder SH, Rivera R. The cost-effectiveness of a school-based overweight program. Int J Behav Nutr Phys Act. 2007; 1 (4):47. 
46. Cradock AL, Barrett JL, Kenney EL, Giles CM, Ward ZJ, Long MW, et al. Using cost-effectiveness analysis to prioritize policy and programmatic approaches to physical activity promotion and obesity prevention in childhood. Prev Med. 2017;95:S17-S27.

47. Gortmaker SL, Wang YC, Long MW, Giles CG, Ward ZJ, Barrett JL, et al. Three Interventions That Reduce Childhood Obesity Are Projected To Save More Than They Cost To Implement. Health Aff. 2015;34(11):1932-9.

48. Graziose MM, Koch PA, Wang YC, Lee H, Gray L, Contento IR. Cost-effectiveness of a Nutrition Education Curriculum Intervention in Elementary Schools. J Nutr Educ Behav. 2017;49(8):684-691.

49. Kesztyus D, Schreiber A, Wirt T, Wiedom M, Dreyhaupt J, Brandstetter S, et al. Economic evaluation of URMEL-ICE, a school-based overweight prevention programme comprising metabolism, exercise and lifestyle intervention in children. Eur J Health Econ. 2013;14(2):185-95.

50. Kesztyus D, Lauer R, Kesztyus T, Kilian R, Steinacker JM. Costs and effects of a state-wide health promotion program in primary schools in Germany - the Baden-Wurttemberg Study: A cluster-randomized, controlled trial. PLoS One. 2017;12(2).

51. McAuley KA, Taylor RW, Farmer VL, Hansen P, Williams SM, Booker CS, et al. Economic evaluation of a community-based obesity prevention program in children: the APPLE project. Obesity. 2010;18(1):131-6.

52. Meng L, Xu H, Liu A, van Raaij J, Bemelmans W, Hu X, et al. The costs and cost-effectiveness of a schoolbased comprehensive intervention study on childhood obesity in China. PloS One. 2013;8(10):(2013).

53. Rush E, Obolonkin V, McLennan S, Graham D, Harris JD, Mernagh P, et al. Lifetime cost effectiveness of a through-school nutrition and physical programme: Project Energize. Obes Res Clin Pract. 2014;8(2).

54. te Velde SJ, Veerman JL, Tak NI, Bosmans JE, Klepp KI, Brug J. Modeling the long term health outcomes and cost-effectiveness of two interventions promoting fruit and vegetable intake among schoolchildren. Econ Hum Biol. $2011 ; 9(1): 14-22$.

55. Wang LY, Gutin B, Barbeau P, Moore JB, Hanes J, Johnson MH, et al. Cost-effectiveness of a school-based obesity prevention program. J Sch Health. 2008;78(12):619-24.

56. Wang H, Li T, Siapush M, Chen LW, Huberty J. Cost-effectiveness of Ready for Recess to Promote Physical Activity in Children. J Sch Health. 2017;87(4):278-285.

57. Swinburn BA, Jolley D, Kremer PJ, Salbe AD, Ravussin E. Estimating the effects of energy imbalance on changes in body weight in children. Am J Clin Nutr. 2006;83(4):859-63.

58. Hall KD, Butte NF, Swinburn BA, Chow CC. Dynamics of childhood growth and obesity: development and validation of a quantitative mathematical model. Lancet Diabetes Endocrinol. 2013;1(2):97-105.

59. Edwards RT, Charles JM, Lloyd-Williams H. Public health economics: a systematic review of guidance for the economic evaluation of public health interventions and discussion of key methodological issues. BMC Public Health. 2013;13:1001.

60. Jönsson B. Ten arguments for a societal perspective in the economic evaluation of medical innovations. Eur J Health Econ. 2009; 10(4):357-9.

61. Trueman P, Anokye NK. Applying economic evaluation to public health interventions: the case of interventions to promote physical activity. J Public Health. 2013;35(1):32-39.

62. McBrien KA, Manns B. Approach to economic evaluation in primary care: Review of a useful tool for primary care reform. Canadian Family Physician. 2013;59(6):619-27.

63. Lehnert T, Sonntag D, Konnopka A, Riedel-Heller S, König HH. The long-term cost-effectiveness of obesity prevention interventions: systematic literature review. Obes Rev. 2012;13(6):537-553.

64. Washington State Institute for Public Policy (WSIPP). Benefit-cost technical documentation. 2017c. [Available from: http://www.wsipp.wa.gov/BenefitCost]. Accessed 20th May 2017. 


\section{Appendix 1}

\section{Details on modelling approaches}

1 Extrapolating BMI over ten years with the Childhood Obesity Intervention CostEffectiveness Study (CHOICES) model or adapted CHOICES-model for the US population (Babey et al., 2014; Cradock et al., 2017; Gortmaker et al., 2015a). The CHOICES model was populated with height and weight data of adults, and parent-reported height and weight data of children and adolescents (Gortmaker et al., 2015a). In this model, cohort effects were calculated to reflect BMI levels between 2010 and 2030. Height and weight trajectories were calculated from multiple longitudinal cohort studies and were combined to model lifetime trajectories (Gortmaker et al., 2015a, 2015b). Individuals were classified by obesity status (non-obese or obese). It was assumed that diseases and their consequences on HR-QoL did not occur over the ten-year time period. The healthcare costs of obesity in childhood were included.

2 Extrapolating obesity to 40 years of age with a lifetime obesity progression model for the US population (Brown et al., 2007). Weight status was extrapolated in three steps. The proportion of 40 year-olds being obese was calculated from the proportion of children being at risk or overweight at age 11, the probability of becoming obese at age 21-29 conditional on weight status at age 11, and the probability of becoming obese age 40 conditional on being weight status at age 21-29 (Brown et al., 2006). QALYs, healthcare costs, and productivity costs were related to being overweight or obese at 40-64 years of age.

3 Extrapolating obesity to $\mathbf{4 0}$ years of age with a longitudinal decision-analytic model for the US population (Graziose et al., 2017). Weight status was extrapolated in two steps. The proportion of 40 year-olds being obese was calculated from the proportion of children with a $\mathrm{BMI} \geq 85$ th percentile at age 10 , and the probability of becoming obese at age 40 conditional on weight status (BMI $\geq 85$ th percentile) at age 15. QALYs and healthcare costs of obesity were discounted to age 10 years.

4 Extrapolating BMI over lifetime and modelling obesity-related diseases and mortality effects with the Assessing Cost-effectiveness model (ACE) for the Australian population (Moodie et al., 2011, 2009, 2013, 2010). The ACE model was populated with Australian-specific data on childhood BMI levels (Haby et al., 2006). By means of various cross-sectional studies, cohort and age effects were calculated. Cohort effects were added to baseline values to reflect actual BMI levels. Age effects were added to baseline 
levels to extrapolate BMI over the remaining lifetime (in 5-year age increments). DALYs and healthcare costs were related to obesity-related diseases in adulthood. The relative risks for chronic diseases (e.g. ischaemic heart disease, ischaemic stroke, hypertensive heart disease, type 2 diabetes, osteoarthritis, endometrial cancer, colon cancer, post-menopausal breast cancer and kidney cancer) started to increase from 25 years of age.

5 Extrapolating BMI over lifetime, modelling obesity-related diseases and mortality effects with the Chronic Disease Model (CDM) adapted for the New Zealand population (Mernagh et al., 2010; Rush et al., (2014). The CDM model was originally developed to model cost-effectiveness of health interventions for the Dutch population. Rush et al. (2014) and Mernagh et al. (2010) used New Zealand-specific data on BMI levels. It was assumed that individuals above 75 years had the same BMI levels as the cohort at 75 years of age. Cohort effects were not applied (Mernagh et al., 2010). Individuals were classified by weight status (overweight, obese, and healthy). As New-Zealand specific incidence rates of chronic diseases and relative risks for overweight and obesity were not available, inputs for the Dutch population were used. QALYs and healthcare costs were related to obesity-related diseases in adulthood. The relative risks for chronic diseases (e.g. acute myocardial infarction, coronary heart disease, congestive heart failure, cerebrovascular disease, diabetes, hip and knee arthritis, dorsopathies, rectum, colon, breast, prostate, kidney, and endometrium cancer) started to increase from 20 years of age.

6 Extrapolating fruit and vegetable intake over lifetime, modelling dietary-related diseases and mortality effects for the Dutch population (te Velde et al., 2011). To inform fruit and vegetable intake for the Dutch reference population, national food consumption data of 19 to 30 year olds were used. Mean intake levels in the intervention population were shifted upwards and extrapolated over the remaining lifetime by applying the same proportional increase. An intervention maintenance of 30 percent was applied. DALYs and healthcare costs were related to dietary-related diseases in adulthood.

7 Modeling the benefits of obesity and test scores with the Washington State Institute for Public Policy (WSIPP) benefit-cost model (Washington State Institute for Public Policy, 2017a, 2017b). By means of the model various outcomes are monetized, including the benefits associated with the changes in test scores and obesity (Washington State Institute for Public Policy, 2017c). Obesity and test scores were extrapolated over time. The model estimates the related labour market earnings (e.g. from the changes in test scores, years of secondary education, graduation probability, rate of employment for obesity status), education costs, and healthcare costs. Trumping rules are applied to account for double counting. 


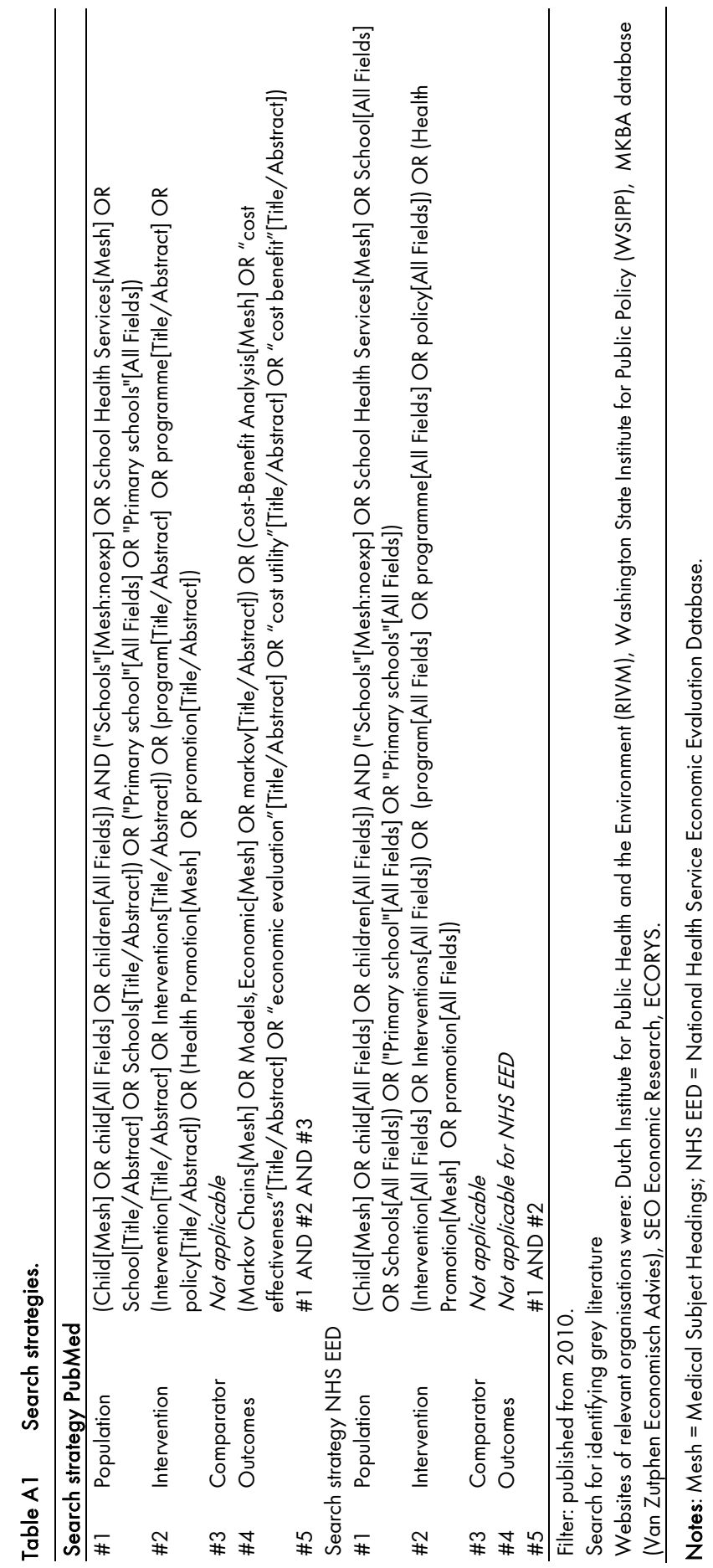




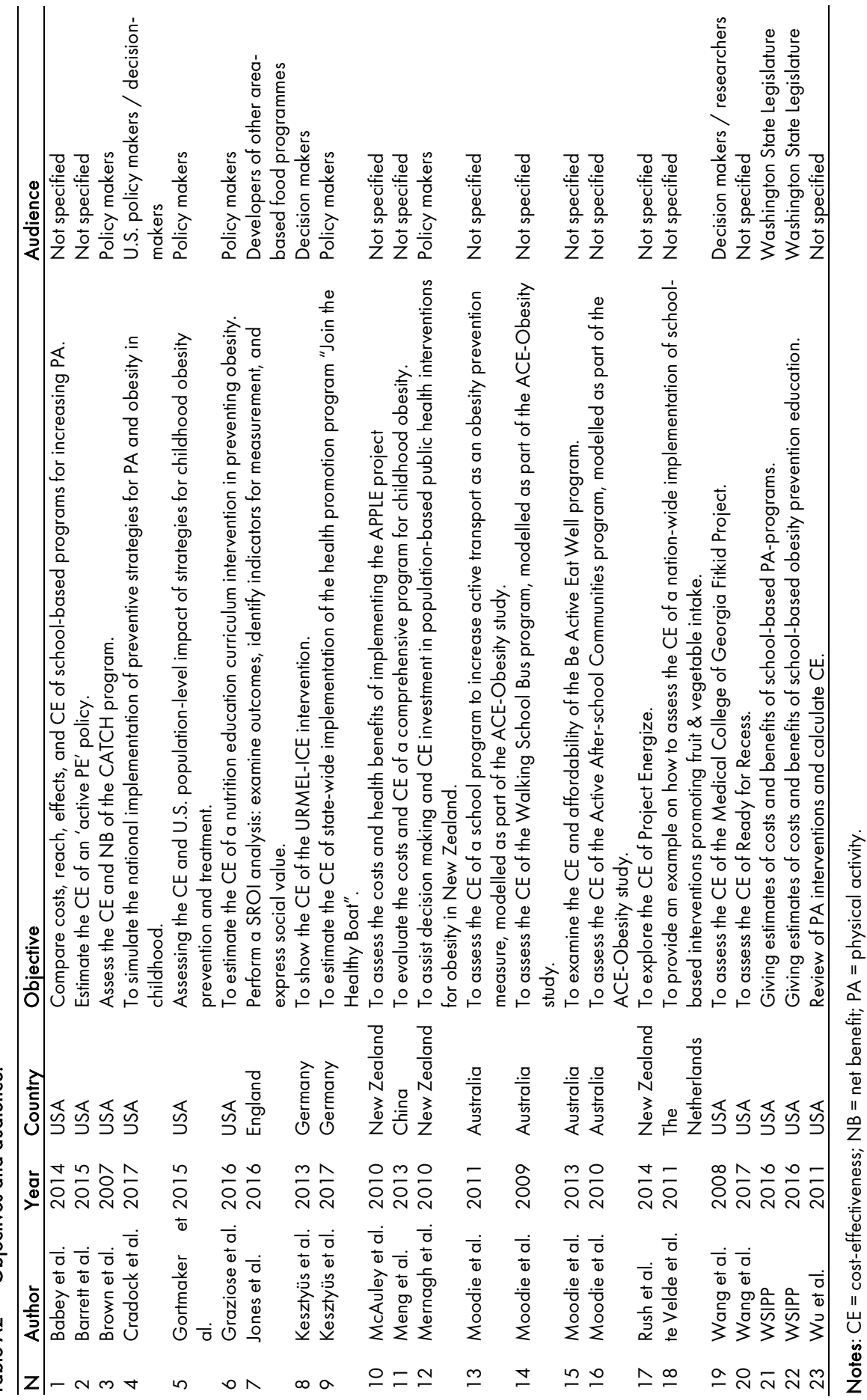




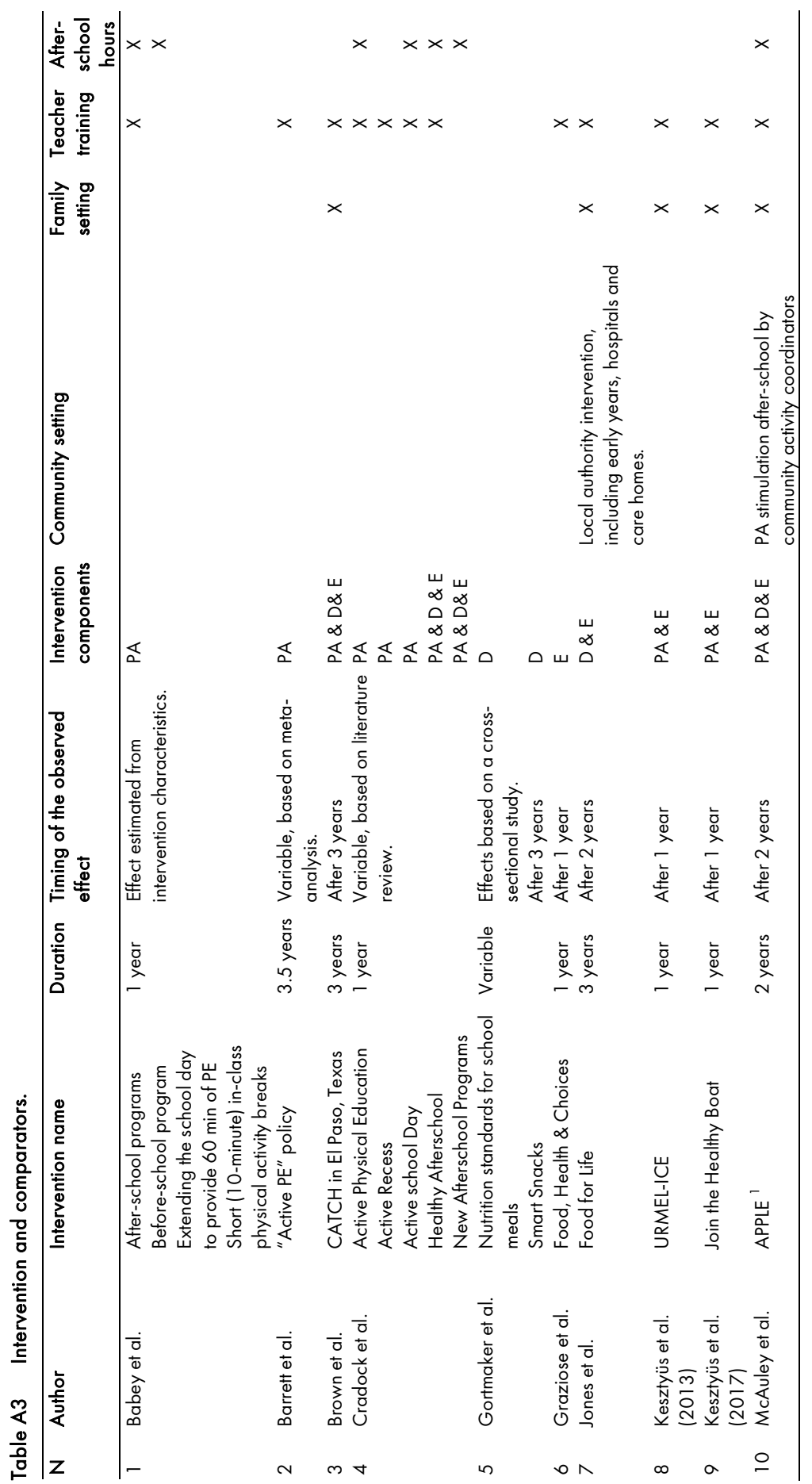




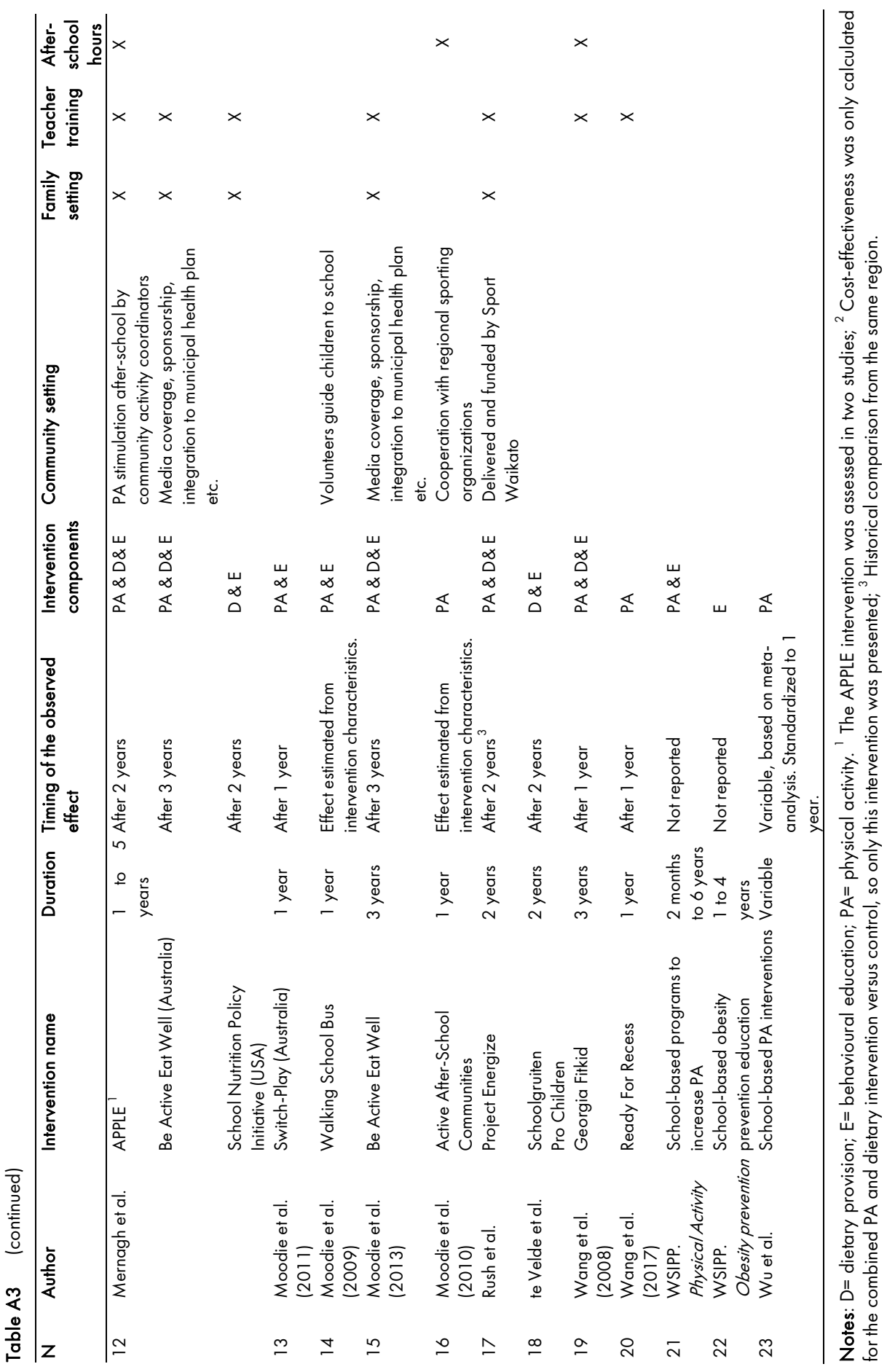




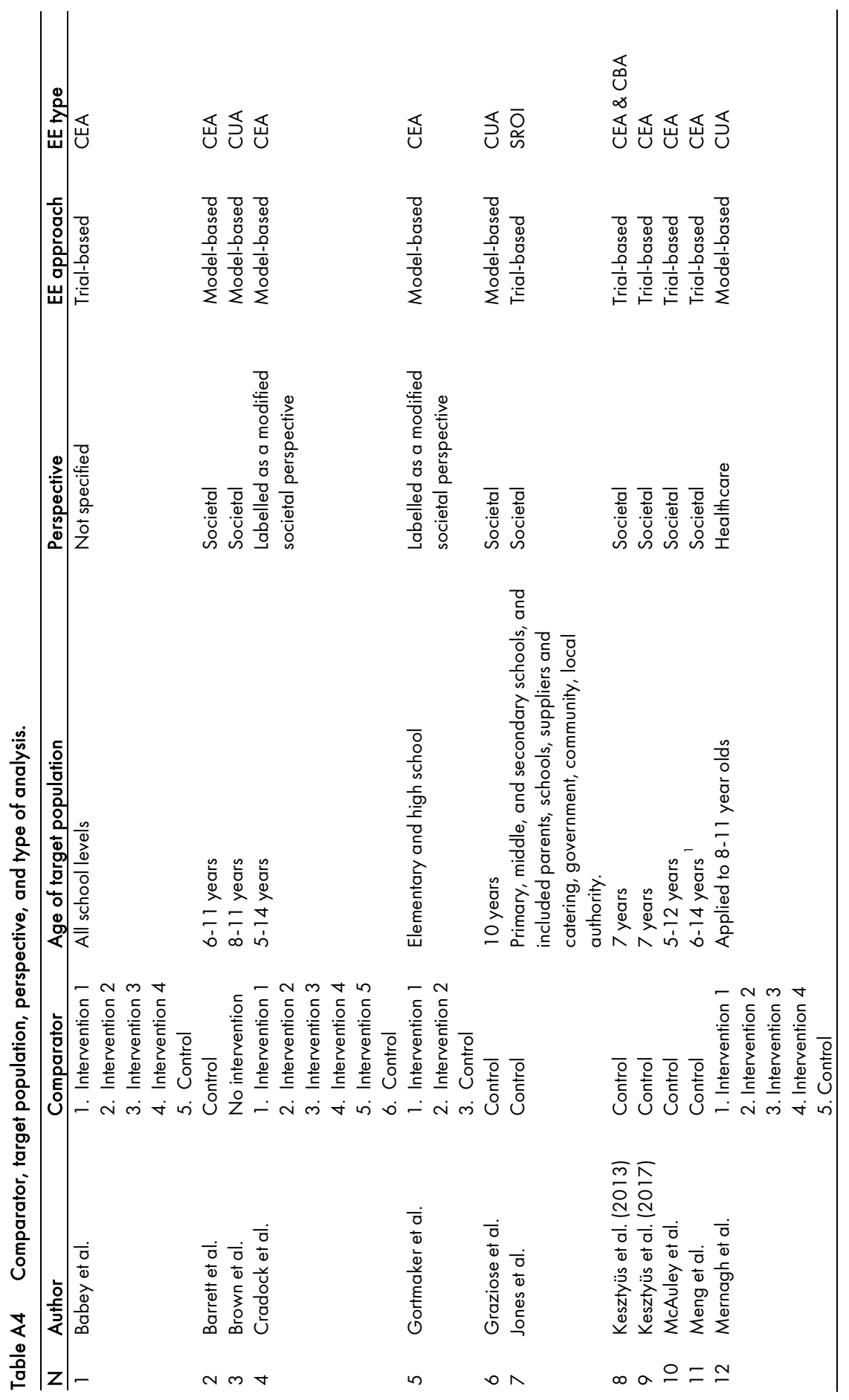




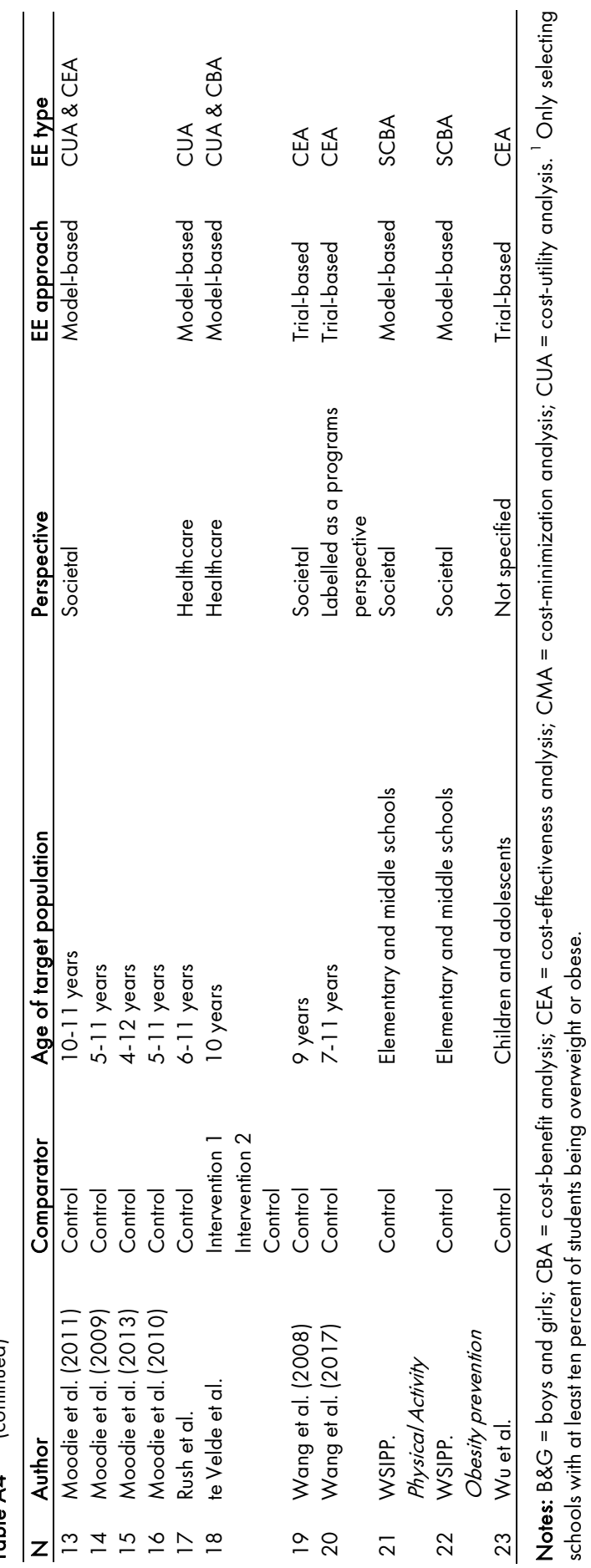




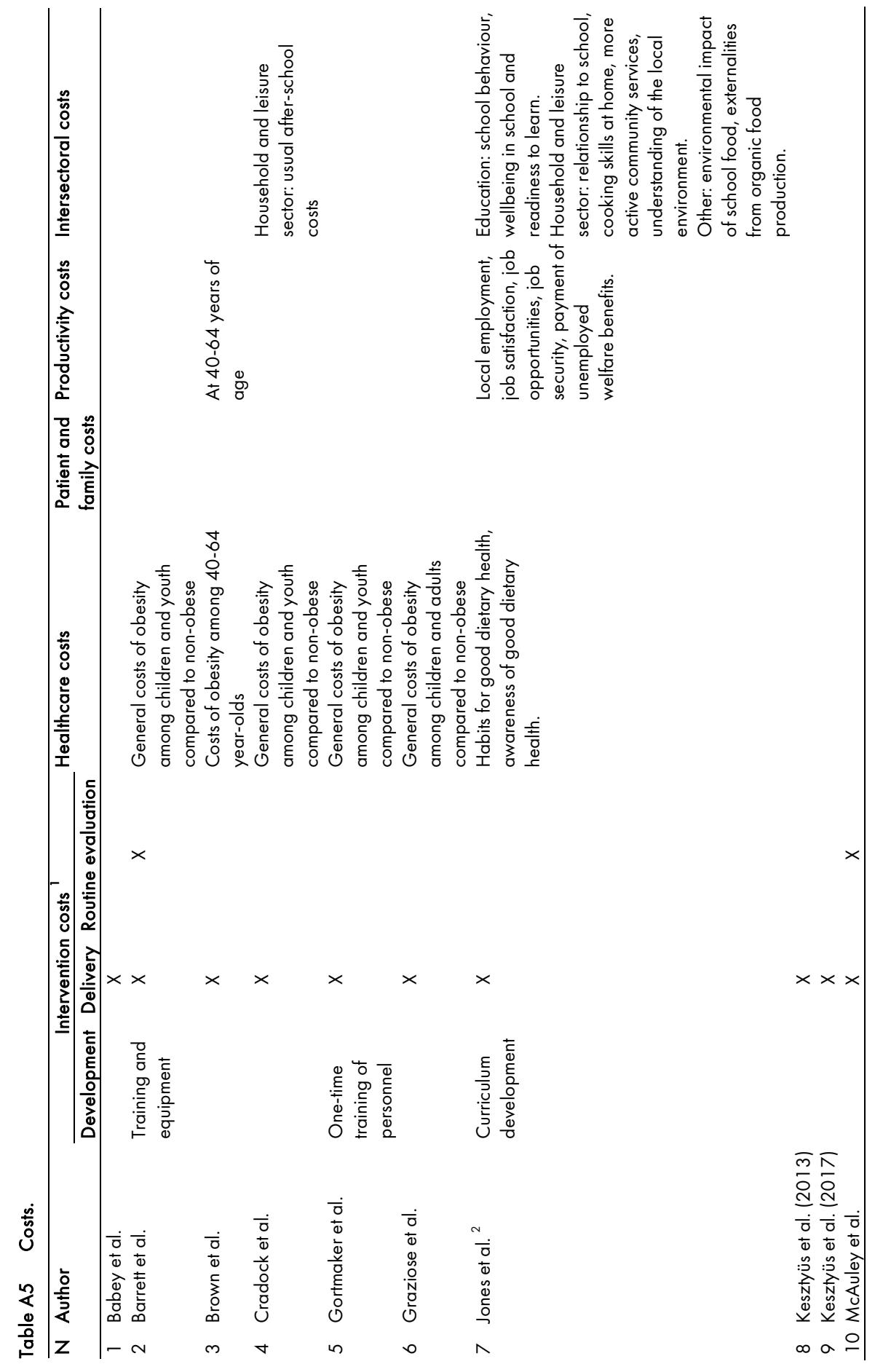




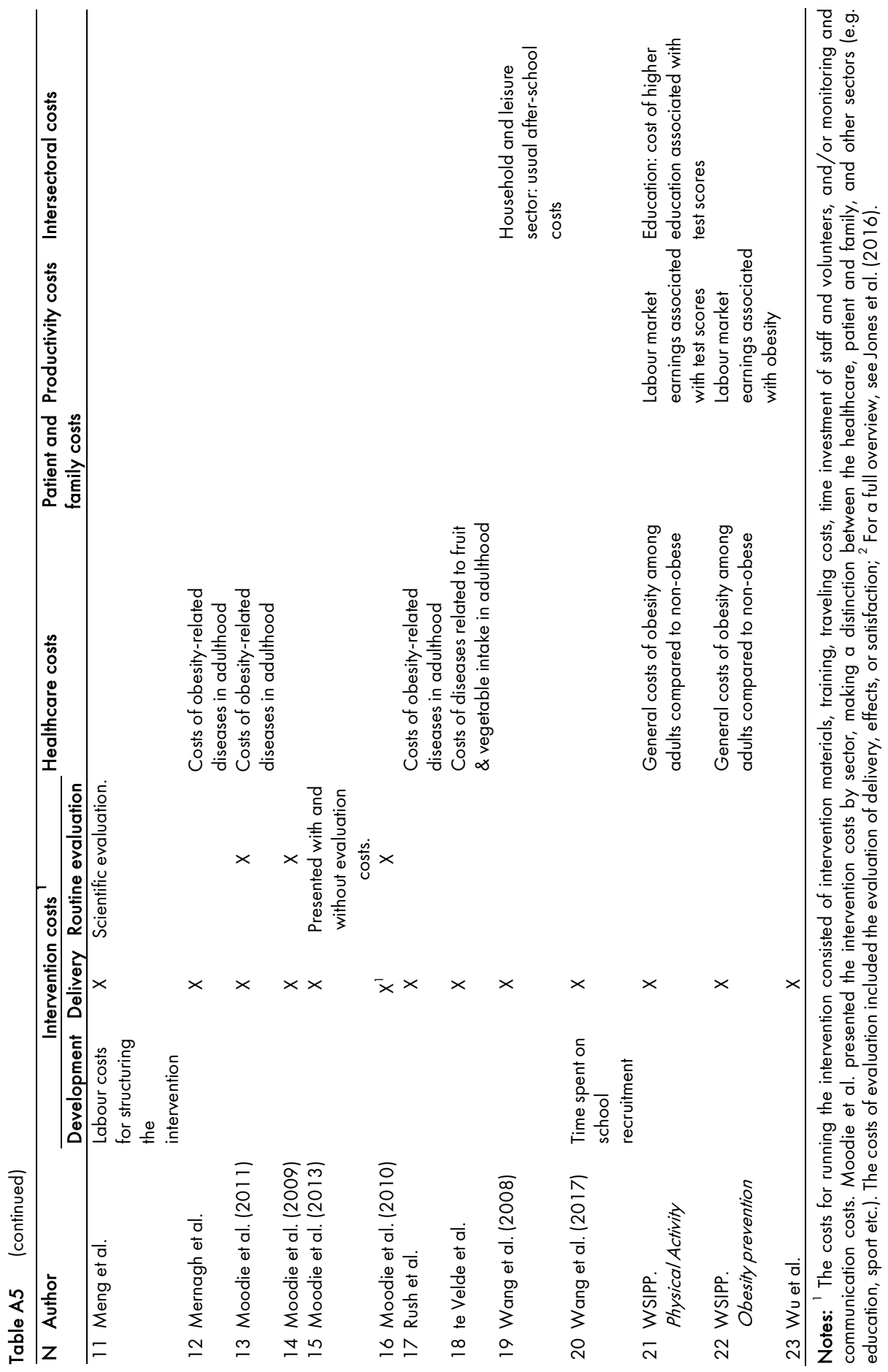



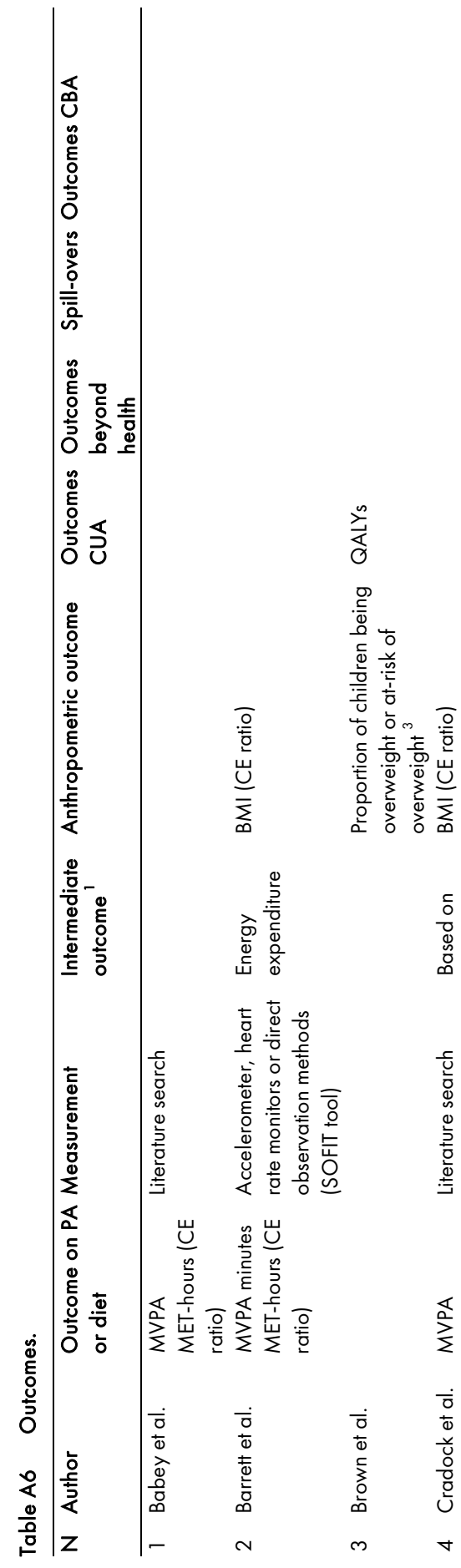

$\frac{n}{0}$
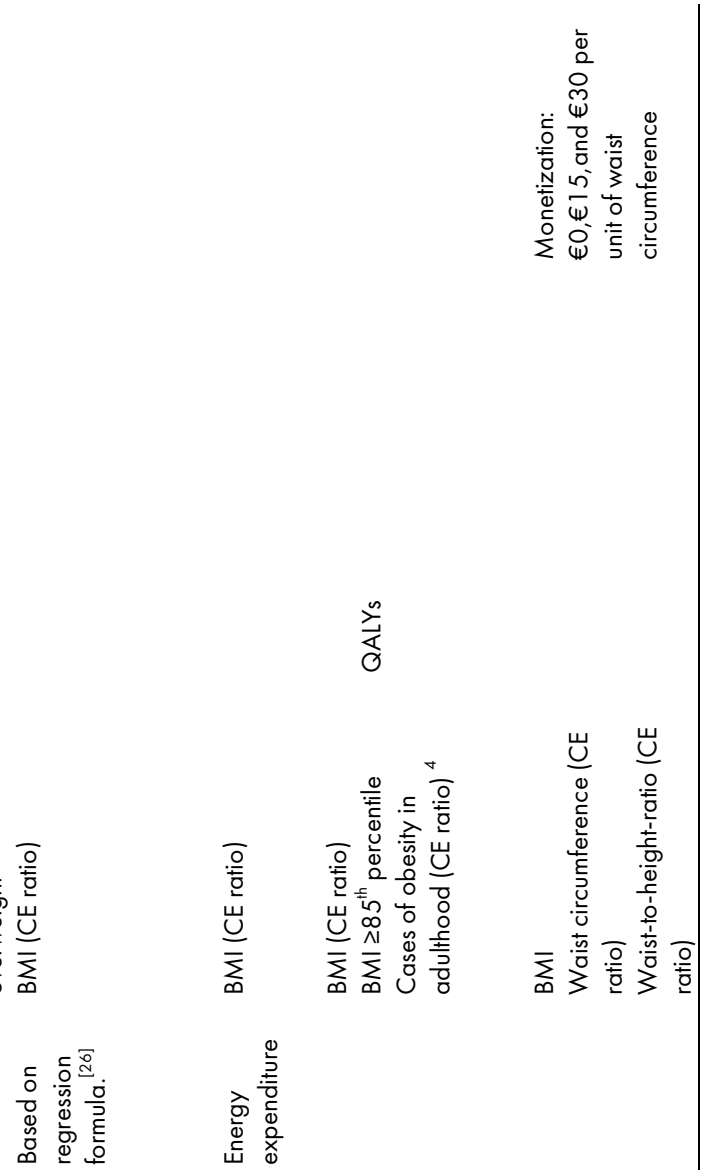


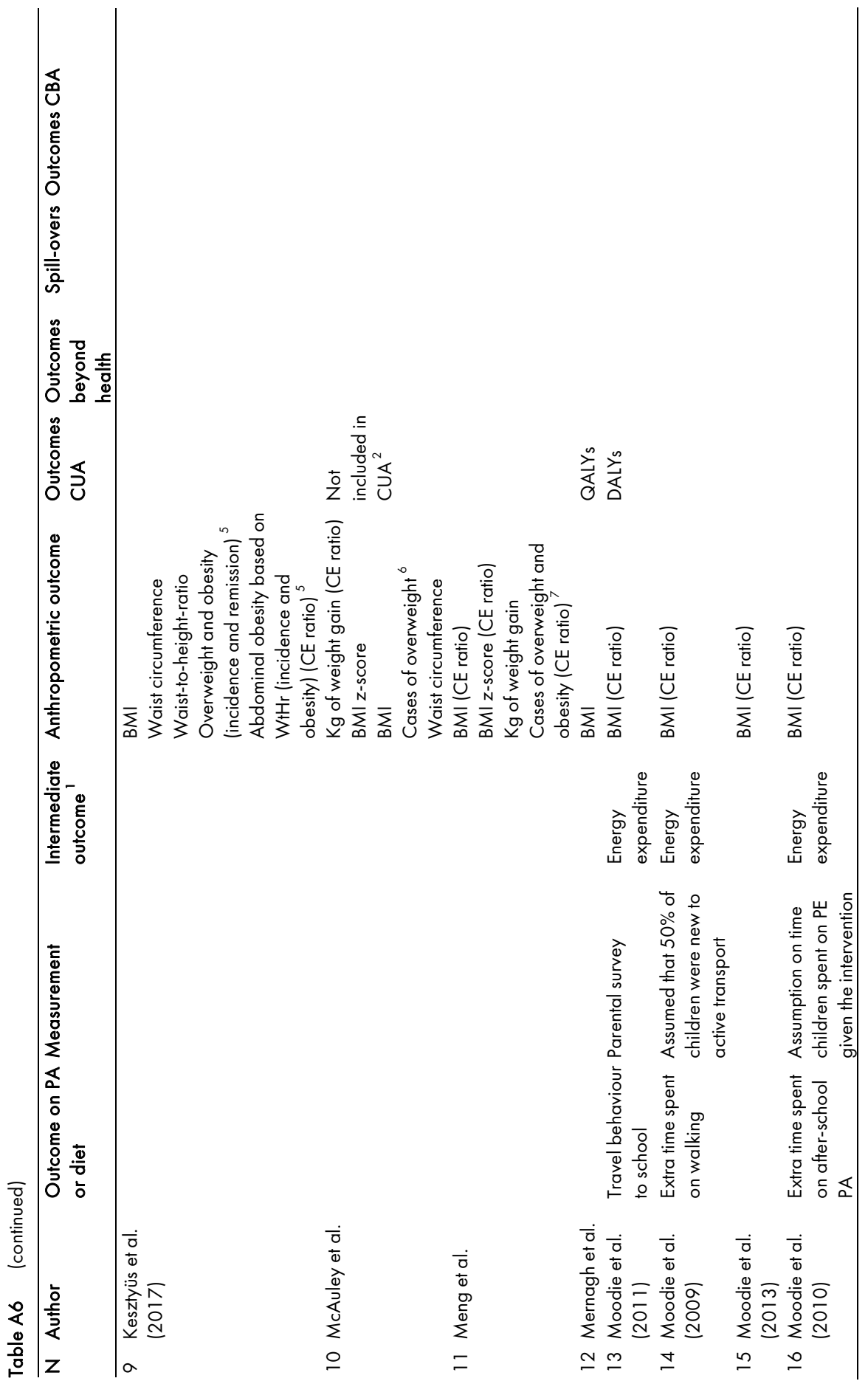




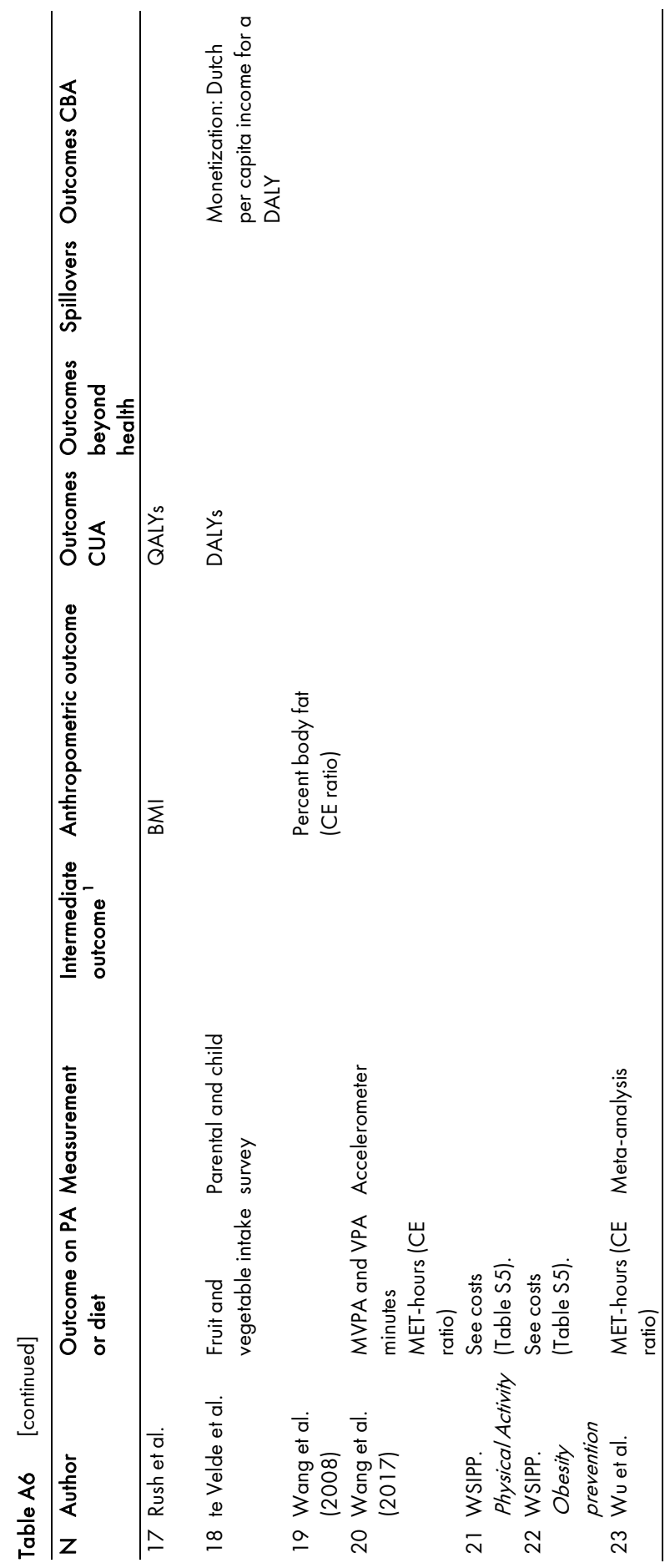

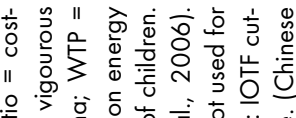
은

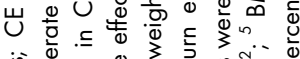

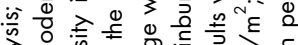
त्रे है

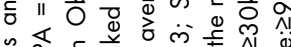

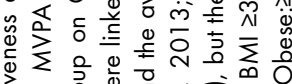

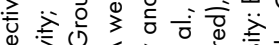

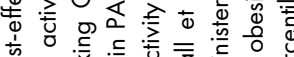

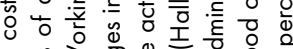

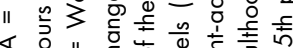

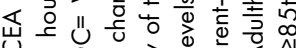

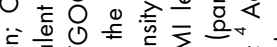

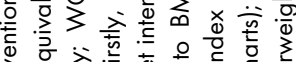

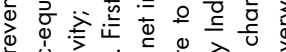

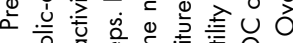

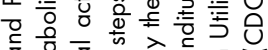

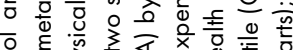

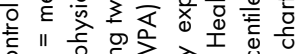
نे

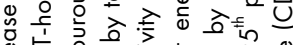

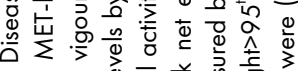
호 is 눈

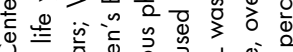

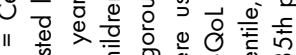

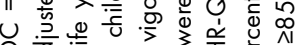

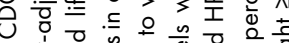

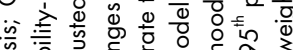

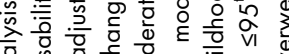

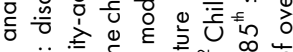

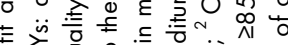

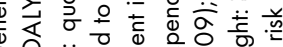
ब0ं

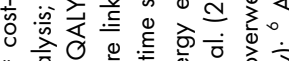
"

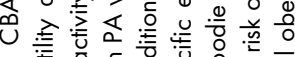

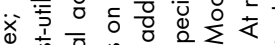
范

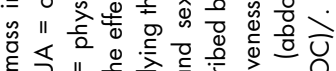
入己屯

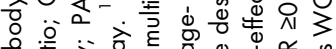

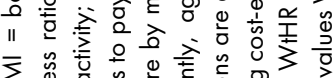

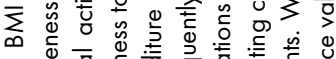

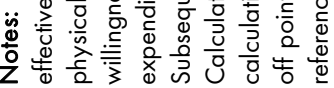




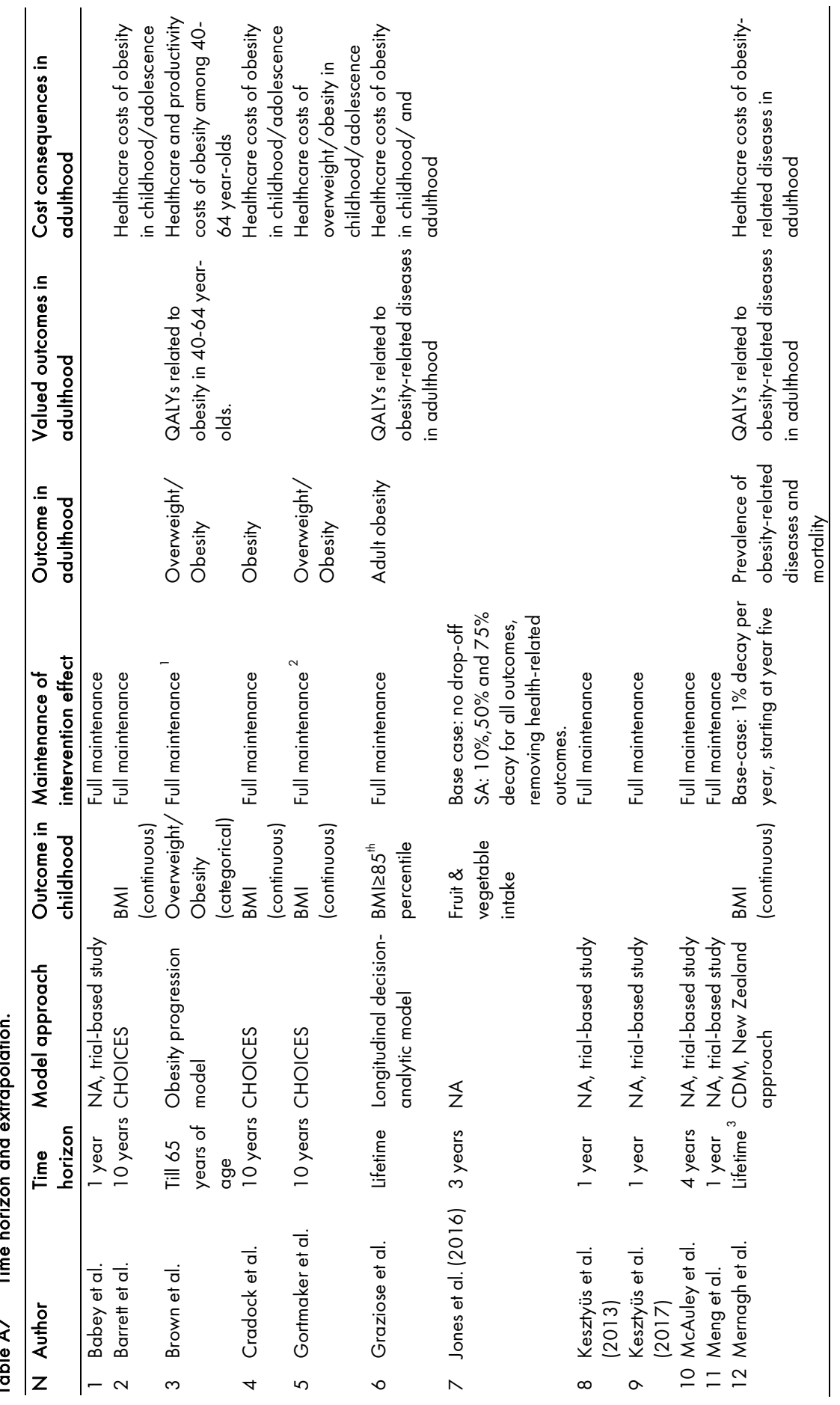




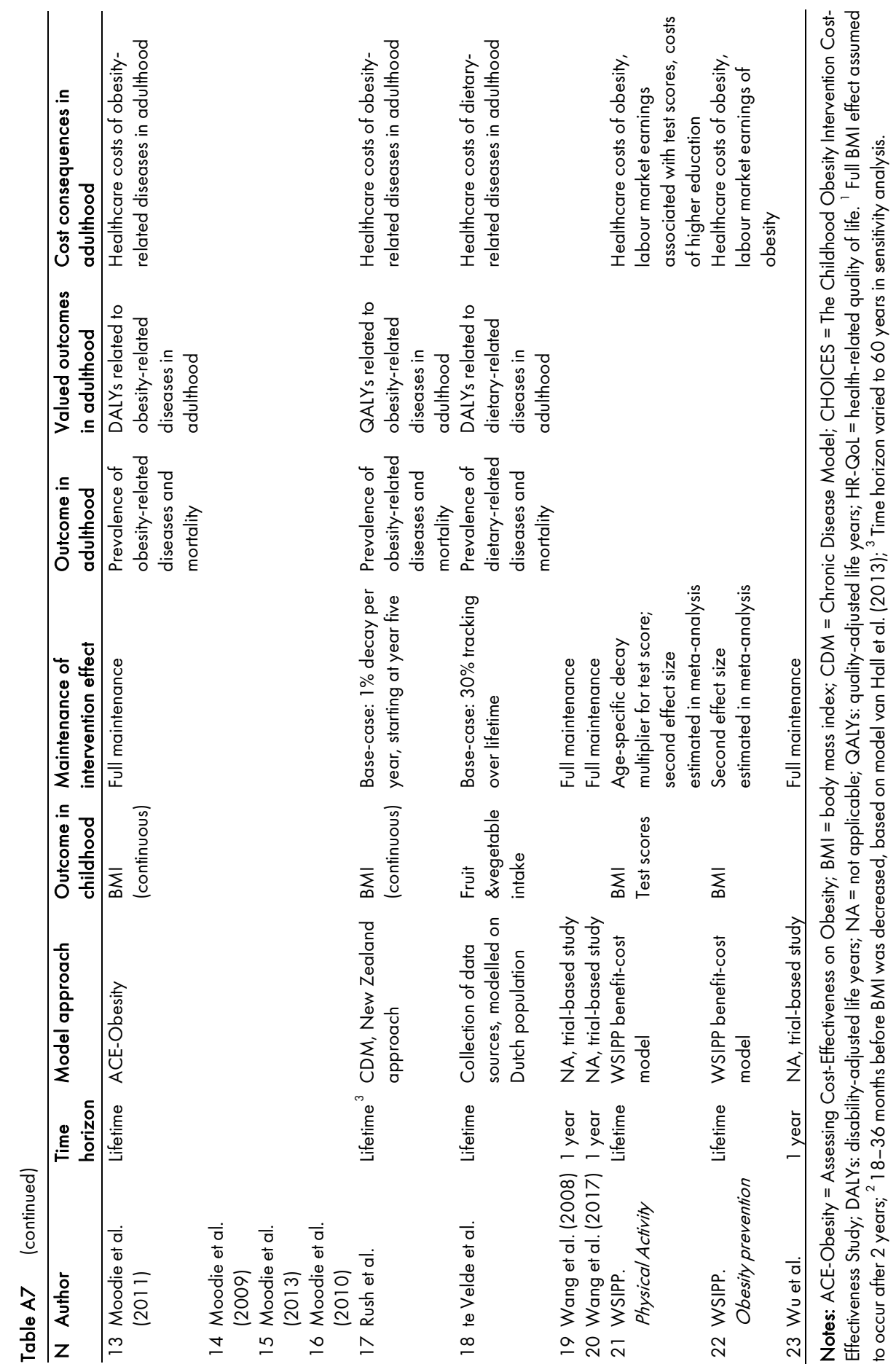





\section{Chapter 5}

\section{A Cost Analysis of School-Based Lifestyle Interventions}

\section{Based on}

Correction to: A Cost Analysis of School-Based Lifestyle Interventions.

Prevention Science, 2019; 20:970:974.

Marije Oosterhoff

Hans Bosma

Onno C.P. van Schayck

Manuela A. Joore

Prevention Science, 2018; 19(6):716:727 


\section{Abstract}

\section{Background}

An uniform approach for costing primary school-based lifestyle interventions is currently lacking. The objective of this study was to develop a template for costing of primary schoolbased lifestyle interventions, and apply this to the costing of the 'Healthy Primary School of the Future' (HPSF) and the 'Physical Activity School' (PAS), which aim to improve physical activity and dietary behaviours.

\section{Methods}

Cost-effectiveness studies were reviewed to identify the cost items. Societal costs were reflected by summing up the education, household and leisure, labour and social security, and health perspectives. Cost inputs for HPSF and PAS were obtained for the first year after implementation. In a scenario analysis, the costs were explored for a hypothetical steady state.

\section{Results}

From a societal perspective, the per child costs were $€ 2.7$ (HPSF) and $€ 3.2$ (PAS) per day during the first year after implementation, and $€ 1.0$ and $€ 2.2$ in a steady state, respectively (2016 prices). The highest costs were incurred by the education perspective (first year: $€ 8.7$ [HPSF] and $€ 4.0$ [PAS]; steady state: $€ 6.1$ [HPSF] and $€ 2.1$ [PAS]), whereas most of the cost offsets were received by the household and leisure perspective (first year: $€-6.0$ [HPSF] and $€-0.9$ [PAS]; steady state: $€-5.0$ [HPSF] and $€ 0.1$ [PAS]).

\section{Conclusions}

The template proved helpful in calculating the costs of HPSF and PAS for various stakeholder perspectives. A societal investment is required for the delivery of HPSF and PAS. 


\section{Background}

It is increasingly being recognised that schools have a key role in the promotion of children's health and wellbeing. ${ }^{1,2}$ A number of studies found that recent primary school-based lifestyle interventions are effective in normalizing children's body mass index (BMI). ${ }^{3,4}$ Much less is known about the costs of these interventions. ${ }^{5}$ This study focuses on performing systematic and standardized cost calculations on school-based lifestyle interventions.

A wide range of cost estimates have been published, ranging from $€ 4$ to $€ 865$ per child per year (adjusted for purchase power parity), ${ }^{6-10}$ which is likely due to the high variation in intervention components, set-up of interventions, and the heterogeneity in costing approaches. The heterogeneity in costing approaches is, amongst others, reflected by the various methods for identifying and selecting cost items. While the recurring resource use of intervention delivery is generally included in cost calculations, a minority of studies included development and evaluation costs, and consensus on this aspect seems to be lacking. ${ }^{11-13}$ In addition to the variability in costing methods, most studies provided little information on how resource consumption was identified, measured, and valued. For example, most studies listed the included cost categories but did not justify why cost categories were excluded (e.g., not applicable to the intervention, not in alignment with the perspective of the costing study). The lack of standardization and transparency makes it difficult to ascertain whether cost estimates are valid and reliable. Standardized and transparent cost calculations are of utmost importance to be able to perform cost comparisons between interventions, and to examine which interventions yield the best value in return for the required investments. The methodological quality of cost estimations is also key for implementation as underestimating the intervention costs will lead to implementation, but delivery will not be sustained when the costs are found to be higher than initially estimated. In contrast, overestimating the intervention costs may withhold children from receiving the benefits of effective interventions. Decision-makers in public health are interested in the social value of school interventions given the fact that most recent school-based lifestyle interventions are aimed at involving multiple stakeholders (e.g., schools, local government, sport clubs, caterers, child care organizations, health staff), and may affect outcomes in others than the child. ${ }^{14,15}$ Additionally, interventions may not only impact on health outcomes, but may also improve wellbeing by creating positive school environments, and improve educational outcomes as a result of the associations with children's health status. ${ }^{16}$ Most economic evaluations have examined the social value of school-based lifestyle interventions by adopting a societal perspective for the calculation of costs and outcomes. In a societal perspective, all the costs and outcomes that change as a result of the intervention are considered, regardless of who incurs them or in which sector they fall. A previous study has identified that the costs and outcomes of public health interventions may fall into the healthcare, education, labour and 
social security, household and leisure, or safety and justice sector. ${ }^{17}$ To effectively inform decision-makers, it is important to perform cost calculations from a societal perspective and take account of the various sectors that are involved or affected by the delivery of schoolbased lifestyle interventions.

To determine their support to an intervention, stakeholders require information on the costs they will incur. So far, few studies distinguished different stakeholder perspectives, but doing so may be helpful to interpret whether the implementation of an intervention is economically feasible or whether a cost redistribution among stakeholder groups would facilitate implementation. ${ }^{12,18-20}$

The objective of this study was to develop a template for the costing of primary school-based lifestyle interventions. The template should enable to perform cost calculations from various stakeholder perspectives and examine the impact of different scenarios, assumptions, or intervention adaptations. To illustrate the applicability of this framework, we calculated the costs of the "Healthy Primary School of the Future" (HPSF) and the "Physical Activity School" (PAS).

\section{Methods}

Firstly, we developed a template for the cost calculation of school-based lifestyle interventions. The template was then used for the cost calculation of HPSF and PAS by selecting the cost items that applied to both interventions and by measuring and valuing the selected cost items.

\section{Template for cost calculation}

The cost items of primary school-based lifestyle interventions were identified from published cost-effectiveness studies on these type of programs. ${ }^{21,22}$ Cost items reflected the incremental resource consumption relative to the regular education program. We focused on the recurrent activities for implementation, delivery, and evaluation. The one-time investments for intervention development and scientific evaluation fell beyond the scope of this study. It was aimed to include all cost items that reflected the social opportunity costs of an intervention. Social opportunity cost takes account of the actual payments and the economic costs. The economic costs represent the value of all resources that are not billed, but which are used for the intervention and are thus no longer available for other purposes (e.g. time investments of volunteers). Cost items could reflect a positive cost (cost increase compared to the regular education program) or a negative cost (cost saving compared to the regular education program). Cost items with a negative cost should be directly related to intervention delivery and not to the outcomes of school-based lifestyle interventions (e.g. provision of lunches at 
school is a cost offset for the household). We refer to this type of cost as a delivery-related offset. In this study, we made a distinction between a societal perspective and various smaller perspectives, which contained of the healthcare, education, labour and social security, and the household and leisure perspective. ${ }^{17}$ Cost items were also classified on the basis of personnel and material costs.

\section{The HPSF and PAS interventions}

The HPSF and PAS interventions are being evaluated in a quasi-experimental study located in the southern region of the Netherlands. The interventions are delivered from October 2015 onwards to children between 4 and 12 years of age. ${ }^{23}$ HPSF ( 2 schools) provide a daily health lunch and morning snack, which are prepared by catering personnel and beneficiaries of unemployment benefits as part of their reintegration to the labour market. The lunch consist of a variety of food products from which children can choose. Lunch is provided in the classroom or at a central location in the school and the lunch sessions are supervised by pedagogical staff and volunteers. Both HPSF and PAS (2 schools) offer additional sports, play, and creative activities for at least 4 days a week during the lunch break being set-up by cross-discipline coordinators. Pedagogical staff from childcare partners guide the activities and are assisted by volunteers.

At HPSF, the lunch break is extended with approximately one hour to enable the provision of lunches and lunch break activities. Children therefore attend school to approximately 15:30/15:45 instead of 15:00, and some of the lunch breaks involve an educational component to meet the education hour requirements. Schools are able to implement additional activities based on a list of relevant and evidence-based activities. In this study, we only focused on the compulsory changes and did not examine the cost of additional activities. The HPSF and PAS schools are compared to four control schools that maintain the regular school curriculum. Further details have been published elsewhere. ${ }^{23}$

\section{Cost analysis of HPSF and PAS}

We examined the incremental costs, which is defined as the additional costs of HPSF and PAS in comparison to the regular school curriculum. The annual social opportunity costs of HPSF and PAS interventions were calculated for the first year after implementation. Key stakeholders were consulted by means of semi-structured interviews to examine which of the cost items from the template applied to HPSF and PAS, and to complement the template.

A calculation sheet was created to incorporate the cost items, volume, and unit prices. The inputs for volume and unit prices were obtained retrospectively from primary sources (budget information, accounting data, stakeholder interviews, curriculum information). Because the activities at HPSF and PAS were all provided in addition to the regular school 
curriculum, the resource use at HPSF and PAS was examined, and the resource use in control schools was set to zero. Volumes were based on the average consumption at HPSF and PAS. For the unit prices, we used both primary data and secondary data sources, with the latter being used to obtain values for resources that were not directly billed le.g. time investments of volunteers). Because the school hours at HPSF were extended with approximately half an hour for 4 days a week, it was assumed that the primary caregiver of the child would spend less time on providing after-school care (reduction in caregiver time). We included the value of this time offset, because the primary caregiver could use this time offset for work or leisure activities. For the calculations, we assumed that the average family size amounted to two children per household. Beneficiaries of unemployment benefits were employed to help at HPSF with preparing the school lunches. This resulted in a saving for the household sector due to the difference between salary and unemployment benefits for beneficiaries. In addition, employing beneficiaries resulted in a cost offset for the social security sector due to the savings from unemployment benefits and earnings from income taxes. A gross approach to costing was used by first measuring and valuing costs at the level of the school and then disaggregating costs to the level of the child. The costs per child were calculated by dividing the total costs by the average number of children per school, because the interventions were provided at the school-level, and children were equally exposed to the interventions. All costs are expressed in 2016 euros. Costs were also converted to American dollars using the purchase power parity (PPP 2016, US\$1=€0.82). ${ }^{24}$ Given the one-year time horizon discounting was not applied.

\section{Scenario analyses}

While the initial delivery of school-based lifestyle interventions takes place during a research period, interventions are only embedded after research has ended. Until interventions become embedded into the school setting, learning-curve effects and efficiency improvements may occur, because more experience of obtained with the delivery of interventions (e.g. some activities may take less time). If interventions are sustained, they become to rely on more structural sources of funding. For this reason, it is interesting to examine whether organizational improvements are feasible (without compromising the intervention's relative effectiveness) in order to increase funding opportunities. In the first scenario analysis, the costs of HPSF and PAS were explored for a hypothetical steady state. The steady state reflected a hypothetical situation in which the HPSF and PAS interventions are delivered at their full capacity, and learning curves and efficiency improvements were no longer applicable. Because a steady state was not yet reached, stakeholders were consulted to define the expected learning curves and efficiency improvements.

Potential areas for cost reduction were examined with a pedagogical staff scenario and an 
efficiency scenario. In the pedagogical staff scenario, it was assumed that lunch breaks and activities were guided by teaching assistants instead of pedagogical staff from external childcare partners. The efficiency scenario was constructed based on the views of stakeholders about the potential areas for further cost reductions. Stakeholders reported that potential cost reductions could be achieved by decreasing the time investments of external parties providing workshops (not considered as an essential intervention component) and volunteers (no volunteers in upper grades), and by reducing the costs of transport (cost reduction of $50 \%$ in the first year after implementation given the limited use of available budgets during the first year).

Furthermore, scenario analyses may be performed when parameters are uncertain. In the extended school day scenario, we relaxed the assumption that the additional school hours at HPSF resulted in a cost offset due to the time being freed up for primary caregivers. In the extended school day scenario, we did not apply a cost offset as it was assumed that the extended school day at HPSF also caused utility losses as primary caregivers might derive utility from being able to provide after-school care.

\section{Sensitivity analyses}

Sensitivity analysis were conducted for the first year after implementation and for the hypothetical steady state. The main input parameters were varied to examine whether the per child costs were influenced by changes in resource consumption and unit prices. Input parameters were varied with \pm 50 percent because volumes and unit prices were not empirically measured and the uncertainty around the parameters was therefore unknown.

\section{Results}

In this study, we developed a template to support cost calculations for lifestyle interventions in the primary school setting and illustrated its applicability.

\section{Template for cost calculation}

Personnel costs contained the time investments of stakeholders that were compensated (e.g. salary, financial contribution) or not compensated. School personnel may invest time in the local planning, coordination, training (and substituting teachers during the training of personnel), delivery, and evaluation of interventions. The time investments of volunteers and primary caregivers belonged to the household sector. Negative costs may come into play when the school day is extended or when interventions are offered during the after-school hours, which results in time being freed-up for the primary caregiver of the child (reduction in 
caregiver time). Personnel costs may apply to multiple stakeholder perspectives. This occurs when stakeholders outside the education sector receive subsidies or financial contributions to compensate their time investments (e.g. time investments of volunteers are costs to the household sector and the financial compensation is a cost to the education sector). To avoid double counting when calculating the costs over multiple perspectives, it is important to only count the net costs for each stakeholder, being the value of time investments minus the received financial contributions. Overheads were not included in the framework as the proportion of overheads may vary between settings and stakeholder perspectives. However, it should be noted that taking account of overheads is highly relevant for the costing of interventions. An overview of the cost items of primary school-based lifestyle interventions is presented in Table 1.

Table 1. Cost items of primary school-based lifestyle interventions.

\begin{tabular}{|c|c|c|c|c|}
\hline \multirow[t]{2}{*}{ Cost item } & \multicolumn{4}{|c|}{ Stakeholder perspective } \\
\hline & Education & $\begin{array}{l}\text { Household } \\
\text { and leisure }\end{array}$ & $\begin{array}{l}\text { Labour and } \\
\text { social security }\end{array}$ & Healthcare \\
\hline \multicolumn{5}{|l|}{ Personnel $^{\mathrm{C}}$} \\
\hline School personnel & $x$ & & & \\
\hline Program coordinator & $x$ & & & \\
\hline School project leader & $x$ & & & \\
\hline Teacher & $x$ & & & \\
\hline Teaching assistant & $x$ & & & \\
\hline $\begin{array}{l}\text { Volunteers, carers, and beneficiaries from the } \\
\text { household sector }\end{array}$ & $x$ & $X^{A}$ & $X^{A}$ & \\
\hline External parties from the leisure sector & $x$ & $X^{A}$ & & \\
\hline $\begin{array}{l}\text { Personnel from the local government } \\
\text { (e.g. cross-discipline coordinators) }\end{array}$ & $x$ & & $x^{A}$ & \\
\hline $\begin{array}{l}\text { Personnel from the labour sector (e.g. pedagogical } \\
\text { staff from childcare partners, catering personnel) }\end{array}$ & $x$ & & $x^{A}$ & \\
\hline Health staff (e.g. local health department) & $x$ & & & $X^{A}$ \\
\hline \multicolumn{5}{|l|}{ Materials } \\
\hline Transport & $x$ & & & \\
\hline Accommodations & $x$ & & & \\
\hline Food & $x$ & $x^{B}$ & & \\
\hline Curriculum materials & $x$ & & & \\
\hline Monitoring equipment & $x$ & & & \\
\hline Advertising and promotion & $x$ & & & \\
\hline Accreditation and certification & $x$ & & & \\
\hline Training materials for personnel & $x$ & & & \\
\hline Communication and administration & $x$ & & & \\
\hline
\end{tabular}

Notes: ${ }^{A}$ There is a potential overlap in costs (see main text). To avoid double counting with the costs in the education sector, it is important to only count the net costs for each stakeholder, being the value of time investments minus the received financial contributions; ${ }^{B}$ Food costs are a positive cost to the education sector and a negative cost to the household sector and do not indicate an overlap in costs; ${ }^{C}$ Stakeholders may invest time for the local planning, coordination, training (and substituting teachers during the training of personnel), delivery, and recurrent evaluation. Furthermore, a per child fee may be required to compensate for the time investments of stakeholders. When beneficiaries of unemployment benefits are employed, this may lead to offsets in the household sector and in the social security sector (see main text). 


\section{Cost analysis of HPSF and PAS}

From a societal perspective, the per child costs amounted to $€ 2.7 /$ day for HPSF and to $€ 3.2$ /day for PAS during the first year after implementation (Table 2). Because the fee for supervision during the lunch break (€1/child/day) was not charged in the first year after implementation, an additional cost reduction or financial contribution of $€ 1.7 /$ day and $€ 2.2$ /day (first year) are required to make HPSF and PAS cost-saving from a societal perspective. The highest costs were incurred by the education perspective (€8.7 [HPSF] and $€ 4.0$ [PAS] per day), whereas most of the cost reductions were received by the household and leisure perspective (€-6.0 [HPSF] and $€-0.9$ [PAS]). Given the education perspective, the personnel costs (HPSF, 69\%; PAS, 94\%) made up the largest proportion of the costs for HPSF and PAS.

\section{Scenario analysis}

With the steady state assumptions such as the reductions in time investments of coordinators and the unit costs of lunches (Table 3, results expressed in American dollars are available online), the per child costs amounted to $€ 1.0 /$ day for HPSF and to $€ 2.2 /$ day for PAS. The costs for the education sector were €6.1 for HPSF and €2.1/child/day for PAS in the steady state. For HPSF, these were almost fully compensated by the savings in the household and leisure sector (€-5.0). The HPSF intervention could become cost-saving from a societal perspective when the unit costs of lunches do not exceed the cost threshold of $€ 1.0$ per child per day, or when the costs of pedagogical staff decreases by $70 \%$. The pedagogical staff scenario led to the highest cost reductions (to $€-0.6$ [HPSF] and $€ 1.9$ [PAS] in the first year after implementation) (Table 4, results expressed in American dollars are available online). Further research should be performed to assess whether these scenarios result in cost reductions without compromising the intervention's relative effectiveness. The extended school day scenario drives up the societal per child costs of HPSF from $€ 2.7$ per day to $€ 6.2$ (HPSF) in the first year after implementation.

\section{Sensitivity analysis}

Figure 1 and 2 show how the per child costs vary with the upper and lower bounds on the key inputs. The time investments on after-school care in the household, the costs of pedagogical staff, and the unit costs of food were the main factors of influence. 


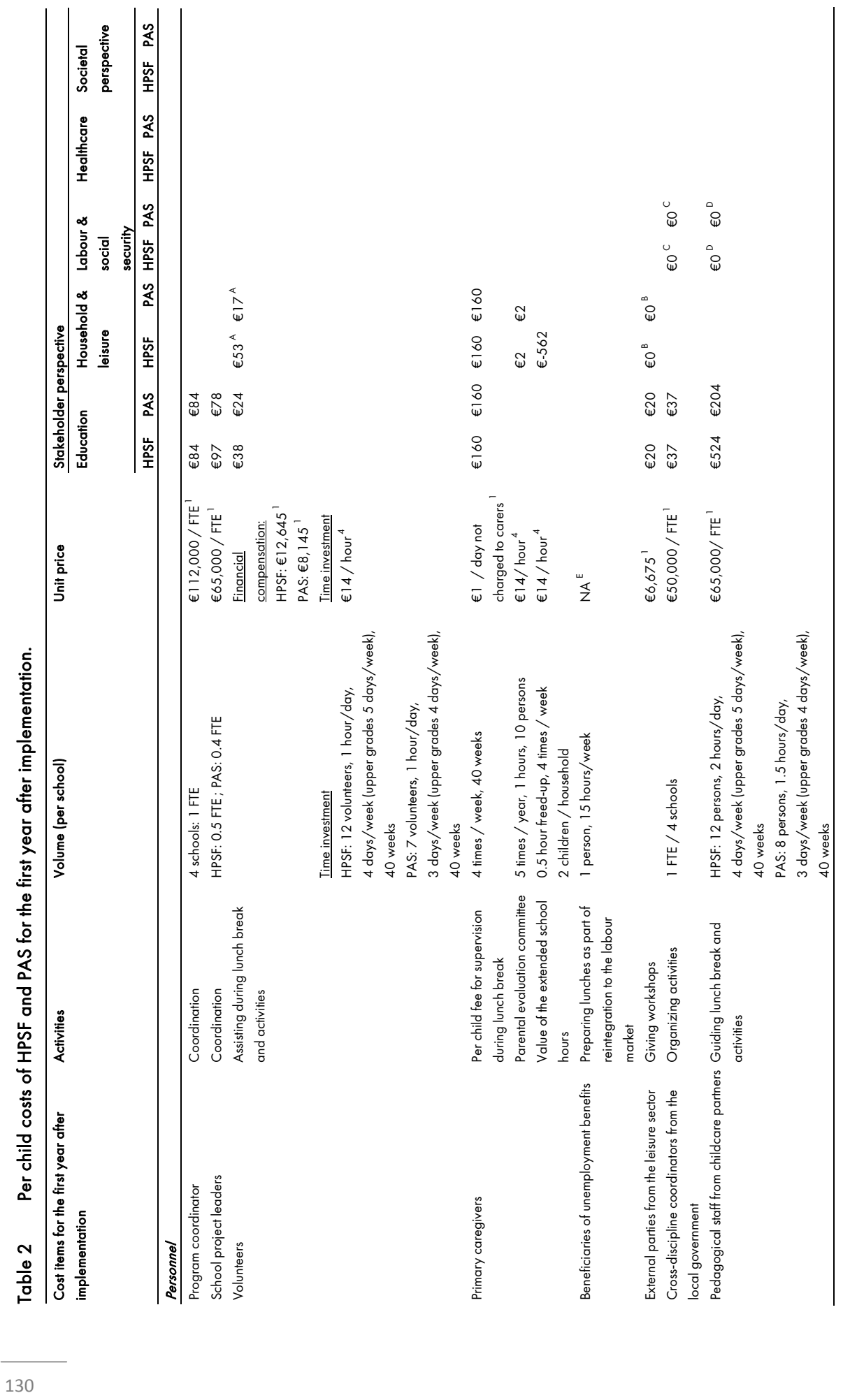




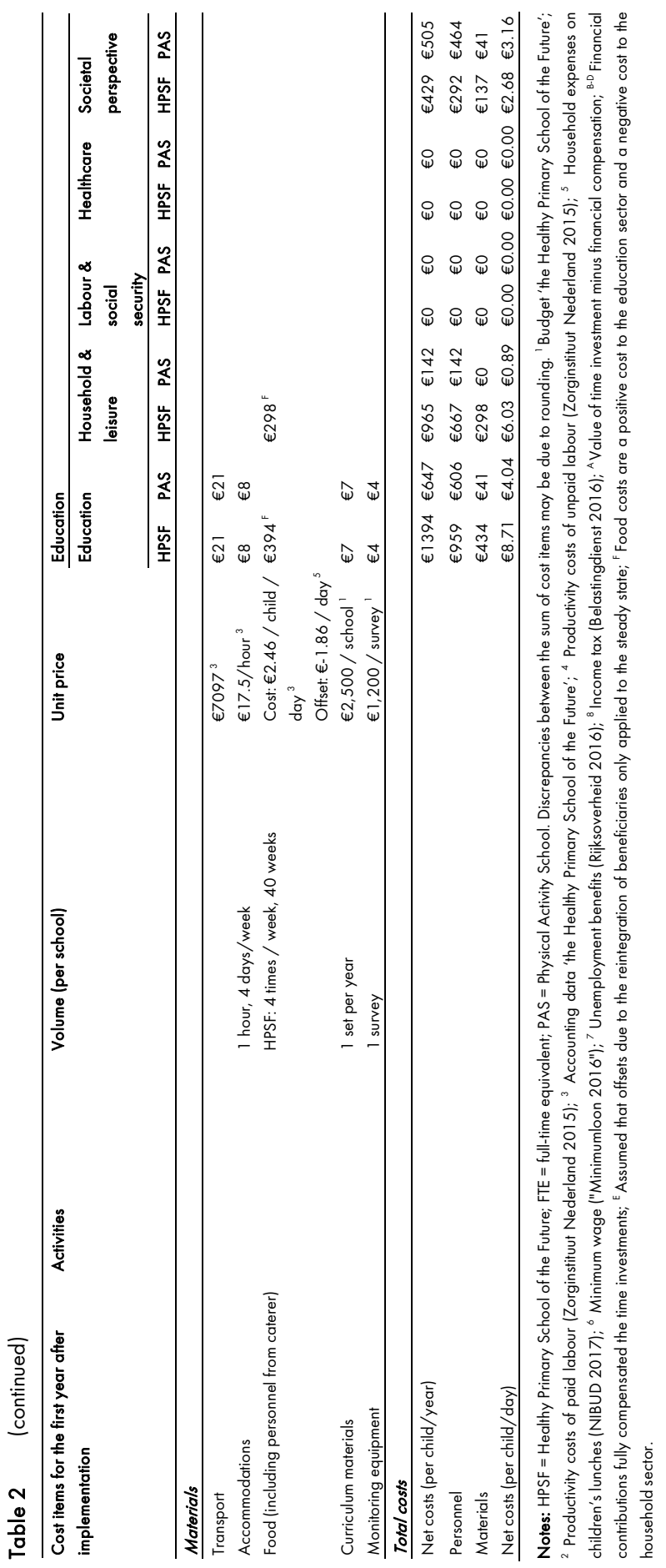




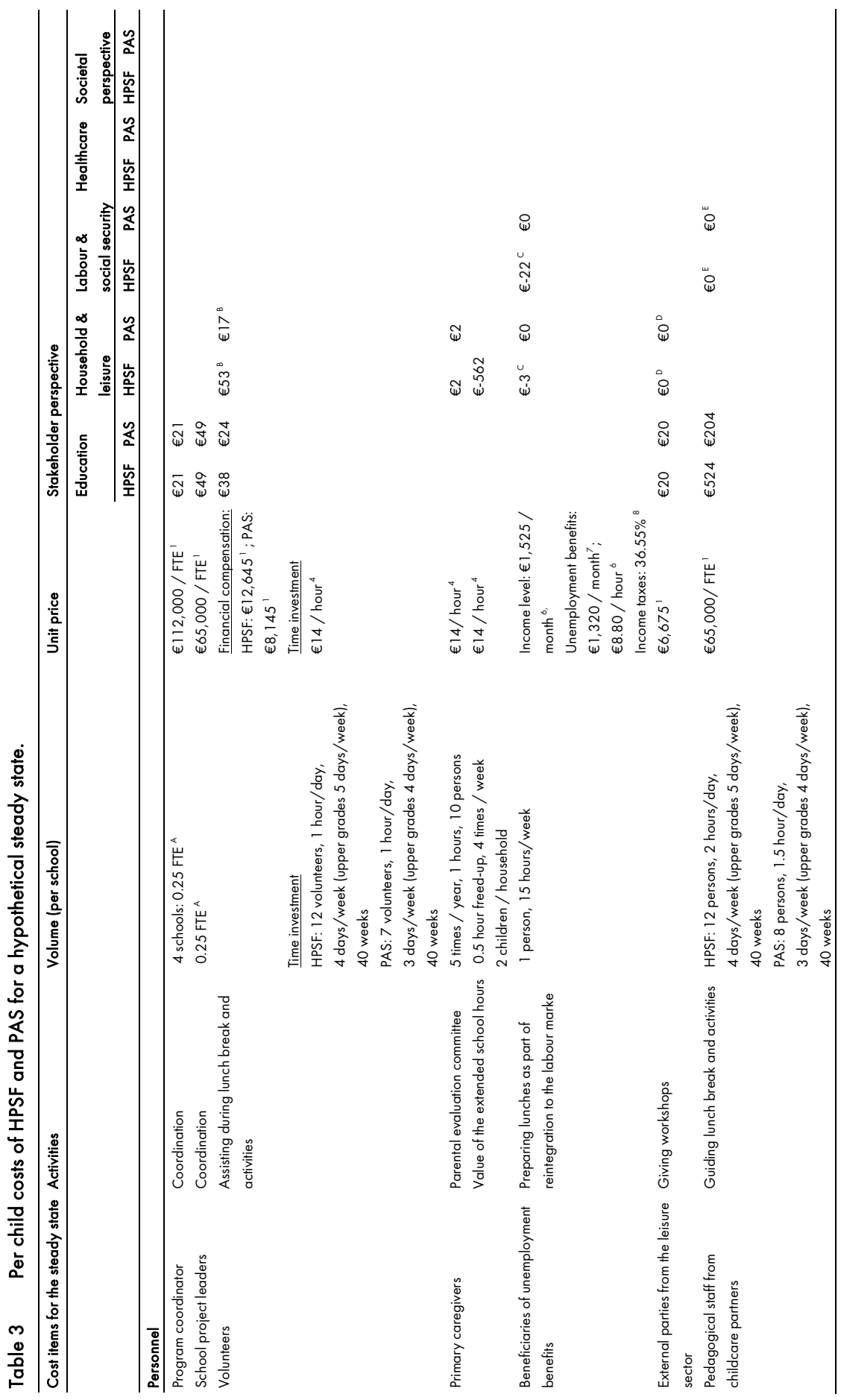


Table 4 Scenario analysis (per child societal costs).

\begin{tabular}{|c|c|c|c|}
\hline Scenario & Description & $\begin{array}{l}\text { First year after } \\
\text { implementation }\end{array}$ & $\begin{array}{l}\text { Hypothetical steady } \\
\text { state }\end{array}$ \\
\hline \multirow[t]{2}{*}{ Base-case } & & HPSF: $€ 429$ (€2.7/day) & \\
\hline & & PAS: $€ 505$ (€3.2/day) & \\
\hline \multirow{6}{*}{$\begin{array}{l}\text { 1.1 Hypothetical } \\
\text { steady state }\end{array}$} & A situation that occurs on the long run, & & HPSF: $€ 153$ \\
\hline & when interventions are delivered at their & & (€1.0/day) \\
\hline & full capacity and learning curves, and & & PAS: $€ 346$ \\
\hline & efficiency improvements do not longer & & (€2.2/day) \\
\hline & occur. Assumptions were defined by & & \\
\hline & stakeholders. & & \\
\hline \multirow{5}{*}{$\begin{array}{l}2.2 \text { Pedagogical staff } \\
\text { scenario }\end{array}$} & A scenario analysis to examine areas & HPSF: $€-95$ & HPSF: $€-371$ \\
\hline & for further cost reductions. Lunch breaks & $(€-0.6 /$ day $)$ & $(€-2.3 /$ day $)$ \\
\hline & and activities were guided by teaching & PAS: $€ 301$ (€1.9/day) & PAS: $€ 143$ \\
\hline & assistants instead of pedagogical staff & & (€0.9/day) \\
\hline & from external childcare partners. & & \\
\hline \multirow[t]{4}{*}{ 2.3 Efficiency scenario } & Views of stakeholders about the & HPSF: $€ 353$ (€2.2/day) & HPSF: €88 \\
\hline & potential areas & PAS: $€ 453$ (€2.8/day) & (€0.6/day) \\
\hline & for further cost reductions & & PAS: $€ 306$ \\
\hline & & & $(€ 1.9 /$ day $)$ \\
\hline \multirow{8}{*}{$\begin{array}{l}2.4 \text { Extended school- } \\
\text { day scenario }\end{array}$} & A scenario analysis to examine the & HPSF: €991 (€6.2/day) & HPSF: $€ 715$ \\
\hline & uncertainty about the & & (€4.5/day) \\
\hline & cost item. It was assumed that the time & & \\
\hline & offset for the & & \\
\hline & primary caregiver due to the extended & & \\
\hline & school day (saving) was fully & & \\
\hline & compensated by the utility loss from & & \\
\hline & being able to provide after-school care. & & \\
\hline
\end{tabular}

Notes: HPSF = Healthy Primary School of the Future; PAS = Physical Activity School. 


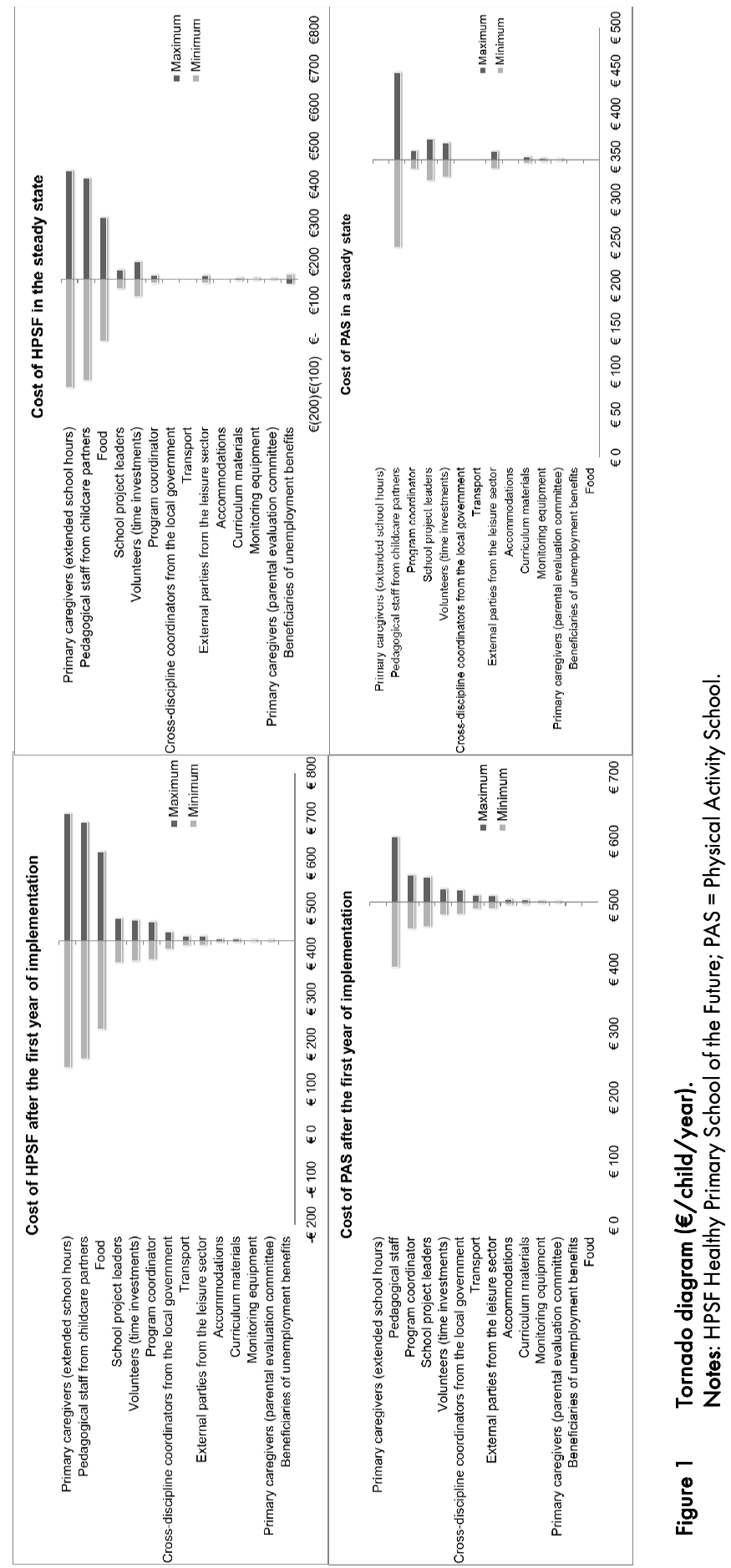



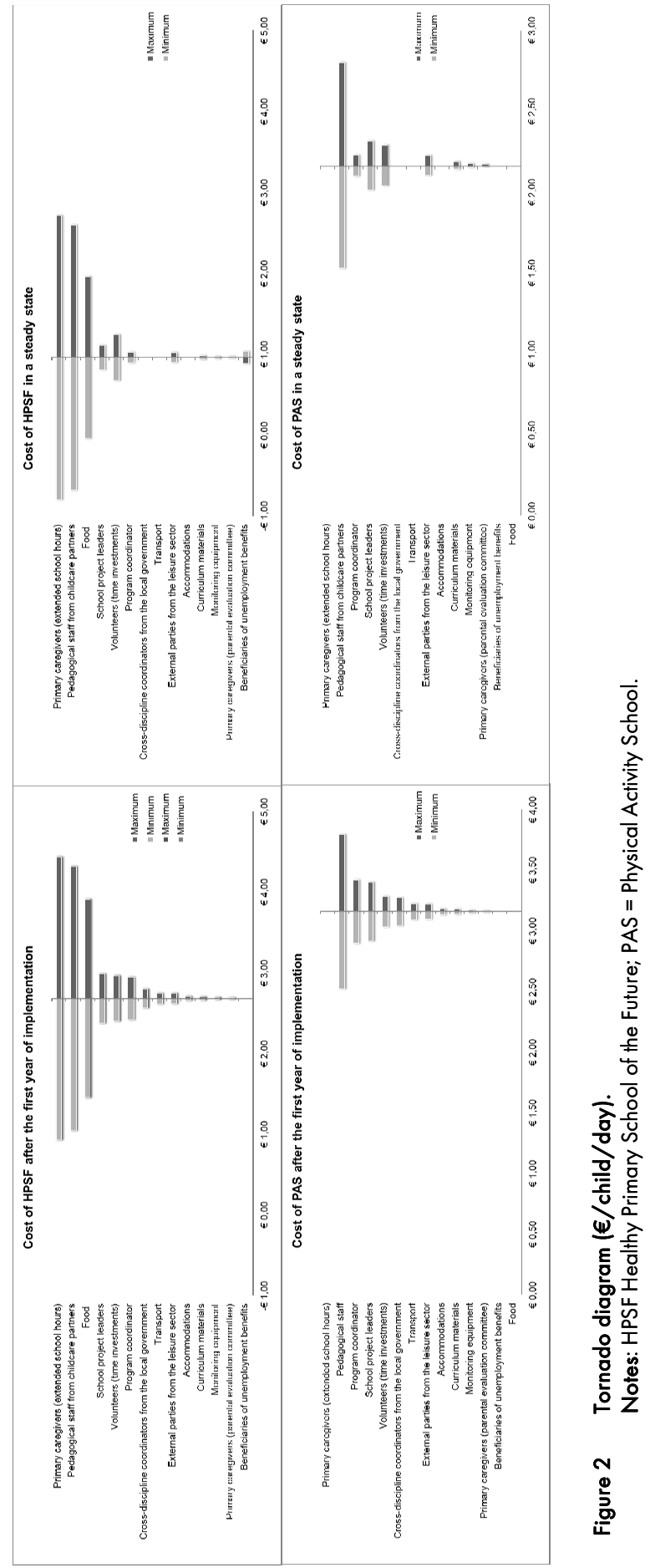


\section{Discussion}

The objective of this study was to develop a template for the costing of primary school-based lifestyle interventions in order to improve the quality and comparability of cost calculations. The framework listed the cost items of primary school-based lifestyle interventions and distinguished between the education, household and leisure, labor and social security, and health perspective. The framework proved useful for calculating the costs of HPSF and PAS: It helped to systematically identify the cost items, distinguish between stakeholder perspectives, and avoid the double counting of cost items. The societal costs were estimated at $€ 2.7$ and $€ 3.2$ per day in the first year after implementation and at $€ 1.0$ (HPSF) and $€ 2.2$ (PAS) for a hypothetical steady state, respectively.

Cost estimates are dependent on the methodological approaches and assumptions that are being used for making cost calculations. For example, we included delivery-related offsets as they may affect the opportunity costs to stakeholders. The impact of the extended school hours was included, assuming that the time freed up for the primary caregiver led to productivity gains. Previous cost-effectiveness studies on after-school interventions also accounted for the cost offsets on after-school care. ${ }^{7,25}$ However, this approach can be debated as it only incorporates the costs of after-school care. Providing after-school care may also lead to gains in utility or wellbeing in primary caregivers. ${ }^{26}$ Combining these utility losses with the productivity gains would result in a lower cost offset. In addition, time offsets may not fully be translated in productivity gains. The scenario analysis showed that the offsets of the extended school day were of major influence on the intervention costs. Future research on the value of after-school care is warranted to be able to generate cost estimates that reflect true social opportunity costs.

Assumptions can also apply to the context of the cost analysis. Cost calculations are often made for interventions in a steady state, meaning that the intervention is implemented at its full effectiveness potential. These cost estimates can be used in economic evaluations to examine the full cost-effectiveness potential of interventions. On the other hand, estimating the intervention costs with the associated learning curves may be more relevant to inform implementation processes. Given the time and resource consuming processes for assessing learning curves, several studies assumed that interventions operated at steady state conditions by excluding the one-off costs for start-up. ${ }^{18,20,27}$ The resulting estimates do not take account of the potential learning effects and cost efficiencies (e.g., changes in time investments, improved capacity utilization, reduction in unit costs) that may occur over time. ${ }^{28}$ In this study, stakeholders were consulted to define the expected learning curves and efficiency improvements. With both approaches (e.g., only excluding one-off costs versus defining a hypothetical steady state), the interventions costs may be underestimated or overestimated. 
The intervention costs should be monitored to examine whether the approaches can be used to produce accurate cost estimates.

The costs of HPSF and PAS were estimated for various perspectives in order to examine the cost distribution among stakeholders groups. The results showed large unbalances between the costs for education sector and the household sector (e.g., education perspective, $€ 8.7 /$ day; household perspective, $€-6.0 /$ day (HPSF, first year)). In the Netherlands, the costs of the usual education program amounts to $€ 32$, per child per day (updated to 2016 prices). ${ }^{29}$ The delivery of HPSF (incremental cost, $€ 8.7 /$ child/day) and PAS (incremental cost, $€ 4.0 /$ child/day) is associated with a $27 \%$ and $13 \%$ increase in the daily educational expenses, respectively. These results indicate that cost redistributions among stakeholder groups might be required to facilitate and support the implementation of the interventions. For example, it can be argued that a per child fee may be charged to primary caregivers who can afford it, as the societal costs of $€ 2.7$ (HPSF first year after implementation) are lower than the total of the general per child fees for supervision during the lunch break $(€ 1 /$ child/day) and the household expenses that are usually required for lunches and morning snacks for children in the regular school curriculum (€1.8/child/day). ${ }^{30}$

In addition to the offsets of the extended school day, the sensitivity analysis showed that personnel costs had a major influence on the costs of the HPSF and PAS interventions. In several countries, primary education, childcare, and after- school care are becoming more integrated with each other. ${ }^{31}$ A close collaboration between multiple professionals and a redistribution of their tasks (e.g., supervision during lunch break, assisting in the classroom, providing after-school care) may possibly lead the way to obtain further cost reductions and facilitate the implementation of lifestyle interventions in primary schools. In addition to the costing study, the relative effectiveness of both interventions on outcomes including health, wellbeing, and educational outcomes will be evaluated to examine whether the additional costs of HPSF and PAS represent value for money when compared to the regular school curriculum.

\section{Conclusion}

The template proved helpful in calculating the costs of school-based lifestyle interventions and distinguishing between various stakeholder perspectives. The education sector incurred the highest per child costs, which were almost fully compensated by the savings in the household sector for HPSF. Societal investments are needed for the delivery of HPSF and PAS. 


\section{References}

1. Hayman J. Personal, social, health and economic education: the bridge between public health and education. Int J Health Prom Educ. 2016;54:157-161.

2. Tang KC, Nutbeam D, Aldinger C, St Leger L, Bundy D, Hoffmann AM, Heckert K. Schools for health, education and development: a call for action. Health Promot Int. 2009;24:68-77.

3. Mei H, Xiong Y, Xie S, Guo S, Li Y, Guo B, Zhang J. The impact of long-term school-based physical activity interventions on body mass index of primary school children-a meta-analysis of randomized controlled trials. BMC Public Health.2016;16:1-12.

4. Sobol-Goldberg S, Rabinowitz J, Gross R. School-based obesity prevention programs: a meta-analysis of randomized controlled trials. Obesity.2016;21:2422-8.

5. John J, Wenig CM, Wolfenstetter SB. Recent economic findings on childhood obesity: cost-of-illness and cost-effectiveness of interventions. Cuur Opin Clin Nutr Metab Care. 2010;13,305-13.

6. Barrett JL, Gortmaker SL, Long MW, Ward ZJ, Resch SC, Moodie ML, Cradock AL. Cost effectiveness of an elementary school active physical education policy. Am J Prev Med. 2015;49:148-59.

7. Cradock AL, Barrett JL, Kenney EL, Giles CM, Ward ZJ, Long MW, Gortmaker SL. Using cost-effectiveness analysis to prioritize policy and programmatic approaches to physical activity promotion and obesity prevention in childhood. Prev Med. 2017;95(Suppl):S17-27.

8. McAuley KA, Taylor RW, Farmer VL, Hansen P, Williams SM, Booker CS, Mann JI. Economic evaluation of a community-based obesity prevention program in children: the APPLE project. Obesity. 2010;18:131-6.

9. te Velde SJ, Lennert Veerman J, Tak NI, Bosmans JE, Klepp KI, Brug J. Modeling the long term health outcomes and cost-effectiveness of two interventions promoting fruit and vegetable intake among schoolchildren. Econ Hum Biol. 201 1;9:14-22.

10. Waters E, Gibbs L, Tadic M, Ukoumunne OC, Magarey A, Okely AD, Gold L. Cluster randomised trial of a school community child health promotion and obesity prevention intervention: findings from the evaluation of fun ' $n$ healthy in Moreland! BMC Public Health. 2017; 18:92.

11. Meng L, Xu H, Liu A, van Raaij J, Bemelmans W, HuX, Ma G. The costs and cost-effectiveness of a schoolbased comprehensive intervention study on childhood obesity in China. PLoS One. 2013;8:e77971.

12. Moodie ML, Herbert JK, de Silva-Sanigorski AM, Mavoa HM, Keating CL, Carter RC, Swinburn BA. The costeffectiveness of a successful community-based obesity prevention program: the be active eat well program. Obesity. 2013;21:2072-80.

13. Wang H, Li T, Siahpush M, Chen LW, Huberty J. Cost-effectiveness of ready for recess to promote physical activity in children. J School Health. 2017; 87:278-85.

14. Middleton G, Evans A, Keegan R, Bishop D, Evans D. The importance of parents and teachers as stakeholders in school-based healthy eating programs. 2014. In Health education: parental and educators' perspectives, current practices and needs assessment. Health Care Issues, Costs and Acces. New York. Retrieved from http://eprints.lincoln.ac.uk/11965/.

15. Warwick I, Aggleton P, Chase E, Schagen S, Blenkinsop S, Schagen I, Eggers M. Evaluating healthy schools: perceptions of impact among school-based respondents. Health Educ Res. 2005;20:697-708.

16. Langford R, Bonell CP, Jones HE, Pouliou T, Murphy SM, Waters E, Campbell R. The WHO Health Promoting School framework for improving the health and well-being of students and their academic achievement. Cochrane Database of Systematic Reviews. 2014.

17. Drost RMWA, Paulus A, Ruwaard D, Evers S. Handleiding Intersectorale Kosten en Baten van (Preventieve) Interventies: Maastricht University, Faculty of Health, medicine and life sciences CAPHRI, school for public health and primary care, Department of Health Services. 2014.

18. Moodie ML, Carter RC, Swinburn BA, Haby MM. The cost-effectiveness of Australia's active after-school communities program. Obesity. 2010;18:1585-92.

19. Moodie ML, Haby M, Galvin L, Swinburn B, Carter R. Cost-effectiveness of active transport for primary school children-Walking School Bus program. Int J Behav Nutr Phys Act. 2009; 14:63.

20. Moodie ML, Haby MM, Swinburn B, Carter R. Assessing cost-effectiveness in obesity: active transport program for primary school children-TravelSMART Schools Curriculum program. J Phys Act Health. 2011;8:503-15. 
21. Kersley $\mathrm{H}, \mathrm{Knuutila} A$. The benefits of procuring school meals through the food for life partnership. London: New Economics Foundation. 2011 . [Retrieved from http://neweconomics.org/201 1/05/benefitsprocuring-school-meals-food-life-partnership/].

22. Oosterhoff M, Bosma H, Van Schayck CP, Evers SMAA, Dirksen CD, Joore MA. Recommendations for economic evaluations on lifestyle interventions in primary schools: issues and ways forward. 2017. Manuscript submitted for publication.

23. Willeboordse M, Jansen MW, van den Heijkant SN, Simons A, Winkens B, de Groot RHM, et al. The healthy primary school of the future: study protocol of a quasi-experimental study. BMC Public Health. 2016;16:1-13.

24. OECD. Purchasing power parities. n.d. Retrieved from: https://data.oecd.org/conversion/purchasingpower-parities-ppp.htm.

25. Wang $H$, Sekine $M$, Chen X, Yamagami T, Kagamimori S. Lifestyle at 3 years of age and quality of life (QOL) in first-year junior high school students in Japan: results of the Toyama Birth Cohort Study. Qual Life Res. 2008; 17:257-65.

26. van den Berg B, Brouwer WBF, Koopmanschap MA. Econ Eval Informal Care. 2004;5:36-45.

27. Cobiac $\amalg$, Vos T, Veerman JL. Cost-effectiveness of interventions to promote fruit and vegetable consumption. PLoS One. 2010;5:e14148.

28. Anderson I, Lopez A, Wilson A, Vos T, Doran C, Barendregt J, Bertram M. Assessing cost-effectiveness in the prevention of non-communicable disease (ACE-Prevention) Project 2005-09. 2007.

29. Ministerie voor Onderwijs Cultuur en Wetenschap [OCW]. Kerncijfers 2009-2013. 2014. Retrieved from https://www.rijksoverheid.nl/documenten/jaarverslagen/2012/05/16/kerncijfers-2007-2011.

30. Nationaal Instituut voor Budgetvoorlichting [NIBUD]. (2017). Wat geeft $u$ uit aan voeding? [Available from: https://www.nibud.nl/consumenten/wat-geeft-u-uit-aan-voeding/].

31. Oostdam R, Tavecchio L, Nøhr K, Ex C. Een integraal kindcentrum als open leer- en ontwikkelingsgemeenschap; Tijd voor een samenhangende visie op opvoeding, educatie en opvang. Pedagogiek. 2014;34:60-73. 



\title{
Chapter
}

6

The short-term value of the 'Healthy Primary School of the Future' initiative: a social return on investment analysis

\author{
Marije Oosterhoff \\ Onno C.P. van Schayck \\ Nina H.M. Bartelink \\ Hans Bosma \\ Maartje Willeboordse \\ Bjorn Winkens \\ Manuela A. Joore
}




\section{Abstract}

\section{Background}

This study examines the social return on investment (SROI) of the 'Healthy Primary School of the Future' initiative after 2 years.

\section{Methods}

Healthy Primary Schools of the Future (HPSF) provide a healthy lunch and daily structured physical activity sessions, whereas Physical Activity Schools (PAS) focus on physical activity only. We evaluated the 2-year investments and effects ( $N=1676$ children) of both school environments (4 schools) compared to control schools (4 schools). Investments and outcomes were grouped within the healthcare, education, household \& leisure, and labour \& social security sector. Outcomes that could be expressed in monetary terms were used for the calculation of social return on investment.

\section{Results}

HPSF and PAS created outcomes for the healthcare sector by favorable changes in health behaviors, body mass index [both significant], and medical resource use [not significant]. Outcomes for the education sector included a favorable impact on perceived social behaviors and school satisfaction, and absenteeism from school [latter not significant], and more engagement with the community was experienced. The per child investments, €859 (HPSF) and $€ 1017$ (PAS), generated a benefit of $€ 8$ (HPSF) and $€ 49$ (PAS) due to reduced school absenteeism and medical resource use.

\section{Conclusions}

Within two years of intervention implementation, the HPSF initiative created outcomes in several sectors, but the benefits did not outweigh the investments. Follow-up assessments as well as modeling long-term outcomes are needed to assess the total value of the interventions. Until then, the SROI framework can inform strategies for obtaining stakeholder support and intervention implementation. 


\section{Introduction}

The environment in which today's children are growing up is characterized by many opportunities for unhealthy dietary intake and few facilities for physical activity. ${ }^{1,2}$ Adverse consequences such as overweight and obesity have been steadily increasing over the last decades. In 2009, 13-15 percent of Dutch boys and girls aged 2-21 years were overweight compared to 5-7 percent in $1980 .^{3}$ As a response to this growing public health concern, the Healthy Primary School of the Future initiative was developed. ${ }^{4}$ Key elements of this initiative are the provision of a daily healthy lunch and structured physical activity sessions, which are innovative elements within the Dutch primary school setting (corresponding to 4-12 years of age). The HPSF initiative consists of a full intervention, named the 'Healthy Primary Schools of the Future' (HPSF), and a partial intervention, referred to as 'Physical Activity Schools' (PAS). Within two years of intervention, Bartelink et al. (2019) found that HPSF was effective in increasing healthy dietary behaviors and physical activity. ${ }^{5}$ Both HPSF and PAS were also effective in lowering children's body mass index (BMI) z-scores (BMI adjusted for age and sex). ${ }^{6}$

Cost-effectiveness studies aim to inform implementation and funding decisions. Ideally, the time over which costs and outcomes of childhood programs are evaluated should go beyond childhood, because the impact of weight reductions on chronic diseases, healthrelated quality of life (HRQOL), and costs do not fully occur within childhood. Evaluations of short-term cost and effects are, however, more in line with the time horizons that policy makers tend to work with (usually $3-5$ years) 7,8 $^{7,8}$ and provide information for decision-making on the implementation, continuation, and scaling-up of interventions.

In the current study, we use the social return on investment (SROI) framework for examining the investments, outcomes, and societal value of HPSF and PAS. The SROI framework aims to examine all outcomes of a program (no matter who incurs them). To aggregate investments and outcomes and calculate return on investment or cost-effectiveness, outcomes are assigned to a monetary value (financial benefits) and are divided by the investments. This calculation (SROI calculation) results in an estimate on the amount of benefits returned for every euro spent. ${ }^{9,10}$ The SROI framework also recognizes that not all outcomes can be assigned to a monetary value (and can be expressed quantitatively). Outcomes that cannot be expressed in monetary terms are included in a SROI story, which articulates the nonmonetary value. The objective of this study is to examine the short-term SROI generated by HPSF and PAS in the first two years of intervention implementation. 


\section{Methods}

A quasi-experimental study, which started in 2015 in the south of the Netherlands, evaluates the effects of two 'Healthy Primary Schools of the Future' (HPSF) and two 'Physical Activity Schools' (PAS) compared to four control schools who maintained the usual school curriculum. No randomization was applied because voluntary participation was key to the intervention implementation. A healthy morning snack and daily healthy lunches were provided (at HPSF only) in combination with structured physical activity sessions including structured sports activities, free play, and creative activities. At HPSF, the lunch break was prolonged to about one hour, which led to an extension of the school day with approximately 30 minutes (some lunch breaks involved an educational component to meet the education hour requirements). Children and their parents were invited to participate in data collection at baseline (no blinding), and could join at all measurement waves as children continuously leave and enter primary school (dynamic cohort design). Further details on the interventions and data collection procedures have been published elsewhere. 4,11

A SROI analysis was performed by taking five steps, according to the methods of Nicholls et al. (2012): 1) defining the scope and identifying key stakeholders; 2) identifying investments and outcomes; 3) evidencing outcomes; 4) establishing impact, and 5) assessing the SROI. $^{12}$

\subsection{Step 1: Scope and key stakeholders}

Whilst the quasi-experimental study examines the effects of HPSF and PAS for a period of 4 years (baseline: school year 2015/2016, year 4: 2019/2020), the current study focuses on the impact after two years (baseline: school year 2015/2016, year 1: 2016/2017, year 2: $2017 / 2018$ ). Several stakeholders contributed to the delivery of HPSF and PAS, and may be directly or indirectly affected by the interventions. Stakeholders were grouped within the healthcare, education, household \& leisure, and labour \& social security sector (Figure 1: box $\mathrm{H}$, box $\mathrm{E}$, box $\mathrm{HL}$, and box $\mathrm{L}$, respectively). 


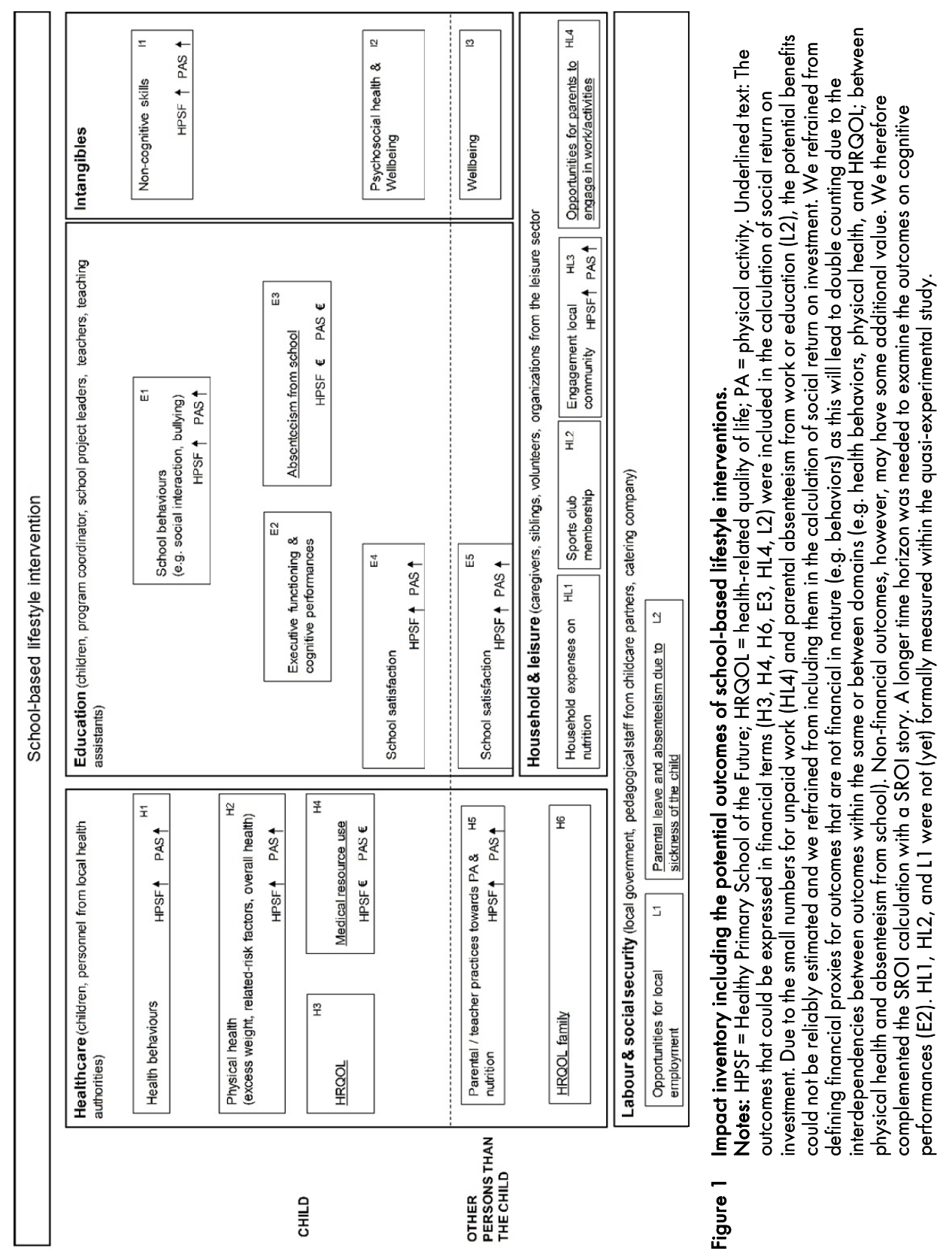




\subsection{Step 2 and 3: Identifying investments \& outcomes and evidencing outcomes}

\subsubsection{Investments}

In a previous study, we made an overview of the activities provided at HPSF and PAS in comparison to the regular school curriculum, and the corresponding investment costs. ${ }^{13}$ The cost analysis also revealed cost offsets: children's lunches were provided at school and led to a cost offset within the household, and the extended school day at HPSF provided caregivers with additional time (productivity cost) that could be spent on paid or unpaid work. These cost offsets were deducted from the investments to calculate the net investments. For more details on the cost calculation see Appendix 2.

\subsubsection{Qualitative outcomes}

Semi-structured interviews with stakeholders were held at the end of the second year about the implementation and perceived changes. " School coordinators $(N=4)$, coordinators of the pedagogical employees $(\mathrm{N}=4)$, school health promoters from the regional Public Health Services $(N=4)$, and the project coordinator $(N=1)$ were interviewed (Figure 1 and Appendix 3). More information can be found in the paper written by Bartelink et al. $(2019) .^{14}$

\subsubsection{Quantitative outcomes}

The selection of quantitative outcomes was made by the interdisciplinary scientific project group, and presented in an impact inventory (Figure 1). ${ }^{4}$ Quantitative outcomes were measured annually (TO: 2015, T1: 2016, T2: 2017) and covered height and weight measurements, child questionnaires, and parental questionnaires. School records contained information on absenteeism from school. Routine school satisfaction surveys were administered among caregivers and children between 2016 and 2018. In the current study, we included children that were enrolled at the participating schools and exposed to the interventions from baseline onwards. Children in grade 8 at baseline were excluded as no follow-up measurements could be obtained. We also excluded the children that switched between schools between 2015 and 2017. Benefits were calculated by multiplying the outcomes over 2 years (measured in volumes/quantity) by the unit cost for that outcome. Benefits were assessed at the group level in order to calculate an average per child benefit. Standardized prices from national costing guidelines were used for outcomes that were financial in nature (medical resource use, productivity), ${ }^{15}$ and published proxy values were applied for other outcomes (QALY and school absenteeism) (Table A3.1). ${ }^{16,17}$ The outcome 
measurement and valuation, and the selection of the study sample $(N=1676)$ are further described in Appendix 3.

\subsection{Step 4: Establishing impact}

This step is used to estimate what proportion of the outcome can be isolated as being added by the intervention. In the current study, the quasi-experimental design with a control group and 2-year time frame was used to account for this element.

\subsection{Step 5: SROI assessment}

The SROI calculation included the outcomes on children's HRQOL, medical resource use (Figure 1: $\mathrm{H} 3$ and $\mathrm{H} 4$ ), and school absenteeism (Figure 1: E3). The outcomes for medical resource use and absenteeism, which represented a cost, were rescaled so that all outcomes would indicate a benefit. Benefits were calculated as the sum of outcomes over year 1 and year 2. Firstly, the per child benefits were aggregated within each sector, and were then summed up across the sectors (within-dimension approach). ${ }^{18}$ An annual discount rate of 2.5 percent was used for investments and benefits to account for the differences in the time at which investments and outcomes occur. ${ }^{16}$ The reasons for in/excluding outcomes from the SROI calculation, and the calculation of benefits are further detailed in Appendix 4.

\subsection{Statistical analysis}

Descriptive statistics were used to explore baseline sociodemographic and outcome variables. Multiple imputation was used to account for possible selective non-response (missing at random assumption) and to use all available data (see Appendix 4 for details on the handling of missing data). Imputations were generated with the MICE package in R using 50 imputed datasets with 20 iterations (for details see Appendix 4) using predictive mean matching. The mean differences in the per child benefits over year 1 and year 2 were examined with a generalized linear model with a Gamma distribution and a log link function to account for the zero values and skewness of the data. The analyses were adjusted for sex, study year at baseline, socioeconomic status (SES), ethnicity, baseline BMI z-scores (BMI adjusted for age and sex), and baseline outcome scores to account for imbalances in covariates (Appendix 4). The social return on investment was calculated as the ratio of benefits to net investments. Additionally, the incremental net monetary benefit was calculated as the difference in benefits (for HPSF and PAS versus control schools) minus the difference in net investments. All statistical analyses were performed in IBM SPSS Statistics for Windows version 23 (Armonk, NY: IBM Corp) and R version 3.5.1. 


\subsection{Scenario and sensitivity analysis}

Scenario analyses were performed to analyse the SROI of HPSF and PAS for specific situations. For details and reasoning behind the scenario analyses we refer to Appendix 5 . 1) Lower investments at HPSF for pedagogical staff ( 8 instead of 12 pedagogical workers) based on changes in the way activities are organized. 2) Lower investments for HPSF and PAS that are expected to occur on the long-term (so-called steady state). ${ }^{13}$ 3) Excluding children in grade 7 at baseline who are leaving school after the eighth grade and missed the two-year follow-up measurement. Sensitivity analyses were conducted to see how the results would change under different assumptions: 1) Including spillover effects on caregiver's HRQOL and productivity (paid work) (Figure 1: H6, HL4). 2) No offsets due to the extended school day at HPSF in the calculation of the net investment for HPSF. 3 \& 4) Willingness to pay (WTP) thresholds of $€ 20,000$ and $€ 50,000$ per QALY gained instead of $€ 36,000$ per QALY gained. 5) No discounting of benefits and investments instead of an annual discount rate of $2.5 \%$. 6) A complete case analysis (non-imputed outcomes). For details on the sensitivity analyses see also Appendix 5.

\section{Results}

At baseline (TO), $\mathrm{N}=1,403,60.3 \%$ children and their parents joined the study. For the current study, $\mathrm{N}=1,676$ children and their parents were included based on the selection of school years and school switchers excluded (See Appendix 1 for the flow diagram). ${ }^{6}$ Children from control schools had higher BMI z-scores (0,232 vs. 0,051 at HPSF and 0,092 at PAS) and chronic diseases were more prevalent $(36 \%$ versus $30 \%$ at HPSF and PAS) (Table 1).

\subsection{Investments}

For the first year of implementation, the total investments amounted to $€ 1,448$ per child for HPSF and $€ 665$ per child for PAS. The offsets for HPSF included the forgone household expenses on children's lunches as they were provided by the schools, the value of the extended school day in terms of parental productivity, and the forgone household expenses on the fee for the lunch break (used for supervision during the lunch break) which was not applied (total €-1,019 per child). The net investment costs of HPSF were $€ 429$ per child for the first year of intervention implementation (€2.68 per child per day) (not discounted). The offsets for PAS only included the forgone household expenses on the fee for the lunch break (the offsets for the lunch and the prolonged school day were not applicable for PAS), and the net investment amounted to $€ 505$ per child for the first year (€3.16 per child per day) 
(not discounted). ${ }^{19}$ In the second year, the costs for transport and accommodations were not incurred, which resulted in a net investment of $€ 399$ (HPSF) and $€ 475$ (PAS) per child (not discounted). The net investment for year 1 and year 2 together were $€ 828$ per child for HPSF (€2.59 per child per day) and €980 for PAS (€3.06 per child per day) (discounted results: $€ 859$ per child year and $€ 2.69$ per child per day for HPSF, and $€ 1,017$ per child year and $€ 3.18$ per child per day for PAS).

\subsection{SROI story (non-monetized outcomes)}

\subsubsection{Child outcomes}

Healthcare. Bartelink et al. (2019) previously reported that water consumption, the intake of different food types during the lunch, and time spent in light physical activity had increased more at HPSF compared to control schools. ${ }^{5}$ Several participants on the interviews reported that dietary behaviours of children at HPSF became more diverse, and children were more willing to taste unfamiliar products (Figure 1: $\mathrm{H1}$ ). ${ }^{14}$ Standardized BMI scores had decreased more in children at HPSF compared to children at PAS and control schools, and for children at PAS in comparison to children at control schools (Figure 1: $\mathrm{H} 2$ ). ${ }^{6}$

Education. From the interviews with stakeholders it emerged that children were less bored during recess time and fewer conflicts happened at the schoolyard and in the classroom (Figure 1: E1). ${ }^{14}$ The school satisfaction surveys showed that children were satisfied with the lunch (60-83\% at the two HPSF schools), and with the PA sessions at HPSF and PAS (75$93 \%)$. Nearly half of the children at HPSF enjoyed the school day more (39-50\%) compared to the pre-intervention period, compared to $46-57 \%$ of children at PAS (Figure 1: E4).

Intangibles. Regarding non-cognitive skills, the interview respondents noticed that children learnt from the offered games as children were better able to create and manage their own activities during recess time (Figure 1: 11). No significant differences were found between groups for children's self-efficacy scores (adjusted mean differences HPSF vs. control: -0.48 [95\% Cl:-1.38;0.42] PAS vs. control: 0.30 [95\% Cl: $-0.60 ; 1.19])$. Self-reported psychosocial health (Figure 1: 12), measured with the Pediatric Quality of Life (PedsQL) instrument, decreased somewhat from baseline to year 2 (no statistically significant differences between groups). This was, however, not observed for parent-reports about children's psychosocial health (Appendix 6).

\subsubsection{Outcomes in other persons than the child}

Healthcare. Some teacher and parental practices (discussing and educating about nutrition and PA) changed in a favourable direction (Figure 1: $\mathrm{H} 5$ ). ${ }^{14}$ 
Education. Caregivers were generally satisfied with the organization (67-74\%) and the content of the lunch (70-76\%) at HPSF, and with the structured sports activities, free play, and creative activities at HPSF and PAS (50-79\%). The majority would recommend HPSF to other caregivers (64-76\%) (Figure 1: E5).

Intangibles. No significant changes over time were found between groups for parental wellbeing (adjusted mean differences HPSF vs. control: 0.28 [95\% Cl: $-0.37 ; 0.93$ ], PAS vs. control: 0.08 [95\% Cl:-0.61;0.76]) (Figure 1: 13).

Household \& leisure. Organizations for sport and leisure were invited to provide workshops. Activities did not only take place at school, but the school gym and the green area around the school were also used for free play and games (Figure 1: HL3). At year 2, 12-18 percent of the respondents on the parental questionnaire reported that their own working hours and/or the working hours of their partner changed as a result of HPSF and PAS, varying from minor to a lot of influence.

Labour \& social security. No statistically significant differences were found for parental absenteeism from work or education (Appendix 6) (Figure 1: L2). As the results were based on only few cases (known for $<10 \%$ of the analyzed study participants) the benefits could not be reliably estimated, we refrained from including this benefit in the calculation of social return on investment.

\subsection{SROI calculation (monetized outcomes)}

No statistically significant differences were found between groups for the number of QALYs accrued by children and for children's medical resource use within the two-years of followup (Figure 1: H3 \& H4). No statistically significant differences were found for health-related and non-health related absenteeism (Figure 1: E3). Because absenteeism represents a cost, absenteeism days were represented as a negative benefit. The monetary value (per child per 2 years) for health-related absenteeism amounted to $€-309$ (PAS) and $€-352$ (HPSF) versus $€-338$ (control schools), and were $€-29$ (PAS) and $€-25$ (HPSF) versus $€-31$ (control schools) for non-health related absenteeism (Table 2).

No significant differences were found between groups for the number of QALYs accrued by caregivers (Figure 1: H6): rate ratio HPSF vs. control: 1.00 [95\% Cl: $0.97 ; 1.04$ ], rate ratio PAS vs. control: 1.01 [95\% Cl: $0.97 ; 1.04]$. No statistically significant differences were found for time spent on paid work (Figure 1: HL4): rate ratio HPSF vs. control: 1.02 [95\% Cl: $0.97 ; 1.08]$, PAS vs. control: 1.05 [95\% Cl: 0.99; 1.12].

The net investment for HPSF (€859/child/2 years), generated a benefit of $€ 8 / \mathrm{child} / 2$ years [95\% Cl: $€-1,085$ to $€ 1,057]$ when considering the financial outcomes in the child (Table 2). The incremental net benefit of HPSF was estimated at $€-851 /$ child/2 years (SROI ratio of 0.01$)$. The net investment costs for PAS $(€ 1,017 /$ child/2years), generated a benefit 
of $€ 49 /$ child $/ 2$ years [ $95 \% \mathrm{Cl}: €-1,041$ to $€ 1,097$ ]. The incremental net benefit of PAS was estimated at $€-968 /$ child/2 years (SROI ratio of 0.05 ). See Appendix 6 for the results when not adjusting for covariates. A breakdown of results by sector shows that most investment were incurred by the education sector, while offsets were received by the household and leisure sector, and most benefits belonged to the healthcare sector (HPSF: 100\%, PAS:40\%) (Table 3).

The results of the scenario and sensitivity analyses were comparable to the base-case (SROI between zero and one), except for excluding children who were in grade 7 at baseline, and for the complete case analysis (Appendix 7). Repeating the analysis without children in grade 7 resulted in extra benefit for both HPSF and PAS (SROI HPSF: 1.70 versus 0.01; PAS: 0.70 versus 0.05 ). Additionally, including spillovers on caregiver's HRQOL and productivity increased the SROI (SROI HPSF: 0.05 vs. 0.01 , PAS: 0.70 vs. 0.05). The complete case analysis showed comparable results with regard to the direction of the regression estimates (Appendix 5). However, due to the number of missing data and the missing data mechanism (not completely at random) the complete case analysis resulted in inefficient and (probably) biased point estimates of the benefits (SROI HPSF: -1.80 versus 0.01 , PAS: 0.60 versus 0.05 ). 


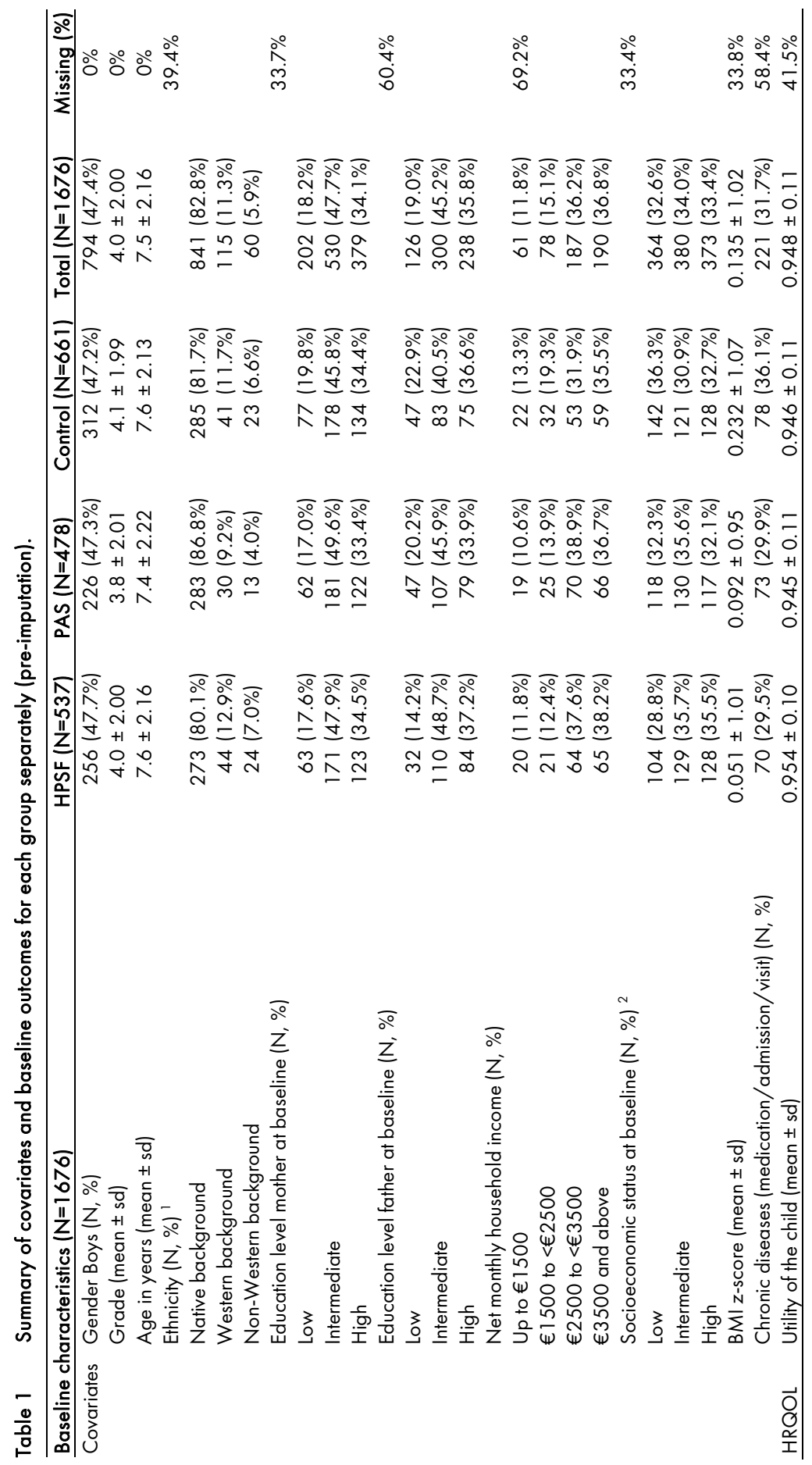




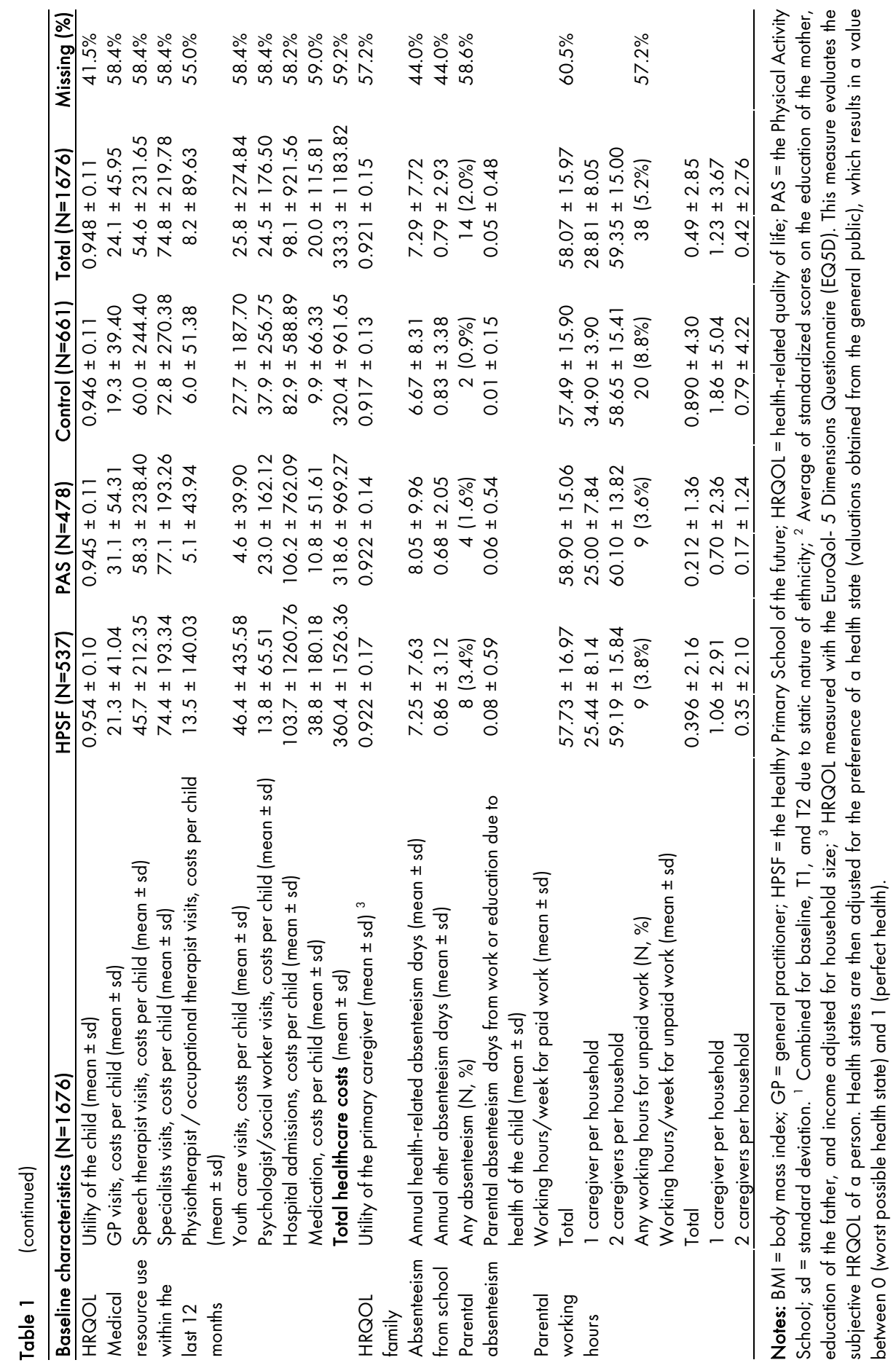




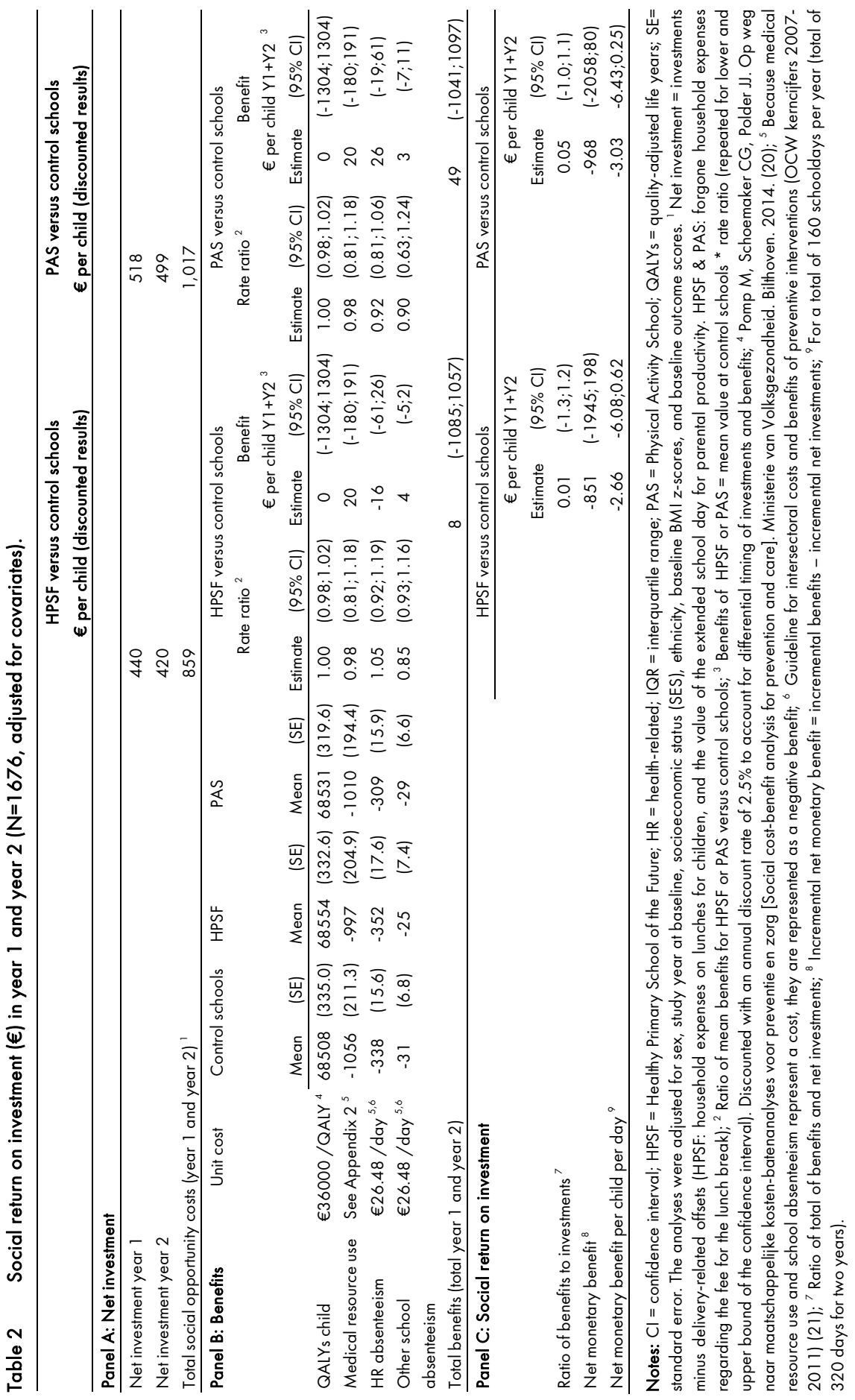




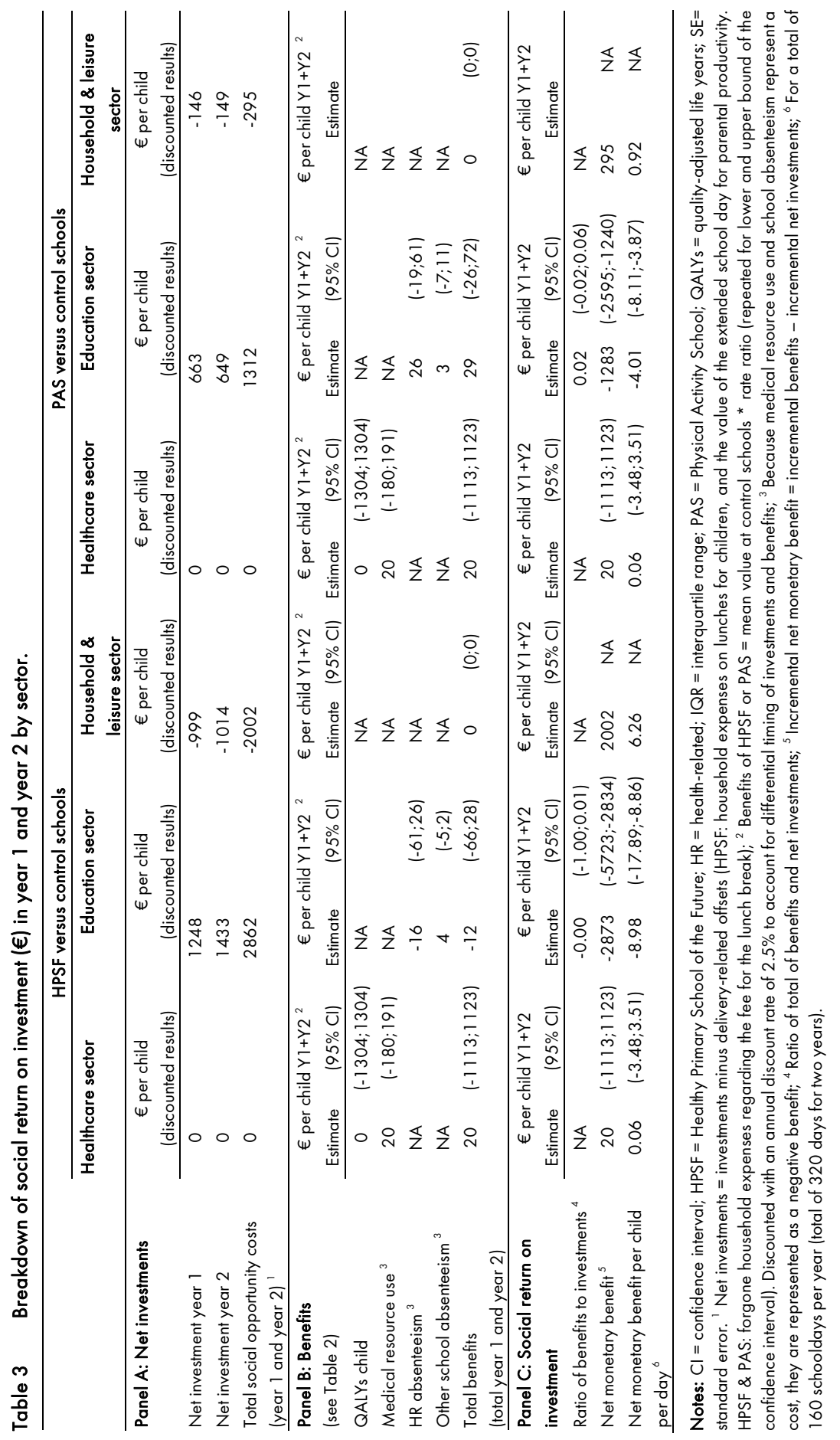




\section{Discussion}

The objective of the current study was to examine the short-term return on investment created by HPSF and PAS after two years of intervention. HPSF and PAS led to outcomes within the healthcare sector (favourable changes in health behaviours and body mass index [both significant], and medical resource use [not significant]), education sector (favourable changes on perceived social behaviours at school and school satisfaction, and absenteeism from school [later not significant]), and household \& leisure sector (perceived engagement with the community). The benefits (HPSF: €0.05 per child/day, PAS: €0.31/child/day), did not outweigh the net investment costs of HPSF and PAS (HPSF: €2.69/child/day, PAS: $€ 3.18 /$ child/day). For every euro invested, HPSF and PAS generated a benefit of $€ 0.01$ [95\% Cl: $€-1.3 ; € 1.2]$ and $€ 0.05[95 \% \mathrm{Cl}: €-1.0 ; € 1.1]$, respectively. In the paper of Bartelink et al. (2019) it was shown that HPSF resulted in more favourable effects on children's BMI scores compared to PAS. ${ }^{6}$ The authors suggested that HPSF may be more effective in targeting health behaviours, since HPSF simultaneously addressed nutrition and physical activity, and the activities at HPSF led to additional health-promoting changes in the school. ${ }^{5}$ In contrast, the SROI calculation revealed that PAS led to more financial benefits than HPSF, which was mainly due to the favourable effects of PAS on absenteeism from school (not statistically significant). The results, however, do not suggest that PAS had a more favourable SROI as compared to HPSF, because HPSF led to more favourable results on the non-monetized outcomes (see SROI story). The findings on financial benefits need to be interpreted with caution. Benefits were not statistically significant and therefore uncertain, but a trend towards favourable outcomes was observed. The SROI of HPSF and PAS increased substantially after including spillover effects, which was driven by the monetization of the relative small effects on caregivers' HRQOL (WTP for a QALY), as well as by the favourable effects on caregiver productivity. In the sensitivity analysis, it can also be seen that the SROI was sensitive to the QALY gains. Most short-term cost-effectiveness studies on childhood lifestyle interventions examined cost-effectiveness by the ratio of costs and health outcomes such as body mass index improvements, cases of overweight prevented, or units of waist circumference prevented. ${ }^{20}$ WTP thresholds are not available for these outcomes, and interpreting their cost-effectiveness results therefore remains difficult. In contrast to these studies, we combined a qualitative and quantitative approach for examining the health- and non-health outcomes of HPSF and PAS. By using the SROI framework we were able to integrate the outcomes for multiple sectors. ${ }^{21,22}$ If we would have examined the interventions from a healthcare perspective alone, a substantial part of the outcomes would have been ignored (HPSF: 49 percent of financial benefits, PAS: 59 percent of financial benefits). Jones et al. (2011) examined the SROI of the Food for Life programme, and also considered both health-related and non-health outcomes for local suppliers, school catering services, 
schools, parents, and local authorities. ${ }^{23}$ Financial proxies were defined by stakeholders, such as using the costs of a trip to the farm for valuing the knowledge of children about the origin of foods, which resulted in a SROI ratio of 4.4. Defining monetary values for nonfinancial outcomes is challenging as methods for obtaining proxies are not standardized. In the current study, we used standard cost prices only and refrained from defining financial proxies ourselves. This could have resulted in a conservative estimate of the SROI of HPSF and PAS. Due to the non-response on the parental questionnaire and the dynamic cohort design, our study suffered from missing data on covariates and longitudinal outcomes, which required multiple imputation.

Decisions on school-based lifestyle interventions should not be based on only the intervention's short-term return on investment. Follow-up assessments, as well as modelling to extrapolate short-term results beyond the trial period, are required to examine the full merits of school-based lifestyle interventions. Long-term information is, however, not always available for decision-making, because follow-up assessments are dependent on previous intervention implementation. To ensure successful intervention implementation and continuation it is crucial to have support from all stakeholders. The SROI framework allowed for comprehensively assessing the distribution of investments and outcomes over stakeholder groups. The results of the current study showed that the short-term benefits did not outweigh the investments of the HPSF initiative, but outcomes were generated for multiple sectors. The majority of investments were incurred by the education sector, while outcomes were received by the healthcare, household \& leisure, and education sector. This information can be used as input for continuation decisions and investment strategies on the HPSF initiative by, for example, exploring alternative modes of intervention delivery (e.g. changing the organization of activities so that fewer pedagogical employees are needed), and examining whether a redistribution of investments over, amongst others, schools, parents, and the government is desired. The SROI framework can therefore serve as a tool in obtaining stakeholder support, foster intervention implementation and continuation, and facilitate follow-up research and decision-making on school-based lifestyle interventions. In accordance to others, we recommend that further research should focus on the valuation of outcomes in different sectors, $18,22,24$ and on the methods for valuing outcomes across different sectors to further develop the methodology and enhance the implementation of the SROI methodology. ${ }^{18,25}$ Future research is also needed to examine if SROI evaluations adequately meet the information needs of different stakeholders and optimally support the various decision-making processes on school-based lifestyle interventions. 


\section{References}

1. Lake A, Townshend T. Obesogenic environments: exploring the built and food environments. J R Soc Promot Health. 2006; 1 26(6):262-7.

2. Guthold R, Stevens GA, Riley LM, Bull FC. Worldwide trends in insufficient physical activity from 2001 to 2016: a pooled analysis of 358 population-based surveys with 1.9 million participants. Lancet. 2018;6(10):e 1077-86.

3. Schönbeck Y, Talma H, van Dommelen P, Bakker B, Buitendijk SE, Hirasing RA, et al. Increase in Prevalence of Overweight in Dutch Children and Adolescents: A Comparison of Nationwide Growth Studies in 1980, 1997 and 2009. PLoS One. 2001;6(11):e27608.

4. Willeboordse M, Jansen MW, van den Heijkant SN, Simons A, Winkens B, de Groot RH, et al. The Healthy Primary School of the Future: study protocol of a quasi-experimental study. BMC public health. 2016;16:639.

5. Bartelink NHM, van Assema P, Kremers SPJ, Savelberg HH, Oosterhoff M, Willeboordse M, et al. One- and Two-Year Effects of the Healthy Primary School of the Future on Children's Dietary and Physical Activity Behaviours: A Quasi-Experimental Study. Nutrients. 2019;11(3).

6. Bartelink N, Van Assema P, Kremers SPJ, Savelberg HH, Oosterhoff M, Willeboordse M, et al.. Can the Healthy Primary School of the Future offer perspective in the on-going obesity epidemic in young children? a quasi-experimental study. BMJ Open. 2019;9(10):e030676.

7. Masters R, Anwar E, Collins B, Cookson R, Capewell S. Return on investment of public health interventions: a systematic review. J Epidemiol Community Health. 2017;71:827-34.

8. Finkelstein EA, Trogdon JG. Public Health Interventions for Addressing Childhood Overweight: Analysis of the Business Case. Am J Public Health. 2008;98(3):411-5.

9. Laing CM, Moules NJ. Social Return on Investment: A New Approach to Understanding and Advocating for Value in Healthcare. J Nurs Adm. 2017;47(12):623-8.

10. Banke-Thomas AO, Madaj B, Charles A, van den Broek N. Social Return on Investment (SROI) methodology to account for value for money of public health interventions: a systematic review. BMC Public Health. 2015; 15:582.

11. Bartelink NHM, van Assema P, Jansen MWJ, Savelberg HH, Willeboordse M, Kremers SPJ. The Healthy Primary School of the Future: A Contextual Action-Oriented Research Approach. Int J Environ Res Public Health. 2018;15(10):2243.

12. Nicholls J, Lawlor E, Neitzert E, Goodspeed T. A guide to social return on investment. 2012. [Accessed 1 March 2019].

13. Oosterhoff M, Bosma H, van Schayck OCP, Joore MA. A Cost Analysis of School-Based Lifestyle Interventions. Prev Sci. 2018;19(6):716-27.

14. Bartelink NHM, van Assema P, Jansen MWJ, Savelberg HH, Moore GF, Hawkins J, et al. Process evaluation of the Healthy Primary School of the Future: the key learning points. BMC Public Health. 2019; 19:698.

15. Zorginstituut Nederland. Kostenhandleiding: Methodologie van kostenonderzoek en referentiepriizen voor economische evaluaties in de gezondheidszorg [Methodology of cost research and cost prices for heal economic evaluations]. 2015. [Accessed November 14, 2019].

16. Pomp M, Schoemaker CG, Polder JJ. Op weg naar maatschappelijke kosten-batenanalyses voor preventie en zorg [Social cost-benefit analysis for prevention and care]. Ministerie van Volksgezondheid. 2014. [Accessed March 1, 2019].

17. Drost R, Paulus A, Ruwaard D, Evers S. Handleiding intersectorale kosten en baten van (preventieve) interventies [Guideline for intersectoral costs and benefits of preventive interventions]. 2014.

18. Walker S, Griffin S, Asaria M, Tsuchiya A, Sculpher M. Striving for a Societal Perspective: A Framework for Economic Evaluations When Costs and Effects Fall on Multiple Sectors and Decision Makers. Appl Health Econ Health Policy. 2014.17(5):577-590.

19. Oosterhoff M, Bosma H, van Schayck OCP, Joore MA. Correction to: Cost Analysis of School-Based Lifestyle Interventions. Prev Sci. 2019. 
20. Oosterhoff $M$, Bosma H, van Schayck OCP, Evers S, Dirksen CD, Joore MA. A systematic review on economic evaluations of school-based lifestyle interventions targeting weight-related behaviours among 412 year olds: Issues and ways forward. Prev Med. 2018;1 14:1 15-22.

21. Goebbels AF, Lakerveld J, Ament AJ, Bot SD, Severens JL. Exploring non-health outcomes of health promotion: the perspective of participants in a lifestyle behaviour change intervention. Health policy. 2012;106(2): 177-86

22. van Mastrigt GA, Paulus AT, Aarts MJ, Evers SM, Alayli-Goebbels AF. A qualitative study on the views of experts regarding the incorporation of non-health outcomes into the economic evaluations of public health interventions. BMC public health. 2015;15:954.

23. Jones RA, Sinn N, Campbell KJ, Hesketh K, Denney-Wilson E, Morgan PJ, et al. The importance of long-term follow-up in child and adolescent obesity prevention interventions. Int J Pediatr Obes. 201 1;6(3-4):178-81.

24. Sanders GD, Neumann PJ, Basu A, Brock DW, Feeny D, Krahn M, et al. Recommendations for Conduct, Methodological Practices, and Reporting of Cost-effectiveness Analyses: Second Panel on Cost-Effectiveness in Health and Medicine. JAMA. 2016;316(10): 1093-103.

25. Hutchinson CL, Berndt A, Gilbert-Hunt S, George S, Ratcliffe J. Valuing the impact of health and social care programmes using social return on investment analysis: how have academics advanced the methodology? $\mathrm{A}$ protocol for a systematic review of peer-reviewed literate. BMJ Open. 2018;8;e022534. 


\section{Appendix 1}

\section{Flowchart of children participating in the measurements}

\begin{tabular}{|c|c|c|}
\hline \multicolumn{3}{|c|}{$\begin{array}{c}\text { Baseline } \\
\text { Total participating children: } n=1403 \text { (60.3\% of all children) }\end{array}$} \\
\hline \multicolumn{3}{|c|}{$\begin{array}{l}\text { Selection for the current study } \\
\text { Participating children in classes 1-7: } n=1255\end{array}$} \\
\hline $\operatorname{HPSF}(n=361)$ & PAS $(n=408)$ & Control $(n=486)$ \\
\hline \multicolumn{3}{|c|}{$\begin{array}{l}\text { One year follow up (Year } 1) \\
\text { Total participating children: } n=1489 \text { ( } 60.7 \% \text { of all children) }\end{array}$} \\
\hline \multicolumn{3}{|c|}{$\begin{array}{l}\text { Selection for the current study } \\
\text { Participating children in classes 2-8: } n=1455 \\
\text { Newly included }(n=264) \text {; Drop-out }{ }^{*}(n=64)\end{array}$} \\
\hline $\begin{array}{l}\text { HPSF }(n=469) \\
\text { New included: } n=132 \\
\text { Drop-out: } n=24\end{array}$ & $\begin{array}{l}\text { PAS }(n=428) \\
\text { New included: } n=33 \\
\text { Drop-out: } n=13\end{array}$ & $\begin{array}{l}\text { Control }(n=558) \\
\text { New included: } n=99 \\
\text { Drop-out: } n=27\end{array}$ \\
\hline \multicolumn{3}{|c|}{$\begin{array}{l}\text { Two year follow up (Year } 2) \\
\text { ticipating children: } n=1470(61.7 \% \text { of all children) }\end{array}$} \\
\hline \multicolumn{3}{|c|}{$\begin{array}{l}\text { Selection for the current study } \\
\text { Participating children in classes 3-8: } n=1323 \\
\text { Newly included ( } n=158) \text {; Drop-out * }(n=290)\end{array}$} \\
\hline $\begin{array}{l}\text { HPSF }(n=432) \\
\text { New included: } n=44 \\
\text { Drop-out: } n=81\end{array}$ & $\begin{array}{l}\text { PAS }(n=376) \\
\text { New included: } n=38 \\
\text { Drop-out: } n=90\end{array}$ & $\begin{array}{l}\text { Control }(n=515) \\
\text { New included: } n=76 \\
\text { Drop-out: } n=119\end{array}$ \\
\hline \multicolumn{3}{|c|}{ Total participating children in study period: $n=1974$} \\
\hline \multicolumn{3}{|c|}{ Selection for the current study: $n=1676$} \\
\hline HPSF $(n=537)$ & PAS $(n=478)$ & Control $(n=661)$ \\
\hline
\end{tabular}

Notes: The flow diagram is similar to Bartelink et al. (2019). ${ }^{4}$ HPSF $=$ Healthy Primary School of the Future; PAS = Physical Activity School; Year 1 = after 12 months; Year 2 = after 24 months. " Reasons drop out Year 1: switched to other included school $(n=2)$, other reasons e.g. moved out or actively stopped participation $(n=62) .{ }^{* *}$ Reasons drop out Year 2: finished school ( $n=228)$, switched to other included school ( $n=17)$, other reasons e.g. moved out or actively stopped participation $(n=45)$. 


\section{Appendix 2}

\section{Identifying and evidencing investments}

In a previous study, we made an overview of the activities that were provided at HPSF and PAS in addition to the regular school curriculum. ' We calculated the corresponding net investments, which is the sum of all investments from the different sectors (see above) minus the cost offsets that were directly related to intervention delivery. Investments were either material costs (food, curriculum materials, monitoring equipment) or personnel costs (project and school coordinators, pedagogical staff, time costs of volunteers, compensation for external parties giving workshops). Direct cost offsets applied to HPSF, and included the offsets for food costs for the household sector as lunches were provided at school, and the value of the extended school day as the extended school hours at HPSF provided caregivers with additional time that could be spent on paid or unpaid work (productivity cost). In the first year of intervention implementation, there were also direct cost offsets for the household sector as the fee for the lunch break was not applied. Information on investments and cost offsets were retrieved from a literature review, stakeholder interviews, budget information, and curriculum information. Costs were measured in 2016 prices. 


\section{Appendix 3}

\section{Identifying and evidencing outcomes}

Table S. 1 details the outcome measures, the informants and sources, and the method of data collection. Outcomes that were measured qualitatively were obtained from semi-structured interview with stakeholders (see main text). Outcomes were measured quantitatively as part of the quasi-experimental study, with objective measurements on weight and height, child questionnaires, parental questionnaires, and school records (see main text). ${ }^{2}$ To participate in data collection, participants completed an informed consent form signed by both parents/caregivers, and by the children in case they were 12 years or older (need for ethical approval has been waived by the Medical Ethics Committee Zuyderland in Heerlen). A total of 1,403 (TO), 1,489 (T1), and 1,470 (T2) children and their parents joined the study at the specific time points. Child questionnaires which were administered in grade 5-8, were completed by a total of 585 out of 1,403 participants (41.7\%) at T0 [not administered in eight grade at baseline], 843 out of 1,489 participants $(56.6 \%)$ at $\mathrm{T} 1$, and for 813 children out of $1,470(55.3 \%)$ at T2. The parental questionnaire was completed by 836 out of 1,403 participants $(59.6 \%)$ at T0, 725 out of $1,489(48.7 \%)$ at $\mathrm{T} 1$, and by 733 respondents out of $1,470(49.9 \%)$ at $\mathrm{T} 2$.

The study has a dynamic cohort design as children continually enter and leave primary school; therefore. Children and their parents are were therefore also invited to join participate during the study. In the current study, we included a cohort of children that were enrolled at the participating schools and thus exposed to the interventions from baseline onwards, including children from study year one to seven at baseline, children from study year two to eight at $\mathrm{T} 1$, and children from study year three to eight at $\mathrm{T} 2$. Children in grade 8 were excluded from the baseline measurement as no follow-up could be obtained.

We excluded the children that switched between schools between 2015 and 2017 . For the current study, $\mathrm{N}=1676$ children and their parents were included based on the selection of school years and school switchers excluded (see methods). 


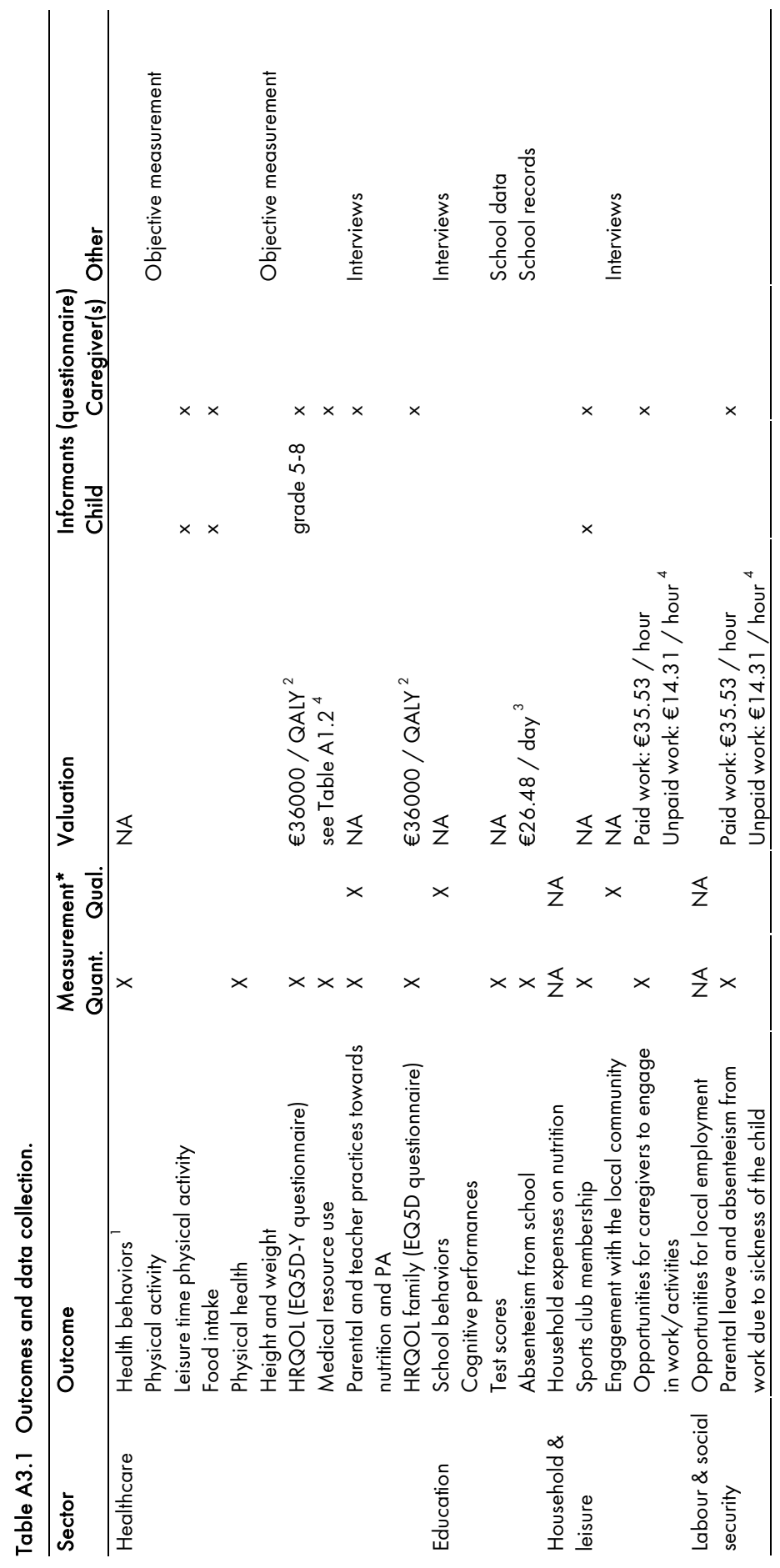




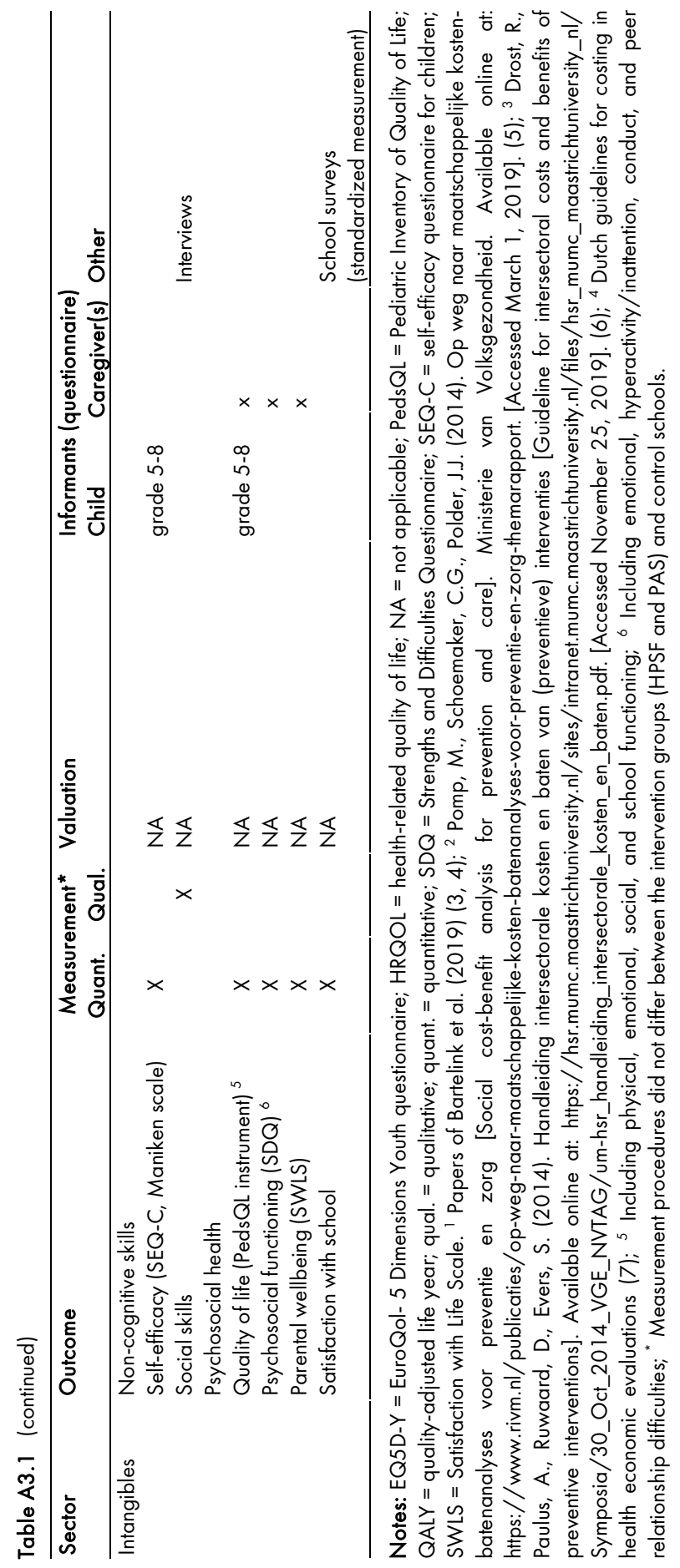




\section{Appendix 4}

\section{SROI assessment}

\section{Outcomes expressed in the SROI calculation and SROI story}

The reasons for in/excluding outcomes from the SROI calculation are further detailed in Table A4.1. The details on the outcomes for the SROI calculation are provided in Table A4.2.

Table A4.1 Details on outcomes included in the SROI story.

\begin{tabular}{|c|c|c|c|}
\hline Sector & See Fig 1. & Outcomes & Justification for exclusion from SROI calculation \\
\hline \multirow[t]{12}{*}{ Healthcare } & $\mathrm{Hl}$ & Health behaviors ( 3 ) & When including all impacts for the healthcare sector, \\
\hline & & - Physical activity & this would result in double counting as it is assumed that \\
\hline & & - Leisure time physical activity & changes in children's health behaviours and health \\
\hline & & - Food intake & status affect their HRQOL and medical resource use. As \\
\hline & $\mathrm{H} 2$ & Physical health (4) & such, changes in health behaviours and physical health \\
\hline & & - Height and weight & are intermediate outcomes for the impacts on $\mathrm{HRQOL}$ \\
\hline & & & and medical resource use. \\
\hline & H5 & Parental and teacher practices & Including the impacts on health behaviours and $\mathrm{HRQOL}$ \\
\hline & & towards nutrition and PA & could lead to double counting of outcomes. It is \\
\hline & & & assumed that the changes in practices towards nutrition \\
\hline & & & and PA are an intermediate outcome of the potential \\
\hline & & & impact on family HRQOL. \\
\hline \multirow[t]{4}{*}{ Education } & El & School behaviours (e.g. bullying) & Measured qualitatively. \\
\hline & E2 & Executive functioning and cognitive & A longer time horizon is required to examine the \\
\hline & & performance & potential financial returns. \\
\hline & $\mathrm{E} 4, \mathrm{E} 5$ & School satisfaction & $\begin{array}{l}\text { No financial proxy available to express the effects in } \\
\text { financial returns. }\end{array}$ \\
\hline \multirow[t]{11}{*}{ Intangibles } & 11 & Non-cognitive skills & \\
\hline & & - Self-efficacy & No financial proxy available to express the effects in \\
\hline & & & financial returns. \\
\hline & & - Social skills & Measured qualitatively. \\
\hline & 12 & Psychosocial health and wellbeing & \\
\hline & & - Quality of life (PedsQL instrument) & No financial proxy available to express the effects in \\
\hline & & - Psychosocial functioning (SDQ) & financial returns. \\
\hline & 13 & Wellbeing family (SWLS) & No financial proxy available to express the effects in \\
\hline & & & financial returns. \\
\hline & & & No financial proxy available to express the effects in \\
\hline & & & financial returns. \\
\hline \multirow[t]{4}{*}{$\begin{array}{l}\text { Household } \\
\text { leisure }\end{array}$} & \& HLl & $\begin{array}{l}\text { Household expenses on healthy } \\
\text { nutrition }\end{array}$ & $\begin{array}{l}\text { Not formally measured within the quasi-experimental } \\
\text { study. }\end{array}$ \\
\hline & $\mathrm{HL2}$ & Sports club membership & No financial proxy available to express the effects in \\
\hline & & & financial returns. \\
\hline & HL3 & Engagement with the local community & Measured qualitatively. \\
\hline Labour & \& L1 & Opportunities for local employment & Not formally measured within the quasi-experimental \\
\hline \multicolumn{2}{|c|}{ social security } & & study. \\
\hline
\end{tabular}

Notes: $\mathrm{HRQOL}=$ health-related quality of life; PA = physical activity; PedsQL = Pediatric Inventory of Quality of Life; SDQ = Strengths and Difficulties Questionnaire; SEQ-C = self-efficacy questionnaire for children; SWLS = Satisfaction with Life Scale. 
Table A4.2 Details on outcomes included in the SROI story.

\begin{tabular}{|c|c|c|c|c|}
\hline Sector & $\begin{array}{l}\text { See } \\
\text { Fig } 1\end{array}$ & Outcomes & Measurement & Valuation \\
\hline \multirow[t]{3}{*}{ Healthcare } & $\mathrm{H} 3$ & $\mathrm{HRQOL}$ & $\begin{array}{l}\text { Measured with the EQ5D-Y } \\
\text { questionnaire, self-report for } \\
\text { children in grade } 5-8 \text {, proxy report } \\
\text { by caregivers for children < grade } \\
5 \text {. }\end{array}$ & $€_{1} 36000 / \mathrm{QALY}$ \\
\hline & $\mathrm{H} 4$ & Medical resource use & $\begin{array}{l}\text { Included in the parental } \\
\text { questionnaire }{ }^{2}\end{array}$ & see Table S. $4^{3}$ \\
\hline & $\mathrm{H} 6$ & HRQOL family & $\begin{array}{l}\text { Measured with the EQ5D } \\
\text { questionnaire }\end{array}$ & $\bigoplus_{1}^{€ 36000 / Q A L Y}$ \\
\hline Education & E3 & Absenteeism from school & School records & $€ 26.48 /$ day $^{4}$ \\
\hline $\begin{array}{l}\text { Household \& } \\
\text { leisure }\end{array}$ & $\mathrm{HL} 4$ & $\begin{array}{l}\text { Opportunities for caregivers to } \\
\text { engage in work/activities } 5\end{array}$ & $\begin{array}{l}\text { The volume was based on the } \\
\text { duration of the extended school } \\
\text { day }\end{array}$ & $\begin{array}{l}\text { Paid work: } \\
€ 35.53 \text { / hour } \\
\text { Unpaid work: } \\
€ 14.31 \text { / } \text { hour }^{3}\end{array}$ \\
\hline $\begin{array}{l}\text { Labour \& social } \\
\text { security }\end{array}$ & $\mathrm{L} 2$ & $\begin{array}{l}\text { Parental leave and absenteeism } \\
\text { from work due to sickness of the } \\
\text { child }\end{array}$ & Parental questionnaire ${ }^{6}$ & $N A^{6}$ \\
\hline
\end{tabular}

Notes: EQ5D-Y = EuroQol- 5 Dimensions Youth questionnaire; HRQOL = health-related quality of life; $Q A L Y=$ quality-adjusted life year. 'Pomp, M., Schoemaker, C.G., Polder, J.J. (2014). Op weg naar maatschappelijke kosten-batenanalyses voor preventie en zorg [Social cost-benefit analysis for prevention and care]. Ministerie van Volksgezondheid. Available online at: https://www.rivm.nl/publicaties/op-weg-naar-maatschappelijke-kostenbatenanalyses-voor-preventie-en-zorg-themarapport. [Accessed March 1, 2019]. (5); ${ }^{2}$ Healthcare resource use was measured by a parental questionnaire with a 12-month recall about the number of healthcare visits (including visits to the general practice and physicians, and use of mental health and youth care services), hospital admissions and medication use; ${ }^{3}$ Dutch guidelines for costing in health economic evaluations (7); ${ }^{4}$ Drost, R., Paulus, A., Ruwaard, D., Evers, S. (2014). Handleiding intersectorale kosten en baten van (preventieve) interventies [Guideline for intersectoral costs and benefits of preventive interventions]. Available online at: https://hsr.mumc.maastrichtuniversity.nl/sites/intranet.mumc.maastrichtuniversity.nl/files/hsr_mumc_maastrichtuni versity_nl/Symposia/30_Oct_2014_VGE_NVTAG/um-hsr_handleiding_intersectorale_kosten_en_baten.pdf.

[Accessed November 25, 2019]. (6); ${ }^{5}$ In the calculation of the investments of HPSF, the consequences of the extended school day were included in terms of increased parental productivity. The opportunities for caregivers to engage in work (parental productivity) could not only be affected by the extended school hours at HPSF, but could also be affected by child and parental health and HRQOL. 


\subsection{Calculation of benefits for the social return on investment calculation}

Benefits are the product of outcomes (volume) and the financial proxy or unit cost. The reported volumes after year 1 and year 2 were combined to calculate the aggregated results over the total follow-up period of two years. The aggregated volumes were then multiplied with the unit costs (2017 prices).

There were two methods for summing up volumes:

1) When volumes were obtained with a recall period of 12 months, volumes were summed up:

$$
V_{i}=v_{i, y 1}+v_{i, y 2}
$$

where $V$ represents the total volume, $y 1$ is the 12 month period from baseline to $T 1$, and $y 2$ is the 12 month period from $\mathrm{T} 1$ to $\mathrm{T} 2$.

2) When volumes were obtained for the specific time points, volumes were summed up with the area under the curve method:

$$
V_{i}=\frac{v_{i, t 0}+\mathrm{v}_{i, t 1}}{2} *(t 1-t 0)+\frac{v_{i, t 1}+\mathrm{v}_{i, t 2}}{2} *(t 2-t 1)
$$

where $\mathrm{V}$ represents the total volume, t0 the time point of the baseline measurement, $t 1$ the time point of the first follow-up measurement (after 12 months), and 22 the time point of the first follow-up measurement (after 24 months).

\section{H3: HR-Qol of the child}

Children's HR-QoL was measured by the EuroQol 5 dimensions Youth questionnaire (EQ5D-Y) which was completed by children in grade 5-8 (8-12 year-olds), and by the EQ5$5 \mathrm{D}-\mathrm{Y}$ proxy questionnaire which was completed by parental report. In the base-case analysis, we used the self-reports on HR-QoL in 8-12 year-olds and proxy-reports for children between 4-8 years of age. The EQ5D questionnaire contains five questions regarding mobility, self-care, usual activities, pain/discomfort, and anxiety/depression, scored on a 3-point (child and proxy questionnaire) or 5-point (carer) rating scale. The corresponding health states were converted to utility values with valuations obtained from the general public. ${ }^{8}$ Quality-adjusted life years (QALYs) were calculated by means of the area under the curve method, in which the time in a certain health state was multiplied by the utility value (see method 2). With this method it is assumed that the utility between two consecutive measurements equals the mean of those two measurements. QALYs were valued using a financial proxy of $€ 36000$ per QALY. ${ }^{5}$ 


\section{H4: Medical resource use}

Healthcare resource use was measured by a parental questionnaire with a 12-month recall about the number of healthcare visits (including visits to the general practice and physicians, and use of mental health and youth care services), hospital admissions and medication use (see method 1). The costs of medication use were calculated according to the recommendations of the Dutch guidelines for costing in health economic evaluations. ${ }^{7}$ Information on the costs of pharmaceuticals was obtained from the website of the Dutch healthcare institute (www.medicijnkosten.nl).

Table A4.3 Unit costs for medical resource use.

\begin{tabular}{ll}
\hline Resources & Unit costs $^{3}$ \\
\hline GP visits & $€ 35.53^{B}$ \\
Speech therapist visits & $€ 30.49^{B}$ \\
Specialist visits & $€ 92.47^{B}$ \\
Physiotherapist / Occupational therapist visits & $€ 33.53^{B}$ \\
Youth care visits (Dutch: jeugdzorg en jeugdhulpverlening) & $€ 62.24^{C}$ \\
Psychologist / social worker visits & $€ 65.04^{B}$ \\
Hospital admissions days & $€ 483.71^{B}$ \\
Costs of prescribed medication & See methods \\
\hline
\end{tabular}

Notes: GP $=$ general practitioner. ${ }^{A}$ Guideline for intersectoral costs and benefits of preventive interventions (OCW kernciifers 2007-2011) (6); ${ }^{B}$ Dutch guidelines for costing in health economic evaluations (7); ${ }^{C}$ [Inzicht in tarieven WMO en jeugdzorg Fase 2. KPMG] (9).

\subsubsection{H6: HRQOL family}

HR-QoL of carers (one respondent per child) was assessed with the EuroQol 5 dimensions 5 levels questionnaire (EQ-5D-5L). Health states were converted to utility values with valuations obtained from the general public. Quality-adjusted life years (QALYs) were calculated by means of the area under the curve method (see method 2). QALYs were valued using a financial proxy of $€ 36000$ per QALY. ${ }^{5}$

\subsubsection{E3: Absenteeism from school}

School absenteeism days, with a recall period of one school year, were retrieved from school records (see method 1). Annual school absenteeism days were calculated, with making a distinction between health-related school absenteeism and non-health related school absenteeism. School absenteeism days were valued with the standard cost price. ${ }^{6}$ 


\subsubsection{L2: Parental leave and absenteeism from work}

Parental leave and absenteeism from work or education were measured as the annual leave or absenteeism days from work or education due to the illness of the child. Leave and absenteeism days were measured with a recall period of 12 months, for both the primary caregiver and the partner (see method 1). Productivity losses associated with absenteeism from work or education were valued using the friction cost method using an average of 8 working hours per day. ${ }^{7}$

\subsubsection{HL4: Opportunities for caregivers to engage in work/activities}

Parental labour participation was measured as the number of annual working hours for paid work and unpaid work for the primary caregiver and the partner, for each time point specifically (see method 2). The costs of unpaid labour were valued with the proxy good method which values unpaid labour at the costs of housekeeping services, representing a close market substitute of unpaid labour. ${ }^{7}$ We used an average of 45 working weeks per year to calculate the value of parental productivity.

\subsection{Statistical analysis}

Multiple imputation was used to account for possible selective non-response (missing at random assumption) and to use all available data. Imputations were generated with the MICE package in $\mathrm{R}$ using 50 imputed datasets with 20 iterations. Missing data on covariates were predicted by all other variables measured at baseline. Missing data on outcome variables were imputed for each time point using all covariates and the specific outcome variable at other time points. Total healthcare costs were defined as the sum of all cost categories, where imputation was performed at the level of cost categories (see Table 1 - Medical Resource Use).

The mean differences in aggregated benefits over year 1 and year 2 were examined with a generalized linear model with a Gamma distribution and a log link function to account for the zero values and skewness of the data. The analyses were adjusted for sex, study year at baseline, socioeconomic status (SES), ethnicity, baseline BMI z-scores, and baseline outcome scores. Children's SES was calculated as the mean of standardized scores on maternal education level, paternal educational level, and household income ladjusted for household size) which were obtained from the parental questionnaire. ${ }^{10}$ The mean scores were categorized in low, middle and high SES scores based on tertiles. Children's ethnicity (native background, Western background, non-Western background) was determined by the country of birth of both parents. ${ }^{11}$ BMI z-scores were calculated by using Dutch reference values. ${ }^{12}$ 


\subsection{Scenario and sensitivity analysis}

Scenario analyses were performed to analyze the SROI of HPSF and PAS for specific situations: 1) First of all, we assumed that 8 instead of 12 pedagogical workers would be needed at HPSF when children from different grades would not have lunch at the same time and when pedagogical staff, teachers, and teaching assistants would share/shift tasks. 2) In a second scenario, we included lower investments for HPSF and PAS for e.g. coordination and the lunch that are expected occur in a so-called steady state due to efficiency improvements and learning effects. ${ }^{1,13} 3$ ) Thirdly, we excluded children who are in grade 7 at baseline and thus are leaving school during the 2-year study period. This analysis was used to examine whether the SROI would be different when HPSF and PAS were only offered to children who received the interventions for multiple years during the school-age period, compared to children who were nearly leaving school.

Sensitivity analyses were conducted to see how the results would change under different assumptions: 1) Including spillovers on parental HRQOL and productivity. Spillover effects occur when a persons' actions or behaviors indirectly affect other persons' outcomes through for example peer effects or social interactions. It was assumed that HPSF and PAS would first impact on outcomes in the child, which may subsequently transfer to impacts in the household. Previous studies found that school health promotion directed at children was effective in improving lifestyle behaviors and health outcomes of family members. ${ }^{14,15}$ In the calculation of the investments of HPSF, the consequences of the extended school day were already included in terms of increased parental productivity. It is, however, likely that parental productivity may also be affected by children's and caregivers' HRQOL (Figure 1: L2 and HL4). Due to the small numbers (<10 percent) for parental absenteeism from work (Figure 1: L2), the potential benefits could not be reliably estimated and we refrained from including them in the calculation of financial return on investment. 2) No offsets in the investment costs of HPSF due to the extended school day. In the base case analysis we included the effects of the extended school day at HPSF on the opportunities for caregivers to engage in working activities. In the sensitivity analysis we excluded these offsets due to the uncertainty of this outcome (see costing study). ${ }^{1,13} 3 \& 4$ ) Willingness to pay (WTP) thresholds of $€ 20,000$ and $€ 50,000$ per QALY gained instead of $€ 36,000$ per QALY gained. No formal thresholds exist for the willingness to pay per QALY gain in the area of prevention. Although it is advised to use a WTP threshold of $€ 36.000$ per QALY gained for social cost-benefit analyses in the Netherlands ${ }^{5}$, an alternative threshold of $€ 20,000$ per QALY gained has been mentioned. ${ }^{16}$ We analyzed the SROI for a WTP threshold of $€ 20,000$ and $€ 50,000$ per QALY gained. 6) No discounting of investments and benefits. 5) A complete case analysis (non-imputed outcomes). 


\section{Appendix 5}

\section{Scenario and sensitivity analysis}

Table A5.1 Scenario and sensitivity analyses ( $€ /$ child/ 2 years).

\begin{tabular}{|c|c|c|c|c|}
\hline \multirow{2}{*}{\multicolumn{2}{|c|}{ Scenario and sensitivity analyses }} & \multirow[t]{2}{*}{ SROI outcome } & HPSF vs. control schools & PAS vs. control schools \\
\hline & & & Estimate $\quad(95 \% \mathrm{Cl})$ & Estimate $(95 \% \mathrm{Cl})$ \\
\hline \multirow{20}{*}{$\begin{array}{l}\text { Scenario } \\
\text { analyses }\end{array}$} & Base case analysis & Net investment & 859 & 1017 \\
\hline & & Benefits & $8(-1085 ; 1057)$ & $49(-1041 ; 1097)$ \\
\hline & & Net monetary benefit & $-851(-1945 ; 198)$ & $-968(-2058 ; 80)$ \\
\hline & & Ratio of benefits to investment & $0.01(-1.3 ; 1.2)$ & $0.05(-1.0 ; 1.1)$ \\
\hline & & Net monetary benefit / child / day ${ }^{1}$ & $-2.66(-6.08 ; 0.62)$ & $-3.03(-6.43 ; 0.25)$ \\
\hline & 8 instead of 12 & Net investment & 497 & 1017 \\
\hline & pedagogical & Benefits & $8(-1085 ; 1057)$ & $49(-1041 ; 1097)$ \\
\hline & employees at HPSF & Net monetary benefit & $-488(-1582 ; 560)$ & $-968(-2058 ; 80)$ \\
\hline & & Ratio of benefits to investment & $0.02(-2.2 ; 2.1)$ & $0.10(-1.0 ; 1.1)$ \\
\hline & & Net monetary benefit / child / day ${ }^{1}$ & $-1.53(-4.94 ; 1.75)$ & $-3.03(-6.43 ; 0.25)$ \\
\hline & Lower investments for & Net investment & 318 & 719 \\
\hline & HPSF and PAS & Benefits & $8(-1085 ; 1057)$ & $49(-1041 ; 1097)$ \\
\hline & expected to occur on & Net monetary benefit & $-309(-1403 ; 740)$ & $-670(-1760 ; 378)$ \\
\hline & the longer-term (steady & Ratio of benefits to investment & $0.03(-3.4 ; 3.3)$ & $0.15(-1.4 ; 1.5)$ \\
\hline & state) & Net monetary benefit / child / day ${ }^{1}$ & $-0.97(-4.38 ; 2.31)$ & $-2.09(-5.50 ; 1.18)$ \\
\hline & Excluding children in & Net investment & 859 & 1017 \\
\hline & grade 7 at baseline, & Benefits & $1482(-1418 ; 3929)$ & $708(-2134 ; 3293)$ \\
\hline & who are nearly leaving & Net monetary benefit & $622(-2277 ; 3070)$ & $-309(-3151 ; 2276)$ \\
\hline & school & Ratio of benefits to investment & $1.70(-1.6 ; 4.6)$ & $0.70(-2.1 ; 3.2)$ \\
\hline & & Net monetary benefit / child / day ${ }^{1}$ & $1.94(-7.12 ; 9.59)$ & $-0.97(-9.85 ; 7.11)$ \\
\hline \multirow{20}{*}{$\begin{array}{l}\text { Sensitivity } \\
\text { analyses }\end{array}$} & Including spillovers on & Net investment & 859 & 1017 \\
\hline & caregiver's HRQOL & Benefits & $40(-2969 ; 3631)$ & $739(-2894 ; 3733)$ \\
\hline & and productivity & Net monetary benefit & $-820(-3829 ; 2772)$ & $-278(-3911 ; 2716)$ \\
\hline & (Appendix 2: unit & Ratio of benefits to investment & $0.05(-3.5 ; 4.2)$ & $0.70(-2.8 ; 3.7)$ \\
\hline & costs) & Net monetary benefit / child / day ${ }^{1}$ & $-2.56(-11.96 ; 8.66)$ & $-0.87(-12.22 ; 8.49)$ \\
\hline & No delivery-related & Net investment & 2025 & 1017 \\
\hline & offsets in social & Benefits & $8(-1085 ; 1057)$ & $49(-1041 ; 1097)$ \\
\hline & opportunity costs of & Net monetary benefit & $-2017(-3111 ;-968)$ & $-968(-2058 ; 80)$ \\
\hline & HPSF due to the & Ratio of benefits to investment & $0.00(-0.5 ; 0.5)$ & $0.05(-1.0 ; 1.1)$ \\
\hline & extended school day & Net monetary benefit / child / day ${ }^{1}$ & $-6.30(-9.72 ;-3.02)$ & $-3.03(-6.43 ; 0.25)$ \\
\hline & Willingness to pay & Net investment & 859 & 1017 \\
\hline & threshold of & Benefits & $8(-506 ; 478)$ & $49(-462 ; 517)$ \\
\hline & $€ 20.000 /$ QALY & Net monetary benefit & $-851(-1365 ;-382)$ & $-968(-1479 ;-500)$ \\
\hline & gained instead of & Ratio of benefits to investment & $0.01(-0.6 ; 0.6)$ & $0.05(-0.5 ; 0.5)$ \\
\hline & $\begin{array}{l}€ 36.000 / Q A L Y \\
\text { gained }\end{array}$ & Net monetary benefit / child / day ${ }^{1}$ & $-2.66(-4.27 ;-1.19)$ & $-3.03(-4.62 ;-1.56)$ \\
\hline & Willingness to pay & Net investment & 859 & 1017 \\
\hline & threshold of & Benefits & $8(-1593 ; 1565)$ & $49(-1548 ; 1604)$ \\
\hline & $€ 50.000 / Q A L Y$ & Net monetary benefit & $-851(-2452 ; 705)$ & $-968(-2565 ; 587)$ \\
\hline & gained & Ratio of benefits to investment & $0.01(-1.9 ; 1.8)$ & $0.05(-1.5 ; 1.6)$ \\
\hline & $\begin{array}{l}\text { instead of } \\
€ 36.000 / Q A L Y \\
\text { gained }\end{array}$ & Net monetary benefit / child / day ${ }^{1}$ & $-2.66(-7.66 ; 2.20)$ & $-3.03(-8.02 ; 1.83)$ \\
\hline
\end{tabular}


Table A5.1 (continued)

\begin{tabular}{|c|c|c|c|c|}
\hline \multicolumn{2}{|c|}{ Scenario and sensitivity analyses } & \multirow{3}{*}{ SROI outcome } & \multirow{2}{*}{$\begin{array}{l}\text { HPSF vs. control schools } \\
\text { Estimate }(95 \% \mathrm{Cl})\end{array}$} & \multirow{2}{*}{$\begin{array}{l}\text { PAS vs. control schools } \\
\text { Estimate }(95 \% \mathrm{CI})\end{array}$} \\
\hline & & & & \\
\hline Sensitivity & Willingness to pay & & 859 & 1017 \\
\hline \multirow[t]{14}{*}{ analyses } & threshold of & Benefits & $8(-1593 ; 1565)$ & $49(-1548 ; 1604)$ \\
\hline & $€ 50.000 /$ QALY & Net monetary benefit & $-851(-2452 ; 705)$ & $-968(-2565 ; 587)$ \\
\hline & gained & Ratio of benefits to investment & $0.01(-1.9 ; 1.8)$ & $0.05(-1.5 ; 1.6)$ \\
\hline & $\begin{array}{l}\text { instead of } \\
€ 36.000 / Q A L Y \\
\text { gained }\end{array}$ & Net monetary benefit / child / day ${ }^{1}$ & $-2.66(-7.66 ; 2.20)$ & $-3.03(-8.02 ; 1.83)$ \\
\hline & No discounting instead & Net investment & 828 & 980 \\
\hline & of an annual discount & Benefits & $9(-1140 ; 1111)$ & $51(-1094 ; 1152)$ \\
\hline & rate of & Net monetary benefit & $-820(-1969 ; 282)$ & $-929(-2074 ; 172)$ \\
\hline & $2.5 \%$ for costs and & Ratio of benefits to investment & $0.01(-1.4 ; 1.3)$ & $0.05(-1.1 ; 1.2)$ \\
\hline & outcomes & Net monetary benefit / child / day ${ }^{1}$ & $-2.56(-6.15 ; 0.88)$ & $-2.90(-6.48 ; 0.54)$ \\
\hline & Complete case analysis & Net investment & 859 & 1017 \\
\hline & & Benefits & $-1581(-3588 ; 264)$ & $582(-1527 ; 2564)$ \\
\hline & & Net monetary benefit & $-2440(-4447 ;-596)$ & $-435(-2544 ; 1547)$ \\
\hline & & Ratio of benefits to investment & $-1.80(-4.2 ; 0.3)$ & $0.60(-1.5 ; 2.5)$ \\
\hline & & Net monetary benefit / child / day ${ }^{1}$ & $-7.62(-13.90 ;-1.86)$ & $-1.36(-7.95 ; 4.84)$ \\
\hline
\end{tabular}

Notes: $\mathrm{Cl}=$ confidence interval; HPSF = Healthy Primary School of the Future; INB = incremental net benefit; PAS = Physical Activity School; $Q A L Y=$ quality-adjusted life year; SROI = social return on investment; WTP = willingness to pay. ${ }^{1}$ For a total of 160 schooldays per year (total of 320 days for two years). 


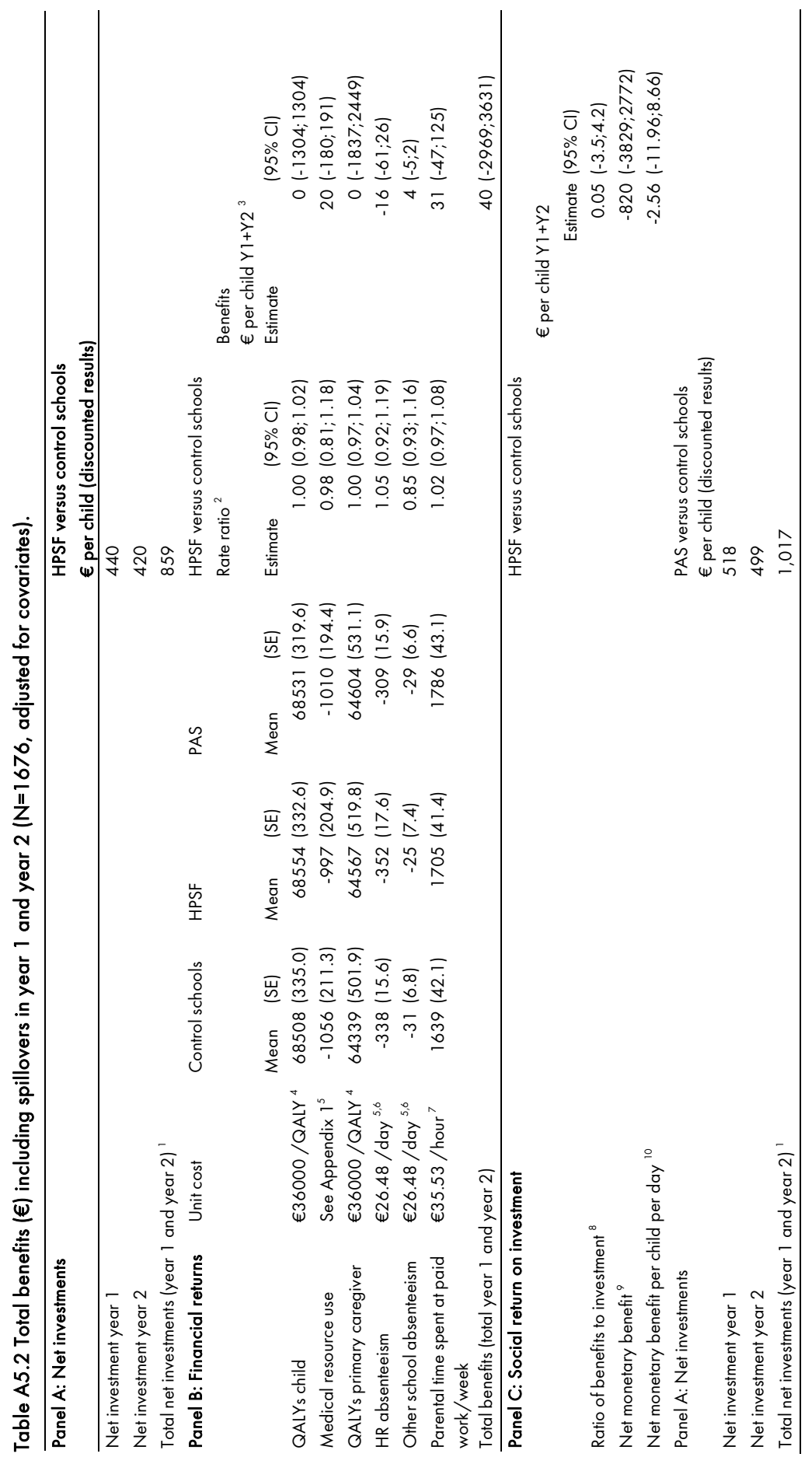




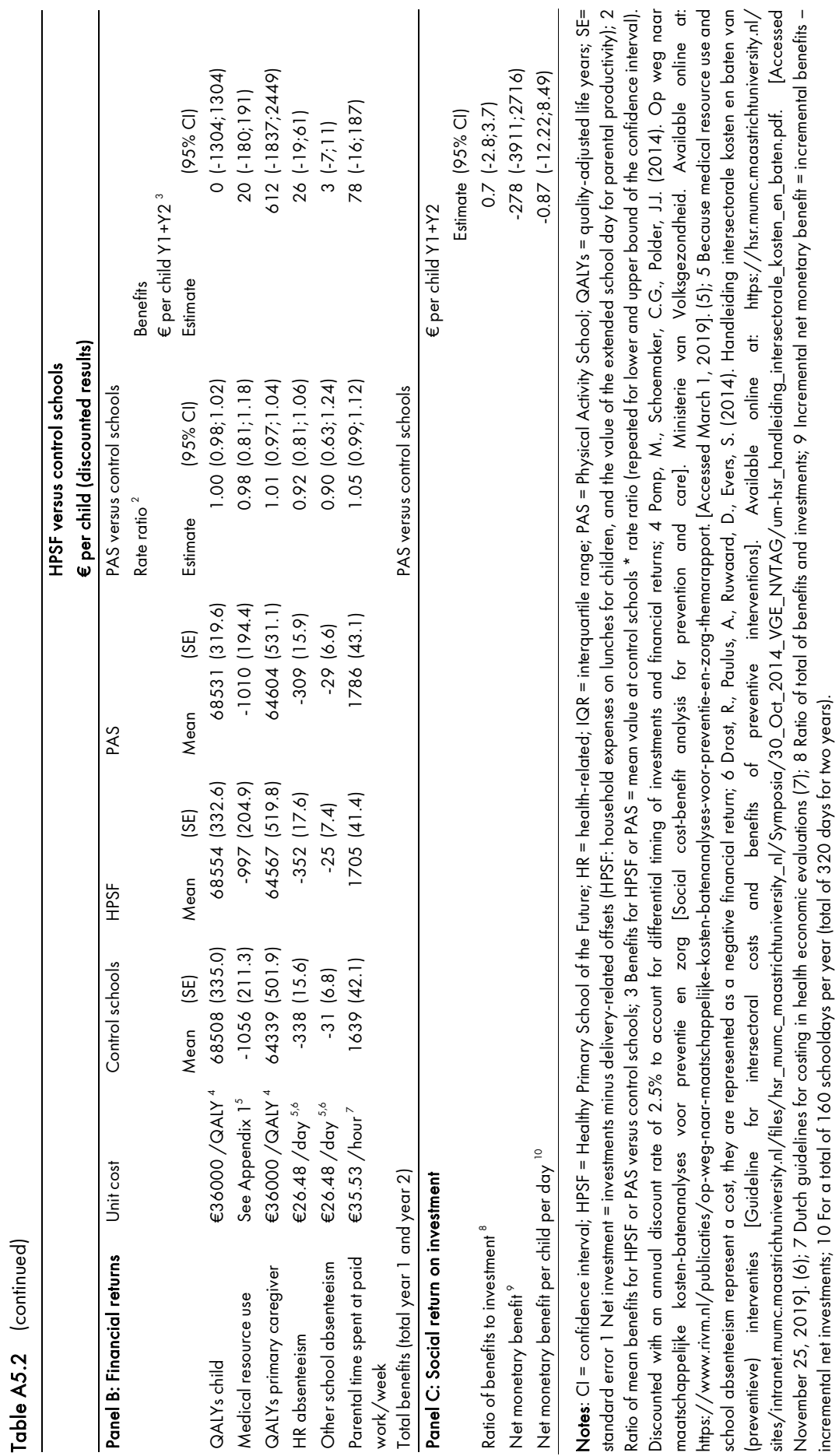




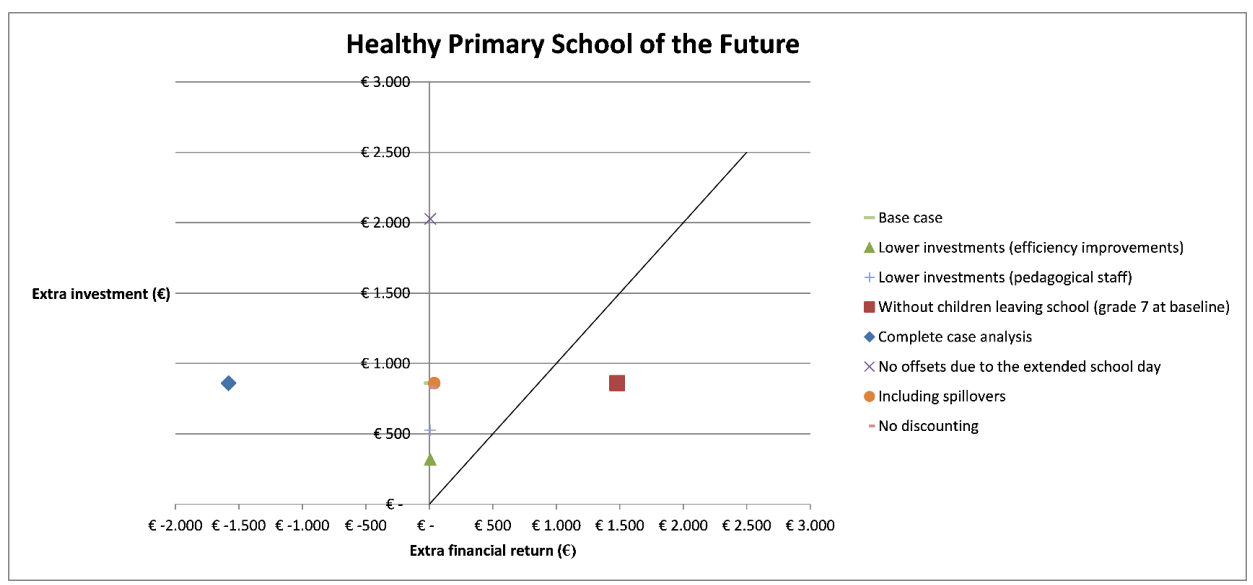

Figure A5.1 Point estimates of the investments and benefits for the scenario and sensitivity analyses (HPSF). Notes: $\mathrm{HRQOL}=$ health-related quality of life; $\mathrm{QALY}=$ quality-adjusted life year; $\mathrm{WTP}=$ willingness to pay. The line represents a SROI ratio of 1 . For all points above the line the ratio of benefits / investments $<1$. For all points under the line the ratio of benefits / investments $>1$.

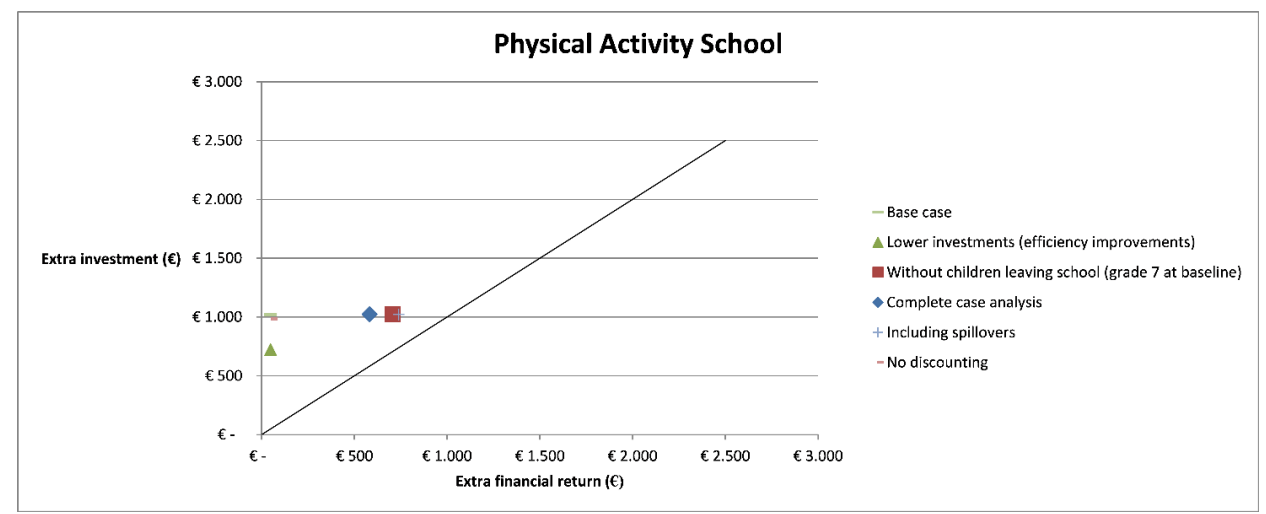

Figure A5.2 Point estimates of the investments and benefits for the scenario and sensitivity analyses (PAS). Notes: $\mathrm{HRQOL}=$ health-related quality of life; $\mathrm{QALY}=$ quality-adjusted life year; WTP = willingness to pay. The line represents a SROI ratio of 1 . For all points above the line the ratio of benefits / investments $<1$. For all points under the line the ratio of benefits / investments $>1$. 
Lower investments (efficiency improvements)

Lower investments (pedagogical staff) Without children leaving school (grade 7 at baseline) Including spillovers

Complete case analysis

No offsets due to the extended school day

WTP for a QALY (€20.000/QALY)

WTP for a QALY (€50.000/QALY)

No discounting

Healthy Primary School of the Future

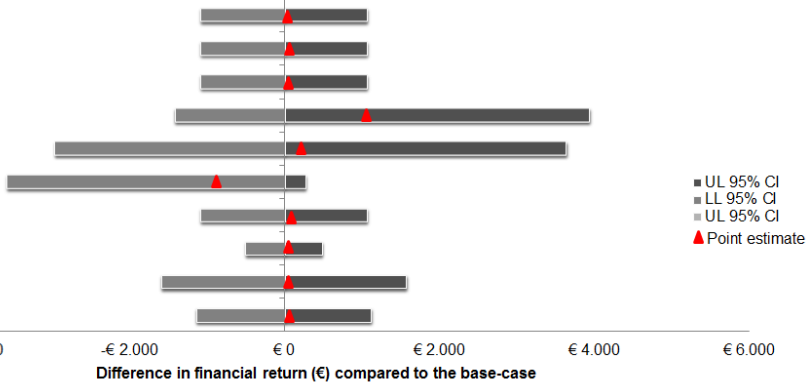

Figure A5.3 Point estimates and uncertainty of the around the benefits for the scenario and sensitivity analyses (HPSF).

Notes: $H R Q O L=$ health-related quality of life; $Q A L Y=$ quality-adjusted life year; WTP = willingness to pay.

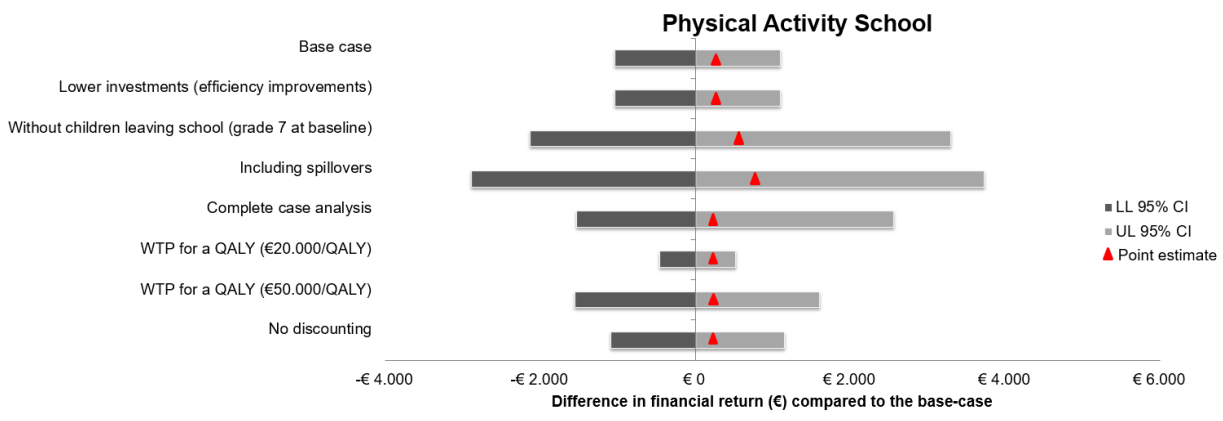

Figure A5.4 Point estimates and uncertainty of the around the benefits for the scenario and sensitivity analyses (PAS).

Notes: $\mathrm{HRQOL}=$ health-related quality of life; $Q A L Y=$ quality-adjusted life year; $\mathrm{WTP}=$ willingness to pay. 


\section{Appendix 6}

\section{Quantitative outcomes not included in the SROI calculation}

Table A6.1 Outcomes on children's psychosocial health, post-imputation adjusted for covariates (PedsQL).

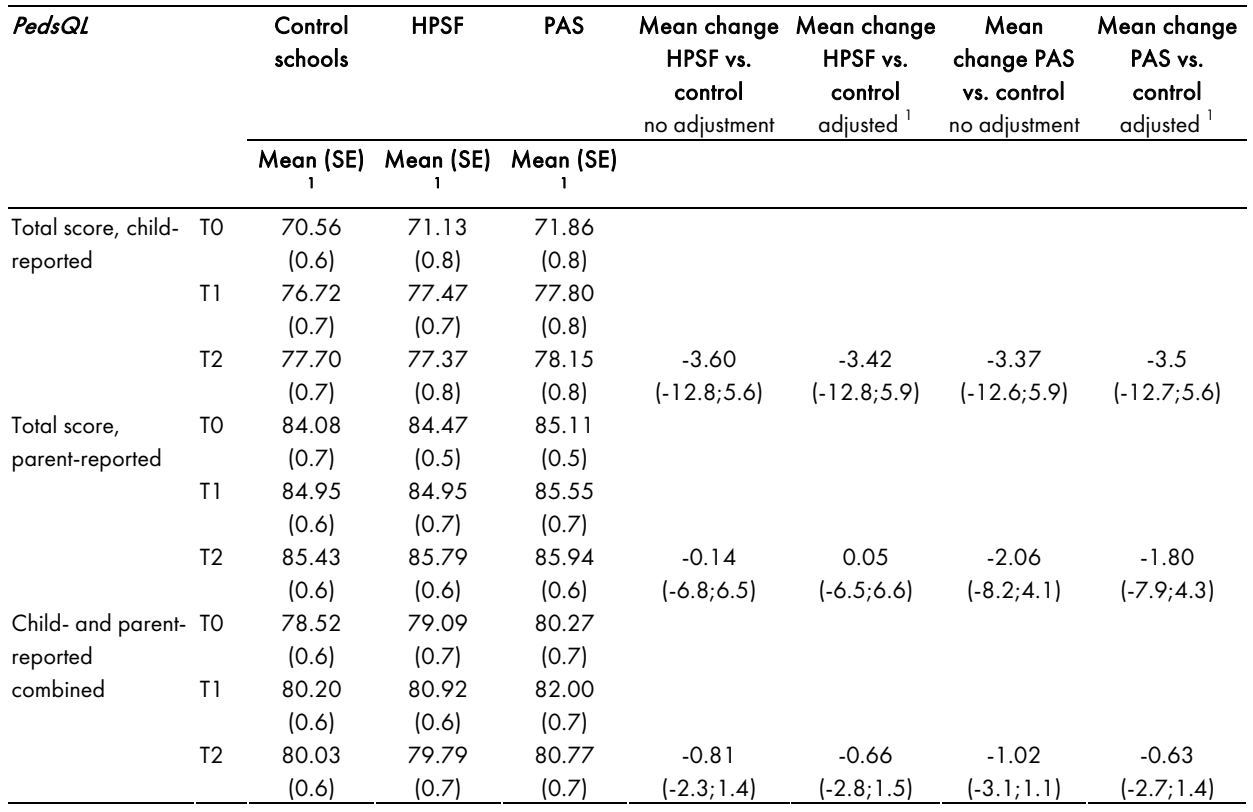

Notes: HPSF $=$ Healthy Primary School of the Future; PAS = Physical Activity School; PedsQL = Pediatric Quality of Life Inventory; SE= standard error. 'Mean difference adjusted for baseline values and covariates (sex, age, SES, ethnicity, BMI z-score at baseline).

Table A6.2 Outcomes on parental absenteeism and parental time spent at unpaid work, post-imputation adjusted for covariates.

\begin{tabular}{|c|c|c|c|c|c|c|}
\hline Outcome & Unit costs & $\begin{array}{c}\text { Control } \\
\text { schools } \\
\text { (any } \\
\text { absenteeism / } \\
\text { time spent in } \\
\text { unpaid work) }\end{array}$ & $\begin{array}{c}\text { HPSF } \\
\text { (any } \\
\text { absenteeism / } \\
\text { time spent in } \\
\text { unpaid work) }\end{array}$ & $\begin{array}{c}\text { PAS } \\
\text { (any } \\
\text { absenteeism / } \\
\text { time spent in } \\
\text { unpaid work) }\end{array}$ & $\begin{array}{c}\begin{array}{c}\text { HPSF vs. } \\
\text { control }\end{array} \\
\text { Odds ratio }^{3} \\
\text { Estimate (95\% } \\
\text { CI) }\end{array}$ & $\begin{array}{c}\begin{array}{c}\text { PAS vs. } \\
\text { control }\end{array} \\
\text { Odds ratio }^{3} \\
\begin{array}{c}\text { Estimate }(95 \% \\
\text { CI) }\end{array}\end{array}$ \\
\hline $\begin{array}{l}\text { Parental } \\
\text { absenteeism } \\
\text { from work due to } \\
\text { sickness of the } \\
\text { child }\end{array}$ & $\begin{array}{l}\text { Paid work: } \\
€ 35.53 / \\
\text { hour }^{2}\end{array}$ & $7.9 \%$ & $6.2 \%$ & $6.2 \%$ & $\begin{array}{c}0.79 \\
(0.29 ; 2.12)\end{array}$ & $\begin{array}{c}0.79 \\
(0.29 ; 2.21)\end{array}$ \\
\hline $\begin{array}{l}\text { Parental time } \\
\text { spent at unpaid } \\
\text { work/week }\end{array}$ & $\begin{array}{l}€ 14.31 / \\
\text { hour }^{2}\end{array}$ & $8.7 \%$ & $7.7 \%$ & $7.5 \%$ & $\begin{array}{c}0.89 \\
(0.58 ; 1.37)\end{array}$ & $\begin{array}{c}0.86 \\
(0.56 ; 1.30)\end{array}$ \\
\hline
\end{tabular}

Notes: HPSF = Healthy Primary School of the Future; PAS = Physical Activity School; SE= standard error. ${ }^{1}$ Due to the small numbers $(<10 \%)$, the potential benefits could not be reliably estimated and we refrained from including them in the calculation of financial return on investment; ${ }^{2}$ Dutch guidelines for costing in health economic evaluations (7); ${ }^{3}$ Ratio of any absenteeism/time spent in unpaid work for HPSF or PAS versus control schools. 


\section{Appendix 7}

Pre-imputation results

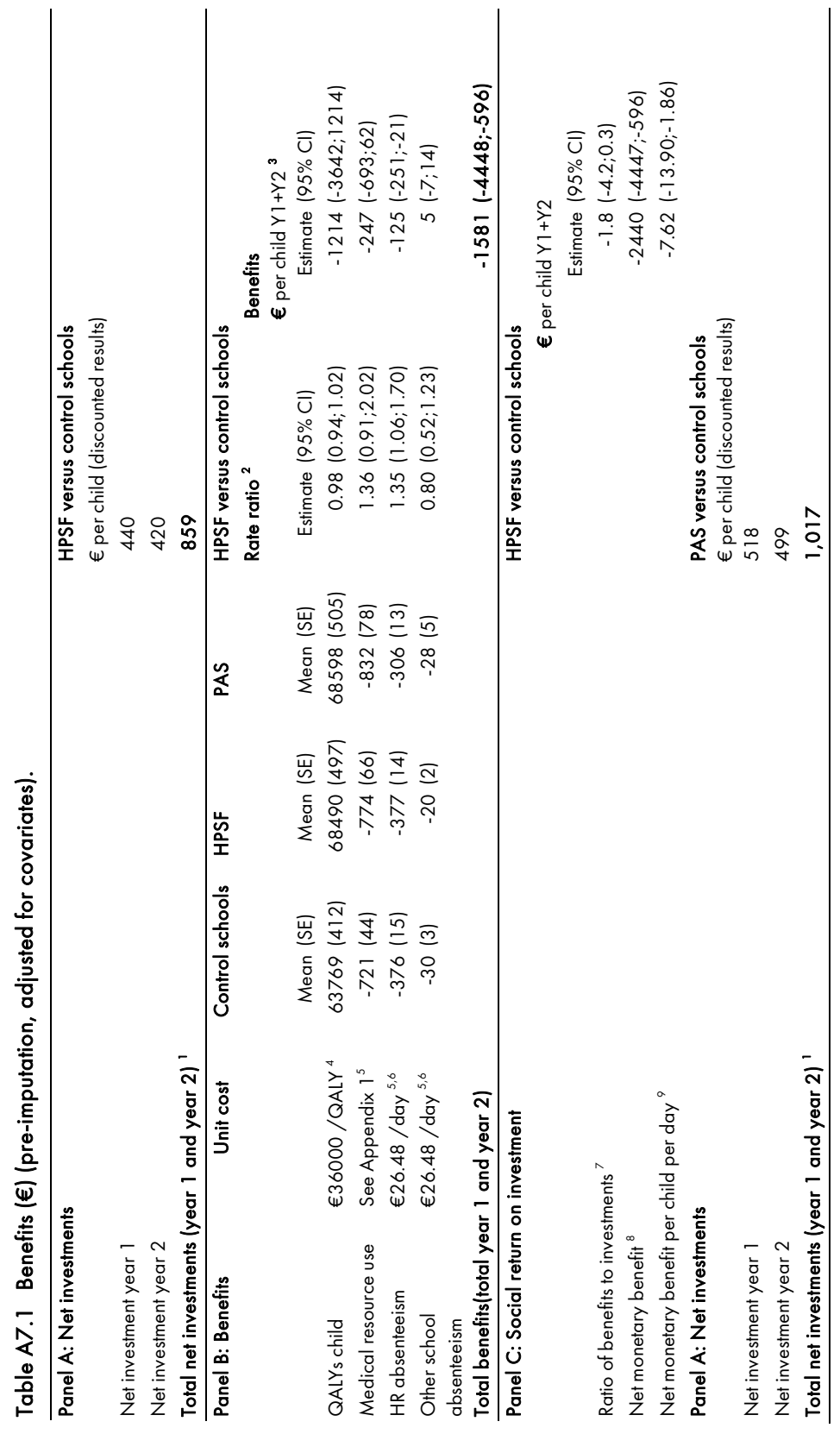




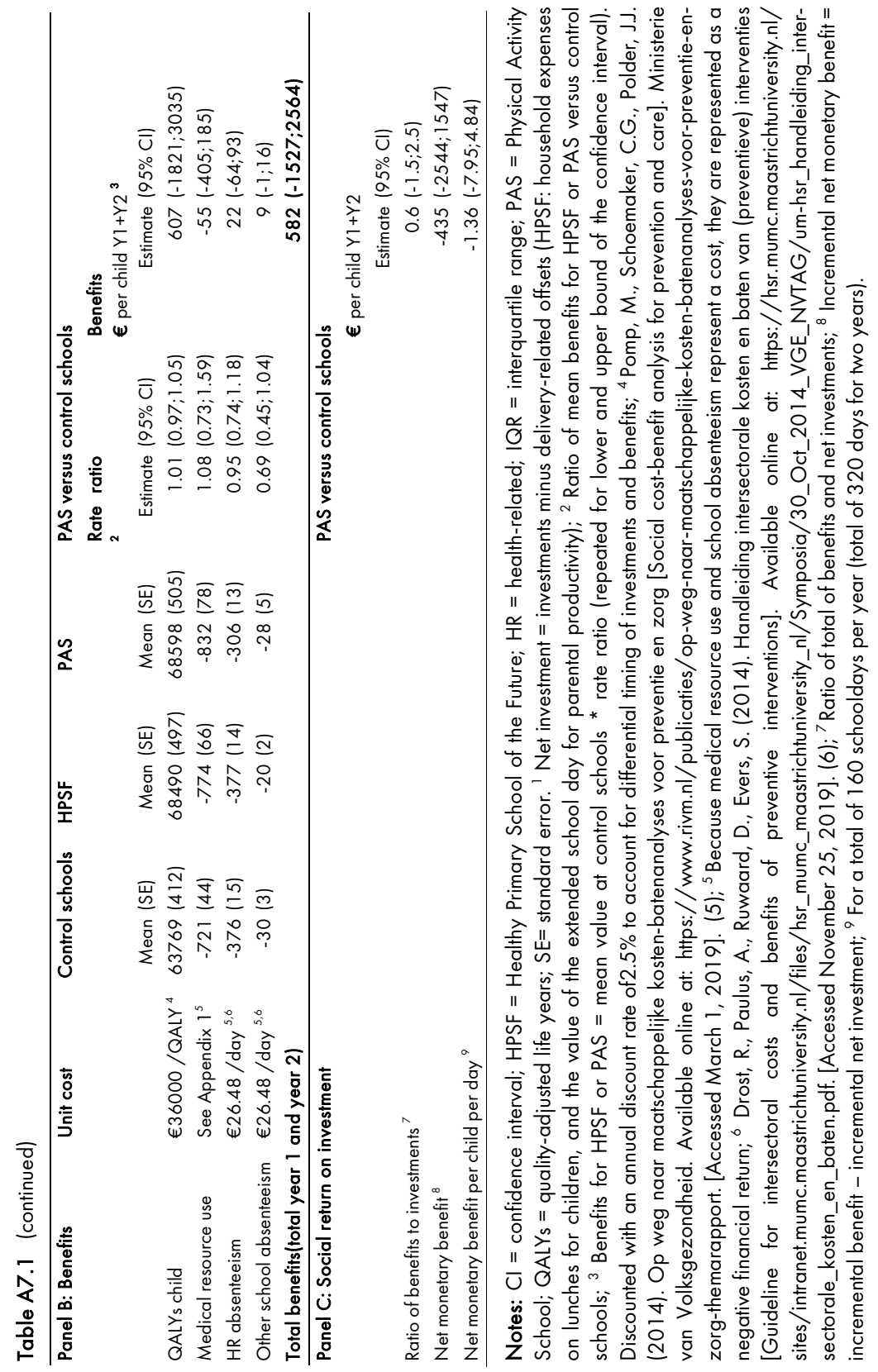




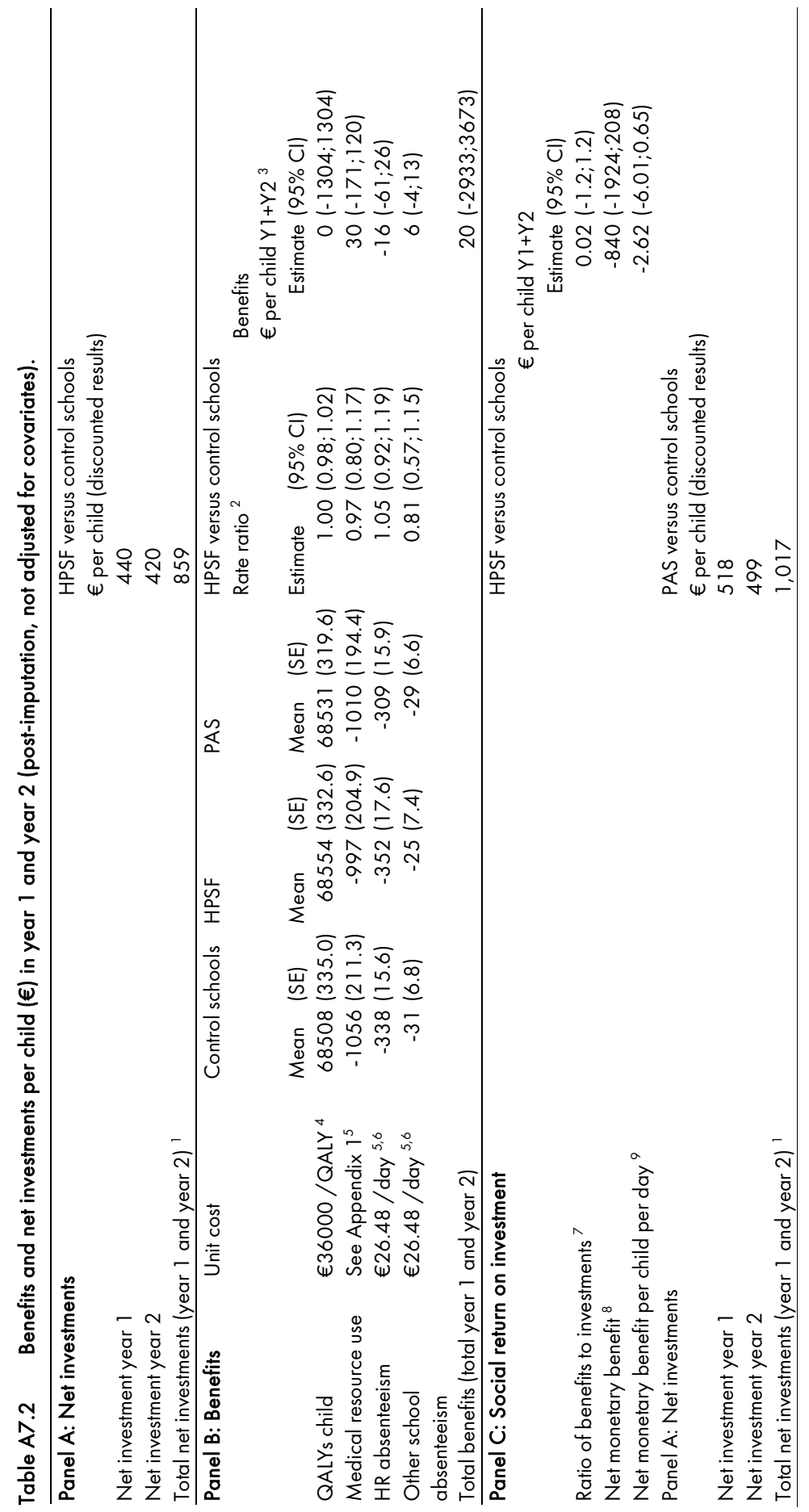




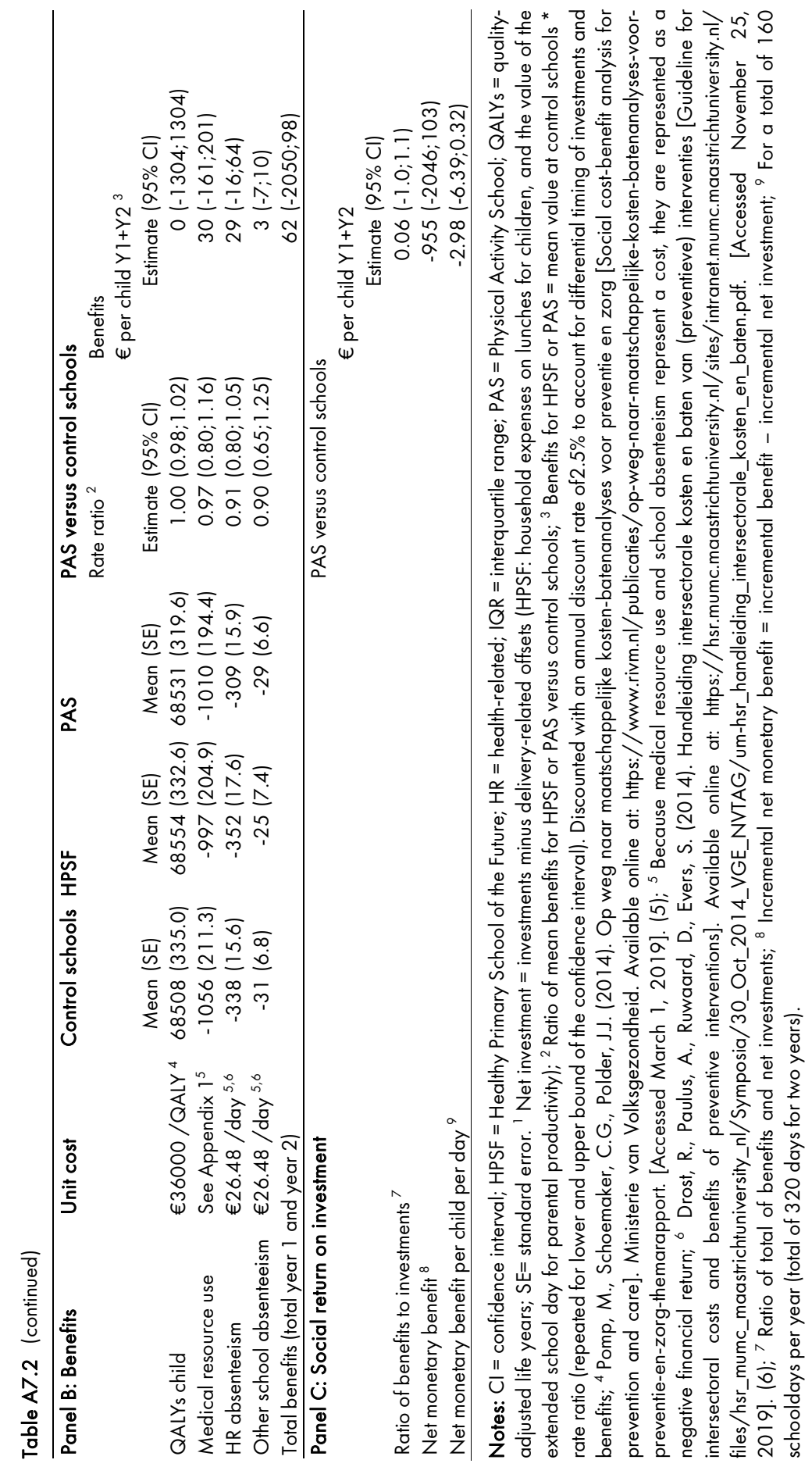




\section{References appendices}

1. Oosterhoff M, Bosma H, van Schayck OCP, Joore MA. A Cost Analysis of School-Based Lifestyle Interventions. Prev Sci. 2018;19(6):716-27.

2. Willeboordse M, Jansen MW, van den Heijkant SN, Simons A, Winkens B, de Groot RH, et al. The Healthy Primary School of the Future: study protocol of a quasi-experimental study. BMC public health. 12016;6:639.

3. Bartelink NHM, van Assema P, Kremers SPJ, Savelberg HH, Oosterhoff M, Willeboordse M, et al. One- and Two-Year Effects of the Healthy Primary School of the Future on Children's Dietary and Physical Activity Behaviours: A Quasi-Experimental Study. Nutrients. 2019;11(3).

4. Bartelink N, Van Assema P, Kremers SPJ, Savelberg HH, Oosterhoff M, Willeboordse M, et al. Can the Healthy Primary School of the Future offer perspective in the on-going obesity epidemic in young children? a quasi-experimental study. BMJ Open. 2019;9(10):e030676.

5. Pomp M, Schoemaker CG, Polder JJ. Op weg naar maatschappelijke kosten-batenanalyses voor preventie en zorg [Social cost-benefit analysis for prevention and care]. Ministerie van Volksgezondheid. 2014. [Accessed March 1, 2019].

6. Drost R, Paulus A, Ruwaard D, Evers S. Handleiding intersectorale kosten en baten van (preventieve) interventies [Guideline for intersectoral costs and benefits of preventive interventions]. 2014. [Accessed November 25, 2019].

7. Zorginstituut Nederland. Kostenhandleiding: Methodologie van kostenonderzoek en referentieprijzen voor economische evaluaties in de gezondheidszorg [Methodology of cost research and cost prices for heal economic evaluations]. 2015. [Accessed November 14, 2019].

8. Lamers LM, Stalmeier PF, McDonnell J, Krabbe PF, van Busschbach JJ. [Measuring the quality of life in economic evaluations: the Dutch EQ-5D tariff]. NTvG. 2005; 149(28):1574-8.

9. KPMG. Inzicht in tarieven WMO en jeugdzorg Fase 2. [Tariffs for WMO and Youth Care]. 2014. [Accessed August 12, 2019].

10. Shavers VL. Measurement of socioeconomic status in health disparities research. J Natl Med Assoc. 2007;99(9):1013.

11. Keij I. Hoe doet het CBS dat nou? Standaarddefinitie allochtonen [Definition immigrants]. Index: Feiten en Cijfers over onze Samenleving. 2000; 10:24-5.

12. Schönbeck Y, Talma H, van Dommelen P, Bakker B, Buitendijk SE, Hirasing RA, et al. Increase in Prevalence of Overweight in Dutch Children and Adolescents: A Comparison of Nationwide Growth Studies in 1980, 1997 and 2009. PLoS ONE. 2001;6(11):e27608.

13. Oosterhoff M, Bosma H, van Schayck OCP, Joore MA. Correction to: Cost Analysis of School-Based Lifestyle Interventions. Prev Sci. 2019.

14. Fornari LS, Giuliano I, Azevedo F, Pastana A, Vieira C, Caramelli B. Children First Study: how an educational program in cardiovascular prevention at school can improve parents' cardiovascular risk. Eur J Prev Cardiol. 2013;20(2):301-9.

15. Gunawardena N, Kurotani K, Indrawansa S, Nonaka D, Mizove T, Samarasinghe D. School-based intervention to enable school children to act as change agents on weight, physical activity and diet of their mothers: a cluster randomized controlled trial. Int J Behav Nutr Phys Act. 2016;13:45.

16. van den Berg M, De Wit GA, Vijgen SMC, Busch MCM, Schuit AJ. Kosteneffectiviteit van preventie: kansen voor het Nederlandse volksgezondheidsbeleid [Cost-effectiveness of prevention]. NTvG. 2008; 152: 1329-34. 


\title{
Chapter

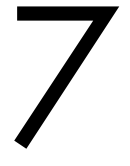

BMI trajectories after primary school-based lifestyle intervention: unravelling an uncertain future a mixed methods study

\author{
Marije Oosterhoff \\ Shahab Jolani \\ Daisy Geraets \\ Hans Bosma \\ Onno C.P. van Schayck \\ Manuela A. Joore
}

Accepted for publication in Preventive Medicine Reports 


\section{Abstract}

\section{Background}

This mixed methods study aimed to examine plausible body mass index (BMI) trajectories after exposure to a primary school-based lifestyle intervention to aid in estimating the longterm intervention benefits.

\section{Methods}

BMI trajectories for children at control schools (mean 7.5 years) were modelled until 20 years of age through extrapolating trial evidence $(\mathrm{N}=1676)$. A reference scenario assumed that the observed 2-year effects of the 'Healthy Primary Schools of the Future' (HPSF) and 'Physical Activity Schools' (PAS) were fully maintained over time. This was modelled by applying the observed 2-year BMI effects until 20 years of age. Expert opinions on likely trends in effect maintenance after the 2-year intervention period were elicited qualitatively and quantitatively, and were used for developing alternative scenarios.

\section{Findings}

Expert elicitation revealed three scenarios: (a) a constant exposure-effect and an uncontrolled environment with effect decay scenario, (b) a household multiplier and an uncontrolled environment with effect decay scenario, and (c) a household multiplier and maintainer scenario. The relative effect of HPSF at 20 years of age was $-0.21 \mathrm{~kg} / \mathrm{m}^{2}$ under the reference scenario, and varied from $-0.04 \mathrm{~kg} / \mathrm{m}^{2}(\mathrm{a})$ to $-0.06 \mathrm{~kg} / \mathrm{m}^{2}(\mathrm{~b})$, and $-0.50 \mathrm{~kg} / \mathrm{m}^{2}$ (c). For PAS, the relative effect was $-0.17 \mathrm{~kg} / \mathrm{m}^{2}$ under the reference scenario, and varied from $-0.04 \mathrm{~kg} / \mathrm{m}^{2}(\mathrm{a}, \mathrm{b})$, to $-0.21 \mathrm{~kg} / \mathrm{m}^{2}(\mathrm{c})$.

\section{Interpretation}

The mixed methods approach proved to be useful in modelling plausible BMI trajectories and specifying uncertainty on effect maintenance. Further observations until adulthood could reduce the uncertainty around future benefits. 


\section{Background}

Primary school-based lifestyle interventions aim to optimize children's health and wellbeing by encouraging them to adopt healthy behaviours. While the investments for intervention implementation have to be made early in life, the main health benefits and cost savings may only be realized beyond the timeframe of empirical studies and beyond childhood. ${ }^{1,2}$

Population health models are available, which link short-term intervention impacts to chronic disease risk. Body mass index (BMI) is frequently used as a risk factor in population health models. Available population health models, however, generally start in adulthood. To estimate the long-term impacts of primary school-based lifestyle interventions, the gap between childhood (observation range of empirical studies) and adulthood (captured in population health models) has to be filled. Few empirical studies included long-term followup measurements after primary school-based lifestyle interventions in order to assess the effect maintenance. ${ }^{2}$ Whilst some studies found a fast decay of the intervention effect, ${ }^{3,4}$ others reported some sustained effects in the overall study sample or in subgroups only (e.g. children with a high socioeconomic background). ${ }^{5,6}$ In modelling long-term benefits, several cost-effectiveness studies on primary-school based lifestyle interventions have used a range of alternative 'hypothetical' estimates on effect maintenance. ${ }^{7-11}$ These results show that estimates on the maintenance of the intervention effect are paramount in modelling the longterm benefits of childhood lifestyle interventions. ${ }^{9-11}$ This also indicates that making transparent and plausible assumptions on the effect maintenance is crucial to adequately inform implementation and funding decisions on primary school-based lifestyle interventions.

In a quasi-experimental study in the Southern region of the Netherlands, two interventions were evaluated. The 'Healthy Primary School of the Future' (HPSF) implemented a daily healthy lunch and daily physical activity sessions, whereas the 'Physical Activity School' (PAS) focused on physical activity only. ${ }^{12}$ The objective of this study is to model plausible BMI trajectories for children at HPSF, PAS, and control schools, from the primary school age up to young adulthood (20 years).

\section{Methods}

\section{The 'Healthy Primary School of the Future' initiative}

The 'Healthy Primary School of the Future' (HPSF) initiative aims to integrate health promotion in the primary school setting. In the Netherlands, children attend primary school 
for eight years (grade 1-8, from 4-12 years of age). In a quasi-experimental study, two interventions were examined and compared to schools that maintained the regular curriculum (control schools). A full intervention named 'the Healthy Primary School of the Future' (HPSF) offered an extended curriculum, including daily healthy lunches, and daily structured physical activity and cultural sessions. A partial intervention, named the 'Physical Activity School' (PAS) included the same changes, except for the healthy lunch. ${ }^{12}$ Details on the interventions and the quasi-experimental study have been previously published. ${ }^{12,13}$

\section{Study sample and growth data}

For the current study, the three-wave data collection of the quasi-experimental study was used. Only participants that were enrolled at the participating schools from baseline onwards were selected, to reflect a two-year intervention exposure for all children. ${ }^{13}$ The study sample consisted of $\mathrm{N}=1676$ children (Appendix 1). Trained research assistants measured children's height and weight (measured to the nearest $0.1 \mathrm{~cm}$ and $0.1 \mathrm{~kg}$ ) (September-November). Children were measured with light clothing and no shoes. Information on children's age (in years) and gender was retrieved from the educational board Movare. BMI values were calculated from age 5 to 12 years, because height and weight was measured from age 5 onwards, and because only few children in the last grade did already turn 12 years at the start of the school year. Socioeconomic status (SES) was measured with a parental questionnaire, and calculated as the mean of standard scores on maternal education, paternal education, household income (adjusted for household size), and neighbourhood SES score. SES was categorized (low, average, high) based on tertile scores.

\section{Unobserved effects: two phases}

We distinguished two phases: 1) primary school period, and 2) after the primary school period up to 20 years.

\section{Estimation of BMI trajectories without expert information}

\section{BMI trajectory of children at control schools}

\section{Phase 1: primary school period}

Two models were compared: a linear mixed model and a piecewise mixed model as both have been used in the literature (Box 1). ${ }^{14,15}$ BMI values were log-transformed to accommodate for the right-skew of BMI-values for older children. ${ }^{14,15}$ Both models used all 
available data under the missing at random assumption as BMI data was unavailable for $1.7 \%$ of the study sample $(\mathrm{N}=28)$.

Box $1 \quad$ BMI trajectory models

Model 1: Linear mixed model *
$\mathrm{BMI}_{\mathrm{i}, \mathrm{t}}=\beta_{0, \mathrm{i}}+\beta_{1, i}{ }^{*} \mathrm{Age}_{\mathrm{i}, \mathrm{t}}+\beta_{2}{ }^{*} \mathrm{Age}_{\mathrm{i}, \mathrm{t}}{ }^{2}+\beta_{3}{ }^{*} \mathrm{Age}_{\mathrm{i}, \mathrm{t}}{ }^{3}+\beta_{4}{ }^{*} \mathrm{HPSF}_{\mathrm{i}}+\beta_{5}{ }^{*} \mathrm{PAS}_{\mathrm{i}}+$
$\beta_{6}\left(\mathrm{HPSF}_{\mathrm{i}}{ }^{*} \mathrm{Age}_{\mathrm{i}, \mathrm{t}}\right)+\beta_{7}\left(\mathrm{PAS}_{\mathrm{i}}{ }^{*} \mathrm{Age}_{\mathrm{i}, \mathrm{t}}\right)+\beta_{8}{ }^{*} \operatorname{lowSES}_{\mathrm{i}}+\beta_{9}{ }^{*} \mathrm{highSES}_{\mathrm{i}}+\mathrm{e}_{\mathrm{i}, \mathrm{t}}$

Notes: $\mathrm{BMI}_{\mathrm{i}, \mathrm{t}}=\mathrm{BMI}$ value at a specific age of the child, $\mathrm{t}=$ time point (baseline, year 1, year 2 ), $\mathrm{i}=$ individual $(N=1676), \beta o, i=$ random intercept parameter, $A g e_{i, t}=$ age (in years) of the child, $\beta_{1, i}=$ random linear slope parameter, $\beta_{2, i}=$ quadratic slope parameter, $\beta_{3, i}=$ cubic slope parameter, HPSF $F_{i, 1}=$ Healthy Primary School of the Future, $\mathrm{PAS}_{\mathrm{i}, \mathrm{t}}=$ Physical Activity School, lowSES $\mathrm{i}_{\mathrm{t}}=$ low socioeconomic background, lowSES $\mathrm{S}_{\mathrm{i}, \mathrm{t}}=$ high socioeconomic background, $\mathrm{e}_{\mathrm{i}, \mathrm{t}}=$ error term (residual variance).

*Addition of the second order and third order effects for age was assessed by comparing the the Loglikelihood, Akaike information criterion (AIC), and the Bayesian information criterion to the null model (only first order effects of age). The Loglikelihood and AIC showed that a model predicting InBMI by the third order effects of age showed a good fit to our data, and this model has previously been used to model BMI trajectories in European youth (14).

Model 2: Piecewise mixed model

$\mathrm{BMI}_{\mathrm{i}, \mathrm{t}}=\beta_{0, \mathrm{i}}+\beta_{1, i}{ }^{*} \mathrm{Age}_{\mathrm{i}, \mathrm{t}}+\beta_{2, \mathrm{i}}{ }^{*} \mathrm{D}($ Age, $\geq 6$ years $)+\beta_{3, i}{ }^{*} \mathrm{D}($ Age, $\geq 9$ years $)+\beta_{4}{ }^{*} \mathrm{HPSF}_{\mathrm{i}}+\beta_{5}{ }^{*} \mathrm{PAS}_{\mathrm{i}}+$ $\beta_{6}\left(\mathrm{HPSF}_{\mathrm{i}}{ }^{*} \mathrm{D}[\text { Age, } \geq 6 \text { years }]_{i}\right)+\beta_{7}\left(\mathrm{PAS}_{\mathrm{i}}{ }^{*} \mathrm{D}[\text { Age }, \geq 6 \text { years }]_{\mathrm{i}}\right)+\beta_{8}\left(\mathrm{HPSF}_{\mathrm{i}}{ }^{*} \mathrm{D}[\text { Age }, \geq 9 \text { years }]_{\mathrm{i}}\right)+\beta_{9}\left(\mathrm{PAS}_{\mathrm{i}}{ }^{*} \mathrm{D}[\right.$ Age, $\geq 9$ years $\left.]_{i}\right)+\beta_{10}{ }^{*}$ lowSES ${ }_{i}+\beta_{11}{ }^{*}$ highSES $_{i} e_{i, t}$

Notes: $\mathrm{BMI}_{\mathrm{i}, \mathrm{t}}=\mathrm{BMI}$ value at a specific age of the child, $\mathrm{t}=$ time point (baseline, year 1, year 2 ), $\mathrm{i}=$ individual $(\mathrm{N}=1676), \beta 0, i=$ random intercept parameter, $A_{\mathrm{ge}_{i, t}}=$ age (in years) of the child, $\mathrm{D}($ Age,$\geq 6$ years) $=$ dummy variable $(1=\geq 6$ years, $0=<6$ years $), D($ Age,$\geq 9$ years $)=$ dummy variable $(1=\geq 9$ years, $0=<9$ years $), H_{P S F_{i, t}}=$ Healthy Primary School of the Future, PAS $_{i, t}=$ Physical Activity School, lowSES ${ }_{i, t}=$ low socioeconomic background, lowSES ${ }_{i, t}=$ high socioeconomic background, $e_{i, t}=$ error term (residual variance).

Firstly, a linear mixed model was built. Model selection criteria (AIC, BIC, Loglikelihood) were used to test whether addition of second and third order effects of age improved the model fit (Box 1). Secondly, a piecewise mixed model (broken stick model) was used to mimic the differences in BMI growth at different ages. ${ }^{14} \mathrm{~A}$ breakpoint at age 6 was used to reflect the transition in children's BMI growth rates between 4-6 years of age. ${ }^{16}$ Additionally, a breakpoint at the age of nine years was selected to reflect the timing of the mid-growth spurt that may occur at pre-puberty. ${ }^{17}$ The two models included random intercepts and a random slope (linear effect of age) in order to model individual BMI development and account for the correlation of repeated measurements within children. ${ }^{18}$ The models were adjusted for SES due to the SES-specific BMI trends in the study sample. ${ }^{13}$ 
Dummy variables for HPSF and PAS (and HPSF/PAS * age) were added in the fixed part of both models to control for the baseline differences between the three school types.

Next, BMI values were estimated for children at control schools with an average SES background. Results were stratified for each age- and sex strata (in years). This was done in order to specify the BMI trajectory at the group-level and to be able to deduct the overall relative effects of HPSF and PAS in the next steps. All analyses were performed in R version 3.5.1.

\section{Phase 2: after the primary school period}

BMI trajectories for the control group were extrapolated to the period after primary school ( 12 up to 20 years of age). To examine whether the extrapolated models yielded plausible BMI trajectories, the face validity of the fitted results was inspected. Crossectional data from the Fifth Dutch Growth Study, representing BMI values among Dutch youth in 2009, was used for inspecting face validity. ${ }^{19}$

\section{BMI trajectory of children at HPSF and PAS (reference scenario)}

In a reference scenario, the trajectories for children at 'Healthy Primary Schools of the Future' (HPSF) and 'Physical Activity Schools' (PAS) were modelled by lowering the BMI trajectory of children at control schools (see above). The BMI trajectory was lowered by deducting the BMI reductions (HPSF and PAS vs. control schools) that were obtained after a 2 -year intervention period. The BMI trajectories were lowered from age 6 (2-year effects settling in from age six onwards [2 years after the start of primary school and intervention exposure]) until 20 years of age. This was done in order to compare the reference scenario with other effect maintenance scenarios as specified by the experts. The effects on children's standardized BMI values (BMI z-score) after two-years of intervention were previously analysed. ${ }^{13}$ The average analysed effect on BMI z-scores was converted to the average BMI reduction within the study sample, based on the standard deviation at baseline $(S D=2.55)$, because this would resemble the 'true' variation in our study sample (as suggested by experts). The overall 2-year intervention effects were applied, as no statistically significant differences between age groups, sex, and SES groups were found. ${ }^{13}$ Adapting the whole trajectory (reference scenario) based on short-term (observed) effects is in accordance with the approach of previous cost-effectiveness studies.

\section{Estimation of BMI trajectories with expert information}

To obtain a representative and information-rich panel, experts were selected by purposive sampling $(\mathrm{N}=11) .{ }^{20} \mathrm{~A}$ semi-structured interview was performed face-to-face or by telephone 
(interview led by $\mathrm{MO}$ ), and followed a pre-developed interview guide consisting of qualitative and quantitative questions (see Appendix 2 for more details). We aimed to elicit experts' views on the future trends in effect maintenance and the underlying mechanisms through qualitative questions, as well as eliciting quantitative estimates on the future relative effects and the corresponding uncertainty. For the quantitative part, graphical displays from the interactive MATCH Uncertainty Elicitation Tool were used (Roulette method) to specify the mean relative effect/effect maintenance and the variance (probability distribution) during and after the primary school period. ${ }^{21}$

The qualitative answers were first analysed. Transcriptions were anonymized, and themes relating to the direction of the effect maintenance were identified and grouped in scenarios (thematic content analysis) (MO and DDBG). Scenarios were drafted for the effect maintenance during the primary school period (1) and after the primary school period (2). Scenarios were summarized by using the context-mechanism-outcome configuration of the realist evaluation method to provide insight in the mechanisms underlying effect maintenance. ${ }^{22}$ A summary of the expert's answers and the constructed scenarios were given to the experts for feedback (member check), which was incorporated in the revision of the scenarios. Identification of scenarios and data saturation were discussed between $M O$ and DDBG.

After drafting the scenarios, we scored the chosen scenario for each expert and sorted the (individually) elicited probability distributions accordingly. Scenario-specific probability distributions were calculated by averaging the means and variances of the expert probability distributions with equal weights for experts.

Last, scenarios for the primary and post-primary school period were combined. The combinations mentioned by the experts were used for further analysis and comparison.

\section{Results}

Characteristics of the study sample are described in Table 1. The study sample consisted of children ( $47.4 \%$ boys) who were on average 7.5 years old at baseline. Children at control schools had higher BMI values as compared to their peers at HPSF or PAS (Table 1). 


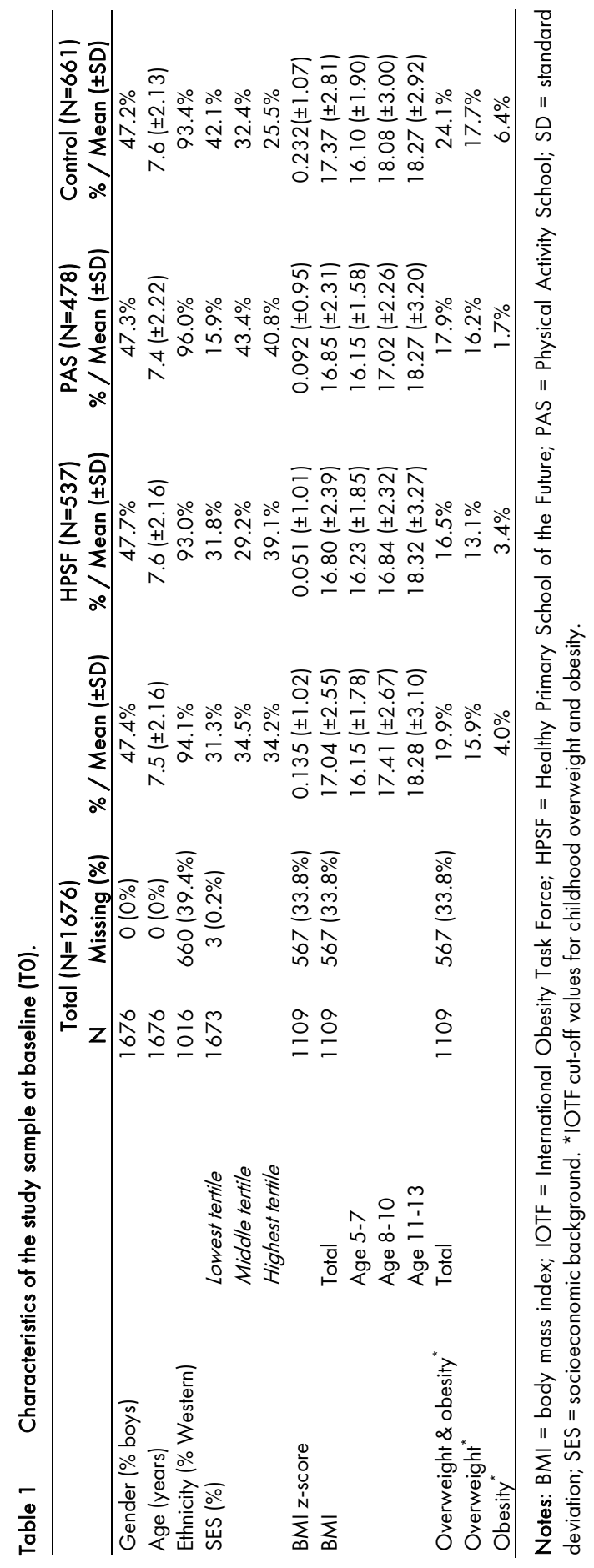




\section{Phase 1: primary school period}

The fitted BMI trajectories for boys and girls with an average SES at control schools are presented in Figure 1. Fitted values showed an increase in variation with age similar to the observed values (see Appendix 3). The trajectory of the observed median BMI values showed a decline for boys at age 7 years, which was also present in the fitted models (Figure 1, Panel 1).

Panel 1. Boys

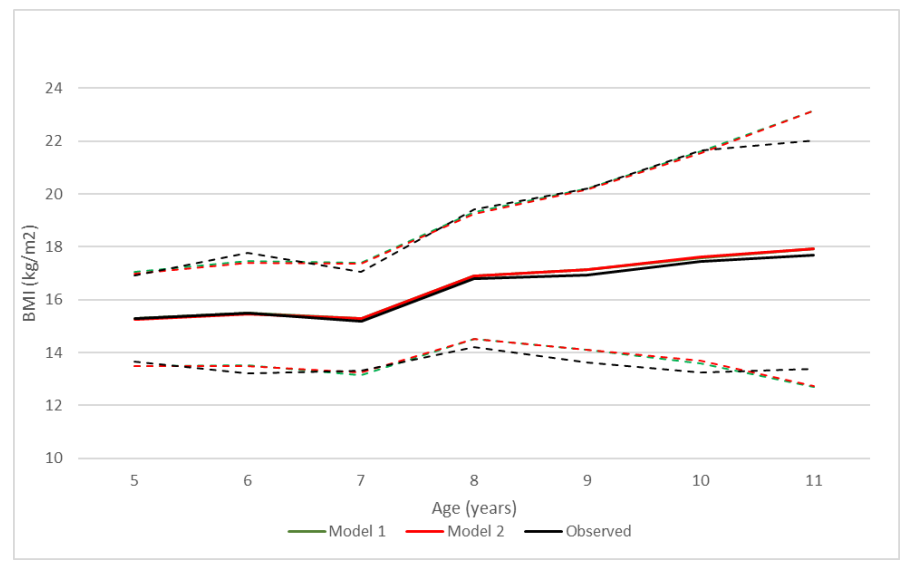

Panel 2. Girls

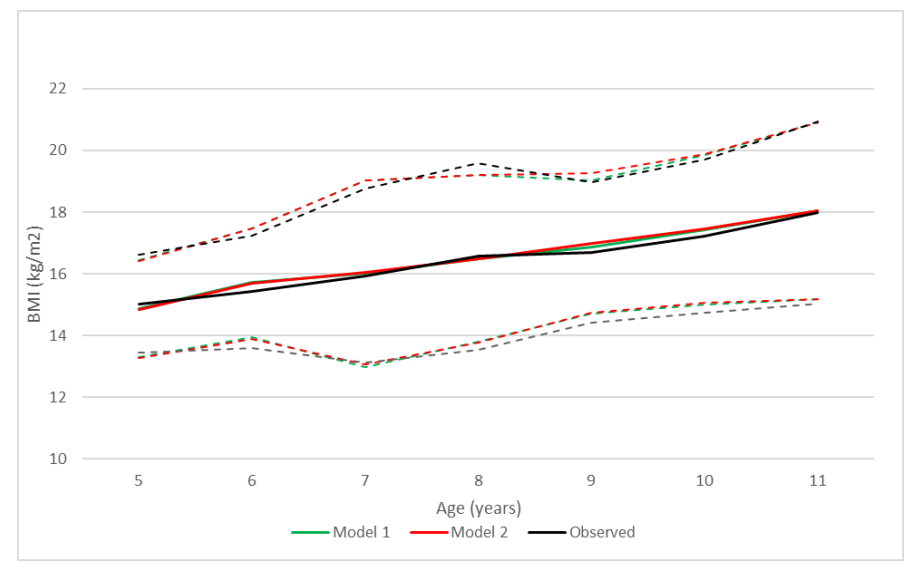

Figure 1 Observed and predicted BMI values.

Notes: $\mathrm{BMI}=$ body mass index. Dashed lines: median - interquartile range; median + interquartile range. Solid lines: median BMI values. Model 1: linear mixed model (see Box 1). Model 2: piecewise mixed model (see Box 1). Where separate lines are not visible, the values of Model 1 and Model 2 do overlap. 
Phase 2: after the primary school period

Based on the comparison with the Fifth Dutch Growth Study, the decreasing BMI values for boys from 15 years of age in model 1 were not considered plausible, and Model 2 was selected (Appendix 4). For girls, model 1 adequately reflected the cubic BMI trend. The selection of model 2 for boys and model 1 for girls is supported by literature, which shows that BMI trajectories for boys are relatively linear as compared to a more concave growth in girls due to the early onset of puberty. ${ }^{23}$

Because the downward slope in BMI growth was not captured from 18 years onwards, the BMI increases from 18-19 years and 19-20 years of age in the Fifth Dutch Growth Study were applied. Median BMI values increased to 22.06 (boys) and 22.18 (girls) at age 20 years of age (Figure 2). In the reference scenario 2-year observed relative effects of HPSF and PAS were applied to the entire trajectory, which resulted in a 0.22 and $0.17 \mathrm{~kg} / \mathrm{m}^{2}$ lower BMI trajectory, respectively (Appendix 5).

\section{Estimation of BMI trajectories with expert information}

\section{Scenarios}

Phase 1: primary school period

Expert's motivations revealed three scenarios (Table 2):

\section{Constant exposure-effect scenario}

Most experts indicated that the observed relative effects (after 2 years) would stay about the same when exposure is maintained during the primary school period (mentioned by $\mathrm{N}=8$ respondents).

\section{Household multiplier scenario}

Some experts anticipated that prolonged exposure (longer than the observed two years) during the primary school period and new learned behaviours might lead to behaviour changes within the household (mentioned by $\mathrm{N}=3$ respondents). This would probably lead to more favourable results.

\section{Personal factors}

Last, experts indicated that in addition to the constant effect-exposure scenario, internal/psychosocial mechanisms (e.g. reducing feelings of 'not feeling comfortable' with participating in sports) and physical mechanisms (e.g. increase in muscle mass) could contribute to sustained effects (mentioned by $\mathrm{N}=4$ respondents). 
Panel 1. Boys - model 2

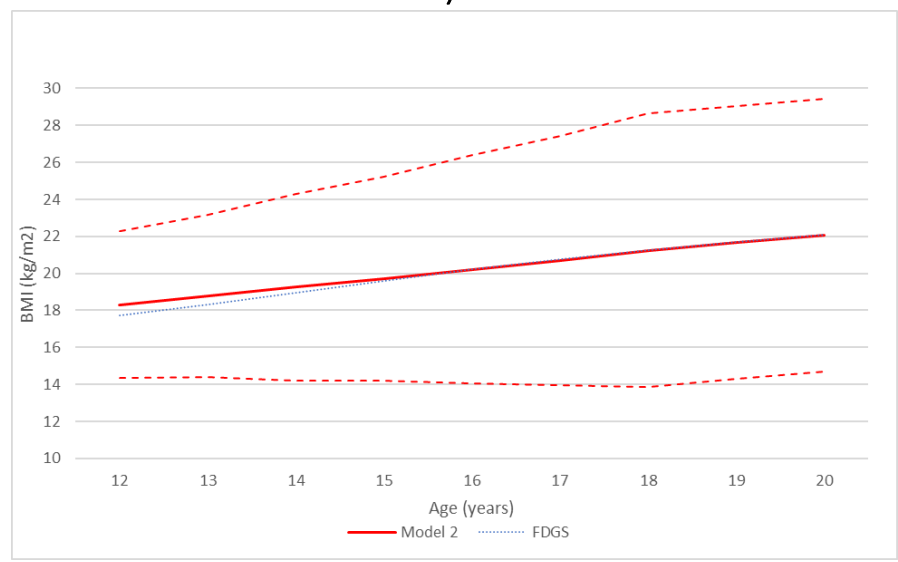

Panel 2. Girls - model 1

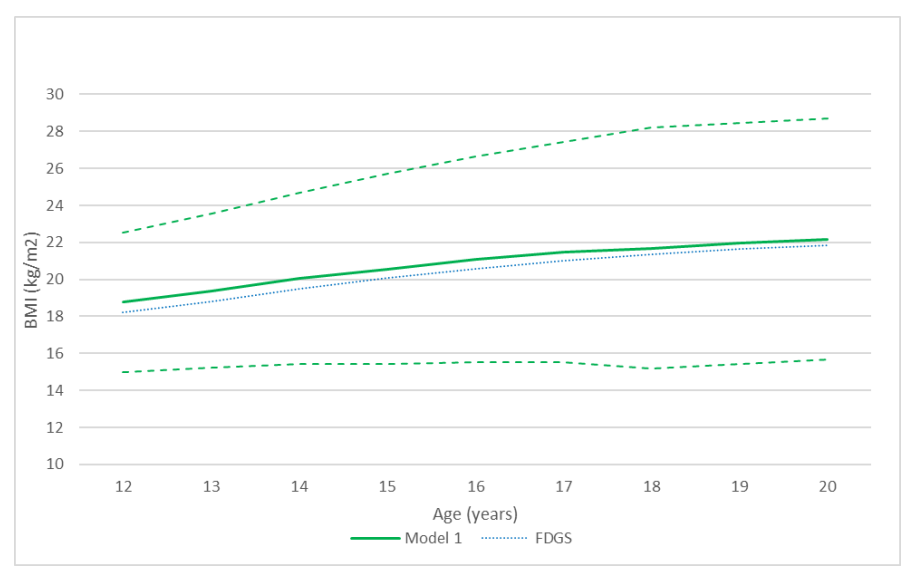

Figure 2 Projected median BMI values for children at control schools [average SES].

Notes: $\mathrm{BMI}=$ body mass index; FDGS = Fifth Dutch Growth Study; SES = socioeconomic status. Dashed lines: median - interquartile range; median + interquartile range. Solid lines: median BMI values. Model 1: linear mixed model (see Box 1). Model 2: piecewise mixed model (see Box 1)

\section{Phase 2: after the primary school period}

\section{Uncontrolled environment scenario}

Nearly all respondents expected an effect decay after the primary school period (mentioned by $\mathrm{N}=10$ respondents). It was anticipated that the transition to secondary school would lead to a disruption of children's pre-existing acquired health behaviours. 


\section{Household maintainer scenario}

One expert indicated that the relative effects could be sustained via improved health behaviours in the household (Table 3).

The respondents highlighted that numerous characteristics in the environment (e.g. facilities in the neighbourhood, knowledge and beliefs, marketing, media, and policy factors) influence health behaviours and BMI. Most factors will affect children from both the control and intervention groups, and the relative effects will therefore not change greatly. Some experts indicated that it was too difficult for them to make quantitative estimations, due to the lack of specific expertise, and/or the multifactorial nature of the uncertainties ( $N=4$ experts, $N=2$ interviews). Quantitative estimates for the scenarios 'personal factors' were not further quantitatively specified as they were considered too multifactorial by the respondents.

\section{Relative effects}

Three different combinations of scenarios were mentioned (Figure 3):

A) The constant exposure-effect scenario and the uncontrolled environment scenario (mentioned by $\mathrm{N}=8$ respondents). This led to a relative reduction of -0.21 [HPSF] and -0.17 [PAS] $\mathrm{kg} / \mathrm{m}^{2}$ during the primary school period, and a reduction of -0.04 [HPSF and PAS] after the primary school period.

B) The household multiplier scenario and the uncontrolled environment scenario (mentioned by $\mathrm{N}=2$ respondents). This led to a relative reduction of -0.30 [HPSF] and -0.19 [PAS] $\mathrm{kg} / \mathrm{m}^{2}$ during the primary school period, and a reduction of -0.06 [HPSF] and -0.04 [PAS] $\mathrm{kg} / \mathrm{m}^{2}$ after the primary school period.

C) The household multiplier scenario and the household maintainer scenario (mentioned by $\mathrm{N}=1$ respondent). This led to a relative reduction of -0.30 [HPSF] and -0.19 [PAS] $\mathrm{kg} / \mathrm{m}^{2}$ during the primary school period, and a reduction of -0.50 [HPSF] and -0.21 [PAS] $\mathrm{kg} / \mathrm{m}^{2}$ after the primary school period. 


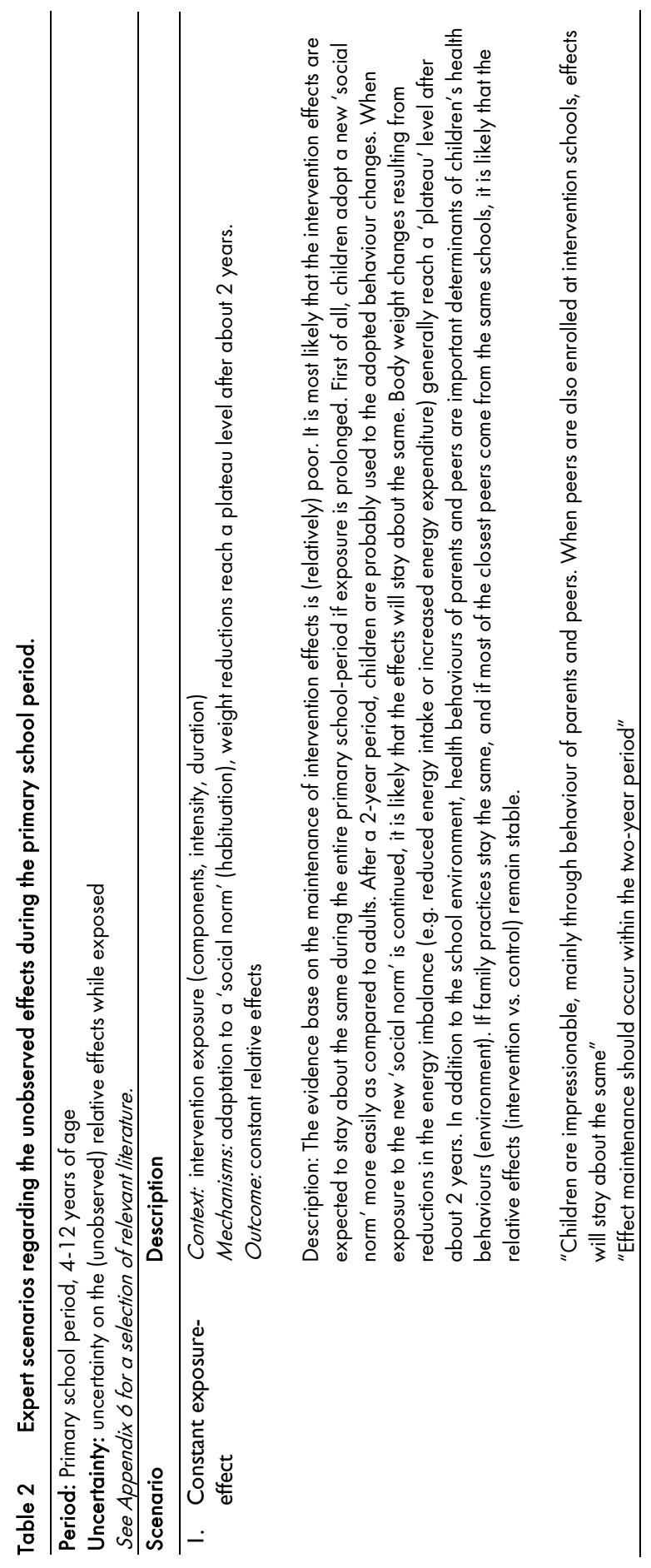




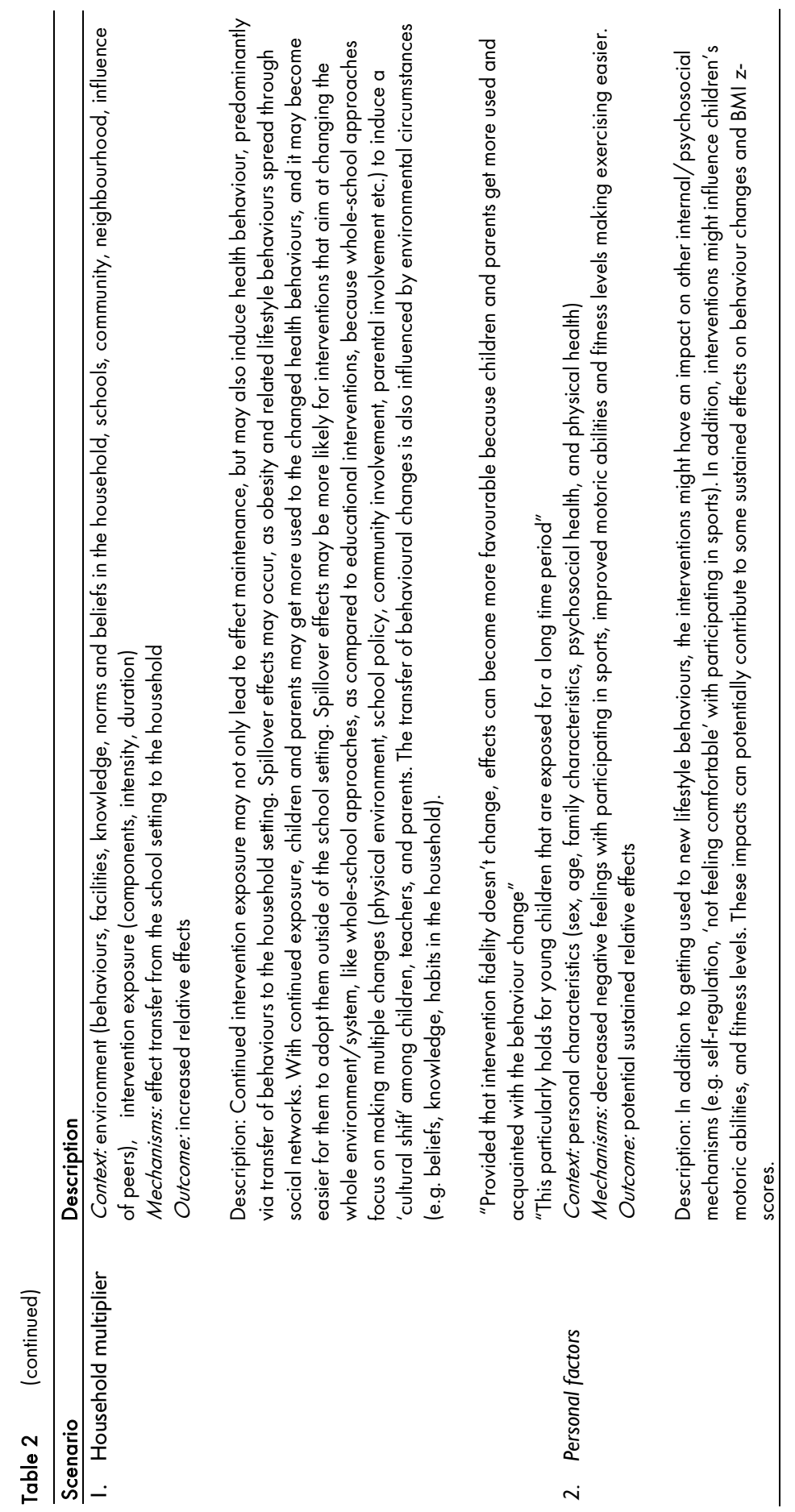




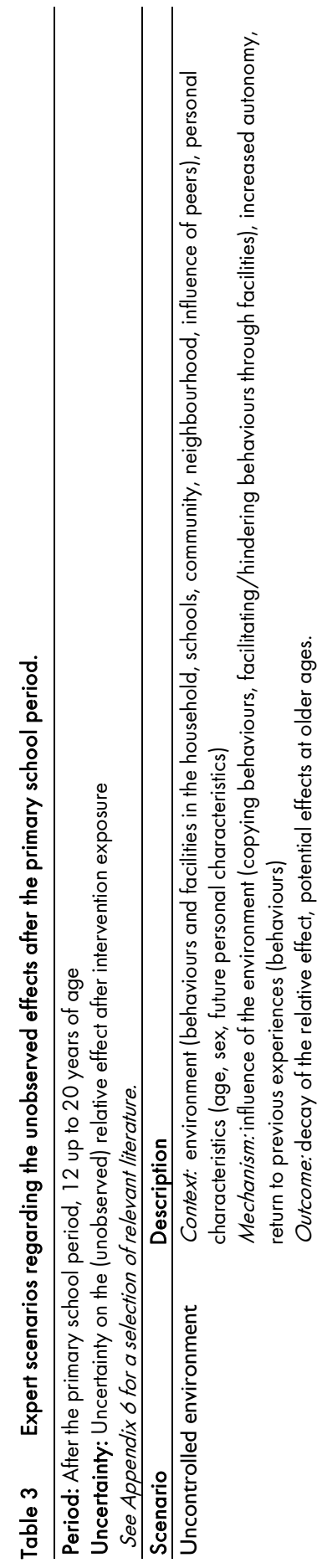

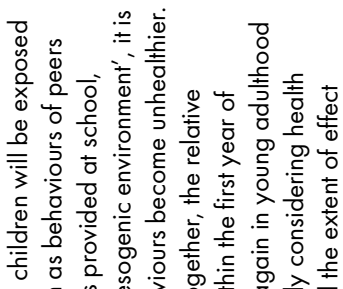

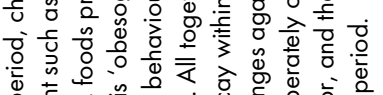

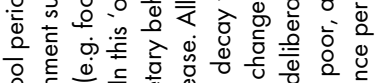

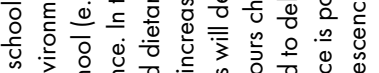

帘

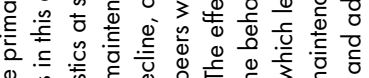

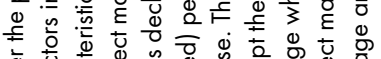

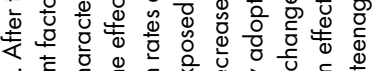

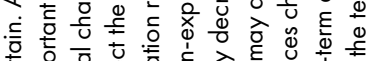

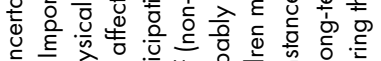

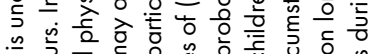

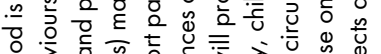

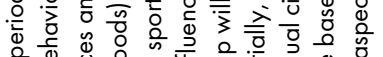

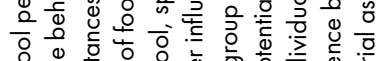

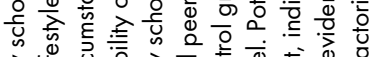

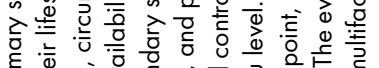

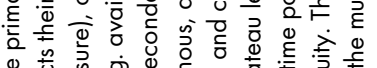

兽总审

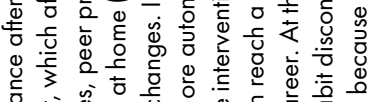

రิ

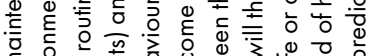

它

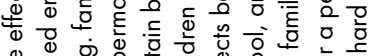

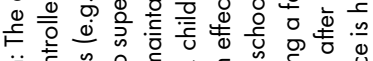

ธั่

은

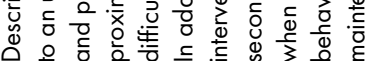

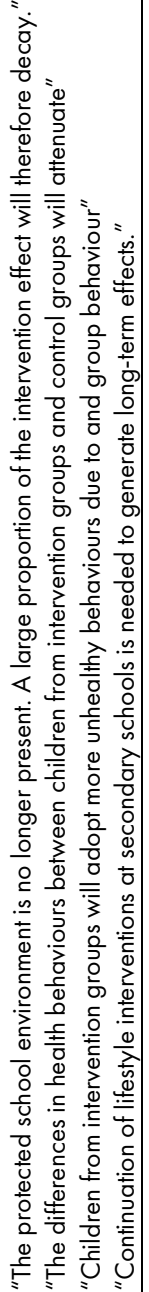




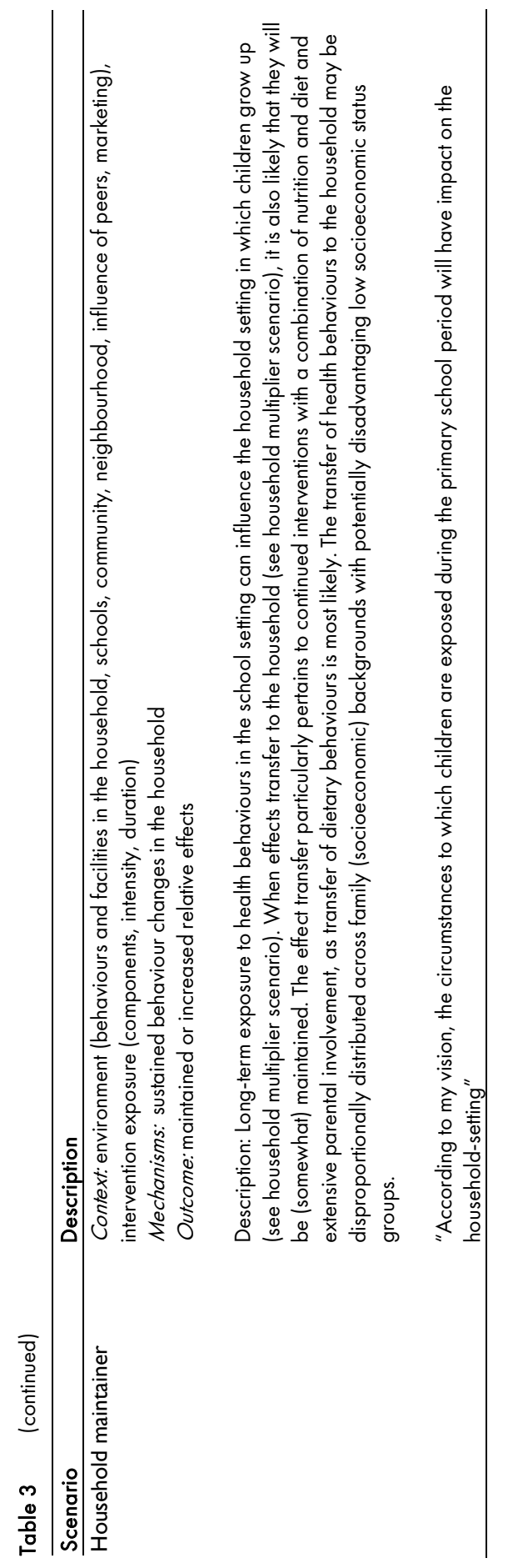




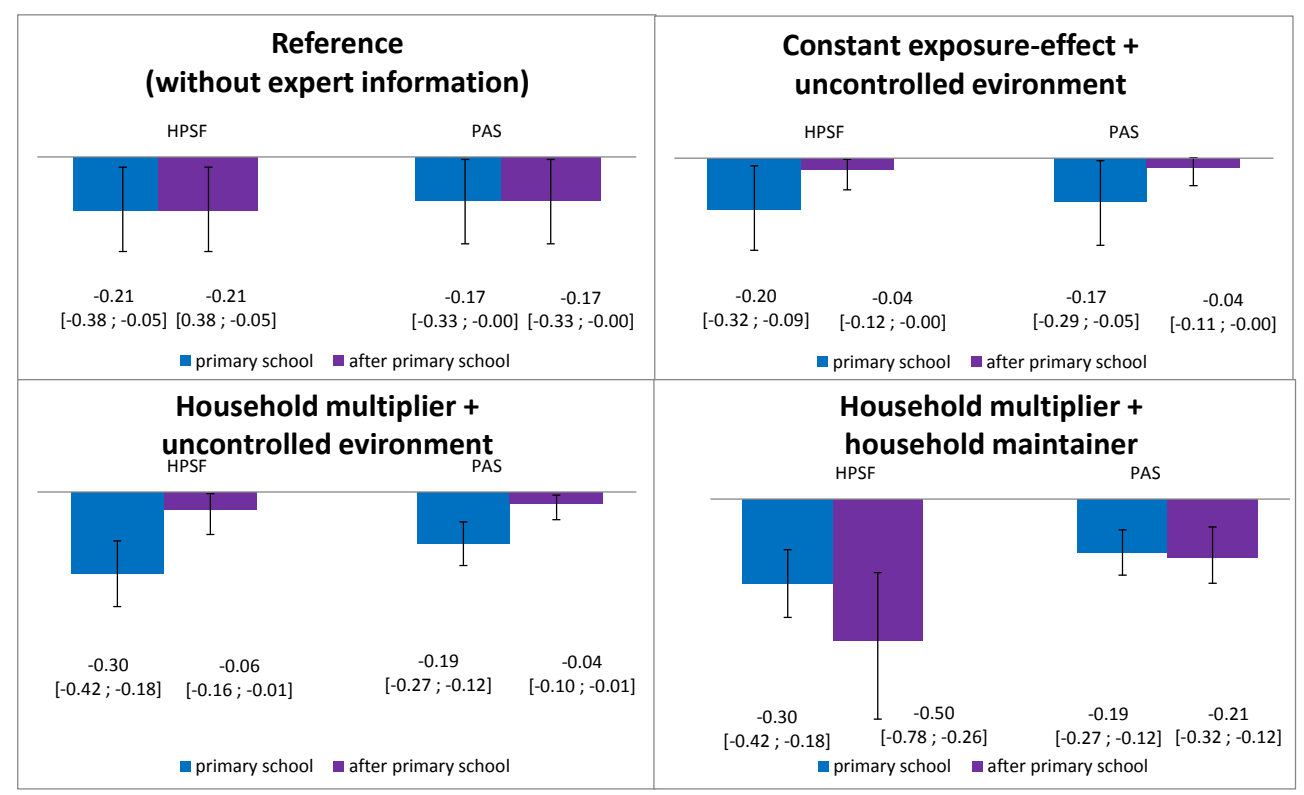

Figure 3 Combination of uncertainty scenarios.

Notes: $\mathrm{BMI}=$ body mass index; $\mathrm{Cl}=$ confidence interval; HPSF = Healthy Primary School of the Future; PAS = Physical Activity School.

\section{Discussion}

This study aimed to model plausible BMI trajectories after exposure to HPSF and PAS until early adulthood. Relying on the 2-year observed effects resulted in a relative effect of -0.21 (HPSF) and $-0.17 \mathrm{~kg} / \mathrm{m}^{2}$ (PAS). Experts indicated that intervention effects could be maintained during the primary school period (constant exposure-effect scenario) or become more favourable due to the adoption of behaviour changes in the household (household multiplier scenario). After the primary school period, effects could decay (uncontrolled environment scenario) or be maintained due to sustained behaviour changes in the household (household maintainer scenario). The smallest relative effects were found under a constant exposure-effect (primary school) and uncontrolled environment scenario (after primary school) (mean difference at 20 years of age: $-0.04 \mathrm{~kg} / \mathrm{m}^{2}$ [HPSF and PAS vs. control). The highest relative effects corresponded to a household multiplier (primary school) and household maintainer scenario (after primary school) (mean difference at 20 years of age: $-0.50 \mathrm{~kg} / \mathrm{m}^{2}$ [HPSF vs. control], $-0.21 \mathrm{~kg} / \mathrm{m}^{2}$ [PAS vs. control]). 


\section{BMI trajectories from childhood to adulthood}

Different statistical models can be used to describe growth trajectories in children, which may depend on the study aim, the measure of growth, the frequency of measurements, and the period of growth of children being investigated. ${ }^{24}$ We aimed to predict the BMI growth trajectory at a group-level instead of accurately resembling individual BMI development. We used the fixed and random effects from the primary school models for extrapolating BMI trajectories. Theoretically, this approach is suboptimal, because BMI growth (fixed effects) and variability (random effects) is different for adolescents as compared to primary school aged children. To derive at plausible BMI trajectories data of the Fifth Dutch Growth Study was used for guiding model selection and for performing minor calibration (see above). ${ }^{19}$ The fitted values were not fully comparable to the results of the Fifth Dutch Growth Study due to differences in the study population (children from the Parkstad region vs. general Dutch population) and secular trends (2015-2018 vs. 2009). Instead of the face validity criterion, databased criteria (maximum difference [\%] between estimated and observed values) could be used to further improve the predictive ability of the BMI trajectory models.

\section{Expert judgement}

At least six experts were invited for participation in accordance to recommendations by Cooke et al. (2006). ${ }^{25}$ The different backgrounds from health promotion experts, health economists, and epidemiologists led to the discovery of different scenarios. Not all participants felt confident with making quantitative estimations due to their unfamiliarity with the relative effects of primary school-based lifestyle interventions on BMI or due to the multifactorial nature of effect maintenance and secular trends. Using intermediate outcome measures, like the increase in minutes of moderate physical activity or calorie intake, instead of BMI, may potentially aid in making estimations on relative effects. Overall, we feel that integrating expert elicitation into the extrapolation of databased statistical models is a first step towards assessing the impact of effect maintenance on the intervention's benefits in a more valid (expert informed estimates vs. uninformed scenario analyses) and informative manner.

\section{Relative effectiveness of HPSF and PAS in childhood and adolescence}

Regarding the primary school period, most experts anticipated constant relative effects. Bartelink et al. (2019) found that the BMI reductions in children at HPSF and PAS were smaller in the second year as compared to the first year of intervention, while the relative effects became larger due to the BMI growth at control schools. ${ }^{13}$ A decreased enthusiasm was mentioned as a potential explanation for the smaller intervention effects in the second 
year. ${ }^{13}$ Analysis of the 4 -year effects will be carried out to investigate whether the effects in the second year are sustained. Another anticipated scenario was the uptake of lifestyle changes in the household. The 2-year quantitative analysis did not show an overall effect for physical activity and dietary behaviour at home, but more favourable effects in physical activity at home were found for children with a higher SES background. ${ }^{26}$ Further research could focus on the transfer of effects to the household and the impact on effect maintenance during and after the primary school period. Follow-up research in secondary schools is of utmost need to investigate the effect maintenance of primary school-based lifestyle interventions into adolescence and young adulthood.

\section{Relative effectiveness of HPSF and PAS in adulthood}

It may be difficult for readers to understand the impact and consequences of our findings as the uncertainty is only expressed in terms of the intermediate BMI outcome. In a modelling study, we will estimate the impact of the different scenarios on the long-term health and economic impacts of HPSF and PAS (e.g. healthcare cost savings, years lived with overweight). In order to provide more insight on the relevance of our findings, we converted the results on BMI into the effects on excess calorie intake, which is another intermediate outcome but may be easier to interpret. Wang et al. (2012) and Plachta-Danielzik et al. (2008) calculated that children's excess energy intake should be reduced by $41 \mathrm{kcal} / \mathrm{day}$ and $27-58 \mathrm{kcal} /$ day in order to meet the goals for childhood obesity prevention in the US and Germany, respectively. ${ }^{27,28}$ By applying the same mathematical model, we calculated that the relative effects for HPSF $0.21 \mathrm{~kg} / \mathrm{m}^{2}$ in the reference scenario and $0.50 \mathrm{~kg} / \mathrm{m}^{2}$ in the household multiplier and maintainer scenario) translated to a reduction of 17 and 40 $\mathrm{kcal} /$ day for an 8-year old boy, respectively.

\section{Conclusions}

The mixed-methods approach proved to be useful for unravelling uncertainty, for identifying evidence gaps, and for providing inputs for estimates on medium and long-term intervention benefits. The specification of uncertainty on intervention effect maintenance is a first step towards better informing adoption decisions on primary school-based lifestyle interventions. Future research should focus on long-term observations to reduce uncertainty. 


\section{References}

1. Hamilton D, Dee A, Perry IJ. The lifetime costs of overweight and obesity in childhood and adolescence: a systematic review. Obes Rev 2018;19:452-63.

2. Jones RA, Sinn N, Campbell KJ, et al. The importance of long-term follow-up in child and adolescent obesity prevention interventions. Int J Ped Obes. $2011 ; 6: 178-81$.

3. James J, Thomas P, Kerr D. Preventing childhood obesity: two year follow-up results from the Christchurch obesity prevention programme in schools (CHOPPS). BMJ. 2007;335:762.

4. Stea TH, Tveter ET, Te Velde SJ, Vik FN, Klepp KI, Bere E. The effect of an extra piece of fruit or vegetables at school on weight status in two generations - 14 years follow-up of the Fruit and Vegetables Makes the Marks study. PLoS One. 2018;13(10):e0205498.

5. Marcus $B H$, Dubbert $P M$, Forsyth $\mathrm{LH}$, et al. Physical activity behavior change: issues in adoption and maintenance. Health Psychol. 2000;19(1s):32-41.

6. Taylor RW, McAuley KA, Barbezat W, Farmer VL, Williams SM, Mann JI. Two-year follow-up of an obesity prevention initiative in children: the APPLE project. Am J Clin Nutr. 2008;88:1371-7.

7. Rush E, Obolonkin V, McLennan S, et al. Lifetime cost effectiveness of a through-school nutrition and physical programme: Project Energize. Obes Res \& Clin Pract. 2014;8:e1 15-22.

8. Ekwaru JP, Ohinmaa A, Tran BX, Setayeshgar S, Johnson JA, Veugelers PJ. Cost-effectiveness of a schoolbased health promotion program in Canada: A life-course modeling approach. PLoS One. 2017;12: e0177848.

9. Ananthapavan J, Sacks G, Brown V, et al. Assessing cost-effectiveness of obesity prevention policies in Australia. http://www.aceobesitypolicy.com.au/. Date accessed March 01, 2020.

10. Brown V, Ananthapavan J, Sonntag D, Tan EJ, Hayes A, Moodie M. The potential for long-term costeffectiveness of obesity prevention interventions in the early years of life. Ped Obes. 2019;14:e12517.

11. Dalziel K, Segal L. Point: uncertainty in the economic analysis of school-based obesity prevention programs: urgent need for quality evaluation. Obesity. 2006;14:1481-2.

12. Willeboordse $M$, Jansen $M W$, van den Heijkant $S N$, et al. The Healthy Primary School of the Future: study protocol of a quasi-experimental study. BMC Public Health. 2016;16:639.

13. Bartelink N, Van Assema P, Kremers S, et al. Can the Healthy Primary School of the Future offer perspective in the on-going obesity epidemic in young children? - a quasi-experimental study. BMJ Open. 2019;9:e030676.

14. Buscot M, Wotherspoon SS, Magnussen CG, et al. Bayesian hierarchical piecewise regression models: a tool to detect trajectory divergence between groups in long-term observational studies. BMC Med Res Methodol. 2017;17: 86.

15. Graversen L, Howe LD, Sorensen TI, et al. Body mass index trajectories from 2 to 18 years - exploring differences between European cohorts. Ped Obes. 2017;12:102-9.

16. Tilling K, Macdonald-Wallis C, Lawlor DA, Hughes RA, Howe LD. Modelling childhood growth using fractional polynomials and linear splines. Annals of nutrition \& metabolism. 2014;65:129-38.

17. Robinson HA, Dam R, Hassan L, Jenkins D, Buchan I, Sperrin M. Post-2000 growth trajectories in children aged 4-11 years: A review and quantitative analysis. Prev Med Rep. 2019;14:100834.

18. Liem ET, van Buuren S, Saver PJ, Jaspers M, Stolk RP, Reijneveld SA. Growth during infancy and childhood, and adiposity at age 16 years: ages 2 to 7 years are pivotal. J Pediatr. 2013;162:287-92.e2.

19. Schönbeck Y, Talma H, van Dommelen $P$, et al. Increase in Prevalence of Overweight in Dutch Children and Adolescents: A Comparison of Nationwide Growth Studies in 1980, 1997 and 2009. Plos One. $2011 ; 6: e 27608$.

20. Zondervan-Zwijnenburg M, Peeters M, Depaoli S, Van de Schoot R. Where Do Priors Come From? Applying Guidelines to Construct Informative Priors in Small Sample Research. Res Hum Dev. 2017; 14: 305-20.

21. Morris DE, Oakley JE, Crowe JA. A web-based tool for eliciting probability distributions from experts. Env Model Soft. 2014;52:1-4.

22. Pawson R, Tilley N. Realist Evaluation. Sage Publications Ltd. 2004. http://www.communitymatters.com.au/ RE_chapter.pdf. Date accessed: March 01, 2020. 
23. Cole TJ, Bellizzi MC, Flegal KM, Dietz WH. Establishing a standard definition for child overweight and obesity worldwide: international survey. BMJ. 2000;3:1240-3.

24. Chirwa ED, Griffiths PL, Maleta K, Norris SA, Cameron N. Multi-level modelling of longitudinal child growth data from the Birth-to-Twenty Cohort: a comparison of growth models. Ann Hum Biol. 2014; 41:168-79.

25. Cooke R, Probst KN. Highlights of the Expert Judgment Policy Symposium and Technical Workshop. Conference summary; 2006. https://media.rff.org/documents/Conference-Summary.pdf. Date accessed: March 01, 2020.

26. Bartelink N, van Assema P, Kremers S, Savelberg H, Gevers D, Jansen M. Unravelling the Effects of the Healthy Primary School of the Future: For Whom and Where is It Effective? Nutrients. 2019;1 1:211 19.

27. Plachta-Danielzik S, Landsberg B, Bosy-Westphal A, Johannsen M, Lange D, Müller M. Energy gain and energy gap in normal-weight children: longitudinal data of the KOPS. Obesity. 2008; 16:777-83.

28. Wang YC, Orleans CT, Gortmaker SL. Reaching the Healthy People Goals for Reducing Childhood Obesity: Closing the Energy Gap. Am J Prev Med. 2012;42:437-44. 


\section{Appendix 1}

\section{Flowchart}

\begin{tabular}{|c|c|c|}
\hline \multicolumn{2}{|c|}{\begin{tabular}{|l} 
Baseline \\
Total participating children: $n=1403$ (60.3\% of all children)
\end{tabular}} & \\
\hline \multicolumn{3}{|c|}{$\begin{array}{l}\text { Selection for the current study }{ }^{*} \\
\text { Participating children in classes } 1-7: n=1255\end{array}$} \\
\hline $\begin{array}{l}\text { HPSF }(n=361) \\
\text { schools }\end{array}$ & $\begin{array}{l}\text { PAS }(n=408) \\
2 \text { schools }\end{array}$ & $\begin{array}{l}\text { Control }(n=486) \\
4 \text { schools }\end{array}$ \\
\hline \multicolumn{3}{|c|}{$\begin{array}{l}\text { One year follow up (Year } 1) \\
\text { Total participating children: } n=1489(60.7 \% \text { of all children) }\end{array}$} \\
\hline \multicolumn{3}{|c|}{$\begin{array}{l}\text { Selection for the current study } \\
\text { Participating children in classes 2-8: } n=1455 \\
\text { Newly included }(n=264) ; \text { Drop-out }{ }^{*}(n=64)\end{array}$} \\
\hline $\begin{array}{l}\text { HPSF }(n=469) \\
\text { New included: } n=132 \\
\text { Drop-out: } n=24\end{array}$ & $\begin{array}{l}\text { PAS }(n=428) \\
\text { New included: } n=33 \\
\text { Drop-out: } n=13\end{array}$ & $\begin{array}{l}\text { Control }(n=558) \\
\text { New included: } n=99 \\
\text { Drop-out: } n=27\end{array}$ \\
\hline \multicolumn{3}{|c|}{$\begin{array}{l}\text { Two year follow up (Year } 2 \text { ) } \\
\text { Total participating children: } n=1470 \text { (61.7\% of all children) }\end{array}$} \\
\hline \multicolumn{3}{|c|}{$\begin{array}{l}\text { Selection for the current study } \\
\text { Participating children in classes } 3-8: n=1323 \\
\text { Newly included }(n=158) ; \text { Drop-out }{ }^{* * *}(n=290)\end{array}$} \\
\hline $\begin{array}{l}\text { HPSF }(n=432) \\
\text { New included: } n=44 \\
\text { Drop-out: } n=81\end{array}$ & $\begin{array}{l}\text { PAS }(n=376) \\
\text { New included: } n=38 \\
\text { Drop-out: } n=90\end{array}$ & $\begin{array}{l}\text { Control }(n=515) \\
\text { New included: } n=76 \\
\text { Drop-out: } n=119\end{array}$ \\
\hline \multicolumn{3}{|c|}{ Total participating children in study period: $n=1974$} \\
\hline \multicolumn{3}{|c|}{ Selection for the current study: $n=1676^{* * * *}$} \\
\hline HPSF $(n=537)$ & PAS $(n=478)$ & Control $(n=661)$ \\
\hline
\end{tabular}

Figure A1. Flowchart of children participating in the measurements.

Notes: HPSF = Healthy Primary School of the Future; PAS = Physical Activity School; Year $1=$ after 12 months; Year 2 = after 24 months. *All children from study year one to eight (age 4 to 12) enrolled at the eight participating schools were eligible to participate in the study, which is internationally comparable to two years of Kindergarten and six grades; ${ }^{\star *}$ Reasons drop out Year 1: switched to other included school $(\mathrm{n}=2)$, other reasons e.g. moved out or actively stopped participation ( $n=62) ;{ }^{* * *}$ Reasons drop out Year 2: finished school ( $\left.n=228\right)$, switched to other included school $(n=17)$, other reasons e.g. moved out or actively stopped participation $(n=45)$; Children who joined the study at year 1 one or year2 were included because they were already enrolled in the participating school at baseline. 


\section{Appendix 2}

\section{Elicitation protocol}

The expert elicitation followed the seven steps as described by Knol et al. (2010), and reporting was in accordance to the COREQ guidelines (reporting for qualitative studies). ${ }^{1,2}$

\section{Characterization of uncertainties and typology of uncertainties}

Empirical studies that evaluate childhood lifestyle interventions generally have a short duration of 1 to 4 years, and do not go beyond childhood. Population health models, are available for estimating the long-term health and cost impacts of lifestyle interventions as they link risk factors to diseases, morbidity, mortality, and costs, but generally start from adulthood onwards. To estimate the long-term health and cost impacts of childhood lifestyle interventions, the gap between childhood (observation range of empirical studies) and adulthood (captured in population health models) has to be filled. Filling this gap comes with uncertainty. The aim of the expert elicitation is to gather informed opinions of experts on the unobserved effects, effect maintenance, and the associated uncertainty. We distinguish two uncertainties that are associated with plugging the evidence gap. The first type of uncertainty pertains to the primary school period (4-12 years of age corresponding to the Dutch setting). Children are still exposed to the intervention, but the effects are partially or no longer observed within the empirical study. The second type refers to the uncertainty on the relative effect after the primary school period when exposure to the intervention has ended.

\section{Scope/format of elicitation}

The elicitation will be performed by means of a semi-structured interview, performed face-toface or by telephone (MO), and will follow a pre-developed interview guide. It is aimed to elicit experts' views on the future trends in effect maintenance and the underlying mechanisms, as well as eliciting quantitative estimates on the future relative effects and the corresponding uncertainty (indicated by a mean estimate and an uncertainty distribution). The interviewer (MSc, female) is trained as a health scientist with expertise in health technology assessment. Expert's views will be elicited in individual interviews where possible, to obtain individual views on the uncertainties, as recommended by Knol et al. (2010). 'The team will review whether additional group elicitation may be useful for sharing knowledge and for better appreciation of different disciplinary viewpoints. 


\section{Selection of experts}

In accordance to the recommendations of Cooke et al. (2006) we will invite at least 6 experts. ${ }^{3}$ It is aimed to have an information-rich and diverse panel. Therefore, we strive to get a mixed panel of experts (health promotion specialists, epidemiologists, costeffectiveness researchers, dieticians/paediatricians) from different universities/institutions. Experts will be selected based on purposive sampling $(N=11)$. A relationship with some of the experts was established prior to study commencement $(\mathrm{N}=4)$. A total of six experts are familiar with the Healthy Primary School of the Future initiative. Data saturation will be determined by the point at which no new unique themes are introduced (inductive thematic saturation).

\section{Design of elicitation protocol}

We will ask experts about their views on the presence of the two uncertainties (qualitatively), and subsequently ask to define a plausible parameter space to reflect the amount of uncertainty. As background information for the quantitative part, we will show the 2-year relative effects of HPSF and PAS vs. control schools. Participants will be asked to specify the unobserved relative effects during and after the primary school period. Graphical displays from the interactive MATCH Uncertainty Elicitation Tool will be used in which experts can specify the uncertainty around the anticipated mean relative effect. Participants are asked to specify the plausible parameter space based on the Roulette method (SHELF elicitation template), in order to retrieve the prior mean and variances for the model parameters. We will make use of the Roulette method, because this method is experienced as most intuitive by participants. ${ }^{4}$ Participants are asked to provide motivation for their answers in order to reduce biases and increase the interpretation of results and potential outliers. No seed variables were included in the interview protocol (actual values are known to analysts but unknown to experts) to minimize the burden and time investments for participants ( a minimum of 8 to 10 variables is required to use the seed variables for the analysis). 'The MATCH Elicitation software (MATCH tool) will be used for recording of quantitative answers, and detailed notes are taken for the qualitative answers during and after the interview. The expert elicitation protocol will be piloted among two experts.

\section{Preparation of the elicitation session}

Experts will receive an email with background information and the overall study objective, and are asked to participate in the study. During the interview (of about 45 minutes), the experts will receive additional information on the study aim, background of the researcher 
(PHD candidate researching cost-effectiveness on the Healthy Primary School of the Future initiative), the interventions, and the elicitation procedure.

\section{Background information on the problem}

School-based lifestyle interventions have the potential to generate outcomes within and beyond childhood, due to the likely persistence of health behaviours and excess weight over time, and because excess weight is associated with considerable morbidity, mortality, and cost impacts from young adulthood onwards. Ignoring these long-term outcomes most likely underestimates the value of school-based lifestyle interventions. In order to employ obesity models for estimating the long-term cost-effectiveness of school-based lifestyle interventions, it is key to plug the evidence gap between the time horizon of empirical studies and young adulthood. Estimating outcomes for the unobserved period comes, however, with uncertainty.

\section{Goal}

The aim of this study is to model the BMI trajectories for children (4-12 years of age) who participated in the 'Healthy Primary School of the Future' project up to young adulthood (20 years of age). BMI trajectories are modelled 'the Healthy Primary School of the Future' (HPSF) and the 'Physical Activity School' (PAS), and for a control group without any intervention. We aim to obtain information on the extent of the uncertainty associated with plugging this evidence gap. We will therefore ask you some questions on the long-term unobserved effects and the uncertainty around these values.

\section{Uncertainties}

Most of the empirical studies on childhood lifestyle interventions include a school cohort, with children from varying ages (e.g. children in the age range 4-12 years), which are followed over the time horizon of the empirical study with an average duration of 1-4 years. Given the limited time horizon of most empirical studies, the weight trajectories of individual children are usually partially observed during the primary school period. We distinguish two uncertainties that are associated with plugging the evidence gap between. The first type of uncertainty pertains to the primary school period (4-12 years of age corresponding to the Dutch setting). Children are still exposed to the intervention, but the effects are partially or no longer observed within the empirical study. The second type refers to the uncertainty on the relative effect after the primary school period when children when exposure to the intervention has ended (effect maintenance). 


\section{Elicitation procedure}

In an expert interview, the templates of the Sheffield Elicitation Framework (SHELF) and the web-based MATCH Uncertainty Elicitation Tool will be used for presenting questions and to guide the elicitation of uncertainty information. ${ }^{4}$ The interview will motivate the respondents to explain and provide rationale for their answers. Participants will be asked how difficult it was for them to answer the questions, and which background/expertise they found useful for answering the questions.

We will ask you to provide your view on the uncertainties that I just explained. I provided background information on the problem and the aim of this interview. I will provide you with some information on childhood BMI development and provide relevant data. You are also invited to add relevant literature. I will then ask you to make some estimates. We will use this to explore the different views on the uncertainty of extrapolating childhood weight trajectories. I will ask you to define a range of plausible values, and which values you consider more or less plausible. We will ask you to provide your personal view. We will interview multiple experts to obtain multiple views on this topic.

We will show you a grid comprising a number of columns and a range of possible values of $X$. These columns are called bins. We will ask you to specify the bin boundaries, which indicate the lowest and the highest plausible values of $X$. You will get a number of counters; each of them represents an amount of probability. You will receive 10 counters, so each of them represents a probability of $0.1(10 \%)$. You are asked to place the counters in the bins on your grid, to specify your beliefs about X. Please check if you have used all your counters.

\section{Questions}

1A. Are the observed relative effects of HPSF and PAS after 2 years, representative for the entire primary school period if children are exposed to the interventions during the entire primary school period? Why?

1B. Realistically, what is the lowest plausible value for the relative effect of HPSF versus control schools at age 12 (end of primary school period)?

Realistically, what is the highest plausible value for the relative effect of HPSF versus control schools at age 12 (end of primary school period)?

Please place the counters on the presented grid to represent your beliefs regarding the uncertainty on the relative effect.

Idem for PAS.

$2 A$. Are the observed relative effects representative for the period after the primary school 
period (corresponding to age 13 up to 20 years of age) when children are no longer exposed to the primary school interventions? Why?

2B. Effect maintenance or decay is expressed in percentages: $0 \%$ (no sustained effects) $100 \%$ (all effects maintained).

Realistically, what is the lowest plausible value for the effect maintenance of HPSF versus control schools at age 20 (end of primary school period)?

Realistically, what is the highest plausible value for the effect maintenance of HPSF versus control schools at age 20 (end of primary school period)?

Please place the counters on the presented grid to represent your beliefs regarding the uncertainty on the effect maintenance.

Idem for PAS.

\section{Elicitation of expert judgments}

To capture the variation in the experts' set of assumptions, qualitative answers will be analysed after the interviews with thematic content analysis (MO and DDBG). Mechanisms of effect maintenance will be specified using the context-mechanism-outcome configuration of the realist evaluation method. ${ }^{5}$ Scenarios are drafted for the effect maintenance during the primary school period (1), and after the primary school period (2) (MO and DDBG).

A member check questionnaire (written) will be used to verify and validate the interpretation of experts' answers. Based on a summary of the participant's answers (drafted by MO), participants are asked whether they recognize their answers, and whether something is missing or unclear. In addition, critical peer review between two authors (MO and DDBG) will be performed to check the interpretation and aggregation of outcomes in scenarios. The synthesized information will also be part of the member check (synthesized member check). ${ }^{6}$ Participants are asked about whether they recognize their views in one of the scenarios, if something is missing, and are asked to indicate the likelihood of each of the scenarios. This information will be used to update the synthesized results.

\section{Possible aggregation and reporting}

Differences in judgements between experts might stem from different background information on which the experts make their judgement or from different schools of thought. ${ }^{7}$ Diversity of expert views itself carries valuable information and should be part of the open reporting of the study results. We will examine whether disparate views are present. We will do this via first synthesizing the views on the uncertainties that emerge from the qualitative questions. Scenarios will be described, and participant quotations will be presented. Due to limitations in time, and to keep the interview concise, we will not include seed variables for determining expert weights. Instead, we will use linear pooling, in accordance to others. 


\section{Appendix 3}

Model details primary school period

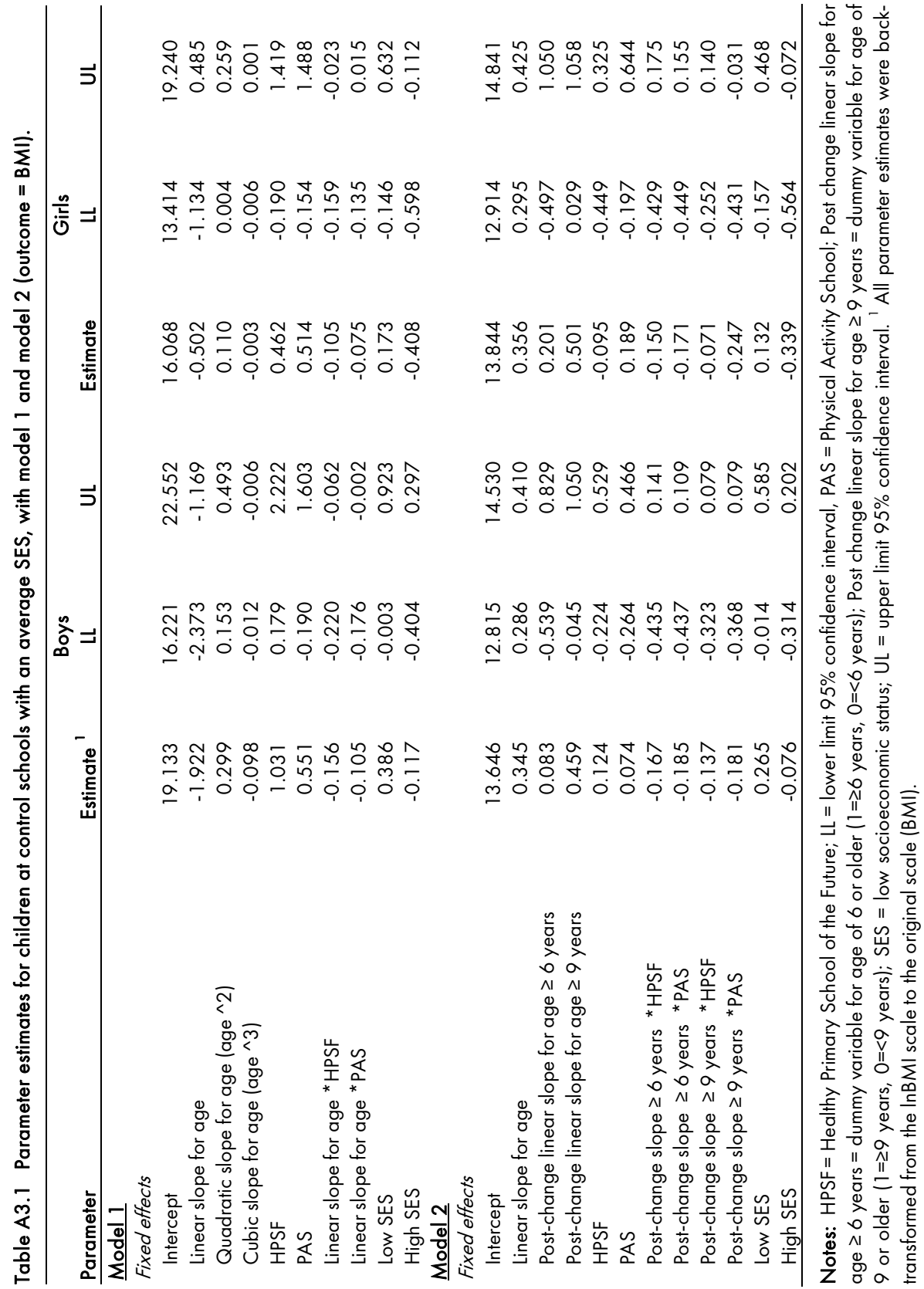




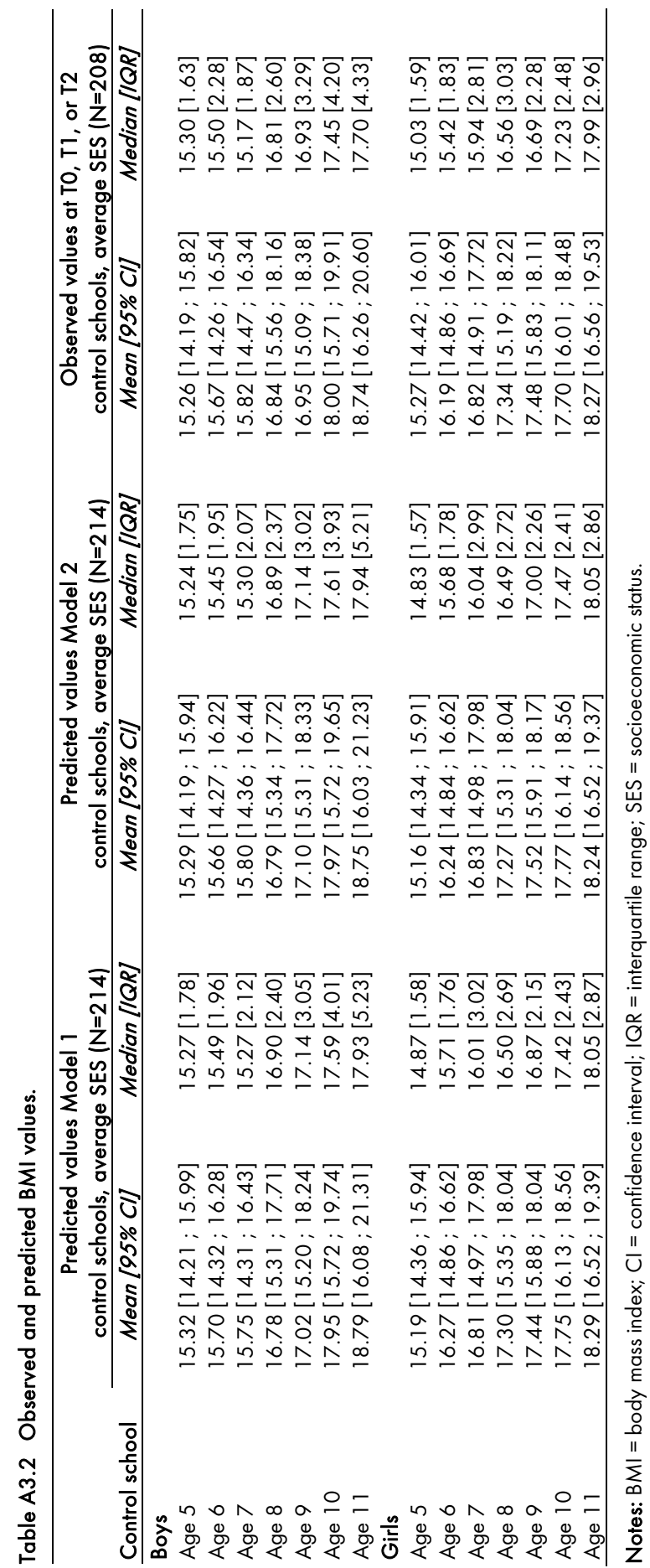


12 year olds boys

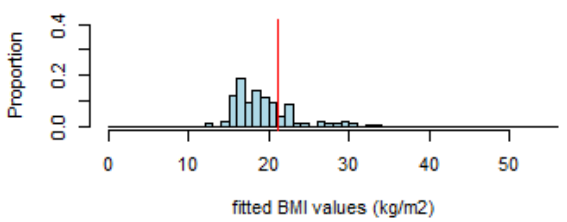

13 year olds boys

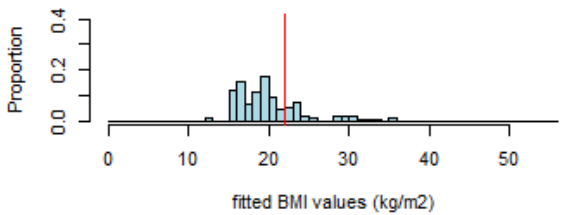

14 year olds boys

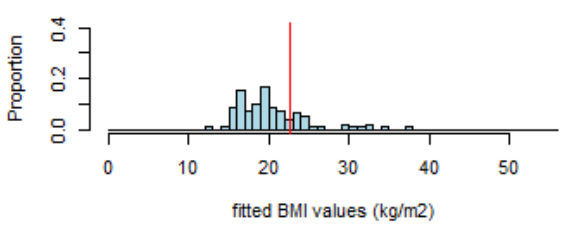

15 year olds, boys

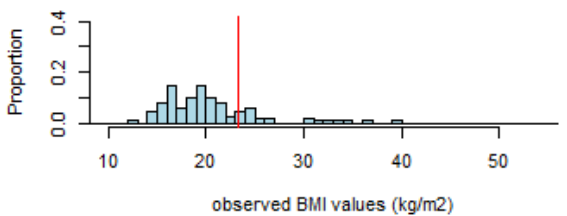

12 year olds boys

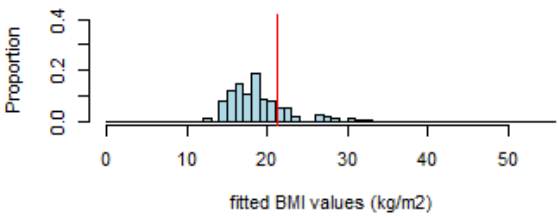

13 year olds boys

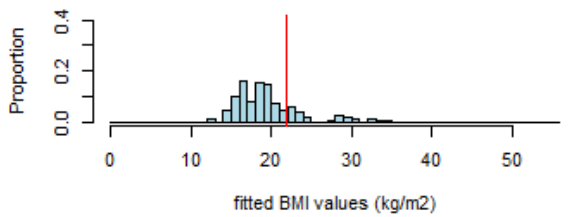

14 year olds boys

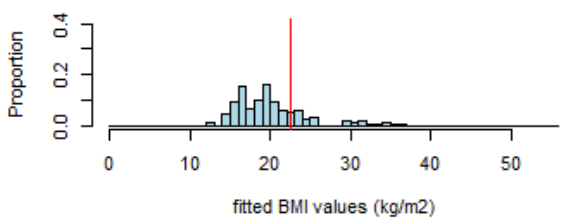

15 year olds boys

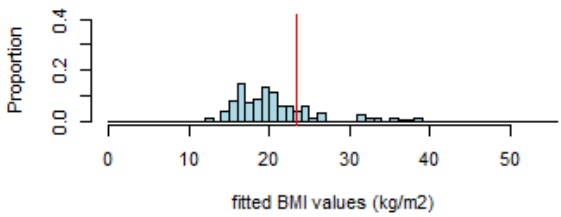


16 year olds boys

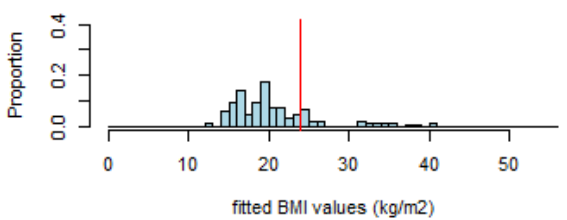

17 year olds boys

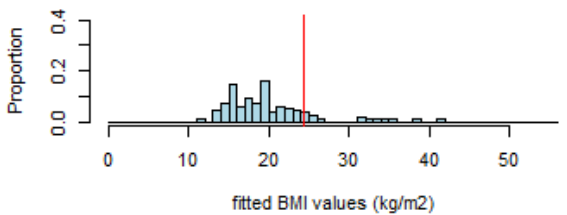

18 year olds boys

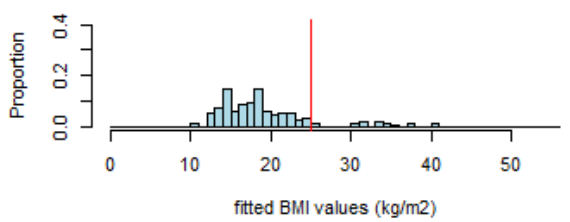

19 year olds boys

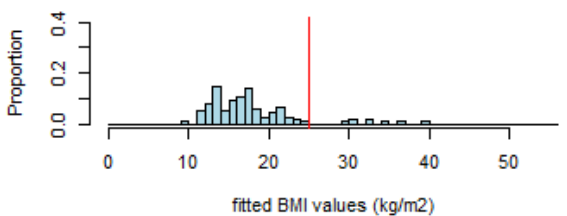

20 year olds boys

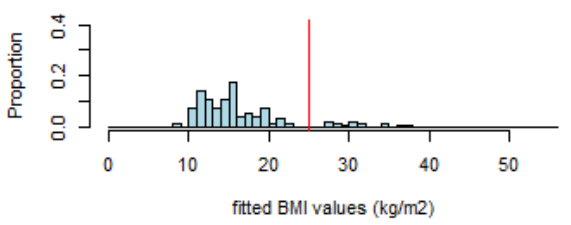

16 year olds boys

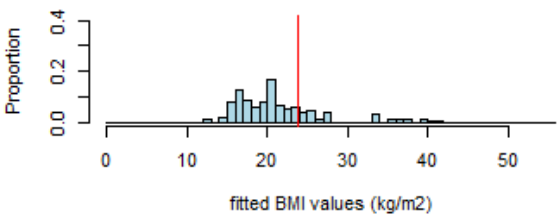

17 year olds boys

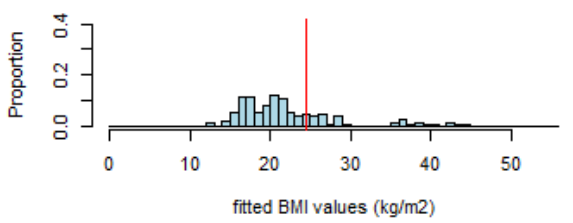

18 year olds boys

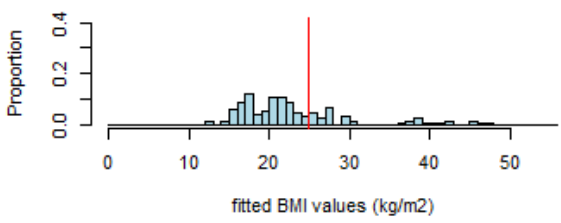

19 year olds boys

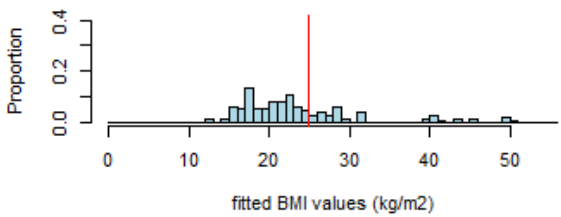

20 year olds boys

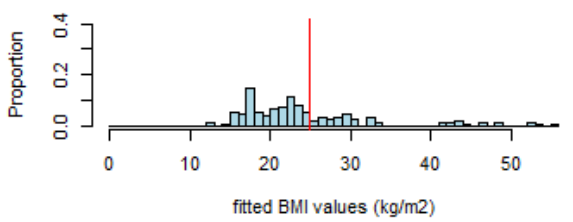

Figure A3.1 Histogram of fitted values with model 1 (column 1), and fitted values with model 2 (column 2) for boys at control schools with an average SES.

Notes: $\mathrm{BMI}=$ body mass index; IOTF = International Obesity Task Force; SES = socioeconomic status. Red vertical line = IOTF cut-off points for childhood overweight and obesity lage- and sexspecific). ${ }^{9}$ 


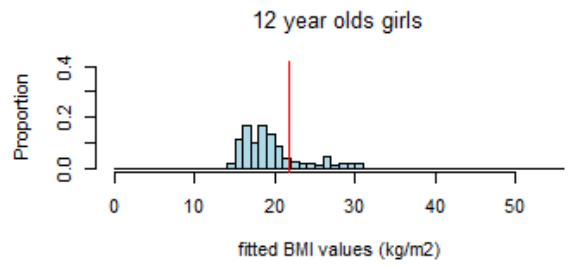

13 year olds girls

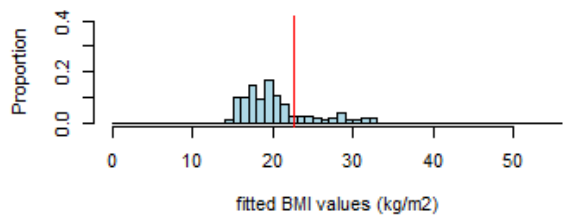

14 year olds girls

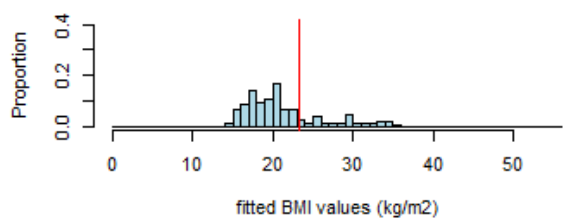

15 year olds, girls

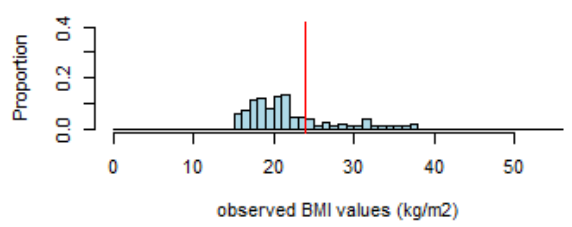

12 year olds girls

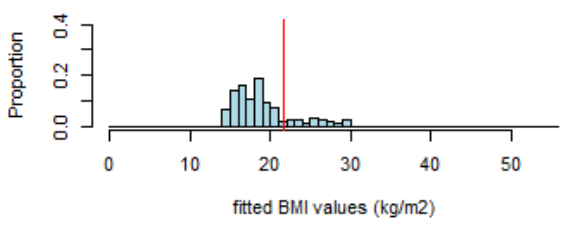

13 year olds girlsboys

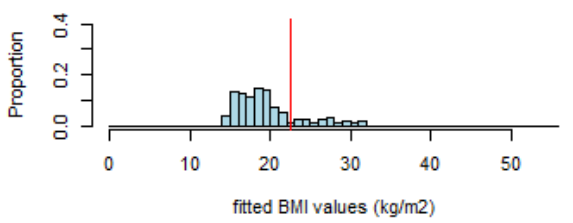

14 year olds girls

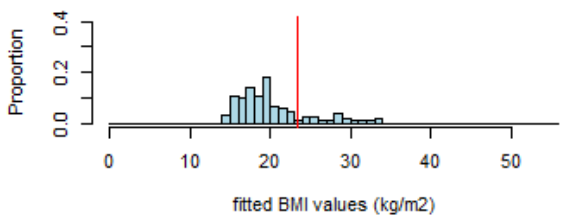

15 year olds girls

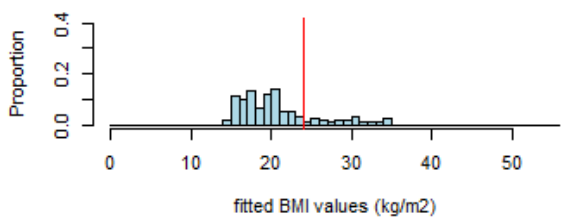




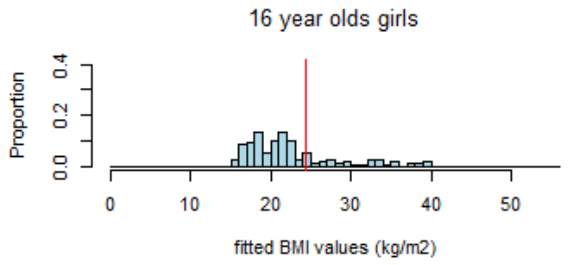

17 year olds girls

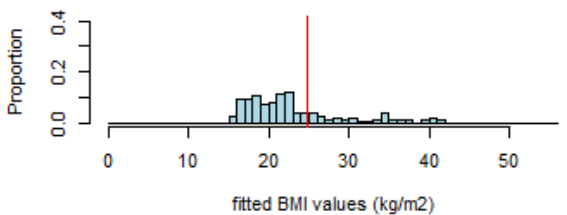

18 year olds girls

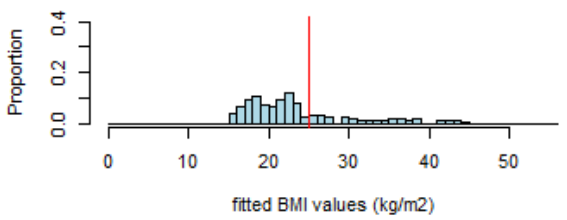

19 year olds girls

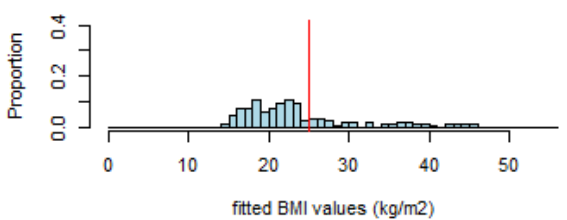

20 year olds girls

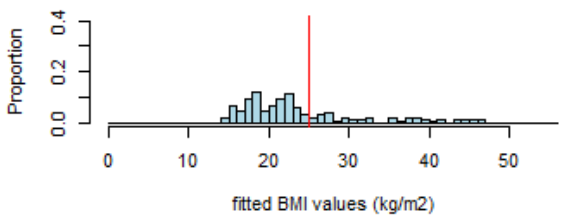

16 year olds girls

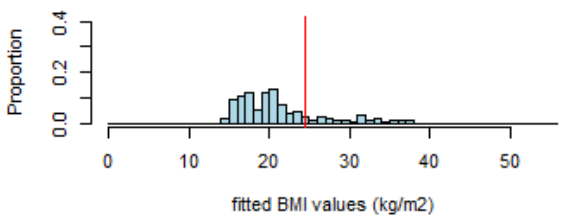

17 year olds girls

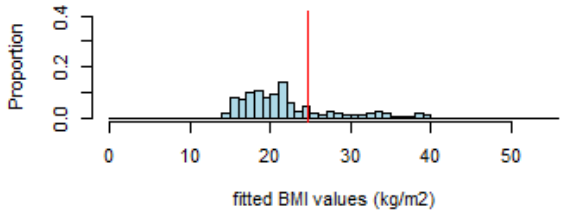

18 year olds girls

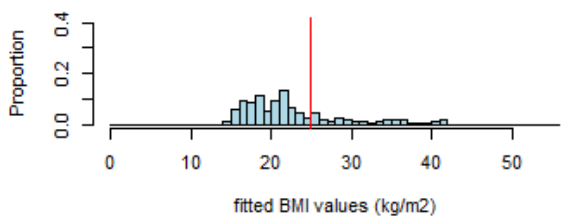

19 year olds girls

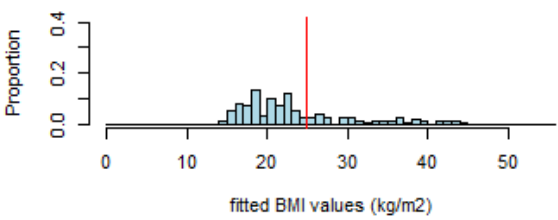

20 year olds girls

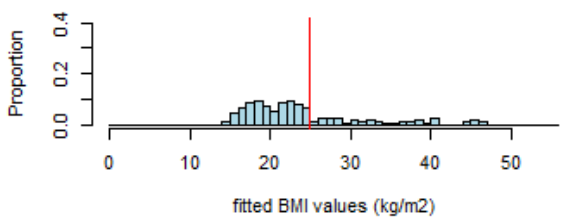

Figure A3.2 Histogram of fitted values with model 1 (column 1), and fitted values with model 2 (column 2) for girls at control schools with an average SES.

Notes: $\mathrm{BMI}=$ body mass index; IOTF = International Obesity Task Force; SES = socioeconomic status. Red vertical line = IOTF cut-off points for childhood overweight and obesity lage- and sexspecific). ${ }^{9}$ 


\section{Appendix 4}

Table A4.1 Observed and predicted BMI values.

\begin{tabular}{|c|c|c|c|c|c|}
\hline & \multicolumn{2}{|c|}{$\begin{array}{l}\text { Predicted values Model } 1 \\
\text { control schools, average SES }\end{array}$} & \multicolumn{2}{|c|}{$\begin{array}{c}\text { Predicted values Model } 2 \\
\text { control schools, average SES }\end{array}$} & \multirow{2}{*}{$\begin{array}{l}\text { FDGS } \\
\text { Median }\end{array}$} \\
\hline & Mean [95\% CI] & Median [IQR] & Mean $[95 \% \mathrm{Cl}]$ & Median [IQR] & \\
\hline \multicolumn{6}{|l|}{ Boys } \\
\hline Age 12 & $19.27[16.57 ; 20.35]$ & $18 \cdot 74[3 \cdot 78]$ & $18.87[16 \cdot 19 ; 20 \cdot 15]$ & $18.31[3.96]$ & $17 \cdot 75$ \\
\hline Age 13 & $19 \cdot 88[16.81 ; 21.05]$ & $19 \cdot 29[4 \cdot 24]$ & $19 \cdot 43[16.41 ; 20.80]$ & $18 \cdot 77[4.39]$ & $18 \cdot 31$ \\
\hline Age 14 & $20.31[16.94 ; 21.64]$ & $19 \cdot 57[4 \cdot 70]$ & $20.01[16.61 ; 21.64]$ & $19 \cdot 25[5 \cdot 03]$ & 18.94 \\
\hline Age 15 & $20.47[16.79 ; 21.98]$ & $19 \cdot 74[5 \cdot 19]$ & $20.59[16.89 ; 22.39]$ & $19 \cdot 72[5 \cdot 50]$ & $19 \cdot 59$ \\
\hline Age 16 & $20 \cdot 40[16.49 ; 22.07]$ & $19 \cdot 58[5 \cdot 58]$ & $21 \cdot 24[17 \cdot 10 ; 23 \cdot 28]$ & $20 \cdot 22[6 \cdot 18]$ & $20 \cdot 21$ \\
\hline Age 17 & $19 \cdot 88[15 \cdot 85 ; 21 \cdot 68]$ & $19 \cdot 03[5 \cdot 83]$ & $21.86[17.35 ; 24.07]$ & $20 \cdot 71[6 \cdot 73]$ & $20 \cdot 78$ \\
\hline Age 18 & $18.89[14.84 ; 20.79]$ & $17 \cdot 88[5 \cdot 96]$ & $22.53[17.56 ; 24.94]$ & $21 \cdot 25[7 \cdot 38]$ & $21 \cdot 26$ \\
\hline Age 19 & $17 \cdot 71[13.70 ; 19.56]$ & $16 \cdot 68[5 \cdot 86]$ & $23.26[17.85 ; 25.56]$ & $21 \cdot 81[7 \cdot 72]$ & $21 \cdot 68$ \\
\hline Age 19 * & NA & NA & $22.95[17.98 ; 25.36]$ & $21 \cdot 67[7 \cdot 38]$ & $21 \cdot 68$ \\
\hline Age 20 & $16.00[12 \cdot 12 ; 17 \cdot 65]$ & $15 \cdot 03[5 \cdot 53]$ & $24.01[17.99 ; 26.67]$ & $22 \cdot 34[8 \cdot 67]$ & $22 \cdot 07$ \\
\hline Age 20 * & NA & NA & $23.34[18.37 ; 25.75]$ & $22 \cdot 06[7 \cdot 38]$ & $22 \cdot 07$ \\
\hline \multicolumn{6}{|l|}{ Girls } \\
\hline Age 12 & $19 \cdot 46[16.86 ; 20.63]$ & $18 \cdot 77$ [3.77] & $18.98[16.53 ; 20.16]$ & $18 \cdot 25[3.64]$ & $18 \cdot 21$ \\
\hline Age 13 & $20 \cdot 20[17 \cdot 26 ; 21 \cdot 43]$ & $19 \cdot 38[4 \cdot 17]$ & $19.50[16.77 ; 20.94]$ & $18 \cdot 71[4 \cdot 17]$ & $18 \cdot 83$ \\
\hline Age 14 & $20.92[17.66 ; 22.29]$ & $20 \cdot 04[4 \cdot 63]$ & $20.06[17.07 ; 21.54]$ & $19 \cdot 08[4 \cdot 47]$ & $19 \cdot 47$ \\
\hline Age 15 & $21 \cdot 60[17 \cdot 98 ; 23.11]$ & $20 \cdot 56[5 \cdot 14]$ & $20.61[17.31 ; 22.28]$ & $19.54[4.97]$ & $20 \cdot 06$ \\
\hline Age 16 & $22 \cdot 28[18.29 ; 23.87]$ & $21 \cdot 08[5.57]$ & $21.21[17.57 ; 23.01]$ & $19.98[5 \cdot 44]$ & $20 \cdot 58$ \\
\hline Age 17 & $22.82[18.53 ; 24.48]$ & $21 \cdot 48[5 \cdot 95]$ & $21.81[17.86 ; 23.81]$ & $20.36[5.94]$ & $21 \cdot 01$ \\
\hline Age 18 & $23.22[18.58 ; 25.09]$ & $21.69[6.51]$ & $22 \cdot 45[18.20 ; 24.65]$ & $20 \cdot 98[6 \cdot 45]$ & $21 \cdot 36$ \\
\hline Age 19 & $23.43[18.56 ; 25.31]$ & $21 \cdot 88[6 \cdot 75]$ & $23.08[18.37 ; 25 \cdot 19]$ & $21.35[6.82]$ & $21 \cdot 63$ \\
\hline Age 19 * & $23.49[18.85 ; 25.36]$ & $21.96[6.51]$ & NA & NA & $21 \cdot 63$ \\
\hline Age 20 & $23 \cdot 74[18.57 ; 25 \cdot 82]$ & $21.99[7 \cdot 25]$ & $23.77[18.76 ; 25.99]$ & $21.92[7 \cdot 24]$ & $21 \cdot 85$ \\
\hline Age 20 * & $23.71[19.07 ; 25.58]$ & $22 \cdot 18[6.51]$ & NA & NA & $21 \cdot 85$ \\
\hline
\end{tabular}

Notes: $\mathrm{BMI}=$ body mass index, $\mathrm{Cl}=$ confidence interval, $\mathrm{FDGS}=$ Fifth Dutch Growth Study, $I Q R=$ interquartile range, $N A=$ not applicable, $S E S=$ socioeconomic status. ${ }^{*}$ Calibration based on the trend in the Fifth Dutch Growth Study (see main text) 

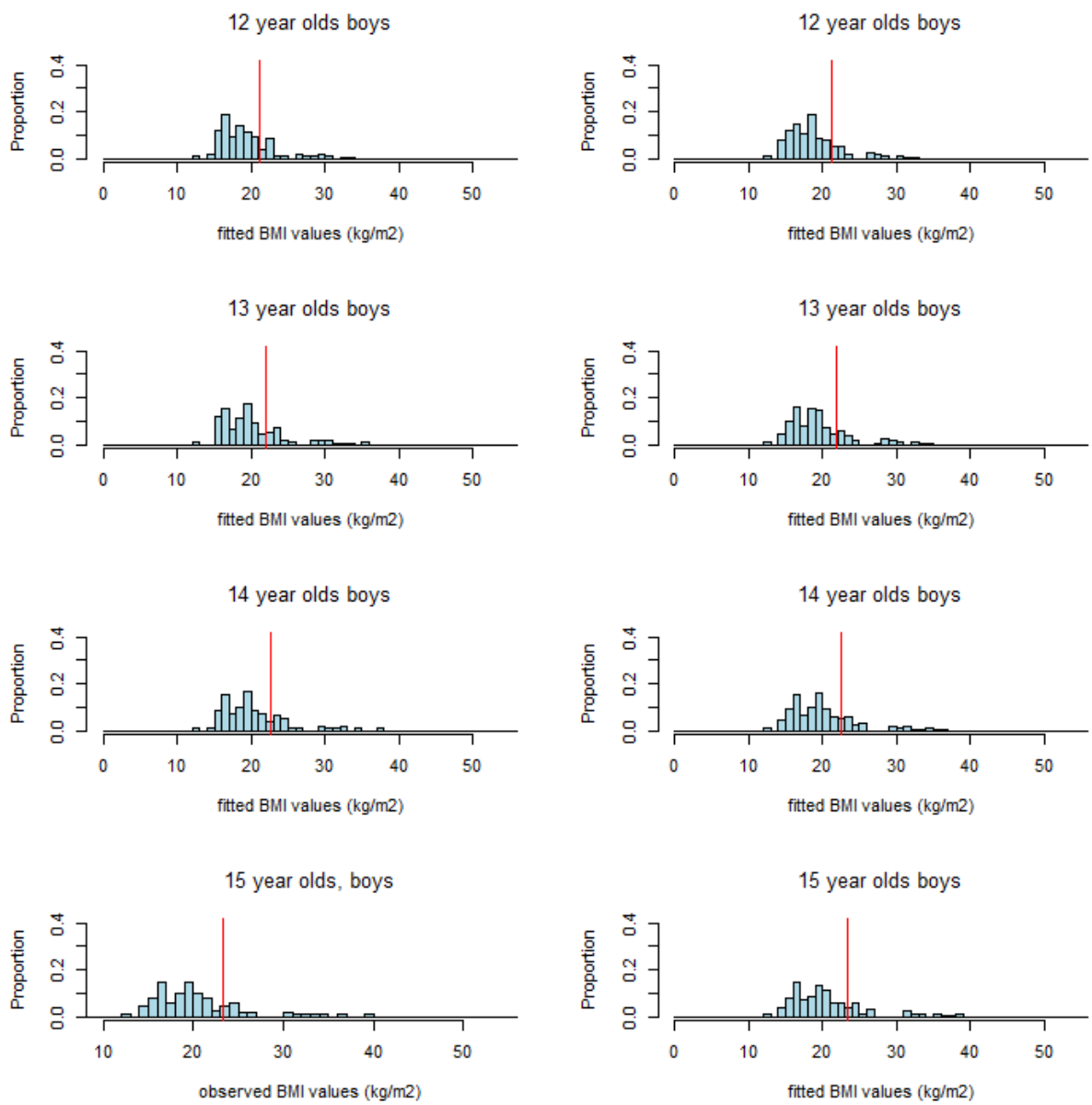
16 year olds boys

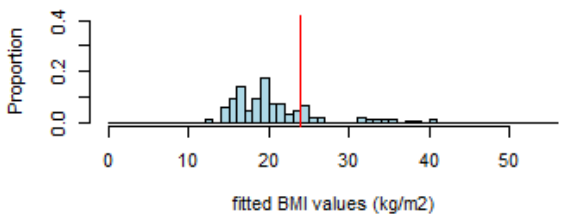

17 year olds boys

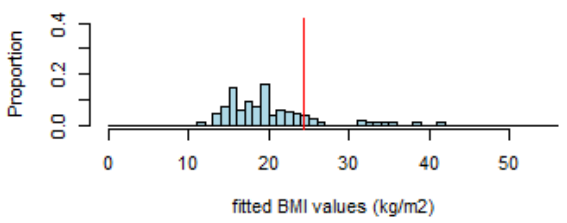

18 year olds boys

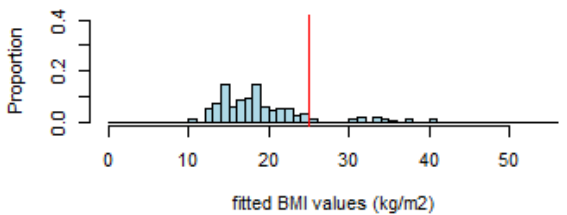

19 year olds boys

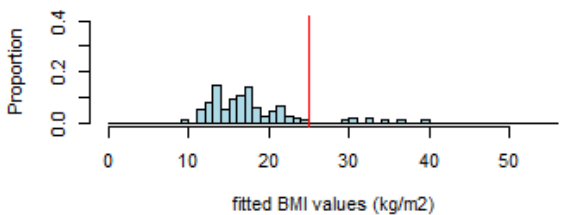

20 year olds boys

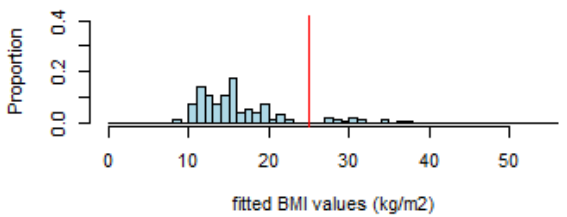

16 year olds boys

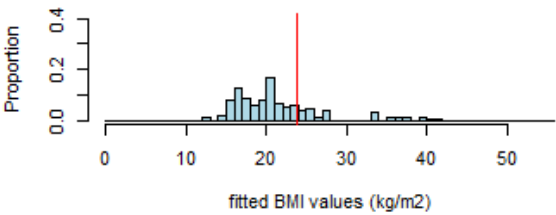

17 year olds boys

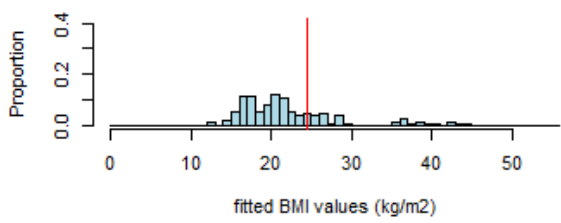

18 year olds boys

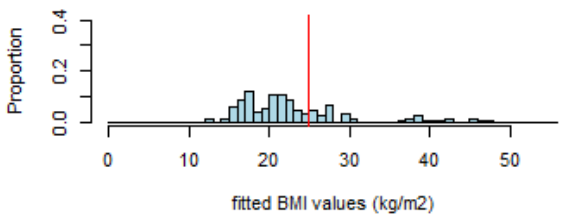

19 year olds boys

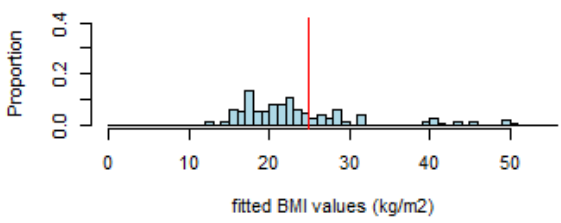

20 year olds boys

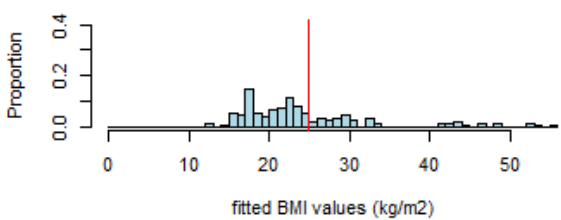

Figure A4. 1 Histogram of fitted values with model 1 (column 1), and fitted values with model 2 (column 2) for boys at control schools with an average SES.

Notes: $\mathrm{BMI}=$ body mass index, IOTF = International Obesity Task Force. Red vertical line $=$ IOTF cut-off points for childhood overweight and obesity (age- and sex-specific). ${ }^{9}$ 


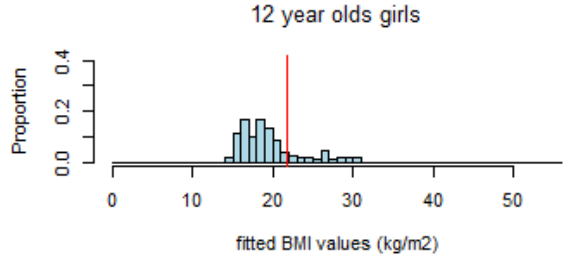

13 year olds girls

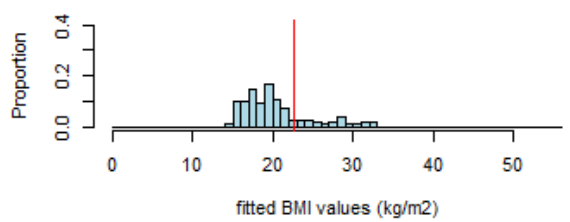

14 year olds girls

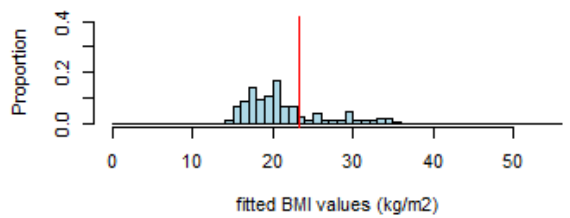

15 year olds, girls

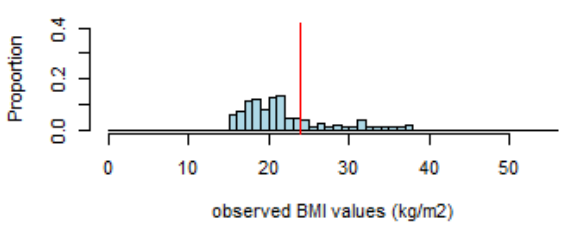

12 year olds girls

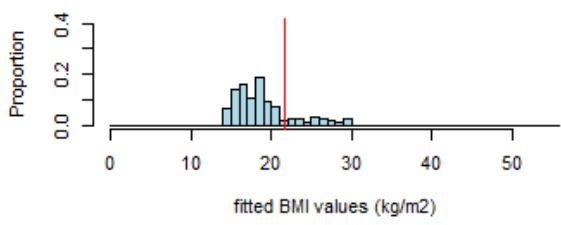

13 year olds girlsboys

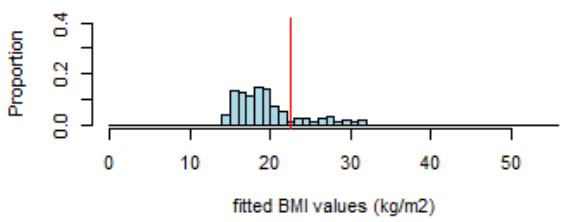

14 year olds girls

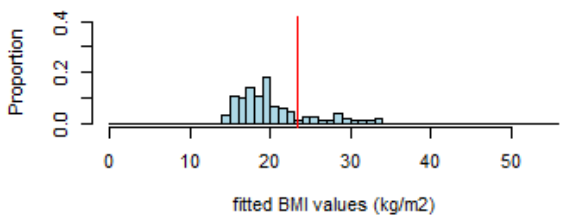

15 year olds girls

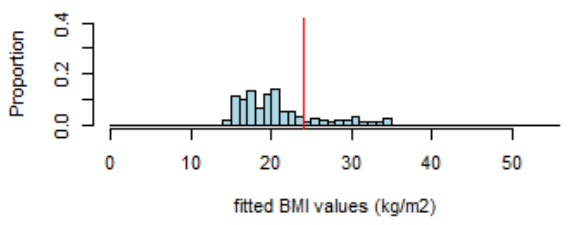


16 year olds girls

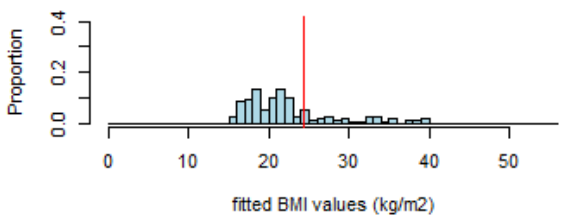

17 year olds girls

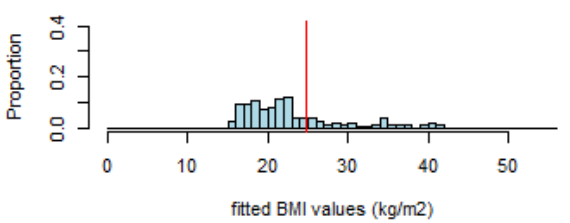

18 year olds girls

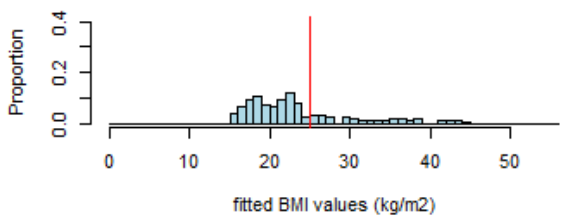

19 year olds girls

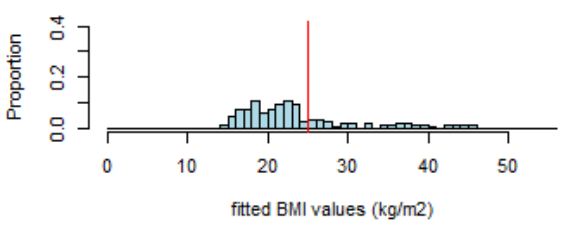

20 year olds girls

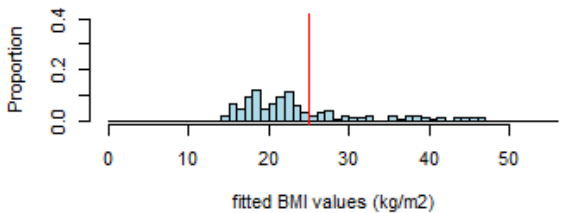

16 year olds girls

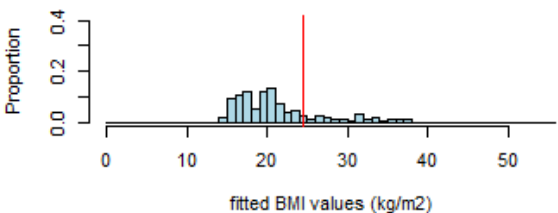

17 year olds girls

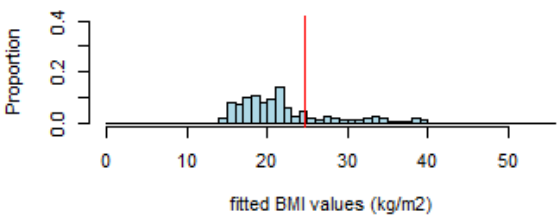

18 year olds girls

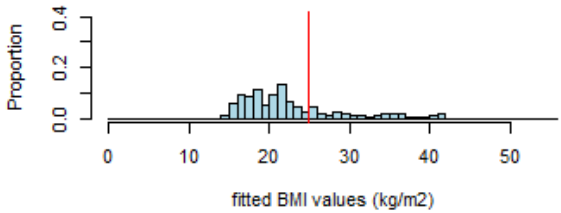

19 year olds girls

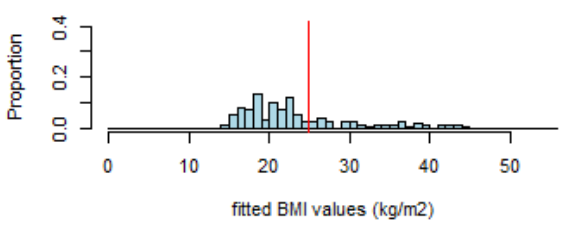

20 year olds girls

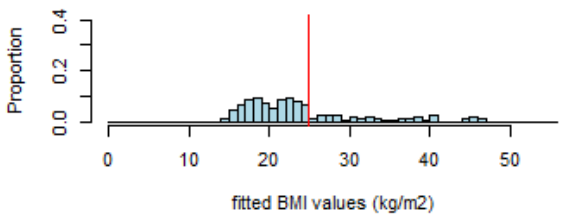

Figure A4.2 Histogram of fitted values with model 1 (column 1), and fitted values with model 2 (column 2) for girls at control schools with an average SES.

Notes: $\mathrm{BMI}=$ body mass index, IOTF $=$ International Obesity Task Force. Red vertical line $=$ IOTF cut-off points for childhood overweight and obesity (age- and sex-specific). ${ }^{9}$ 


\section{Appendix 5}

\section{Model details}

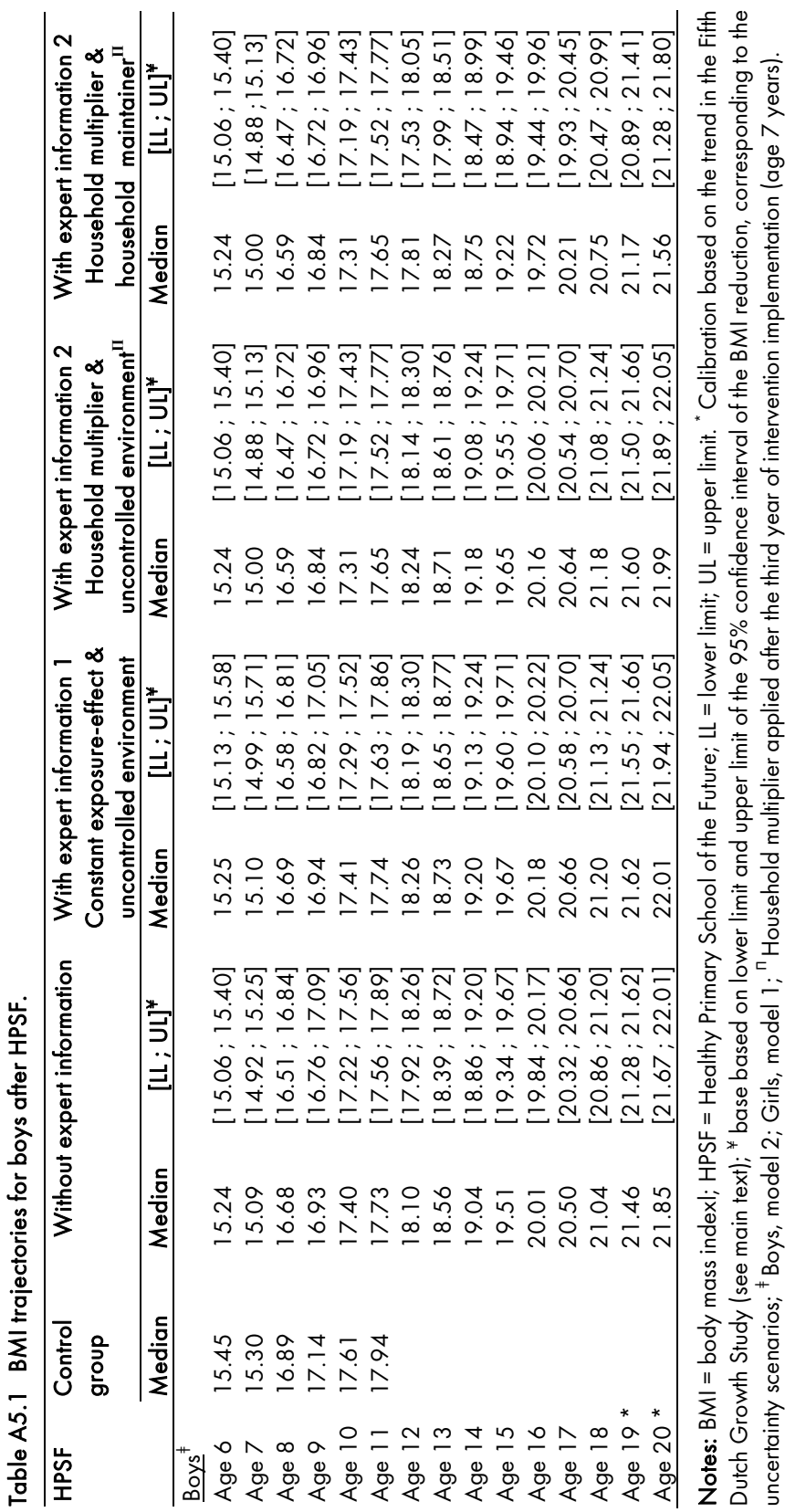




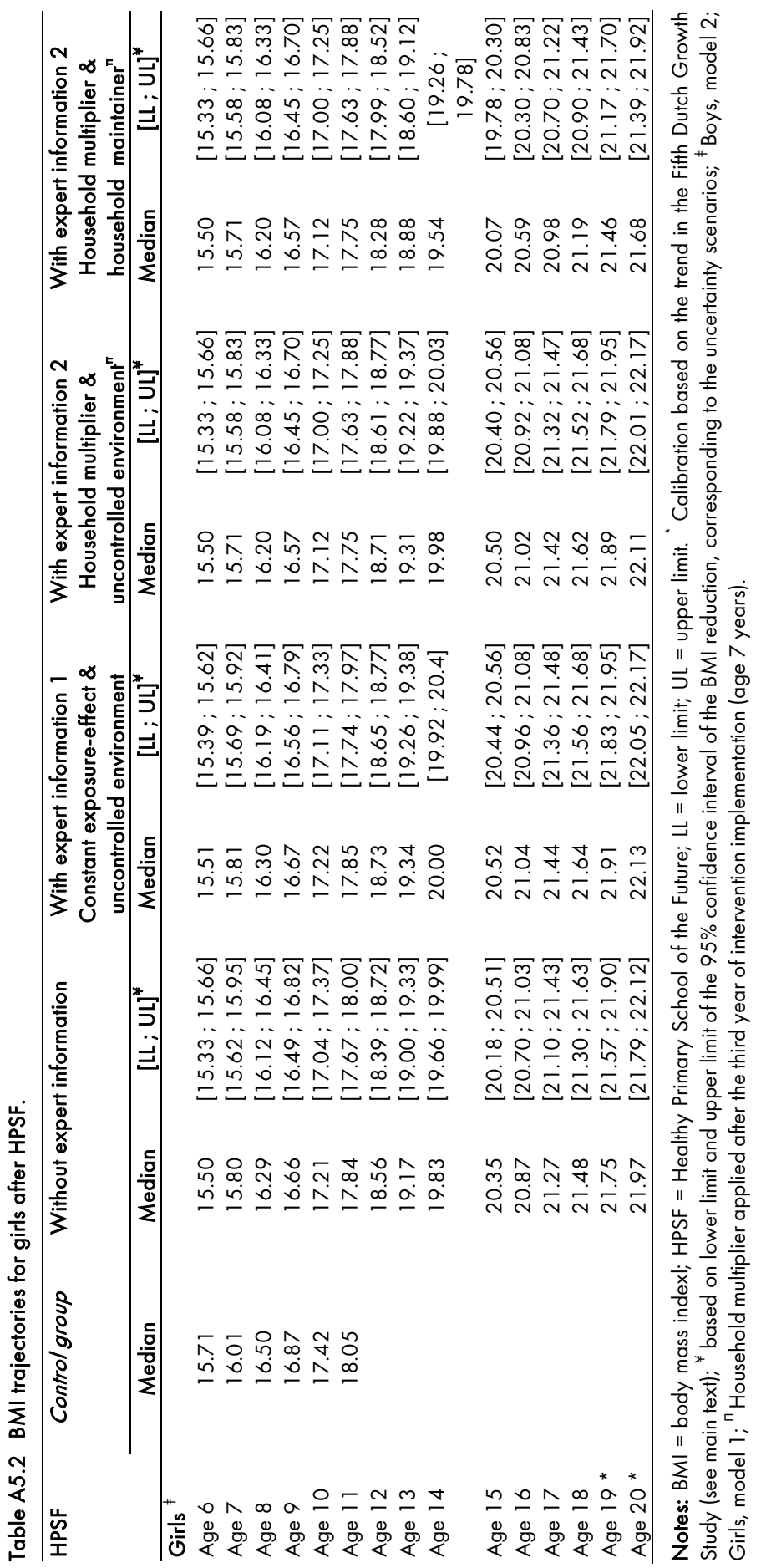




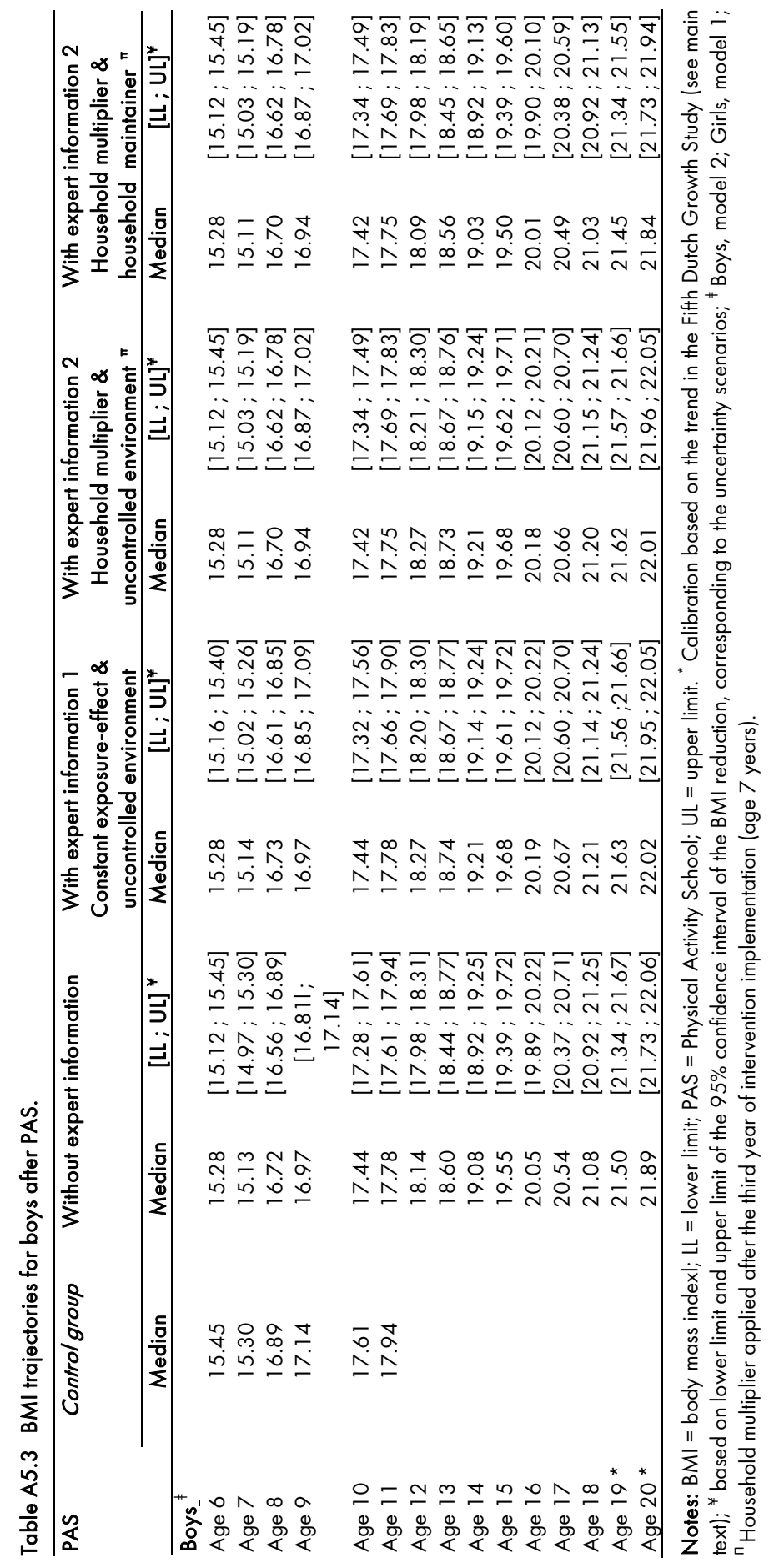




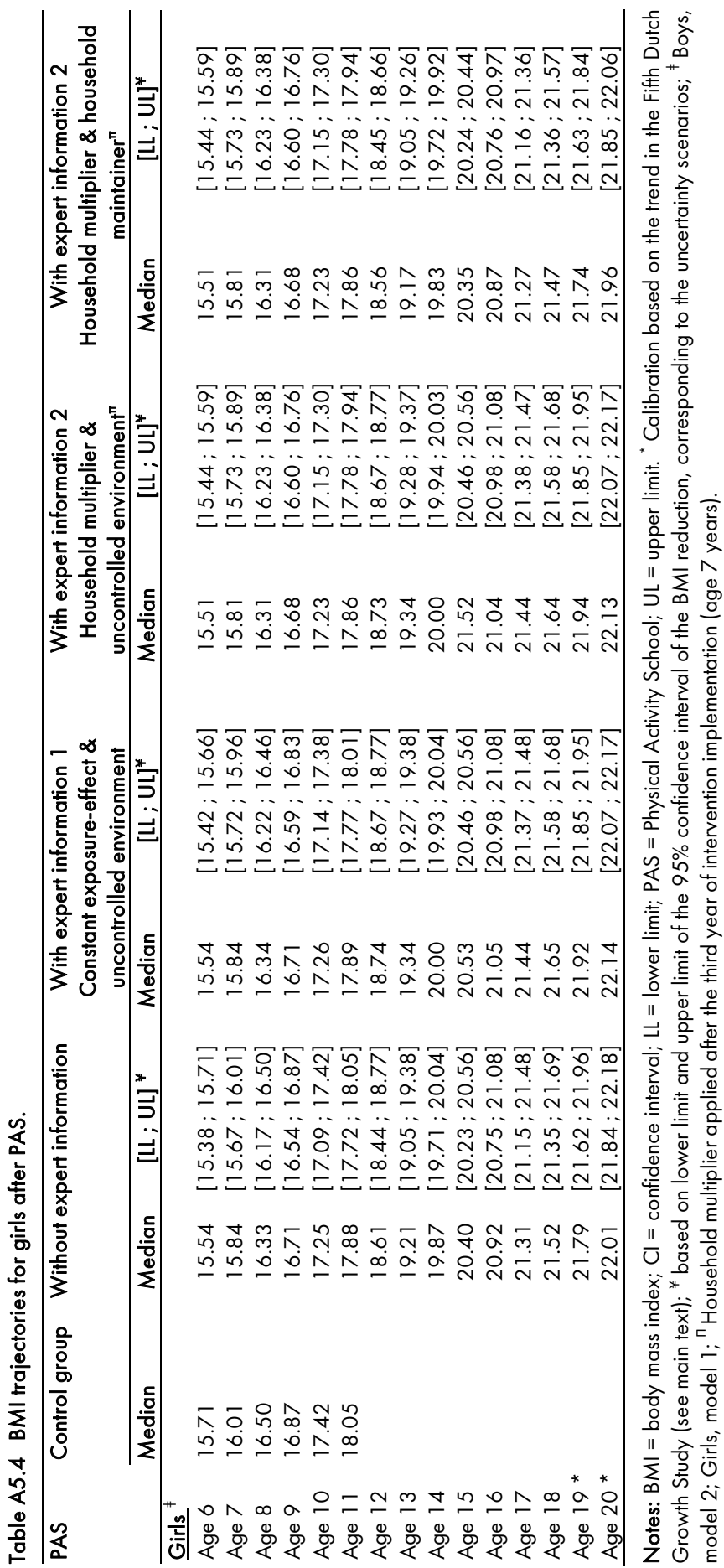




\section{Appendix 6}

\section{A selection of relevant literature}

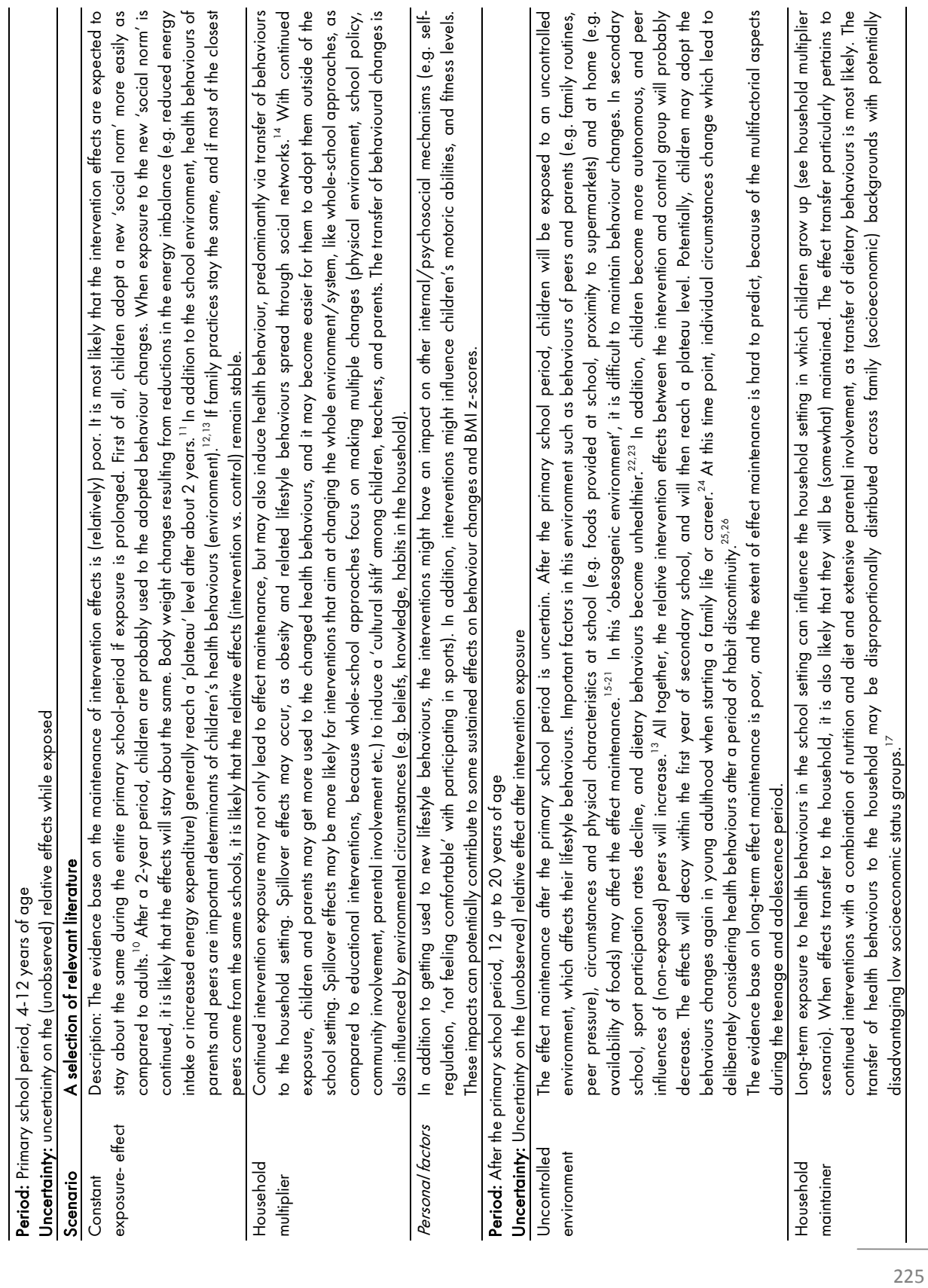




\section{References}

1. Knol AB, Slottje $P$, van der Sluijs JP, Lebret $E$. The use of expert elicitation in environmental health impact assessment: a seven step procedure. Env Health. 2010;9:19.

2. Tong A, Sainsbury P, Craig J. Consolidated criteria for reporting qualitative research (COREQ): a 32-item checklist for interviews and focus groups. Int J Qual Health Care. 2007; 19:349-57.

3. Cooke R, Probst KN. Highlights of the Expert Judgment Policy Symposium and Technical Workshop. Conference summary; 2006. https://media.rff.org/documents/Conference-Summary.pdf. Date accessed: March 01, 2020.

4. Morris DE, Oakley JE, Crowe JA. A web-based tool for eliciting probability distributions from experts. Env Model Soft.2014;52:1-4.

5. Pawson R, Tilley N. Realist Evaluation. Sage Publications Ltd. 2004. http://www.communitymatters.com.au/ RE_chapter.pdf. Date accessed: March 01, 2020.

6. Birt L, Scott S, Cavers D, Campbell C, Walter F. Member Checking: A Tool to Enhance Trustworthiness or Merely a Nod to Validation? Qual Health Res. 2016;26:1802-11.

7. Slottje P, Van der Sluijs JP, Knol AB. Expert Elicitation. Methodological suggestions for its use in environmental health impact assessments. Bilthoven: National Institute for Public Health and the Environment. 2008. https://www.rivm.nl/bibliotheek/rapporten/630004001.html. Accessed February 10, 2020.

8. Usher W, Strachan N. An expert elicitation of climate, energy and economic uncertainties. Energy Policy. 2013;61:811-21.

9. Cole TJ, Bellizzi MC, Flegal KM, Dietz WH. Establishing a standard definition for child overweight and obesity worldwide: international survey. BMJ. 2000;320:1240-3.

10. Rose G. Sick individuals and sick populations. Int J Epid. 2001;30:427-32.

11. de Ruyter JC, Olthof MR, Seidell JC, Katan MB. A trial of sugar-free or sugar-sweetened beverages and body weight in children. New Engl J Med. 2012;367:1397-406.

12. de Heer HD, Koehly L, Pederson R, Morera O. Effectiveness and spillover of an after-school health promotion program for Hispanic elementary school children. Am J Pub Health. 201 1; 101:1907-13.

13. Mollborn S, Lawrence E. Family, Peer, and School Influences on Children's Developing Health Lifestyles. J Health Soc Behav. 2018;59:133-50.

14. Christakis NA, Fowler JH. The spread of obesity in a large social network over 32 years. New Eng J Med. 2007;357:370-9.

15. Brown HE, Corder K, Atkin AJ, van Sluijs EMF. Childhood predictors of adolescent behaviour: The prospective association of familial factors with meeting physical activity guidelines. Prev Med Rep. 2017;6:221-7.

16. Ovrebo B, Stea TH, Te Velde SJ, Bjelland M, Klepp KI, Bere E. A comprehensive multicomponent schoolbased educational intervention did not affect fruit and vegetable intake at the 14-year follow-up. Prev Med. 2019;121:79-85.

17. Plachta-Danielzik S, Landsberg B, Lange D, Seiberl J, Muller MJ. Eight-year follow-up of school-based intervention on childhood overweight--the Kiel Obesity Prevention Study. Obes Facts. 201 1;4:35-43.

18. Taylor RW, McAuley KA, Barbezat W, Farmer VL, Williams SM, Mann JI. Two-year follow-up of an obesity prevention initiative in children: the APPLE project. Am J Clin Nutr. 2008;88:1371-7.

19. Kafatos A, Manios Y, Moschandreas J. Health and nutrition education in primary schools of Crete: follow-up changes in body mass index and overweight status. Eorp J Clin Nutr. 2005;59:1090-2.

20. Neumark-Sztainer D, Story M, Hannan PJ, Rex J. New Moves: a school-based obesity prevention program for adolescent girls. Prev Med. 2003;37:41-51.

21. James J, Thomas $P$, Kerr D. Preventing childhood obesity: two year follow-up results from the Christchurch obesity prevention programme in schools (CHOPPS). BMJ. 2007;335:762.

22. Nader PR, Bradley RH, Houts RM, McRitchie SL, O'Brien M. Moderate-to-vigorous physical activity from ages 9 to 15 years. Jama. 2008;300:295-305.

23. Winpenny EM, van Sluiis EMF, White M, Klepp K-I, Wold B, Lien N. Changes in diet through adolescence and early adulthood: longitudinal trajectories and association with key life transitions. Int J Behav Phys Act. 2018;15:86. 
24. Stea TH, Tveter ET, Te Velde SJ, Vik FN, Klepp KI, Bere E. The effect of an extra piece of fruit or vegetables at school on weight status in two generations - 14 years follow-up of the Fruit and Vegetables Makes the Marks study. PLoS One. 2018;13:e0205498.

25. Verplanken B, Walker I, Davis A, Jurasek M. Context change and travel mode choice: Combining the habit discontinuity and self-activation hypotheses. J Env Psych. 2008;28:121-7.

26. Marcus $B$ H, Dubbert PM, Forsyth LH, et al. Physical activity behavior change: issues in adoption and maintenance. Health Psychol. 2000;19:32-41. 



\section{Chapter}

Lifetime cost-effectiveness and equity impacts of the Healthy Primary School of the Future initiative

Marije Oosterhoff

Eelco A.B. Over

Anoukh van Giessen

Rudolf T. Hoogenveen

Hans Bosma

Onno C.P. van Schayck

Manuela A. Joore

BMC Public Health 2020; 20(1):1887 


\section{Abstract}

\section{Background}

This study estimated the lifetime cost-effectiveness and equity impacts associated with two lifestyle interventions in the Dutch primary school setting (targeting 4-12 year olds).

\section{Methods}

The Healthy Primary School of the Future (HPSF; a healthy school lunch and structured physical activity) and the Physical Activity School (PAS; structured physical activity) were compared to the regular Dutch curriculum $(\mathrm{N}=1676)$. An adolescence model, calculating weight development, and the RIVM Chronic Disease Model, calculating overweight related chronic diseases, were linked to estimate the lifetime impact on chronic diseases, quality adjusted life years (QALYs), healthcare, and productivity costs. Cost-effectiveness was expressed as the additional costs/ QALY gained and we used $€ 20,000$ as threshold. Scenario analyses accounted for alternative effect maintenance scenarios and equity analyses examined cost-effectiveness in different socioeconomic status (SES) groups.

\section{Findings}

HPSF resulted in a lifetime costs of $€ 773$ (societal perspective) and a lifetime QALY gain of 0.039 per child versus control schools. HPSF led to lower costs and more QALYs as compared to PAS. From a societal perspective, HPSF had a cost per QALY gained of $€ 19,734$ versus control schools, $50 \%$ probability of being cost-effective, and beneficial equity impact (0.02 QALYs gained/child for low versus high SES). The cost-effectiveness threshold was surpassed when intervention effects decayed over time.

\section{Interpretation}

HPSF may be a cost-effective and equitable strategy for combatting the lifetime burden of unhealthy lifestyles. The win-win situation will, however, only be realised if the intervention effect is sustained into adulthood for all SES groups. 


\section{Background}

Physical inactivity, unhealthy diets, overweight, and obesity are among the leading risk factors for the burden of disease in many countries worldwide. ${ }^{1,2}$ Before 1990, less than 35 percent of Dutch adults were overweight or obese, which has increased to more than 50 percent in $2018 .^{3}$ This trend is burdensome, because excess weight is a risk factor for (early) development of chronic diseases and concomitant quality of life losses, premature death, ${ }^{4}$ and costs. ${ }^{5-7}$ School-based lifestyle interventions are viewed as a promising strategy to reduce the overweight-related burden as attitudes and behaviours can be changed more easily as compared to later stages in life..$^{8-10}$

Insight on the short, medium, and long-term impacts on health, healthcare costs and costs in other sectors is essential to inform implementation and investment decisions on school-based lifestyle interventions. In addition to an overall cost-effectiveness outcome, decision-makers should be informed on how this estimate changes under different circumstances and choices. Firstly, there is uncertainty on the persistence of the intervention effect from childhood into early adulthood. ${ }^{11,12}$ Secondly, school-based lifestyle interventions may not only impact on healthcare cost but may also affect productivity in later life. Productivity impacts are, however, not always included in cost-effectiveness studies on these interventions. Thirdly, there is a high need for interventions that reduce (or at least do not widen) the disparities in health outcomes between people with a high and low socioeconomic position. Trade-offs can occur when an intervention is cost-effective but increases disparities in health outcomes (e.g. high SES group benefits more). Cost-effectiveness estimates for different socioeconomic status (SES) groups can be used to inform potential trade-offs between efficiency and equity. $^{13}$

In the Southern region of the Netherlands, two new healthy school environments have been introduced which aimed at enhancing health promotion in the Dutch primary school setting (corresponding to 4-12 year olds). ${ }^{14}$ The Healthy Primary School of the Future (HPSF) included a daily healthy school lunch and mid-morning snack and a daily structured physical activity program, while the Physical Activity School (PAS) focused on the structured physical activity program only. The implementation process and the 2-year (cost-) effectiveness have been previously examined. ${ }^{15,16}$ In the current study, the lifetime costeffectiveness and equity impacts of the interventions were compared to the regular school curriculum. Cost-effectiveness was assessed from a healthcare and societal perspective. Scenario analyses were undertaken to assess the influence of alternative effect maintenance scenarios and equity analyses to examine cost-effectiveness in different socioeconomic groups. 


\section{Methods}

The methods and results of this economic evaluation were reported according to the Consolidated Health Economic Evaluation Reporting Standards (CHEERS) Statement (see checklist in Appendix 1).

\section{Strategies}

The 'Healthy Primary School of the Future' initiative aimed to integrate health promotion in the Dutch primary school setting, which starts at 4 years of age until 12 years of age. ${ }^{14}$ Three strategies were compared:

1) Healthy Primary School of the Future (HPSF).

A healthy morning snack and daily healthy lunches were provided in combination with structured sessions including sports, play, and creative activities. To facilitate the implementation of activities the school day was extended with about 30 minutes. ${ }^{14}$

2) Physical Activity School (PAS).

This school environment targeted physical activity only by offering the structured sessions including sports, play, and creative activities during the lunch break.

3) Regular school curriculum in Dutch primary schools.

Control schools maintained the normal school curriculum (no interventions).

In a quasi-experimental study, HPSF (2 schools) and PAS (2 schools) were followed from 2015 to 2019, and compared to 4 control schools from the same region (Parkstad region, Dutch Province of Limburg). ${ }^{14}$ At baseline 1403 (60.3\%) out of 2326 invited children participated in data collection. Bartelink et al. (2019) analysed the 2-year effects of HPSF and PAS versus control schools on dietary and physical activity behaviour, and BMI zscore. $^{15,17}$ These effects are based on all participants who were enrolled at schools from baseline onwards (and had a two-year intervention exposure) and participated in at least one of the measurement waves ( $N=1676$, control: $N=661$, HPSF: $N=537, P A S=478$ ). See Appendix 2 for the baseline characteristics of the study sample.

\section{Cost-effectiveness modelling}

A lifetime horizon was adopted, starting at age 4. Two periods were distinguished: 1) childhood and adolescence and 2) adulthood. The lifetime health and cost impacts of HPSF and PAS were modelled through the changes in BMI development. For children receiving the regular school curriculum, it was assumed that BMI and weight status did only change depending on age. Outcomes were expressed in quality-adjusted life years (QALYs), which combines the impact on health-related quality of life (HRQOL) and length of life. Cost- 
effectiveness was assessed from a healthcare perspective and societal perspective (including productivity costs).

\section{Childhood and adolescence}

The childhood and adolescence model covered the period from 4 up to 20 years of age. The health state transition model consisted of three weight categories: normal weight, overweight, and obesity. The model was implemented in Microsoft Excel with a cycle length of one year.

Information on children's BMI development was obtained from a previous study. ${ }^{18}$ In this study, BMI values were extrapolated until 20 years of age. Based on the 2-year effect on BMI z-score, it was calculated that the the effects of HPSF and PAS on BMI were $-0.21 \mathrm{~kg} / \mathrm{m}^{2}$ [95\% Cl: $-0.38 ;-0.05$ ] (HPSF) and $-0.17 \mathrm{~kg} / \mathrm{m}^{2}$ [95\% Cl: $-0.33 ; 0.00$ ] (PAS) as compared to control schools. ${ }^{15,18}$ The entire trajectory was lowered, assuming that the observed relative intervention effects were fully maintained until 20 years of age (reference scenario: constant intervention effects). BMI values were converted into weight categories by using the Dutch reference values for the skewness and variation and the age- and sexspecific international cut-off points (IOTF) for childhood overweight and obesity. ${ }^{19,20}$

The costs associated with delivery of HPSF and PAS were previously estimated. ${ }^{21}$ The net societal intervention costs were the sum of material costs and time investments (for HPSF and PAS vs. control schools). The costs reflected a 'steady state', representing the costs for routine implementation in daily practice. ${ }^{22}$ Costs were updated to 2018 prices using consumer price indexes. For the societal perspective (€0.96 [HPSF] and €2.16 [PAS] per child per day), the extended school day at HPSF was valued as a productivity gain for caregivers as they could spent this time on work. For the healthcare perspective (HPSF: $€ 4.47$ per child per day), this productivity-related cost offset was not included (see Appendix 2). School absenteeism days were selected as indicator of productivity in childhood. Information on HRQOL weights, healthcare costs (general practitioner and specialist visits), and school absenteeism days for normal weight, overweight, and obese children and adolescents were obtained from the literature (see Appendix 2). Inputs collected with the quasi-experimental study were used in sensitivity analyses as they were derived from a relatively small number of children (4\%, 44 children were obese at baseline). Costs and QALYs were calculated for each age cohort between 4-12 years of age, and were aggregated based on the number of Dutch 4-12 year-olds (2019) to calculate the results for a school cohort. Detailed information on the model inputs and assumptions can be found in Table 1 and Appendix 2. 


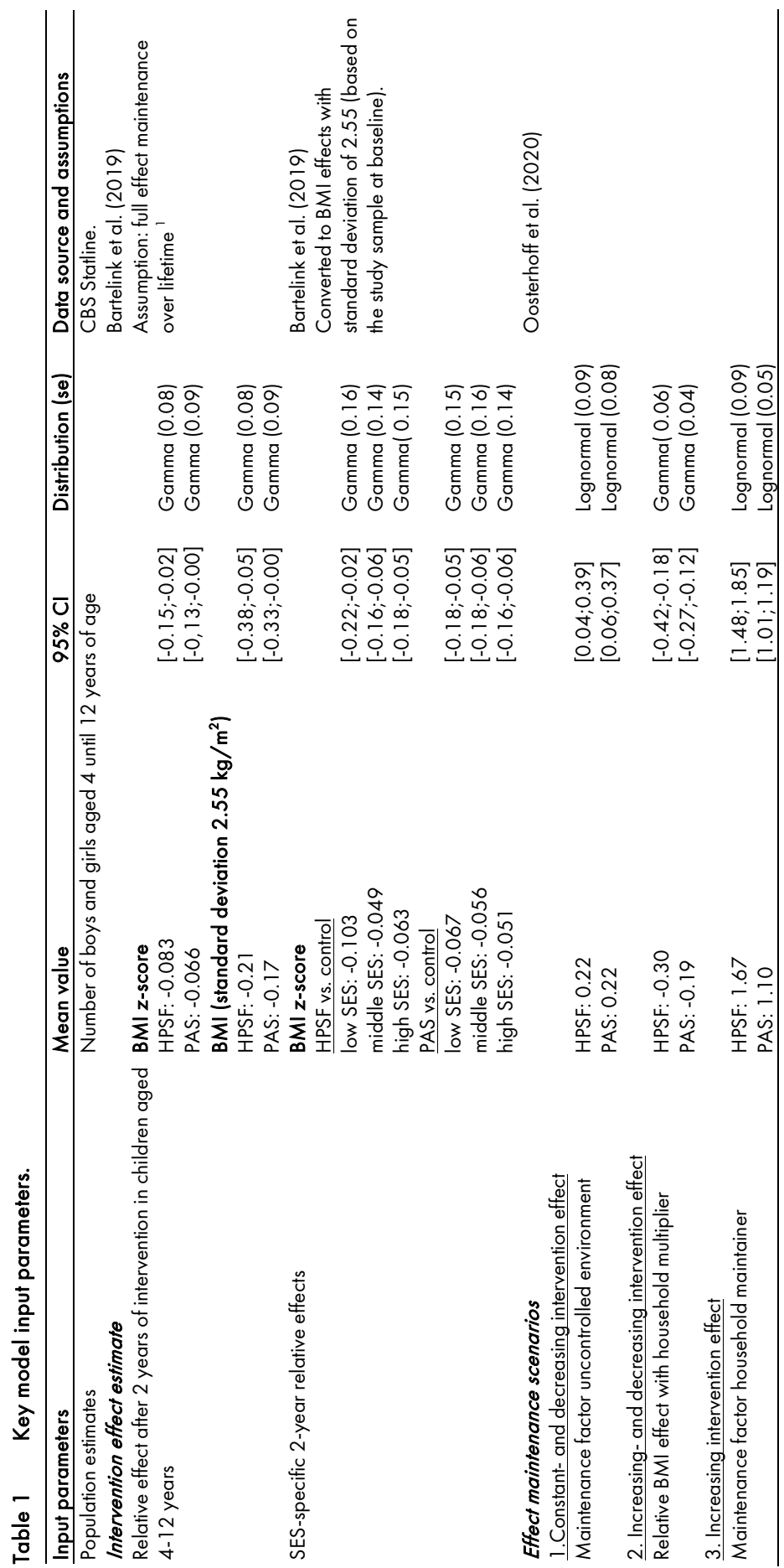




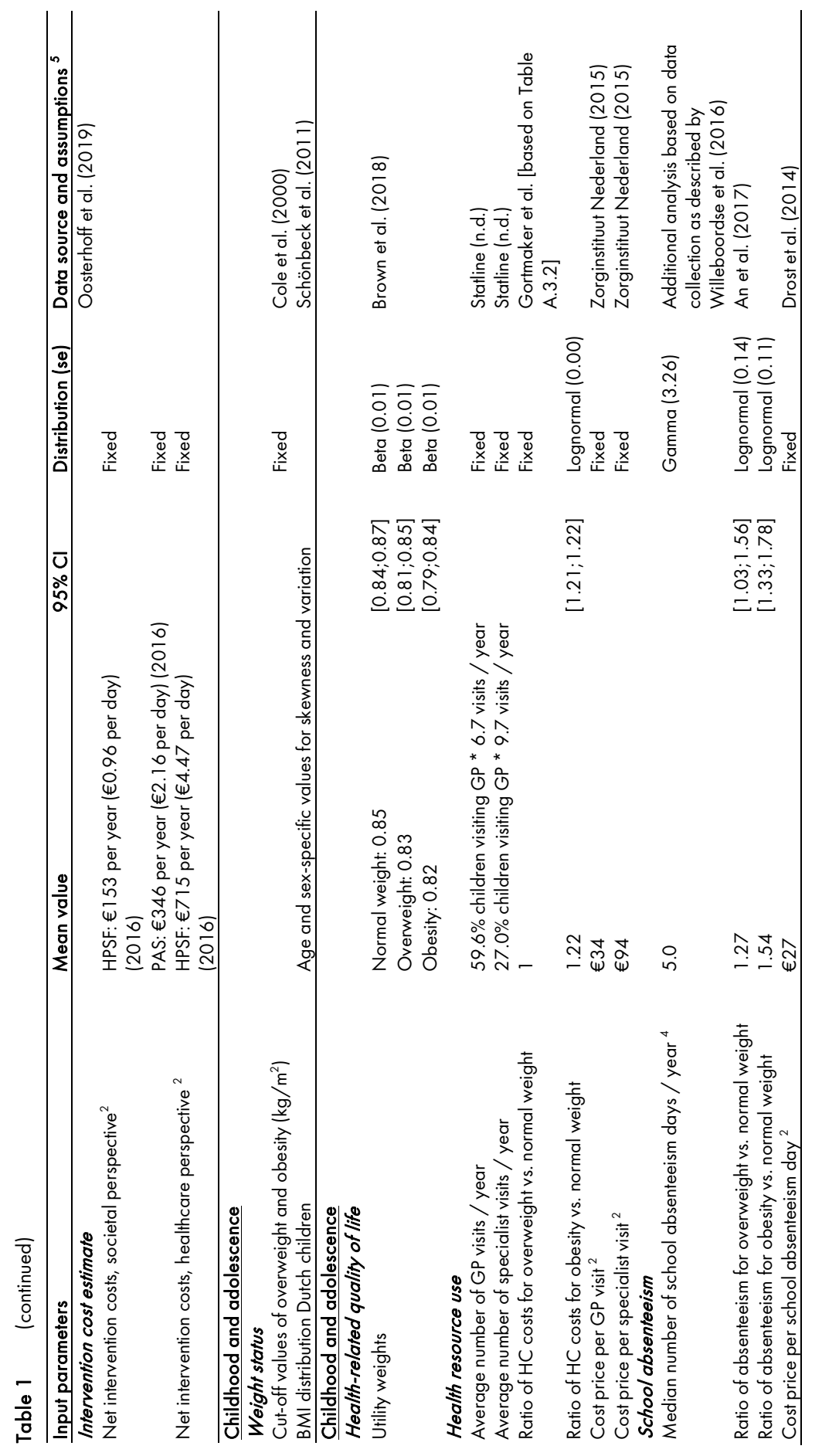




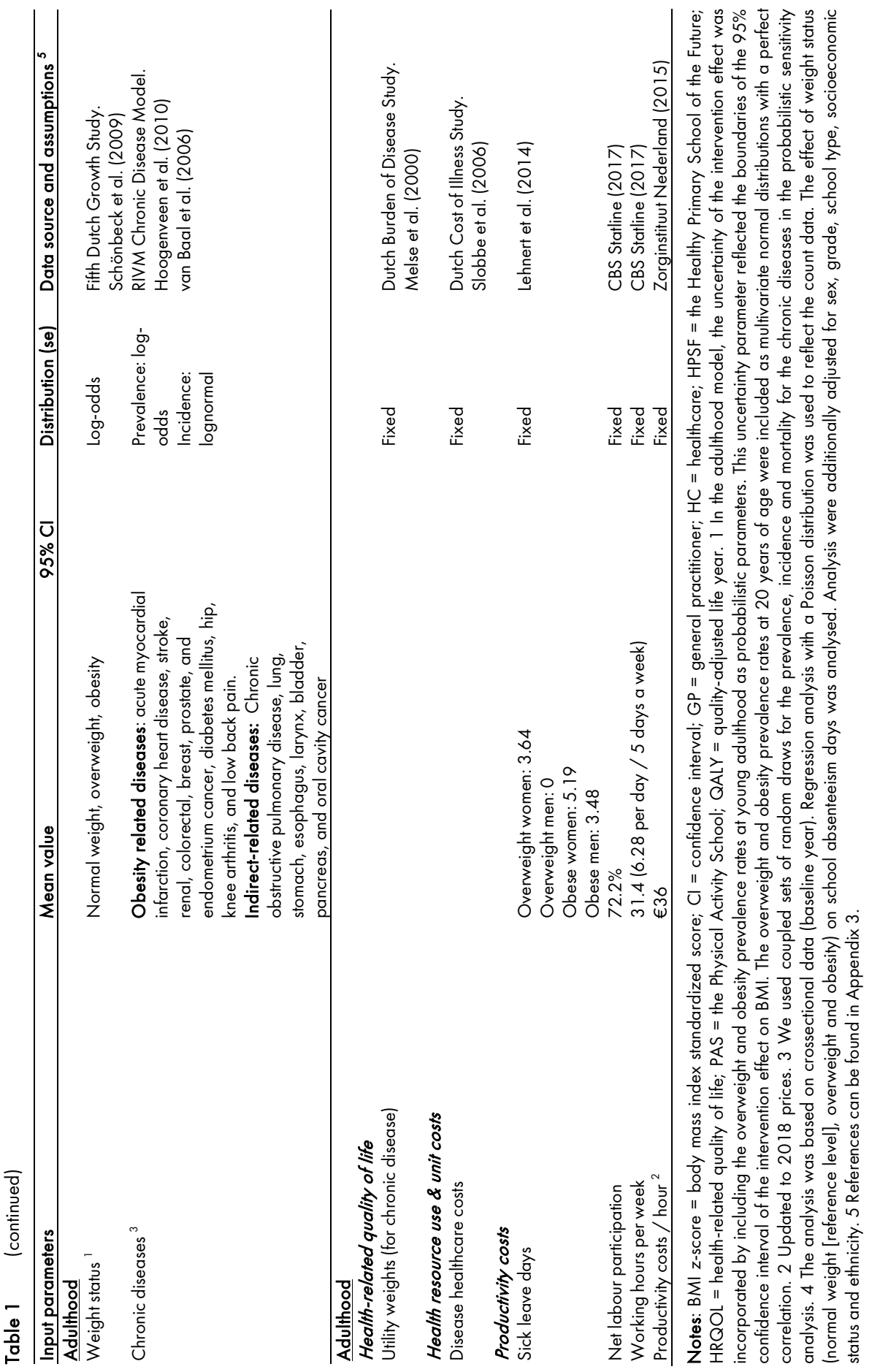




\section{Adulthood}

The RIVM Chronic Disease Model (CDM) was used for projecting effects from 20 years of age until the cohort reached 100 years of age. ${ }^{23}$ This probabilistic health economic model with the Markov property estimates the prevalence, incidence, and mortality of chronic diseases based on changes in risk factors. The model was built in $R$ version 3.5.1. In the current study, the proportions of weight categories (normal weight, overweight, and obesity) were used to estimate the lifetime incidence of obesity-related chronic diseases and other diseases during the life years gained. Utilities, healthcare costs, and mortality were dependent on the prevalence of chronic diseases. Information on the RIVM CDM and the key inputs can be found in Appendix 3 and Table 1. Cost data were indexed to the Dutch 2018 price level using consumer price indexes. Productivity losses in adulthood were incorporated through the relation between weight category up to 67 years of age and the number of annual sick leave days from work as reported by Lehnert et al. (2014). ${ }^{24}$

\section{Analyses}

The per child health effects (QALYs) and costs for the childhood and adolescence period and the adulthood period were summed up. Costs and effects were adjusted for the differences in time at which they occur with a discount rate of $4 \%$ and $1.5 \%$ per year, respectively, according to the Dutch guidelines for costing in economic evaluations. ${ }^{20}$ Incremental cost-effectiveness ratios (ICERs) were calculated by dividing the change in costs between the alternatives by the change in QALYs. Under a healthcare perspective, the change in costs between the strategies was determined by the intervention costs and the differences in healthcare costs. For the societal perspective, the differences in school absenteeism costs and productivity costs in adulthood were also included. Interventions were considered to be cost-effective if the ICERs did not exceed the willingness to pay thresholds of $€ 20,000$ per QALY gained. $^{25}$

\section{Sensitivity and effect maintenance scenario analyses}

Inputs were varied in univariate deterministic sensitivity analyses to explore the impact of input parameters on the results (Appendix 3). Probabilistic sensitivity analyses calculated the probability of cost-effectiveness in relation to the uncertainty in the input parameters (Appendix 4). For the childhood model, results were based on 500 draws per age cohort, whereas 100 random draws were used in the adulthood model. We performed scenario analyses for effect maintenance. In a previous study, we elicited expert opinions on the maintenance of intervention effects from the primary school period after the observed two- 
year period into young adulthood (20 years of age). ${ }^{18}$ This resulted in three potential pathways that were used in scenario analyses (Box 1).

Box 1 Effect maintenance scenarios.

Reference scenario: Constant intervention effect

It was assumed that the 2-year intervention effects were maintained over the entire lifespan.

Alternative effect maintenance scenarios

Scenario 1: Constant- and decreasing intervention effect

It was assumed that effects would remain constant with continued exposure during the primary school period. Effects would decay after primary school when the intervention exposure ends.

This scenario corresponded to a relative BMI effect of $-0.04 \mathrm{~kg} / \mathrm{m}^{2}$ (HPSF and PAS) at 20 years of age.

Scenario 2: Increasing- and decreasing intervention effect

It was assumed that parental involvement would lead to the uptake of behaviour changes by the household over time, leading to more favourable effects during the primary school period with continued exposure. Effects would decay after primary school when the intervention exposure ends. This scenario corresponded to a relative BMI effect of $-0.06 \mathrm{~kg} / \mathrm{m}^{2}$ (HPSF) and $-0.04 \mathrm{~kg} / \mathrm{m}^{2}$ (PAS) at 20 years of age.

Scenario 3. Increasing intervention effect

It was assumed that intensive parental involvement would lead to the uptake of behaviour changes by the household. This would lead to sustained behavioural changes during and after the primary school period.

This scenario corresponded to a relative BMI effect of $-0.50 \mathrm{~kg} / \mathrm{m}^{2}$ (HPSF) and $-0.21 \mathrm{~kg} / \mathrm{m}^{2}$ (PAS) at 20 years of age.

See full details elsewhere. ${ }^{18}$

\section{Equity analyses}

Children's socioeconomic background was measured as the combination of maternal education and paternal education level, and household income adjusted for household size, and was categorized in three groups (low, middle and high SES). ${ }^{15}$ The SES-specific intervention effects were included in the childhood model. ${ }^{17}$ Equity impacts were represented by the difference in health outcomes between the low and high SES group.

The relationship between equity impacts and cost-effectiveness was presented in an equityefficiency impact plane, displaying the (potential) trade-off between cost-effectiveness and health equity. ${ }^{13}$ To specify this trade-off we converted cost-effectiveness and health equity impacts to a health metric. The net health equity impact was expressed as the absolute difference in QALY gains between the high and low SES group. The net cost-effectiveness or net total health impact was calculated as follows: overall QALY gains - (difference costs/ willingness to pay threshold). After two years of intervention, no statistical significant differences were found for the BMI-effects between SES groups. ${ }^{17}$ It is, however, not clear if effects can be equally maintained in all SES groups. Experts indicated that effect 
maintenance throughout adolescence may be higher for children with a high SES background as compared to children with a low SES background. ${ }^{18}$ We therefore also compared the increasing intervention effects scenario (until 20 years of age) for the high SES group to the constant- and decreasing intervention effect scenario for the low SES group.

\section{Results}

Table 2 shows the health outcomes and costs. For illustrative purposes, Figure 1 shows that from young adulthood onwards, HPSF and PAS resulted in a reduction of chronic diseases (e.g. diabetes and knee/hip arthrosis). The avoided cases of chronic diseases reached their maximum around 70 years of age. Subsequently, the differences in disease numbers declined because individuals that were exposed to HPSF and PAS lived longer and experienced chronic disease during these life years gained.

Table 2 Health effects and cost impacts of HPSF and PAS for the childhood and adulthood life span (per child).

\begin{tabular}{|c|c|c|c|c|}
\hline Perspective & Deterministic results (discounted) & $\begin{array}{l}\text { Control } \\
\text { schools }\end{array}$ & PAS & HPSF \\
\hline \multirow[t]{13}{*}{ Healthcare } & Intervention costs ${ }^{1}$ & - & $€ 1,587$ & $€ 3,279$ \\
\hline & Childhood and adolescence ( $4-20$ years of age) & & & \\
\hline & Healthcare costs & $€ 4,855$ & $€ 4,854$ & $€ 4,854$ \\
\hline & Years with overweight & 2.718 & 2.569 & 2.532 \\
\hline & Years with obesity & 0.396 & 0.371 & 0.365 \\
\hline & QALYs & 12.803 & 12.806 & 12.807 \\
\hline & Adulthood ( 20 years of age - death) & & & \\
\hline & Healthcare costs of obesity-related and indirect diseases & $€ 244,680$ & $€ 244,978$ & $€ 245,043$ \\
\hline & LYs & 52.131 & 52.157 & 52.163 \\
\hline & QALYs & 39.362 & 39.390 & 39.397 \\
\hline & Lifetime & & & \\
\hline & Healthcare costs & $€ 249,535$ & $€ 249,832$ & $€ 249,896$ \\
\hline & QALYS & 52.164 & 52.196 & 52.203 \\
\hline \multirow[t]{7}{*}{ Societal } & Intervention costs ${ }^{1}$ & - & $€ 1,587$ & $€ 702$ \\
\hline & Childhood and adolescence ( $4-20$ years of age) & & & \\
\hline & Productivity costs (school absenteeism) & $€ 1,813$ & $€ 1,808$ & $€ 1,807$ \\
\hline & Adulthood (20 years of age - death) & & & \\
\hline & Productivity costs (sick leave days) & $€ 8,031$ & $€ 7,798$ & $€ 7,748$ \\
\hline & Lifetime & & & \\
\hline & Productivity costs & $€ 9,844$ & $€ 9,606$ & $€ 9,554$ \\
\hline
\end{tabular}

Notes: $\mathrm{BMI}=$ body mass index; $\mathrm{HC}=$ healthcare; HPSF = the Healthy Primary School of the Future; LYs = life years; PAS = the Physical Activity School; QALYs = quality-adjusted life years. Costs discounted at $4 \%$ and effects discounted at $1.5 \%$ per year. ${ }^{1}$ The average intervention cost for a school cohort (targeting children from all primary school grades). For the intervention costs under the healthcare perspective, the productivity-related offsets due to the extended school day at HPSF were excluded (see main text). 
The lifetime QALYs per child amounted to 52.164 (control schools), 52.196 (PAS) and 52.203 (HPSF). Under a healthcare perspective, the lifetime cost were $€ 249,535$ (control schools), €251,419 (PAS) and €253,175 (HPSF) per child. The lifetime cost per QALY gained amounted to $€ 58,698$ for PAS vs. the regular school curriculum. The lifetime cost per QALY gained was $€ 248,206$ for HPSF vs. the next best alternative (PAS). When adopting a societal perspective, the total cost were $€ 259,380$ (control schools), $€ 260,152$ (HPSF) and $€ 261,025$ (PAS). The lifetime cost per QALY gained was $€ 19,734$ for HPSF versus the regular school curriculum. HPSF was dominant over PAS, as PAS had a higher cost and a lower QALY gain as compared to HPSF (Table 3).

\section{Sensitivity and effect maintenance scenario analyses}

The parameters in the childhood and adolescence model had little influence on the lifetime cost-effectiveness results (Table 4). When HRQOL in the adulthood model was determined by weight category instead of by chronic disease, the cost per QALY gained decreased. In contrast, a shorter time horizon, discount rates of $3 \%$ and short-term intervention cost instead of steady state cost drove up the cost-effectiveness results.

Under a healthcare perspective, the regular school curriculum had the highest probability of being cost-effective (Table 3, Figure 2). For the societal perspective, HPSF had a $50 \%$ probability of being cost-effective at the $€ 20,000$ threshold $166 \%$ at the $€ 25,000$ threshold) (Figure 2). Cost-effectiveness was also assessed for alternative effect maintenance scenarios. The increasing intervention effects scenario (assuming uptake of behaviour changes by the household) resulted in the lowest cost per QALY gained (Table 5 and Figure 2 ). The cost per QALY gained under the healthcare perspective declined to $€ 51,934$ for PAS vs. control (reference: $€ 58,698$ ), but the regular school curriculum had the highest probability of being cost-effective. For a societal perspective, HPSF became cost-saving in comparison to the regular school curriculum when assuming increasing intervention effects (reference: $€ 19,734$ (Table 5) and HPSF had a $85 \%$ probability of being cost-effective. 

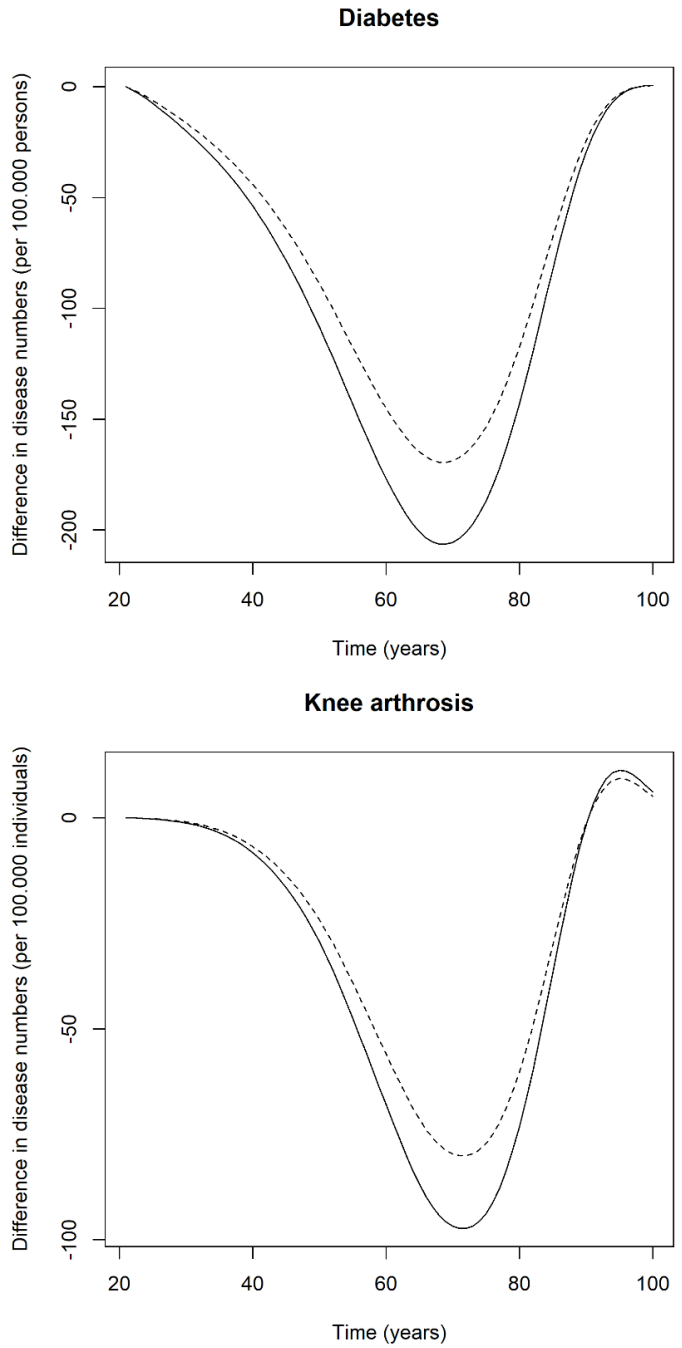

Figure 1 Differences in diabetes and knee arthrosis prevalence numbers.

Notes: Solid line: HPSF versus control schools. Dashed line: PAS versus control schools. 


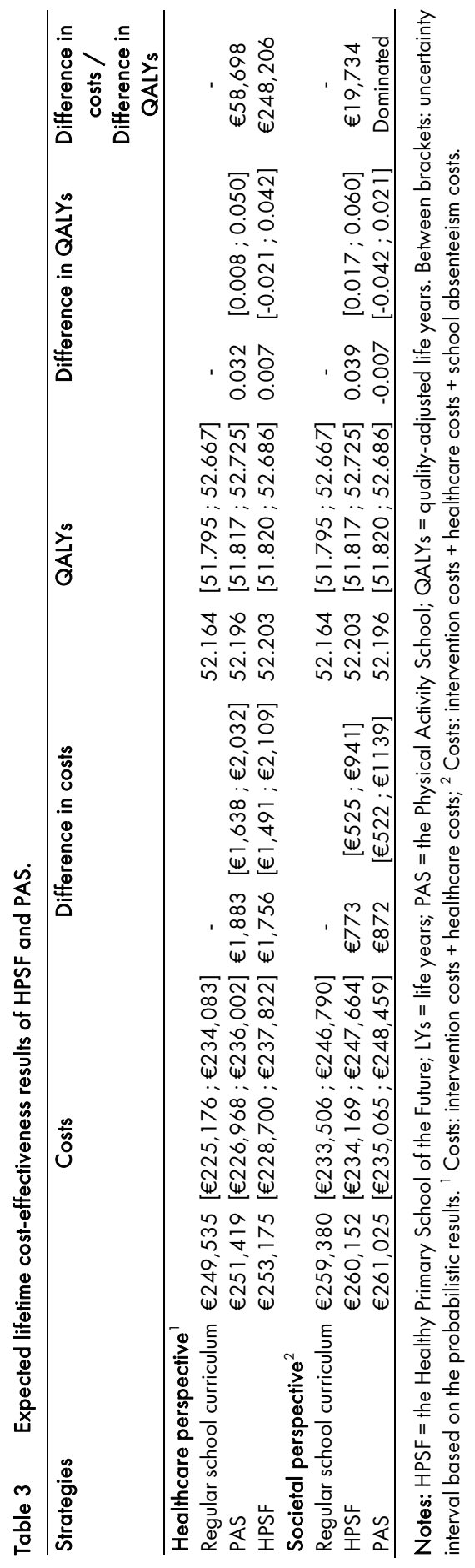




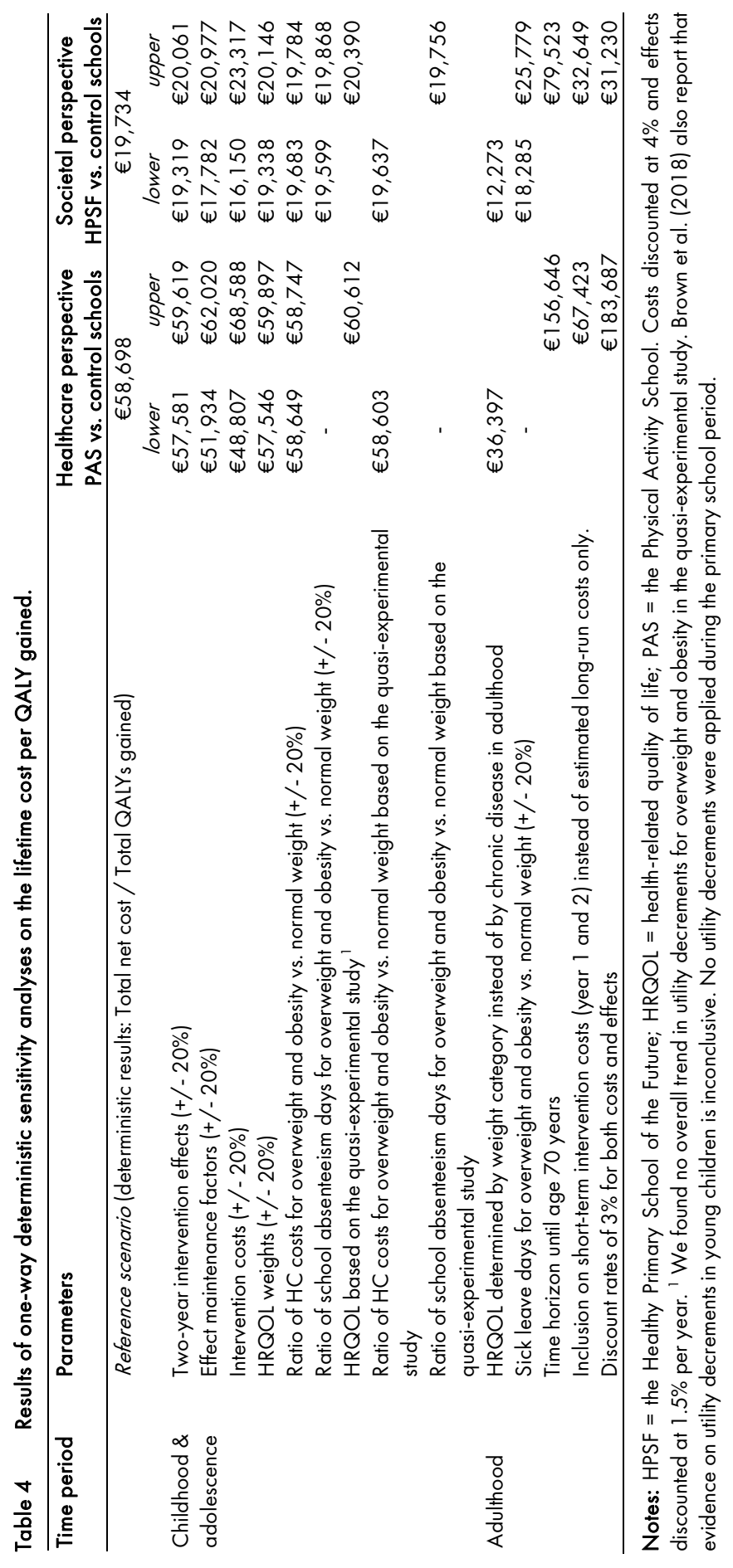




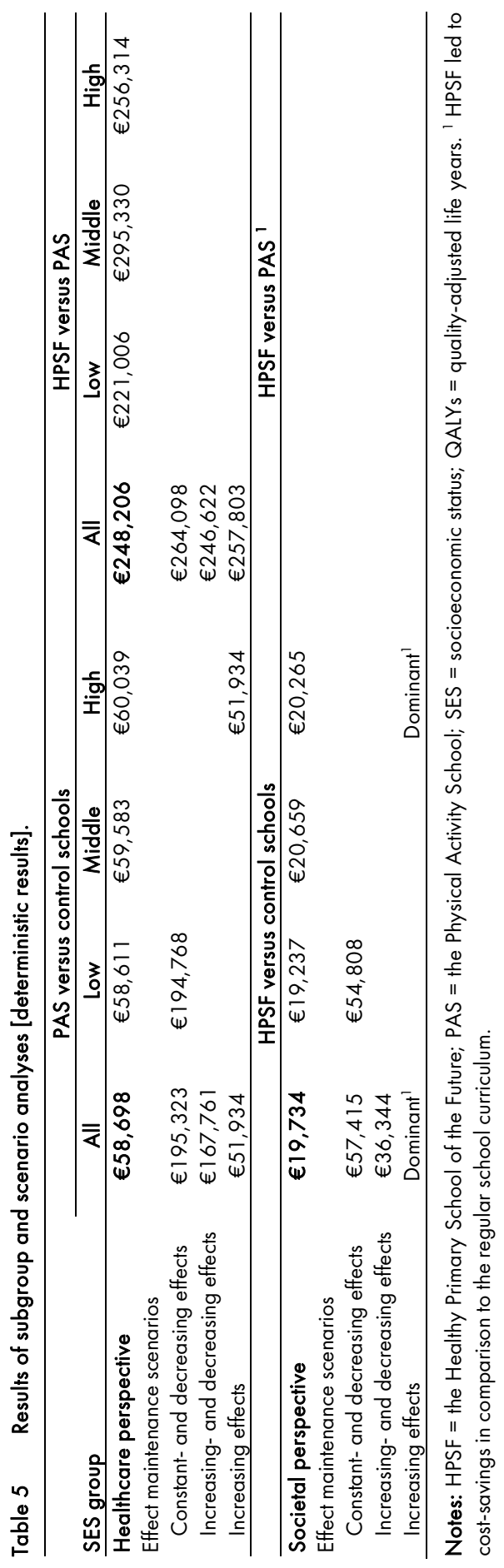




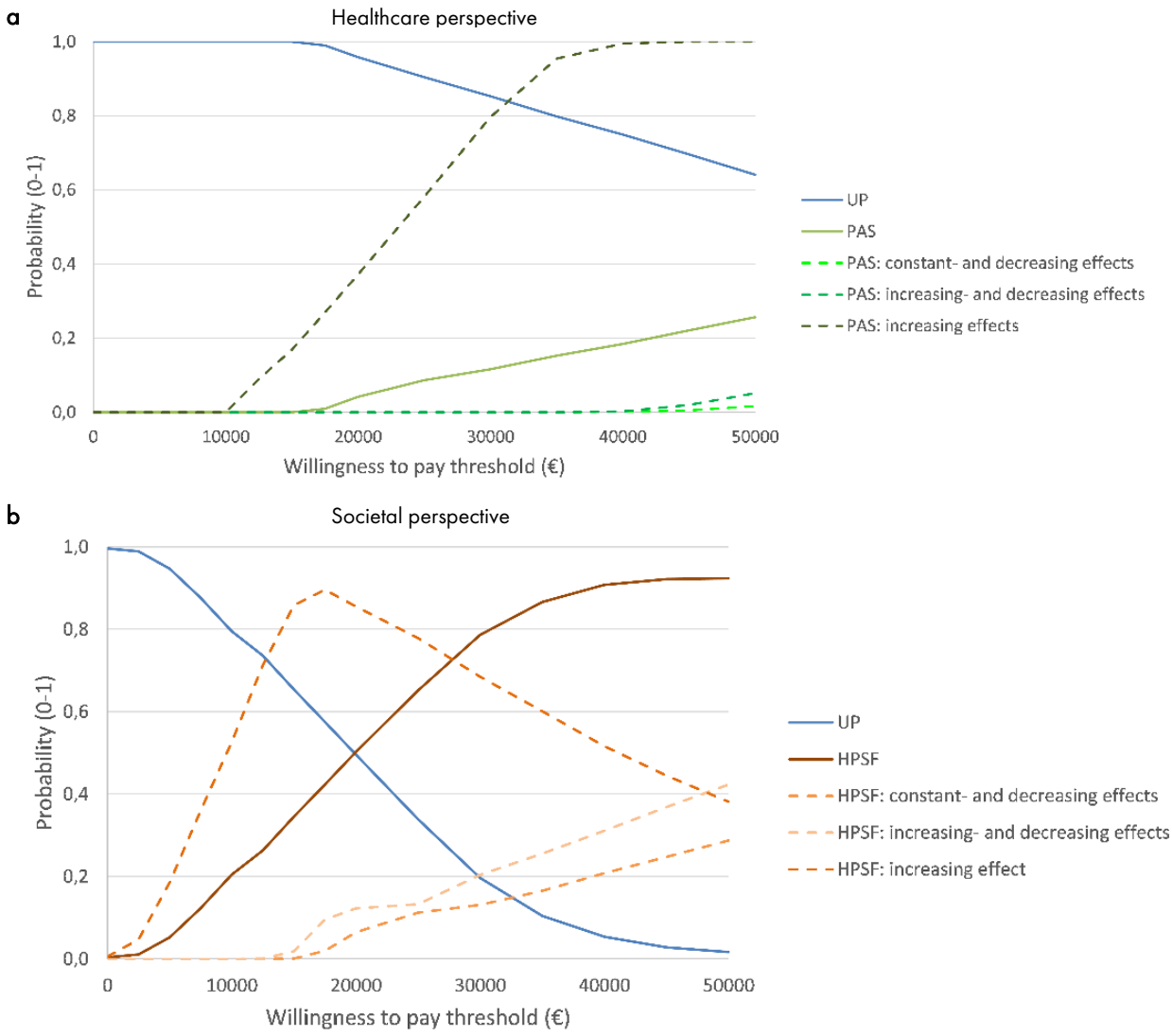

Figure 2 Probability of cost-effectiveness (cost-effectiveness acceptability curve).

Notes: HPSF = the Healthy Primary School of the Future; PAS = the Physical Activity School; UP = usual practice, regular school curriculum. Dashed lines represent the probability of cost-effectiveness for HPSF and PAS under the alternative scenarios. The probability of cost-effectiveness for UP in these scenarios is not presented.

\section{Equity analyses}

HPSF and PAS led to more health benefits and a lower cost per QALY gained in the low SES group as compared to the high SES group. Under a healthcare perspective, PAS fell in the lose-win quadrant of the equity-efficiency impact plane: the cost-effectiveness of PAS vs. the regular curriculum exceeded the willingness to pay threshold and had a harmful costeffectiveness impact (-6207 QALYs per 100,000 persons). On the other hand, PAS resulted in a beneficial equity impact (76 QALYs gained per 100,000 persons for the low versus high SES group). Under the societal perspective, HPSF fell in the win-win quadrant of the equity-efficiency impact plane: the cost-effectiveness of HPSF vs. the regular curriculum fell 
below the willingness to pay threshold and had a positive cost-effectiveness impact (52 QALYs gained per 100,000 persons). At the same time, HPSF also led to a positive equity impact (185 QALYs gained per 100,000 persons). Under the hypothetical situation that the effects would only be maintained throughout adolescence in the high SES group (decreasing intervention effect scenario in low SES groups), HPSF vs. control schools would lead to a win-lose situation: a beneficial cost-effectiveness impact but a harmful health equity impact (297 and -558 QALYs gained per 100,000 persons (Figure 3).

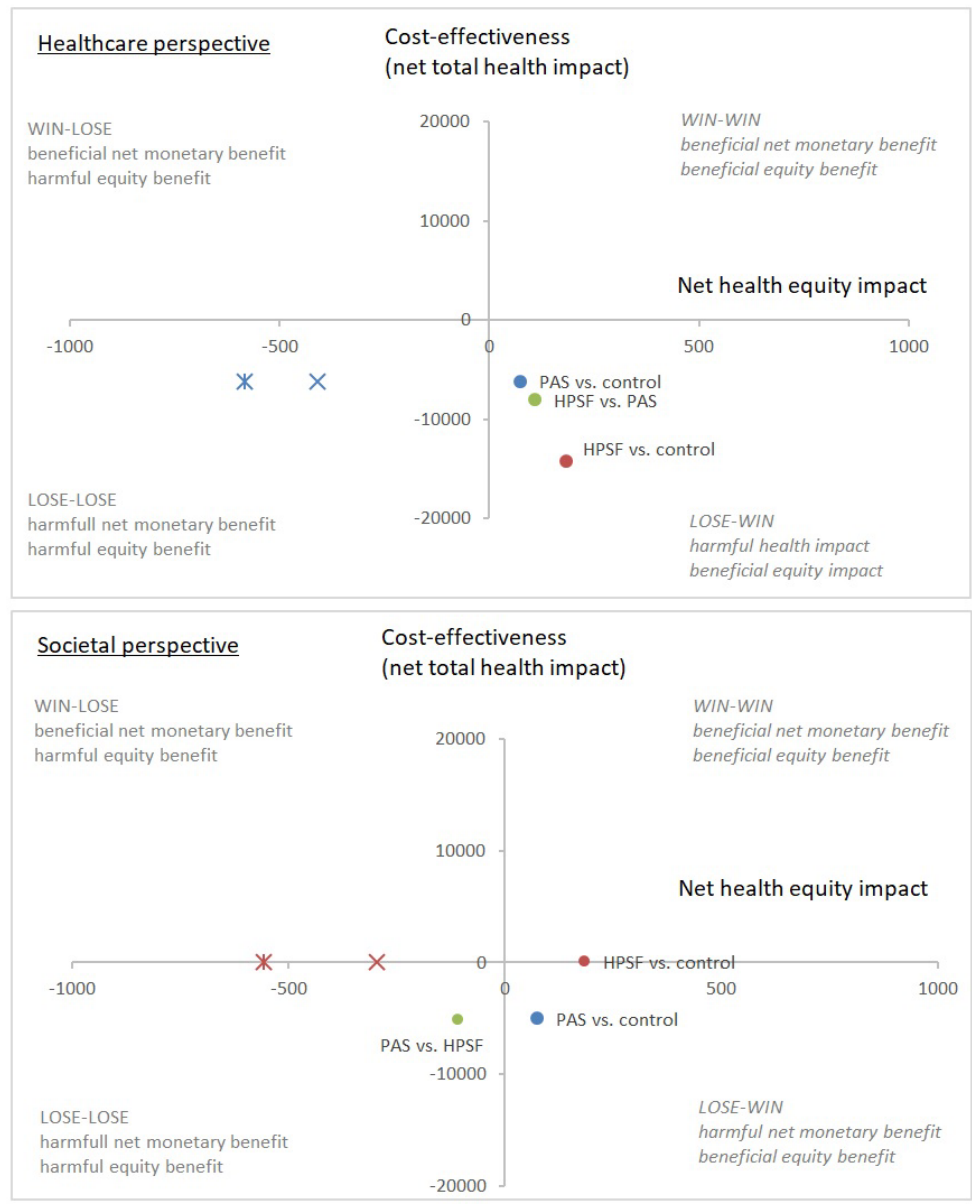

Figure 3 Equity-efficiency impact plane.

Notes: HPSF = the Healthy Primary School of the Future; PAS = the Physical Activity School. Health impact expressed in QALYs per 100,000 persons. ${ }^{*}=$ increasing intervention effects for the high socioeconomic group and constant intervention effects for the low socioeconomic group; * increasing intervention effects for the high socioeconomic group and decreasing intervention effects for the low socioeconomic group. 


\section{Discussion}

Delivering HPSF and PAS to a cohort of primary-school based children (age 4-12 years) resulted in a lifetime QALY gain of 0.039 (HPSF vs. control schools) and 0.032 (PAS vs. control schools) per child. Under a healthcare perspective, the costs of HPSF and PAS per QALY gained exceeded the Dutch threshold value for prevention. ${ }^{25}$ When additionally including the impacts on productivity (societal perspective), HPSF was marginally costeffective in comparison with PAS and the regular curriculum (HPSF vs. regular curriculum: $€ 19,734$ per QALY gained; had a $50 \%$ probability of being cost-effective; HPSF was dominant compared to PAS). In addition, HPSF had a favourable health equity impact in comparison to the regular school curriculum (more QALY gains for the low versus the high SES group). This win-win situation did, however, not apply if effects decayed after the primary school period or if effects were only maintained in high SES groups.

The findings show that the future health and cost impacts of HPSF and PAS are influenced by: the in/exclusion of productivity costs (1), and the assumptions pertaining to the maintenance of the intervention effect (2). The additional costs of HPSF (HPSF vs control schools) were lower under the societal perspective than under the healthcare perspective. This was due to the impact of the extended school day on productivity of parents, of excess weight on school absenteeism, and of morbidity on productivity in later life. Other studies also showed that cost-effectiveness outcomes for school health promotion are substantially lower under a societal perspective, and some interventions even become cost-saving. ${ }^{26,27}$ Including productivity impacts may be relevant in order to gain a full insight into the societal benefits of school health promotion, but it remains unclear whether these impacts are considered important for decision-making on these interventions.

Two assumptions were made regarding the maintenance of the intervention effect: 1) effect maintenance during childhood until young adulthood (20 years), and 2) effect maintenance during adulthood. In the main analysis it was assumed that the observed effects were fully maintained into young adulthood (constant relative effects). The scenario analyses showed that the cost-effectiveness results were sensitive to the assumptions on the effect maintenance until adulthood. In a previous study, expert elicitation revealed that intervention effects could only be maintained into adulthood if the changes in healthy eating and physical activity behaviours are be adopted by the household. ${ }^{18}$ Intensive parental involvement is likely required for this so-called effect transfer. Some effect decay may be therefore likely. Followup measurements (without additional interventions) in secondary school could be undertaken to examine the effect maintenance and reduce the uncertainty around future benefits. The feasibility, costs, and effects of additional actions such as intensive parental involvement 
(particularly for low SES families) and intervention continuation in secondary schools could be examined to foster future impacts.

The effects of the primary-school based lifestyle interventions in adulthood were modelled by adjusting the proportion of normal weight, overweight, and obesity at 20 years of age (see adulthood model). The probabilities of moving from one weight category to another were not adjusted, which implied that the relative intervention effect fades out over the lifetime (e.g. a person eventually moves to the same weight category as in the usual practice situation).

We included the SES-specific BMI-effects of HPSF and PAS and calculated the corresponding lifetime impacts. The main findings showed that the intervention effects and cost-effectiveness outcomes were in favour of the low SES group (reference scenario). It is not known whether the (unobserved) effect maintenance will differ between SES groups. Considering expert beliefs that effects may be only maintained in high SES groups, a tradeoff between cost-effectiveness and health equity will occur. The calculations were based on the presumption that SES does not vary over time, because we did not have detailed information on the tracking of children's socioeconomic position into young adulthood. In reality, children may obtain a different SES position as compared to their parents, induced by the current educational and labour opportunities. We expect that this applies to children from both low and high SES groups (with equal relative differences), as the relative differences in primary school advices in the Netherlands have been stabilized. ${ }^{28} \mathrm{We}$, therefore, think that the dynamic character of children's SES may not greatly affect the estimated lifetime equity impact. Monitoring of the dynamic character of SES is, however, advisable to test this assumption, and to contribute to the inclusion of SES in population health models.

We assessed the cost-effectiveness of HPSF and PAS for a school cohort of 4-12 year old children. Alternatively, an age-cohort such as all 8-year old children (average age) school could have been selected which led to a lower cost per QALY gained. We felt that modelling the impact for a school cohort was most in line with the quasi-experimental study, which focused on assessing effectiveness instead of efficacy. Furthermore, we included HRQOL weights related to chronic diseases and excess weight. Further studies on the $H R Q O L$ effects of excess weight in different subgroups (e.g. age and sex) could contribute to a more precise estimation of the health impacts of obesity prevention programs. Last, it should be noted that the intervention effects of HPSF and PAS were based on the effects after two years of implementation. We are currently examining the effects and cost-effectiveness after the four-year intervention period. 


\section{Conclusions}

Given the societal benefits and the Dutch threshold for prevention, HPSF is a marginally costeffective strategy for combatting the lifetime burden associated with unhealthy lifestyles when assuming constant relative effects. In addition, HPSF has the potential to reduce health inequalities over the lifespan. Implementation is, however, associated with uncertainty: HPSF will not result in a win-win situation if effects fade out during adolescence and/or effects are only maintained among children with a high socioeconomic background. It is therefore paramount to enact upon the uncertain effect maintenance by means of follow-up measurements and by exploring the value of additional interventions. 


\section{References}

1. Lim SS, Vos T, Flaxman AD, et al. A comparative risk assessment of burden of disease and injury attributable to 67 risk factors and risk factor clusters in 21 regions, 1990-2010: a systematic analysis for the Global Burden of Disease Study 2010. Lancet. 2012;380(9859):2224-60.

2. Heyworth ITM, Hazell ML, Linehan MF, Frank TL. How do common chronic conditions affect health-related quality of life? Br J Gen Pract. 2009;59(568):e353.

3. Volksgezondheid en zorg. Trend overgewicht volwassenen 2019. [Available from: https://www.volksgezondheidenzorg.info/onderwerp/overgewicht/cijfers-context/trends\#node-trendovergewicht-volwassenen].

4. Reilly JJ, Kelly J. Long-term impact of overweight and obesity in childhood and adolescence on morbidity and premature mortality in adulthood: systematic review. Int J Obes. 2011;35(7):891-8.

5. Chaker L, Falla A, van der Lee SJ, et al. The global impact of non-communicable diseases on macroeconomic productivity: a systematic review. Eur J Epidemiol. 2015;30(5):357-95.

6. Scharn M, Oude Hengel K, Boot CRL, et al. Influence of chronic diseases on societal participation in paid work, volunteering and informal caregiving in Europe: a 12-year follow-up study. J Epidemiol Community Health. 2019;73(2):136-41.

7. Biener Al, Cawley J, Meyerhoefer $\mathrm{C}$. The medical care costs of obesity and severe obesity in youth: An instrumental variables approach. Health Econ. 2020;29(5):624-639.

8. Nationaal Preventieakoord. Naar een gezonder Nederland.: Ministerie van Volksgezondheid, Welzijn en Sport; 2018.

9. Global Strategy on Diet, Phycial Activity and Health. Geneva: World Health Organization; 2004.

10. European Commission. Promoting healthy lifestyles through health, sport, education and food policies. Brussels; 2017.

11. Ananthapavan J, Sacks G, Brown V, et al. Assessing cost-effectiveness of obesity prevention policies in Australia. Melbourne: Deakin University; 2018.

12. Dalziel K, Segal L. Point: uncertainty in the economic analysis of school-based obesity prevention programs: urgent need for quality evaluation. Obesity. 2006;14(9):1481-2.

13. Cookson R, Mirelman AJ, Griffin S, et al. Using Cost-Effectiveness Analysis to Address Health Equity Concerns. Value Health. 2017;20(2):206-12.

14. Willeboordse M, Jansen MW, van den Heijkant SN, et al. The Healthy Primary School of the Future: study protocol of a quasi-experimental study. BMC Public Health. 2016; 16(1):639.

15. Bartelink N, Van Assema P, Kremers S, et al. Can the Healthy Primary School of the Future offer perspective in the on-going obesity epidemic in young children? - a quasi-experimental study. BMJ Open. 2019;9(10):e030676.

16. Bartelink NHM, van Assema P, Jansen MWJ, et al. Process evaluation of the healthy primary School of the Future: the key learning points. BMC Public Health. 2019;19(1):698.

17. Bartelink NHM, van Assema P, Kremers SPJ, et al. One- and Two-Year Effects of the Healthy Primary School of the Future on Children's Dietary and Physical Activity Behaviours: A Quasi-Experimental Study. Nutrients. 2019; 11 (3):689.

18. Oosterhoff $M$, Jolani S, de Bruijn-Geraets $D$, et al. BMI trajectories after primary school-based lifestyle intervention: unravelling an uncertain future. A mixed methods study. [submitted]. 2020.

19. Cole TJ, Bellizzi MC, Flegal KM, Dietz WH. Establishing a standard definition for child overweight and obesity worldwide: international survey. BMJ. 2000;320(7244):1240-3.

20. Schonbeck $Y$, Talma H, van Dommelen $P$, et al. Increase in prevalence of overweight in Dutch children and adolescents: a comparison of nationwide growth studies in 1980, 1997 and 2009. PloS One. 2011;6(11): e27608.

21. Oosterhoff M, Bosma H, van Schayck OCP, Joore MA. A Cost Analysis of School-Based Lifestyle Interventions. Prev Sci. 2018;19(6):716-27.

22. van Lier LI, Bosmans JE, van Hout HPJ, et al. Consensus-based cross-European recommendations for the identification, measurement and valuation of costs in health economic evaluations: a European Delphi study. Eur J Health Econ. 2018;19(7):993-1008. 
23. Hoogenveen RT, van Baal PH, Boshuizen HC. Chronic disease projections in heterogeneous ageing populations: approximating multi-state models of joint distributions by modelling marginal distributions. Math Med Biol. 2010;27(1):1-19.

24. Lehnert T, Stuhldreher N, Streltchenia P, Riedel-Heller S, Koenig HH. Sick leave days and costs associated with overweight and obesity in Germany. J Occup Eviron Med. 2014;56(1):20-7.

25. van Gils PF, Schoemaker CG, Polder JJ. Hoeveel mag een gewonnen levensjaar kosten? Ned Tijschr Geneeskd. 2014;158.

26. Gortmaker SL, Wang YC, Long MW, et al. Three Interventions That Reduce Childhood Obesity Are Projected To Save More Than They Cost To Implement. Health Aff. 2015;34(1 1):1932-9.

27. Brown HS, Perez A, Li YP, et al. The cost-effectiveness of a school-based overweight program. Int J Behav Nutr Phys Act. 2007;4:47.

28. De staat van het onderwijs 2019. Inspectie van het Onderwijs; 2019. 


\section{Appendix 1}

\section{CHEERS checklist}

\begin{tabular}{|c|c|c|c|}
\hline Section/item & $\begin{array}{l}\text { Item } \\
\text { No }\end{array}$ & Recommendation & $\begin{array}{l}\text { Reported on } \\
\text { page No }\end{array}$ \\
\hline \multicolumn{4}{|l|}{ Title and abstract } \\
\hline Title & 1 & $\begin{array}{l}\text { Identify the study as an economic evaluation or use more specific } \\
\text { terms such as "cost-effectiveness analysis", and describe the } \\
\text { interventions compared. }\end{array}$ & $\begin{array}{l}\text { page 1, } \\
\text { line } 1\end{array}$ \\
\hline Abstract & 2 & $\begin{array}{l}\text { Provide a structured summary of objectives, perspective, setting, } \\
\text { methods (including study design and inputs), results (including } \\
\text { base case and uncertainty analyses), and conclusions. }\end{array}$ & page 1 \\
\hline \multicolumn{4}{|l|}{ Introduction } \\
\hline $\begin{array}{l}\text { Background and } \\
\text { objectives }\end{array}$ & 3 & Provide an explicit statement of the broader context for the study. & $\begin{array}{l}\text { page } 2, \\
\text { line } 33-41\end{array}$ \\
\hline & & $\begin{array}{l}\text { Present the study question and its relevance for health policy or } \\
\text { practice decisions. }\end{array}$ & $\begin{array}{l}\text { page 2, } \\
\text { line } 81-88\end{array}$ \\
\hline \multicolumn{4}{|c|}{ T) } \\
\hline $\begin{array}{l}\text { Target population and } \\
\text { subgroups }\end{array}$ & 4 & $\begin{array}{l}\text { Describe characteristics of the base case population and } \\
\text { subgroups analysed, including why they were chosen. }\end{array}$ & $\begin{array}{l}\text { page } 2 \\
\text { line } 95-98\end{array}$ \\
\hline Setting and location & 5 & $\begin{array}{l}\text { State relevant aspects of the system(s) in which the decision(s) } \\
\text { need(s) to be made. }\end{array}$ & $\begin{array}{l}\text { page } 2 \\
\text { line } 113-126\end{array}$ \\
\hline Study perspective & 6 & $\begin{array}{l}\text { Describe the perspective of the study and relate this to the costs } \\
\text { being evaluated. }\end{array}$ & $\begin{array}{l}\text { page } 3 \\
\text { line } 226-234\end{array}$ \\
\hline Comparators & 7 & $\begin{array}{l}\text { Describe the interventions or strategies being compared and } \\
\text { state why they were chosen. }\end{array}$ & $\begin{array}{l}\text { page } 2, \\
\text { line } 95-112\end{array}$ \\
\hline Time horizon & 8 & $\begin{array}{l}\text { State the time horizon(s) over which costs and consequences are } \\
\text { being evaluated and say why appropriate. }\end{array}$ & $\begin{array}{l}\text { page } 2, \\
\text { line } 128-130\end{array}$ \\
\hline Discount rate & 9 & $\begin{array}{l}\text { Report the choice of discount rate(s) used for costs and outcomes } \\
\text { and say why appropriate. }\end{array}$ & $\begin{array}{l}\text { page } 3, \\
\text { line } 223-227\end{array}$ \\
\hline $\begin{array}{l}\text { Choice of health } \\
\text { outcomes }\end{array}$ & 10 & $\begin{array}{l}\text { Describe what outcomes were used as the measure(s) of benefit } \\
\text { in the evaluation and their relevance for the type of analysis } \\
\text { performed. }\end{array}$ & $\begin{array}{l}\text { page } 3, \\
\text { line 184-190, } \\
\text { line 209-211, } \\
\text { line 221-223 }\end{array}$ \\
\hline \multirow[t]{2}{*}{$\begin{array}{l}\text { Measurement of } \\
\text { effectiveness }\end{array}$} & $11 a$ & $\begin{array}{l}\text { Single study-based estimates: Describe fully the design features } \\
\text { of the single effectiveness study and why the single study was a } \\
\text { sufficient source of clinical effectiveness data. }\end{array}$ & $\begin{array}{l}\text { page } 3 \\
\text { line } 147-161\end{array}$ \\
\hline & $11 b$ & $\begin{array}{l}\text { Synthesis-based estimates. Describe fully the methods used for } \\
\text { identification of included studies and synthesis of clinical } \\
\text { effectiveness data. }\end{array}$ & \\
\hline $\begin{array}{l}\text { Measurement and } \\
\text { valuation of preference } \\
\text { based outcomes }\end{array}$ & 12 & $\begin{array}{l}\text { If applicable, describe the population and methods used to elicit } \\
\text { preferences for outcomes. }\end{array}$ & Not applicable \\
\hline
\end{tabular}


Cheers checklist (continued)

\begin{tabular}{|c|c|c|c|}
\hline Section/item & $\begin{array}{l}\text { Item } \\
\text { No }\end{array}$ & Recommendation & $\begin{array}{l}\text { Reported on } \\
\text { page No }\end{array}$ \\
\hline \multirow[t]{2}{*}{$\begin{array}{l}\text { Estimating resources } \\
\text { and costs }\end{array}$} & $13 a$ & $\begin{array}{l}\text { Single study-based economic evaluation: Describe } \\
\text { approaches used to estimate resource use associated with the } \\
\text { alternative interventions. Describe primary or secondary } \\
\text { research methods for valuing each resource item in terms of its } \\
\text { unit cost. Describe any adjustments made to approximate to } \\
\text { opportunity costs. }\end{array}$ & \\
\hline & $13 b$ & $\begin{array}{l}\text { Model-based economic evaluation: Describe approaches } \\
\text { and data sources used to estimate resource use associated } \\
\text { with model health states. Describe primary or secondary } \\
\text { research methods for valuing each resource item in terms of its } \\
\text { unit cost. Describe any adjustments made to approximate to } \\
\text { opportunity costs. }\end{array}$ & $\begin{array}{l}\text { page } 3 \text {, line } 162- \\
188, \\
\text { line } 209-219\end{array}$ \\
\hline $\begin{array}{l}\text { Currency, price date, } \\
\text { and conversion }\end{array}$ & 14 & $\begin{array}{l}\text { Report the dates of the estimated resource quantities and unit } \\
\text { costs. Describe methods for adjusting estimated unit costs to } \\
\text { the year of reported costs if necessary. Describe methods for } \\
\text { converting costs into a common currency base and the } \\
\text { exchange rate. }\end{array}$ & $\begin{array}{l}\text { page } 3 \text {, line } 213- \\
214\end{array}$ \\
\hline Choice of model & 15 & $\begin{array}{l}\text { Describe and give reasons for the specific type of decision- } \\
\text { analytical model used. Providing a figure to show model } \\
\text { structure is strongly recommended. }\end{array}$ & $\begin{array}{l}\text { page } 3 \text {, line } 142- \\
146, \\
\text { line } 199-209\end{array}$ \\
\hline Assumptions & 16 & $\begin{array}{l}\text { Describe all structural or other assumptions underpinning the } \\
\text { decision-analytical model. }\end{array}$ & $\begin{array}{l}\text { page } 3 \text {, line } 195- \\
197, \text { Table } 1\end{array}$ \\
\hline Analytical methods & 17 & $\begin{array}{l}\text { Describe all analytical methods supporting the evaluation. This } \\
\text { could include methods for dealing with skewed, missing, or } \\
\text { censored data; extrapolation methods; methods for pooling } \\
\text { data; approaches to validate or make adjustments (such as } \\
\text { half cycle corrections) to a model; and methods for handling } \\
\text { population heterogeneity and uncertainty. }\end{array}$ & $\begin{array}{l}\text { page } 3 \text {, line } 198- \\
219, \\
\text { page } 4 \text {, line } 238- \\
310\end{array}$ \\
\hline \multicolumn{4}{|c|}{ 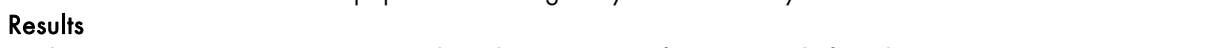 } \\
\hline Study parameters & 18 & $\begin{array}{l}\text { Report the values, ranges, references, and, if used, } \\
\text { probability distributions for all parameters. Report reasons or } \\
\text { sources for distributions used to represent uncertainty where } \\
\text { appropriate. Providing a table to show the input values is } \\
\text { strongly recommended. }\end{array}$ & Table 1 \\
\hline $\begin{array}{l}\text { Incremental costs and } \\
\text { outcomes }\end{array}$ & 19 & $\begin{array}{l}\text { For each intervention, report mean values for the main } \\
\text { categories of estimated costs and outcomes of interest, as well } \\
\text { as mean differences between the comparator groups. If } \\
\text { applicable, report incremental cost-effectiveness ratios. }\end{array}$ & $\begin{array}{l}\text { page } 7 \text {, line } 312 \text { - } \\
334 ; \text { Table } 2 \text { and } \\
3\end{array}$ \\
\hline \multirow[t]{2}{*}{$\begin{array}{l}\text { Characterising } \\
\text { uncertainty }\end{array}$} & $20 a$ & $\begin{array}{l}\text { Single study-based economic evaluation: Describe the effects } \\
\text { of sampling uncertainty for the estimated incremental cost and } \\
\text { incremental effectiveness parameters, together with the impact } \\
\text { of methodological assumptions (such as discount rate, study } \\
\text { perspective). }\end{array}$ & \\
\hline & $20 b$ & $\begin{array}{l}\text { Model-based economic evaluation: Describe the effects on } \\
\text { the results of uncertainty for all input parameters, and } \\
\text { uncertainty related to the structure of the model and } \\
\text { assumptions. }\end{array}$ & $\begin{array}{l}\text { page } 7 \text {, line } 336- \\
\text { 364. Table } 4\end{array}$ \\
\hline
\end{tabular}


Cheers checklist (continued)

\begin{tabular}{|c|c|c|c|}
\hline Section/item & $\begin{array}{l}\text { Item } \\
\text { No }\end{array}$ & Recommendation & $\begin{array}{l}\text { Reported on } \\
\text { page No }\end{array}$ \\
\hline $\begin{array}{l}\text { Characterising } \\
\text { heterogeneity }\end{array}$ & 21 & $\begin{array}{l}\text { If applicable, report differences in costs, outcomes, or cost- } \\
\text { effectiveness that can be explained by variations between } \\
\text { subgroups of patients with different baseline characteristics or } \\
\text { other observed variability in effects that are not reducible by } \\
\text { more information. }\end{array}$ & $\begin{array}{l}\text { page } 7 \text {, line } 366 ; \\
\text { Figure } 3\end{array}$ \\
\hline Discussion & & & \\
\hline $\begin{array}{l}\text { Study findings, } \\
\text { limitations, } \\
\text { generalisability, and } \\
\text { current knowledge } \\
\text { Other }\end{array}$ & 22 & $\begin{array}{l}\text { Summarise key study findings and describe how they support } \\
\text { the conclusions reached. Discuss limitations and the } \\
\text { generalisability of the findings and how the findings fit with } \\
\text { current knowledge. }\end{array}$ & page $8-13$ \\
\hline Source of funding & 23 & $\begin{array}{l}\text { Describe how the study was funded and the role of the funder } \\
\text { in the identification, design, conduct, and reporting of the } \\
\text { analysis. Describe other non-monetary sources of support. }\end{array}$ & page 13 \\
\hline Conflicts of interest & 24 & $\begin{array}{l}\text { Describe any potential for conflict of interest of study } \\
\text { contributors in accordance with journal policy. In the absence } \\
\text { of a journal policy, we recommend authors comply with } \\
\text { International Committee of Medical Journal Editors } \\
\text { recommendations. }\end{array}$ & page 13 \\
\hline
\end{tabular}




\section{Appendix 2}

Details and assumptions pertaining to the childhood and adolescence model

\section{A. Assumptions for model input parameters}

Population. All 4-12 year-olds in the Netherlands are enrolled at primary schools and exposed to HPSF and PAS. In order to calculate the average QALYs and costs for a school cohort of primary school-aged children (4-12 year olds), the results were aggregated based on the number of Dutch 4-12 year-olds (2019). ${ }^{1}$

Relative intervention effects. Information on children's BMI development was obtained from a previous study. ${ }^{2,3}$ In the probabilistic analysis, a negative gamma distribution was used to ensure that the relative effects on BMI range from zero to minus infinity (and thus reflect reductions in BMI for HPSF and PAS versus control schools). In a sensitivity analysis this assumption is relaxed by assuming a normal distribution. BMI values were converted into weight categories by using the Dutch reference values for the skewness and variation of the childhood BMI distribution and the age- and sex-specific international cut-off points (IOTF) for childhood overweight and obesity. ${ }^{4,5}$

Intervention costs. The intervention costs were estimated for a future steady state and were informed by expert opinion. ${ }^{6}$ In the calculation of the intervention costs from a societal perspective, the duration of the extended school day was valued as a productivity gain for caregivers as they could spent this time on work. For the cost-effectiveness calculations under the healthcare perspective, this productivity-related cost offset was not included.

Health-related quality of life. HRQOL weights were obtained from Brown et al. (2018), who meta-analysed preference-based utility values per weight category for 5-18 year olds. It was assumed that the HRQOL effects associated with overweight and obesity were perceived by all 4-20 year-olds and remained constant over time. In a sensitivity analysis, the HRQOL effects were not applied during the primary school period, based on the inconclusive findings on the HRQOL effects for young children. ${ }^{7}$ Analysis of EQ5D-Y data in our study sample (baseline data), however, showed larger differences for children younger than 8 years (scored by parental proxies) as compared to older peers (scores by children themselves).

Healthcare costs. Inputs for excess healthcare costs associated with overweight and obesity were obtained from Gortmaker et al. (2015), and combined with the number of healthcare visits and standard cost prices for children in the Netherlands. ${ }^{8-10}$ We assumed that the 
relative risks for the impact of overweight and obesity on healthcare costs were are applicable for all 4-20 year-olds and remained constant over time. The healthcare costs were assumed to be fixed, because the data was based on a large study (Gezondheidsenquete, random sample of the Dutch population, $\mathrm{N}=9500$ ) and because variance parameters could not be obtained.

Productivity costs. The excess missed school days associated with overweight and obesity were obtained from the meta-analysis by An et al. (2017) and were combined with the number of missed schooldays for children with a healthy weight and the Dutch shadow price for school absenteeism. ${ }^{11-13}$ It was assumed that the education costs of primary schools in the Netherlands represented (shadow price) the 'soft costs' associated with absenteeism from school. These costs were applied to both the primary and secondary school period.

Effect maintenance. In the constant exposure-effect scenario, we used the 2-year observed intervention effects instead of the probability distributions obtained from expert opinion. This was done in order to be able to model the SES-specific impacts for this scenario. The probability distributions defined by experts were also close to the analysed 2-year effects, because experts anticipated that the 2-year intervention effects would (more or less) remain constant over the primary school period. ${ }^{3}$ For the household multiplier scenario in the primary school period, the 2-year relative effects were first applied, after which the multiplier scenario started (from year 3 onwards).

Equity impacts. The HRQOL effects, healthcare and productivity costs were held constant over the different SES groups, based on the assumption that the impacts of overweight and obesity on HRQOL and costs were equal for low, middle, and high SES groups.

\section{B. Structural model uncertainty}

The analysis adopted a societal perspective. Although intervention costs were assessed from a societal perspective, and both healthcare and productivity costs were included, it may not reflect a fullsocietal perspective. Other potential impacts are:

- Wellbeing losses experienced by caregivers due to the forgone caregiver time as result of the extended school day at HPSF.

- Stigmatization/ bullying and wellbeing effects related to overweight and obesity and related to the interventions at HPSF and PAS.

- Wellbeing effects (effects not fully captured with the EQ5D-Y instrument) due to improved lifestyle behaviours.

- The impact of improved lifestyle behaviours on school behaviours and school outcomes: e.g. concentration, cognitive and non-cognitive functioning. 


\section{Appendix 3}

Details and assumptions pertaining to the adulthood model

\section{A. Assumptions for model input parameters}

Chronic disease model. The RIVM Chronic Disease Model (CDM), a probabilistic health economic model with the Markov property, estimates the prevalence, incidence, and mortality of major chronic diseases based on changes in risk factors. ${ }^{14}$ Risk factors for which the impact on chronic diseases can be modelled are, for example, smoking, body mass index, physical activity, and fruit and vegetable intake. In the CDM, body weight is defined by three classes: normal weight, overweight (BMI 25-30 kg/m ${ }^{2}$ ), and obesity (BMI $\left.\geq 30 \mathrm{~kg} / \mathrm{m}^{2}\right)^{5}$

Chronic diseases. Obesity-related diseases in the CDM include myocardial infarction (AMI), angina pectoris, chronic heart failure, stroke, renal, colorectal, breast, prostate, and endometrium cancer, diabetes mellitus, hip and knee arthritis, and low back pain. The CDM also describes the independent effect of diseases on other diseases (i.e. persons with diabetes have a higher risk of myocardial infarction compared to persons without diabetes, independently from overweight). ${ }^{14}$ In addition, changes in non-overweight related diseases may occur during life years gained. This may be caused by interventions that result in an increase of life years, which are not likely to be lived in full health (i.e. incidence of lung cancer during added life years in case of obesity prevention). Indirect related diseases are chronic obstructive pulmonary disease (COPD), lung, stomach, esophagus, larynx, bladder, pancreas, and oral cavity cancer. ${ }^{15}$

Utilities. The health state utilities in the CDM were obtained from the Dutch Burden of Disease Study containing utilities for several chronic diseases. ${ }^{16}$ The health state utilities for overweight and obesity are not included. Therefore, gains in quality of life result from decreases in the prevalence of chronic diseases, and not from weight loss only. Proportional utility weights for QALYs were used in the CDM, which implies that the disability of comorbidity increases with the number of diseases present, however this effect is less than additive. $^{15}$

Healthcare costs. The model used data of the Dutch Cost of Illness Study for the Dutch healthcare costs. ${ }^{17}$ Cost data were indexed to the Dutch 2018 price level using consumer price indexes. 
Discounting. Because obesity prevention was applied in the primary school period, we further discounted the healthcare costs and effects over 12 years, spanning the time from childhood (mean 8 years of age) into young adulthood (20 years of age).

Productivity costs. Productivity losses in adulthood were incorporated through the relation between weight category up to 67 years of age and the number of annual sick leave days from work as reported by Lehnert et al. (2014). ${ }^{18,19}$

\section{B. Structural model uncertainty}

The analysis adopted a societal perspective. Although both healthcare and productivity costs were included, it may not reflect a full societal perspective. Other potential impacts are:

- Stigmatization and wellbeing effects related to overweight and obesity.

- Wellbeing effects (effects not fully captured with the EQ5D-Y instrument) due to improved lifestyle behaviours.

- The impact of improved lifestyle behaviours on school outcomes and productivity in later life. 


\section{Appendix 4}

\section{Sensitivity analyses}

\section{Univariate sensitivity analysis}

- No overall effects were found in the analysis of baseline HRQOL data from the quasiexperimental study (EuroQol-5D Youth instrument). Similarly, Brown et al. (2018) report that the evidence on the impact of overweight and obesity on HRQOL in young children is scarce and inconclusive. ${ }^{7}$

- Ratio of healthcare costs for overweight and obesity vs. normal weight based on the quasi-experimental study. For obese children who incurred any healthcare costs, we found a rate ratio of 1.87 for general practitioner related healthcare consumption and a rate ratio of 1.59 for specialist visits as compared to normal weight children.

- Ratio of annual school absenteeism days for overweight and obesity vs. normal weight based on the quasi-experimental study. We found a ratio 1.21 for overweight children and a ratio of 1.59 for obese children as compared to children with a normal weight.

- HRQOL determined by weight status instead of by chronic disease in adulthood. The $\mathrm{HRQOL}$ benefits (for intervention versus control) are accrued later in time when they are exclusively linked to the occurrence of chronic disease as when they are related to weight status directly. For this, we used a disutility of 0.017 per unit increase in BMI and assumed and an average 5-unit BMI difference between the weight classes (normal weight, overweight and obesity). ${ }^{20}$

- Time horizon till age 70 years.

- Short-term cost of HPSF and PAS (at year 1 and year 2) instead of the estimated long-run costs only. ${ }^{6}$

- Discount rates of $3 \%$ for both costs and effects.

\section{Probabilistic sensitivity analyses}

\section{Childhood and adolescence model}

Probabilistic analyses were run for every age-cohort. It was assumed that the number of simulations per age cohort and the limited number of probabilistic input parameters mitigated the potential influence of the differences in random draws on cost-effectiveness results.

\section{Adulthood model}

A probabilistic sensitivity analyses was conducted to account for the uncertainty in input parameters. The intervention effect, prevalence rates of weight class in adulthood, and the 
disease prevalence and incidence were included as probabilistic parameters. The uncertainty of the intervention effect was incorporated by including the overweight and obesity prevalence rates at young adulthood as probabilistic parameters. This uncertainty parameter reflected the boundaries of the $95 \%$ confidence interval of the intervention effect on body mass index. The overweight and obesity prevalence rates at 20 years of age were included as multivariate normal distributions with a perfect correlation. Results were analysed as the mean of 100 replications based on random draws of the probabilistic parameters.

Results were summed up, assuming independence between the probabilistic results of the childhood and adulthood model. 


\section{References}

1. Statline. Bevolking; geslacht, leeftiid en burgerlijke staat, 1 januari 2019 [Available from: https://opendata.cbs.nl/statline/\#/CBS/nl/dataset/7461BEV/table?fromstatweb].

2. Bartelink N, Van Assema P, Kremers, et al. Can the Healthy Primary School of the Future offer perspective in the on-going obesity epidemic in young children? - a quasi-experimental study. BMJ Open. 2019;9:e030676.

3. Oosterhoff $M$, Jolani S, De Bruijn-Geraets $D$, et al. BMI trajectories after primary school-based lifestyle intervention: unravelling an uncertain future. A mixed methods study. [submitted]. 2020.

4. Cole TJ, Bellizzi MC, Flegal KM, Dietz WH. Establishing a standard definition for child overweight and obesity worldwide: international survey. BMJ. 2000;320(7244):1240-3.

5. Schonbeck $Y$, Talma $H$, van Dommelen $P$, et al. Increase in prevalence of overweight in Dutch children and adolescents: a comparison of nationwide growth studies in 1980, 1997 and 2009. PloS one. 2011;6(11): e27608.

6. Oosterhoff M, Bosma H, van Schayck OCP, Joore MA. A Cost Analysis of School-Based Lifestyle Interventions. Prev Sci. 2018;19(6):716-27.

7. Brown V, Tan EJ, Hayes AJ, Petrou S, Moodie ML. Utility values for childhood obesity interventions: a systematic review and meta-analysis of the evidence for use in economic evaluation. Obes Rev. 2018; 19(7): 905-16.

8. Gortmaker SL, Wang YC, Long MW, et al. Three Interventions That Reduce Childhood Obesity Are Projected To Save More Than They Cost To Implement. Health Aff. 2015; 34(1 1):1932-9.

9. Central Bureau for Statistics (CBS). Gezondheid en zorggebruik. n.d. [Available from: https://opendata.cbs.nl/statline/\#/CBS/nl/dataset/83005ned/table?fromstatweb].

10. Zorginstituut Nederland. Kostenhandleiding: Methodologie van kostenonderzoek en referentieprijzen voor economische evaluaties in de gezondheidszorg. 2015.

11. An R, Yan H, Shi X, Yang Y. Childhood obesity and school absenteeism: a systematic review and metaanalysis. Obes Rev. 2017;18(12):1412-24.

12. Drost RMWA, Paulus A, Ruwaard D, Evers S. Handleiding Intersectorale Kosten en Baten van (Preventieve) Interventies. Maastricht University, Faculty of Health, Medicine and Life Sciences CAPHRI, School for Public Health and Primary Care Care, Department of Health Services; 2014.

13. Willeboordse M, Jansen MW, van den Heijkant SN, et al. The Healthy Primary School of the Future: study protocol of a quasi-experimental study. BMC Public Health. 2016;16(1):639.

14. Hoogenveen RT, van Baal PH, Boshuizen HC. Chronic disease projections in heterogeneous ageing populations: approximating multi-state models of joint distributions by modelling marginal distributions. Math Med Biol. 2010;27(1):1-19.

15. van Baal PHM, Hoogenveen RT, de Wit GA, Boshuizen HC. Estimating health-adjusted life expectancy conditional on risk factors: results for smoking and obesity. Popul Health Metr. 2006;4(1):4-14.

16. Melse JM, Essink-Bot ML, Kramers PG, Hoeymans N. A national burden of disease calculation: Dutch disability-adjusted life-years. Dutch Burden of Disease Group. Am J Public Health. 2000;90(8):1241-7.

17. Slobbe L, Smit J, Groen J, Poos M, Kommer G. Kosten van Ziekten in Nederland 2007.

18. Lehnert T, Stuhldreher N, Streltchenia P, Riedel-Heller S, Koenig H-H. Sick leave days and costs associated with overweight and obesity in Germany. J Occup Eviron Med. 2014;56(1):20-7.

19. CBS Statline. Arbeidsdeelname 2017 [Available from: https://opendata.cbs.nl/statline/ \#/CBS/nl/dataset/71738NED/table?fromstatweb].

20. Hakim Z, Wolf A, Garrison LP. Estimating the effect of changes in body mass index on health state preferences. PharmacoEconomics. 2002;20(6):393-404. 



\section{Chapter 9}

General discussion 
Chapter 9 
The demand for healthcare is rising due to the ageing population and the increasing incidence of chronic diseases. 'Transformations are needed to keep our health system affordable and accessible. ${ }^{2}$ Overweight is one of the leading contributors of chronic disease. ${ }^{1,3}$ Currently, more than half of Dutch adults are overweight. Given the high prevalence and avoidable nature of overweight, the need for prevention rather than cure is nowadays extremely relevant. ${ }^{2,4}$

Promoting healthy lifestyles from early ages onwards is key for preventing overweight from the start, and for investing in children's current and future health and wellbeing. ${ }^{5}$ Through offering lifestyle programs via schools, children from all backgrounds can be reached. There is a general agreement that school health promotion should be comprehensive, consist of sustained efforts, and should be evidence-based. ${ }^{6,7}$ Implementation of comprehensive strategies, also known as whole-school approaches, requires involvement of multiple parties consisting of teachers, parents, policy makers, and profit and non-profit organizations such as childcare partners and caterers. Deciding upon implementation and investment (a socalled adoption decision) is, however, difficult as investments in terms of scarce time and financial resources precede the potential future benefits of school health promotion.

Economic evaluation is developed as a method to support decision-makers in making the best choices under uncertainty, conflicting objectives, and resource constraints. ${ }^{8}$ By assessing the investments and benefits on the short, medium, and long term, health-economic evidence can inform decisions on school health promotion.

This thesis had three aims: 1) assessing to which extent school health promotion contributes to children's health and wellbeing (Chapter 2 and 3), 2) identifying employed methods for evaluating the health-economic impact of school health promotion (Chapter 4), and 3) investigating the short and long-term health-economic impact of the Healthy Primary School of the Future initiative (Chapter 5, 6, 7 and 8). This chapter summarizes and discusses the main findings, elaborates on implications, and presents recommendations for research, policy, and practice. 


\section{Summary of main findings}

1. To which extent can school health promotion contribute to children's health and wellbeing on the short-term?

Health is disproportionally distributed over socioeconomic groups, favoring individuals with a high socioeconomic position. In order to tackle this socioeconomic gradient, interventions aim at improving health behaviors among low socioeconomic status groups. ${ }^{9}$

Chapter 2 looked at the presence of socioeconomic disparities in health-related outcomes among children and examined the role of health behaviours. We studied two-year follow-up data of 1259 children, and found that children with a higher socioeconomic background had more favourable health outcomes (body mass index [BMI], health resource use, school absenteeism, health-related quality of life, and psychosocial health) in comparison with children from a lower socioeconomic background. After adjustment for other factors, children with a low socioeconomic background had on average a 0.42 -point higher standardized BMI value [95\% confidence interval: 0.22 to 0.62 ] and a 2.21 times higher healthcare consumption [95\% confidence interval: 1.75 to 3.10] (measured in terms of costs) as compared to their peers with a high socioeconomic background. Health disparities in the study sample were not explained by differences in children's health behaviours (physical activity, consumption of fruit and vegetables, and consumption of sweetened beverages). These results suggest that although school-based interventions may be effective in improving health behaviours, on the short-term they are likely not sufficient to tackle socioeconomic inequalities in child health. Appropriate additional actions for combatting child health inequity are described later in the chapter.

School-based lifestyle interventions aim to put an end to the adverse cascade from unhealthy behaviours to overweight, metabolic consequences (e.g. high blood pressure, glucose intolerance), and the development of chronic disease. Chapter 3 reviewed the impact of primary school-based lifestyle interventions (for 4-12 year olds) on body mass index (BMI) and blood pressure by synthesizing the results of 85 randomized controlled trials. A multilevel multivariate meta-analysis was performed, which accounted for the dependence of effect sizes observed within the same study (e.g. for boys and girls, for different study arms, for BMI and blood pressure). Effects were expressed in terms of standardized effect sizes to facilitate the comparison between BMI and blood pressure. The standardized effects in the multivariate analysis were -0.054 for BMI [95\% confidence interval: -0.131 to 0.022 ], -0.182 for systolic blood pressure [95\% confidence interval: -0.266 to -0.098 ], and -0.144 for diastolic blood pressure [95\% confidence interval: -0.230 to -0.057$]$. The stronger standardized effect sizes for systolic and diastolic blood 
pressure indicate that (some) effects on blood pressure may accrue independently of the effects on BMI.

\section{Which methods are used for evaluating the health-economic impact of school health promotion?}

Researchers face methodological challenges in assessing the cost-effectiveness of both health promotion programs and childhood interventions. ${ }^{10-12}$ Examples of these challenges include the following: including benefits in addition to health outcomes ('beyond-health' outcomes), measuring and valuing costs and outcomes in children, and incorporating effects on other persons than the targeted child (e.g. family, community). ${ }^{11}$ Guidelines for health economic evaluations are traditionally made for clinical interventions that aim at better curing disease in adults, and do not address how to handle the aspects that specifically pertain to health promotion and childhood interventions.

In Chapter 4, we reviewed the designs of economic evaluations on primary school-based lifestyle interventions and made suggestions for advancement. The results showed that economic evaluations differed on the selection of cost and outcomes, time horizon, valuation of outcomes, the extrapolation of outcomes, and consideration of effect decay over time. The majority of studies used the cost-effectiveness (CEA) or cost-utility (CUA) framework, which condensed the outcomes of school health promotion in weight-related outcomes or in quality-adjusted life years (QALYs) and did not explicitly capture outcomes in others and non-health outcomes (e.g. cognitive performances, bullying, community involvement, and satisfaction). Overall, these current studies may not optimally inform decision-making on school health promotion, because decision-makers outside the healthcare sector do not work with the CEA and CUA outcomes, and because the studies do not report on the changes in social, emotional, and educational outcomes. ${ }^{13}$ We advocate that economic evaluations should move towards a more societal and multi-outcome perspective that considers costs and outcomes beyond the healthcare sector and accounts for outcomes in children as well as in other persons. ${ }^{11,14,15}$

\section{What is the short- and long-term health-economic impact of the Healthy Primary School of the Future initiative?}

In 2015, a quasi-experimental study started, which examined the implementation and effects of the Healthy Primary School of the Future initiative. Two school environments were launched: 'the Healthy Primary School of the Future' (HPSF) and 'the Physical Activity School' (PAS). The quasi-experimental study followed children at HPSF (2 schools), PAS (2 schools), and control schools (4 schools). ${ }^{16}$ In this thesis, the short, medium, and longterm economic impacts of HPSF and PAS were researched. As such, we examined the case 
for investing in the continuation and dissemination of the Healthy Primary School of the Future initiative.

Chapter 5 details the cost structure of school-based lifestyle interventions and calculates the costs of delivering HPSF and PAS. A societal perspective was taken, which accounted for the time and material investments for all stakeholders. The net societal costs (for HPSF and PAS versus the regular school curriculum) reflected an 'opportunity cost' - the sum of all monetary and non-monetary investments that could not be used for another strategy. The societal costs were calculated for the first year of implementation and for a future hypothetical state in which learning effects and efficiency improvements had already occurred (steady state). The most expensive and recurrent costs were made for the provision of daily healthy lunches and a morning snack (HPSF: $€ 2.00$ per child per day in a steady state) and for the time investments of pedagogical employees from childcare organizations (€3.28 for HPSF and $€ 1.28$ for PAS per child per day). The delivery of HPSF also resulted in forgone household expenses for children's lunches and morning snacks ( $€ 1.86$ per child per day). In addition, the extension of the school day at HPSF was valued as a delivery-related cost-saving, because parents could spent this time on work or other activities (valued at $€ 3.51$ per child per day). Overall, this resulted in a net societal cost of $€ 2.68$ (HPSF) and $€ 3.16$ (PAS) per child per day for the first year of implementation and in a net cost of $€ 0.96$ (HPSF) and $€ 2.16$ (PAS) in a steady state. These results indicate that an ongoing societal investment is needed to deliver HPSF and PAS. An equitable and sustainable distribution of investments over schools, parents, the private sector, and the government is paramount to facilitate continued implementation of the interventions. Given the relatively high personnel cost, task shifting between professionals (teachers, teaching assistants, and pedagogical employees from childcare partners) may lower the cost of HPSF and PAS.

Chapter 6 looked at whether HPSF and PAS generated 'value for money' after two-years of intervention implementation. A social return on investment (SROI) analysis was undertaken to examine the outcomes of both interventions. ${ }^{17}$ Where possible, the SROI converts outcomes into monetary units to calculate a ratio of financial returns and investments. The effects of HPSF and PAS on health-related quality of life (HRQOL), healthcare consumption, and school absenteeism could be converted to euros with available standard cost prices and proxy values. As the changes in these outcomes were small (and not statistically significant), they did not outweigh the societal costs of HPSF and PAS (financial benefits minus investments; -€2.66 [HPSF] and -€3.03 [PAS] per child per day). Other outcomes could not be expressed in monetary units; HPSF and PAS contributed to healthy weight development and resulted in favourable changes in healthy eating and physical activity (HPSF). ${ }^{18,19}$ In addition to the changes in health, various non-health effects were observed. Children's social behaviours improved, an increase in community engagement was observed, and 
children and parents reported to be satisfied with the changes. The impact on educational performances was not yet measured. Overall, the results indicate that under the prerequisite of generating financial returns, HPSF and PAS were not cost-effective after two years of intervention. Under the prerequisite that school health promotion strategies should be effective in promoting physical and social health, particularly HPSF may represent value for money, but this depends on the value that decision-makers attach to these outcomes.

Guidelines for economic evaluations recommend including all relevant differences in cost and outcomes between the intervention and the comparator strategy. The health outcomes and cost savings of school health promotion extend into adolescence and adulthood due to the increased risk of overweight on chronic disease. Modelling techniques are used to make predictions on the avoided cases of chronic disease, healthcare costs, and quality of life. When modelling these long-run intervention impacts, assumptions have to be made on the maintenance of the intervention effect over time.

Chapter 7 focused on modelling plausible BMI trajectories up to early adulthood (20 years of age) after exposure to primary school-based lifestyle interventions. Empirical data on BMI was combined with elicitation of expert views on trends in effect maintenance. Firstly, BMI data from the quasi-experimental study was used to model BMI development for children at control schools up to 20 years of age. In a reference scenario, the BMI trajectories for HPSF and PAS were simulated by lowering the entire BMI trajectory with the observed two-year relative effects of HPSF and PAS. 18 Secondly, experts' views on the effect maintenance after the observed two-year period were elicited in a qualitative and quantitative manner. This led to the identification of three alternative effect maintenance scenarios. In the first scenario, effects would likely be fully maintained during the primary school period and then decay due to the influences of an uncontrolled environment (the physical, social and cultural circumstances at secondary schools, sport clubs, home etc.). The second scenario was that effects could be maintained or even increase with continued intervention exposure if behaviour changes are adopted by the household. Effects would likely decay after the primary school period. The last scenario included favourable effects during and after the primary school period, because parental involvement and behaviour changes in the household could lead to sustained effects. The relative effects at 20 years of age for HPSF ranged from $-0.21 \mathrm{~kg} / \mathrm{m}^{2}$ in the reference scenario to $-0.04 \mathrm{~kg} / \mathrm{m}^{2}$ to $-0.50 \mathrm{~kg} / \mathrm{m}^{2}$ under the alternative scenarios. The relative effects of PAS versus control schools ranged from $0.17 \mathrm{~kg} / \mathrm{m}^{2}$ in the reference scenario to $-0.04 \mathrm{~kg} / \mathrm{m}^{2}$ and $-0.21 \mathrm{~kg} / \mathrm{m}^{2}$ in the alternative scenarios. Intensive parental involvement and intervention continuation were perceived as key mechanisms in generating sustained effects and enhancing future impacts. The study showed that a mixed-methods approach is useful for specifying the uncertainty on the effect 
maintenance of primary school-based lifestyle interventions. The results can be used to inform decision-making by providing insights on knowledge gaps in effect maintenance (qualitative results), and by providing the quantitative inputs for estimating the long-term health and cost impacts.

Chapter 8 modelled the lifetime cost-effectiveness and equity impacts of HPSF and PAS. The costs and outcomes of HPSF and PAS were compared to the regular school curriculum. Firstly, a childhood model was built (up to 20 years of age) to project the changes in overweight and obesity prevalence rates, QALYs, healthcare costs, and school absenteeism costs. Secondly, an adult population health model (RIVM Chronic Disease Model) was used to project the changes in chronic disease, QALYs, healthcare costs, and productivity costs over the remaining lifespan. For the main analysis it was assumed that the observed 2-year effects were maintained (constant relative effects). Additional scenario analyses examined the impact of alternative assumptions pertaining to effect maintenance. A constant- and decreasing effect maintenance scenario assumed effect decay after the primary school period until 20 years of age. An increasing-and decreasing scenario and a increasing effect maintenance scenario assumed that continued exposure with parental involvement would lead to more favourable effects during primary school period and effect decay or maintained effects after the primary school period. Subgroup analyses were performed to assess the impacts on QALYs and cost-effectiveness for different socioeconomic groups. From a healthcare perspective, the costs of HPSF and PAS per QALY gained exceeded the Dutch threshold value for prevention of $€ 20,000$ / QALY gained. (PAS vs. control: $€ 58,698$, HPSF vs. PAS: €248,206 / QALY gained). When additionally including productivity costs (societal perspective), the extra costs per QALY gained for HPSF remained below the Dutch threshold (HPSF vs. control schools: €19,734 / QALY gained; 50\% probability of being cost-effective, HPSF led to lower costs and more QALYs in comparison with PAS). Based on the intervention effects per SES group, HPSF and PAS resulted in beneficial equity impacts (more QALY gains for the low versus the high socioeconomic group). The win-win situation for HPSF, beneficial cost-effectiveness and equity impact, will, however, only be realised under the condition that effects are maintained into young adulthood among all SES groups (constant relative effects and increasing effects scenario).

\section{Implications and recommendations for research, policy, and practice}

The implications and recommendations that follow from the study findings are centred around the following themes: developing actions to address health inequity, measuring 
health outcomes, examining the perspectives on the value of school health promotion, and investing in school health promotion under uncertainty.

\section{Addressing health inequity}

Chapter 2 showed that health-related outcomes in children were disproportionally distributed over socioeconomic groups, disadvantaging children with a lower socioeconomic background. Although school-based interventions may be generally effective in improving health behaviours, the analysis suggested that childhood health inequalities cannot easily be tackled by promoting healthy behaviours. I perceive that broader actions are needed to diminish the presence of child health inequities for the next generation. The reason for this is that children's health is not solely determined by physical activity and dietary behaviour, but is also influenced by other conditions, such as family structure, parental mental health, and family unemployment and debts. ${ }^{20}$ These behavioural, material, social-environmental, and psychosocial factors are also known as the social determinants of health. ${ }^{21,22}$ Broad actions targeting the interplay between social health determinants are also known as health-in-all policies because they stretch out over several policy domains, including education, housing, employment, and welfare. ${ }^{21,23}$ Without such multisectoral policies, I am afraid that child health inequalities will stay prevalent for years. The need for a multisectoral approach evokes challenges for policy and practice on, for example, arranging collaborations and balancing efforts and investments over policy areas. ${ }^{24}$ The focus on multisectoral policies also leads to new research questions: what set of determinants should be addressed in childhood, what is the relative value of combining interventions and addressing multiple determinants, and what research designs are most appropriate for evaluating the credentials of multisectoral policies?

Chapter $\mathbf{8}$ showed that implementation of school-based lifestyle interventions can lead to a trade-off between health equity and (cost-)effectiveness. Interventions may be (cost-) effective for the whole group, but can widen inequalities or vice versa. This trade-off was particularly present if intervention effects could be maintained among children with a high socioeconomic background, but not among children from lower socioeconomic households.

\section{Recommendations}

- Further research should focus on the development of health inequalities in childhood and adolescence and examine the key modifiable determinants. ${ }^{25}$ This should be investigated by adopting a life course perspective, which recognizes that a person's health is shaped by behavioural, material, and social-environmental factors at different critical moments in life. ${ }^{25}$ Ideally, this research should incorporate multiple generations, because health inequalities emerge early in life, and because it may take a long time before intervention effects settle in. ${ }^{8}$ 
- Implementation of health-in-all policies is challenging. Amongst others, it requires a shared vision, accountability, funding arrangements, and a balanced distribution of efforts. ${ }^{24,25}$ An evaluation framework could be helpful to create a shared understanding on determinants and indicators of health and health inequity, and could contribute to specifying the goals of policies. ${ }^{26,27}$ To make such a framework, evaluation frameworks for school-based lifestyle interventions could be extended with determinants and outcomes falling in different policy areas. ${ }^{28}$

- In addition to assessing overall cost-effectiveness, equity impacts can be analysed by performing subgroup analysis, examining the distribution of costs and effects over equity-relevant subgroups. Consequently, trade-offs can be specified by calculating the costs of fairer but less cost-effective strategies in terms of health forgone (expressed in QALYs). ${ }^{29}$ Additionally, the preferences for overall health (keeping people as healthy as possible), affordability of health care, and inequity (supporting vulnerable people) could be specified at the national level. This could aid in weighting cost-effectiveness and equity, and in making and substantiating implementation strategies. ${ }^{30}$

- To enhance future impacts and promote health equity, it is warranted to focus on parental involvement in all households, and in low socioeconomic households particularly.

\section{Measuring health outcomes associated with school health promotion}

$B M I$ is frequently used for examining the health impact of school-based lifestyle interventions because it is non-invasive, easy to measure, and inexpensive. A disadvantage is that BMI does not discriminate between harmful fat mass and lean mass and is therefore not very sensitive in measuring children's metabolic health. ${ }^{31,32}$ This is supported by the findings of Chapter 3. In this study, it was shown that school health promotion could have favourable effects on blood pressure levels, which may accrue independently of the effects on BMI. Longitudinal measurement of weight-related outcomes together with metabolic parameters would aid in our understanding of whether interventions can prevent unhealthy behaviours and the related harm for children's health. To improve evaluation in practice, we should strive to balance the quality and comprehensiveness of outcome measures on the one hand with feasibility considerations, invasiveness, and resource constraints on the other hand.

\section{Recommendations}

- To move towards cardiovascular prevention, the American Heart Association introduced the concept of ideal cardiovascular health. Ideal cardiovascular health in adults is based on seven components: smoking, BMI, physical activity, diet, blood pressure, total cholesterol, and glucose. The concept of ideal cardiovascular health has 
also been examined in children, which showed that poor cardiovascular health is already prevalent at young ages and is predictive of cardiovascular health in preadolescence. ${ }^{33-35}$ To adopt a comprehensive view on the health impact of school health promotion, I advocate to examine changes in behavioural, weight-related (anthropometric), and metabolic outcomes. Further research should focus on the feasibility and measurement burden of combining these outcome measures. Careful consideration should be given to the invasiveness and the measurement burden for healthy children. To this regard, I suggest to prioritize the measurement of blood pressure levels for evaluating the metabolic effects of school health promotion programs.

- There is an ongoing debate on which weight-related outcome discriminates best between healthy children and children with an elevated cardio-metabolic risk. ${ }^{36}$ Although waist circumference and waist-to-height ratio may be better indicators of children's abdominal fat mass than $\mathrm{BMI}^{31}$ the impacts on $\mathrm{BMI}$ can be used for comparison between interventions and can serve as an input for modelling medium and long-term impacts. Until more evidence becomes available, I advise to combine BMI with other anthropometric measurements such as waist circumference or waist to height ratio.

\section{Perspective on the value of school health promotion}

Economic evaluations aim to assess the relative value of interventions by synthesizing information on costs and outcomes. Various countries have recommended to express costeffectiveness of health interventions as a ratio of differences in costs and differences in QALYs (one QALY representing one year lived in full health). ${ }^{37}$ Multiple health decisionbodies nowadays work with this measure and have defined a threshold value: a critical value for the cost per QALY gain up to which an intervention is considered acceptable. The cost per QALY outcome promotes a standard cost-effectiveness assessment, facilitates comparisons across interventions, and makes cost-effectiveness appraisals explicit. A disadvantage is that the cost per QALY outcomes does not include all costs and outcomes pertaining to school-based lifestyle interventions. To be able to include different costs and outcomes, alternative frameworks have been used in employed economic evaluations on school-based lifestyle interventions (Chapter 4). The resulting heterogeneity in included costs and outcomes, and cost-effectiveness outcomes implies that several operationalisations exist regarding the cost-effectiveness of primary school-based lifestyle interventions. Or, as Then et al. (2017) put it: "the glasses used for analysis can have different strengths, coloured lenses, and designs. Concrete decisions when identifying, measuring, and monetising impacts specify the picture within the framework" ${ }^{38}$ 
The heterogeneity (Chapter 4) hinders decision-makers in examining the relative value of a specific intervention over another strategy. To solve this problem, it has been suggested to express outcomes into monetary terms and compare the costs with the total 'financial' value of the outcomes as an aggregated measure of cost-effectiveness. ${ }^{1,39}$ Chapter 6 showed that assessing short-term cost-effectiveness in this way is particularly difficult as most outcomes are intermediate measures and qualitative outcomes, which cannot be easily converted to monetary terms. Currently, there are no guidelines on how to value nonmonetary outcomes. Discrete choice experiments and contingent valuation studies (willingness-to-pay studies) have been carried out to value various outcomes, ${ }^{40,41}$ but designing such studies is challenging because the valuation is dependent on how you ask it and whom you ask (e.g. the general public, decision-makers, or the target group). Standardization on the inclusion, measurement, and valuation of cost and outcomes could enhance the usefulness of economic evidence in decision-making processes. It is, however, a misconception that a complete standardized evaluation framework would be most optimal.

Decisions on the implementation and investments in school health promotion are made by multiple groups (teachers and school boards, parents, (semi)-governmental parties, private and non-private partners et cetera). These decision-makers have different backgrounds and remits. As a result, there can be numerous perspectives on the value of school health promotion programs. For instance, some decision-makers may prioritize effects on children's physical health, while others may give more weight to social behaviours or educational outcomes. $^{42,43}$ It is therefore difficult to aggregate valuations made by multiple decisionmakers into one overall cost-effectiveness outcome and assessment. Instead of fully unifying cost-effectiveness assessments to support decision-making, I advise to tailor (economic) evidence to the preferences and needs of decision-makers. Without tailoring, economic evidence is not fully usable for decision-making, because the provided information does not align with someone's preferences and information needs. ${ }^{44}$

To be able to tailor information it should be clear what decision-criteria are important for school-based lifestyle interventions. This is not always the case because decision-making is also determined by governance principles such as the co-production of policy, shortcuts (e.g. emotional shortcuts), and bounded rationality (e.g. the tendency to base decisions on our familiarity with information). By means of tailored (economic) evidence, it becomes easier to interpret information and to use information in appraising the value of school-based lifestyle interventions. A better understanding of the heterogeneity in decision-criteria between people can also facilitate dialogue between decision-makers and aid in gaining support for an intervention. 


\section{Recommendations}

- Economic evaluations should present information on the short, medium, and long-term benefits of school health promotion. Information on long-term benefits provides information on the full merits of an intervention, while information on short-term benefits can inform stakeholders on the investments that they have to make and the immediate or near outcomes for them.

- Research could examine methods for valuing social and educational outcomes. Some advancements in this area are made as child-specific quality of life and wellbeing instruments and valuation methods are developed. Another method for valuing outcomes that can be further examined is the wellbeing valuation approach. With this method, the impact of certain outcomes on wellbeing is measured as well as the impact of income on wellbeing. As such, the change in outcomes can be linked to required changes in income. ${ }^{45} 46$ It is, however, not clear whether this approach can adequately account for children's preferences.

- Transparent reporting on the measurement and valuation of costs and outcomes is paramount. ${ }^{41,47,48}$ This information is important to assess whether cost-effectiveness results can be compared. For example, it is important to be careful with benchmarking cost-effectiveness results when there is a lot of variation in the employed methods for valuing outcomes. Guidelines for conducting and reporting on outcome valuation could focus on what is valued, how the valuation procedure is performed laccounting for biases such as limited cognitive abilities), and who values outcomes (general public or specific decision-maker groups). ${ }^{41}$ Stated preference research on how parents value caregiver time could contribute to valuing time in economic evaluations on school health promotion.

- Several authors have suggested to develop a core outcome set to promote standardization of economic evaluations on school-based lifestyle interventions. ${ }^{14,49} \mathrm{~A}$ core outcome set typically details an agreed set of outcomes that should be minimally measured and reported. To advance the evaluation on school-based lifestyle interventions, a core outcome set could be extended with decision criteria beyond costeffectiveness (e.g. feasibility, acceptability, equity and sustainability), measurement indicators and instruments, and valuation methods. To promote the tailoring of information, core outcome sets could be combined with a 'heat map' in which different (groups of) decision-makers can indicate the importance of decision criteria, costs, and outcomes. As such, the designs of economic evaluations can be better aligned to the information needs of decision-makers.

- Additionally, multi-criteria decision analyses can be employed for identifying the criteria and outcomes and that are considered in appraisals on the value of school health 
promotion (e.g. affordability or physical health). This type of analysis can also provide insight on the relative importance of the criteria and outcomes. Discussions between decision-makers and evaluators on the pathways between investments, activities, and outcomes could also aid in detecting differences in value judgements. The findings can be used to define a set of criteria that should be minimally evaluated and for tailoring information to the needs of decision-makers (e.g. by aligning the presentation of information with the prioritization of decision-criteria).

- Further research on the intersection of research and policy-making could be carried out to examine how (modelled) health economic evidence can be communicated in a clear, concise, and applicable way. This is key, as limited experience, time, resources, and capacity are regularly mentioned as barriers for the uptake of evidence in decisionmaking.

\section{Investment on school health promotion under uncertainty}

Decisions on primary school-based lifestyle interventions are long-term plans; they aim to promote healthy behaviours and maximize health and wellbeing in the near and longer future. As such, it is inevitable that implementation and investment decisions have to be made before complete evidence on the impact is available. When deciding upon investments for school health promotion strategies, we thus anticipate on changes to occur. ${ }^{50}$ In order to assess whether an investment is affordable and offers value for money, it has to be clear what costs and benefits are relevant for the investment decision. Chapters 5 and 8 showed that these decisions, particularly with regards to the inclusion of productivity-related cost savings, lead to a substantial variation in the results. Whereas HPSF and PAS did not offer sufficient value for money when only including health impacts, this conclusion altered when additionally including productivity impacts.

Chapter 7 revealed that experts consider several trends on effect maintenance plausible. This implies that there is no single model for describing the expected medium and long-term impacts of primary school-based lifestyle interventions. People may prefer to ignore this type of uncertainty as communicating uncertainty may stand in the way of providing a clear message to decision-makers and because ignoring uncertainty will simplify choices. Moreover, decision-makers do not always have formal techniques in place to handle uncertainty in decision-making. ${ }^{51}$ This does not alter the fact that neglecting uncertainty can be risky and costly on the longer run. Ultimately, ignoring uncertainty on the long-term benefits of primary school-based lifestyle interventions is not a desirable way to go. Here lies a challenge for research and practice to find a common ground on how to address uncertainty. In this thesis, the uncertainty on the effect maintenance of school-based lifestyle interventions was condensed in scenarios (Chapter 7). It was shown that the cost- 
effectiveness of HPSF and PAS is highly dependent on the expected maintenance of the intervention effects (Chapter 8).

\section{Recommendations}

- Ongoing implementation and dissemination of HPSF shows that it is feasible to distribute investments for school health promotion over schools, governments, parents, and private partners. These results should be compared with other experiences in other regions to explore how investments can be distributed to promote the affordability of school health promotion, and accommodate a sustainable nationwide implementation of HPSF.

- To best inform decision-making it is recommended to assess the cost-effectiveness of school health promotion programs from at least both a healthcare and a societal perspective.

- The future impacts are uncertain, mainly due to the various possible trends in the effect maintenance. Follow-up measurements could be undertaken to assess the relative intervention effects over time, which would reduce the uncertainty around the estimated future benefits. Both premature and delayed decisions can result in economic loss and suboptimal health and wellbeing. ${ }^{52}$ It is therefore recommended to weigh the costs and benefits of acquiring more information. For example, value of information analysis could be employed to calculate the maximum accepted costs of acquiring further information.

- It should be recognized that effect maintenance will likely not occur without additional efforts. Intensive parental involvement and/or intervention continuation in secondary schools seem key to ensure that effects can be maintained among all children, irrespectively of their socioeconomic background. The feasibility, costs, and effects of these actions should be examined.

\section{Conclusion}

The overall aim of this dissertation was to evaluate the health-economic impact of primary school-based lifestyle interventions. The research showed that most employed economic evaluations on school health promotion have a restricted evaluative scope oriented at weight-related outcomes. A broader framework should include health outcomes (measured by behavioural, anthropometric, and metabolic outcomes), non-health outcomes, and intersectoral costs. It was found that particularly HPSF represents value for money on the long-term if the intervention effects can be sustained over time. To enhance the maintenance 
of the intervention effect, it is advised to strengthen parental involvement, conduct follow-up assessments in adolescence, and explore the possibility for intervention continuation in secondary school. To enhance future impacts and promote health equity, it is warranted to focus on parental involvement in all households, and in low socioeconomic households particularly.

Over the recent years, school health promotion strategies have transformed to comprehensive interventions aimed at effectively targeting unhealthy behaviours. To keep up with these developments, research should move forward: evaluations on school health promotion should broaden their scope and become aligned with the information needs of decision-makers. To unlock the full potential of school health promotion, research and practice should focus on generating sustained effects and embedding school health promotion in multisectoral policies for health and health equity. 


\section{References}

1. VTV. Leefstijl. Hoe (on)gezond leven we in de toekomst? 2018.

2. Naar een toekomstbestendig zorgstelsel. Brede maatschappelijke heroverweging. Inspectie der Rijksfinanciën; 2020.

3. Stenholm S, Head J, Aalto V, Kivimäki M, Kawachi I, Zins M, et al. Body mass index as a predictor of healthy and disease-free life expectancy between ages 50 and 75: a multicohort study. International journal of obesity. 2017;41(5):769-75.

4. Nationaal Preventieakoord. Naar een gezonder Nederland. Ministerie van Volksgezondheid, Welzijn en Sport; 2018.

5. Halfon $N$, Hochstein M. Life course health development: an integrated framework for developing health, policy, and research. 2002;80(3):433.

6. Swinburn B, Gill T, Kumanyika S. Obesity prevention: a proposed framework for translating evidence into action. Obesity reviews. 2005;6(1):23-33.

7. Langford R, Bonell C, Jones H, Pouliou T, Murphy S, Waters E, et al. The World Health Organization's Health Promoting Schools framework: a Cochrane systematic review and meta-analysis. BMC public health. 2015;15:130.

8. Brousselle A, Lessard C. Economic evaluation to inform health care decision-making: Promise, piffalls and a proposal for an alternative path. Social Science \& Medicine. $2011 ; 72(6): 832-9$.

9. Magnee T, Burdorf A, Brug J, Kremers SP, Oenema A, van Assema P, et al. Equity-specific effects of 26 Dutch obesity-related lifestyle interventions. American journal of preventive medicine. 2013;44(6):e57-66.

10. Huter K, Dubas-Jakóbczyk K, Kocot E, Kissimova-Skarbek K, Rothgang H. Economic evaluation of health promotion interventions for older people: do applied economic studies meet the methodological challenges? Cost Effectiveness and Resource Allocation. 2018;16(1):14.

11. Weatherly H, Drummond M, Claxton K, Cookson R, Ferguson B, Godfrey C, et al. Methods for assessing the cost-effectiveness of public health interventions: key challenges and recommendations. Health policy. 2009;93(2-3):85-92.

12. Ungar WJ. Economic Evaluation in Child Health. Oxford University Press. 2010.

13. Canaway A, Frew E, Lancashire E, Pallan M, Hemming K, Adab P, et al. Economic evaluation of a childhood obesity prevention programme for children: Results from the WAVES cluster randomised controlled trial conducted in schools. PloS one. 2019;14(7):e0219500.

14. Döring N, Zethraeus N, Tynelius P, de Munter J, Sonntag D, Rasmussen F. Economic Evaluation of PRIMROSE-A Trial-Based Analysis of an Early Childhood Intervention to Prevent Obesity. Front Endocrinol. 2018;9:104.

15. Boyer N. Economic evaluation of population health interventions aimed at children and delivered at school. University of Glasgow; 2018.

16. Willeboordse M, Jansen MW, van den Heijkant SN, Simons A, Winkens B, de Groot RH, et al. The Healthy Primary School of the Future: study protocol of a quasi-experimental study. BMC Public Health. 2016;16:639.

17. the SROI Network. A guide to social return on investment. 2012. [Available from: http://www.socialvalueuk.org/app/uploads/2016/03/The\%20Guide\%20to\%20Social\%20Return\%20。 n\%20lnvestment\%202015.pdf]

18. Bartelink NHM, van Assema P, Kremers SPJ, Savelberg H, Oosterhoff M, Willeboordse M, et al. Can the Healthy Primary School of the Future offer perspective in the ongoing obesity epidemic in young children? A Dutch quasi-experimental study. BMJ Open. 2019;9(10):e030676.

19. Bartelink NHM, van Assema P, Kremers SPJ, Savelberg HHCM, Oosterhoff M, Willeboordse M, et al. Oneand Two-Year Effects of the Healthy Primary School of the Future on Children's Dietary and Physical Activity Behaviours: A Quasi-Experimental Study. Nutrients. 2019;11(3):689.

20. Victorino $\mathrm{CC}$, Gauthier $\mathrm{AH}$. The social determinants of child health: variations across health outcomes - $a$ population-based cross-sectional analysis. BMC pediatrics. 2009;9:53.

21. Marmot M, Allen JJ. Social determinants of health equity. American journal of public health. 2014;104 Suppl 4(Suppl 4):S517-S9. 
22. Satcher D. Include a social determinants of health approach to reduce health inequities. Public health reports (Washington, DC : 1974). 2010;125 Suppl 4(Suppl 4):6-7.

23. Stahl T. Health in All Policies: From rhetoric to implementation and evaluation - the Finnish experience. Scand J Public Health. 2018;46:38-46.

24. Storm I, den Hertog F, van Oers H, Schuit AJ. How to improve collaboration between the public health sector and other policy sectors to reduce health inequalities? - A study in sixteen municipalities in the Netherlands. Int J Equity Health. $2016 ; 15: 97$.

25. Guglielmin M, Muntaner $C, O^{\prime}$ Campo $P$, Shankardass $K$. A scoping review of the implementation of health in all policies at the local level. Health policy. 2018;122(3):284-92.

26. Van Vliet-Brown CE, Shahram S, Oelke ND. Health in All Policies utilization by municipal governments: scoping review. Health promotion international. 2018;33(4):713-22.

27. Bauman $A E$, King L, Nutbeam D. Rethinking the evaluation and measurement of Health in all policies. Health promotion international. 2014;29:i143-51.

28. Jones NL, Gilman SE, Cheng TL, Drury SS, Hill CV, Geronimus AT. Life Course Approaches to the Causes of Health Disparities. American journal of public health. 2019;109(S1):S48-S55.

29. Cookson R, Mirelman AJ, Griffin S, Asaria M, Dawkins B, Norheim OF, et al. Using Cost-Effectiveness Analysis to Address Health Equity Concerns. Value in Health. 2017;20(2):206-12.

30. Schoemaker CG, van Loon J, Achterberg PW, van den Berg M, Harbers MM, den Hertog FRJ, et al. The Public Health Status and Foresight report 2014: Four normative perspectives on a healthier Netherlands in 2040. Health policy. 2019;123(3):252-9.

31. Hetherington-Rauth M, Bea JW, Lee VR, Blew RM, Funk J, Lohman TG, et al. Comparison of direct measures of adiposity with indirect measures for assessing cardiometabolic risk factors in preadolescent girls. Nutrition journal. 2017;16(1):15.

32. de Hoog MLA, van Eijsden M, Stronks K, Gemke RJBJ, Vrijkotte TGM. Ethnic differences in cardiometabolic risk profile at age 5-6 years: the $A B C D$ study. PloS one. 2012;7(8):e43667.

33. $H e \mathrm{Q}$, Ding ZY, Fong DY, Karlberg J. Blood pressure is associated with body mass index in both normal and obese children. Hypertension. 2000;36(2):165-70.

34. Fyfe-Johnson AL, Ryder JR, Alonso A, MacLehose RF, Rudser KD, Fox CK, et al. Ideal Cardiovascular Health and Adiposity: Implications in Youth. J Am Heart Assoc. 2018;7(8):e007467.

35. Jaspers-Faijer H. Cardiovasculaire gezondheid op 5-6 jaar en cardiovasculaire vitkomsten in de preadolescentie. 2018.

36. Sardinha LB, Santos DA, Silva AM, Grøntved A, Andersen LB, Ekelund U. A Comparison between BMI, Waist Circumference, and Waist-To-Height Ratio for Identifying Cardio-Metabolic Risk in Children and Adolescents. PloS One. 2016;11(2):e0149351.

37. International Society for Health Economics and Outomes Research (ISPOR). Pharmacoeconomic guidelines around the world. n.d. [Available from: https://tools.ispor.org/peguidelines/].

38. Then V, Schober C, Rausher O, Kehl K. Introduction: What is an SROI analysis? How does it relate to other forms of analysis? Why is impact key? Social Return on Investment Analysis: Measuring the Impact of Social Investment. Springer International Publishing. 2017:1.

39. Russell LB, Sinha A. Strengthening Cost-Effectiveness Analysis for Public Health Policy. Am J Prev Med. 2016;50:S6-S12.

40. Alayli-Goebbels AF, Dellaert BG, Knox SA, Ament AJ, Lakerveld J, Bot SD, et al. Consumer preferences for health and nonhealth outcomes of health promotion: results from a discrete choice experiment. Value Health. $2013 ; 16(1): 114-23$.

41. Perry-Duxbury M, van Exel J, Brouwer W. How to value safety in economic evaluations in health care? A review of applications in different sectors. The European Journal of Health Economics. 2019;20(7):1041-61.

42. de Wit A. Economische evaluatie van gezondheidsbevordering- waar staan we nu? 2010.

43. Hamberg-van Reenen H, Bovendeur I, Meijer S, Savelkoul M, van den Berg M. Kosteneffectiviteit van lokaal gezondheidsbeleid. Bilthoven: Rijksinstituut voor Volksgezondheid en Milieu. 2010.

44. Schoemaker C, Proper K, Hamberg H, van Dale D, Baan C, Leurs M, et al. Evidence-based medicine en de integrale gezonde wijkaanpak. Tijdschrift voor gezondheidswetenschappen. 2013;91 (4):199-202. 
45. Fujiwara D, Keohane K, Clayton V, Maxwell C. Measuring social impact. The technical reference paper.: Australian Social Value Bank; n.d. [Available from: https://asvb-media.s3.amazonaws.com/uploads/ 2017/08/20170801-ASVB-Technical-Reference-Paper.pdf].

46. Fujiwara D, Campbell R. Valuation techniques for social cost-benefit analysis. 2011.

47. Payne K, McAllister M, Davies LM. Valuing the economic benefits of complex interventions: when maximising health is not sufficient. Health Econ. 2013;22(3):258-71.

48. Perkins C, Stenbach R, Tompson L. Cost-benefit analysis: methodological challenges of evaluating large-scale public health interventions and a worked example of the costs and benefits of part-night lighting. 2015. In: What is the effect of reduced street lighting on crime and road traffic injuries at night? A mixed-methods study [Internet]. Southhampton (UK). [Available from: https://www.ncbi.nlm.nih.gov/books/NBK3 16508/].

49. Zanganeh M, Adab P, Li B, Frew E. A Systematic Review of Methods, Study Quality, and Results of Economic Evaluation for Childhood and Adolescent Obesity Intervention. Int J Environ Res Public Health. 2019; 16(3).

50. Marchau V, Walker W, Bloemen P, Popper S. Decision Making under Deep Uncertainty. Springer; 2019.

51. Committee on Decision Making under Uncertainty. Uncertainty and decision making: lessons from other public health contexts. In: environmental decisions in the face of uncertainty. Washington: National Academies Press; 2013.

52. Ludwig DS, Brownell KD. Public Health Action Amid Scientific Uncertainty: The Case of Restaurant Calorie Labeling Regulations. Jama. 2009;302(4):434-5. 



\section{Addenda}

Summary 
Addenda 
More than half of the Dutch adulthood population is currently overweight or obese. Overweight leads to adverse consequences in terms of disease risk, reduced quality of life, and high costs. As such, it is key to prevent the occurrence of excess weight from early ages onwards. The school setting is an adequate place for overweight prevention as young children from various backgrounds can be reached. Support from teachers, parents, policymakers, and (non)-profit partners is crucial for the implementation of school-based lifestyle interventions. These stakeholders decide on whether they want to engage and invest in the implementation of a school-based health promotion strategy (so-called adoption decisions). Making such adoption decisions is challenging, because investments have to be made when little is known yet about the likely future benefits. Economic evaluations are directed towards informing these adoption decisions by assessing the costs and (societal) benefits of interventions.

The aim of this thesis is to research the health-economic impact of primary school-based lifestyle interventions. The studies focus on the impact of these interventions in general and on the value of the Healthy Primary School of the Future specifically. This thesis addresses three aims: 1) examining the short-term effects of school health promotion on children's health and wellbeing (Chapters 2 and 3), 2) identifying the employed methods of health-economic evaluations of school-based lifestyle interventions (Chapter 4), and 3) assessing the shortand long-term health-economic impact of the Healthy Primary School of the Future (Chapters 5, 6, 7, and 8).

Chapter 2 reports on the socioeconomic disparities in children's health-related outcomes. Two-year follow-up data of 1259 children on body mass index, healthcare consumption, school absenteeism, quality of life, and psychosocial health was analysed. Socioeconomic status was measured by parental education levels (maternal and paternal) and household income. Mixed model analyses were used to assess the associations between socioeconomic status and health outcomes over time. The results showed that children with a higher socioeconomic background had more favourable health-related outcomes as compared to peers with a lower socioeconomic status. The second objective was to assess whether these disparities can be reduced through changes in health behaviours. The socioeconomic health disparities in the study sample changed very little after adjusting for health behaviours (physical activity, fruit \& vegetable intake, consumption of sweetened beverages), which indicates that the socioeconomic health disparities in the study sample could not be explained by differences in children's health behaviours. Overall, the results suggest that, on the short-term, school-based lifestyle interventions are likely not sufficient for tackling the socioeconomic health disparities among children on the short-term. 
Chapter 3 describes the effects of school-based lifestyle interventions on children's body mass index (BMI) (weight corrected for height) and blood pressure levels. By means of a systematic review, we identified randomized controlled trials on school-based lifestyle interventions (for 4-12 year-olds) with longitudinal data on BMI and/or cardiovascular risk factors. The results of 85 randomised controlled trials were summarized by means of univariate and multivariate multilevel meta-analyses. Mixed effects models accounted for the dependencies of effect sizes within studies (e.g. for the effects for boys and girls, for different study arms, and for BMI and blood pressure). The changes in BMI, systolic, and diastolic blood pressure were expressed in standardized changes to allow for comparison between BMI and blood pressure. In the multivariate analysis, the standardized effects for blood pressure (systolic blood pressure: -0.182 [95\% confidence interval: -0.266 to -0.098 ], diastolic blood pressure: -0.144 [95\% confidence interval: -0.230 to -0.057 ]) were larger in comparison to the effects on BMI (-0.054 [95\% confidence interval: -0.131 to 0.022$]$ ). Based on this result, we concluded that school-based lifestyle interventions have favourable effects on children's blood pressure levels, which may be stronger and which can be accrued independently of the effects on BMI.

Chapter 4 summarizes the methods of cost-effectiveness studies on school-based lifestyle interventions for 4-12 year olds and advises on directions for advancement. A comparison of 23 studies revealed that studies differed considerably, particularly with regards to the included costs and outcomes, time horizon, valuation of outcomes, and the extrapolation of outcomes over time. Most studies used a cost-effectiveness (CEA) $(N=12)$ or cost-utility framework (CUA) (N=9), thereby expressing cost-effectiveness in the extra cost per weightrelated outcome or in the extra cost per quality-adjusted life year (QALY) gained. In addition, a social cost benefit framework $(\mathrm{N}=2)$ and a social return on investment (SROI) analysis $(\mathrm{N}=1)$ were used, of which only the latter included outcomes beyond health and outcomes in other persons than the child. As the information from the CEAs and CUAs did not include outcomes beyond health (social, emotional, and educational outcomes), these frameworks may not optimally inform decision-making on school-based lifestyle interventions. It should also be noted that decision-makers outside the healthcare sector may not work with the outcomes of CUAs and CEAs. To enhance the usefulness of economic evaluations on school-based lifestyle interventions in decision-making, we recommended to improve transparent reporting (e.g. on the chosen perspective and standard practices), move towards a multi-outcome framework (including multiple costs and outcomes within and beyond the healthcare sector), and improve standardization (e.g. minimally select BMI/BMI z-score in CEAs, use multiple effect decay rates). 
The following chapters focused on examining the health-economic impact of the 'Healthy Primary School of the Future' (HPSF) and the 'Physical Activity School' (PAS). HPSF and PAS aimed at improving children's health and health behaviours by offering lifestyle interventions via primary schools. As compared to the regular educational curriculum in Dutch primary schools, HPSF offered daily healthy lunches and morning snacks and implemented daily structured physical activity sessions (consisting of structured sports activities, free play, and creative activities). The school lunch and physical activity sessions were led by pedagogical employees from childcare partners. At HPSF, the lunch break was prolonged to about one hour, which led to an extension of the school day with approximately 30 minutes. PAS only implemented the daily structured physical activity sessions (no daily healthy lunch and no extended school day).

A quasi-experimental study was conducted to examine the effects of HPSF and PAS. From 2015 onwards, a total of 8 schools in the Parkstad region in the Southern Province of Limburg participated in the study. Two schools became HPSF, two schools adopted the changes of PAS, and four schools participated as control schools. Children and their parents/caregivers participated in data collection between 2015 and 2019 by means of annual child and parental questionnaires, measurement of children's height and weight, and by wearing accelerometers for measuring physical activity.

Chapter 5 describes the cost structure of primary school-based lifestyle interventions and calculated the costs of the HPSF and the PAS. Cost items of primary school-based lifestyle interventions were identified from published cost-effectiveness studies. To reflect the net societal opportunity costs - the total amount of resources that cannot be used for another strategy -, the recurrent actual payments (personnel and material costs), economic costs (time investments that were not billed), and delivery-related offsets (cost-savings related to the intervention delivery and not to the intervention outcomes) were listed. Cost items belonged to the education sector, household and leisure sector, labour and social security sector, and the healthcare sector. The net societal costs (for HPSF and PAS versus the regular educational curriculum) were calculated for the first year of implementation and for a future hypothetical steady state in which further learning effects will no longer occur. The majority of the costs consisted of the expenses for lunches and morning snacks ( $€ 2.00$ per child per day in a steady state) and for hiring pedagogical employees (€3.28 per child per day in a steady state). The cost-savings for HPSF consisted of the forgone household expenses for children's lunches and morning snacks (€1.86 per child per day) and the productivityrelated savings for parents as a consequence of the extended school day (€3.51 per child per day). The net societal costs amounted to $€ 2.68$ (HPSF) and $€ 3.16$ (PAS) per child per day for the first year of implementation and to $€ 0.96$ (HPSF) and $€ 2.16$ (PAS) in a steady state. An equitable distribution of investments over schools, parents, the private sector, and 
the government may foster ongoing intervention implementation. Given the high personnel costs, we also suggested that redistributing tasks between teachers, teaching assistants, and pedagogical employees could decrease the costs of the interventions.

Chapter 6 examines the societal value of HPSF and PAS after two years of implementation by conducting a social return on investment (SROI) analysis. The two-year investments (based on Chapter 5) and effects ( $N=1676$ children) of HPSF and PAS versus the regular educational curriculum were examined. The SROI analysis consisted of two parts: the SROI calculation and the SROI story. For the SROI calculation, outcomes were converted into monetary units $(€)$. The effects of HPSF and PAS on health-related quality of life (HRQOL), healthcare consumption, and school absenteeism could be converted to euros with available standard cost prices and proxy values. The financial value of these outcomes (financial benefits) did not exceed the net societal costs of HPSF and PAS (benefits minus investments: $€ 2.66$ [HPSF] and $-€ 3.03$ [PAS] per child per day). The second part of the analysis, the SROI story, included all outcomes that could not be converted into euros. The SROI story showed that HPSF and PAS had a favourable effect on children's dietary behaviour and physical activity and contributed to a healthy weight development. Additionally, children's social behaviour improved, community engagement increased, and children and parents/caregivers reported to be satisfied with the interventions. The effects on educational performances were not yet measured. Based on the results, we concluded that HPSF and PAS did not generate financial benefits after two years of implementation, and were not considered to be cost-effective. Based on the presumption that school-based lifestyle interventions should improve children's physical and social health, HPSF may particularly represent value for money, but this depends on the importance of these outcomes for decision-makers and the 'weight' that they give to these outcomes in the overall value assessment.

Chapter 7 describes children's BMI development after exposure to a primary school-based lifestyle intervention. In this mixed-methods study, we combined empirical data on children's $\mathrm{BMI}$ and expert judgement on future trends in effect maintenance. Firstly, BMI data from the quasi-experimental study ( $\mathrm{N}=1676)$ was used for modelling the BMI development for children at control schools up to 20 years of age, for boys and girls separately. Subsequently, the BMI development for children after exposure to HPSF and PAS was predicted using different scenarios. In a reference scenario, the entire BMI trajectories were lowered with the average observed two-year relative BMI-effect (HPSF and PAS versus control schools). Other scenarios were drafted by eliciting expert's views on effect maintenance trends after the observed two-year period. Expert opinions $(\mathrm{N}=11)$ were elicited by using qualitative (open questions, thematic content analysis) and quantitative 
techniques (eliciting probability distributions with the MATCH Uncertainty Elicitation Tool). This led to three alternative scenarios. Relative effects could remain constant during the entire primary school period and decay after the primary school period due to uncontrolled factors (physical, social, cultural factors) [1 - a constant exposure-effect and an uncontrolled environment with effect decay scenario]. Relative effects could also slight increase during the primary school period due to the uptake of behaviour changes by the household and decay after the primary school period [2 - a household multiplier and an uncontrolled environment with effect decay scenario]. Last, relative effects could be maintained or slightly increase during and after the primary school period due to behaviour changes in the household [3 a household multiplier and maintainer scenario]. The relative effects of HPSF versus control schools ranged from $-0.21 \mathrm{~kg} / \mathrm{m}^{2}$ in the reference scenario to $-0.04 \mathrm{~kg} / \mathrm{m}^{2}$ and $-0.50 \mathrm{~kg} / \mathrm{m}^{2}$ in the alternative scenarios. The relative effects of PAS versus control schools ranged from $-0.17 \mathrm{~kg} / \mathrm{m}^{2}$ in the reference scenario to $-0.04 \mathrm{~kg} / \mathrm{m}^{2}$ and $-0.21 \mathrm{~kg} / \mathrm{m}^{2}$ in the alternative scenarios. The mixed-methods approach proved useful for specifying the uncertainty on the effect maintenance of primary school-based lifestyle interventions. Further observations until young adulthood could reduce the uncertainty around the future potential benefits of these interventions.

Chapter 8 presents the lifetime cost-effectiveness and equity impacts of HPSF and PAS. The health-economic impact of HPSF and PAS was compared with the regular educational curriculum and calculated from a healthcare and societal perspective. In a childhood and adolescence model, calculating weight development until young adulthood (20 years), the effects of HPSF and PAS on BMI were translated to changes in weight status (normal weight, overweight, and obesity), QALYs, healthcare costs, and school absenteeism costs. Secondly, the RIVM Chronic Disease Model (RIVM-CDM) was used to project the impacts on chronic diseases, QALYs, healthcare costs, and productivity costs over the rest of the lifespan. For the main analysis it was assumed that the observed 2-year effects were maintained (constant relative effects). Additional scenario analyses examined the impact of alternative assumptions pertaining to effect maintenance. Subgroup analyses were performed to assess the impacts on QALYs and cost-effectiveness for different socioeconomic groups. From a healthcare perspective, the costs of HPSF and PAS / QALY gained exceeded the Dutch threshold value for prevention of $€ 20,000$. (PAS vs. control: $€ 58,698$, HPSF vs. PAS: €248,206 / QALY gained). When additionally including productivity costs (societal perspective), the extra costs / QALY gained for HPSF remained below the Dutch threshold (HPSF vs. control schools: $€ 19,734$ / QALY gained; 50\% probability of being cost-effective, HPSF led to lower costs and more QALYs in comparison with PAS). 
Based on the intervention effects per SES group, HPSF and PAS resulted in beneficial equity impacts (more QALY gains for the low versus the high socioeconomic group). The win-win situation for HPSF, beneficial cost-effectiveness and equity impact, will, however, only be realised under the optimistic condition that effects are maintained into young adulthood among all SES groups.

Chapter 9 summarizes the study findings and reflects on the implications for research, policy, and practice. Firstly, the research in this thesis showed that school health promotion has a favourable short-term health impact. Although interventions can generally induce favourable health outcomes, additional multisectoral actions are warranted to effectively target the multiple determinants that underlie to the persisting socioeconomic disparities in child health. Secondly, the research showed that most employed health-economic evaluations did not include outcomes beyond health (e.g. social, emotional, educational outcomes). Further research should include outcomes beyond health and tailor information to the needs of decision-makers. To do so, a core outcome set could be developed including outcomes beyond health and criteria beyond cost-effectiveness. This core outcome set could also be extended with a 'heat map' highlighting the importance of outcomes and criteria for decision-makers. Thirdly, the cost-effectiveness of HPSF and PAS was examined. Although HPSF and PAS did not generate short-term financial returns, particularly HPSF may represent 'value for money' given the favourable impact on physical and social outcomes. Given a societal perspective, HPSF is also considered to be a cost-effective and equitable strategy on the long-term, but only if effects can be maintained over time in all SES groups. Follow-up assessments after the primary school period could be performed to monitor effect maintenance and the value of additional actions, such as intensive parental involvement and intervention continuation in secondary schools, could be explored. 
Samenvatting 
Addenda 
Meer dan de helft van de Nederlanders leidt aan overgewicht. Dit heeft negatieve gevolgen voor de gezondheid en kwaliteit van leven en leidt tot hoge kosten. Voor een goede preventie van overgewicht is het belangrijk om op jonge leeftijd te beginnen. Basisscholen zijn hiervoor een goede plek omdat jonge kinderen van verschillende achtergronden bereikt worden. Voor een succesvolle implementatie van leefstijlinterventies is betrokkenheid nodig van leerkrachten, ouders, gemeente en/of landelijke overheid en private partijen zoals de kinderopvang en cateraars. Al deze partijen besluiten of zij willen deelnemen en investeren in de implementatie van een school gebaseerde leefstijlinterventie (een zogeheten adoptie bes/vif). Het nemen van een adoptiebesluit kan lastig zijn. Een belangrijke oorzaak hiervoor is dat er vaak weinig informatie is over de verwachte opbrengsten van school gebaseerde leefstijlinterventies op het moment dat de investeringen gemaakt moeten worden. Economische evaluaties geven inzicht in de kosten en (maatschappelijke) baten van interventies en kunnen gebruikt worden voor besluitvorming.

Het doel van dit proefschrift is om inzicht te krijgen in de gezondheids-economische impact van leefstijlinterventies voor het basisonderwijs. De onderzoeken richten zich op de gezondheids-economische impact van leefstijlinterventies voor basisscholen in het algemeen en op de impact van de Gezonde Basisschool van de Toekomst in het bijzonder. Dit proefschrift heeft drie doelstellingen: 1) onderzoeken in welke mate gezondheidsbevordering op de basisschool kan bijdragen aan de gezondheid en welzijn van kinderen (Hoofdstuk 2 en 3), 2) identificeren van de methoden die worden gehanteerd bij het evalueren van de kosteneffectiviteit van leefstijlinterventies voor het onderwijs (Hoofdstuk 4), en 3) in kaart brengen van de gezondheids-economische impact van de Gezonde Basisschool van de Toekomst op de korte en lange termijn (Hoofdstuk 5, 6, 7 en 8).

Hoofdstuk 2 presenteert de sociaaleconomische verschillen in de gezondheid van kinderen. Voor dit onderzoek analyseerden we longitudinale gegevens (kinderen werden twee jaar lang gevolgd) van 1259 kinderen over gewicht (body mass index, BMI), zorggebruik, schoolverzuim, kwaliteit van leven en psychosociale gezondheid. Sociaaleconomische status was gemeten aan de hand van het opleidingsniveau van de ouders en het gezinsinkomen. We onderzochten de verbanden tussen sociaaleconomische status en vitkomsten over de tijd. De resultaten laten zien dat kinderen met een hogere sociaaleconomische achtergrond gunstigere gezondheidsuitkomsten hebben in vergelijking met leeftijdsgenoten met een lagere sociaaleconomische achtergrond. Het tweede doel van deze studie was om te onderzoeken om deze verschillen verkleind kon worden door veranderingen in gezondheidsgedrag. De associaties tussen sociaaleconomische status en gezondheid veranderden bijna niet wanneer we rekening hielden met het gezondheidsgedrag (fysieke activiteit, fruit \& groente inname, inname van zoete dranken) van kinderen. 
Dit suggereert dat leefstijlinterventies op korte termijn niet alle sociaaleconomische verschillen in de gezondheid van kinderen kunnen wegnemen.

Hoofdstuk 3 beschrijft het effect van leefstijlinterventies in het onderwijs op de body mass index (gewicht gecorrigeerd voor lichaamslengte) en bloeddruk van kinderen. We hebben een systematisch literatuuronderzoek uitgevoerd naar gerandomiseerde studies over leeftijlinterventies in het onderwijs (voor 4-12 jarigen) met longitudinale gegevens over BMI en/of cardiovasculaire risicofactoren. De gegevens van 85 gerandomiseerde studies zijn vervolgens geanalyseerd met univariate en multivariate multilevel meta-analyses. Met behulp van de multilevel methode werd gecorrigeerd voor de afhankelijkheid van effectgroottes binnen een studie (bijvoorbeeld voor de effecten voor jongens en meisjes, voor verschillende studiearmen, voor BMI en bloeddruk etc.). In de multivariate analyse werden veranderingen in $\mathrm{BMI}$, systolische bloeddruk en diastolische bloeddruk gestandaardiseerd waardoor de veranderingen met elkaar vergeleken konden worden. De effecten op bloeddruk (systolische bloeddruk: -0.182 [95\% betrouwbaarheidsinterval: -0.266 tot -0.098] en diastolische bloeddruk: -0.144 [95\% betrouwbaarheidsinterval: -0.230 tot -0.057 ]) waren groter in de multivariate analyse in vergelijking met de veranderingen in BMI (-0.054 [95\% betrouwbaarheidsinterval: -0.131 tot 0.022 ]). Hieruit concludeerden wij dat leefstijlinterventies voor het basisonderwijs een gunstig effect kunnen hebben op de bloeddruk van kinderen en dat deze (gedeeltelijk) onafhankelijk kunnen zijn van de effecten op BMI.

Hoofdstuk 4 gaat in op de methoden die gebruikt worden bij kosteneffectiviteitsonderzoek naar leefstijlinterventies voor het onderwijs. We vergeleken de methoden van 23 studies en vonden verschillen in de aanpak van studies. Er waren met name veel verschillen in de typen kosten en uitkomsten die meegenomen worden in het onderzoek, de tijdshorizon, de waardering van uitkomsten en in de extrapolatie (het voorspellen) van vitkomsten over de tiid. De meeste studies hanteerden een kosteneffectiviteit (KEA) ( $N=12)$ of kosten-utiliteit (KUA) ( $N=9$ ) raamwerk. In zulke studies wordt kosteneffectiviteit bijvoorbeeld uitgedrukt in de ratio van kosten en $\mathrm{BMI}$-effecten of in de extra kosten per toegenomen gezond levensjaar (quality adjusted life year, QALY). De maatschappelijke kosten-baten analyse $(\mathrm{N}=2)$ en de social return on investment methode (SROI) ( $N=1)$ werden ook gebruikt. Uitkomsten buiten gezondheid en uitkomsten in andere personen dan het kind werden alleen meegenomen in de SROI analyse. Hoofdstuk 4 bevat ook aanbevelingen voor toekomstige economische evaluaties. Om de bruikbaarheid van toekomstige evaluaties te vergroten deden we de volgende aanbevelingen: op een transparante manier rapporteren (bijv. ten aanzien van het perspectief en de vergelijkingen), kosten en uitkomsten buiten gezondheid 
includeren en standaardisatie vergroten (bijv. ten minste BMI/BMI z-score gebruiken in KEA's, meerdere schattingen gebruiken voor het effectbehoud).

De volgende hoofdstukken richten zich op het evalueren van de gezondheids-economische impact van de 'Gezonde Basisschool van de Toekomst' (volledige interventiescholen) en de 'Beweegschool'

(gedeeltelijke interventiescholen). Beide interventies hadden als doel om het gezondheidsgedrag en de gezondheid van kinderen op de basisschool te verbeteren. De gedeeltelijke interventiescholen (beweegscholen) verschilden van het reguliere schoolprogramma door het invoeren van een dagelijks gestructureerd beweegaanbod. De volledige interventiescholen (gezonde basisschool van de toekomst) verzorgden daarnaast ook een dagelijks gezonde lunch. De schoollunch en het beweegaanbod (bestaande vit sport, vrij spel en culturele activiteiten) werden geleid door pedagogisch medewerkers van de kinderopvang. Op de volledige interventiescholen werd de lunchpauze opgerekt en eindigde de schooldag ongeveer een half uur later.

Een quasi-experimentele studie is uitgevoerd om de effecten van beide schooltypen te onderzoeken. Vanaf 2015 deden 8 scholen uit Parkstad van de onderwijsstichting Movare (Zuid-Limburg) mee aan het onderzoek. Twee volledige interventiescholen, twee scholen gedeeltelijke interventiescholen en vier controlescholen werden gevolgd. Kinderen en hun ouders/verzorgers werden uitgenodigd om mee te doen aan de verzameling van gegevens (van 2015-2019) via kind- en oudervragenlijsten, metingen van gewicht en lengte en metingen met behulp van beweegmeters.

Hoofdstuk 5 zet de kostenstructuur van leefstijlinterventies in het onderwijs uiteen en berekent de vitvoeringskosten van de volledige interventieschool en de gedeeltelijke interventieschool. De kostenonderdelen uit gepubliceerde economische evaluaties werden samengevat. Kostenonderdelen behoorden tot de directe vitgaven (kosten voor personeel en materiaal), indirecte kosten (tijdsinvesteringen die niet zijn gefactureerd) of tot implementatie-gerelateerde besparingen (gerelateerd aan de vitvoering en niet aan de effecten van een interventie). Gezamenlijk weerspiegelen ze de netto maatschappelijke opportuniteitskosten - alle middelen die niet kunnen worden aangewend voor een andere interventie. Kosten komen terecht bij de onderwijssector, het huishouden en vrije tijds-sector, de arbeids- en overheidssector en de gezondheidszorg sector. De maatschappelijke kosten werden berekend voor het eerste jaar van vitvoering en werden geschat voor een toekomstige fase waarbij de implementatie volledig bestendigd is. Het merendeel van de kosten bestond uit de uitgaven voor de lunch en een tussendoortje $(€ 2,00$ per kind per dag voor de volledige interventieschool in de bestendigde fase) en het inhuren van pedagogisch medewerkers $(€ 3,28$ per kind per dag voor de volledige interventieschool in de 
bestendigde fase). Bij de volledige interventieschool traden ook directe besparingen op. De aangeboden schoollunch leidde tot een huishoudelijke besparing (€1,86 per kind per dag). De verlengde schooldag op de volledige interventieschool werd ook meegenomen als een besparing omdat ouders/verzorgers deze tijd kunnen besteden aan werk (€3,51 per kind per dag). De netto maatschappelijke kosten waren $€ 2.68$ (volledige interventieschool) en $€ 3.16$ (gedeeltelijke interventieschool) per kind per dag voor het eerste jaar en $€ 0.96$ (volledige interventieschool) en $€ 2.16$ (gedeeltelijke interventieschool) in de bestendigde fase. Deze resultaten laten zien dat een rechtvaardige verdeling van de kosten over scholen, ouders/verzorgers, de private sector en de overheid essentieel is om de interventies te kunnen continueren. Ook concludeerden we dat de personele kosten hoog waren en een herverdeling van taken tussen leerkrachten, onderwijsassistenten en pedagogisch medewerkers mogelijk kan leiden tot lagere interventiekosten.

Hoofdstuk 6 beschrijft de maatschappelijke meerwaarde van de volledige en gedeeltelijke interventieschool na een tweejarige implementatieperiode. Hiervoor gebruikten we de social return on investment methode (SROI) (in Nederlands: het maatschappelijk rendement van een investering). De investeringen (gebaseerd op Hoofdstuk 5) en de uitkomsten ( $N=1676$ kinderen) voor de interventiescholen versus controle scholen werden bestudeerd. De SROI analyse bestond vit twee delen: de berekening van het maatschappelijk rendement en de (verhalende) omschrijving van het maatschappelijk rendement. Voor de berekening werden vitkomsten vitgedrukt in euro's. Wii drukten de effecten van de interventiescholen op gezondheids-gerelateerde kwaliteit van leven, zorggebruik en schoolverzuim uit in euro's. Hiervoor gebruikten we standaard kostprijzen en gepubliceerde schaduwprijzen. De financiële waarde van de korte-termijn uitkomsten woog niet op tegen de maatschappelijke vitvoeringskosten (baten minus kosten; -€2.66 [volledige interventieschool] en -€3.03 [gedeeltelijke interventieschool] per kind per dag). Uit de omschrijving van het maatschappelijk rendement kwam naar voren dat de interventies een gunstig effect hadden op het eetgedrag, de fysieke activiteit en het BMI van kinderen. Daarnaast werd een verbetering in sociaal gedrag en meer betrokkenheid vanuit de omgeving van de school waargenomen. Ook rapporteerden ouders en kinderen tevreden te zijn over de interventies. De effecten op leerprestaties waren nog niet gemeten. Op basis van de bevindingen stelden we dat de interventies na twee jaar van uitvoering niet hebben geleid tot kostenbesparingen. Echter, de volledige interventieschool kan wel een investering zijn die loont vanwege de (niet-monetaire) vitkomsten op fysieke en sociale gezondheid, maar dit hangt af van het 'gewicht' (belang) dat gegeven wordt aan deze vitkomsten in de besluitvorming.

Hoofdstuk 7 omschrifft het verloop van BMI bij kinderen na blootstelling aan een leefstijlinterventie op de basisschool. Voor deze mixed-methods studie combineerden we 
gegevens uit onze quasi-experimentele studie met expertoordelen over de trends in effectbehoud. Allereerst modelleerden we het beloop van BMI voor kinderen op controle scholen tot op 20-jarige leeftijd op basis van gegevens van de lengte en gewicht van kinderen uit onze quasi-experimentele studie (voor jongens en meisjes apart). Vervolgens voorspelden we het BMI-traject voor kinderen van een volledige interventieschool en de gedeeltelijke interventieschool. We hielden rekening met verschillende scenario's. In het basis scenario (referentiescenario) verlaagden we het gehele BMI traject door de geanalyseerde tweejaars-effecten van de interventies toe te passen. Alternatieve scenario's werden gemaakt op basis van de antwoorden van experts over de trends in effectbehoud na de geobserveerde periode. Expert opinie $(\mathrm{N}=11)$ werd verkregen door kwalitatieve en kwantitatieve vragen te stellen (kansverdelingen werden vitgevraagd met de MATCH Uncertainty Elicitation Tool). Hieruit kwamen drie scenario's. Relatieve effecten konden mogelijk gelijk blijven tijdens de basisschoolperiode en afzwakken na de basisschool periode door invloeden vanuit de omgeving van kinderen (zoals fysieke, sociale en culturele factoren tijdens de middelbare schoolperiode) [scenario 1 - constante blootstelling-effect en verwatering van effecten door een ongecontroleerde omgeving]. In het tweede scenario konden relatieve effecten tijdens de bassischool periode behouden worden of zelfs toenemen door het overnemen van gedragsveranderingen door het huishouden. Effecten zouden vervolgens afzwakken tijdens de middelbare schoolperiode [scenario 2 versterking door het huishouden en verwatering van effecten door een ongecontroleerde omgeving]. In het derde scenario zouden relatieve effecten behouden blijven of een klein beetje toenemen door gedragsveranderingen in het huishouden tijdens en na de basisschoolperiode [scenario 3 - versterking en behoud door het huishouden]. De relatieve effecten voor de volledige interventieschool versus controle scholen varieerden van -0.21 $\mathrm{kg} / \mathrm{m}^{2}$ in het basisscenario tot $-0.04 \mathrm{~kg} / \mathrm{m}^{2}$ en $-0.50 \mathrm{~kg} / \mathrm{m}^{2}$ in de alternatieve expertscenario's. De relatieve effecten voor de gedeeltelijke interventieschool versus controle scholen varieerden van $-0.17 \mathrm{~kg} / \mathrm{m}^{2}$ in het basisscenario tot $-0.04 \mathrm{~kg} / \mathrm{m}^{2}$ en $-0.21 \mathrm{~kg} / \mathrm{m}^{2}$ in de alternatieve expert-scenario's. De mixed-methods gerichte aanpak was behulpzaam bij het specifiëren van onzekerheid rondom effectbehoud van school gebaseerde leefstijlinterventies. Verdere observaties tijdens de middelbare schoolperiode kunnen de onzekerheid rondom toekomstige mogelijke opbrengsten verkleinen.

Hoofdstuk 8 presenteert de kosteneffectiviteit van de volledige en gedeeltelijke interventieschool en beschrijft de effecten op sociaaleconomische gezondheidsverschillen. De gezondheids-economische impact van de interventiescholen werd vergeleken met een regulier schoolprogramma en werd berekend vanuit een gezondheidszorgperspectief en maatschappelijk perspectief. In een kind-adolescentie model werden de effecten van de interventies op BMI vertaald naar de veranderingen in gewichtsklasse, gezondheids- 
zorgkosten, QALYs en schoolverzuim tot 20-jarige leeftijd. Vervolgens werden de gevolgen voor chronische aandoeningen, QALYs, gezondheidszorgkosten en productiviteitskosten over de rest van de levensloop gemodelleerd met het RIVM Chronisch Ziekten Model (RIVM-CDM). Voor de hoofdanalyse werd verondersteld dat de geobserveerde 2-jaar effecten werden behouden (constante relatieve effecten). Aanvullende scenario analyses werden uitgevoerd om te kijken hoe de resultaten veranderden door rekening te houden met andere scenario's voor effectbehoud (Hoofdstuk 7). Met subgroep analyses werd gekeken naar de kosteneffectiviteit voor verschillende sociaaleconomische groepen. Voor het gezondheidszorgperspectief waren de kosten per gewonnen QALY lgedeeltelijke interventieschool vs. controle: $€ 58,698$, volledige vs. gedeeltelijke interventieschool: $€ 248,206$ / gewonnen QALY) voor de volledige en gedeeltelijke interventieschool hoger dan de Nederlandse drempelwaarde voor preventie (€20,000 per gewonnen QALY). Voor de volledige interventieschool en een maatschappelijk perspectief bleven de kosten per gewonnen QALY onder de drempelwaarde (volledige interventieschool vs. controle school: $€ 19,734$ / gewonnen QALY; 50\% kans op kosteneffectiviteit; de volledige interventieschool leidde tot lagere kosten en meer QALYs in vergelijking met de gedeeltelijke interventieschool). Op basis van de interventie-effecten per sociaaleconomische groep, leidden de interventies tot een gunstige impact op gelijkheid (gemiddeld meer gewonnen QALYS in de lage versus de hoge sociaaleconomische groep). Deze win-win situatie voor de volledige interventieschool, de gunstige impact op kosteneffectiviteit en gezondheidsverschillen, kan echter alleen gerealiseerd worden onder de optimistische voorwaarde dat de interventie-effecten in alle sociaaleconomische groepen blijven behouden tot jongrolwassenheid.

Hoofdstuk 9 vat de onderzoeksresultaten samen en reflecteert op de implicaties voor onderzoek, beleid en praktijk. Allereerst laat het onderzoek in dit proefschrift zien dat leefstijlinterventies voor het onderwijs op de korte termijn een gunstige invloed hebben op de gezondheid van kinderen. Hoewel interventies over het algemeen leidden tot gunstige gezondheidsuitkomsten, is een overstijgende aanpak nodig om meerdere oorzaken van sociaaleconomische gezondheidsverschillen bij kinderen aan te pakken. Het tweede doel was de methoden van kosteneffectiviteitsonderzoeken naar leefstijlinterventies voor het onderwijs in kaart te brengen. Uit het onderzoek bleek dat de meeste economische evaluaties geen uitkomsten buiten gezondheid includeerden (bijv. sociale, emotionele en cognitieve vitkomsten). Verder onderzoek zou vitkomsten buiten gezondheid moeten meenemen en informatie afstemmen op de behoeften van besluitvormers. Om dit te bereiken zou een uitkomstenraamwerk (core outcome set) ontwikkeld kunnen worden. Dit raamwerk zou vitkomsten buiten gezondheid en diverse besluitvormingscriteria moeten bevatten. Het raamwerk zou ook vitgebreid kunnen worden met een 'heat map' die het gewicht (belang) 
van vitkomsten en criteria voor besluitvormers aangeeft. Het derde doel was om de kosteneffectiviteit van de volledige en gedeeltelijke interventieschool te berekenen. Op de korte termijn hebben de interventies niet geresulteerd in financiële opbrengsten. Afhankelijk van het belang dat wordt gehecht aan niet-financiële vitkomsten zoals verbetering van fysieke en sociale gezondheid, kan met name de volledige interventieschool wel een strategie zijn die loont. Vanuit een maatschappelijk perspectief bekeken is de volledige interventieschool op de lange termijn een kosteneffectieve interventie en heeft het geen negatieve gevolgen voor gezondheidsverschillen. Dit geldt alleen wanneer effecten in alle sociaaleconomische groepen kunnen worden behouden over de tijd. Metingen na de basisschoolperiode kunnen worden vitgevoerd om de onzekerheid rondom toekomstige gezondheids-economische impact te verkleinen. Om de toekomstige gezondheidsopbrengst te vergroten kunnen beleid en praktijk focussen op het verkennen van de waarde van aanvullende acties zoals intensieve ouderbetrokkenheid en voortzetting van de interventies op de middelbare school. 
Addenda 
Valorisation 
Addenda 
This part of the dissertation focuses on the valorisation of the results. Valorization of knowledge is the process of making knowledge suitable and available for social (and/or economic) use. The value of the results for children, policymakers, collaborators, and researchers will be described. Secondly, the activities that have been completed and should be undertaken to disseminate the results are outlined.

\section{Societal value}

\section{Children and their families}

The Healthy Primary School of the Future aimed at encouraging and helping children to adopt a healthy lifestyle. The project would not have been successful without the help and enthusiasm of all children and their families. Appendix 1 includes an infographic to summarize the Healthy Primary School of the Future for children (in Dutch).

\section{Policymakers}

In the Netherlands, as well as in other countries, local municipalities have been given a formal task for health promotion (Wet publieke gezondheid). Although municipalities do not decide on the specific interventions for schools, they support school health promotion through policies and regulations (gezondheidsnota's), collaboration arrangements, and investments. Local health departments (GGD) are commissioned by municipalities to support schools with implementing health promotion strategies. Provinces and national governments also shape the conditions for implementation of school health promotion through policies, investments, and collaboration networks.

Many policy documents emphasize the role of school health promotion in avoiding future chronic disease. This dissertation offered insight on the magnitude of the potential benefits of school health promotion. It also showed the uncertainty around future benefits, which may create awareness at the national level on the importance of uncertainty for securing the anticipated future benefits of school health promotion. Incentives at the national level would support local policy-makers in acting upon uncertainty by focusing on intensive parental involvement, follow-up, and intervention continuation in secondary school. Furthermore, the thesis informed policymakers on the distribution of outcomes over socioeconomic groups. These results can be used in developing and substantiating policies and implementation strategies.

The chapters focusing on the investments and two-year outcomes of the Healthy Primary School of the Future showed which resources are required and which changes are realized for children, parents, school personnel, and others. The chapter on the social value of the 
Healthy Primary School of the Future showed that cost-effectiveness or 'value for money' are not static concepts. Creating a shared vision on the 'added value' of school health promotion is an important step in making implementation and investment decisions. As this vision is context-specific, we did not provide a blueprint for measuring the value of school health promotion, but showed an overview of outcomes that can be used as a starting point in selecting critical outcomes. This can guide policymakers and their partners in setting goals, in making agreements on intended outcomes, and in developing a monitoring and evaluation framework. Last, the detailed overview of the required investments can help policymakers in determining the level of investment and in creating conditions (e.g. regulations) to facilitate a targeted and fair distribution of investments among stakeholders.

\section{Collaborators}

Participation of community members and private and public organizations is key in school health promotion. The implementation of the Healthy Primary School of the Future initiative was realized through engagement of the following persons: teachers, school boards, parents, public health professionals from local health departments, childcare providers, and (non-) private organizations involved in sports and nutrition. The commitment of all these parties is pivotal to be able to deliver interventions like the Healthy Primary School of the Future. In addition to the required support (through consent, organizational support, time investments etc.), they may experience certain benefits. Before deciding on their involvement, these persons will therefore evaluate the 'added value' that a school health promotion strategy has for them. These value judgements are shaped by, amongst others, people's beliefs, experiences, success stories of others, and (scientific) knowledge. This dissertation offers scientific information on the outcomes that can be attained at the short, medium, and long term, which can be used in the communication on school health promotion, and can thereby contribute to informed decisions.

\section{Researchers}

The costing study, the summary of economic evaluations, and the evaluations on HPSF and PAS provided researchers and evaluators with examples and suggestions for designing costeffectiveness studies. The study assessing the short-term value of the Healthy Primary School of the Future moved away from conventional approaches and integrated health outcomes and outcomes beyond health to assess the cost-effectiveness. Researchers can consider this approach in evaluating school health promotion strategies. The long-term cost-effectiveness study examined equity impacts and cost-effectiveness simultaneously, which can also be employed for modeling studies on other health promotion interventions. 


\section{Dissemination of findings}

The results of this dissertation have already been distributed via various channels. To disseminate the results to the scientific community, the findings have been published in national and international peer-reviewed journals and have been presented at (inter)national conferences (in the area of health technology assessment and school health promotion).

Other strategies have been undertaken to disseminate the findings on the Healthy Primary School of the Future initiative to children and parents, local policy-makers, and professionals. Overall, they aimed at sharing results to inform other about the Healthy Primary School of the Future, to ensure that others can learn from our experiences, and to seek new opportunities for collaboration and dissemination of the Healthy Primary School of the Future. A shortlist of valorization products can be found in Appendix 2.

The results of this research have been communicated to local, regional, and national policymakers via round table discussions, annual reports, and via communication for/with the Province of Limburg. In addition, results were presented to professionals by presenting the findings at local symposia and events (e.g. Roadshow Healthy Primary School of the Future, Symposium Healthy Primary School of the Future, presentation for the 'Alles is Gezondheid' network in South-Limburg). Short summaries on the findings have been posted on our website (www.degezondebasisschoolvandetoekomst.nl). Study findings have also been shared with schools and parents via factsheets, information letters, and short videos. Moreover, the project team shared experiences and results on the Healthy Primary School of the Future by a public friendly book, inviting policy makers, teachers, and journalists to visit schools, collaborating on newspaper articles, and so on (see Appendix 2).

We have worked together with the National Institute for Public Health and the Environment (RIVM), Wageningen University, and the VU Amsterdam on a policy report informing the Dutch Minister of Health on the feasibility and impact of implementing healthy school lunches and structured physical activity at the national level. We also intend to develop a tool to aid policymakers and partners in creating a shared vision on the value of school health promotion. With such a tool, they should be able to select and specify criteria that determine 'added value', select measurement indicators and instruments, set goals, and specify the overall value assessment. As such, we aim to further translate the results into practicable and usable knowledge for others. 


\title{
Appendix 1
}

\section{Summary for children}

\section{G De Gezonde Basisschool van de Toekomst}

\author{
OP SCHOOL.
}

Gezond eten en bewegen is belangrijk om goed te groeien en gezond te blijven. Als je een gezond lichaam hebt wordt je minder snel ziek. Daarom hebben we de Gezonde Basisschool van de Toekomst gemaakt!

Jij gaat tussen de middag misschien naar huis om te lunchen of je neemt je eigen boterham mee naar school. Tijdens de kleine pauze kun je buitenspelen.

Op de Gezonde Basisschool van de Toekomst kun je kiezen wat je wilt eten. Ook kun je 's middags langer buiten spelen.

Sommige kinderen in Zuid-Limburg zijn al naar een Gezonde Basisschool van de Toekomst gegaan. Hieronder kom je meer te weten over deze school.

\section{ETEN}

Tijdens de pauze staan verschillende soorten brood, beleg, fruit, groente en andere lekkere dingen op tafel. Dit is elke dag een beetje anders. Hierdoor proef je nieuwe dingen en leer je hoe je gezond kunt eten. Je drinkt vaker water en eet meer groente en fruit tijdens de lunch.

\section{BEWEGEN}

Samen buitenspelen is leuk! Je speelt nu vaker met andere kinderen en leert nieuwe spelletjes. Door goede regels af te spreken krijg je minder vaak ruzie. Je krijgt soms les van de sportvereniging of de theaterclub. Zo weet je wat er in jouw buurt te doen is.

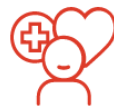

\section{GEZOND}

Wat je eet en hoeveel je beweegt is beter in balans. Zo blijf je fit en wordt je niet te dik.

\section{DE SCHOOL NOG BETER MAKEN}

Het is belangrijk dat de Gezonde Basisschool van de Toekomst zo goed mogelijk werkt. Wat misschien nog wat beter kan is dat je ouders, broertjes en zusjes en vriendjes en vriendinnetjes op een andere school ook leren om gezond te blijven. Dit helpt jou om gezond te blijven als je naar de middelbare school gaat.

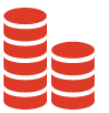

GELD

De Gezonde Basisschool van de Toekomst kost best veel geld. Dat is niet erg want als je : gezond bent wordt je minder vaak ziek.

\section{WAT VIND JIJ?}

Wat vind iij van de Gezonde Basisschool van de Toekomst?

Zou je naar zo'n school willen gaan?

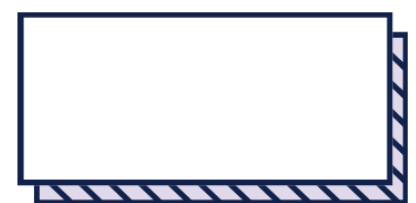




\section{Appendix 2}

Shortlist of valorisation products on the Healthy Primary School of the Future project

- Article. 'Onderzoek naar landelijke vitrol Gezonde Bassischool van de Toekomst'. November 20, 2019. Accessible via: https://www.maastrichtuniversity.nl/nl/nieuws/ onderzoek-naar-landelijke-uitrol-gezonde-basisschool-van-de-toekomst

- News article 'Gezonde lunch heeft effect, veel meer scholen haken aan'. De Limburger. November 19, 2019. Accessible via: https://www.limburger.nl/cnt/ dmf20191118_00133221/gezonde-lunch-heeft-effect-veel-meer-scholen-hakenaan

- NOS Jeugdjournaal. 'Langere lunchpauze is gezond'. November 19, 2019. Accessible via: https://jeugdjournaal.nl/artikel/2311154-langere-lunchpauze-isgezond.html

- NOS Journaal. November 19, 2019. Accessible via: https://www.npostart.nl/nosjournaal/19-11-2019/POW_04056948 (1 1:58).

- News article 'Papa, dat mag ik niet eten, dat is ongezond'. NRC. October 29, 2019. Accessible via: https://www.nrc.nl/nieuws/2019/10/29/pap-dat-mag-ik-niet-etendat-is-ongezond-a3978336

- News item. 'Waarom alle leerlingen van De Schatgraver met een lege broodtrommel naar school komen'. May 6, 2019. Accessible via: https://www.verus.nl/ actueel/blogs/hester-van-de-kaa/waarom-alle-leerlingen-van-de-schatgraver-meteen-lege-broodtrommel

- Booklet 'Gezonde bassischool van de toekomst: van leer- naar leefschool'. April 2019. Jansen, M. \& Burhenne, K. Provincie Limburg. Accessible via: https://www.degezondebasisschoolvandetoekomst.nl/upload/1902712gezondeba sisschoolvandetoekomst-DEF.pdf

- News item. '\#WiizijnLimburg: Gezonde Basisschool van de Toekomst. January 30, 2019. Accessible via: https://I1.nl/wijzijnlimburg-gezonde-basisschool-van-detoekomst-147193/

- News item. 'Compilatie belevingsbezoek Gezonde Basisschool van de Toekomst Kerkrade'. Alles is Gezondheid. November 30, 2016. Accessible via: https://www.youtube.com/watch? $v=S B w X m+C 4 k b k \& f e a t u r e=e m b \_t i t l e$

- News item. 'Staatssecretaris Dekker op bezoek in Limburg'. May 23, 2016. De Limburger. Accessible via: https://11.nl/staatssecretaris-dekker-op-bezoek-in-limburg2518 
Addenda 
List of publications 
Addenda 
Peer-reviewed international publications as part of this thesis

Oosterhoff M, Jolani S, de Bruijn-Geraets DP, van Giessen A, Bosma H, van Schayck OCP, Joore MA. BMI trajectories after primary school-based lifestyle interventions: unravelling an uncertain future. A mixed methods study. Accepted for publication in Preventive Medicine Reports.

Oosterhoff M, Over EAB, van Giessen A, Hoogenveen RT, Bosma H, van Schayck OCP, Joore MA. Lifetime cost-effectiveness of the Healthy Primary School of the Future considering uncertain effect maintenance and equity impacts. BMC Public Health. 2020; 20(1):1887.

Oosterhoff M, van Schayck OCP, Bartelink NHM, Bosma H, Willeboordse M, Winkens B, Joore MA. The short-term value of the 'Healthy Primary School of the Future' initiative: a social return on investment analysis. Front Public Health. 2020; 8:401.

Oosterhoff M, Joore MA, Bartelink NHM, Winkens B, Schayck OCP, Bosma H. Longitudinal analysis of health disparities in childhood. Arch Dis Child. 2019;104(8):781788.

Oosterhoff M, Bosma H, van Schayck OCP, Evers SMAA, Dirksen CD, Joore MA. A systematic review on economic evaluations of school-based lifestyle interventions targeting weight-related behaviours among 4-12 year olds: Issues and ways forward. Prev Med. 2018;114:115-122.

Oosterhoff M, Bosma H, van Schayck OCP, Joore MA. A Cost Analysis of School-Based Lifestyle Interventions. Prev Sci. 2018;19(6):716-727. Erratum in: Prev Sci. 2019;20(6):970-974.

Oosterhoff $M$, Joore $M$, Ferreira I. The effects of school-based lifestyle interventions on body mass index and blood pressure: a multivariate multilevel meta-analysis of randomized controlled trials. Obes Rev. 2016;17(1 1):1131-1153.

Scientific articles in national journals

Oosterhoff $M$, Bosma $H$, van Schayck OCP, Joore MA. Leefstijlinterventies in het onderwijs: hoe zit het met de kosten? TSG. 2018;96:120-123. Addendum in: TSG. 2019;97:106107. 
Van Schayck OCP, Willeboordse $M$, Oosterhoff $M$, Bartelink NHM, van Assema $P$, Kremers SPJ, Winkens B, Savelberg HHCM, Jansen MWJ, Joore MA, Vreugdenhil A. De effecten en kosten van de Gezonde Basisschool van de Toekomst. TSG.

\section{Other international publications}

Schwander B, Nuijten M, Hiligsmann M, Queally M, Leidl R, Joore M, Oosterhoff $M$, Frew E, Van Wilder P, Postma M, Evers E. Identification and expert panel rating of key structural approaches applied in health economic obesity models. Health Policy and Technology. 2020; 9(3):314-322.

Bartelink NHM, van Assema $P$, Kremers SPJ, Savelberg HHCM, Oosterhoff $M$, Willeboordse M, van Schayck OCP, Winkens B, Jansen MWJ. Can the Healthy Primary School of the Future offer perspective in the ongoing obesity epidemic in young children? $A$ Dutch quasi-experimental study. BMJ Open. 2019; 9(10):e030676.

Bartelink NHM, van Assema $P$, Kremers SPJ, Savelberg HHCM, Oosterhoff $M$, Willeboordse M, van Schayck OCP, Winkens B, Jansen MWJ. One- and Two-Year Effects of the Healthy Primary School of the Future on Children's Dietary and Physical Activity Behaviours: A Quasi-Experimental Study. Nutrients. 2019;11(3):E689.

Vermeiren AP, Willeboordse $M$, Oosterhoff $M$, Bartelink N, Muris P, Bosma $H$. Socioeconomic multi-domain health inequalities in Dutch primary school children. Eur $J$ Public Health. 2018;28(4):610-616.

Ramaekers BLT, Wolff RF, Pouwels X, Oosterhoff M, Van Giessen A, Worthy G, Noake C, Armstrong N, Kleijnen J, Joore MA. Ixekizumab for Treating Moderate-to-Severe Plaque Psoriasis: An Evidence Review Group Perspective of a NICE Single Technology Appraisal. Pharmacoeconomics. 2018;36(8):917-927.

Willeboordse M, Jansen MW, van den Heijkant SN, Simons A, Winkens B, de Groot RH, Bartelink N, Kremers SP, van Assema P, Savelberg HH, de Neubourg E, Borghans L, Schils $T$, Coppens KM, Dietvorst R, Ten Hoopen R, Coomans F, Klosse S, Conjaerts MH, Oosterhoff M, Joore MA, Ferreira I, Muris P, Bosma H, Toppenberg HL, van Schayck CP. The Healthy Primary School of the Future: study protocol of a quasi-experimental study. BMC Public Health. 2016; 16:639. 


\section{Reports}

Van Giessen A, Oosterhoff $M$, Hoekstra J, Over EAB, Joore MA, van Schayk OCP, Willeboordse M, Dijkstra SC, Seidell JC, van Kleef E, Soethoudt $H$, Vingerhoeds $M H$, Gezonder op de basisschool: schoollunches en meer bewegen. Een verkenning naar draagvlak, haalbaarheid, betaalbaarheid en impact. 2020. Bilthoven: Rijksinstituut voor Volksgezondheid en Milieu. DOI 10.21945/RIVM-2020-016.

\section{Oral presentations at (inter)national conferences}

Oosterhoff M, van Schayck OCP, Bartelink NHM, Bosma H, Willeboordse M, Winkens B, Joore MA. The short-term social return on investment of 'the Healthy Primary School of the Future' initiative. $5^{\text {th }}$ European Conference on School Health Promotion, 20-22 November 2019, Moscow, Russia

Oosterhoff M, Jolani S, de Bruijn-Geraets DP, van Giessen A, Bosma H, van Schayck OCP, Joore MA. Comparing different extrapolation methods for weight trajectory analyses after a childhood lifestyle intervention. 2019 International Health Economics Association (IHEA) World Congress, 13-17 July 2019, Basel, Switserland.

Oosterhoff M, van Schayck OCP, Bartelink NHM, Bosma H, Willeboordse M, Winkens B, Joore MA. An intersectoral short-term evaluation on the social return on investment of 'the Healthy Primary School of the Future' initiative. 2019 International Health Economics Association (IHEA) World Congress, 13-17 July 2019, Basel, Switserland.

Oosterhoff $M$, Joore MA. Crossectional validity of the EQ-5D-Y in a general sample of primary school-aged children. European Health Economics Association (EUHEA) Conference 2018, 11-14 July 2018, Maastricht, the Netherlands.

Oosterhoff $M$, Bosma $H$, van Schayck OCP, Evers SMAA, Dirksen CD, Joore MA. Designing economic evaluations on lifestyle interventions in primary schools: issues and ways forward. LolaHESG ("lowlands Health Economics' Study Group"), 12-13 May 2017, Rotterdam, the Netherlands.

Oosterhoff M, Joore MA. Potential cost-effectiveness of school-based obesity prevention. $11^{\text {th }}$ World Congress in Health Economics, International Health Economics Association (iHEA), 12-15 July 2015, Milano, Italy. 
Oosterhoff $M$, Joore MA. The potential cost-effectiveness of school-based obesity prevention including adult costs and health benefits. LolaHESG ("lowlands Health Economics' Study Group"), 28-29 May 2015, Maastricht, the Netherlands. 
About the author 
Addenda 
Marije Oosterhoff was born in Groningen, the Netherlands on April 8, 1991. She studied Health Sciences at the University of Twente from 2009-2012 and obtained her Bachelors of Science degree. She continued her education in Maastricht, where she graduated cum laude in 2014 from the Health Sciences Research Master. After her graduation, she started working as a junior consultant at Panaxea in Enschede, where she conducted healtheconomic analyses for health technology innovators.

In 2015, Marije started her PhD project in Maastricht on

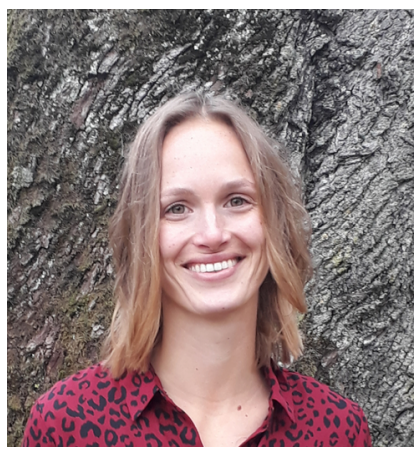
the Healthy Primary School of the Future project. Her PhD research focused on the healtheconomic impact of a lifestyle intervention in the primary school setting. Marije has presented her work at several national and international conferences and symposia. In 2019, she was selected to join the Research Talent Program of the Care and Public Health Research Institute (CAPHRI) for talented young researchers. Marije was also selected to join the European Doctoral Summer School in York. During the PhD project, Marije performed coordination tasks for the Healthy Primary School of the Future project and was president of the ISPOR Maastricht University Student Chapter. In 2020, Marije wrote a policy brief for the Dutch Ministry of Health, Welfare, and Sports on the feasibility, acceptability, and impact of healthy school lunches and physical activity together with the Dutch Institute for Public Health and the Environment, Wageningen University \& Research, and Vrije Universiteit Amsterdam.

Marije currently works at the Dutch Institute for Public Health and the Environment (RIVM). 
Addenda 
Dankwoord 
Addenda 
Na mooie jaren is er nu een einde gekomen aan mijn promotieonderzoek en de tijd in Maastricht. Ik wil alle collega's, vrienden en familie bedanken voor de hulp bij mijn onderzoek, de gezelligheid, (mentale) steun en afleiding. Een aantal mensen wil ik in het bijzonder bedanken.

Manuela, ik leerde je al in 2014 kennen tijdens de master. Jij hebt mij het enthousiasme voor ons werkveld bijgebracht en speelde een belangrijke rol bij mijn ontwikkeling als onderzoeker. Tijdens onze talloze overleggen hielp iij mij om mijn gedachten op een rijtie te zetten met je kenmerkende schema's. Je bood een luisterend oor en gaf complimenten juist wanneer ik dat nodig had. Dat heb ik erg gewaardeerd, dankjewel daarvoor.

Onno, iii introduceerde me bij het team van de Gezonde Basisschool van de Toekomst. Bedankt voor het vertrouwen dat je in me hebt gehad. Je motiveerde me om nieuwe dingen aan te pakken ook wanneer ik dat ontzettend spannend vond. Meehelpen met de organisatie van het project, verschillende soorten presentaties geven, een beleidsrapport schrijven, ik heb er veel van geleerd. Heel veel dank daarvoor.

Hans, iij maakte het team compleet. Je razensnelle feedback, schrijftips en interesse zijn heel waardevol geweest. We hebben vaak gelachen om mijn hardnekkige 'komma-ziekte', ik hoop dat ik daar nog eens van af kom.

Ik wil de leden van de beoordelingscommissie hartelijk bedanken voor het lezen en beoordelen van mijn proefschrift en voor het opponeren tijdens de verdediging.

Alle co-auteurs die hebben meegewerkt aan de artikelen van dit proefschrift, bedankt voor de fijne samenwerking. Isabel, your drive and enthousiasm to apply new methodologies sometimes made my head spinning, but also inspired me. I thank my first publication to you! Bjorn en Shahab, dank dat jullie altijd waren bereikbaar op Deb voor statistische vragen en verse koffie.

Eelco en Anoukh, jullie hebben me wegwijs gemaakt in de gezondheidsmodelleringsaanpak van het RIVM. Via de mail, telefoon en online vergaderingen heb ik veel van jullie geleerd en dat is gelukkig nog niet voorbij! Ik kijk er naar uit om samen met jullie mooie projecten uit te gaan voeren.

Carmen, Daisy, Rudolf en Silvia, bedankt voor jullie co-auteurschap.

Ik wil iedereen bedanken die heeft meegewerkt aan de Gezonde Basisschool van de Toekomst: onderzoekers, onderzoeksassistenten, studenten en stagaires, projectleiders en leerkrachten, ouders en kinderen, de medewerkers van de GGD en MEMIC, en alle anderen die het project tot een succes hebben gemaakt. Weet dat jullie allen een essentieel puzzelstukje hebben gelegd aan het project. 
Nina, Renate en Elise, PhD-collega's, ik heb ervan genoten om met jullie ervaringen uit te wisselen tijdens koffiemomentjes en etentjes. Nog even en we hebben allemaal een mooie doctorstitel op zak.

Nina, mijn collega aan 'de overkant'. Onze samenwerking is voor mij heel waardevol geweest. Naast de vele uren data-cleaning blijven vooral de goede gesprekken en de wandelingen mij bij.

Maartje, jouw organisatietalent rondom alle meetweken en nog zo veel meer was onmisbaar. Daarnaast vond ik het erg leuk dat we het afgelopen jaar nog regelmatig hebben samengewerkt aan vervolgprojecten.

Onderzoeksassistenten, (WESP)studenten, stagaires en stand-ins, de gezelligheid tijdens de autoritjes naar Parkstad en jullie harde werken waren onvergetelijk.

Andrew en Maria, jullie hebben ontzettend veel ijver en enthousiasme laten zien om het project naar grotere hoogten te brengen, chapeau.

KEMTA-collega's, dat ik een mooie PhD-tijd heb gehad is mede aan jullie te danken. Hoewel we weinig inhoudelijk samenwerkten had ik veel contact met jullie door alle koffiewandelingen, lunches, kletspraatjes bij de printer en ga zo maar door. In het bijzonder ook veel dank aan alle (oud)KEMTA-junioren, ik kijk met heel veel plezier terug op de zomerborrels bij Thembi, carnaval, de Lola-feestjes, kerstborrels enzovoort.

Ik wil ook de collega's van HAG bedanken. Ik heb maar heel kort een werkplek gehad bij jullie op de vakgroep. Toch voelde ik me altijd welkom, dank daarvoor.

Mijn lieve vrienden en vriendinnen, jullie hebben gezorgd voor heel wat afleiding. Anneke en Marieke, ik zie ons nog zitten als kersverse brugklassers op het Wessel Gansfort. Ik vind het mooi om te zien dat we ons eigen pad hebben gevonden maar elkaar nog altijd goed begrijpen.

Sara, ik kijk altijd weer uit naar de Outlander-marathons (moeten we weer vaker gaan doen!) en je verjaardagen waarbij je de bachelor-doegroep weer samenbrengt.

Ellen, Jessica, Sanne, wat is het leuk dat we elkaar nog altijd treffen (en altijd weer op wisselende woonplekken). Na onze vakanties en logeerweekenden voel ik me weer een ander mens. Sanne, dankjewel dat je je creativiteit wilde inzetten voor het ontwerpen van de prachtige cover.

Arjan, wat hebben we een avonturen beleefd in het huis bij DuChateau. Ook al ben je verhuisd naar Delft, je bent me nog vaak komen opzoeken in Maastricht zodat we de goede oude tijd weer konden herbeleven.

Laura en Sylvia, onze studie en PhD frustraties konden we bij elkaar kwijt maar we hebben ook veel gelachen samen. Sylvia, je mag nog vaker gaan verhuizen, zo kunnen Laura en ik je overal opzoeken ook al is het maar voor 24 uur. 
Anne et Alain, Ronald, Johan et Annabelle ( $\&$ co), même si on ne peut pas (encore) parler, discuter, et échanger comme nous le désirons, je me sens toujours la bienvenue. Merci pour votre acceuil chaleureux!

Zussen, jullie zijn altijd benieuwd hoe het met me gaat en staan met jullie mannen altijd paraat voor een verhuizing.

Janke, mijn grote dappere zus. Ik kijk vol bewondering naar alle stappen die je samen zet met Emiel en Owen. Wanneer ik mijn proefschrift verdedig verwachten jullie een kindje en kleine broer, sorry voor de ongelukkige timing! Ik heb ontzettend veel zin in alle toekomstige speelmomenten.

Ilse, mijn stoere kleine zus. Hoewel je maar kort in Sittard verbleef vond ik het heel fijn om mijn kleine zusje even dichtbij te hebben. De stappen die iij hebt gemaakt op het gebied van studie, werk en privé samen met Tim zijn ontzettend leuk om te volgen. Dankjewel Ilse dat je mijn paranimf wilt zijn. Tim, dankjewel voor het opmaken van de cover.

Pap en Mam, jullie zijn altijd dichtbii, ook al zat er een behoorlijke fysieke afstand tussen Maastricht en Bedum. Wanneer ik als klein meisje voor een uitdaging stond riepen we samen: "Ik wil het, ik kan het en ik doe het ook!". Dit laat wel zien dat jullie me stimuleren om op mezelf te vertrouwen. Ik ben jullie eindeloos dankbaar voor jullie luisterend oor, begrip en onvoorwaardelijke steun.

Lieve Xavier, het mooiste van dit proefschrift is dat ik het samen met jou heb kunnen afmaken. Je geruststellende en motiverende woorden, rust, geduld en zorgzaamheid betekenen heel veel voor me. Ik kan je niet genoeg bedanken voor alles wat we samen delen. Ik kan niet wachten op de avonturen van ons nieuwe hoofdstuk. 
